\title{
Los espacios de la antropología en la obra de Robert Lehmann-Nitsche, 1894-1938
}

\author{
Diego Alberto Ballestero \\ Directora: Dra. Irina Podgorny \\ Facultad de Ciencias Naturales y Museo - UNLP
}

2013

Tomo I 




\section{Resumen}

El propósito de esta Tesis Doctoral es el análisis de las condiciones de posibilidad para las prácticas y el trabajo antropológico en la Argentina de fines del siglo XIX y principios del siglo $\mathrm{XX}$. Especialmente, se examina la cultura material, las redes de circulación de información, los espacios de encuentro así como las prácticas de observación y registro, a través del análisis de las producciones del antropólogo alemán Robert Lehmann-Nitsche. Se busca relevar cómo se constituyó el "trabajo de campo" a través de los distintos espacios de encuentro y actores que mediaron/intervinieron entre los objetos de estudio elegido, los distintos espacios involucrados y los sectores científicos.

Asimismo se busca dar cuenta de las estrategias para obtener información y colecciones así como los distintos circuitos en los que participaron los objetos o individuos estudiados, tal como ferias o exposiciones. Estas cuestiones permiten vislumbrar diferentes aspectos de cómo trabajaron los científicos pero también hablan de la naturaleza colectiva de la producción de conocimientos y de las interacciones con ámbitos no académicos 



\section{Agradecimientos}

Primeramente quiero agradecer a mi Directora, Irina Podgorny, por haberme dado la oportunidad de llevar adelante este proyecto con entera libertad. Por brindarme constantemente su guía, su sincero juicio crítico, sus exhaustivas y valiosas correcciones, y su enorme paciencia. A Miguel Saghessi y Marta Roa por haberme abierto las puertas del mundo de la investigación y por su constante apoyo a lo largo de los primeros años. En distintos momentos de esta investigación Silvia Ametrano, Gustavo Politis, Margaret Lopes, Nelia Dias, Barbara Göbel han sabido brindarme su apoyo a través de cartas de presentación a becas, apoyo institucional, sugerencias bibliográficas, y discusión de datos e ideas relevantes que han enriquecido enormemente el resultado final de esta investigación.

Mis compañeros de equipo: Máximo Farro, Susana García, Tatiana Kelly, Andrea Pegoraro, Alejandra Pupio y Alejandro Martínez merecen un especial agradecimiento. Por haber contribuido a mi formación académica, soportando estoicamente la lectura de mis primeros trabajos. Por repetir el mismo heroicismo al leer versiones de los borradores de esta tesis, contribuyendo con ideas fundamentales. Pero más que nada por haber sabido estar en los momentos más necesarios de la redacción de este trabajo.

Especialmente quiero agradecer al Prof. Dr. Wolfgang Schäffner de la cátedra de Historia del Conocimiento y la Cultura del Instituto de Estudios Culturales de la Universidad Humboldt de Berlín. Gracias a él pude realizar una estadía de investigación de 2 años en Berlín, pudiendo acceder a innumerables espacios de formación científica y académica que siempre pensé lejanos. Su paciencia, su erudición y fundamentalmente su enorme calidad humana han sido pilares fundamentales en este proceso.

Al grupo de Berlín: Liliana Gómez-Popescu, Ricardo Cedeño Montaña, Nadia Guevara, José Muñoz, y Fabio Schillaci, por escuchar ideas, corregir versiones previas de este trabajo, sugerencias y el aliento constante. En este sentido quiero destacar la invalorable ayuda y las pacientes lecturas de Settimio Pessuoto quien, junto a Lutz Matsche, supieron acompañarme desde mis primeros días en Berlín, y por saber estar.

Asimismo debo agradecer a los empleados de las diversas bibliotecas, institutos, bibliotecas y fondos documentales por su paciencia y predisposición al momento de ayudarme a encontrar gran parte del material utilizados en este trabajo. Mi agradecimiento a: la Biblioteca del Museo de La Plata, la Biblioteca de la Universidad Nacional de La Plata, la Biblioteca Nacional, el Archivo Histórico de la Provincia de Buenos Aires, el Archivo General de la Nación, el Archivo del Museo Etnográfico de la Facultad de Filosofía y Letras. En Alemania debo agradecer especialmente a los empleados de: el Ibero-Amerikanisches Institut de Berlín, el Ethnologisches Museum Berlin 
Staatliche Sammlungen Berlin Preußischer Kulturbesitz, la Berliner Gesellschaft für Anthropologie, Ethnologie und Urgeschichte, el Geheimes Staatsarchiv Preußischer Kulturbesitz Berlin, y finalmente el Universitätsarchiv der Humboldt-Universität Berlin.

Esta investigación fue apoyada institucionalmente por una Beca de Investigación Científica de tipo Inicial otorgada por la Agencia Nacional de Promoción Científica y Tecnológica de la Argentina, financiando la investigación entre los años 2008 y 2010. Posteriormente gracias a una Beca Sandwich del Servicio Alemán de Intercambio Académico (DAAD) se pudo realizar una estadía de investigación en la ciudad de Berlín entre los años 2010 y 2012. Asimismo, esta investigación se enmarcó en los proyectos "El mapa de una controversia científica: los debates sobre la antigüedad de la formación pampeana, 1880-1925" (PIP 5675); "El comercio de datos y artefactos en la cultura de las ciencias de los Siglos XIX y XX" (PIP-CONICET 0116), y "Cultura Material y medios técnicos” (PICT 2005 ET 32111), dirigidos por la Dra. Irina Podgorny.

A mis amigos de una parte del mundo: Matías Fortunato, Julián Tabuenca, Rada Castillo, Ana Marchetti, Pía Arnedillo, Nahuel González, Alfredo Leaden, Natalia Badino, Solana Vila Moret, Lili, Griselda Späth, Diana Ramos, Mailen de Santis, Mery Braco, Emiliana Carricondo, Gisela Tissone, Matias Ferraro, Ariel Raggio, Federico Biancuzzo. Por haber estado siempre, por haber escuchado (aguantando la risa) aquellas cosas "raras" que estudiaba, y por saber perdonar todas mis llegadas tarde. A los amigos que el estudio de las cosas "raras" me permitió conocer: Gisela Ferraro, Ezequiel Meza Hidalgo, Alexander Araya López, Orlando Venegas Valencia, José Romero, Luis Espinales Delgado, Diego Gormaz Lobo, Claudia Andres, Sabine Gabriele, Enrique Sulbaran Romero, Yarua Jaimes, Mira Cecile Merks, Vanesa Sepulveda Medialdea, Maine Ochoa, Claudia, María Virginia Carrero, Elisa Meza Vilalón y Liliana Zerpa. Por que me acompañaron en la etapa final de este camino e iniciaron uno nuevo.

A mi madre Miriam, a mis hermanas María y Letiziá, a mi hermano Ezequiel. Por su amor y su apoyo incondicional. Por creer fielmente en mí en todos estos años. Nada hubiese sido posible sin ellos.

A Annika, por su paciencia, por su ayuda, por su enorme conocimiento y por haber soportado siempre con una sonrisa las etapas más intensas de la redacción de este trabajo. Por que gracias al estudio de las cosas "raras" pude conocerla. Pero fundamentalmente por su amor, por su ternura y la enorme alegría de estos años.

Finalmente a mi mejor amigo, mi mentor, mi guía y ejemplo: a mi padre Alberto 
A la memoria de mi padre A Miriam, María, Ezequiel y Letizía A Annika 



\section{Resumen}

Los espacios de la antropología en la obra de Robert Lehmann-Nitsche, 1894-1938

El propósito de esta tesis doctoral es el análisis de las condiciones de posibilidad para las prácticas y el trabajo antropológico en la Argentina de fines del siglo XIX y principios del siglo XX. Especialmente, se examina la cultura material, las redes de circulación de información, los espacios de encuentro así como las prácticas de observación y registro, a través del análisis de las producciones del antropólogo alemán Robert Lehmann-Nitsche. Con este fin se recurrió a un amplio corpus documental conformado por un conjunto de fuentes editas e inéditas depositadas en diversos archivos en Argentina e Alemania.

La tesis da cuenta del carácter colectivo en la construcción del conocimiento, en la cual actores e instituciones interactúan en diversos espacios. Lejos de ser otra reconstrucción histórica basada en la biografía de un personaje, esta tesis demuestra que las prácticas antropológicas no responden a un desarrollo histórico lineal ni pueden ser reducidas a una "escuela" antropológica. En este sentido revela la existencia simultánea y la superposición de una serie de prácticas y discursos que, al mismo tiempo, delimitarán y caracterizaran los espacios de la práctica antropológica y la construcción de su objeto de estudio.

A través del estudio de las redes de aprovisionamiento de datos y objetos, se plantea que las intenciones de Robert Lehmann-Nitsche por insertarse dentro de los programas de investigación de las instituciones científicas alemanas, determinarán, en parte, la elección de los temas a estudiar. De la misma manera afectarán la incorporación de determinados recursos técnicos y metodológicos en la recolección, clasificación, procesamiento y envío de datos y objetos. Finalmente, el trabajo plantea la inexistencia de un programa definido para la profesionalización y la institucionalización de las prácticas antropológicas en la Argentina. De esta forma la tesis muestra que los espacios de la antropología no se refieren a espacios físicamente definidos, sino a un complejo entramado de prácticas asociadas a un conjunto de tecnologías materiales y discursivas. 


\begin{abstract}
The Spaces of Anthropology in the Works of Robert Lehmann-Nitsche, 1894-1938

The aim of this doctoral thesis is to analyze the conditions which enabled anthropological work and practices in Argentina towards the end of the $19^{\text {th }}$ and the beginning of the $20^{\text {th }}$ century. The study investigates material culture, networks in which information circulates, spaces of exchange and encounter as well as methods of observation and recording with particular reference to the work of the German anthropologist Robert Lehmann-Nitsche. To this end, a comprehensive corpus of documents consisting of unpublished and edited sources deposited in various archives in Argentina and Germany has been examined.
\end{abstract}

The thesis illustrates the collective character of the construction of knowledge, taking into account the interaction of multiple actors and institutions in diverse spaces. Far from being another historical reconstruction based on the biography of an individual, this thesis demonstrates that anthropological practices neither responded to a linear historical development nor can they be reduced to an anthropological "school". In this sense, the simultaneous existence and superposition of a series of practices and discourses becomes apparent, which at the same time delimitates and characterizes the spaces of anthropological practices as well as the construction of its object of study.

Based on the analysis of the networks supplying data and objects, it is argued that LehmannNitsche's intentions of inserting himself into the investigation programs of German scientific institutions will partly determine the choice of topics to be studied. Furthermore, this will affect the incorporation of specific technical and methodological means with regard to the collection, classification, processing and the transfer of data and objects. In addition, the results indicate the nonexistence of a clearly defined program in order to professionalize and institutionalize anthropological practices in Argentina. Consequently, the doctoral thesis shows that the spaces of anthropology are not to be understood as outlined physical spaces but refer to a complex network of practices associated with material and discursive technologies. 


\section{Índice General}

\section{Tomo I}

Introducción general...........................................................

Algunas cuestiones teórico- metodológicas....................................09

Robert Lehmann-Nitsche...................................................17

1. La Antropología entre fines del siglo XIX y principios del siglo XX ........................... 28

2. Caos y orden en la Antropología Argentina...................................... 65

3. El estudio de las colecciones osteológicas del Museo de la Plata................................. 72

4. La observación sobre individuos vivos: Antropometría y Somatología ........................ 94

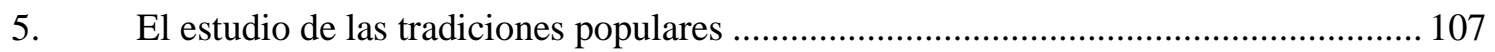

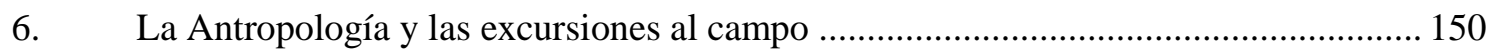

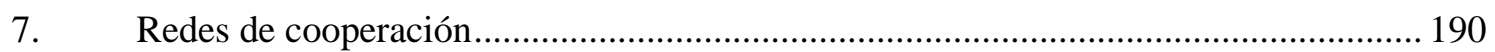

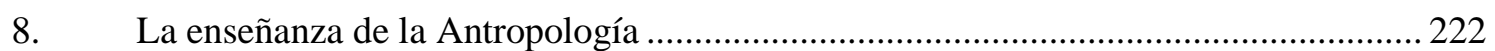

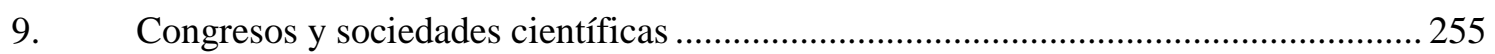

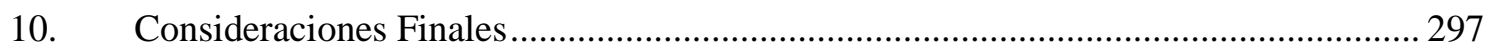

\section{Tomo II}

Bibliografía y Anexos 


\section{Introducción general}

El objetivo general de esta tesis es analizar el desarrollo de los espacios de la antropología argentina entre fines del siglo XIX y principios del siglo XX. Como ha señalado Bruno Latour, este tipo de análisis implica desentrañar las redes institucionales que envuelven la práctica científica, a fin de poder historizar y contextualizar un objeto en particular que, estabilizado y estandarizado en tiempo y espacio, cobra existencia como objeto científico ${ }^{1}$. En este sentido Hans-Jörg Rheinberger ha remarcado la necesidad de preguntarse por " [...] the peculiar historical character of scientific objects, or epistemic things and that of our historical narratives, what it means to speak of scientific objects and what it means to organize our stories around them"2.

Los espacios de las prácticas antropológicas de la Argentina de fines del siglo XIX y principios del siglo XX no pueden ser considerados campos aislados. Su desarrollo será atravesado por un número indefinido de relaciones, ya sea a través de personas y/o instituciones que vincularán distintos espacios donde el estudio del hombre ocupará un espacio central. En este sentido el periodo temporal abarcado por la producción científica de Paul Adolf Robert Lehmann-Nitsche nos permitirá identificar, describir y analizar el trayecto histórico de una serie de epistemes específicas que delimitarán y caracterizaran los espacios de las prácticas antropológicas desarrolladas en la Argentina en el marco temporal señalado en el titulo de esta tesis doctoral. La elección del mismo entre los años 1894 y 1938 responde al periodo en el cual será publicada la producción científica de Lehmann-Nitsche. En la primera de estas fechas aparecía la primera de sus tesis doctorales, en la cual sintetizaba las investigaciones que venia realizando desde 1890. Finalmente en 1938, año de su muerte, se editaba su último trabajo póstumo en el cual se compendiaban los resultados de los trabajos realizados a partir de la década de 1930.

La elección de la obra de Lehmann-Nitsche lejos esta de radicar en la importancia y el rol que este último desempeño en la antropología argentina, y más específicamente en el contexto platense. Como veremos en detalle en los capítulos que componen esta tesis doctoral la elección de la misma se debe al recorrido temporal, institucional y temático que la misma implica. Lehmann-Nitsche, a lo largo de 30 años de residencia en la Argentina, sabrá participar, principalmente, y articular un complejo entramado de relaciones sociales e institucionales a escala nacional e internacional a fin de colectar elementos y datos para la redacción de sus trabajos. Al mismo tiempo los vínculos sostenidos con distintos estudiosos alemanes; residentes tanto en América como en Alemania; le granjearan la posibilidad de introducir nuevos temas,

\footnotetext{
${ }^{1}$ Latour 1990, 1992.

${ }^{2}$ Rheinberger 2000.
} 
instrumentos y metodologías al estudio del hombre en el contexto de la antropología argentina. La conjugación de estos elementos le permitirá a Lehmann-Nitsche constituirse en una de las figuras "centrales" del desarrollo de la antropología argentina, tal como detallan las reconstrucciones biográficas del mismo ${ }^{3}$. Sin embargo, dicha "centralidad" debe vincularse a la posibilidad y la habilidad de Lehmann-Nitsche de articular estos elementos para sus propios beneficios, los cuales serán principalmente la construcción una trayectoria científico-académica que le permitiera volver a Alemania y continuar la misma allí.

La amplitud temática de la obra publicada de Lehmann-Nitsche será uno de los elementos que ciertos autores ven como el producto de sus múltiples intereses y el resultado una perspectiva innovadora. Lejos de preguntarse el por qué de dichos intereses, estas reconstrucciones biográficas han descripto y definido a Lehmann-Nitsche como el "fundador" o "inaugurador" de las temáticas por el estudiadas ${ }^{4}$. La multiplicidad de intereses nos habla de la ausencia de un plan sistemático de investigación a largo plazo. Si bien es cierto que en este punto es necesario considerar los condicionamientos institucionales, económicos y sociales del contexto en el cual Lehmann-Nitsche desarrolla sus trabajos, podemos observar una continuidad temática en los trabajos de otros estudiosos alemanes con amplia residencia en América, como Rudolf Lenz Danziger en Chile, Hermann von Ihering en Brasil o Franz Boas en Estados Unidos.

A diferencia de estos Lehmann-Nitsche ira adaptando sus trabajos a las necesidades y objetivos de proyectos muchos más amplios, principalmente aquellos llevados adelante por los principales espacios científicos europeos -especialmente alemanes-, y en menor medida los que llevaban adelante otros estudiosos alemanes residentes en América. En este sentido es necesario comprender, en palabras de Michel Foucault, “[...] las formaciones discursivas, de las positividades y del saber en sus relaciones con las figuras epistemológicas y las ciencias [...] el conjunto de las relaciones que pueden unir, en una época dada, las prácticas discursivas que dan lugar a figuras epistemológicas, a ciencias, eventualmente a sistemas formalizados; el modo según el cual, en cada una de estas formaciones discursivas, se sitúan y se operan los pasajes a la epistemologización, a la cientificidad, a la formalización”, en este sentido estas epistemes serán "[...] el conjunto de relaciones que se pueden descubrir, para una época dada, entre las ciencias cuando se las analiza en el nivel de las regularidades discursivas".

El amplio espectro temático presente en la obra de Lehmann-Nitsche, por otro lado, nos permite ver la discontinuidad, las fracturas y el caos que caracterizarán las prácticas antropológicas desarrolladas en la Argentina entre fines del siglo XIX y principios del siglo XX.

\footnotetext{
${ }^{3}$ Entre otros: Aretz 1991; Bilbao 2004; Carrizo 1953; Chertudi 1964; Chertudi y Newbery 1978; Cortazar 1964; Danero 1962; Guido 1975; Rama 1977.

${ }^{4}$ Ibídem.

${ }^{5}$ Foucault 1994, p. 249-250.
} 
Lehmann-Nitsche mostrará un escaso interés en homogeneizar o establecer una regularidad en la forma en la cual estas prácticas eran desarrolladas. Esto se observa en el poco éxito y la escasa preocupación mostrada al momento de formar un grupo de discípulos que lo auxiliarán y continuaran su obra. Este hecho puede ser explicado, en parte, por los verdaderos objetivos de Lehmann-Nitsche al aceptar el puesto de encargado de la Sección de Antropología del Museo de la Plata. En diversas cartas a sus familiares y a otros estudiosos alemanes manifestaba que el trabajo en la institución platense solo seria temporal, siendo un proceso transitorio entre el final de sus estudios universitarios y un puesto permanente en algún espacio de investigación y/o académico alemán ${ }^{6}$.

Esto no será ajeno a otros estudiosos alemanes residentes en América. En muchos casos estos accedían a trabajar en los institutos y academias del Nuevo Mundo para poder acumular experiencia; y principalmente publicaciones; con el objetivo de insertarse en el mundo académico y científico europeo. A fin de convencer a Lehmann-Nitsche para que aceptara ponerse al frente de la Sección de Antropología del Museo de la Plata, remarcaba el médico y antropólogo suizo Rudolf Martin (1864-1925) que poco podía esperar un joven graduado en los principales espacios académicos y científicos de Europa si no contaba con un considerable número de importantes monografías publicadas.

Hacia fines del siglo XIX; como se detallará extensamente en el capitulo I; el estado de la práctica antropológica en Europa, y especialmente en Alemania, distaba de ser ideal. A lo largo de la segunda mitad del siglo XIX los estudiosos alemanes abocados al estudio del hombre centrarán sus esfuerzos en documentar la pluralidad y la especifidad histórica de las culturas ${ }^{7}$. Como han señalado Glenn Penny y Matti Bunzl, entre otros, esto llevará a que para comienzos del siglo XX el estado de la práctica y de las instituciones antropológicas estuviera sumido en el caos $^{8}$. Este no solo referirá al estado de las colecciones museísticas, sino también a una estructura de investigación que se encontraba saturada de estudiosos.

Hacia fines del siglo XIX las principales instituciones alemanas no solo sufrían la falta de espacio físico para la enorme cantidad de objetos acumulados, sino también de plazas de investigación para los estudiosos, en parte como resultado de los procesos de profesionalización e institucionalización de las prácticas antropológicas. Al momento en el cual Lehmann-Nitsche finaliza sus estudios universitarios los espacios disponibles para realizar una carrera científicoacadémica en Alemania serán muy escasos. Esto se vincula; como veremos en el Capítulo I; con las características de los procesos de institucionalización de las prácticas antropológicas en la

\footnotetext{
6 Principalmente en la correspondencia a su madre Ida Laura Auguste Stephan, pero también a otras personas de su circo familiar como Paul Ennke, Else Lehmann-Nitsche, Franz Stephan, Eugen LehmannNitsche, Claire Brinckmann, Rudolf Lehmann-Nitsche y Frieda Lehmann-Nitsche. Legado Robert Lehmann-Nitsche, IAI.

${ }^{7}$ Penny y Bunzl 2003.

${ }^{8}$ Penny 2002 a, 2003, 2005.
} 
Alemania de la segunda mitad del siglo XIX como así también los objetivos de los programas de investigación que se implementarían. Esto llevara, entre otras cosas, a que un considerable número de antropólogos alemanes, entre los cuales se encuentra Lehmann-Nitsche, migren al Nuevo Mundo en busca de oportunidades para construir su carrera científico-académica.

Si bien no es el objetivo ni la finalidad de este trabajo realizar una lista detallada de todas las personas que hacia época se encontraban realizando investigaciones y/o trabajos antropológicos, si podemos mencionar a una serie de individuos que sabrán organizar, estructurar y capitalizar los medios, instrumentos y recursos necesarios para llevarlos adelante. En Berlín tendremos al etnólogo alemán Philipp Wilhelm Adolf Bastian (1826-1905); director del Museum für Völkerkunde de Berlin; y al médico alemán Rudolf Ludwig Karl Virchow (1821-1902). A estos se sumaban personajes como: el médico y antropólogo austriaco Félix Ritter von Luschan (1854-1924), el antropólogo alemán Paul Ehrenreich (1855-1914), el médico alemán Karl von den Steinen (1855-1929), el americanista alemán Eduard Georg Seler (1849-1922), el anatomista y patólogo alemán Heinrich Wilhelm Gottfried Waldeyer (18361921), el anatomista alemán Gustav Theodor Fritsch (1838-1937), el anatomista y médico alemán Hans Virchow (1852-1940), el antropólogo alemán Arthur Baessler (1857-1907), el etnólogo alemán Robert Fritz Graebner (1877-1934), el indologo alemán Albert Grünwedel (1856-1935), el etnógrafo alemán Andreas Fedor Jagor (1816-1900), el arqueólogo alemán Richard Schöne (1840-1922) y el explorador alemán Georg August Schweinfurth (1836-1925) entre otros.

El caso de Hamburg y Leipzig no será muy distinto al de Berlin. En la primera de estas podemos mencionar al jurista alemán Justus Brinckmann (1843-1915), el malacólogo y etnólogo alemán Hermann Wilhelm Strebel (1834-1914), el médico y etnólogo alemán Georg Christian Thilenius (1868-1937) y al geólogo y paleontólogo alemán Carl Christian Gottsche (1855-1909). En el caso de la segunda tendremos al geógrafo y etnólogo alemán Karl Weule (1864-1926), el médico alemán Hemann Obst, el geógrafo alemán Hans Heinrich Josef Meyer (1858-1929) y el etnólogo alemán Leo Frobenius (1873-1938). Finalmente en München junto con el médico alemán Johannes Ranke (1836-1916) debemos mencionar al médico y etnógrafo alemán Max Joseph August Heinrich Markus Buchner (1846-1921) y al geógrafo alemán Eduard Pechuel-Loesche (1840-1913) entre otros.

A esta situación se sumaba la necesidad; por parte de los programas y los objetivos de las principales instituciones germánicas; de contar con individuos que pudieran establecer y/o participar en las redes de aprovisionamiento de datos y objetos fuera de las fronteras alemanas. Esto llevará a que muchos estudiosos alemanes migren viendo esto como una oportunidad de formar parte y contribuir con dichos programas y objetivos, y al mismo tiempo como la mejor oportunidad de poder obtener un puesto académico y/o de investigación en Alemania. De esta forma, y por una serie de interés personales que veremos más adelante, Rudolf Martin describía 
el material de estudio disponible en el museo platense como un valioso recurso desaprovechado por la escasa presencia de profesionales formados que pudieran sacar provecho de los mismos. Estos elementos se conjugaban, en palabras de Martin, como el acceso de Lehmann-Nitsche a un promisorio futuro científico y académico. Este tipo de prácticas no será exclusivo del ámbito antropológico, siendo caracterizadas por Lewis Pyenson como una de las principales estrategias de los estudiosos franceses y alemanes vinculados a la difusión de las ciencias exactas en Latinoamérica entre 1850 y 1930. En este sentido caracterizará su tarea como similar a la realizada por los misioneros jesuitas de ultramar, ya que "A missionary should have expected to retreat home to retirement after an exhausting overseas career; if he came earlier, he could well have benn typecast in an uncomfortable role".

A partir de esto es posible reconsiderar la imagen innovadora que las reconstrucciones biográficas han tenido sobre la producción científica de Lehmann-Nitsche ${ }^{10}$. Esta se alejará de la innovación en el campo metodológico y/o teórico, siendo lo novedoso de la misma consecuencia de la incorporación de técnicas e instrumentos provenientes del Viejo Mundo a los trabajos de laboratorio y a los estudios de campo realizados en Sudamérica. Esto junto con el intercambio de materiales y datos a través del Atlántico y dentro del propio Continente Americano dará un significativo impulso al estudio del hombre; ya fuera a través de sus cuerpos o de sus expresiones culturales.

La incorporación de nuevas técnicas e instrumentos al estudio de estos elementos por parte de Lehmann-Nitsche se vinculará con la intención de continuar investigaciones previas llevadas adelante por otros estudiosos. Esto nos permite observar por un lado el carácter colectivo de la construcción del saber, en la cual las investigaciones individuales se articulan en proyectos que trascienden las fronteras de los contextos locales en los cuales los estudiosos extranjeros residentes en América realizaban su trabajo. Por otro lado nos permitirá identificar la continuidad de estas investigaciones como una de las estrategias implementadas por los estudiosos al momento obtener el reconocimiento que le permitiera obtener un puesto en los espacios académicos y científicos europeos.

Como ha señalado Lewis Pyenson "[...] in Germany publications were seen as a route to success" ${ }^{\prime 1}$. En consecuencia Lehmann-Nitsche expresará en su correspondencia privada que era consciente de que los enfoques teórico/metodológicos de sus trabajos no eran novedosos para el contexto europeo, pero que los datos aportados por él a las discusiones internacionales eran producto de los materiales depositados en el Museo de La Plata, sobre los cuales tenía acceso exclusivo. A si mismo esto nos permite valorar de otra forma la producción científica de

\footnotetext{
${ }^{9}$ Pyenson 1985 b, p.389.

10 Entre otros: Aretz 1991; Bilbao 2004; Carrizo 1953; Chertudi 1964; Chertudi y Newbery 1978; Cortazar 1964; Danero 1962; Guido 1975; Rama 1977.

${ }^{11}$ Pyenson 1985 b, p. 392.
} 
Lehmann-Nitsche, limitada a aquellos temas que ocupaban un lugar central en las agendas de los principales centros de estudios del Viejo Mundo, especialmente los de Alemania.

El tomar la obra de Lehmann-Nitsche como punto de referencia para nuestro análisis, nos permitirá deconstruir la historia de los elementos que fueron objeto de de las prácticas antropológicas desarrolladas en la Argentina entre fines del siglo XIX y principios del siglo XX. Como ha señalado Rheinberger esto permite caracterizar las redes institucionales, sociales y científicas en las cuales estos objetos se desenvuelven; ya que el "movimiento" de los objetos a través de estas redes contribuye a la construcción y determinación de estas ${ }^{12}$. Por consiguiente las poblaciones humanas, o sus restos materiales, serán objeto de una actividad epistémica específica, generando, en un periodo de tiempo determinado, una serie de desarrollos teóricos y prácticos a fin de "estabilizarlos" en tiempo y espacio, constituyendo de esta manera un objeto de estudio especifico.

Como ha señalado Michel Foucault "En lugar de ocuparse de una historia económica, social, política, abarcando una historia del pensamiento (la cual sería como la expresión y como el doblete), en lugar de ocuparse de una historia de las ideas que haría referencia (ya sea por un juego de signos y expresiones o por las relaciones de causalidad) a las condiciones extrínsecas, habría que ocuparse de una historia de las prácticas discursivas en las relaciones específicas que las articulan con otras prácticas"13. En este sentido las preguntas esenciales al momento de analizar las prácticas y los discursos asociados a ellas no deben centrarse sobre la biografía individual, sino que estas deben articularse alrededor de los modos de existencia de los discursos y las prácticas, como estos han sido usados, como han circulado, cuales son los espacios posibles para que los sujetos las lleven a cabo. Detrás de todas estas preguntas yace el nodo central en este tipo de análisis: No importa quién es el que habla, la función de los individuos se torna esencial en la existencia, circulación y funcionamiento de ciertos discursos ${ }^{14}$.

Los temas que componen los capítulos de esta tesis doctoral pretender dar cuenta de la interacción de los objetos, las relaciones, los discursos y las estructuras a partir de las cuales se constituyen las prácticas y los espacios antropológicos. Al mismo tiempo se pretende revalorar y ofrecer otra mirada sobre de los distintos espacios de encuentro y actores que mediaron/intervinieron entre los objetos de estudio elegido, los distintos espacios involucrados y los sectores científicos. Estos elementos son la fundamentación subyacente a la elección de los temas desarrollados en los capítulos de esta tesis doctoral. Al mismo tiempo estos se organizan siguiendo un orden temático, dando cuenta de los principales objetos/sujetos de investigación

\footnotetext{
${ }^{12}$ Rheinberger 2000.

${ }^{13}$ Foucault 1994, p. 68.

${ }^{14}$ Ibídem.
} 
presentes en la obra de Lehmann-Nitsche; buscando dar cuenta de las estrategias para obtener información y colecciones así como los distintos circuitos en los que participaron los objetos o individuos estudiados.

Previamente a los capítulos que componen esta tesis doctoral se incluye una biografía descriptiva de Lehmann-Nitsche en la cual analizamos de forma crítica los trabajos previos a su llegada al Museo de La Plata. Posteriormente se consideran y se mencionan en forma breve los principales aspectos de las actividades desarrolladas por Lehmann-Nitsche a lo largo de sus 30 años como de jefe de la Sección de Antropología del Museo de La Plata. Dichos elementos serán profundizados en los capítulos principales de esta tesis doctoral. No es el objetivo de esta tesis; ni tampoco se condice con la metodología en ella empleada; una reconstrucción biobibliográfica de la vida de Lehmann-Nitsche. De todos modos se incluye un anexo en el Tomo II en el cual se presenta una "línea de tiempo" con una cronología de los acontecimientos biográficos "relevantes" de este último a fin de facilitar la lectura al lector.

En el capítulo I se presenta el estado de la práctica antropológica entre fines del siglo XIX y principios del siglo XX, caracterizada por los intentos de orden ante el caos de la propia disciplina. En este sentido se da cuenta de los principales debates en torno a la búsqueda de una estandarización de los métodos craneométricos en la Antropología. Se prestará especial atención a las discusiones surgidas en Alemania, Francia y en menor medida Inglaterra y Estados Unidos. Hacia comienzos de la segunda mitad del siglo XIX tanto en Francia como en Alemania se darán una serie de discusiones vinculadas a los procesos de institucionalización de las prácticas antropológicas, los cuales buscaban estandarizar un/los programa/s de investigación. Como ha sido advertido por otros autores, las instituciones y los estudiosos de estos dos países tendrán una notable influencia en el desarrollo de las prácticas antropológicas a escala internacional ${ }^{15}$. En este sentido es preciso dar cuenta de dichas discusiones a fin de entender la incidencia de las mismas en el contexto específico del Museo de La Plata. Los principales elementos a analizar serán la sucesión de congresos antropológicos, los manuales, las instrucciones y los intentos de acuerdos antropométricos, haciendo especial énfasis en el cráneo.

Seguidamente el Capítulo II analiza el estado "caótico" de la práctica antropológica en la Argentina hacia fines del siglo XIX. Primeramente se presentan los intereses particulares de Rudolf Martin para la designación de Robert Lehmann-Nitsche como encargado de la sección antropológica del Museo de la Plata.

Consecutivamente en el capítulo III, y tomando como referente empírico las colecciones osteológicas, abordamos la re-orientación de los estudios y las colecciones antropológicas a los proyectos desarrollados en Europa, especialmente Alemania. En particular, este capítulo se

${ }^{15}$ Blanckaert 1988, 1989 b; Penny y Bunzl 2003; Pyenson 1985 b. 
estructura alrededor del análisis de las siguientes cuestiones: a) la re-orientación de los estudios craneológicos; b) el uso y el estudio de cráneos y elementos arqueológicos en los debates sobre la "medicina prehistórica"; y c) el traslado de elementos de las colecciones craneológicas a Europa.

El capítulo IV se centra en ciertos espacios donde las prácticas antropológicas son realizadas. Se mostrará como el trabajo de campo no implicaba, en la época, un desplazamiento geográfico, y que en muchos casos será resultado de situaciones fortuitas aprovechadas por los antropólogos. Se atenderá especialmente a los estudios llevados adelante en: a) cárceles, comisarías y la actuación de los antropólogos como "peritos judiciales"; b) ferias comerciales y asilos de inmigrantes; c) instituciones mentales. Estos espacios, como veremos, se contarán entre los predilectos de los estudiosos de la época para la realización del "trabajo de campo", especialmente por formar parte esencial de los circuitos donde los objetos de estudio; ya fuera una pieza arqueológica o un individuo; transitaban.

Es preciso mencionar que si bien los capítulos II a IV versan sobre los estudios sobre individuos, ya fuera sobre sus cuerpos o sobre sus restos materiales, la separación de la temática en capítulos distintos responde principalmente a la necesidad de enfocar sobre ciertos aspectos específicos en la idealización, diagramación y ejecución de dichos trabajos por parte de Lehmann-Nitsche. Al mismo tiempo dicha división responde, en menor medida, a la organización temática de los trabajos que implementara este último.

En concordancia con la justificación esgrimida para el capítulo IV, en el capítulo V se analizan la recolección y el estudio de las tradiciones "populares" a comienzos del siglo XX prestando especial atención a los siguientes puntos: a) las redes de circulación de las tradiciones "populares": libros, panfletos y la prensa diaria; b) el uso de bares, fondas, prostíbulos y puertos como espacios donde observar la pluralidad de las tradiciones "populares" y donde articular redes de aprovisionamiento de datos; c) la implementación de nuevas tecnologías en los procesos de recolección de datos, específicamente el caso del fonógrafo. A partir de los mismos se pretende demostrar que las "innovaciones" por parte de Lehmann-Nitsche en este tipo de trabajos se vinculan esencialmente a la incorporación de tecnologías novedosas para el contexto local y al uso de espacios no considerados en la época por parte de los antropólogos locales.

En el capítulo VI nos centralizamos en las dinámicas y los procesos implicados en la diagramación y la ejecución de las excursiones al campo. Prestando especial atención a los viajes realizados por Lehmann-Nitsche a Tierra del Fuego (1902) y el Noroeste argentino (1906), se atenderá esencialmente: a) la influencia de los estudios etnográficos alemanes emprendidos al Alto Xingú en la construcción del indígena sudamericano; b) las redes de comunicación y transporte; c) los espacios elegidos para la realización de los estudios. De esta forma procuramos demostrar que la importancia y la incidencia de estos elementos al momento de la elección de los lugares en donde llevar a cabo las excursiones al campo, elección que 
como observaremos en el caso de Lehmann-Nitsche está supeditada a los objetivos de los programas de investigación alemanes.

En el capítulo VII se presentan y analizan, a través de los estudios linguísticos, mitológicos y astronómicos, las redes de cooperación locales e internacionales establecidas por Lehmann-Nitsche a fin de auxiliarlo en sus proyectos. Se detallan: a) la red de colonos ingleses; b) la red de informantes indígenas y c) la red de estudiosos alemanes. Este grupo de actores serán una parte fundamental en esta serie de trabajos, no solo recolectando información, datos y objetos; sino en algunos casos llegando a realizar ellos mismos los trabajos.

Seguidamente en el capítulo VIII se analizan los espacios de enseñanza de la Antropología. Para esto tomamos los casos de: a) la enseñanza de la Antropología en la Universidad Nacional de Buenos Aires y b) la enseñanza de la Antropología en la Universidad Nacional de la Plata. Si bien estos dos espacios se presentan como claves al momento de fomentar los procesos de institucionalización y profesionalización de las prácticas antropológicas en la Argentina, esto estará muy lejos de los objetivos de Lehmann-Nitsche, para el cual será solo otro elemento que le podría facilitar la adquisición de un lugar en los espacios de investigación y enseñanza alemanes.

Por ultimo en el capítulo IX se analizan los espacios de interacción con otros estudiosos. Para esto analizaremos sucintamente: a) congresos nacionales e internacionales y b) instituciones científicas nacionales e internacionales. Estos serán las estructuras institucionales sobre los cuales se organicen y definan objetivos, metodologías, estrategias y programas de investigación. En el caso especifico de Lehmann-Nitsche serán los medios a partir de los cuales se podrá actualizarse en lo concerniente a esto últimos puntos mencionados y además los espacios en los cuales podrá reforzar y establecer nuevos vínculos profesionales. Finalmente en el Anexo se presentan las imágenes y los cuadros complementarios mencionadas a lo largo del texto.

\section{Algunas cuestiones teórico- metodológicas}

La historia del saber -entendida como la historia de la memoria, de la comunicación y de la transformación de las ideas- no se constituye a través de objetos y de operaciones ideales del pensar. La historia del conocimiento, por el contrario, debe entenderse como un estudio de la materialidad y de la localización de los distintos modos de conocer. Hablar del espacio del saber se refiere al vínculo con los espacios concretos donde se produce ${ }^{16}$.

En los últimos años, los trabajos realizados sobre los laboratorios en el marco que ha sido llamado "ciencia en acción" consideraron a la actividad experimental dentro de un amplio

\footnotetext{
${ }^{16}$ Blanckaert 1995, 1996; Daston y Galison 2010; Daston y Lunbeck 2011; Galison 1988; Rudwick 1976, 1985; Shapin y Schaffer1985.
} 
contexto del equipamiento y las prácticas culturales asociadas. En ese marco, lejos de ser solo un espacio físico en el cual los experimentos y observaciones son producidos, el laboratorio emerge como un importante aspecto para nuestro entendimiento de la ciencia. Los estudios del laboratorio sugieren que este espacio se constituye como un medio de trasformar el mundo natural en una vía que permite a los científicos una manipulación diferencial o mayor del orden natural en relación con el orden social ${ }^{17}$.

El laboratorio aparece, entonces, como un ambiente reforzado que permite capitalizar los apremios humanos y las restricciones socioculturales generando una mayor "maleabilidad" de los objetos naturales a través de la creación de sus propias coordenadas geográficas y temporales. Desde el punto de vista temporal y espacial, ciertos procesos se tornan mensurables u observables para la visión humana. Los investigadores en el laboratorio no necesitan acomodarse a los tiempos y ambientes de los objetos o a sus ciclos naturales: estos se pueden sustituir por versiones parciales o totales, intentando que sucedan con una frecuencia suficiente para su estudio continuo y plausible de ser reproducido las veces necesarias, o por lo menos, a una escala de tiempo acotada a los tiempos de los científicos. Los estudios de laboratorios sugieren que precisamente escapando a esa necesidad de acomodar los objetos al mundo natural, los laboratorios constituyeron su ventaja epistemológica. Esto es, la separación de los objetos de su ambiente natural y su instalación en un nuevo campo fenomenal definido por los agentes sociales $^{18}$.

En los últimos años, la localización de las instituciones científicas y del conocimiento se ha vuelto un eje importante para examinar temas tales como las arquitecturas de los edificios que albergan la investigación como medio técnico e instrumento de observación. Entre ellos, se cuentan los museos en su doble dimensión: espacio de exhibición pública y locus del trabajo científico $^{19}$.

\section{Trabajos historiográficos sobre las ciencias antropológicas}

En el caso concreto de la antropología, la historiografía ha considerado el período comprendido entre los años 1870 y 1930 como un momento "fundacional" para las ciencias antropológicas. En los últimos 30 años, los trabajos de Claude Blanckaert, Curtis Hinsley, George Stocking, Glenn Penny y Nélia Dias han profundizado en ese período y planteado nuevos problemas. En particular, estos autores se han preocupado por analizar las prácticas de la antropología ligadas al armado de colecciones, establecimiento de museos, definición de protocolos y modos de observación de los seres humanos vivos y fallecidos, su cultura material, su lengua y aquello que empieza a ser conceptualizado como "patrimonio intangible" (música,

\footnotetext{
${ }^{17}$ Latour 1992; Latour y Woolgar 1986; Shapin y Schaffer1985.

${ }^{18}$ Ibídem.

${ }^{19}$ Dias 1991; Findlen 1994.
} 
tradiciones, relatos, etc. $)^{20}$. El espacio del gabinete se empezaría a plantear en oposición o complementación de ese nuevo espacio llamado "campo" ("field" en la tradición inglesa, el "terrain" de la tradición francesa), definido en los inicios del Siglo XX como un espacio que debe ser controlado por los mismos científicos. En esta tesis nos proponemos retomar estos debates para analizar la constitución de los espacios de observación de la antropología en la Argentina tomando como caso de estudio la obra de Robert Lehmann-Nitsche, con todas las ramificaciones que esto implica ${ }^{21}$.

Aunque en la Argentina la historiografía de las ciencias antropológicas de este período cuenta con una cierta bibliografía, la misma no solo desconoce el estado internacional del problema sino que analiza el estado de la antropología local en desconexión de los debates de otros centros académicos. Asimismo, se ha basado principalmente en fuentes publicadas y secundarias. Esto estableció una serie de imágenes del quehacer antropológico que asentaron una serie de hechos que, al no ser cuestionados en profundidad, ofrecen una efigie parcializada y reifican ciertos lugares comunes. La gran mayoría de los trabajos, especialmente los de la década de 1980 en adelante se centraron en las biografías de determinados personajes, o bien en historias institucionales simplificadas en base a lecturas de fuentes de orden terciario ${ }^{22}$.

En esta tesis se asume que las prácticas de la antropología se vinculan a la constitución y establecimiento de una serie de redes de intercambio de objetos y de información para la recopilación de datos más acá y más allá de las fronteras nacionales e internacionales. Asimismo, presupone que la ciencia es una práctica colectiva y asociativa que trasciende las fronteras nacionales. Irina Podgorny, siguiendo la postura de Kaeser, recordó las raíces internacionales de la prehistoria en asociación con otras disciplinas del siglo XIX como la geología y la paleontología; es decir “[...] aceptar la idea de un desarrollo histórico de la naturaleza y de la humanidad comparable en todo el globo[...]" lo cual llevó a "[...] tender una infraestructura material para generar, transmitir y procesar la información procedente de lugares remotos" $" 23$.

El mero surgimiento del conocimiento experimental se vincula a las convenciones para producir "hechos" 24 . En ese marco, el testimonio ocular, colectivo y público, presencial o virtual, adquiere un papel constitutivo. Los resortes mismos de la producción del conocimiento parecieron accesibles gracias a la articulación de dos espacios: el espacio físico del testimonio directo -los nuevos "laboratorios" y gabinetes- y el espacio abstracto del testimonio virtual, generado por las llamadas "tecnologías literarias" "25. Podríamos afirmar que la consolidación, en

\footnotetext{
${ }^{20}$ Blanckaert 1995, 1996; Dias 1991; Hinsley 1983; Penny 2002 a.

${ }^{21}$ Podgorny 2001 a, 2001 b., 2004, 2006, 2008.

${ }^{22}$ Ibídem.

${ }^{23}$ Podgorny 2007 b, p. 125.

${ }^{24}$ Shapin y Schaffer 1985.

${ }^{25}$ Shapin y Schaffer 1985; Findlen 1994; Podgorny 2001, 2004, 2006, 2008.
} 
los inicios del siglo XX, de ciencias tales como la antropología y la prehistoria, se define por la creación y control de un tercer espacio público, concreto y abstracto a la vez: el campo o terreno $^{26}$. La existencia del campo como espacio objetivo surgirá a través de tecnologías literarias similares a las del inicio de la modernidad, entre ellas, el "lenguaje visual" de las publicaciones científicas del siglo XIX y las tecnologías del transporte de la era del Imperio ${ }^{27}$. Por otro lado, los criterios de credibilidad se concentrarán en el científico presente en el campo, una exigencia metodológica consolidada en los inicios del siglo XX.

\section{El campo y el gabinete como espacios objetivos}

La antropología y las ciencias de la naturaleza de fines del siglo XIX e inicios del siglo XX reposan sobre la existencia de corresponsales y comisionados "en el campo", que se encargan de recolectar objetos, vocabularios e información para mandar a las instituciones metropolitanas, laicas o religiosas. Esta perspectiva permitirá por un lado analizar la conformación de una logística "cooperativa" y de alianzas, estructurada de manera transnacional para intercambiar objetos, imágenes e información ${ }^{28}$. Pretendemos recuperar el lugar de importancia que merecen los actores sociales involucrados y las redes sociales en las que estos interactúan, oscurecido por la historiografía nacida en el mismo siglo XIX, con las biografías de los grandes científicos y la épica del progreso de la ciencia.

Como ha señalado Irina Podgorny la afirmación de Leroi-Gourhan sobre la prehistoria moderna debe entenderse en ese sentido: "c'est sur le terrain que se déroule l'étape majeure de la recherche" ${ }^{\text {29 }}$. De allí surgirá un personaje compuesto por el conocimiento del hombre de letras, la mente del ingeniero y la autoridad del juez, testigo de los hechos. Lo acompañará la famosa figura del "sabio de gabinete", usada para desprestigiar el estudio basado en la evidencia recolectada por corresponsales y comisionados especiales ${ }^{30}$. En consonancia, el papel de los aficionados y de las sociedades eruditas en el desarrollo de estas disciplinas, algo aceptado hasta bien entrado el siglo XX, reaparece, ligado al problema de la autoridad del científico y la construcción del objeto arqueológico ${ }^{31}$. La condena a los "científicos de gabinete" y a la división del trabajo parece ser una invención del siglo XX, reafirmada por la historiografía que vio en la reunión del trabajo de campo y de síntesis en un solo individuo una suerte de avance definitivo y fundamental en la consolidación de la profesionalización de las disciplinas ${ }^{32}$.

Otro de los espacios que se estudiará en este trabajo se refiere a las colecciones antropológicas, partiendo de una concepción de las mismas como imprescindibles para el

\footnotetext{
${ }^{26}$ cf. Blanckaert 1996; Podgorny 2007 b.

${ }^{27}$ Rudwick 1976

${ }^{28}$ Rudwick 1997.

${ }^{29}$ Podgorny 2004, 2005, 2008.

${ }^{30}$ Bourguet 1997; Rudwick 1997

${ }^{31}$ Leroi-Gourhan 1950; cf. Levine 1986.

${ }^{32}$ Podgorny 2002 a, 2006, 2008.
} 
avance de las ciencias naturales. Planteamos por lo tanto una relación de modificación mutua entre las condiciones de las colecciones y el desarrollo teórico de la Antropología. De modo que un cambio en el dominio interno de estudio se traducirá en una modificación en la manera de observar, registrar y catalogar los objetos. Este punto tendrá su correlato en la disposición y clasificación de las colecciones. Las colecciones, como ha afirmado Nélia Dias, son indispensables en la enseñanza y la investigación. Hacen tangible la Antropología, que por un lado legitima su apariencia como Ciencia Natural; y por otro lado preserva ese saber de las esferas filosóficas y metafísicas.

\section{Las instrucciones, la recolección de materiales y colecciones}

Los trabajos de Claude Blanckaert en Francia han insistido en la relación entre la encuesta y la definición del campo como un espacio de la antropología y de la etnografía. Recordemos que la práctica de la historia natural se basaba en una división, adoptada en casi todas las instituciones del mundo desde inicios del siglo XVIII, entre quienes clasificaban y sistematizaban en los gabinetes y aquellos que se relacionaban con el terreno. La recolección de especímenes y de datos estaba, sin embargo, dirigida y ordenada desde las "instrucciones" de las sociedades e instituciones metropolitanas.

Las primeras de estas instrucciones, bajo la forma de encuestas que debían seguir los viajeros, provienen de Inglaterra y datan de la segunda mitad del siglo XVII. A lo largo del siglo XVIII, diversas sociedades y academias del continente europeo producirán incontables de estas instrucciones que procuraban educar la vista y los gestos del viajero-colector ante una naturaleza distante. Como señala Bourguet la empresa del inventario y descripción del mundo precisaba "disciplinar y codificar el viaje, educar al viajero, disciplinar su curiosidad y su conducta”, es decir la mirada del que viajaba debía ser dirigida, así como debían crearse los gestos correctos para que el espíritu de síntesis del centro tuviera la certeza que esos materiales habían sido recogidos con la extensión de sus propias manos ${ }^{33}$.

Las "instrucciones" consistían en procedimientos que se debían seguir en la recolección de plantas, animales y minerales o en el uso de instrumentos. Por otro lado, a principios del siglo XIX el conocimiento procedente de las exploraciones no tenía un status similar al producido en los gabinetes y hacer ciencia en el terreno de continentes extraños era visto con suspicacia . No sólo se dudaba de lo que se decía sino, sobre todo, de la necesidad de emprender el viaje. Entre el naturalista viajero y el sedentario, el segundo gozaba de la confianza dada por la posesión del tiempo, de las colecciones y de los libros necesarios para la observación y comparación. El viajero, por el contrario, disponía de un tiempo limitado que fragmentaba su

\footnotetext{
${ }^{33}$ Bourguet 1997; Bourgeut et.all 2002.
} 
capacidad de observación en piezas que sólo tenían sentido una vez depositadas en los gabinetes $^{34}$.

El mismo espacio del estudio o del museo aparecía, entonces y singularmente, como más amplio, más representativo del universo total que el camino del viajero transitable en un solo sentido. La posibilidad que el terreno rompiera la capacidad de observación del naturalista debe entenderse en un contexto en el que se aceptaba que las colecciones podían recomponer un todo y que, como sostiene Pomian, las colecciones -como lo visible- representaban y completaban la relación entre los europeos y lo invisible de los espacios distantes. Las colecciones, los catálogos, las bibliotecas y los archivos componían los espacios a los que se podía recurrir una y otra vez y recorrer en tantos sentidos como se deseara ${ }^{35}$. Estos trabajos sobre la codificación de la mirada y la estandarización de la observación por parte de los corresponsales constituyen un antecedente primordial para nuestra investigación. Es interesante la concepción utilizada por Irina Podgorny en cuanto al estudio de la disciplina antropológica en la cual se interrelaciona, a través del estudio de los lugares de intercambio y circulación de ideas, objetos, personas e información, dirigiendo la historia de la ciencia al estudio de los procesos geopolíticos y de las tecnologías de comunicación y la información ${ }^{36}$.

\section{Redes de colaboración-Constitución de la evidencia}

En el marco teórico que se viene discutiendo, aparece el problema de cómo se constituye la evidencia y los resortes utilizados para que un objeto sea considerado "verdadero" (perteneciente al contexto al que se atribuye). Por otro lado, desde el punto de vista de la materialidad de las prácticas científicas es de suma importancia analizar cuáles son los medios en los cuales se registran o inscriben los objetos recolectados (sean estos tangibles o intangibles) para que puedan ser aceptados como evidencia antropológica.

Este marco teórico presupone, además, hacer historia cuestionando la separación entre "aficionados" y "profesionales", distinción que desde la historia de la ciencia, se vuelve anacrónica para el período que nos interesa estudiar. Desde este marco metodológico, pretendemos reconstruir las redes de circulación de objetos y de información y las estrategias para la obtención de los mismos (quiénes coleccionan, cómo se recolectan los objetos, cómo se registra lo recolectado, cómo se envía a los centros de acopio o a los museos locales, cómo se archivan en los museos, cómo se catalogan, cómo se clasifican).

El campo no está aislado de la confluencia de distintos factores que interactuarán con él en la configuración del objeto a ser estudiado. En consonancia con el punto anterior planteamos el análisis de la relación entre el conocimiento generado en el campo y el trabajo de gabinete, lo

\footnotetext{
${ }^{34}$ Ibídem.

${ }^{35}$ Podgorny 2002 a, 2006, 2008.

${ }^{36}$ Podgorny 2007 b.
} 
cual nos lleva a indagar los contextos particulares en los cuales los distintos actores, involucrados en la construcción del conocimiento antropológico, establecen las relaciones a analizar. El trabajo de campo es también un conjunto de elementos materiales que permiten el traslado, la comunicación, registro, archivo y la relación entre el "campo" y el "gabinete". Nuestro trabajo pretende colaborar con este nuevo campo de atención para una historia de la antropología que en vez de reconstruir linajes o escuelas que se reemplazan unas a otras, muestre la complejidad de la práctica concreta de la ciencia.

En esta tesis planteamos la necesidad, a partir de esta particularidad de la aparición de estos dos espacios contrapuestos del campo y del gabinete, articulados por la colección, de encarar el análisis de las distintas tecnologías de comunicación, circulación e intercambio de objetos. Para ello tomaremos el caso de la obra de Robert Lehmann-Nitsche debido al recorrido temporal, institucional y temático que permite. En este sentido nuestro marco metodológico es el de una historiografía de la ciencia que concibe a la práctica científica como una actividad colectiva y cooperativa, en el sentido que estas palabras cobran en los trabajos de Steven Shapin y Martin Rudwick. Se trata de analizar la aparición de los objetos científicos en función de las redes de circulación de los mismos y la infraestructura material que sostiene dichas redes (redes de comunicación, medios de transporte). Al afirmar que se trata de prácticas cooperativas y colectivas no se está excluyendo la competencia, muy por el contrario, cooperación y competencia son las dos caras de la misma moneda: tratar de armar un universo imposible de reconstruir desde la individualidad del coleccionista u observador aislado ${ }^{37}$.

Queremos señalar aquí que los trabajos de Lehmann-Nitsche se basan, en gran medida, en una extensa red de corresponsales que le envían datos de los más diversos puntos de América. Esta red hasta ahora no ha sido estudiada, como tampoco se ha prestado atención a los mecanismos que Lehmann-Nitsche utilizó para el tendido de esta red o las pautas que brindaba para poder obtener datos comparables y, en este sentido, útiles para sus trabajos planteados a escala sudamericana. Por el contrario, la gran mayoría de los trabajos que han analizado este periodo se ha centrado principalmente en la vertiente bio-bibliográfica.

\section{Trabajos previos sobre Lehmann-Nitsche}

Los trabajos sobre Lehmann-Nitsche pueden ser agrupados en aquellos que lo analizaron desde los aportes en lo que refiere al análisis del lunfardo ${ }^{38}$; los que focalizan en la poesía gauchesca y popular ${ }^{39}$; los análisis de los aportes al estudio de la lírica y la composición

\footnotetext{
${ }^{37}$ Ibídem.

${ }^{38}$ Cancela 1946; Chucoy y Hlavacka de Bonzo 1993; Rey de Guido 1989; Soler Cañas 1965.

${ }^{39}$ Bunge 1914; Chávez 1962; Fernandez Latour de Botas 1966; Lissi 1986.
} 
del tango ${ }^{40}$ y los que se centran exclusivamente en lo referente a los estudios de dialectos indígenas ${ }^{41}$. Podemos resumir algunos de estos trabajos de la siguiente manera:

a) Una de las primeras menciones a los trabajos de Lehmann-Nitsche, posterior a su muerte, fue la nota necrológica que le dedico Márquez Miranda (1938), donde destaca la importancia de Lehmann-Nitsche para la constitución de la sección de Antropología del Museo como un gabinete científico digno de compararse con los de Europa o Estados Unidos, aspecto que poco se ha estudiado. Asimismo, Márquez Miranda destaca la función de Lehmann-Nitsche como educador y científico para el desarrollo de la práctica antropológica en la Argentina.

b) Torres Revello (1945) fue uno de los primeros en retomar las contribuciones biobibliográficas a la obra de Lehmann-Nitsche. Su trabajo contiene una pequeña reseña biográfica de Lehmann-Nitsche. El aporte más sustancial de este trabajo radica en el hecho de presentar por primera vez una reseña sistemática de toda la producción científica del investigador alemán.

c) Los análisis de la producción científica de Lehmann-Nitsche en el plano de los estudios folklóricos se centran principalmente en dar cuenta de la "inauguración" de estos tipos de estudios ${ }^{42}$. En el mismo plano de análisis podemos encontrar los estudios que se centran en el plano lingüístico.

d) Más tarde Mario Teruggi (1997) recuerda la importancia de Lehmann-Nitsche en la constitución del plantel profesional del Museo. Este trabajo no pasa de ser una reseña biográfica y una exaltación de la importancia de Lehmann-Nitsche como uno de los llamados, según Teruggi, "prohombres" del Museo.

e) Por último, mencionaremos uno de los últimos trabajos dedicados a LehmannNitsche: el estudio de Santiago Bilbao (2004). Con el objetivo de rememorar la vida y obra del investigador alemán, Bilbao pasa revista a los puntos más destacados de la producción del mismo, principalmente la producción sobre investigaciones folklóricas como así también su participación en las problemáticas indígenas de la época. El mayor aporte lo constituye la mención a la correspondencia mantenida por Lehmann-Nitsche con distintos investigadores del mundo, complementado en forma sustancial con los debates mantenidos por Lehmann-Nitsche con distintos investigadores del plano nacional e internacional con respecto a las cuestiones referidas a la antigüedad de la fauna sudamericana y a los análisis somáticos de los grupos indígenas.

\footnotetext{
${ }^{40}$ Azzi 1995; Gobello 1975; Selles 1977; Vega 1936.

${ }^{41}$ Landaburu 1999; Nardi 1959; Pineda 1998

${ }^{42}$ Cf. Aretz 1991, Cortazar 1964; Carrizo 1953; Chertudi 1964; Chertudi y Newbery 1978; Danero 1962; Guido 1975; Rama 1977.
} 


\section{Fuentes utilizadas}

En esta investigación se recurrió a un corpus documental conformado por un conjunto diverso de fuentes editas e inéditas. Las primeras están detalladas en el apartado bibliográfico. En cuanto al material inédito utilizado este corresponde a documentos depositados en diversos archivos. Los principales trabajos fueron realizados en: a) Archivo Histórico del Museo de La Plata y del Museo Etnográfico de la Universidad Nacional de Buenos Aires, donde se analizo cartas y documentos personales de Robert Lehmann-Nitsche; b) Archivo Histórico de la Provincia de Buenos Aires, donde se examino y realizo un registro fotográfico de los documentos vinculados al funcionamiento del Museo General de La Plata (expedientes y notas elevadas al Ministro de Obras Públicas, documentación contable vinculadas a las actividades diarias y expediciones del Museo). En menor medida se consultaron los siguientes archivos: c)

Archivo General de la Nación, donde se relevaron los expedientes del Fondo Francisco P. Moreno y d) Museo Mitre donde se consultó la correspondencia y otra documentación vincula a las actividades de Robert Lehmann-Nitsche.

En cuanto a los fondos documentales internacionales que permitieron analizar y describir los espacios, personas e instituciones involucradas en la producción científica de Robert Lehmann-Nitsche debemos mencionar en orden de importancia: a) el Legado Robert Lehmann-Nitsche depositado en el Ibero-Amerikanisches Institut de Berlin; b) Ethnologisches Museum Berlin Staatliche Sammlungen Berlin Preußischer Kulturbesitz, donde se consultaron los materiales y documentación vinculados a sus registros fonográficos; c) Berliner Gesellschaft für Anthropologie, Ethnologie und Urgeschichte, donde se consultó el fichero astronómico relevado por Lehmann-Nitsche, cartas y cuestiones vinculadas a su condición de miembro correspondiente; d) Geheimes Staatsarchiv Preußischer Kulturbesitz Berlin, donde se consultó el intercambio de correspondencia sobre la adquisición del legado por parte del Instituto IberoAmericano; e) Universitätsarchiv der Humboldt-Universität Berlin, donde se consulto el expediente personal de Lehmann-Nitsche.

\section{Robert Lehmann-Nitsche}

Robert Lehmann nacía el 9 de noviembre de 1872 en Radomitz, un pequeño poblado de la por entonces provincia prusiana de $\operatorname{Posen}^{43}$ (Fig. 1). Hijo de Eduard Adolph Robert Lehmann (1838-1885) y de Ida Laura Auguste Stephan (1842-1918). El apellido compuesto que adoptará posteriormente será resultado de agregar a su apellido paterno el nombre del condado al cual

\footnotetext{
${ }^{43}$ Al momento que naciera Lehmann-Nitsche el poblado pertenecía al Reino de Preußen (en alemán Königreich Preußen) y por ende al Imperio Alemán (en alemán Deutsches Kaiserreich). Desde 1946 formará parte del territorio de la República Popular de Polonia.
} 
pertenecía el poblado de Radomitz: El distrito rural de Nitsche-Schmiegel. La apacible vida de la finca del predio agrícola-ganadero familiar no durará mucho. Su padre adquirirá un establecimiento de campo en Jozanowo, lugar al cual se trasladará toda la familia.

Los estudios secundarios los realizará en el Königliches Gymnasium zu Bromberg, en la ciudad de Bydgoszcz (conocida en alemán como Bromberg). A lo largo de 7 años estudiará materias como religión; alemán, latín, griego, francés, hebreo, historia, geografía y matemática ${ }^{44}$. Una vez finalizados sus estudios secundarios su "curiosidad intelectual" ${ }^{45}$ lo llevará a tomar cursos en distintas universidades alemanas. Los primeros años de la década de 1890 lo encontraremos realizando cursos en la Albert-Ludwigs-Universität de Freiburg y en la Ludwig-Maximilians-Universität de München. En la primera de éstas solo se registran los cursos realizados hacia 1892, en la Facultad de Medicina por un lado, y en la de Matemáticas y Ciencias Naturales por el otro ${ }^{46}$.

En la Ludwig-Maximilians-Universität sus estudios serán más sistemáticos y continuos. Los registros más antiguos de los cursos realizados datan de abril de 1891, año en el cual lo encontramos inscripto en la Facultad de Filosofía. En esta tomaría clases con estudiosos que habían participado en forma activa en las discusiones al interior de la antropología alemana a lo largo de la segunda mitad del siglo XIX, entre otros podemos mencionar al anatomista Nikolaus Rüdinger (1832-1896), Johannes Ranke o el filósofo y psicólogo Carl Stumpf (1848-1936) ${ }^{47}$.

Posteriormente realizará en dicha universidad sus estudios en la Facultad de Medicina; donde a lo largo de 10 semestres, asistirá a cursos que abarcaban desde "Anatomía General" a "Asistencia en el parto" o "Hidroterapia". Estos serían complementados con ejercicios prácticos en laboratorios, hospitales y morgues; donde los alumnos asistirían a demostraciones y podrían trabajar en forma "práctica" con individuos vivos y muertos". Al momento de estudiar medicina también asistirá, durante el semestre 1895/96, a la Königliche Friedrich-WilhelmsUniversität de Berlín, donde podemos constatar su participación en 5 cursos $^{49}$.

Entre 1894 y 1897 publicará dos trabajos en forma de tesis doctoral que sintetizaban las investigaciones llevadas a cabo desde principios de la década de 1890. Desde el campo de la

\footnotetext{
${ }^{44}$ El certificado de aprobación de sus estudios estará fechado el 24 de febrero de 1891 a nombre de Robert Lehmann. Legado Robert Lehmann-Nitsche, IAI, Carpeta N-0070 19.

${ }^{45}$ Márquez Miranda 1938, p. 126

46 En esta realizará cursos de "Ejercicios prácticos y trabajo científico en laboratorios químicos"; "Química inorgánica experimental"; "Curso microscópico orientado a la Anatomía” y "Historia evolutiva de la humanidad”. Legado Robert Lehmann-Nitsche, IAI, Carpeta N-0070 110 y N-0070 116.

${ }^{47}$ Para una lista detallada de los cursos realizados y los docentes ver Legado Robert Lehmann-Nitsche, IAI, Carpeta N-0070 110.

${ }^{48}$ Para una lista detallada de los cursos realizados ver: Legado Robert Lehmann-Nitsche, IAI, Carpeta N0070110.

${ }^{49}$ Legado Robert Lehmann-Nitsche, IAI, Carpeta N-0070 110.
} 
"medicina prehistórica",50; y haciendo especial énfasis en el estudio de los huesos "largos",51; buscará comprender "la imagen del hombre prehistórico" los que no se podía "obtener información directa ni pruebas de la tradición escrita"53.

Los elementos óseos constituían elementos materiales que ofrecían pruebas concretas y objetivas al momento de reconstruir la historia evolutiva de los grupos humanos y al trazar un límite entre los seres humanos modernos y aquellos contemporáneos primitivos. Los huesos, como elementos pertenecientes al mundo de la naturaleza, ofrecerán al estudioso un objeto factible de ser analizado y comprendido a través del método empírico e inductivo de las ciencias naturales. En este sentido sabrán contener en sí mismos la doble dimensión de la naturaleza y la historia. El trabajo directo con estos aseguraba una lectura veraz en aquellos casos de estudio en los que era en vano "hurgar en los tomos antiguos de la historia escrita" ${ }^{\text {" }}$.

Si bien los historiadores habían "[...] sacado a la luz la historia de ciertas razas, todavía existían personas que vivían en "las brumas de la prehistoria" Nitsche sobre la antropología física de las antiguas poblaciones bávaras; trabajo que le valdrá el doctorado en ciencias naturales; y el estudio de las antiguas prácticas quirúrgicas alemanas; con el cual obtendrá su doctorado en medicina; buscará contribuir a dilucidar parte de este pasado sumido en la oscuridad de la agrafia.

\section{Primer trabajo doctoral: Sobre la antropología física de los bávaros}

El primero de estos trabajos se titulaba Beiträge zur physischen Anthropologie der Bajuvaren: über die langen Knochen der südbayerischen Reihengräber Bevölkerung (Contribuciones a la antropología física de los bávaros: sobre los huesos largos de las tumbas renanas de la población de Baviera del Sur). El mismo era defendido el 23 de julio 1894 e impreso un año más tarde en los talleres universitarios. ${ }^{56}$

\footnotetext{
50 Según Lehmann-Nitsche esta estaba compuesta por la medicina convencional y la medicina "tradicional" de los pueblos indígenas. Lehmann-Nitsche 1895 a, p. 4.

${ }^{51}$ Señalaba Lehmann-Nitsche que, en comparación con aquello que se sabía sobre el cráneo, era escaso el conocimiento sobre los huesos largos, la escápula, la pelvis, la columna vertebral, así como el esqueleto de la mano y el pie. Lehmann-Nitsche 1895 a.

${ }^{52}$ Lehmann-Nitsche 1898 a, p. 8.

${ }^{53}$ Ibídem.

${ }^{54}$ En este sentido la historia, entendida como el estudio del pasado de la humanidad, abarcaba segmentos temporales que habían acontecido mucho antes del surgimiento de los registros escritos, razón por la cual era distinto el conocimiento que se tenía sobre el conjunto de las distintas "razas". Ibídem, p. 28. Nuestra traducción.

${ }^{55}$ Ibídem, p. 8.

${ }^{56}$ El comité evaluador estaba compuesto por Ranke, el zoólogo y botánico Richard Wilhelm Karl Theodor Ritter von Hertwig (1850-1937) y el físico Eugen Cornelius Joseph von Lommel (1837-1899). Estos le otorgaban la segunda nota más alta: magna cum laude. Un año más tarde, el 26 de julio de 1895, Ranke le confirmaba a Lehmann-Nitsche haber recibido los 100 marcos alemanes como pago parcial por
} 
Dicho trabajo será el resultado del trabajo con los materiales depositados en el Anatomisches Institut München. Los mismos provenían de 350 tumbas "descubiertas" a mediados de 1860 en la construcción de las líneas ferroviarias para el trayecto MünchenIngolstadt. Esto le será comunicado a Lehmann-Nitsche a comienzos de 1891 por Wolfgang M. Schmid, por entonces bibliotecario del Königliches Bayerisches Nationalmuseum. LehmannNitsche obtendrá a través de las gestiones de Ranke el respaldo institucional y la infraestructura laboral provista por la Königliche Bayerische Akademie der Wissenschaften y la Münchener Anthropologische Gesellschaft. Las excavaciones tendrán lugar entre 1891 y 1893; participando de las mismas Lehmann-Nitsche, Wolfgang Schmid y el encargado adjunto de la empresa ferroviaria $^{57}$. Al tiempo que analizaba dichos materiales publicará una serie de cortos trabajos que tenían por objetivo contribuir a la historia regional de la provincia de $\operatorname{Posen}^{58}$.

El estudio de los huesos largos por parte de Lehmann-Nitsche será resultado de un pedido expreso de Ranke; el cual buscaba compilar un vasto cuerpo de datos antropométricos que; junto con aquellas mediciones realizadas sobre la población contemporánea; permitiera trazar un esquema evolutivo de la zona de Bayern ${ }^{59}$. En este sentido procederá a la descripción osteológica y antropométrica del húmero, el radio, el cúbito, la clavícula, el fémur y la tibia. De esta forma se centraba en aquellos elementos que 10 años atrás el médico francés Paul Topinard (1830-1911) definiera como centrales a la hora de tratar de determinar la talla ${ }^{60}$.

Tal como reseñarán los franceses Georges Papillault (1863-1934), director del Laboratoire d'Anthropologie des Hautes Études, y Arthur Chervin, gran parte de los métodos

la impresión de dicho trabajo. Robert Lehmann-Nitsche a Ida Lehmann-Nitsche. Legado Robert Lehmann-Nitsche, 25.07.1894, IAI, Carpeta N-0070 1092.

${ }^{57} \mathrm{El}$ inventario final de las excavaciones incluirá: cráneos, húmeros, radios, cúbitos, clavículas, fémures, tibias, y fíbulas. Los huesos correspondientes a omoplatos, pelvis, vértebras y falanges estaban incompletos, fragmentarios y defectuosos, por lo cual no se incluirán en la investigación. LehmannNitsche, 1895 a.

${ }^{58}$ El primero de estos sería publicado en las páginas del Nachrichten über deutsche Altertumsfunde, y trataría sobre dos cámaras mortuorias de la por entonces región prusiana de Kujawy (en alemán Kujawien), cuya parte norte correspondía a la ciudad de Bydgoszcz, donde Lehmann-Nitsche había realizado sus estudios secundarios. El segundo correspondía a una serie de antiguos anillos de bronce provenientes del distrito polaco de Szczodrowo, trabajo que sería publicado en el Prähistorische Blätter. Para estos trabajos no descartaría la consulta de archivos y diversas fuentes documentales; de las cuales extraería valiosa información sobre investigaciones arqueológicas previas y datos históricos sobre las tumbas de la región. En este sentido realizará una serie de consultas con el historiador Bolesław Erzepki (1852-1932), para ese entonces bibliotecario y conservador de la Poznańskiego Towarzystwa Przyjaciót Nauk (Sociedad de Amigos de la Ciencia de Posen). Lehmann-Nitsche, 1893,1894; Bolesław Erzepki a Robert Lehmann-Nitsche. Legado Robert Lehmann-Nitsche, 26.09.1893, IAI, Carpeta N-0070 b 193.

${ }^{59}$ Hacia 1895 Rudolf Martin recibía una copia de dicho trabajo. En carta a Lehmann-Nitsche manifestaba el júbilo que le provocaba ver que alguien realizara un estudio de este tipo. Al mismo tiempo recordaba que la ausencia de investigaciones de este tipo se debía a la falta de una técnica satisfactoria que fuera plausible de ser utilizada por cualquier investigador. En este sentido exhortaba a Lehmann-Nitsche a que definiera y estandarizara un método métrico para el estudio de los componentes óseos de las extremidades inferiores y superiores, con la seguridad de que se propagaría rápidamente Rudolf Martin a Robert Lehmann-Nitsche. Legado Robert Lehmann-Nitsche, IAI, 26.7.1895, Carpeta N-0070 b 489.

${ }^{60}$ Topinard 1885. 
utilizados por Lehmann-Nitsche serán aquellos promovidos por el Laboratoire d'Anthropologie, especialmente los trabajos del antropólogo francés Léonce-Pierre Manouvrier (1850-1927) sobre los huesos largos y la determinación de la talla ${ }^{61}$. Siguiendo los planteos de este último, calculará los valores referentes a la longitud máxima, el ancho y el grosor en primer lugar, particularizando posteriormente detalles y anomalías.

La preeminencia de los métodos provistos por la "escuela" francesa en el estudio de los miembros inferiores será reconocida por gran parte de los estudiosos que en la última década del siglo XIX se avocaban a su investigación. Aquellas investigaciones llevadas a cabo por Manouvrier, Paul Topinard y Pierre Paul Broca (1824-1880) serán consideradas el punto de partida necesario al momento de emprender una empresa de este tipo. La aceptación y el uso extendido de estos métodos y técnicas se vinculan también con la necesidad de establecer un control sobre los resultados obtenidos. Parte del mismo resultará del contraste con aquellos obtenidos por otros investigadores. Por lo tanto puede vincularse la promoción de estos métodos y técnicas como una forma de regular y verificar los conocimientos generados ${ }^{62}$.

$\mathrm{Al}$ igual que en otras investigaciones antropológicas a lo largo de la segunda mitad del siglo XIX la elección de determinado método o instrumento estará sujeta a la "efectividad" del mismo al momento de dar cuenta de tal o cual característica. En este sentido Lehmann-Nitsche seleccionará y clasificará los huesos en base a las recomendaciones de Topinard; hará uso de la tabla osteométrica ${ }^{63}$ y del tropometro ${ }^{64}$ de Broca para el cálculo del largo y del grado de torsión de los huesos ${ }^{65}$, con modificaciones introducidas por él y por Ranke ${ }^{66}$; y se valdrá de cintas

\footnotetext{
${ }^{61}$ Papillault y Chervin señalaban que: "Il a relevé toutes les mesures dont il donne la technique dans la quatrième partie de son ouvrage. Ce sont, pour la plupart, celles qui sont en usage en France, au Laboratoire d'Anthropologie, tels que les principaux diamètres destinés à représenter le développement en longueur et en épaisseur de l'os, les indices qui en expriment la forme, et en particulier la platymérie, la platycnémie, la saillie pilastnque, etc. sur lesquelles il a longuement insisté". Chervin y Papillault 1897, p. 482.

${ }^{62}$ Con esto Lehmann-Nitsche pretendía "estimular" las comparaciones entre sus trabajos y aquellos realizados por los estudiosos franceses. Lehmann-Nitsche 1895 a, p. 72.

${ }^{63}$ Este será uno de los instrumentos preferidos por antropólogos y médicos. Consistía en 2 placas unidas entre sí, una de las cuales se encontraba gradada en milímetros. Para su medición el hueso era fijado, en posición horizontal, sobre una de las tablas, siendo fijado en uno de los extremos por la placa vertical. Lehmann-Nitsche, 1895 a; Rollet, 1888; Schmidt, 1888; Topinard 1885.

${ }^{64}$ Este consistía en una mesa sobre la cual se elevaba una escuadra. Esta tenía en su sección vertical una corredera sobre la cual se deslizaba su parte horizontal, ajustándose a cualquier altura por medio de un tornillo y una tuerca. Sobre la superficie de la mesa se situaba un círculo de bronce dividido en grados con una punta de acero en la cual se colocaba la parte inferior del hueso, quedando fijo en su sección superior por la punta en la que acababa la parte horizontal de la escuadra. Cuando se deseaba medir el ángulo de torsión de algún hueso se marcaba con la ayuda de un hilo la línea meridiana de la cabeza del mismo, ya que estando fijado sólo en dos puntas metálicas, él hueso podía girar sobre sí mismo. La intersección de este con la tabla se marcaba en el círculo de bronce. Al medir el ángulo entre este plano y el eje de la parte inferior del hueso se obtenía el ángulo de torsión. Broca 1881; Ranke 1887; Rollet 1885; Topinard 1885.

${ }^{65}$ Dichos instrumentos eran promovidos desde los espacios científicos franceses como más efectivos, precisos y simples que el procedimiento de superposición de dibujos utilizado por los alemanes. Consistía en tomar el dibujo de dos extremidades y sobreponerlos entre sí, midiendo el ángulo que se formaba. En
} 
métricas de diverso largo y el compás de corredera ${ }^{67}$ de Rudolf Martin para el cálculo del ancho mayor y menor de los huesos (Fig. 2, 3 y 4). Es menester mencionar que esto no llevará a un rechazo total de los instrumentos franceses; siendo recomendados a Lehmann-Nitsche por parte de estudiosos como Johannes Ranke o el arqueólogo alemán August Wilhelm Naue (18711911); lo cual no los exceptuaba de la crítica.

Los instrumentos promovidos desde los espacios científicos franceses podían ser precisos, efectivos y de uso mucho más simple que aquellos promovidos por los estudiosos alemanes. Sin embargo esto no era garantía de resultados seguros u interpretaciones significativas al conjunto de la ciencia antropológica. En esta forma se expresaban estudiosos como Ranke o Naue al responder cartas previas de Lehmann-Nitsche en las cuales éste les consultaba sobre diversos puntos de su tesis ${ }^{68}$. Es preciso mencionar que la advertencia sobre el uso poco crítico de los métodos e instrumentos franceses no provenía en forma exclusiva desde el campo de la antropología, tal como lo atestiguan las cartas del farmacéutico suizo Burkhard Reber (1848-1926). Este último; arqueólogo amateur y coleccionista de antigüedades; afirmaba que los métodos de medición y de dibujo promovidos por los estudiosos franceses no eran tan óptimos como se pensaba ${ }^{69}$.

Finalmente el 23 de julio de 1894; el rector de la Ludwig-Maximilians-Universität de München, el teólogo alemán Alois Knöpfler (1847-1921); hacia entrega del título de doctor en filosofía a "Roberto Lehmann", tal cual rezaba el diploma ${ }^{70}$. Una vez impreso su trabajo Johannes Ranke le recomendaba que entregará copias del mismo a distintos estudiosos y

su última contribución a la Revue d'anthropologie señalaba Broca su propia experiencia a la hora de utilizar este método: "Ce procédé est bon; mais outre qu'on n'a pas déterminé suffisamment la direction qu'il fallait donner à l'os, on doit reprocher à cette méthode d'être très longue; aucun auteur n'a pu prendre ainsi plus de cinq ou six observations sur le nègre; on en a, il est vrai, une trentaine sur le blanc, mais le nombre de ces mesures est en somme insuffisant". Broca 1881, p. 716; Lehmann-Nitsche 1895 a; Ranke 1887.

${ }^{66}$ Ranke centrará su atención en la escuadra del tropometro, la cual reforzará con un soporte extra en forma de abrazadera a fin de que el hueso se encuentre, en todo momento, firmemente fijado en las puntas metálicas sobre la cual era colocado. Debido a la fragilidad de los huesos estudiados Lehmann-Nitsche agregara a las puntas dos pequeñas placas concéntricas de cera. Estas al dejar marcas en la superficie del hueso, permitirán determinar y observar el movimiento de las agujas, pudiendo de esta manera corregir la posición del hueso. Lehmann-Nitsche1895 a; Ranke 1887.

${ }^{67}$ Este consistía en una varilla de metal con una escala métrica y dos varillas transversales más pequeñas y ajustables que podían desplazarse hacia arriba o abajo, pudiendo de esta manera medir o trazar los espacios entre dos o más líneas paralelas. Martin 1899, 1903; Lehmann-Nitsche 1895 a.

${ }^{68}$ En una de estas cartas Naue le recomendaba enfáticamente la lectura del trabajo Beiträge zur physischen Anthropologie der Aino del médico japonés; formado en Alemania; Yoshikigo Koganei (1858-1944), caracterizándolo como de suma importancia para la antropología y la prehistoria alemana. Johannes Ranke a Robert Lehmann-Nitsche. Legado Robert Lehmann-Nitsche, 25.07.1895, IAI, Carpeta N-0070 b 558. August Wilhelm Naue a Robert Lehmann-Nitsche. Legado Robert Lehmann-Nitsche, 13.06.1895, IAI, Carpeta N-0070 b 492.

${ }^{69}$ Burkhard Reber a Robert Lehmann-Nitsche. Legado Robert Lehmann-Nitsche, 01.04.1895 y 07.10.1895, IAI, Carpeta N-0070 b 560.

${ }^{70}$ Legado Robert Lehmann-Nitsche, IAI, Carpeta N-0070 110. 
sociedades científicas de la época a fin de contribuir con la promoción de la metodología de trabajo implementada en el Anatomisches Institut München ${ }^{71}$.

El trabajo será galardonado con la mitad del premio Godard ${ }^{72}$, y no con la totalidad del mismo, tal como afirman ciertas reconstrucciones biográficas ${ }^{73}$. Dicho premio; establecido por el anatomista francés Ernest Godard (1824-1862); será entregado cada dos años por la Société d'anthropologie de Paris "[...] au meilleur mémoire sur un sujet se rattachant a l'anthropologie [...],74. En la edición de 1897 Lehmann-Nitsche compartirá esta distinción con el trabajo Climatologie médicale de la République argentine et des principales villes d'Amérique (1895) del tisiólogo, higienista y obstetra argentino Samuel Gache (1859-1907) ${ }^{75}$. Charles Letourneau; en calidad de secretario general de la Société d'anthropologie de Paris, le comunicaba a finales del año 1897 la decisión de otorgarle la mitad del premio, consistente en 250 marcos franceses y una medalla conmemorativa ${ }^{76}$.

Tampoco se ha señalado que dicho trabajo recibirá críticas por parte de los miembros del comité francés encargado de asignarle la distinción, el cual se componía por el médico y antropólogo Joseph Louis Capitan (1854-1929), Georges Papillault, Arthur Chervin y Réné Collignon. Entre las principales objeciones destacaban la forma de edición del trabajo; el rechazo de Lehmann-Nitsche por dar una explicación detallada de las técnicas, algo que obligaba al lector a constantes interrupciones y a búsquedas que cansaban la atención; y finalmente el bajo número de elementos óseos con los que trabajo, algo que llevaba a que "[...] les déductions qu'il en tire pèchent ainsi par la base"77. A pesar de estas desavenencias el carácter general de la obra contribuía “[...] connaissance remarquable de la science

\footnotetext{
${ }^{71}$ De esta forma las primeras copias serían distribuidas entre personas vinculadas en forma directa e indirecta a dicho instituto. Seguidamente lo haría con institutos y sociedades científicas de su Posen natal, tal como el Pracownia Antropologiczna Nauk Poznaniu (Laboratorio de Ciencias Antropológicas de Posen). Una vez instalado en Argentina Lehmann-Nitsche comenzará el envío de copias de su trabajo doctoral a diversas instituciones extranjeras con el objetivo de que sea distribuida en diversos países del continente americano. Yoshikigo Koganei a Robert Lehmann-Nitsche. Legado Robert Lehmann-Nitsche, 05.11.1895, IAI, Carpeta N-0070 b 372. Pracownia Antropologiczna a Robert Lehmann-Nitsche. Legado Robert Lehmann-Nitsche, 29.01.1896, IAI, Carpeta N-0070 b 988. William Henry Holmes a Robert Lehmann-Nitsche. Legado Robert Lehmann-Nitsche, 07.06.1898, IAI, Carpeta N-0070 b 326.

${ }^{72}$ Farro 2008, 2009, 2011; Podgorny 2007 a.

${ }^{73}$ Bilbao 2004; Cáceres Freyre 1972; Márquez Miranda 1939; Teruggi 1997; Torre Revello 1945 entre otros.

${ }^{74}$ Papillault 1897, p. 4.

${ }^{75}$ Hacia noviembre de 1898 se comunicaba con Lehmann-Nitsche sugiriéndole; ante su insistencia; que le escribiera a los miembros de la SAP por las demoras en la entrega del premio. Samuel Gache a Robert Lehmann-Nitsche. Legado Robert Lehmann-Nitsche, 10.11.1898, IAI, Carpeta N-0070 b 252.

${ }^{76} \mathrm{El}$ valor del premio sería transferido; a pedido de Lehmann-Nitsche; a unas de las sucursales bancarias del banquero alemán Maximilian Benedikt Hayum Goldschmidt (1843-1940). Société d'anthropologie de Paris a Robert Lehmann-Nitsche. Legado Robert Lehmann-Nitsche, 28.12.1897, IAI, Carpeta N-0070 b 1006. Société d'anthropologie de Paris a Ida Lehmann-Nitsche. Legado Robert Lehmann-Nitsche, 10.03.1898, IAI, Carpeta N-0070 b 1006.

${ }^{77}$ Chervin y Papillault 1897, p. 483.
} 
anthropologique" ${ }^{, 78}$, producto esto de que "Dans sa méthode et sa technique il a largement emprunté à la science française" ${ }^{\text {79 }}$.

Entre este trabajo doctoral y el segundo que le valiera el título de doctor en medicina, publicará Lehmann-Nitsche una serie de breves trabajos que, desde la arqueología y la medicina, pretendían contribuir a la comprensión del pasado alemán. Dichos trabajos; que abarcaban desde el estudio de una serie de hachas de la actual región polaca de Śląsk hasta particularidades evolutivas del trocánter del fémur humano; serán presentados en diversos encuentros de la Berliner Gesellschaft für Anthropologie, Ethnologie und Urgeschichte; y publicados tanto en las páginas de la Verhandlungen der Berliner Anthropologischen Gesellschaft $^{80}$; como en la sociedades científicas de Posen ${ }^{81}$.

\section{Segundo trabajo doctoral: Sobre la cirugía prehistórica}

Su segundo trabajo doctoral será realizado bajo la la supervisión del médico alemán Ottmar von Angerer (1850-1918). Esta breve monografía se intitulará Beiträge zur prähistorischen Chirurgie nach Funden aus deutscher Vorzeit (Contribuciones para la cirugía prehistórica según hallazgos de la antigüedad alemana) ${ }^{82}$. El uso de los mismos instrumentos, métodos y técnicas empleados en su trabajo de 1894, permitirá a Lehmann-Nitsche analizar los materiales procedentes de las colecciones prehistóricas del Münchner Stadtmuseum, las del Paulus Museum de Worms y los restos del fósil de Neanderthal de Düsseldorf. Estos elementos le permitirán trazar un panorama general de la patología, trauma, lesiones, enfermedades y tratamientos de los huesos en las poblaciones prehistóricas alemanas.

$\mathrm{Al}$ igual que sucediera con su anterior tesis, esta sería repartida entre diversos estudiosos e instituciones; ya fuera antes de su partida a la Argentina como una vez arribado a dicho país ${ }^{83}$. Para el biólogo y antropólogo húngaro Aurél von Török (1842-1912), el trabajo desarrollado por Lehmann-Nitsche en su disertación doctoral auguraba un prometedor futuro a la

\footnotetext{
${ }^{78}$ Ibídem.

${ }^{79}$ Ibídem.

${ }^{80}$ Lehmann-Nitsche 1895 b, 1896, 1897 a, 1897 b.

${ }^{81}$ Historische Gesellschaft für den Netzedistrikt a Robert Lehmann-Nitsche. Legado Robert LehmannNitsche, 18.08.1895 y 03.10.1897, IAI, Carpeta N-0070 b 938.

${ }^{82}$ Este será presentado el 12 de marzo de 1897. Legado Robert Lehmann-Nitsche, IAI, Carpeta N-0070 1 10.

83 Pracownia Antropologiczna a Robert Lehmann-Nitsche. Legado Robert Lehmann-Nitsche, 29.01.1896, IAI, Carpeta N-0070 b 988. George Amos Dorsey a Robert Lehmann-Nitsche, Legado Robert Lehmann-Nitsche, 10.10.1898, IAI, Carpeta N-0070 b 161. Museo Nacional de Santiago de Chile a Robert Lehmann-Nitsche. Legado Robert Lehmann-Nitsche, 30.10.1899, IAIs Carpeta N-0070 b 1088. Museum Schlesischer Altertümer a Robert Lehmann-Nitsche. Legado Robert Lehmann-Nitsche, 14.11.1907, IAI, Carpeta N-0070 b 1039. Stadbibliothek Hamburg a Robert Lehmann-Nitsche. Legado Robert Lehmann-Nitsche, 13.02.1908, IAI, Carpeta N-0070 b 1088.
} 
antropología alemana por lo preciso del mismo y por cierto "espíritu fresco" ${ }^{84}$ que poseía. El ímpetu del trabajo y de su autor, eran vistos por von Török como dos elementos que calificaban a Lehmann-Nitsche como un prometedor docente. Tal como le recordaba el estudioso húngaro la antropología demandaba, hacia fines del siglo XIX, individuos que sistematizarán los procesos de investigación y de enseñanza. No solo bastaba con organizar y normalizar los métodos y técnicas al interior de la disciplina, también era necesario entrenar a las futuras generaciones. Este objetivo jamás podrá ser cumplido por Lehmann-Nitsche, quien demostrará un escaso interés en formar un grupo de trabajo que lo auxiliara en su trabajo y que posteriormente continuará con sus líneas de investigación ${ }^{85}$.

\section{Llegada a la Argentina}

El 10 de julio de 1897 Lehmann-Nitsche arribaba a la Argentina ${ }^{86}$. Una vez instalado en La Plata y comenzando sus trabajos en el museo local continuará las temáticas de sus dos trabajos doctorales, centrándose en el estudio del sistema óseo-morfológico humano. En este sentido la mayor parte de sus trabajos referirán al campo de la medicina prehistórica y la antropometría. En este último punto articulará los estudios craneológicos y la medición de los restos óseos depositados en el Museo de La Plata por un lado; y el trabajo sobre individuos vivos por el otro ${ }^{87}$. Es también en estos años donde comenzará a sintetizar una serie de trabajos que tendrán por objetivo dar a conocer una variedad de material folklórico. Esta re-orientación de sus estudios estará vinculado a otra de las problemáticas de la práctica antropológica y es la economicización en la recolección, almacenamiento y traslado de los objetos de estudio.

De esta forma las tradiciones orales brindarán elementos materiales, concretos y objetivos de fácil transporte. Estos estudios contribuirán al establecimiento de cartografías a escala global que permitirían visualizar el origen y el desplazamiento de los grupos humanos en tiempo y espacio. Los cilindros de cera utilizados en las grabaciones efectivizarán la transmisión de datos y objetos a través de soportes materiales más resistentes, transportables y con mayor

\footnotetext{
${ }^{84}$ En el original alemán "frischer Geist”. Aurél von Török a Robert Lehmann-Nitsche. Legado Robert Lehmann-Nitsche, 08.02.1896, IAI, Carpeta N-0070 b 696.

${ }^{85}$ Los problemas vinculados a la formación de antropólogos serán abordados con mayor detalle en el Capítulo I. Por otro lado el papel de Lehmann-Nitsche en la enseñanza y formación de profesionales serán vistos en el Capítulo VII.

${ }^{86}$ Los motivos y los detalles de su contratación serán vistos en profundidad en el Capítulo II.

${ }^{87}$ En esta última serie de monografías puede apreciarse lo maleable y permeable del concepto de "trabajo de campo". Bajo este rótulo podemos apreciar investigaciones realizadas en las excursiones emprendidas a Tierra del Fuego (1902); el Ingenio Azucarero La Esperanza (1906); Bariloche (1915), Los Toldos (1920); la reducción indígena de Napalpi y el Ingenio Azucarero Ledesma (1924) o Cura Malal (Buenos Aires, 1925). Al mismo tiempo tendremos aquellas realizadas en el propio Museo de la Plata; en poblaciones de indígenas re-localizados en distintos conjuntos habitacionales de la ciudad de La Plata o sus cercanías; en diversas instalaciones mentales y policiales; o bien en el domicilio particular de Lehmann-Nitsche.
} 
capacidad de acumulación. Al mismo tiempo posibilitarán la repetición de la experiencia en un espacio controlado y regulado por los propios estudiosos ${ }^{88}$.

A lo largo de la segunda década del siglo XX Lehmann-Nitsche profundizará; en concordancia con lo que se venía desarrollando en otras partes del mundo; en la recolección, compilación y transcripción de las explicaciones e interpretaciones indígenas sobre los fenómenos astronómicos y meteorológicos, tratando de demostrar la existencia de un sustrato mitológico-explicativo Pan-americano ${ }^{89}$. Esto también puede apreciarse en sus publicaciones arqueológicas, las cuales tendrán por objetivo brindar sustento y pruebas materiales en donde estos componentes esenciales de la cosmovisión se plasmaban ${ }^{90}$.

Lehmann-Nitsche se jubilará en 1930, volviendo a Alemania. Desde su residencia berlinesa en Innsbrucker Straße $\mathrm{n}^{\circ} 7$, seguirá contribuyendo en distintos medios con publicaciones que serán el resultado de la síntesis de más de 30 años de recolección de datos e información en tierras sudamericanas. Uno de los principales tópicos abordados será el de la astronomía indígena ${ }^{91}$. Sus últimos años de vida lo hallarán indagando en la historia de los primeros alemanes en el Río de La Plata por un lado y la etimología toponímica de diversas ciudades rioplatenses, principalmente a través de personajes como el Lansquenete ${ }^{92}$ alemán Hans Staden (1525-1579) o las crónicas del explorador alemán Ulrich Schmidl o Schmidel (1510-1579?). De esta forma buscará transmitir al público alemán parte de la historia de aquellas geografías que supieron acogerlo por 30 años, intentando a la vez acercar al público argentino una comprensión más profunda de su propio pasado ${ }^{93}$. Acorde a su espíritu de recolector sistemático, indagará en la profundidad de los archivos de la historia en búsqueda de elementos que le brindarán un mejor entendimiento y una acabada comprensión de sus 30 años de residencia en la Argentina; las cuales lo encontrarán en todo momento documentando y clasificando lo cotidiano del "ser" argentino y sus manifestaciones materiales.

Tal vez las palabras que mejor describan la obra y los objetivos de Lehmann-Nitsche sean aquellas que le dedicara el argentino Luis María Torres (1878-1937) hacia 1905 como

\footnotetext{
${ }^{88}$ Innis 2002; Kittler 1985, 1992, 1997; Latour 1990; McLuhan 1964.

${ }^{89}$ Lehmann-Nitsche 1936 i, 1938 h.

${ }^{90}$ Lehmann-Nitsche 1925 a, 1926 a, 1928 b, 1928 c, 1930 b.

${ }^{91}$ Ampliando el contexto geográfico, comenzará a incluir trabajos sobre la zona de las islas centrales del Caribe, del Pacífico y de Oceanía a fin de poder establecer vínculos entre América y Asia. A través de las similitudes en la arquitectura de los mitos; buscaba colaborar con el establecimiento de estructuras de pensamiento elementales comunes a la humanidad. Al igual que en la segunda década del siglo XX, Lehmann-Nitsche vinculará estos estudios a las investigaciones arqueológicas, dando lugar a la interpretación etno-astronómica de emplazamientos y objetos arqueológicos.

${ }^{92}$ En el original alemán: Landsknecht. Este término cuya traducción etimológica se desglosa en Land (tierra y/o país) por un lado y Knecht (siervo) por el otro, fue acuñada por Peter von Hagenbach (14201474) para referirse a los milicianos de infantería suavos del Sacro Imperio Romano Germánico. Más adelante el término acabara derivando en Lanzknecht debido a la asociación del mismo con la palabra Lanze (lanza), la cual era el arma más utilizada por este grupo.

${ }^{93}$ Lehmann-Nitsche 1909 c, 1915 a, 1923 b, 1925 b, 1926 b, 1927 c, 1927 d, 1930 g.
} 
parte de la introducción de los estudios realizados sobre un túmulo indígena de las islas del Delta del Paraná. Luego de destacar la figura de Lehmann-Nitsche, subrayaba que el merito intrínseco de sus trabajos era [...] el esclarecimiento de la historia primitiva por medio de la acumulación coordinada de materiales. Tal es la vía recta y directa. El periodo de la generalización y, por consiguiente, el de las conclusiones está aún lejano" ${ }^{94}$. Las palabras de Torres encuentran validez 108 años después, ya que las conclusiones de los trabajos de Lehmann-Nitsche todavía se hacen esperar.

Sus 30 años al frente de la Sección de Antropología del Museo de la Plata se caracterizarán exactamente por la acumulación de material que, amontonándose tanto en los gabinetes del museo como en su residencia particular, nunca responderán a los objetivos de un plan de investigación a largo plazo. Cráneos, vasijas, huesos, panfletos, recortes de periódicos, grabaciones sobre folklore y tango jamás tendrán por destino final formar parte de un cuerpo de saberes integrados. Si en un primer momento el estudio de estos objetos fue visto como un modo de obtener una posición estable en el Viejo Mundo, el paso de los años y el consecuente alejamiento de esta posibilidad, los condenará a ser parte de una reunión de elementos dispersos y sin sentido.

\footnotetext{
${ }^{94}$ Luis María Torres en Lehmann-Nitsche 1905 b, p.1. El resaltado es de nuestra autoría.
} 


\section{La Antropología entre fines del siglo XIX y principios del siglo XX}

Hacia 1901 Rudolf Martin; posteriormente clave en la llegada de Lehmann-Nitsche al Museo de la Plata; realizaba la charla inaugural del semestre de verano en la Universität Zürich. Haciendo una síntesis del estado de la práctica antropológica concluía que este solo podía ser definida con una palabra: caótico. Al mismo tiempo encomendaba a los oyentes de su presentación a ser aquellos "amigos y trabajadores"95 que pudieran llevar a la antropología a un nuevo nivel tanto en la práctica como en la enseñanza; aspectos del quehacer antropológico que Martin encontraba indisolubles.

La antropología será para Martin una práctica científica que no debía ser limitada solamente a la investigación, sino que debía contar entre sus principales objetivos con la instrucción y la educación de aquellas personas interesadas en la misma. Esta enseñanza combinaba teoría y práctica, elementos que debían aprenderse y practicarse por igual si se querían obtener resultados científicos. Al mismo tiempo existía cierta obligación moral implícita, por la cual se esperaba que el estudioso también se preocupara por la educación de las futuras generaciones. En este sentido Martin buscará generar espacios de formación e instrucción donde además del predominio de los saberes generados desde el campo de los estudios biológicos; especialmente la zoología o la anatomía humana; se comenzará a dar lugar a aquellos conocimientos concebidos en las ciencias humanas, con especial énfasis en la psicología, la sociología o la historia de la cultura ${ }^{96}$.

El caos imperante denunciado por Martin era el resultado de la falta de consenso en la metodología de investigación, siendo esto una consecuencia de la ausencia de un sistema y un método estandarizado de enseñanza ${ }^{97}$. La formación de individuos se presenta como uno de los pasos y las estrategias al momento de definir y capitalizar los espacios de las prácticas científicas. Parte de los estudiosos alemanes sabrán reconocer la necesidad y la importancia de esta instancia. Ya fuera en Alemania o en el extranjero estos insistirán en el entrenamiento y la formación de estudiantes a fin de profesionalizar la práctica antropológica. Uno de los casos más emblemáticos en América será el del médico y antropólogo alemán Franz Boas (18581942). A lo largo de 55 años de residencia en los Estados Unidos formará un grupo de alumnos que; junto con personas cercanas; ocuparán los principales centros académicos y científicos de los Estados Unidos a lo largo de las dos primeras décadas del siglo XX. Esto imprimirá una forma de hacer antropología sintetizada en los trabajos de los estudiantes de Boas, los cuales

\footnotetext{
${ }^{95}$ Martin 1901, p.4.

${ }^{96}$ En la tradición alemana las mismas se englobaban bajo la denominación de Geisteswissenschaften.

${ }^{97}$ Martin 1901.
} 
definirán claramente los espacios de las prácticas antropológicas ${ }^{98}$. Si bien, como ha señalado Regna Darnell no puede hablarse de una "escuela boasiana", es necesario notar como hacia la década de 1920 el núcleo de la antropología estadounidense estaba centrado alrededor de los estudiantes de Boas. A pesar de sus intereses personales, todos compartirán un núcleo de preocupaciones teórico-metodológicas.

A lo largo de la segunda mitad del siglo XIX estas discusiones se darán principalmente en el contexto de los modos de observación, análisis e interpretación de los componentes morfoosteológicos. Uno de los factores que auxiliará notablemente las mismas será la presencia de representantes indígenas en distintos contextos de exhibición. Con un considerable impulso a partir de la década de 1850; estos individuos comenzarán a ocupar un lugar privilegiado en la agenda de los estudiosos europeos. El surgimiento de la "arqueología prehistórica o geológica" consolidaba la conexión entre los antiguos tiempos geológicos y la historia contemporánea, haciendo de grupos como los "esquimales", "australianos" y los "fueguinos" laboratorios vivientes a través de los cuales observar el pasado para bosquejar una comprensión de los tiempos presentes ${ }^{99}$.

Para 1901 los estudios antropológicos habían permitido colectar un importante cuerpo de datos somatométricos y somatológicos. A medida que estos se acumulaban se desarrollaban nuevas técnicas e instrumentos antropométricos, manuales y cursos sistemáticos y finalmente programas de enseñanza e instrucción. A partir de estos se tratará de homogeneizar no solo técnicas y métodos, sino también concepciones, miradas y compromisos hacia el interior de la disciplina ${ }^{100}$. El caos denunciado por Martin no era propio de la antropología suiza o alemana, era un estado general de la práctica de dicha disciplina. En 1911 el zoólogo alemán Hermann von Ihering (1850-1930) le sugería a Florentino Ameghino (1854-1911) abandonar las discusiones en torno al hombre fósil sudamericano; un campo caracterizado por las subjetividades, la multiplicidad de interpretaciones y la falta de consenso ${ }^{101}$. Como podemos ver lejos de solucionarse el caos será la única constante de la antropología a lo largo del periodo abarcado por este trabajo.

En el caso específico de la antropología alemana esta situación se ha vinculado; en parte; con los objetivos del programa de investigación bastiano; en referencia a Adolf Bastian; en el cual el primer paso es la acumulación extensa y sistemática de elementos materiales que

\footnotetext{
${ }^{98}$ Darnell 1998; Hinsley 1976; Hyatt 1979; Jacknis 2002; Liss 1990; Stocking 1974 a

${ }^{99}$ Podgorny 2000, p.54.

100 Martin 1901.

${ }^{101}$ Von Ihering hacía votos por que Ameghino no perdiera "su precioso tiempo en este terreno resbaloso". Podorny y Lopes 2008, p. 249.
} 
permitan un estudio comparativo ${ }^{102}$. Sin embargo la presencia de grandes colecciones no significará un número similar de puestos de investigación/trabajo. Las características de los procesos de institucionalización de las prácticas antropológicas en la Alemania de la segunda mitad del siglo XIX llevarán a que un reducido grupo de antropólogos profesionales puedan negociar un espacio en el mundo académico alemán ${ }^{103}$. Según ciertos autores esto se vincula a la tradición humanista de las universidades alemanas. Las pocas personas que serán capaces de hacer carrera por fuera del mundo académico de las ciencias humanas serán los cientos de aficionados de la clase media que acudían a las reuniones de la Deutschen Gesellschaft für Anthropologie, Ethnologie und Urgeschichte (Sociedad Alemana de Antropología, Etnología y Prehistoria) y sus ramas locales ${ }^{104}$.

Otro de los elementos a tener en cuenta al momento de evaluar el estado de la antropología alemana a comienzos del siglo XX será la injerencia de la Berliner Gesellschaft für Anthropologie, Ethnologie und Urgeschichte (Sociedad Alemana de Antropología, Etnología y Prehistoria) ${ }^{105}$; sección berlinesa de la sociedad antropológica alemana; y del Königliches Museum für Völkerkunde (Museo Real de Etnografía) ${ }^{106}$. A pesar de que al mismo tiempo se fundaban en Leipzig, Würzburg, München, Hamburg, Freiburg, Wien, Bonn, Frankfurt, Mainz, and Heidelberg secciones locales de la Deutschen Gesellschaft für Anthropologie, Ethnologie und Urgeschichte ${ }^{107}$; el museo y la sociedad berlinesa serán los espacios institucionales donde se nuclearán importantes colecciones antropológicas y al mismo tiempo donde se estructurarán y ejecutarán los principales programas de investigación. A pesar de las importantes colecciones

${ }^{102}$ En este sentido Glenn Penny ha señalado que el diseño humboldtiano del Museum für Völkerkunde reflejaba “[...] Bastian's empiricist commitments, the museum contained a vast, geographically arranged collection of material culture from all over the world. Unparalleled in size and scope by any other museum, the collections Bastian and his assistants were gathering were meant to lead them toward fundamental truths about humanity-truths that they believed would give them a better understanding of their society and themselves.". Sin embargo hacia 1900 el estado de las colecciones había cobrado un interés público, viendo el museo berlinés más cercano a los antiguos gabinetes de curiosidades que a una institución científica. Penny 2003, p. 88.

${ }^{103}$ Recordemos que el propio Bastian tendrá problemas al momento de obtener un puesto en la academia alemana. Hacia 1866 la Königliche Friedrich-Wilhelms-Universität de Berlín (actualmente Humboldt Universität) le otorgaba a el doctorado honorario en filosofía por su trabajo Der Mensch in der Geschichte; zur Begründung einer psychologischen Weltanschauung (1860), el cual era, en parte, resultado de los viajes realizados por Bastian en la década de 1850 alrededor del mundo en calidad de médico de un barco. Al mismo tiempo le ofrecían la oportunidad de dar cursos en etnología general y antropología, mitología comparada e historia del colonialismo. A pesar del bajo número de asistentes a los mismos; lo cual llevará a la cancelación de los mismos; Bastian se convertía en uno de los pocos antropólogos profesionales que accedían a los espacios académicos. Roth E 1905; Zimmerman 2001.

${ }^{104}$ Penny 2002 a, 2003, 2005; Zimmerman 2001

105 Esta era fundada en 1869 como una iniciativa de Rudolf Virchow, al cual se sumaban Bastian, el historiador Leopold Karl Wilhelm August Freiherr von Ledebur (1799-1877), el geógrafo Johann Samuel Heinrich Kiepert (1818-1899), el botánico Alexander Carl Heinrich Braun (1805-1877), el geólogo Heinrich Ernst Beyrich (1815-1896) y el banquero Carl Gustav Henckel (1841-1902).

${ }^{106}$ Inaugurado en 1866. Bastian será director de sus colecciones etnográficas, al igual que aquellas presentes en los museos reales desde 1869. Lewerentz 2009; Penny 2002 a, 2003, 2005, 2009; Pfeffer 2009; Roth E 1905; Zimmerman 2001

107 Correspondenz-Blatt der Deutschen Gesellschaft für Anthropologie, Ethnologie und Urgeschichte 1870. 
antropológicas presentes en otros museos; como los de Leipzig y los de Hamburg; y los esfuerzos por alentar actividades de y en los distintos grupos locales; el uso de diversos mecanismos institucionales por parte de personajes como Bastian llevará al centralizamiento de objetos, recursos y financiamiento ${ }^{108}$.

La importancia de repasar las discusiones al interior de la antropología alemana a lo largo de la segunda mitad del siglo XIX estiba en que, a pesar de las diferencias existentes en los programas de investigación de las sociedades e institutos de Berlin, Hamburg, Leipzig y München; los principales centros antropológicos de la Alemania de fines del siglo XIX ${ }^{109}$; sus integrantes sabrán crear una red internacional de colección, cooperación e intercambio, jugando una importante función en el desarrollo internacional de la antropología ${ }^{110}$. En este sentido los estudiosos alemanes jugarán un papel importante en la organización y la conformación de las prácticas antropológicas a escala internacional ${ }^{111}$.

Como veremos a lo largo de este capítulo, las discusiones acaecidas al interior de la antropología alemana a lo largo de la segunda mitad del siglo XIX también tendrán lugar en el contexto de la antropología francesa. Si bien no es objetivo de este trabajo realizar una minuciosa observación sobre el desarrollo histórico de estos dos espacios, es preciso señalar que aquellas discusiones en torno a los métodos, técnicas e instrumentos utilizados en la observación y clasificación de los objetos de estudio de la antropología se darán con gran intensidad en Francia y Alemania. En estos países; como en menor medida en Inglaterra; podremos observar un complejo proceso de institucionalización y profesionalización de las prácticas antropológicas; como en parte dan cuenta el establecimiento temprano de sociedades especializadas en el estudio del hombre en dichos países. El análisis de las teorías, las prácticas, las instituciones y las redes de estudiosos en Francia, Alemania; y en menor medida Inglaterra; nos permitirán entender las características, los objetivos y las finalidades de los trabajos antropológicos que comienzan a darse hacia fines del siglo XIX en la Argentina

De esta forma la figura Rudolf Martin es interesante para introducir estas discusiones. Nacido de padres alemanes en Suiza, recibirá toda su formación educativa en Alemania,

\footnotetext{
108 En el caso de la promoción de actividades el médico Alexander von Frantzius (1821-1877) le comunicaba a Rudolf Virchow que uno debía ser ciego para no darse cuenta que el foco de todas las actividades antropológicas alemanas se centraban en Berlín. Por otra parte recordemos que una ley imperial que tuvo vigencia entre 1899 y 1914 intensificará las relaciones entre la sociedad antropológica berlinesa y el estado alemán. Dicha ley establecía que cualquier colección adquirida por ciudadanos alemanes que vivían fuera de los límites del Reich o se encontrarán de viaje en el extranjero debía ser ofrecida al museo berlinés antes que a cualquier otro. De esta forma hacia principios del siglo XX este último poseía la mayor colección antropológica del mundo. Andree 1976; Anweisung betreffend die Behandlung der aus den Deutschen Schutzgebieten eingehenden wissenschaftlichen Sendungen 1899; Lewerentz 2009; Penny 2002 a, 2003, 2005, 2009; Pfeffer 2009; Zimmerman 2001.

${ }^{109}$ Glenn Penny, retomando los conceptos de Latour sobre el ejemplo del mapa del marino francés JeanFrançois de Galaup de La Pérouse (1741-1788), denomina a las instituciones presentes en estas ciudades como centros de los"cycles of accumulation". Latour 1992; Penny 2002 a

${ }^{110}$ Penny 2002 a, 2003, 2005, 2009; Penny y Bunzl 2003; Zimmerman 2001.

${ }^{111}$ Penny 2002 a, 2003, 2005, 2009; Penny y Bunzl 2003.
} 
efectuando posteriormente una serie de trabajos y estudios especializados en los principales centros e instituciones antropológicas francesas. Será en estos espacios donde conocerá las colecciones antropológicas provenientes de Argentina, despertando un interés particular en las mismas. La instrucción en ambos espacios le permitirá combinar en sus trabajos los métodos y técnicas más convenientes; ya fueran aquellos promovidos desde la antropología francesa o alemana; adaptándolos al objeto de estudio en particular; proceder ecléctico que LehmannNitsche tratará de aplicar a sus trabajos. Al mismo tiempo los intereses particulares de Martin al momento de gestionar la contratación de Lehmann-Nitsche como encargado de la Sección de Antropología del Museo de La Plata, nos sirve por un lado para dimensionar en forma precisa los motivos de la llegada de Lehmann-Nitsche a la institución platense; lejos de serlo por los meritos profesionales y/o académicos de este último; y por el otro para observar un escenario internacional de la práctica científica en la cual la colaboración entre los estudiosos lejos estará de ser un acto desinteresado y altruista.

\subsection{El Caos reinante y los intentos de orden}

Luego de sus primeros años en Zürich, Rudolf Martin se trasladaba con su familia a la ciudad alemana de Offenburg, de donde era originaria su madre. Será en esta ciudad donde realizará sus estudios primarios y el Gymnasium (bachillerato), finalizando en $1884^{112}$. El contexto en el cual Martin realizará estas etapas de su formación no se alejaba de aquel que podía apreciarse en gran parte de la Alemania posterior a la revolución de 1848, donde una "nueva" cultura comenzaba a tomar forma alrededor de la educación y la ciencia como una "vía" para la libertad y la realización individual. Esto auxiliaba, parcialmente, a que ciencia, religión y política empezarán a formar parte de las esferas públicas y las discusiones diarias ${ }^{113}$. De esta manera actividades tales como salidas de campo, visitas a museos locales o

${ }^{112}$ Los traslados de la familia de Martin estarán condicionados principalmente por las actividades del padre. Los primeros años en Suiza se deberán a que este último; proveniente de la ciudad alemana de Württenberg, trabajaba temporalmente como ingeniero mecánico en dicha ciudad. Posteriormente podrá establecer su propio taller de construcción de máquinas en Offenburg. Fischer E., 1926; Fischer I., 1962; Saller, 1925

${ }^{113}$ Entre 1830 y 1870 Europa experimentará un profundo periodo de transformación social e intelectual. Países como Inglaterra, Francia, y Alemania serán testigos de las maravillas de la industrialización y la "popularización" del conocimiento científico en los distintos espacios de la sociedad. En el ámbito educativo podemos mencionar las reformas educacionales que se vivirán luego de 1800 y que darán lugar a la fundación de la Universität zu Berlín en 1810 (Friedrich-Wilhelms-Universität a partir de 1828 y finalmente Humboldt Universität zu Berlín en 1949) y el establecimiento de los Gymnasium, hechos que contribuirán, en parte, al establecimiento del concepto de Bildung (autodesarrollo intelectual y moral) en las disciplinas históricas, filosóficas y filológicas. También es preciso referir los eventos y personas acaecidos por fuera del ámbito de la academia o de los círculos de estudiosos. Entre estos podemos mencionar a los llamados "divulgadores" o "educadores populares" los cuales se encargarán a través de visitas a sitios históricos, salidas al campo, observación de la naturaleza y publicaciones periódicas, de expandir y hacer accesible el conocimiento y el pensamiento científico a personas con ansías por la observación y explicación de los fenómenos de la naturaleza, ya fueran parte de la burguesía como al sector de los trabajadores. Blackbourn 1998; Blackbourn y Eley 1984; Bruckner 1999; Daum 1998; Hardtwig 1993; Manner 2001; Mommsen 1993; Saller 1925; Zimmerman 2001. 
publicaciones en los periódicos entrelazarán la observación y explicación de la naturaleza en la vida diaria de las personas con ansías por desentrañar y entender sus fenómenos.

Martin realizará estudios universitarios en la Albert-Ludwigs-Universität de Freiburg y en la Universität Leipzig ${ }^{114}$. Será en la primera de estas instituciones donde asistirá a las lecturas ofrecidas por el médico y zoólogo alemán Friedrich Leopold August Weismann (1834-1914), el cual lo motivará a diagramar un viaje a lo largo de las principales ciudades europeas de la época con el objeto de completar sus estudios ${ }^{115}$.

De esta forma luego de presentar su tesis doctoral decidirá realizar un viaje de tres años a lo largo de Europa, visitando las principales colecciones antropológicas ${ }^{116}$. En dicho viaje decidirá realizar una estadía de estudios en Francia. En París asistirá a los cursos que se dictaban en la École d'Anthropologie, pudiendo relacionarse con alguno de los profesores que allí enseñaban ${ }^{117}$. De esta forma; la insistencia y persuasión de los hermanos Mortillet; llevarán a Martin a trabajar dos veces como voluntario en las colecciones que poseía la Société d'Anthropologie, las cuales eran las que mayor cantidad de objetos poseía ${ }^{118}$. Al mismo tiempo seguirá muy de cerca las tareas de inventariado de las colecciones del Institut Anthropologique $^{119}$. Entre los objetos allí presentes podrá observar fotografías y cráneos de

${ }^{114}$ En Freiburg comenzará a estudiar abogacía. Sin embargo los últimos meses del segundo semestre se acercará al campo de la Filosofía, razón por la cual se mudará a Leipzig. El principal interés filosófico de Martin será la obra del alemán Immanuel Kant (1724-1804).

${ }^{115}$ Weismann había cursado estudios de química y medicina en la Städtische Klinik de la Georg-AugustUniversität de Göttingen. Posteriormente será enviado inmediatamente a Italia donde tendrá la oportunidad de visitar Viena y Paris. En esta última comenzará su acercamiento a la zoología en el Jardin des Plates. Volviendo a Alemania en 1860 decidirá especializarse en el mencionado campo de estudio, por lo cual entre 1860 y 1861 se pondrá bajo la guía del naturalista Karl Georg Friedrich Rudolf Leuckart (1822-1898) en la Justus-Liebig-Universität de Gießen. A pesar de haberse especializado en Alemania, Weismann insistirá en sus clases sobre la importancia de los espacios parisinos si se quería lograr un conocimiento acabado de las ciencias naturales. Churchill 1970; Conklin 1915; Mayr 1985; Petrunkevitch 1964.

${ }^{116}$ La tesis de Martin se titulaba Kants philosophische Anschauungen in den Jahren 1762-1766 y será presentada bajo la tutela del filósofo austríaco Alois Adolf Riehl (1844-1924). Este último también lo acercará al campo de la historia y de la geografía, disciplinas que había estudiado en las universidades de Wien, München, Innsbruck y Graz.

${ }^{117}$ La École se encontraba en el mismo espacio físico que la Société d'Anthropologie y el Laboratoire d'Anthropologie bajo el nombre de Institut Anthropologique. Entre las diversas lecturas y cursos ofrecidos por la École Martin concurrirá a los de antropología general de Paul Topinard (1830-1911), antropología zoológica y embriología comparada de Mathias-Marie Duval (1844-1907), antropología anatómica de George Hervé, antropología prehistórica de Louis Laurent Gabriel de Mortillet (18211898), etnografía comparada de Adrien de Mortillet (1853-1931), antropología lingüística de Abel Hovelacque (1843-1896) y André Lefèvre, y finalmente los cursos de etnología con Léonce Manouvrier (1850-1927). Manteniéndose un tanto ajeno a los conflictos y tensiones que se vivían al interior de la École, Martin sabrá entablar estrechos vínculos con representantes de los distintos sectores. Recordemos que este periodo estará caracterizado por las tensiones, conflictos e intereses personales de cada uno de los profesores que, a la muerte de Paul Broca, pretendían reformar el programa y el método de enseñanza ofrecido por la École. Blanckaert 1988,1991; Dias 1989, 1998

${ }^{118}$ Fischer E., 1926; Fischer I., 1962; Saller, 1925.

${ }^{119}$ Hacia 1891 el inventario de las colecciones permitía comprobar la presencia de 15 a 18.000 objetos que pertenecían en proporciones desiguales a cada uno de los tres establecimientos. Esta colección había estado dividida por François-Xavier Fauvelle en tres partes distintas: Anatomía humana; Anatomía zoológica y Etnografía. La mayor parte de la colección pertenecía a la Société, la cual a lo largo de más 
indígenas del extremo sur argentino. Esto lo llevará a realizar entre 1891 y 1896 una serie de 3 trabajos sobre la antropología física de las poblaciones indígenas de Tierra del Fuego ${ }^{120}$. Será a partir del trabajo publicado en 1892 que obtendrá su "Habilitación" (Habilitationsschrift) como "Privatdozent"" de antropología física en la Philosophische Fakultät de la Universität Zürich $^{122}$.

A partir de las discusiones surgidas en estos trabajos, y en forma paralela a los mismos, comenzaba Martin una serie de conferencias universitarias. En las mismas se destacaba la importancia del método comparativo en los estudios antropológicos. Al mismo tiempo se advertía que los ojos del especialista y las descripciones elaboradas podían no bastar o bien generar datos que, debido a la variedad de métodos utilizados, imposibilitarán la comparación. La mensuración de los elementos materiales ocupará un lugar central en estas discusiones ${ }^{123}$. El registro y la mensuración de los hechos se presentarán como pasos importantes para la comparación de los mismos y como instancia previa al surgimiento de las causas explicativas ${ }^{124}$.

Como lo definiera Martin, allí donde el ojo y el lenguaje no eran suficientes o eficaces las técnicas antropométricas aparecerán como "[...] un importante recurso técnico [...]"125. Sin embargo esto no estará exento de controversias y dificultades. La implementación y modificación de determinadas técnicas e instrumentos se vincularán estrechamente a una serie de debates que a lo largo del siglo XIX ocupará un importante lugar en la antropología,

de 30 años de existencia había sabido acumular objetos de casi todas las regiones de Francia y el mundo. El lote de la École era mucho más modesto, constaba sobre todo de compras de piezas necesarias para las lecturas, los cursos y las demostraciones. Las colecciones del Laboratoire, estaban constituidas por el producto de sus trabajos. Adrien de Mortillet como representante de la Société; Manouvrier como representante del Laboratoire y Ch. Letourneau por la École; fueron elegidos como los conservadores que llevarían a cabo el ordenamiento de las colecciones. Revue d' Anthropologie 1891.

${ }^{120}$ En 1892 publicaba Ein Beitrag zur Osteologie der Alacaluf, la cual sentará las bases para el posterior Zur physischen Anthropologie der Feuerländer publicado un año más tarde. Finalmente en 1896 aparecia su trabajo "Altpatagonische Schädel”. Los materiales utilizados en los trabajos de 1892 y 1893 serán cedidos por el Prof. Stor y Johannes Seitz (1839-1922), el cual abarcaba 5 esqueletos completos y los preparados de órganos internos del grupo de indígenas Alakaluf transportados en 1881 en Europa, y depositados en el Anatomisches Institut de la Zürich Universität. Para el trabajo de 1896 contará con una serie de antiguos cráneos patagónicos que le facilitará el director del Musée d'historie naturelle de Genève, Maurice Bedot (1859-1927). Estos habían sido desenterrados hacia mediados de la década de 1870 , en la frontera india entre el río Negro y el río Chubut, por el expedicionario y naturalista suizo Georg Claraz (1832-1930) y el geólogo y mineralogista suizo Jakob Christian Heusser (1826-1909. Martin 1892, 1893, 1896.

${ }^{121}$ El término "Privatdozent", cuya traducción literaria sería "Profesor/Docente privado", es un título académico conferido en algunas universidades europeas, particularmente aquellas de países de habla alemana. El mismo es conferido luego de que el candidato presenta un trabajo científico que le vale su "habilitación" (Habilitationsschrift). Para un análisis sobre la cultura académica alemana de fines del siglo XIX ver especialmente el clásico de Ringer 1969

${ }^{122}$ Hugentobler-Schwager 1990; Martin 1893; Oetteking 1926; Saller 1925.

${ }^{123}$ En este sentido Glenn Penny ha señalado que los descubrimientos arqueológicos de la segunda mitad del siglo XIX sirvieron, en parte, para persuadir a los etnólogos que la cultura material tanto de los pueblos contemporáneos como los extintos, podían ser leídas como textos históricos, no limitándose su valor y significado empírico como sucedía con los textos escritos. Penny 2002 a.

${ }^{124}$ Cannon 1978; Penny 2002 a, 2002 b.

${ }^{125}$ En el original: "ein wertvolles technisches Hilfsmittel“. Martin 1901, p.15. 
principalmente aquellos asociados a: las convenciones craneométricos; los instrumentos de mensuración y de representación; y finalmente el lenguaje utilizado en la observación, estudio y registro de los individuos y los restos óseos.

Estos problemas no serán exclusivos del contexto de la antropología alemana. A lo largo de la segunda mitad del siglo XIX se sucederán una serie de innovaciones y modificaciones tecnológicas en el campo de la comunicación y el transporte. En la década de 1830 comenzarán las inauguraciones de las grandes líneas ferroviarias ${ }^{126}$; una década más tarde los barcos de vapor comienzan a cruzar el Atlántico con periocidad y hacia 1851 el telégrafo del inventor estadounidense Samuel Finley Breese Morse (1791-1872) se adoptaba como estándar oficial de la telegrafía europea. Estos elementos permitirán el movimiento de cantidades masivas de información, datos, objetos e individuos a través del globo; al mismo tiempo que las controversias, el caos y los intentos por solucionarlo.

\subsubsection{Acumulación de objetos: Estrategias, espacios e intentos de orden}

Una de las principales características en los trabajos antropológicos acontecidos a partir de la segunda mitad del siglo XIX será el establecimiento de largas series comparativas, las cuales no se limitarán solamente a la compilación de datos antropométricos. A fin de poder contar con la mayor cantidad de datos posibles se hará uso de trabajos previos, coordinando los mismos con el material procedente de las colecciones albergadas en museos o en institutos de anatomía. En este sentido Rudolf Virchow señalaba, entre otros tantos estudiosos, la importancia de las colecciones en el estudio del hombre, las cuales constituían un archivo objetivo en el cual el investigador podía indagar y contrastar con las colecciones impresas que proveían los archivos de la historia ${ }^{127}$.

Esto mismo era señalado casi 20 años antes por el médico y coleccionista inglés Joseph Barnard Davis (1801-1881). En 1867 publicaba Thesarus Craniorum, un catálogo en el cual se detallaban los cráneos y esqueletos de su colección particular. En el prefacio de dicha obra Davis daba cuenta de la conformación de su colección de 1.474 cráneos. Entre las principales estrategias empleadas destaca la compra, canjes e intercambios con instituciones y particulares. Las mismas serán las que sabrán utilizar la casi totalidad de los estudiosos de la época. Este trabajo también nos permite apreciar en detalle la historia de las principales colecciones craneológicas existentes en Europa y en Estados Unidos en la segunda mitad del siglo XIX ${ }^{128}$.

\footnotetext{
${ }^{126}$ El 15 de septiembre de 1830 se inauguraba en Inglaterra The Liverpool and Manchester Railway. El 7 de diciembre de 1835 comenzaba sus servicios la Bayerische Ludwigseisenbahn en Alemania. Francia comenzaría con los planes de establecimiento de una gran línea ferroviaria en 1832, los cuales concretaría una década después.

${ }^{127}$ Virchow 1886.

${ }^{128}$ Davis 1867.
} 
En 1875 Davis publicaba un suplemento de dicho trabajo, donde afirmaba el notable impulso dado a los estudios craneológicos en Europa y Estados Unidos. Destacaba el rol desempeñado por las sociedades antropológicas y/o etnológicas, las cuales, a pesar de sus diferencias, acordaban en "[...] placing the study of the human skull first among the objects of their inquiry" ${ }^{\prime 29}$. De esta forma una de las principales características de la antropología desde el último tercio del siglo XIX será la necesidad de contar con un amplio material de trabajo. Esto permitirá realizar observaciones múltiples y variadas sobre vastos conjuntos, obteniendo a través de la comparación resultados cuantitativos seguros y válidos ${ }^{130}$. Al mismo tiempo, el establecimiento empírico de "tipos raciales" dará prioridad al estudio de las características morfológicas del rostro y del cráneo ${ }^{131}$. Como ha señalado Stocking esto llevará a “[...] the multiplied dissections and observations of the living and the dead, from which the scientific enquirer infers the structure of the lower forms of life, and connects them with the structure of the higher" ${ }^{\prime 32}$. La observación de representantes vivos de aquellos grupos indígenas considerados "primitivos"; como los andaman de Australia, los bosquimanos de África o los fueguinos en América del Sur; se pensaba como una forma de "[...] penetrate nature and to

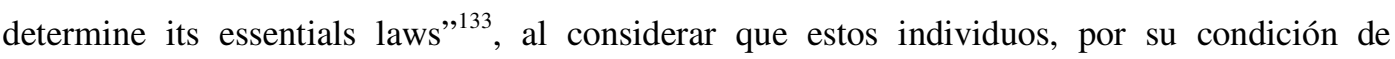
"primitividad" eran menos susceptibles a los cambios evolutivos.

Uno de los factores que impulsará notablemente la circulación de individuos, objetos y datos a lo largo de la segunda mitad del siglo XIX será la expansión de las principales potencias europeas. Las colonias establecidas por estas serán importantes redes de circulación y aprovisionamiento. En los cursos de de antropología brindados en 1901, Rudolf Martin señalaba a sus estudiantes la enorme expansión de los horizontes geográficos alemanes a partir de la segunda mitad del siglo XIX. El crecimiento del comercio mundial se traducía en la posibilidad de nuevas rutas para viajes de investigación. Martin, al igual que Bastian o Heinrich Waldeyer, afirmaba que las aspiraciones coloniales de los estados modernos habían contribuido al cambio experimentado en la antropología de mediados del siglo $\mathrm{XIX}^{134}$.

Las colonias contarán en mayor y en menor medida con distintas instituciones que ofrecerán a los antropólogos claras ventajas al momento del trabajo de campo. Entre estas podemos mencionar: escuelas, cuarteles militares apostados en las fronteras y finalmente los hospitales, cuarteles policiales y prisiones. La concentración de individuos en estos espacios será vista por los estudiosos como una posibilidad de ampliar el número de datos antropométricos

\footnotetext{
${ }^{129}$ Ibídem 1875, p. v.

${ }^{130}$ Blanckaert 1988, 1991; Dias 1989, 2004.

${ }^{131}$ Blanckaert 1988, 1991; Stocking 1985, 1987, 1998; Zimmerman 2001.

132 Stocking 1987, p. 174.

${ }^{133}$ Ibídem 1982, p. 22.

134 Martin 1901, 1905, 1914. Para un análisis de los vínculos entre la antropología y la expansión económica alemana ver especialmente Penny 2002 c.
} 
relevados. En algunos casos los estudiosos proveerán a las personas encargadas de estas instituciones con cuestionarios e instrucciones a fin de que continúen con el acopio de datos.

Estas estrategias no serán exclusivas de los antropólogos. Recordemos por ejemplo los trabajos frenológicos llevados adelante por el naturalista inglés Francis Galton (1822-1911) ${ }^{135}$ en el marco de la International Health Exhibition, celebrada en Londres en 1884 (Fig. 5). El principal objetivo de Galton será compilar "[...] testing and measuring the efficiency of the various mental and bodily powers" ${ }^{, 136}$, tal como rezaba un panfleto que había hecho circular en 1883. El plan original de montar un laboratorio antropométrico había sido concebido junto con el filósofo escocés George Croom Robertson (1842-1892), el cual estaba al frente de la cátedra "Mental Philosophy and Logic" en el University College de Londres. Galton consultará también con diversos psicólogos ingleses sobre los instrumentos más adecuados para establecer una serie de mediciones que incluirán la agudeza visual y auditiva, percepción del color, respiración, el tiempo de reacción ante estímulos externos, fuerza, altura y peso de los individuos ${ }^{137}$.

Un año más tarde Galton evaluaba que uno de los principales objetivos del laboratorio antropométrico había sido "[...] the reduction of expense to a minimum gives a much broader field for work, especially in introducing periodic systematic measurements into schools, which is one of the ultimate objects of this demonstration" ${ }^{" 138}$. El número de datos obtenidos; que incluirán la medición de 9.337 individuos; le permitirán a Galton profundizar en su estudio sobre la herencia y las actividades mentales y fisiológicas. Al mismo tiempo comenzará a delinear una serie de trabajos sobre psicometría, los cuales estarán supeditados principalmente a la línea frenológica del estudio de las diferencias psicológicas ${ }^{139}$. Ese mismo año Galton se encargaba de afirmar como esta demostración había despertado el interés de miembros de las colonias, diversos ámbitos educativos y de personas que deseaban conseguir reproducciones de los instrumentos a fin de colaborar con la construcción de un cuadro comparativo de mediciones de los individuos de Gran Bretaña $^{140}$.

\footnotetext{
${ }^{135}$ Para la vida y obra de Fancis Galton ver el trabajo clásico de Karl Pearson 1914, 1924, 1930.

${ }^{136}$ Galton 1908, p. 213.

${ }^{137}$ Galton 1908.

${ }^{138}$ Galton 1885 a, p. 294. El resaltado es de nuestra autoría.

139 Galton tendrá múltiples contactos con la frenología. En 1834, con tan solo 12 años de edad, a instancias del obispo François Jeune (1806-1868); director del King Edward's School; será estudiado por un frenólogo, el cual se encontraba compilando datos sobre los varones que asistían al colegio. En 1841, en el marco de unas vacaciones en Escocia será introducido a un tal Dr. Schmidt. Galton cuenta en su biografía que este era un reconocido frenólogo alemán, por lo cual no dudará en hacer que palpe su cabeza. Dos años más tarde, en el contexto de un viaje vacacional, se alojará en Dresden. Los dueños de la casa lo pondrán al tanto de la presencia del escritor escocés George Combe (1788-1858), uno de los más reconocidos frenologistas de la época, con el cual se encontrarían. Recordemos también que Galton realizará una serie de visitas y constantes consultas con el frenologista inglés Cornelius Donovan (18201872) antes de emprender su excursión a África del Sudoeste. Galton 1908; Pearson 1914, 1924, 1930 ${ }^{140}$ Colonias y escuelas serán, en palabras de Galton, "An ideally perfect laboratory, whether a plain or an elaborate one, would admit a stream of persons passing continuously through it". Galton 1885, p. 208.
} 
Es preciso mencionar que las conclusiones y las implicaciones de los estudios desarrollados por Galton y otros frenologistas serán rechazadas en el ámbito de la antropología. Esto no significa que ciertos estudiosos dentro de este campo mostraran un marcado interés en el estudio morfológico y fisiológico de los cerebros y las posibles asociaciones con los rasgos de la personalidad ${ }^{141}$. Recordemos la positiva repercusión del trabajo de Theophile Chudzinski (18401897) y Leonce Manouvrier sobre el estudio anatómico del cerebro del médico Louis-Adolphe Bertillon (1821-1883) y su comparación con el del político Léon Gambetta (1838-1882) ${ }^{142}$. Al mismo tiempo podemos constatar una serie de artículos sobre la anatomía de los cerebros de criminales y asesinos que tendrán una amplia repercusión en los boletines de la Société d'anthropologie de Paris.

Como hemos señalado hospitales, cuarteles policiales, prisiones y escuelas serán espacios de importancia al momento de la compilación de datos antropométricos. En 1898 Carlos C. Closson, en un trabajo sobre el significado pedagógico del índice cefálico, daba cuenta de los trabajos antropométricos llevados adelante por el sociólogo francés Henry Muffang (1864-1907) en el Lycée de Saint-Brieuc en el año 1897. Closson afirmaba que el trabajo con los escolares "[...] give an admirable basis for the comparison of the ethnic composition not only between urban and rural residents, but also between different social classes and professions and between persons of different intellectual proclivities and attainments" ${ }^{\text {"143 }}$. Ese mismo año Galton informaba como el trabajo en conjunto con los colegios, las universidades y la Royal Irish Academy habían permitido llevar adelante un verdadero laboratorio antropométrico, compilando un valioso y voluminoso número de datos; destacando a los estudiantes de medicina como los más entusiastas colaboradores $^{144}$.

Profesores universitarios como Martin, Virchow o Waldeyer impulsaban a sus estudiantes a que realizarán estudios en las colonias alemanas. Haciendo uso de las redes político-económicas coloniales, la antropología podrá abastecerse de los objetos que formarán parte de sus colecciones, especialmente los restos óseos ${ }^{145}$. Sin embargo como veremos más adelante esto también contribuirá al caos en el cual se subsumía la antropología. Los individuos que intervenían en el proceso de recolección de los objetos se multiplicaban, al igual que el número de instrucciones, manuales e instrumentos destinados a homogeneizar y uniformar los procesos de observación.

\footnotetext{
${ }^{141}$ Stocking ha sugerido el contacto "indirecto" de Boas con los trabajos biométricos de Galton, cuando el primero se encontraba en Londres en 1889. También es interesante ver los trabajos de Blanckaert sobre el impacto de la frenología en la antropología francesa. Blanckaert 1987, 1989 b, 1994; Stocking 1974 a.

${ }^{142}$ Chudzinski ; Manouvrier 1887.

${ }^{143}$ Closson 1898, p. 254.

${ }^{144}$ Galton 1898.

${ }^{145}$ Penny 2002 a, 2002 b, 2005, 2006; Zimmerman 2001.
} 
La amplia acumulación de elementos óseos y su preeminencia en los estudios antropológicos acontecidos a lo largo de la segunda mitad del siglo debe ser entendida, como ha señalado Nelia Dias, tanto en su carácter científico como en las razones técnicas. Si estos permitirán el estudio de los "tipos primitivos de las razas""146, será gracias a que su estabilidad, fijeza y resistencia los hacía plausibles de ser mensurados y comprobados a partir de la observación externa ${ }^{147}$. Sin embargo la forma en la cual estos elementos serán medidos, descriptos y analizados nos mostrará la falta de anuencia en un campo antropológico que se encontraba en formación y en cierta medida ejemplificarán un estado de la práctica antropológica con un grado de heterogeneidad en el cual debe tenerse en cuenta intereses personales, institucionales y nacionales. Tal como señalaba Joseph Barnard Davis en 1875, "Much has been written upon the mensuration of the skull, a very irregular and very difficult object to measure, whether in its interior or externally; and various attempts have been made to reduce its method of mensuration to uniformity" ${ }^{, 148}$.

La evaluación hecha por Davis puede ampliarse a los estudios antropométricos en general. Hacia 1919 el antropólogo checo Aleš Hrdlička (1869-1943) realizaba un recuento sobre el desarrollo histórico de la antropometría y señalaba "In the development of the system it was soon found that diversity of method was very prejudicial to progress, which led to attempts at regulation of the methods and instruments by schools, by national, and finally by international agreements" ${ }^{149}$. De acuerdo con esta afirmación Claude Blanckaert ha señalado que aquellos métodos y técnicas desarrollados en Europa a partir de la segunda mitad del siglo XIX, y, consignados a esclarecer el lugar biológico del hombre en la naturaleza y delimitar las particularidades de cada "raza", darán lugar al surgimiento de la antropometría, entendida como " [...] el deseo de situar al hombre entre los seres vivos, y sobre todo de clasificar a las personas, distribuirlas en diferentes grupos, de acuerdo con los principios objetivistas y jerarquicistas" ${ }^{\text {"150 }}$. Sin embargo la diferenciación de estos grupos y sobre todo los elementos a partir de los cuales establecerla -junto con los métodos y técnicas empleados- serán parte central de los debates de la antropología europea de la segunda mitad del siglo XIX.

Como tempranamente señalara Lucile Hoyme: "With new corners of the world being opened up by traders, missionaries, explorers, and colonists, it was only natural that the new kinds of plants and animals and men they brought back should engage the attention of the

\footnotetext{
${ }^{146}$ Dias 1989, p. 209

${ }^{147} \mathrm{Su}$ importancia, como señalaban muchos de los manuales de antropología que existían en la época, radicaba en que a partir de los mismos era posible "[...] non seulement d'étudier « les types primitifs des races ", mais aussi d'en suivre les modifications à travers les temps sous l'influence du mélange racial" Ibídem, p. 209.

${ }^{148}$ Davis 1875 , p. vi. El resaltado es de nuestra autoría.

${ }^{149}$ Hrdlička 1919, p.45.

${ }^{150}$ Blanckaert 2001, p. 146.
} 
naturalists of the day. The realization that groups of men differed from each other in more than skin color and clothing was slow in coming" ${ }^{151}$. Este proceso, sin embargo, estará caracterizado por la existencia simultánea de manuales, instrucciones, acuerdos e instrumentos destinados a sistematizar, uniformizar y homogeneizar los procesos de observación, medición e interpretación de los datos; buscando orden dentro de la práctica antropológica.

\subsection{Manuales, instrucciones $y$ acuerdos: Los debates y convenciones en torno al estudio del cráneo}

Hacia la segunda mitad del siglo XIX un amplio número de individuos, tanto profesionales como no profesionales, se encontraban implicados en la recolección de elementos destinados a la conformación de las amplias series comparativas antropológicas; condición primordial al momento de establecer la comparación entre dos objetos a partir del método de las ciencias naturales.

En relación a este último punto comenzarán a surgir programas, manuales e instrucciones de observación, ya fueran para uso de los estudiosos o de personas fuera de los ámbitos de la academia, que buscarán lograr un consenso en cuanto a la observación y el estudio del hombre. De esta forma se proveía una explicación científica de las diferencias raciales, lejos del tratamiento puramente artístico y visual ${ }^{152}$.

La premisa de someter los caracteres físicos a la medición y a la clasificación dará lugar a la existencia simultánea de distintos procedimientos e instrumentos en la observación, mensuración e interpretación de los mismos. En los congresos y reuniones de las distintas sociedades científicas es donde podemos apreciar la larga serie de debates, discusiones y contradicciones implicadas al momento de darle orden y un carácter científico a la práctica antropológica durante la segunda mitad del siglo XIX ${ }^{153}$.

En 1839 el médico inglés James Cowles Prichard (1786-1848) leía ante los miembros de la British Association for the Advancement of Science un trabajo titulado "On the Extinction of some varieties of the Human Race". En el mismo repasaba casos de extinción masiva y otros en los cuales la disminución progresiva de los miembros de una población específica la habían llevado a la desaparición total. A si mismo señalaba la perdida que significaba para la ciencia si "many tribes of the human family are suffered to perish, before those highly important questions

\footnotetext{
${ }^{151}$ Hoyme 1953, p. 408.

${ }^{152}$ Los primeros interesados en las diferencias raciales serán personas vinculadas al mundo de las artes. Esta tendencia se mantendrá a lo largo del siglo XVIII y la primera mitad del siglo XIX. En este sentido Claude Blanckaert ha manifestado que "Em primeiro lugar, a antropometria se opôs ao julgamento visual que dominava até então e que sería desacreditado como impressionista”. Blanckaert 2001, p. 147.

${ }^{153}$ Podgorny 2009.
} 
of a physiological, psychological, philological, and historical character, in relation to them, have been investigated" ${ }^{154}$.

Se creará un comité especial ${ }^{155}$ encargado de redactar un cuestionario destinado a los miembros de la administración de las colonias británicas y viajeros a fin de obtener información precisa sobre " $[\ldots]$ those tribes which are threatened with extinction, but also to the rest of the human family" ${ }^{\prime 56}$. El mismo será publicado en 1841 bajo el nombre de Queries respecting the Human Race, to be addressed to Travellers and others. Drawn up by a Committee of the British Association for the Advancement of Science. Prichard estaba seguro que la gran cantidad de dinero invertida en la distribución de aquella serie de preguntas era una garantía segura de su éxito.

Hacia 1851 un subcomite de la British Association for the Advancement of Science, compuesto por el médico Thomas Hodgkin (1798-1866) y el secretario honorario Richard Cull, será responsable de re-editar, ampliar y estructurar el cuestionario redactado hacia 1839. El resultado del mismo será A Manual of Ethnological Inquiry. El mismo incluirá las siguientes secciones: caracteres físicos, lenguaje, gramática, vida individual y familiar, edificios y monumentos, arte, animales domésticos, gobierno y leyes, geografía y estadística, relaciones sociales, y finalmente religión y superstición. Los redactores del mismo se encargaban de señalar que el mismo estaba destinado al estudio y la comprensión de la variabilidad humana ${ }^{157}$.

Sus integrantes se encargaban de resaltar que las mismas no serán una simple traducción de las Instruction générale adressée au voyageurs editado en 1841 por la Société Ethnologique de Paris. Estas tomaban por base el trabajo Considerations sur les methodes a suivre dans l'observations des peuples sauvages (1800) redactado por el lingüista, pedagogo y filántropo francés Joseph-Marie Degérando (1772-1842) y publicado por la Société des Observateurs de l'homme de París ${ }^{158}$. Las instrucciones publicadas en 1841 tendrán las mismas secciones detalladas en A Manual of Ethnological Inquiry, pero descriptas con una mayor profundidad; lo cual hace suponer que el trabajo francés pudo haber servido como referencia al momento en que Hodgkin y Cull redactarán su trabajo. Llamativamente el primer volumen del Bulletin de la Société Ethnologique, se encargaba de remarcar la simultaneidad en la cual iban apareciendo los proyectos de las sociedades científicas inglesas y francesas dedicadas a la observación de

\footnotetext{
154 JESL 1854, p. 193.

${ }^{155}$ El mismo estaba compuesto por el propio Prichard, el naturalista Charles Robert Darwin (1809-1882), los médicos Thomas Hodgkin (1798-1866) y James Yates (1789-1871), el zoólogo John Edward Gray (1800-1875), el botánico y zoólogo Richard Taylor (1781-1858), el naturalista y editor Nicholas Wiseman (1802-1865), y el librero y naturalista William Yarrell (1784-1856).

156 JESL 1854, p. 194.

${ }^{157}$ Se aclaraba que "In using this little manual, it should be borne in mind that it is not a mere guide to inquire into those tribes that are threatened with extinction, nor to make out certain details which are desiderata in our knowledge of the people of any given locality, but is intended to direct inquiry generally respecting the varieties of man". Ibídem, p.208.

${ }^{158}$ Blanckaert 1988; Copans y Jamin 1994; Jorion 1980.
} 
indígenas; al mismo tiempo que notaba las estrechas similitudes entre los programas y guías de observación $^{159}$.

Unos años más tarde a la publicación de Hodgkin y Cull; un subcomité de la Royal Geographical Society; compuesto por el vice-almirante Robert FitzRoy (1805-1865) y el teniente de marina Henry Raper (1799-1859); publicaba Hints to Travellers Scientific and General (1854). El mismo se centraba específicamente en la recomendación de los instrumentos más adecuados al momento de realizar algún tipo de observación. Según los editores del trabajo, ante las frecuentes demandas de aquellas personas interesadas en colaborar con la sociedad se vieron ante la difícil tarea de redactar una serie de instrucciones. Dicha tarea no estará exenta de dificultades. Por un lado la redacción de un detallado programa de observación seria enciclopédico, por otro lado unas consideraciones generales no terminarían generando los resultados esperados por los miembros de la Royal Geographical Society ${ }^{160}$.

La calidad y el tipo de observación que podían llegar a efectuar los observadores casuales dependerán, según Fitzroy y Raper, en la calidad de los instrumentos que transportaba. La redacción de una lista que detallará las cualidades, funcionalidades, ventajas y desventajas de cada instrumento; se presentaba excesiva y extensa. La formación científica y profesional de un individuo demandaba un tiempo que los miembros de la Royal Geographical Society no estaban dispuestos a asumir, por lo cual detallarán una lista de instrumentos que creían suficientes para satisfacer las demandas de los viajeros y que al mismo tiempo eran funcionales a las investigaciones llevadas adelante por sus miembros ${ }^{161}$. Los instrumentos serán concebidos como dispositivos a partir de los cuales obtener resultados "no contaminados" por la intervención de los individuos que los utilizaban. De esta forma los miembros de la Royal Geographical Society se aseguraban de obtener valiosos datos para sus investigaciones. Si bien las personas podían carecer de entrenamiento formal o cometer errores, los instrumentos se encontraban exentos de estos pormenores, sea quien fuera el que los utilizará estos mismos garantizaban la objetividad y utilidad de los datos.

A lo largo de la segunda mitad del siglo XIX la única constante en la práctica antropológica será la existencia simultánea de proyectos destinados a la redacción de

${ }^{159}$ BSE 1841.

160 La introducción aclaraba "A complete system of instructions adapted to general application would embrace every point which could present itself to the notice of the accomplished traveller, and such a work would be an encyclopedia. On the other hand, a few general remarks of an elementary nature would be superfluous to an individual of moderate attainments, while it could not possibly impart the necessary qualifications to one who had no other knowledge or experience of the subject". FitzRoy y Raper 1854, p. 328.

${ }^{161}$ Como daba cuenta las sucesivas ediciones de estas sugerencias "The following remarks are to be understood as addressed to a person who for the first time in his life, proposes to explore a wild country and who asks "What astronomical and mapping instruments and other scientific outfit ought I to take with me? and what are the observations for latitude and longitude, on which I should chiefly rely?" To this end we give a list of instrumentbs, books, and stationery, complete in itself, so that an intending traveller may order his outfit at once" Back y Galton 1871, p.6. 
programas, manuales, guías e instrucciones de observación. Estos se irían solapando uno a otro. Las similitudes serán mayores que las diferencias, por lo cual la falta de consenso a nivel internacional debe vincularse a factores tales como los intereses personales de las instituciones e individuos involucrados, la disponibilidad de elementos materiales y condiciones estructurales que posibilitarán estos trabajos y finalmente los intereses económicos de las personas asociadas al desarrollo, construcción, venta y distribución de instrumentos.

Hacia mediado de la década de 1860 gran parte de los antropólogos concordaban en el estudio de las "razas" a partir de la medición de cráneos, sin embargo esto abrirá un amplio marco de cuestiones vinculadas a la técnica y a la metodología a utilizar. El cráneo, con su forma irregular en la cual cualquier número de medidas lineales podían ser tomadas, sería el elemento central a la hora de estudiar las variabilidades individuales e interraciales. A partir del establecimiento de ejes y planos de referencia que se mantuvieran invariables se buscaba establecer los principales puntos que definieran al cráneo como objeto de estudio y superar las barreras impuestas por los lenguajes maternos a través del uso de un lenguaje neutral y compartido $^{162}$.

El cráneo; en esta sucesión de manuales, debates y convenciones en torno a los procesos de observación y mensuración del cuerpo humano; ocupara un lugar primordial. Este será una de las principales partes del cuerpo humano utilizadas para la determinación de los tipos "raciales". En este sentido Adolf Bastian señalaba que si bien había que ser muy precavido al momento de utilizar un solo elemento en la clasificación étnica de los grupos humanos, de ser así el foco principal debía estar en el cráneo ${ }^{163}$.

Tanto en Francia como en Alemania la búsqueda de la objetividad en las investigaciones antropológicas se traducirá en el establecimiento de medidas cuantitativas y comparaciones precisas en el estudio del cráneo. La elección del mismo por sobre otras partes del cuerpo será en parte arbitraria. Sin embargo los estudiosos creían que tomando ciertas medidas estandarizadas del mismo era posible calcular en forma matemática el cráneo "típico" de un determinado grupo humano. De esta forma podía establecerse tipos "raciales" que podían ser comparados entre sí. Al mismo tiempo; como causa y efecto; el cráneo será el principal elemento suministrado por las distintas redes de aprovisionamiento establecidas por los estudiosos y las instituciones científicas de la época. La política económica de las partes corporales requeridas por los estudiosos llevará a que sea el objeto antropológico más valioso y el más recolectado ${ }^{164}$. Recordemos que muchas de las prospecciones de las épocas serán

\footnotetext{
${ }^{162}$ Podgorny 2009.

163 Señalaba Bastian “Dann weit lieber den abgerundeten Schadel der Craniologie, als solch' einen pkilologiselien Knochenschwanz, um damit die Volker am Schopfe zu fassen und in die Eintlieilungsfacker zureclit zu stellen”. Bastian 1869, p. 2.

${ }^{164}$ Blanckaert 1988; Dias 1989, 1991, 2004; Penny 2002 a, 2002 b, 2002 c; Penny y Bunzl 2003; Zimmerman 2001.
} 
realizadas en cementerios, entierros o sitios coloniales donde las particulares condiciones de los mismos y la premura en la obtención de elementos colocará al cráneo por encima de otras partes corporales $^{165}$. En este sentido el zoólogo y paleontólogo alemán Reinhold Hensel (18261881), en su artículo sobre los Coroados de Brasil, afirmaba que la posibilidad de ser sorprendido por los indígenas en el momento que él estaba abriendo un grupo de tumbas lo llevo a recolectar solamente los cráneos ${ }^{166}$.

La necesidad de que el conocimiento generado por la antropología se base en largas series de muestras llevará a que solo grupos organizados con un gran número de miembros y colaboradores; como las sociedades antropológicas de Francia y Alemania y en menor medida Inglaterra; puedan obtener datos y conclusiones convincentes en torno a la determinación racial a partir del cráneo. En este sentido, y como veremos en las páginas siguientes, los principales debates se darán en estos países.

\subsubsection{El encuentro antropológico de Göttingen en 1861}

En 1861 el médico y fisiólogo norteamericano James Aitken Meigs (1829-1879) publicaba una de las primeras síntesis en torno a las principales técnicas, puntos de referencias e instrumentos utilizados en las mediciones antropométricas. Esto será el resultado de su trabajo junto con las colecciones de la Academy of Natural Sciences of Philadelphia, colaborando estrechamente con el médico norteamericano Samuel George Morton (1799-1851) ${ }^{167}$.

El mismo año de la publicación de Meigs se celebraba en la ciudad alemana de Göttingen el "Encuentro antropológico de Göttingen"168. El mismo era organizado y promocionado por el zoólogo Karl Ernst von Baer (1792-1876), un alemán del Báltico que junto con el anatomista y fisiólogo alemán Rudolf Wagner (1805-1864). Los objetivos principales serán establecer una sociedad profesional para la promoción del intercambio científico por un

\footnotetext{
${ }^{165}$ Los enfrentamientos que se suscitaban en las colonias establecidas por Francia, Alemania e Inglaterra alrededor del mundo, sumado a las particularidades de las respectivas administraciones resultaban, en gran parte de los casos, en la muerte de individuos. Los cuerpos de estos últimos serán objeto de interés por parte de los estudiosos. Las personas encargadas de enviarlos muchas veces optarán por el envío de las piezas más compactas y fáciles de enviar, entre las cuales se encontraba el cráneo. Al mismo tiempo, estudiosos como Virchow recomendaban a los viajeros casuales que recolectarán piezas óseas de lugares como campos de batalla, prisiones, hospitales y lugares de ejecución pública. Virchow 1875 b. Para prácticas similares acontecidas en la Argentina ver especialmente Podgorny et. all 2011.

${ }^{166}$ Hensel 1870.

${ }^{167}$ El resultado de estos trabajos serán una serie de importantes trabajos craneológicos, entre otros podemos mencionar: The Cranial Characteristics of the Races of Men (1857) Catalogue of Human Crania in the Collection of the Academy of Natural Sciences of Philadelphia (1857), The Observations on the Occiput in Various Races (1860); The Hints to Craniographers (1858) y The Mensuration of the Human Skull (1861). Meigs 1861; Hrdlicka 1914.

168 El mismo tendrá lugar entre el 24 y el 26 de septiembre, siendo el nombre oficial Göttinger Anthropologentreffen.
} 
lado, y la estandarización de las metodologías y técnicas empleadas en la antropología física de los países donde el alemán era la lengua principal ${ }^{169}$.

Los asistentes a dicho encuentro serán individuos con interacción dentro del acotado y exclusivo espacio social conformado por la red de espacios académicos, o bien se encontrarán al frente de importantes colecciones anatómicas o zoológicas; dos de los espacios primordiales al momento de establecer un consenso al interior de la disciplina ${ }^{170}$. Al igual que en el caso de Meigs, será el trabajo con las colecciones craneológicas lo que llevará a von Baer a cuestionar el uso del material y los instrumentos metodológicos y tecnológicos asociados a su interpretación. Dichas colecciones no se limitarán solamente al contexto ruso. Recordemos que en 1859 von Baer realizará una serie de viajes que le permitirán visitar las colecciones antropológicas en París, Londres y Copenhague, en donde destacaba la falta de uniformidad o sistematización a la hora de su ordenamiento ${ }^{171}$.

A través de un intercambio epistolar sostenido con Wagner, ambos estudiosos concluían en que el verdadero problema se hallaba en la ausencia de un método estandarizado al momento de describir e ilustrar las piezas; tornando el material "poco utilizable" para los distintos investigadores ${ }^{172}$. Esto se evidenciaba en una serie de publicaciones en las cuales se daba cuenta sobre el estado confuso y desorganizado hacia el interior de la antropología física, y en los que se planteaba la conveniencia de un acuerdo metodológico entre los antropólogos ${ }^{173}$.

Otro de los problemas al momento de establecer un acuerdo a nivel internacional será la barrera impuesta por la lengua madre a la hora de realizar las investigaciones. Citaba el caso del

169 De Alemania asistirán: los anatomistas Johann Christian Gustav Lucae (1814-1885), Hermann Welcker (1822-1897), Johann Alexander Ecker (1816-1887), Georg Meißner (1829-1905), Wilhelm Krause (1833-1910); los fisiólogos Hermann Schaaffhausen (1816-1893), Ernst Heinrich Weber (17951878) y Carl Georg Lucas Christian Bergmann (1814-1865); y el médico Friedrich Gustav Jakob Henle (1809-1885). De Austria: el explorador y diplomático Karl Ritter von Scherzer (1821-1903), junto con el médico y marino Eduard Schwarz (1839-1912). De Holanda: el médico y zoólogo Jan van der Hoeven (1801-1868); el patólogo y anatomista Willem Vrolik (1801-1863) y el botánico y anatomista Pieter Harting (1812-1885) . Von Baer y Wagner 1861.

${ }^{170}$ Welcker, Schaaffhausen y Henle habían estudiado en la Rheinische Friedrich-Wilhelms-Universität de Bonn; mientras que Vrolik y Harting lo habían hecho en la Rijksuniversiteit de Utrecht. Meissner y Krause eran profesores en la Georg-August-Universität de Göttingen. Ecker y Welcker en la RuprechtKarls-Universität de Heidelberg. Entre los directores de institutos o colecciones anatómicas o zoológicas tendremos a: Henle al frente del Institut für Anatomie der Universität Göttingen; Harting era director del Zoölogisch Museum de Rijksuniversiteit de Utrecht. Posterior al encuentro de Göttingen Welcker será designado director del Instituts für Anatomie der Universität Heildeberg en 1876; y Krause del Instituts für Anatomie der Universität Berlin en 1892. Finalmente podemos mencionar el caso de von Scherzer el cual tenía un estrecho vínculo con la familia Wagner. Knußmann 1988; Spiegel-Rösing y Schwidetzky 1982.

${ }^{171}$ Remarcaba von Baer "Da in der letzten Zeit sehr viele Schädelformen beschrieben und gemessen waren, die Messungen aber nach sehr verschiedenen Principen unternommen waren, also unmittelbare Vergleichungen gar nicht zuließen, denn oft wurde die Art der Messung nicht einmal angegeben, so schien es wünschenswerth, dass ein Versuch gemacht würde, sich über eine gemeinschaftliche Methode zu einigen" Von Baer y Wagner 1861, p. 436-437.

172 Ibídem, p. 4.

${ }^{173}$ Para una lista de los trabajos ver: Ibídem, p. 6-7. 
Bulletins de la Société d'anthropologie de Paris como un "instrumento de almacenamiento múltiple" 174 necesario para el progreso de la ciencia antropológica y que, llamativamente, no existía en Alemania. A través de este tipo de publicaciones; según von Baer y Wagner; los estudiosos franceses tenían para sí un inmenso archivo de datos y colecciones a las cuales acceder. En este sentido remarcaba von Baer que la ciencia era una práctica universal que trascendía las fronteras geográficas, las lenguas no ${ }^{175}$. Este será uno de los motivos esgrimidos al momento de limitar el número de asistentes. De esta forma podían evitarse los posibles obstáculos ocasionados por la utilización de diferentes idiomas. Una vez logrado el consenso al interior de un grupo de estudiosos que compartían la misma lengua madre podía plantearse la difusión a escala internacional.

A pesar de estos argumentos, los principales obstáculos se encontraban en los propios individuos que ejercían la práctica de la disciplina. El mismo hecho de realizar este encuentro, da cuenta del estado caótico y anárquico de la práctica antropológica. Esto se refleja en los 7 puntos que definían el programa del "Encuentro antropológico de Göttingen". Los principales objetivos serán establecer el uso de una metodología y un conjunto de instrumentos en común al momento de describir y representar las distintas partes del cuerpo humano. Al mismo tiempo se remarcaba la necesidad de comunicación mutua entre los distintos espacios de investigación, a fin de poder contar con material comparativo antropológico. Observando el caso francés se buscaba el establecimiento de una publicación periódica como órgano de representatividad de la comunidad antropológica alemana ${ }^{176}$.

La presentación de nuevos instrumentos también será una de las características de este tipo de encuentros. Tal como afirmaban varios estudiosos, ante las limitaciones impuestas por las instrucciones, manuales y convenciones la solución estibaba en el desarrollo de nuevos instrumentos o bien la modificación de aquellos pre-existentes ${ }^{177}$. Este énfasis en la parte instrumental debe entenderse en un contexto en el cual los restos materiales; a diferencia del lenguaje subjetivo y mutable; serán aquellos que, estables a lo largo del tiempo, permitirán caracterizar a los pueblos "primitivos"178.

Los conocimientos técnicos vinculados a la matemática, la física y la ingeniería serán de gran utilidad al momento de desarrollar o colaborar en la construcción de estos instrumentos. Al momento en que Broca presentará sus instrucciones lo hará asociado a un considerable número de instrumentos, en cuya construcción había tenido una activa participación. Recordemos que en

\footnotetext{
${ }^{174}$ Ibídem, p. 26.

175 Ibídem.

176 Ibídem.

${ }^{177}$ Flower 1879; Garson 1886; Martin 1893, 1896, 1905, 1914; Welcker 1886.

${ }^{178}$ Barth 2005; Blanckaert 1988; Evans 2002; Massin 1996; Penny 2002 a, 2005, 2006; Stocking 1973.
} 
su intento de ingresar a la École Polytechnique de Paris obtendrá un sólido e importante conocimiento en física y matemática ${ }^{179}$.

Francis Galton, en Inglaterra, se encargaba de remarcar ante los asistentes a la International Health Exhibition de Londres que el mismo se había encargado de construir los elementos antropométricos utilizados en el laboratorio antropológico instalado en dicha exhibición. Galton afirmaba que esto estaba destinado a "familiarizar" al público con "[...] with (the) simple methods of measuring and recording many of the physical characteristics of man" ${ }^{180}$. Tal como afirmaba Broca, los programas de observación y los instrumentos antropométricos debían tener un carácter didáctico, ya que estos eran uno de los caminos por los cuales asegurarse la colaboración de individuos dentro y fuera del mundo académico-científico ${ }^{181}$.

En el encuentro celebrado en Göttingen, Pieter Harting presentará su instrumento para la representación gráfica de los cráneos: el "Kephalographe"182 (Fig. 6). A continuación Johann Christian Gustav Lucae presentaba su método geométrico para dibujar cráneos junto con el instrumento utilizado para tal fin. El "Lucaesian apparatus"183 consistirá en una estructura rectangular de madera donde era fijado el cráneo y que en su zona media contenía una superficie plana de cristal y un lente a partir del cual observarlo constantemente (Fig. 7). La lente aseguraba que la mirada del antropólogo siempre se encontrara fija y siguiendo una línea perpendicular que pasaba por el punto que dibujaba. El cráneo se dibujaba en tinta y directamente sobre la superficie plana de cristal, donde una vez finalizado el dibujo se colocaba, a través de una fuerte presión, una pieza de papel donde se transfería la tinta. A diferencia de las fotografías, los dibujos realistas o las pinturas, que usaban una proyección en perspectiva para representar los objetos tal como eran vistos por el ojo humano, el aparato de Lucae forjaba una proyección geométrica, en la cual todos los puntos en el dibujo eran tomados de la intersección de las líneas que cruzaban el plano de representación perpendicularmente frente al objeto ${ }^{184}$.

Fuertemente promovido por von Baer y Wagner, y luego ratificado por Kollmann, Ranke y Virchow en los congresos de la Deutsche Gesellschaft für Anthropologie, Ethnologie und Urgeschichte de 1877, 1880 y 1882; se convertirá en el medio convencional de

\footnotetext{
${ }^{179}$ Para una lista de los instrumentos ver especialmente: Broca 1861, 1864,1868, 1869, 1872, 1873 a, b, $1874 \mathrm{a}, \mathrm{b}, 1875,1879,1881$.

${ }^{180}$ Galton 1885, p.294.

${ }^{181}$ Broca 1875.

${ }^{182}$ Este estaba compuesto por una serie de planchas de madera que se deslizaban y permitían determinar el contorno de la cabeza tanto en la circunferencia horizontal, como para fijar en el plano transversal y el plano medio. Esta serie de planchas podían inmovilizarse por medio de tornillos lo cual permitía la representación gráfica en papel. Harting recomendaba el instrumento especialmente para el trabajo sobre individuos vivos, siendo de gran utilidad para "[...] aquellos viajeros que desean determinar la forma de la cabeza de los pueblos extranjeros [...]". Hartig 1861; Von Baer y Wagner 1861, p. 38-39.

${ }^{183}$ Landzert 1867, p. 1.

${ }^{184}$ Fritsch 1872; Landzert 1867; Lucae 1873.
} 
representación craneométrica dentro del contexto de la antropología alemana ${ }^{185}$. Sin embargo su uso e implementación no estará exento de invectivas. John George Garson, haciéndose eco de los argumentos esgrimidos por los franceses, sintetizaba las principales críticas contra su uso. El aparato ideado por Lucae era visto como un obstáculo al momento de establecer un diagrama geométrico preciso, por lo cual desde los espacios franceses e ingleses abogarán por el uso del estereógrafo de Broca o bien por el diagrafo de Garard, debido a su efectividad y principalmente su simpleza (Fig. 8). El argumento cardinal de esta detracción será el uso del plano horizontal alemán para establecer la colocación, medición y representación gráfica del cráneo ${ }^{186}$ (Fig. 9) ${ }^{187}$. Para el mismo se proponía el uso del borde superior de la arcada zigomática. La determinación de este plano será de vital importancia para los estudios craneométricos, ya que este determinaba la posición del cráneo y permitirá calcular los valores en torno al largo, el grosor y el alto del cráneo; el ancho máximo de la frente, el ángulo de inclinación del foramen magnum y el del perfil de la cara; condicionando de esta forma los valores de ciertos índices craneales y faciales $^{188}$.

A pesar de las futuras críticas esgrimidas desde los espacios ingleses, von Baer y Wagner determinaban el sistema métrico ingles como el más apto a la hora de realizar estudios métricos. Si bien este sistema era usado por distintos estudiosos en Francia, Bélgica, Holanda, Rusia y Alemania; el objetivo de von Baer era estandarizarlo a nivel internacional a partir del congreso de Göttingen. Detrás de este objetivo se escondía en realidad el deseo de los organizadores del congreso de hacer frente y suprimir el sistema de medición de meridianos utilizado por los franceses. Ante esto von Baer y Wagner acusaban al sistema francés de ser poco preciso ante la exactitud y simpleza ofrecida por el sistema métrico y los decimales ${ }^{189}$.

\footnotetext{
${ }^{185}$ Uno de los principales inconvenientes que los estudiosos alemanes encontrarán en los aparatos de representación gráfica será que estos no podrán reproducir los objetos tal como los veía el ojo humano. Cuando los antropólogos comenzaron a interesarse por el índice cefálico; la proyección geométrica de la parte frontal y lateral del cráneo se convertirá, como ya hemos visto, en una de las medidas más importantes. Si bien el aparato de Lucae no podía representar fielmente la apariencia del cráneo, reproducirá, a diferencia de los instrumentos empleados por los franceses, las dimensiones del mismo. Gildemeister 1875 .

${ }^{186}$ Apuntaba Garson: "I refer to the system of measuring the skull in relation to the Frankfort horizontal plane, to which we cannot assent, and which we would faint hope to see abandoned by our brethren in Germany for the more practical method adopted by the majority of anthropologists elsewhere". Garson 1885, p.81.

${ }^{187}$ Ibídem.

${ }^{188}$ Broca 1873 a; Martin 1893.

${ }^{189}$ Von Baer y Wagner 1861.
} 


\subsubsection{Los trabajos de Paul Pierre Broca en 1862}

Como hemos mencionado uno de los principales puntos definidos en el encuentro de Göttingen será la determinación del plano utilizado para la orientación del cráneo al momento de ser estudiado. A lo largo de la segunda mitad del siglo XIX los diversos encuentros antropológicos acontecidos en Europa tendrán entre sus principales objetivos la discusión de dicho plano.

Un año después de dicho encuentro Pierre Paul Broca implementará una serie de instrumentos, desarrollados en los espacios académicos franceses, a fin de rebatir las propuestas de von Baer y Wagner. Su objetivo será la determinación del "verdadero" plano horizontal. A través del uso de instrumentos como el cranioforo y el craneostato, buscaba demostrar Broca el posicionamiento "artificial" del cráneo ${ }^{190}$. Según este último la posición "natural" del cráneo corresponderá a la dirección que asume la mirada de un sujeto vivo; es decir cuando las cuencas oculares del cráneo se encontraban en forma paralela a un plano horizontal.

Luego de descartar una serie de propuestas ${ }^{191}$, planteará que el cráneo se encontraba en posición "natural", cuando el plano alveolo-condilar era tangente a la cara inferior de ambos cóndilos occipitales, y pasaba en forma horizontal por el centro del borde alveolar. Broca justificaba su elección fundamentando que el plano alveolo-condilar se mantenía constante a pesar de las condiciones de edad, género y "raza", y por otro lado el paralelismo "casi perfecto" con el plano orbital ${ }^{192}$. Llamativamente dicha posición se obtenía fácilmente al colocar el cráneo en el cranioforo de su propia invención, el cual al momento de la representación gráfica era reemplazado por el craneostato (Fig. 10 y 11$)^{193}$.

190 Junto con la propuesta de von Baer y Wagner discutirá las de: el médico francés Louis Jean-Marie D’Aubenton (1716-1800); el médico holandés Petrus Camper (1722-1789); el zoólogo y anatomista alemán Johann Friedrich Blumenbach (1752-1840); el anatomista y fisiólogo escocés Charles Bell (17741842) y el geógrafo irlandés Joseph Barclay Pentland (1797-1873). Broca 1862, 1873 a.

${ }^{191}$ La primera propuesta será utilizar el plano de masticación como plano horizontal. Si bien a nivel teórico le parecerá factible de ser utilizada, la comprobación práctica hará que descarte inmediatamente esta propuesta. Broca planteaba que cuando la dentadura estaba completa e intacta, el plano horizontal se encontraba muy cercano a la dirección horizontal. Pero al momento de ser comprobada empíricamente esta propuesta padecerá de serias objeciones. En primer lugar, las superficies de las coronas, incluso en pacientes que todavía eran jóvenes y con un estado dental sano, no pasaban siempre por el mismo plano. En segundo lugar el desgaste al que eran sometidos los dientes dificultaba la localización del plano de masticación. Ibídem.

${ }^{192}$ Broca 1873 a, p.72.

${ }^{193}$ Este último instrumento estaba compuesto por una tabla en medio de la cual se fijaba una pieza cúbica de 4 a 5 centímetro denominada soporte, sobre el cual se colocaban los cóndilos. De esta manera el cráneo quedaba en equilibrio, evitando el movimiento del cráneo hacia atrás o hacia delante a partir de unos complementos. El movimiento de "bascula" hacia atrás era evitado colocando una pieza adicional detrás del soporte que se deslizaba por un bastidor. El movimiento hacia delante se evitaba al colocar una barra de hierro colocada en un deslizador horizontal y situado exactamente en el mismo plano que la superficie superior de apoyo. Con el cráneo sostenido en una mano se empujaba el fijador hasta que su punta se encontrará en el medio del borde alveolar. De esta forma Broca aseguraba que cuando el punto alveolar y la cara inferior de los cóndilos estaban en un plano paralelo al craneostato, este fuera horizontal. Ibídem. 
La exactitud de este método era comprobada al momento de determinar si desde el punto de vista fisiológico el cráneo se encontraba en una "attitude naturelle", la cual correspondía a cuando el individuo de pie observaba el horizonte ya que esta era la "direction naturelle du regard"194. Para esto determinará la posición del plano de masticación, ya que este era paralelo al plano de visión horizontal. Para poder determinar este último hará uso de una aguja que; insertada en el agujero óptico y pasando por el centro de la abertura orbital; indicaba con una aproximación suficiente la dirección horizontal de la mirada ${ }^{195}$ (Fig. 12). Esto también le permitía descartar todas las demás propuestas de plano horizontal ${ }^{196}$. El desarrollo de nuevos instrumentos permitirá a Broca comprobar empíricamente su propuesta para el plano horizontal y descartar la de otros estudiosos. De esta forma los intentos de los estudiosos por uniformizar la forma en la cual las diferencias raciales podían ser observadas, descriptas y mensuradas, favorecerán el aumento de la variabilidad de las mismas al suprimir o modificar puntos y planos craneales pre-existentes.

Los trabajos de Broca tendrán una gran aceptación, especialmente entre los estudiosos franceses e ingleses. Similar recepción tendrá Instructions Générale pour les Recherches Anthropologiques. Anatomie et Physiologie, publicado en $1865^{197}$. A partir de dicha obra Broca buscaba obtener la anuencia de las distintas personas que, a lo largo del mundo, procuraban colaborar en el campo de la observación y estudio del hombre. Broca se encargaba de resaltar que las instrucciones no estaban dirigidas solamente a los anatomistas, sino que incluían médicos, cirujanos y en particular "à toutes les personnes de bonne volonté qui désirent s'initier aux études craniologiques" ${ }^{\prime 198}$. De esta forma sintetizaba una serie de métodos rápidos, simples y

\footnotetext{
${ }^{194}$ Broca recurría a la medicina y a la fisiología. Por un lado se sabía que cuando el ojo se encontraba en reposo el centro de la pupila ocupaba la zona media de la abertura orbital; por el otro se conocía que el hemisferio posterior del globo ocular, el punto donde acaba el nervio óptico, se encontraba más o menos sobre el mismo nivel que el agujero óptico. Para fijar la aguja en esta posición se cortaba una pieza de cartón, de la forma y tamaño de la abertura orbital, donde se practicaba un pequeño agujero a igual distancia de los bordes superior e inferior. El trozo de cartón podía ser reemplazado con una abrazadera de presión, similar a las utilizadas para mantener los párpados abiertos en algunas operaciones quirúrgicas, pero provista de un resorte bastante fuerte para superar la resistencia de un tubo de caucho vulcanizado fijado en la extremidad de sus dos ramas. En la mitad de su longitud, el tubo elástico se perforaba con un orificio para el paso de la aguja. Finalmente la parte exterior de la aguja era la que daba la dirección de la mirada. Una vez colocado el cráneo sobre el craneostato podía comprobarse la dirección de la "aguja orbital" en las distintas líneas propuestas para oficiar de plano horizontal. Ibídem p.65.

${ }^{195}$ Esta pieza era denominada orbistato. Ibídem.

${ }^{196}$ En las demás propuestas la mirada asumirá una posición ascendente u oblicua. Ibídem.

${ }^{197}$ Este manual de instrucciones redactado, impreso y comercializado por la Societe d' anthropologie de París a un precio de 1.50 francos; estaba destinado a Senegal, Perú, México, Chile, el litoral del Mar Rojo, Sicilia y Francia. Sin embargo las instrucciones podían ser modificadas según la demanda del viajero a partir de la indicación del lugar a donde se viajaba. Broca 1875 b.

${ }^{198}$ Ibídem p. 337.
} 
fáciles a través de los cuales uniformizar la manera en la que aquellas personas deseosas de contribuir con el desarrollo de la antropología física, realizaban sus observaciones ${ }^{199}$.

La importancia de este trabajo radicará en la reforma y síntesis de los métodos craneométricos. Tal como señalaba Broca el programa descrito en estas instrucciones se limitaba a cuestiones concernientes a la anatomía de las "razas humanas" ${ }^{200}$. El trabajo de Broca sentará un importante precedente que servirá como base a los trabajos realizados en Francia, Bélgica, Italia, España, Suiza e Inglaterra principalmente; siendo los espacios alemanes donde este manual encontrará más reticencia ${ }^{201}$. Las discusiones en torno al uso del plano horizontal y los instrumentos promovidos desde Göttingen o desde Francia se acrecentarán en las dos tres últimas décadas del siglo XIX.

\subsubsection{Los trabajos en Suiza y Francia en 1864}

En 1864 se publicaba Crania helvetica. Sammlung schweizerischer Schädelformen del médico suizo Wilhelm His-Vischer (1831-1904) y el zoólogo y paleontólogo suizo Karl Ludwig Rütimeyer (1825-1895). Esta obra será resultado del trabajo; junto con el médico alemán George Meißner (1829-1905); sobre diversas colecciones craneológicas suizas ${ }^{202}$. El trabajo constará de la descripción e ilustración de 76 cráneos. Al momento de representarlos gráficamente harán uso del aparato que Lucae presentará en el congreso de Göttingen en $1861^{203}$. A pesar del rechazo de los instrumentos promovidos desde los espacios franceses dicho trabajo no contará con mucha repercusión fuera de los espacios académicos suizos. Tal como afirmaban un año más tarde los médicos ingleses John Thurnam (1810-1873) y Joseph Barnard Davis al publicar Crania Britannica, al tratar de ordenar las abarrotadas colecciones antropológicas la proliferación de métodos y técnicas solamente contribuía a la acumulación de $\operatorname{caos}^{204}$. En un intento de comprender las múltiples causas de este fenómeno Aleš Hrdlička puntualizará sobre los efectos de la guerra franco-prusiana de 1870 en el espacio de la antropología europea. Posterior a este conflicto, el sistema de Broca aceptado casi

\footnotetext{
${ }^{199}$ Lineamientos básicos de este manual pueden ser encontrados en un trabajo previo de Broca, publicado hacia 1860, y dedicado a la etnología de Francia. En este bosquejaba los métodos y técnicas que él consideraba primordiales a la hora de elaborar un trabajo antropométrico. Broca 1860; Buxton 1933; Huard 1961.

${ }^{200}$ En este Claude Blanckaert ha señalado que "Broca pretendía precisar los límites de la variabilidad del género humano a fin de llegar a las consecuencias fisiológicas de la adaptación — o la inadaptación — de los pueblos civilizados. Por su capacidad de organizar la investigación, torno profesional una disciplina que fue durante mucho tiempo objeto del amateurismo". Blanckaert 2001, p. 147.

${ }^{201}$ Blanckaert 1989 a, 1991, 2001; Dias 1989; Huard 1961.

${ }^{202}$ His y Rütimeyer 1864.

${ }^{203}$ De esta manera en el trabajo podrán encontrarse representaciones de cráneos desde su superficie superior, algunas sobre los rostros, algunas de la sección occipital, y finalmente representaciones de la sección vertical del cráneo y su molde interior, mostrando la forma general del cerebro y las proyecciones de las circunvoluciones principales. Alix 1864; Bay 1986; His y Rütimeyer 1864.

${ }^{204}$ Davis y Thurnam 1865.
} 
universalmente será reemplazado a partir de "[...] the rapidly growing tendency in Germany for individualism $[\ldots]^{, 205}$.

\subsubsection{Los trabajos en Alemania, Inglaterra y Estados Unidos hacia la década de 1870}

En 1873 el zoólogo alemán Hermann von Ihering (1850-1930); en el marco del 19 congreso de la Deutsche Gesellschaft für Anthropologie, Ethnologie und Urgeschichte, propondrá una serie de medidas a fin de estandarizar y homogeneizar los estudios craneométricos. Junto con el índice cefálico, von Ihering propondrá la determinación del plano horizontal a partir de dos puntos: el punto más bajo del borde inferior de las órbitas y el borde superior de la apertura del oído ${ }^{206}$. Esta propuesta, sin embargo, no será tan fácilmente aceptada por los estudiosos presentes. Al igual que en otros casos, la fuerte resistencia se vinculaba principalmente a dos motivos: por un lado la reconsideración de todos los trabajos previos, y por el otro la necesidad de comprar nuevos instrumentos acordes a lo establecidos por las convenciones craneométricas ${ }^{207}$.

En algunos casos los antropólogos carecerán de los conocimientos que le permitan construir por si mismos los instrumentos antropométricos. Esto no significaba que no participarán activamente en el desarrollo de los mismos, asociándose con diversos fabricantes. En este sentido podemos mencionar el estrecho vínculo entre Rudolf Martin y el ingeniero mecánico suizo Paul Hermann ${ }^{208}$. Este tendrá una decisiva actuación en el desarrollo del "Instrumental de viaje"209 (Fig.13). La promoción y venta de los instrumentos por parte de los antropólogos debe entenderse dentro de un contexto donde la compra de los mismos no dependerá exclusivamente de la adscripción a tal o cual convención antropométrica, sino a la posibilidad de adquirir equipos a bajo costo.

\footnotetext{
${ }^{205}$ Hrdlička 1919, p. 45.

206 Jhering 1873; Ottow 1966; Virchow 1891.

207 Jhering 1875.

${ }^{208}$ Este colaborará también en el desarrollo y modificación de instrumentos ortopédicos a pedido del médico suizo Wilhelm Schulthess-Wyder (1855-1917). A partir de esto Hermann publicará "Wissenschaftliche Messinstrumente für Anthropologie nach Prof. Dr. Rud. Martin und für Orthopädie nach Dr. Wilhelm Schulthess" en 1911. Martin 1899, 1903, 1914.

${ }^{209}$ En el original alemán se lo describe como "Reise-Instrumentarium". El mismo constaba de un compás normal, para la medición de la cabeza y el cráneo, con un peso de 200 gramos; un compás de corredera, para tomar medidas generales del cuerpo y el esqueleto, con un peso de 160 gramos; una cinta métrica de 1.50 metros y con un peso que variaba entre 1 y 2 gramos; un dermografo; y un lápiz. El conjunto instrumental sumaba un total de 53.60 marcos o 66 francos; por 107.20 marcos o 132 francos se adquiría además un estuche antropométrico, fabricado en una lona impermeable, que contaba con un bolsillo especial para libretas de apuntes y tenía un peso total de 920 gramos. Al mismo sabrá articular los trabajos de otros especialistas a fin de concretar la construcción de los instrumentos solicitados por Martin. Katsch 1906; Martin 1914; Waldek y Wagner 1905; Zimmermann 1928.
} 
Al mismo tiempo en Inglaterra se publicaba la primera edición de Notes and Queries on Anthropology, for the Use of Travellers and Residents in Uncivilized Lands (1874). El mismo era el resultado de una serie de discusiones, que habían tenido lugar dos años antes, en las que se cuestionaba la calidad de los datos disponibles al momento de estudiar la antigüedad del hombre. Ante esto el oficial de la armada y arqueólogo ingles Augustus Henry Lane Fox Pitt Rivers (1827-1900), decidirá formar un comité especial encargado de la redacción de un conjunto de instrucciones destinado a "[...] travellers, ethnologists and other anthropological observers". El énfasis de esta serie de instrucciones estará explícitamente puesto en la observación y en la descripción, más que en la teoría y en la interpretación. Como ha señalado Stocking "[...] the emphasis was on detailed and careful observation, and the prefatory orientations seem intended largely to counteract prior assumption that migth be present in the mind of untrained observer,"210. La sección de antropología física; que incluirá técnicas antropométricas y test de sangre, estará dispuesta en 24 páginas. Las restantes secciones serán: "field antiquities" (arqueología) con 10 páginas, antropología social con 194 páginas y cultura material con 122 páginas.

Los primeros resultados de esta guía de instrucciones llegarán recién en 1883, cuando Edward Horace Man (1846-1929) presentaba sus observaciones sobre los indígenas de las islas Andamán, posibilitadas por su trabajo de 12 años como asistente de superintendente de las islas Andamán y Nicobar. En su presentación mencionaba "I have been greatly assisted, and would here acknowledge gratefully the invaluable help afforded me, by the small volume published a few years ago by the British Association for the Advancement of Science with the object of aiding travellers and others in their researches among savages and uncivilised nations, indeed I may say that I have worked almost entirely upon the lines therein laid down"211.

Al mismo tiempo que comenzaban a producirse estos resultados, el antropólogo inglés Edward Burnett Tylor (1832-1917) auguraba la idea de instaurar un comité encargado de redactar guías de observación destinadas a dar cuenta de las características físicas de las poblaciones indígenas de la región noreste de Canadá. Según George Stocking este proyecto de Tylor se fundaba en las investigaciones llevadas adelante por miembros del Bureau of Ethnology de los Estados Unidos, los cuales habían comenzado a enviar "qualified agents" para residir entre las tribus canadienses y llevara adelante estudios antropológicos ${ }^{212}$.

Como ha señalado Curtis Hinsley, en el último cuarto del siglo XIX varios estudiosos se encontrarán realizando trabajo de campo en Estados Unidos “[...] in a conscious, sustained effort to record, study, and understand the remaining Native American peoples" ${ }^{\text {"213 }}$. Como en el

\footnotetext{
${ }^{210}$ Stocking 1987, p. 259.

${ }^{211}$ Man 1883, p. 69.

${ }^{212}$ Stocking 1983, 1987.

${ }^{213}$ Hinsley 1981, p.54.
} 
caso de Inglaterra, Francia o Alemania, los trabajos individuales en el campo llevados adelante en los Estados Unidos tratarán ser encauzados institucionalmente a través de una serie de instrucciones, guías y recomendaciones. Según el militar y explorador norteamericano John Wesley Powell (1834-1902); director del Bureau of Ethnology; el plan de operaciones de la institutción a su cargo tenía como primer objetivo "The direct employment of scholars and specialists to conduct investigations and prepare the results for publication" y en segundo lugar "[...] inciting and guiding research immediately conducted by collaborators not directly connected with the Bureau of Ethnology"214.

La recepción de colaboraciones tanto de los Estados Unidos como de otras partes del mundo, eran para Powell la prueba material del cumplimiento de los objetivos delineados anteriormente. El éxito era atribuido a la circulación del First Annual Report of the Bureau of Ethnology to the Secretary of the Smithsonian Institute (1881), en el cual se detallaban diversas introducciones a los estudios lingüísticos y arqueológicos ${ }^{215}$. Para Powell estos trabajos servían de ejemplo y por ende de guía y programa de observación para todas aquellas personas que deseaban colaborar con las investigaciones llevadas adelante por la institución a su cargo. Tal como aclaraba en la introducción del primer informe anual, parte del mismo consistía en una serie de trabajos " $[\ldots]$ designed to exhibit the methods and results of my administration of this trust" ${ }^{\text {216 }}$. Esto se complementaba con las comunicaciones personales establecidas con diversas personas especializadas en algunos de los campos de acción de la antropología. Según Powel "By these agencies it has become generally known that contributions of the character explained were invited and would be published speedily with due credit. The numerous and important responses to requests for assistance have been and will continue to be thankfully acknowledged in the several publications to which they are germane"217. Como veremos más adelante, en los sucesivos informes anuales del Bureau of Ethnology, esto no traerá aparejado el nivel de orden y organización esperado por Powell.

\subsubsection{Los encuentros e instrucciones antropológicas en Alemania en 1875}

En 1875 von Ihering denunciaba que, a pesar de que la Deutsche Gesellschaft für Völkerkunde declarara la estandarización de tal o cual método, cada antropólogo mostraba un denotado interés en preservar sus propios esquemas, métodos e instrumentos; adoptando libremente las convenciones que le fueran de mayor utilidad ${ }^{218}$. En este sentido uno de los

\footnotetext{
${ }^{214}$ Powell 1883, p. xv.

${ }^{215}$ Estos eran: "Introduction to the Study of Indian Languages", "Introduction to the Study of Mortuary Customs", y "Introduction to the Study of Sign Language". Ibídem.

${ }^{216}$ Ibídem 1881, p. iii-iv.

${ }^{217}$ Ibídem 1883, p. xvi.

${ }^{218}$ Jhering 1875.
} 
principales críticos de las propuestas de von Ihering será Hermann Schaaffhausen. Tildando de arbitrarios los puntos elegidos para la determinación del plano horizontal, Schaaffhausen exhortará su demarcación determinando la forma en la que el individuo en vida habría sostenido normalmente su propia cabeza ${ }^{219}$.

El origen de estas críticas debe buscarse, en realidad, en la propuesta de Schaaffhausen de establecer la clasificación jerárquica de las "razas" a partir del grado de prognatismo de los cráneos. Según Schaaffhausen al colocar los cráneos siguiendo la propuesta de von Ihering se producía un descenso del mentón hacia el pecho y un adelantamiento del puente nasal; provocando el aplazamiento de la mandíbula. El resultado era la disminución del ángulo de prognatismo. Del mismo modo, si el cráneo se inclinaba hacia atrás, la frente se alejaba proyectando la mandíbula hacia adelante, aumentando de esta forma el ángulo de prognatismo. De esta forma las afirmaciones de Schaaffhausen, sobre el alto grado de prognatismo como característica de los "pueblos naturales", se tornaba inverosímil de sustentar con datos craneométricos ${ }^{220}$.

Esto suscitará una larga discusión al interior de la antropología alemana. El sistema de Schaaffhausen ofrecerá considerables ventajas, permitiendo al antropólogo fijar el cráneo acorde a sus propias predilecciones ${ }^{221}$. Gran parte del conjunto de antropólogos alemanes integrarán rápidamente las propuestas de Schaaffhausen. Este último será designado responsable de catalogar las colecciones craneológicas depositadas en los distintos museos alemanes. Desestimando las investigaciones previas comenzará con la re-clasificación y el reordenamiento de las piezas a partir de su heterodoxo método clasificatorio ${ }^{222}$. Esto provocará un inmediato rechazo por parte de los antropólogos alemanes al método propuesto por Schaaffhausen $^{223}$.

En 1875 el geofisico y botánico alemán Georg Balthasar Neumayer (1826-1909) editaba Anleitung zu wissenschaftlichen Beobachtungen auf Reisen. Mit besonderer Rücksicht auf die Bedürfnisse der Kaiserlichen Marine. Este era resultado de una reunión efectuada hacia marzo de 1874 por diversos estudiosos, en la cual se debatirá sobre la necesidad de contar con una

\footnotetext{
${ }^{219}$ Jhering 1873; Ottow 1966; Schaaffhausen 1871, 1875, 1879; Zängl-Kumpf 1989

${ }^{220}$ Schaaffhausen 1871, 1875, 1879.

${ }^{221}$ El horizonte "natural” propuesto por Schaaffhausen se obtendrá colocando el cráneo de forma tal que una línea que pasara por el centro de la órbita ocular corriera paralela al piso. Ya que un número infinito de líneas traspasa un solo punto solo, uno podría colocar el cráneo en cualquier ángulo que prefiriera. El sistema de Ihering no permitía esto, ya que el plano horizontal era determinado por una línea que traspasa dos puntos bien definidos en el cráneo. Jhering 1873; Ottow 1966; Schaaffhausen 1871, 1875, 1879.

${ }^{222}$ Schaaffhausen 1875; Spengel 1875.

${ }^{223}$ A tal punto de tensión llegaran las negociaciones entre Schaaffhausen y el resto de la comunidad antropológica alemana que en 1880, en el marco de la reunión anual de la Deutsche Gesellschaft für Anthropologie, Ethnologie und Urgeschichte, el fisiólogo Johannes Ranke (1836-1916) y el zoólogo y anatomista Julius Konstantin Ernst Kollmann (1834-1918) pedirán su expulsión, propuesta que será rechazada por Rudolf Virchow. CBDGAEU, 1880.
} 
publicación destinada a los viajeros o personas residentes fuera de Alemania. La misma no buscará dar un entrenamiento especializado a los casuales observadores sino ofrecer una sencilla guía que permitiera sacar provecho de aquellos individuos de paso o con permanencia estable en el extranjero ${ }^{224}$. Sin embargo esto no descartaba la cientificidad del trabajo, implicada en la finalidad que se le daría a los datos recolectados. Este trabajo también pretendía colaborar con aquellos esfuerzos de unificar los métodos de observación e interpretación en antropología llevados adelante por los estudiosos alemanes. Una de las condiciones para la definición y puesta en práctica de cualquier método estandarizado era la posibilidad de contar con datos y elementos materiales a través de los cuales dar pruebas materiales de la eficacia de tal o cual método. En la redacción de estas instrucciones estarán implicados estudiosos que tendrán una activa participación en los debates craneométricos acontecidos a lo largo de la segunda mitad del siglo XIX en Alemania, tales como Bastian, Fritsch, Hartmann, Weiss y Virchow ${ }^{225}$.

El principal modelo para la redacción de este trabajo será Manual of scientific enquiry; prepared for the use of Officers in Her Majesty Navy; and Travellers in general (1849) editado por el astrónomo inglés John Frederick William Herschel (1792- 1871). Este definía esta compilación como "[...] a Manual (to give) general instructions for observation and for record in various branches of science, ${ }^{, 26}$. Al igual que la compilación efectuada por Neumayer, este trabajo no pretendía dar una formación especializada y focalizada a los destinatarios del mismo, sino una guía simple y sencilla para ser utilizada por los miembros de la marina británica o bien casuales viajeros. Ambos trabajos contarán con secciones de: astronomía, botánica, geografía, geología, mineralogía, magnetismo, meteorología, estadística y zoología. El trabajo de Neumayer incluirá además trabajos de antropología, prehistoria y lingüística ${ }^{227}$.

La complementariedad entre los trabajos editados por Neumayer y aquellos realizados por las sociedades científicas inglesas era remarcada, entre otros, por el editor alemán Max Jänecke (1869-1912), en ocasión de la tercera edición de Anleitung zu wissenschaftlichen Beobachtungen auf Reisen. El mismo remarcaba que "With this work and the "Hints to Travellers," published by the Royal Geographical Society, no traveller can feel that he lacks literary helps in the prosecution of his work" ${ }^{, 228}$. Llamativamente el trabajo de Neumayer se publicaba simultáneamente a la novena edición de Hints to Travellers Scientific and General (1906), editado por la Royal Geographical Society. En la misma linea que Jänecke una reseña

${ }^{224}$ Tal como rezaba la introducción "Einerseits musste der wissenschaftliche Charakter des Werkes stets gewahrt bleiben, anderseits war Bedacht darauf zu nehmen, dass auch der nicht fachmännisch Ausgebildete daraus werthvolle Winke zu erhalten vermöchte, welche ihn befähigten, jede dargebotene Gelegenheit für die Beobachtung eines Phänomenes oder für eine wissenschaftliche Erhebung in einer solchen Weise auszunützen, dass die Resultate von wirklichem Werthe wären”. Neumayer 1875, p. v.

${ }^{225}$ Neumayer 1875.

${ }^{226}$ Herschel 1849, p. iii.

${ }^{227}$ Herschel 1849; Neumayer 1875.

${ }^{228}$ Jänecke 1906, p. 123. 
de The Geographical Journal señalaba "[...] both of these works are intended to furnish guidance for the intending travellers on scientific matters, ${ }^{, 229}$.

Solo dos años después de la edición del trabajo de Neumayer y las denuncias de von Ihering ante la imposibilidad de adoptar un método craneométrico estandarizado al interior de la antropología alemana; Paul Broca publicaba el último de sus trabajos en torno al plano horizontal. En este breve trabajo de 10 páginas discutirá la importancia del ángulo orbitooccipital, el cual permitirá medir la inclinación del plano entre el agujero occipital y las orbitas; determinando la posición de la cabeza en la columna vertebral y por consiguiente " [...] l'attitude plus ou moins bipède, plus ou moins quadrupède des animaux" ${ }^{230}$. Broca determinará dos métodos para la medición del ángulo orbito-occipital: uno gráfico a partir de la utilización de un transportador, y otro consistente en la aplicación del método trigonométrico ${ }^{231}$. A partir de la medición de este ángulo se obtenía la dirección del plan bi-orbitario, el cual será para Broca el verdadero plano horizontal del cráneo (Fig. 14 y 15).

\subsubsection{Los trabajos en Inglaterra, Alemania y Suiza en 1878}

En 1878 Pitt Rivers relataba los esfuerzos del comité de antropometría de la Anthropological Society of London a fin de sistematizar las instrucciones para sus observadores $^{232}$. Pitt Rivers era consciente de que a pesar de contar con un manual de instrucciones detallado y preciso, era imposible evitar el surgimiento de errores en el trabajo de campo o en el laboratorio. En estos dos contextos el investigador se encontraba sujeto a variables de naturaleza fortuita, lejos de su influencia directa. Esto justificaba la redacción de un manual de instrucciones, el cual servía para atenuar o minimizar el efecto de estas sobre el resultado de la investigación. Uno de los principales errores en cualquier investigación se vinculaba con el factor subjetivo del proceso observacional por parte del estudioso. Dos investigadores observando un mismo objeto o fenómeno determinado podían obtener impresiones totalmente distintas ${ }^{233}$. Si se querían obtener datos plausibles de comparación; y principalmente abogar por el avance de la antropología física; el observador debía ser preciso en las mediciones antropométricas y en el uso de los términos empleados; por lo cual la solución

\footnotetext{
${ }^{229}$ TGJ 1907, p. 395.

${ }^{230}$ Broca 1877 , p.325.

${ }^{231}$ Este método consistía en la medición rápida del ángulo de inclinación de cualquier plano craneal sobre el plano bi-orbitario. La medición no se realizaba sobre el ángulo mismo, sino una de sus líneas trigonométricas en relación con un radio de 100 milímetros. Esto permitirá medir ángulos que no era posible de hacer con el goniómetro. Este último instrumento; aplicable a planos laterales y divergentes y a las normas anterior, superior y posterior; permitirá obtener la dirección relativa de dos planos y reemplazar el método de la "aguja orbitaria" la cual solo será aplicable a planos simétricos. Broca 1880.

${ }^{232}$ Esta publicación correspondía al encuentro celebrado en la ciudad de Londres en 1877.

${ }^{233} \mathrm{Al}$ respecto comentaba Pitt Rivers "[...] it is still to be expected that mistakes will be made by different observers, affecting the uniformity of the tests and invalidating the results". Pitt Rivers 1878, p. 393.
} 
era la redacción de una serie de instrucciones que homogeneizarán miradas, acciones y palabras $^{234}$.

Con esto Pitt Rivers pretendía lograr control sobre los resultados de las distintas observaciones, los cuales debían ser recibidos con la mayor cautela posible ${ }^{235}$. Sin embargo la solución final a este dilema no se encontrará exclusivamente en el uso de las instrucciones de observación: todos los resultados obtenidos deberían ser supervisados y aprobados por un profesional capacitado ${ }^{236}$. Esto llevará a la acumulación de datos sin procesar que; junto con los elementos materiales que desbordaban las colecciones; alejaban a estos proyectos del tan ansiado orden.

En 1878, entre el 24 y 26 de septiembre, se celebraba en la ciudad alemana de Konstanz un nuevo congreso de la Deutsche Gesellschaft für Anthropologie, Ethnologie und Urgeschichte donde las discusiones sobre la estandarización de métodos y técnicas empleados en la investigación del cuerpo humano volverán a ser el tema central del encuentro ${ }^{237}$. La comisión craneológica encargada de definir un posible acuerdo craneométrico trabajará en forma directa con las colecciones craneológicas y anatómicas de la Universität Bonn ${ }^{238}$. Estas, al igual que las de otras ciudades alemanas, se caracterizaban por la excesiva acumulación de piezas que eran un reflejo del estado teórico y metodológico de la disciplina. En este sentido Schaaffhausen afirmaba que recibía constantes comunicaciones personales de los encargados de las distintas colecciones en las cuales estos arguían por contar con un método que les permitiera comparar entre si las "hileras de calaveras" que componían las mismas ${ }^{239}$. Los 22 puntos craneométricos propuestos por la comisión, según Schaaffhausen, permitían resolver la mayoría de las diferencias de forma simple, aún el controvertido plano horizontal, para el cual la comisión

\footnotetext{
${ }^{234}$ Según Pitt Rivers esto evitaría "[...] far as possible the errors which have arisen from misunderstanding the regulations issued for collecting data" ya que "...in the descriptions are essential, without which it is impossible to draw up statistics or arrive at general results.” Ibídem p. 391.

${ }^{235}$ Ibídem.

${ }^{236}$ Señalaba Pitt Rivers: "It is therefore proposed that all persons who propose to make observations, should have the use of the various instruments explained to them, and should qualify, by going through the different measurements under the superintendence of an instructor" Ibídem p. 393.

${ }^{237}$ Estas discusiones no serán exclusivas del ámbito de la antropología. En este sentido es interesante mencionar la participación de miembros del encuentro de Konstanz en la 50va. reunión de médicos y naturalistas alemanes realizada en diciembre de ese mismo año en la ciudad alemana de München, donde se discutirán varios de los temas desarrollados en la reunión de Konstanz. En la sección de antropología Julius Kollmann presentaba un resumen sobre los trabajos craneológicos llevados a cabo en Alemania desde 1869, focalizando especialmente en aquellos dedicados al estudio de las formas craneales prehistóricas. En esa misma reunión Johannes Ranke exponía sus trabajos sobre las formas craneales de las poblaciones bávaras. Finalmente el anatomista Nikolaus Rüdinger (1832-1896) presentaba las diferencias cerebrales entre braquicéfalos y dolicocéfalos. CBDGAEU 1877, n 9.

${ }^{238}$ Su elección estibaba en la "riqueza" de las mismas, resultado; según Schaaffhausen; de los abnegados trabajos del anatomista y fisiólogo alemán August Franz Joseph Karl Mayer (1787-1865). Ibídem, n 9.

${ }^{239}$ Ibídem p.91.
} 
instaba a seguir el propuesto por von Baer y Wagner en el encuentro celebrado hacia 1861 en Göttingen $^{240}$.

El consenso en cuanto a los métodos de observación e interpretación de los objetos antropológicos se encontraba, aún, lejos de resolverse. Al mismo tiempo que sucedían esta serie de encuentros en Alemania, David Kaltbrunner (1829-1894) publicaba en Zürich el Manuel du Voyageur (1879) con el objetivo de "[...] remplir une lagune dans la littérature française [...]"241. La misma se originaba, según Kaltbrunner, en la limitación de los programas de observación; los cuales redactados desde la academia para los académicos, privaban ciencia de la infinidad de materiales que los viajeros podían recoger ${ }^{242}$. La obra estará destinada principalmente a turistas y excursionistas, es decir aquellas personas para las cuales el viaje es solo un evento de descanso y diversión en medio de las ocupaciones que los absorben diariamente. Es preciso remarcar que este trabajo será un simple manual para viajeros y no un conjunto de instrucciones redactado y avalado por alguna institución antropológica. Sin embargo el mismo será útil en el sentido de que buscará precisar de la forma más exacta indicaciones concretas y puntuales al momento de realizar observaciones sobre otros países y sus habitantes ${ }^{243}$.

Como ha remarcado Nelia Dias al momento de analizar la obra de Kaltbrunner "Le voyage devient un art qu'il faut cultiver, notamment par la faculté d'observation; il est en sus une source d'instruction" ${ }^{\text {"244 }}$, algo advertido con anterioridad entre los estudiosos franceses ${ }^{245}$. Kaltbrunner, al igual que lo hiciera Broca, reconocerá la importancia del viaje como instancia de

${ }^{240}$ Al igual que Schmidt y Ecker, admitía que esta línea podía llegar a presentar variaciones en los cráneos de las distintas "razas". Sin embargo la "línea de la mirada" era particular para cada grupo. Esta última estaba condicionada por la posición del cuerpo humano y la forma de la columna vertebral, la cual alcanzaba la peculiar forma de doble "s" curvada en los pueblos "más educados". Ibídem, p.92.

${ }^{241}$ Kaltbrunner 1879 , p.7.

${ }^{242}$ Señalaba este que: "Il en résulte, non-seulement qu'ne foule de personnes sont privées d'une distraction agréable; mais qu'une infinité de matériaux que des milliers d'observateurs pourraient recueillir, sont perdus pour la science". Ibídem.

${ }^{243}$ Broca aseguraba que "De toutes les parties des sciences naturelles, celle qui embrasse l'étude des races humaines est certainement la plus interessante, la plus utile, et c'est pourtant la moins avancée. II ne faut pas attribuer ce triste résultat a l'indifference des voyageurs et des observateurs" Broca 1865, p.1; Kaltbrunner 1879.

${ }^{244}$ Dias 1989, p.73.

${ }^{245}$ En este sentido hacia 1871 la Societe d' anthropologie de París creaba una "Commission permanente pour les Instructions anthropologiques" dedicada a satisfacer la demanda de viajeros por instrucciones destinadas a países específicos. Nelia Dias ha demostrado con exactitud que esta serie de instrucciones y manuales impulsados desde la academia, dará lugar a una dicotomía entre la observación de aquellos elementos depositados en los museos y aquellas sobre los individuos vivos realizados en el terreno. De esta forma los estudiosos se centrarán en el estudio del cráneo y el esqueleto; mientras que las personas no-legas, como viajeros, militares o exploradores, se concentraran en el registro de características externas como el color de la piel, la forma de los ojos o el tipo de cabello. Dias 1989, 2004. 
la investigación científica ${ }^{246}$. Por lo tanto era preciso contar con una guía de observación precisa que fuera de utilidad a aquellos observadores casuales que, carentes de una formación académica o entrenamiento científico, deseaban colaborar con los diversos programas de investigación. Emil Kollbrunner (1846-1918) en la traducción al alemán, señalaba que esta obra será considerada como "muy favorable" por los estudiosos alemanes ${ }^{247}$.

\subsubsection{El encuentro antropológico de Berlín en 1880}

Este acercamiento entre las metodologías francesas y alemanas puede entreverse también en el encuentro anual de la Deutschen Gesellschaft für Anthropologie, Ethnologie und Urgeschichte, celebrado en la ciudad de Berlin en 1880. El 9 de agosto la comisión encargada de realizar un protocolo craneométrico presentaba sus resultados. Este informe reconocía primeramente la amplia guía de puntos de medición establecida por los franceses, la cual evaluaban como de una amplia aceptación en Francia. Al mismo tiempo Virchow, Gildemeister, Stieda y Kollmann reconocían públicamente la utilidad de muchos de los puntos establecidos por sus colegas franceses ${ }^{248}$. A pesar de que para este entonces se buscaba establecer un "programa sólido"249 en conjunto con los franceses; negociación llevada adelante por Schaaffhausen; estos rechazarán la propuesta de Ihering para el plano horizontal ${ }^{250}$. Virchow señalaba que los franceses estaban "más que dispuesto a hacer concesiones respecto al plano horizontal"; por lo cual era necesario, en primera instancia, poder resolver las diferencias hacía el interior de la antropología alemana.

His, Ecker, Ranke y Virchow proponían mantener aquellos puntos definidos en Konstanz. Ranke se lamentaba de no poder establecer un acuerdo a nivel internacional con los franceses. Kollmann argumentaba; dando cuenta de una carta de Topinard a Schaaffhausen; que el establecimiento de una convención con los franceses era algo que iba a llevar su tiempo, más que nada cuando los estudiosos alemanes buscaban una precisión que los franceses no parecían estar entusiasmados en alcanzar. Schaaffhausen explicaba que la visión de Topinard debía tomarse como una expresión individual y no como la voz en conjunto de los estudiosos

\footnotetext{
${ }^{246}$ Kaltbrunner pensaba que la utilidad de los viajes “[...] n'a pas besoin d'etre démontrée. Mais elle n'est réelle que pour ceux qui savent voir et observer". Ibídem p.6.

${ }^{247}$ Entre otros mencionaba al cartógrafo austriaco Josef Chavanne (1846-1902); al historiador austriaco Friedrich Anton Heller von Hellwald (1842-1892); al químico y explorador alemán Otto Kersten (18391900); y finalmente al botánico y etnólogo alemán Georg August Schweinfurth (1836-1925). Kollbrunner 1882.

${ }^{248}$ CBDGAEU 1880.

${ }^{249}$ Ibídem p. 104.

${ }^{250}$ Antes de la realización de este encuentro Broca había declarado explícitamente que el establecimiento de una convención craneométrica entre franceses y alemanes sería el "factor determinante" para todos en futuros trabajos, y por lo tanto, se "deseaba con fuerza". A la muerte de Broca, Topinard comunicaba a Virchow la necesidad de tomarse más tiempo de análisis antes de definir un acuerdo internacional. Ibídem p. 104-105.
} 
franceses. Al mismo tiempo le contestaba a Kollmann que él mismo no podría recomendar algo que ni siquiera aceptaba. Esto da cuenta de que el primer obstáculo a la hora de establecer un acuerdo a nivel internacional serán las disputas al interior de la antropología alemana ${ }^{251}$.

$\mathrm{Si}$ bien la mayoría de los asistentes estaban de acuerdo en continuar con las conclusiones del encuentro celebrado en 1877 , las diferencias personales entre los principales encargados de definir un acuerdo craneométrico a escala nacional e internacional, serán el elemento protagónico. Schaaffhausen expresaba su descontento con la convención que se buscaba establecer, algo que provocará la sorpresa y cólera de gran parte de los asistentes al congreso. En este sentido Kollmann esgrimía que "[...] un científico que representa la ciencia alemana no puede reconocer "parcialmente" el sistema craneométrico alemán” ${ }^{252}$ y más cuando esta persona era uno de los responsables de llevar adelante las conversaciones con los franceses en búsqueda de un acuerdo común. Schaaffhausen, lejos de explicar y responder estas acusaciones, declaraba que las negociaciones para llegar a un método de craneométrico internacional, las cuales le habían sido confiadas, no continuarían ${ }^{253}$. Las negociaciones al interior de la antropología alemana, sin embargo, continuarían.

\subsubsection{El encuentro antropológico de Frankfurt en 1882}

En 1882 se celebraba en la ciudad alemana de Frankfurt el decimotercero congreso general de la Deutsche Gesellschaft für Anthropologie, Ethnologie und Urgeschichte. Julius Kollmann, Johannes Ranke y Rudolf Virchow, presentaban la síntesis de las deliberaciones que habían tomado lugar previamente. El informe, que incluirá los métodos utilizados por la mayoría de los antropólogos alemanes de la época, será publicado por primera vez en 1883 en las páginas del Correspondenz-Blatt der Deutschen Gesellschaft für Anthropologie, Ethnologie und Urgeschichte. Luego de casi una década de intentos, los antropólogos seguirán a Virchow en la adopción del sistema de Ihering, que pasaría a ser conocido como "Convención de Frankfurt" ${ }^{\text {"254 }}$. Esta incluirá 33 mediciones craneométricas, entre ellas: el controversial plano horizontal, el ángulo facial, la capacidad craneal y nueve índices.

Según Virchow a partir de esta convención podrían medirse todos los cráneos, pertenecieran a individuos vivos o muertos ${ }^{255}$. Sin embargo, esto traerá un fuerte rechazo por

\footnotetext{
${ }^{251}$ Ibídem.

${ }^{252}$ En el original "ein Wissenschaftler, der deutsche Wissenschaft repräsentiert, kann nicht 'nur teilweise' das Deutsche kraniometrische System anerkennen”. Ibídem p. 106.

${ }^{253}$ Ibídem 1880.

${ }^{254}$ En el original: Frankfurter Verständigung. La adaptación realizada por Virchow reconocerá el horizonte "natural" propuesto por Schaaffhausen. Kollmann et.al. 1883; Virchow 1891.

255 Esto radicaba, en palabras de Virchow, en la facilidad para encontrar los puntos utilizados para determinar el "deutsche Horizontalebene" (plano horizontal alemán): el punto más bajo de la borde inferior de las órbitas y el borde superior de la apertura del oído. Virchow 1891.
} 
parte de otros investigadores europeos, principalmente franceses e ingleses, acrecentando aún más el clima de incertidumbre y disparidad a nivel internacional. Finalmente hacia 1885 una tercera versión será publicada en el Archiv für Anthropologie, siendo la misma la versión final de la convención craneométrica ${ }^{256}$. Esta será ratificada y firmada por 67 antropólogos, de los cuales 56 trabajaban en Alemania y Austria-Hungría. La ausencia de representantes de Francia, Bélgica, España o Inglaterra exhibía la escasa iniciativa por parte de los antropólogos alemanes de conferir un carácter internacional al acuerdo ${ }^{257}$. Como señalara el antropólogo inglés Leonard Halford Dudley Buxton (1889-1939) en 1933 “The Frankfort Agreement ensured for many years the standardization of craniometric technique in German-speaking countries, and it was there that the most important work was being done at the time" ${ }^{\text {"258 }}$.

La mayoría de los caracteres craneales tratados por la "Convención de Frankfurt" eran similares a aquellos considerados y delimitados por Broca, pero en la mayoría de los casos las definiciones de las medidas serán considerablemente diferentes ${ }^{259}$. Las principales divergencias serán la elección del plano horizontal y los límites utilizados en la clasificación de los índices. Esto llevaba a sentenciar a John George Garson (1861-1932) "It is also to be regretted that anthropologists in Germany have separated themselves from those in the rest of the world [...] the result of which will only be to cause confusion and detract from the value of certain convenient terms" ${ }^{, 260}$.

Esta confusión era resaltada por el antropólogo alemán Emil Ludwig Schmidt (18371906), el cual publicaba, en 1888, Anthropologische Methoden. Comparando los avances logrados en campos como la zoología o la botánica en lo referente a definir un programa consensuado de observación, señalaba Schmidt el escaso progreso logrado por la antropología. La causa, según este último, era la ausencia de un método y una instrucción sistemática, señalando que en esto "[...] radica el escaso progreso de nuestro conocimiento del hombre y sus razas, y no en la indiferencia del observador" ${ }^{261}$.

El resultado de esta problemática se evidenciaba en las contradicciones generadas a partir de la observación de un mismo fenómeno u objeto por parte de dos personas distintas,

\footnotetext{
${ }^{256}$ Esta reportará cambios menores en la terminología, la numeración e incorporará tres nuevas medidas. AFA 1885.

${ }^{257}$ Buxton 1933; Hrdlička 1919; Hoyme 1953; Schmidt 1888; Starr 1892; Ottow 1966.

${ }^{258}$ Sin embargo hacia el final de su trabajo señalará Buxton la diferencia existente entre los métodos alemanes y los franceses. Buxton 1933, p.23-24.

${ }^{259}$ De las 47 medidas craneales absolutas definidas por Broca y las 31 definidas por la "Convención de Frankfurt" solo 8 podían ser consideradas similares. Buxton 1933; Hrdlička 1919; Schmidt 1888; Ottow 1966.

${ }^{260}$ Garson 1885, p. 80.

${ }^{261}$ En el original “ [...] liegt die Ursache für die geringeren Fortschritte unseres Wissens vom Menschen und seiner Rassen nicht in der Gleichgültigkeit der Beobachter”. Schmidt 1888, p.1
} 
algo que también señalaba los estudiosos franceses ${ }^{262}$. Para Schmidt la solución debía provenir del mismo seno de la antropología; debiendo los hombres de ciencia sentirse "agradecidos" de elaborar una serie de instrucciones, ya que de esta manera colaboraban con el progreso y promoción de la antropología.

Con un argumento similar al esgrimido por Kaltbrunner, Schmidt reconocerá la existencia e importancia de instrucciones previas. Sin embargo, para él, ninguna cumplía con los estándares de precisión y exactitud científica que la antropología demandaba, condiciones que sus instrucciones pretenderán solucionar. Estas, según Schmidt, consideraban por igual al viajante u observador casual como aquellas personas que se desenvolvían en otro importante espacio de producción del conocimiento: el gabinete ${ }^{263}$.

Cuando hacia 1892 el antropólogo norteamericano Frederick Starr (1858-1933) reseñara el libro de Schmidt, lo definirá como un crítico y cuidadoso trabajador que con sus trabajos pretendía articular "[...] the profound abyss separating German and French workers [...]"264. En este sentido la obra de Schmidt incluirá en un total de 40 instrumentos antropométricos, 19 diseñados y promovidos por Broca ${ }^{265}$. Esto junto con la importante crítica a la "Convención de Frankfurt" ${ }^{266}$; a la cual había adherido en 1882; generará un rechazo por parte de los espacios académicos alemanes, especialmente aquellos bajo la influencia de Virchow y Bastian, dos de los principales promotores del acuerdo de Frankfurt ${ }^{267}$.

La expansión colonial europea de la segunda mitad del siglo XIX traerá aparejado, entre otras cosas, la cercanía a las poblaciones que, habitando en geografías alejadas en el espacio y aisladas en el tiempo constituirán los elementos claves en los estudios antropológicos que buscaban una comprensión científica de la propia sociedad europea. De esta forma la tradicional secuencia evolutiva, que comenzando en el "salvajismo" atravesaba distintas etapas hasta llegar al estadio de "civilización”, tomará una significancia biológica que debía ser estudiada ${ }^{268}$.

\footnotetext{
${ }^{262}$ Reflexionaba Schmidt que "Ein Jeder beobachtet und misst nach seiner eigenen Methode, alles andere aufgesammelte Material ist für ihn unvergleichbar, werthlos!“. Similar a lo planteado por Broca cuando afirmaba: "Chacun voit ces choses à sa manière et les voit souvent autrement que ses voisins. Telle est la cause des contradictions sans nombre qui existent entre les descriptions des divers voyageurs. Et même ces contradictions ne portent pas seulement, comme on pourrait le croire, sur des détails accessoires ou sur des nuances plus ou moins délicates [...] Lorsqu'on remonte à la cause de ces contradictions, on trouve le plus souvent qu'elles sont dues a la divergence des procedes d'observation, a la variation des points de repère usités dans la mensuration des diverses parties du corps". Broca 1865, p. 3-20; Schmidt 1888.

${ }^{263} \mathrm{Su}$ trabajo pretendía colaborar e instruir en la observación llevada a cabo en espacios como los museos o los gabinetes de estudio. Según Schmidt este era el único modo de poder establecer la comparación entre los distintos objetos observados. Frederick Starr señalaba que el libro de Schmidt era el mejor "hand-book" para los estudiantes, ya fuera en el espacio del laboratorio o en el campo. Schmidt 1888, Starr 1892.

${ }^{264}$ Starr 1892, p. 57.

${ }^{265}$ Buxton 1933; Hoyme 1953; Schmidt 1888; Starr 1892.

${ }^{266}$ En el orginal alemán: Frankfurter Verständigung.

${ }^{267}$ Buxton 1933; Martin 1914; Starr 1892.

${ }^{268}$ Stocking 1987, 1988.
} 
Los manuales, instrucciones e instrumentos utilizados en la observación y el estudio anatómico de las poblaciones no-europeas buscarán contribuir a la profesionalización e institucionalización de la práctica antropológica a través de elementos empíricos que dieran cuenta de la variedad humana ${ }^{269}$. Este apremio estaba dado también por la naturaleza de un objeto de estudio que se pensaba en el inevitable camino de la desaparición. En un contexto donde parecía inevitable la "extinción" de los pueblos, idiomas, animales y objetos que por siglo habían permanecido "inmutables", el registro, clasificación y estudio de estos futuros vestigios vivientes del pasado se volvía un imperativo, y se expresaba tanto en la necesidad de investigar como en la imperiosidad de enseñar cómo ${ }^{270}$.

${ }^{269}$ Blanckaert 1988; Martin 1901, 1905; Stocking 1988.

${ }^{270}$ Blanckaert 1988; Martin 1914; Podgorny 2008; Proctor 1988; Ryding 1975; Stocking 1988 


\section{Caos y orden en la antropología argentina}

El 19 de noviembre de 1882 se fundaba oficialmente la ciudad de La Plata. Luego de la traslación poderes públicos de la provincia de Buenos Aires a esta, el por entonces Presidente argentino Julio Argentino Roca (1843-1914) sancionaba, el 10 de enero de 1884, un decreto por el cual se designaba una comisión encargada de convenir con el gobierno de la provincia de Buenos Aires la nacionalización de diversas instituciones, establecimientos, archivos y objetos históricos. En este contexto serán trasladadas las colecciones del Museo Arqueológico y Antropológico de Francisco Pascasio Moreno (1852-1919) ${ }^{271}$. Estas serán depositadas en diversos locales, hasta que finalmente recalarían en la planta alta del edificio del Banco Hipotecario de la provincia ${ }^{272}$. El 17 de septiembre de 1884 se aprobaba por decreto el proyecto del nuevo edificio. Dos días más tarde se designaba a Moreno como director y se creaba el Museo General de La Plata. Finalmente en abril de 1887 se inauguraba parte del nuevo edificio.

Los elementos que componían la sección de antropología eran parte de las colecciones de cráneos y esqueletos que Moreno había recolectado durante sus viajes al interior de Buenos Aires, Catamarca, San Juan, Mendoza, el Río Negro, Chubut y el río Santa Cruz. Al mismo tiempo Moreno encomendará, desde 1885, a los preparadores y naturalistas viajeros del Museo que recolectarán cráneos y restos esqueletarios a fin de conformar una serie representativa de los grupos de América del Sur. A esto debemos sumarle los restos de los indígenas patagónicos que vivieron en el establecimiento entre 1885 y 1890; y finalmente los intercambios establecidos con otras instituciones científicas, las compras, y las donaciones particulares ${ }^{273}$.

Hacia 1892 arribaba a la Argentina el antropólogo holandés Herman Frederik Carel ten Kate Jr. (1858-1931) (Fig. 16). Al momento de su llegada al país contaba con una formación en diversos espacios académicos de Francia, Alemania y los Estados Unidos. Dicho lugares contarán con importantes colecciones, entre las cuales habrá presente diversos elementos óseos procedentes de Sudamérica. Moreno aprovechará la presencia fortuita de ten Kate para ofrecerle el puesto de curador de las colecciones del Museo de la Plata, las cuales contaban por aquel momento con cerca de 1.500 cráneos $^{274}$.

La presencia de estos elementos; junto con los esqueletos montados y los huesos sueltos; le permitirán a ten Kate elaborar una serie de trabajos sobre osteología en los cuales combinará métodos y técnicas promovidos desde los círculos académicos franceses e ingleses (Fig. 17). Luego de 7 meses de estadía volverá a Europa, donde complementará sus observaciones con aquellas realizadas sobre colecciones allí presentes y, principalmente,

${ }^{271}$ Este será establecido en 1877. Farro 2008, 2009.

${ }^{272}$ Farro 2008, 2009; Podgorny 2009; Podgorny y Lopes 2008; Teruggi 1988.

${ }^{273}$ Para un análisis histórico detallado sobre la constitución de las colecciones antropológicas en el Museo de La Plata ver especialmente Farro 2008, 2009.

${ }^{274}$ Farro 2008, 2019. 
analizará sus datos a partir de la bibliografía especializada ${ }^{275}$. La importancia de los viajes a Europa no solo estibará en la posibilidad de contar con instrumentos de características técnicas superiores o bien con recursos bibliográficos actualizados; en diversas instituciones y museos podremos encontrar colecciones procedentes de Sudamérica que; a pesar de su carácter fragmentario; contarán con importantes elementos óseos y arqueológicos ${ }^{276}$.

Los viajes de los estudiosos a Europa o Estados Unidos se transformaban en una posibilidad de completar el conocimiento de las ricas, pero fragmentadas, colecciones argentinas. En 1896 ten Kate regresaba a la Argentina para hacerse cargo de la Sección Antropológica del Museo de la Plata. Sus principales tareas estarán enfocadas en la realización de un viaje de estudio a Paraguay por un lado y en los trabajos con las colecciones de la sección, la cual para ese entonces contaba con cerca 1.000 cráneos de indígenas sudamericanos. Si bien durante su ausencia ingresarán nuevas colecciones, permitiendo el estudio de problemas relativos a la anatomía de los grupos de América del Sur aún poco conocidos, o restringidos a casos específicos, la acumulación de material contribuirá también al estado confuso y desorganizado de las mismas. Ante esto ten Kate optará por sistematizar y/o ordenar aquellos elementos que eran funcionales a sus objetivos. En similar manera procederá con las colecciones fotográficas de indígenas, las cuales organizará con el fin de aprovecharlo en sus estudios comparados de tipos raciales ${ }^{277}$.

Como ha señalado Máximo Farro, la importancia que las series del Museo de la Plata implicaban para los estudios de antropología física a fines del siglo XIX, puede dimensionarse si se comparan sus cerca de 1.500 cráneos con la mundialmente celebrada colección de cráneos del médico estadounidense Samuel George Morton (1799-1851) la cual, con cerca de 1.000 cráneos, constituirá la base de su Crania Americana or, A Comparative View of the Skulls of

\footnotetext{
${ }^{275}$ Farro 2008, 2011.

${ }^{276}$ En este sentido podemos mencionar con fotografías y cráneos de indígenas del extremo sur argentino depositados en la École d'Anthropologie de Paris con el objetivo de poder establecer comparaciones entre el indígena "salvaje" americano y el hombre prehistórico europeo. Esta temática surgirá en la ciencia europea en la década de 1860, siendo 10 años después tópico de discusión en la Argentina. Las colecciones americanas del Musée d'Ethnographie du Trocadéro comprenderán cerca de 10.000 elementos procedentes de donaciones particulares y campañas científicas. Importantes colecciones americanas también se encontraban presentes en instituciones como el Peabody Museum de los Estados Unidos. Los catálogos de adquisiciones correspondientes a la segunda mitad del siglo XIX registran entre sus principales adquisiciones antropológicas las colecciones del paleontólogo suizo Jean Louis Rodolphe Agassiz (1807-1873) y las del estadounidense Samuel Kirkland Lothrop (1804-1886). Junto con compras y adquisiciones a particulares e instituciones; el Peabody Museum conformará una colección osteológica de casi 1.700 elementos. Más de la mitad de los mismos procederán de Perú. En orden de importancia le seguirán aquellos restos procedentes de Chile y Bolivia; finalizando con Argentina, Brasil, Colombia y Ecuador. En 1857, James Aitken Meigs daba cuenta de 248 cráneos provenientes de Sudamérica depositados en las colecciones craneológicas de la Academy of Natural Sciences of Philadelphia. De estos 12 eran clasificados como "araucanos" y 2 como "patagónicos". ARPM 1866-1897; Dias 1989, 1991; Farro 2009, 2011; Meigs 1857; Podgorny 2005.

${ }^{277}$ Farro 2009, 2011.
} 
Various Aboriginal Nations of North and South America, publicada en $1839^{278}$. En este sentido es que Rudolf Martin evaluaba la salida de ten Kate como una oportunidad única al momento de ocupar una vacante en un "extraordinario espacio de trabajo"279.

Los proyectos de gran parte de las instituciones antropológicas alemanas de la segunda mitad del siglo XIX estarán caracterizados por la recolección y acumulación sistemática de material, con la premisa de "salvarlo" del inexorable paso del tiempo. Estos proyectos estarán caracterizados por ser expansivos, masivos, y caros. La búsqueda de financiamiento o bien la articulación de mecanismos que permitieran la adquisición económica de objetos dará lugar a un mercado de alta competitividad entre los antropólogos. Como ha destacado Glenn Penny "By the end of the 1870s a doctrine of scarcity emerged that fed a growing desire for irreplaceable artifacts among ethnologists and their supporters in a variety of cities and lands; it quickly led to a fierce competition on an international scale. This competition transformed almost immediately into a collecting frenzy that lasted well into the twentieth century, attracting a range of new competitors to the objects most coveted by the ethnologists in museums" ${ }^{280}$.

En relación a este último punto habrá un cambio al interior de la antropología en torno a quienes, como y que se recolectaba. La "profesionalización" de la antropología alemana estará estrechamente vinculada a la expansión del mercado internacional en el cual circulaban los objetos y la información. Esto comenzará a llamar la atención de los principales representantes de la antropología alemana, los cuales demandarán un control más riguroso sobre los objetos, la información y sobre las personas encargadas de proveerlos. La necesidad de contar con información contextual precisa de los objetos recolectados, llevará a la demanda de contar con recolectores entrenados científicamente, diferenciándolos de los colaboradores amateurs ${ }^{281}$. Ante la posibilidad de que personas con escasa o nula formación académica atentarán contra una empresa científica; la cual demandaba una larga preparación y la búsqueda de financiamiento económico; los antropólogos optarán por emprender personalmente el trabajo en el campo. En el contexto de competición internacional en el cual se encontraba la antropología esto no será una tarea sencilla, por lo cual otra de las tácticas adoptadas por los antropólogos será colocar; en aquellos lugares de interés; individuos que les proveyeran de aquellos elementos necesarios para sus investigaciones.

Hacia 1896 Francisco Moreno; frente a la salida de ten Kate al frente de la Sección de Antropología del Museo de la Plata; se comunicaba con Rudolf Martin consultando la posibilidad de que alguno de sus estudiantes ocupara dicho puesto. Este último consideraba que

\footnotetext{
${ }^{278}$ Farro 2009, 2011.

${ }^{279}$ Rudolf Martin a Robert Lehmann-Nitsche. Legado Robert Lehmann-Nitsche, 26.09.1896, IAI, Carpeta N-0070 b 489. Nuestra traducción.

${ }^{280}$ Penny 2002 a, p. 53.

${ }^{281}$ Kuklick 2008; Penny 2002 a, 2002 b, Stocking 1985, 1987, 1998; Zimmerman 2001.
} 
el pago por el mismo tal vez no era el más adecuado, al mismo tiempo el museo platense aparecía ante los ojos del estudioso de Zürich como el depósito de una significativa colección antropológica, disfrazado tras la fachada de un monumental e imponente edificio. Sin embargo, las fastuosas decoraciones no se correspondían con los pobres e intrascendentes resultados científicos, productos de la carencia; con contadas excepciones; de profesionales que produjeran "resultados juiciosos"282.

La presencia de colecciones junto con la ausencia de personas entrenadas científicamente para su estudio será uno de los puntos considerados por los estudiosos al momento de comenzar a trabajar en determinadas instituciones. Franz Boas consideraba que los estudios científicos en Estados Unidos eran de una muy baja calidad, y que los trabajos antropológicos llevados adelante en New York se caracterizaban por la ausencia de su importancia. Esta ciudad en particular era considerada por el estudioso alemán como aislada del resto de las actividades científicas del país. El ostracismo y el vacio de resultados científicos serán considerados por Boas como el espacio ideal al partir del cual construir su carrera científica, aceptando en consecuencia un puesto en el American Museum of Natural History ${ }^{283}$.

Para Rudolf Martin la posibilidad de contar con un acceso ilimitado a los materiales depositados en los institutos de estas ciudades carentes de profesionales era una posibilidad que no debía ser desaprovechada. Al mismo tiempo recordemos, tal como se vio en el apartado 1.1, el interés particular de Martin sobre las colecciones osteológicas argentinas, el cual se vincula a su formación académica y a sus primeros trabajos sobre antropología física. De esta forma comenzará un intercambio de correspondencia con ten Kate, consultándolo principalmente por las condiciones laborales y académicas en la mencionada institución ${ }^{284}$. Ten Kate le aclaraba a Martin que las causas de su renuncia eran estrictamente personales, ya que luego de haber podido trabajar con las colecciones en las cuales se encontraba interesado, se veía en la necesidad de complementar estos conocimientos con trabajo de campo $^{285}$. Describiendo la cantidad de horas de trabajo, los asistentes, el tipo de actividades, el sueldo y el modo de adaptarse rápidamente a la Argentina, le deseaba a Martin y a Lehmann-Nitsche la mejor de las suertes en esta empresa que se disponían a emprender ${ }^{286}$.

\footnotetext{
${ }^{282}$ Martin referirá soslayadamente a los trabajos llevados adelante por ten Kate. Rudolf Martin a Robert Lehmann-Nitsche. Legado Robert Lehmann-Nitsche, 26.09.1896, IAI, Carpeta N-0070 b 489. Nuestra traducción.

${ }^{283}$ Darnell 1998; Hinsley 1976; Hyatt 1979; Jacknis 2002; Liss 1990; Stocking 1974 a.

${ }^{284}$ Herman ten Kate a Robert Lehmann-Nitsche. Legado Robert Lehmann-Nitsche, 01.02.1897, IAI, Carpeta N-0070 b 489.

${ }^{285}$ Ten Kate escribía a Martin y a Lehmann-Nitsche destacando el buen trato tanto con Moreno como con los demás trabajadores del Museo de la Plata. Detallaba la seguridad y las buenas condiciones de trabajo en la institución platense, algo que, agregaba Ten Kate, no se condecía con la situación económica argentina. Ibídem.

${ }^{286}$ Ibídem.
} 
En forma inmediata Martin se comunicará con Lehmann-Nitsche. Su condición de joven graduado y la dificultad para acceder a un puesto científico y/o académico en Alemania serán las principales justificaciones que esgrimirá Martin para convencer a Lehmann-Nitsche de que acepte el puesto. Primeramente le aseguraba que el salario de 300 pesos; el cual creía equivalente a 450-480 marcos alemanes; era suficientes para vivir en La Plata. Al mismo tiempo le aseveraba que una residencia de 5 a 6 años en el extranjero bastaba para producir buenas monografías científicas, experiencia que se traducía en la formación de docentes de excelencia ${ }^{287}$. Gracias a esto uno podía regresar a Europa para desarrollar una carrera científica en profundidad y, si así lo deseaba, realizar la habilitación para convertirse en profesor. Martin presentaba el valioso material de estudio y la escasa presencia de profesionales formados como el acceso de Lehmann-Nitsche a un promisorio futuro científico y académico. La llegada de este último al Museo de La Plata debe ser entendida en un contexto donde la ausencia de relaciones personales e institucionales que le permitieran insertarse en el campo científico y académico alemán tornaba su futuro económico y profesional inseguro e improbable.

Los primeros días de abril de 1897 Rafael Cattani, por entonces secretario del Museo de la Plata le comunicaba a Lehmann-Nitsche su designación como conservador de la Sección Antropológica, incluyendo la suma de 1.000 francos en concepto de gastos de viaje ${ }^{288}$. Lehmann-Nitsche arribaba a Buenos Aires el 10 de julio de 1897, con tan solo 25 años y prácticamente una nula experiencia a comparación de ten Kate ${ }^{289}$. Luego de tres días en Buenos Aires, donde recorrerá diversos espacios sociales frecuentados por alemanes, se trasladará a la ciudad de La Plata.

Hacia fines del siglo XIX el número de alemanes viviendo en el país ascendía a 17.143 individuos. Como veremos más adelante estos individuos serán de gran importancia en los trabajos de Lehmann-Nitsche, ya fuera recolectando datos y distintos elementos materiales y/u ofreciendo la infraestructura material/económica necesaria para la realización de los trabajos de campo. Esto será posible a la temprana migración de alemanes al país y la forma en la cual se irán intercalando en los distintos niveles de la sociedad. La primera generación llegaba al país entre 1820 y 1830 , y se componía principalmente de mercaderes, artesanos, y agricultores ${ }^{290}$.

\footnotetext{
${ }^{287}$ Martin esperaba que Lehmann-Nitsche pudiera cumplir con ambos objetivos, ya que de otra forma no hubiera intercedido ante Moreno. Rudolf Martin a Robert Lehmann-Nitsche. Legado Robert LehmannNitsche, 10.01.1898, IAI, Carpeta N-0070 b 489. Nuestra traducción.

${ }^{288}$ Rafael Cattani a Robert Lehmann-Nitsche. AHMLP, 02.04.1897, AHMLP, LCC 5: folio 331. Rafael Cattani a Robert Lehmann-Nitsche. Legado Robert Lehmann-Nitsche, 02.04.1897 y 23.04.1897, IAI, Carpeta N-0070 b 122.

${ }^{289}$ Ese mismo día en el Registro Oficial de la Provincia de Buenos Aires se publicaba el decreto por el cual era nombrado "Encargado de la sección de antropología del Museo de la Plata". RO, 1897 p. 801.

${ }^{290}$ Podemos mencionar también ciertos casos aislados como el de los maestros Johann Georg Frey y Ferdinand Camping que arribaban al país hacia 1813. El del comerciante Luis Elias Vernet (1791-1871), el cual llegando a la Argentina en 1819 terminaría oficiando como el "Primer Comandante político
} 
Estos sabrán adaptarse rápidamente al contexto local, consolidando una red laboral en base a las profesiones liberales y al comercio. Hacia 1850 los lazos comerciales darán lugar a la formalización de las relaciones políticas ${ }^{291}$. Al mismo tiempo nuevos inmigrantes se sumaban a la segunda o tercera generación de familias alemanas residentes en el país ${ }^{292}$. Los miembros de muchas de estas familias formarán parte de la burguesía terrateniente local, a través de una combinación de adquisición de tierras y matrimonios con familias locales ${ }^{293}$.

Hacia la década de 1870 las políticas migratorias promoverán la inmigración de alemanes a la Argentina ${ }^{294}$. En ese sentido una ley del 14 de agosto de 1873 establecerá la subvención del Deutsche La Plata Kalender con la obligación de que la mitad de cada número fuera destinado a dar a conocer las ventajas de la República Argentina a los ojos de potenciales inmigrantes alemanes. Gracias a esto podemos dimensionar la importancia de los emprendimientos alemanes en aquel entonces: 43 casas dedicadas a la importación-exportación; 18 almacenes para depósitos de productos; 19 casas dedicadas al Gastwirtschaft (servicios de huéspedes) como restaurantes; bares, cafés, hoteles, etc.; y cerca de 100 negocios dedicados a pequeños y medianos emprendimientos, como librerías, mueblerías, relojerías, tapicerías, etc. ${ }^{295}$.

Al mismo tiempo podemos mencionar diversas instituciones sociales como el primer Club Alemán (1838); la Congregación de la Iglesia Evangélica (1843); el Banco Alemán Transatlántico (1887); el Hospital Alemán (1878); y el establecimiento de diversas escuelas, como las de Barracas Norte (1893), Belgrano (1897), Balvanera (1898) o Quilmes (1898). Junto con esto tendremos la circulación de prensa periódica en alemán desde mediados de la década de 1860. Sin embargo su circulación no será estable hasta la aparición del Deutsche La Plata Zeitung en 1878 y el Argentinisches Tageblatt en $1889^{296}$.

militar" en las Islas Malvinas. Ese mismo año tenemos la llegada del militar Friedrich Rauch (17901829), el cual participaría en forma activa en la vida militar del país.

${ }^{291}$ Para este entonces cerca de 5.000 comerciantes alemanes realizaban o habían realizado negocios en Argentina. Entre 1843 y 1845 las provincias de Preußen, Bremen y Hamburg establecían relaciones diplomáticas con el gobierno del gobernador Juan Manuel de Rosas (1793-1877). Lütge 1981; Newton 1977; Sauveur-Henn 2010.

${ }^{292}$ Según el Registro Estadístico de la República Argentina (1871) para 1858 se registran el ingreso de 4.658 inmigrantes en el puerto de Buenos Aires. De ese total cerca de 1.000 personas serán alemanes. PCN 1869.

${ }^{293}$ Un caso representativo será el de Klaus Stegmann Kophen (1797-1854), el cual arribando al país en 1818 cimentará una fortuna personal a partir de su actividad comercial con firmas inglesas. El 18 de agosto de 1830 contraía matrimonio con Narcisa Victoria de los Santos Pérez Millán de la Quintana (1810-¿?), viuda de Friedrich Rauch. De esta unión nacerían 11 hijos, dos de los cuales; Claudio Federico Stegmann Pérez Millán (1833-1887) y Jorge Raimundo Pérez Millán (1836-1879); se encontrarán entre los socios fundadores de la Sociedad Rural Argentina.

${ }^{294}$ El primer Censo Nacional, realizado en 1869, registrará 4.989 alemanes viviendo en la Argentina. Hacia 1873 el gobierno nacional buscará "encauzar" el flujo inmigratorio a través del decreto sancionado el 28 de abril de dicho año, nombrando un agente en el recientemente integrado territorio alemán de Elsaß-Lothringen con la finalidad de promover la inmigración de alemanes a la Argentina. BO 1873.

295 DLPK 1873.

${ }^{296}$ Bryce 2008; Lütge 1981; Newton 1977; Sauveur-Henn 2010. 
En lo que respecta al plano científico también es posible observar una importante migración de científicos alemanes a lo largo de la segunda mitad del siglo XIX. Para ese entonces la Argentina era un país en expansión que necesitaba controlar y explotar adecuadamente sus territorios y sus recursos naturales. Los científicos alemanes arribarán al país junto con sus técnicas, procedimientos, métodos e instrumentos. Trabajos con diversos enfoques metodológicos y objetivos han analizado la incidencia de individuos, instituciones y proyectos científicos alemanes en el desarrollo y diversificación del sistema científico $\operatorname{argentino~}^{297}$. La serie de trabajos realizados por sus miembros, la sistematización de la investigación y la enseñanza de la ciencia en sus distintas ramas, como la participación activa en la vida social del país le había hecho merecedora de un respeto y prestigio social por parte de sus congéneres argentinos ${ }^{298}$.

Diversos autores que han estudiado el papel de estudiosos alemanes en la sistematización de la enseñanza y la práctica científica en la Argentina. Sin embargo estos trabajos plantean el análisis en conjunto de los estudiosos alemanes que se desempeñaran a lo largo de la segunda mitad del siglo XIX en la Argentina ${ }^{299}$. Esta serie de trabajos han plantado un estudio lineal y continúo de los distintos estudiosos alemanes, a pesar de cada uno de estos personajes provendrán de formaciones académicas disímiles y responderán a intereses particulares e institucionales completamente distintos. De esta forma vincularán a los miembros alemanes de la Academia Nacional de Ciencias de Córdoba ${ }^{300}$, los cuales comenzarán a arribar al país hacia 1870, con aquellos que posteriormente actuarán en diversos institutos científicos en Buenos Aires y en la ciudad de La Plata. Como hemos mencionado este tipo de análisis, priorizando en muchos casos un enfoque biográfico, no permite ver el complejo entramado social e institucional en el cual se desenvuelven y al cual responden estos individuos. Los únicos puntos de coincidencias serán la deficiencia, carencia o ausencia de espacios o materiales adecuados en los contextos en que este tipo de prácticas se desenvolverán.

\footnotetext{
${ }^{297}$ Ver entre otros: Carreras 2010 a, 2010 b; Farro 2009, 2011; García S. 2010 a; Göbel 2011; Lütge 1981; Podgorny 2008; Pyenson 1985 a; Vera de Flachs 2002.

${ }^{298}$ Blackbourn y Eley 1984; Cocks y Jarausch 1990; Kitchen 2006; McClelland 1991; Retallack 2008.

${ }^{299}$ Castellano 1970; Cutolo 1968; Frahm y Eggers 2001; Hertel 2009; Lütge 1981; Marsal 1970 a, 1970 b; Pyenson 1985 a;.Tognetti 2004; Vera de Flachs 1994, 1999, 2002 entre otros.

${ }^{300} \mathrm{Su}$ antecedente inmediato será la Ley 322; sancionada durante la presidencia de Domingo Faustino Sarmiento (1811-1888); la cual autorizaba al Poder Ejecutivo a "[...] contratar dentro y/o fuera del país hasta veinte profesores, que serán destinados a la enseñanza de ciencias especiales en la Universidad de Córdoba y en los colegios nacionales [...]”. Dicha tarea sería encomendada a Karl Hermann Konrad Burmeister, el cual se encontraba al frente del único centro científico del país; el Museo Público de Buenos Aires; y contaba con una respetable trayectoria científica. BO 1869.
} 


\section{El estudio de las colecciones osteológicas del Museo de la Plata}

\subsection{La re-orientación de los estudios craneológicos}

En la semblanza que el arqueólogo argentino Fernando Márquez Miranda (1897-1961) le dedicará en 1939 a Lehmann-Nitsche, recordaba que "A su llegada, múltiples problemas de la vida primitiva solicitan su interés" ${ }^{301}$. Para cumplir dicho objetivo comenzará con una serie simultánea de trabajos: la recolección de tradiciones folklóricas y populares, trabajos sobre craneología, antropometría, paleoantropología y medicina prehistórica ${ }^{302}$. A partir de estos buscará compilar datos; basado principalmente en aquellos datos obtenidos a partir de la mensuración de individuos vivos o bien sobre sus restos; que le permitieran construir un esquema comparativo que sintetizara los procesos evolutivos de las poblaciones indígenas argentinas.

Es preciso mencionar que estos trabajos no responderán a un plan sistemático de investigación, sino que serán resultado de la posibilidad de contar con acceso a materiales ausentes en las instituciones y colecciones europeas. En este sentido la dinámica de las prácticas está, en parte, condicionada y estructurada por la distribución y el acceso a los recursos materiales y conceptuales de los diversos contextos locales. Como ha señalado Timothy Lenoir "Innovations in theoretical or technical practice are evaluated by scientific actors in terms of the opportunities the offer for furthering their own theoretical or experimental interests. Crucial to such decisions are the resources available within the local context. Thus, the adaptation of different contexts is constrained by a host of factors, including material, theoretical and technical expertise, financial resources, and not least of all social factors relating to career strategies $[\ldots]^{\prime 303}$.

De esta forma los primeros trabajos de Lehmann-Nitsche en el Museo de La Plata deben ser vistos como el resultado de un acceso casí exclusivo a los materiales depositados en el Museo de La Plata, lo cual le permitirá generar una serie de datos que buscaban integrarse en un cuerpo de discusiones más amplio. Este tipo de estrategias podemos observarlo en varios estudiosos alemanes residentes en América. Rudolf Lenz, luego de llegar a Chile, comenzará a estudiar y clasificar los materiales lingüísticos en base a las doctrinas psicológicas de Wund y las recomendaciones metodológicas dada por el sinólogo y lingüista alemán Hans Georg Conon von der Gabelentz (1840-1893) en su obra Die Sprachwissenschaft, ihre Aufgaben, Methoden und bisherigen Ergebnisse (1891) ${ }^{304}$.

\footnotetext{
${ }^{301}$ Márquez Miranda 1939, p.126.

${ }^{302} \mathrm{Al}$ mismo tiempo podremos observar en la segunda y tercera década de trabajo algunas publicaciones sueltas referidas a estos temas, siendo principalmente ampliaciones o traducciones de trabajos previos.

${ }^{303}$ Lenoir 1988, p. 14.

${ }^{304}$ Lenz 1893.
} 
Una estrategia similar ha sido señalado por Lewis Pyenson para los físicos alemanes residentes en Chile y Argentina para la primera década del siglo XX, señalando que estos “ $[\ldots]$ reporte don their progress in Spanish in the observatory's house organs, at the same time sending research communications to the usual German journals. Ristenpart [en referencia al astrónomo alemán Friedrich Wilhelm Ristenpart (1868-1913)] faced the familiar problema of appearing to promote local interests while at the ssame time contributing to the advancement of learning in general ${ }^{, 305}$. Este espíritu colectivo de la construcción del conocimiento redundaba en otros beneficios para el estudioso que encontrándose en América enviaba datos a los centros de estudios en Europa. Tal como le detallaba Lehmann-Nitsche en cartas a miembros de su familia o cercanos a esta, la publicación de trabajos en revistas alemanas le permitía aportar datos sobre materiales al que no todos los investigadores tenían acceso, construyendo su carrera en Alemania desde Argentina ${ }^{306}$.

En consecuencia estos primeros trabajos de Lehmann-Nitsche buscarán insertarse dentro de esquemas más amplios que indagaban en la evolución y la caracterización de aquellas poblaciones que la tradición alemana denominaba como "pueblos naturales" (Naturvölker). Estos últimos se diferenciaban de los "pueblos culturales" (Kulturvölker) y constituían la división básica de la humanidad. Los primeros; pueblos sin historia escrita; se encontraban más cercanos a la naturaleza y ofrecían, por lo tanto, una forma de "acceder" al pasado y comprender el camino evolutivo de las poblaciones europeas ${ }^{307}$.

Lehmann-Nitsche contará con acceso a aquellos materiales depositados en el Museo de la Plata, principalmente, y en otras instituciones argentinas. La formación académica y los nexos con diversos estudiosos residentes en el Viejo Mundo le permitirán contar con herramientas teóricas que darán cuenta de las principales características de aquellos objetos de interés para la Antropología. Dicha actividad estará supeditada a los intereses institucionales de los programas de investigación europeos, especialmente los de Alemania. La colaboración con sus pares europeos sustentará la "credibilidad" de sus investigaciones, al mismo tiempo que le proveerá la sensación de pertenencia al grupo científico que estos constituían ${ }^{308}$. En el caso específico de la antropología alemana estas extensas redes de colaboración se basarán en una visión humboldtiana de la ciencia, en la cual el estudio de la naturaleza debía basarse en evidencia empírica sólida a partir de la cual poder lograr una imagen total y armónica del

\footnotetext{
${ }^{305}$ Pyenson 1985 b, p. 412.

306 Principalmente a su madre Ida Laura Auguste Stephan, pero también a otras personas de su circulo familiar como Paul Ennke, Else Lehmann-Nitsche, Franz Stephan, Eugen Lehmann-Nitsche, Claire Brinckmann, Rudolf Lehmann-Nitsche y Frieda Lehmann-Nitsche. Legado Robert Lehmann-Nitsche, IAI.

${ }^{307}$ Penny; Bunzl 2003

${ }^{308}$ Gallison 2003; Schaffer 1992; Shapin 1988
} 
mundo $^{309}$. En este sentido los logros individuales formaban parte de un proyecto más amplio que excedía las metas y/o objetivos individuales de sus miembros ${ }^{310}$.

\subsection{Las colecciones antropológicas del Museo de La Plata}

Como hemos mencionado previamente el ordenamiento de las colecciones óseas depositadas en el Museo de La Plata estará caracterizado por la total ausencia de un plan sistemático. El resultado de esto será una acumulación de material que dificultará notablemente el trabajo con las mismas. Dicha situación era advertida por ten Kate, el cual encontraba el origen en tener en un mismo espacio el material de estudio y el de exhibición. Paciencia, energía, la instalación de armarios especiales destinados a la exposición del material y el metodismo en la clasificación eran la solución que el estudioso holandés le recomendaba a Lehmann-Nitsche. Junto con esto, advertía Ten Kate a Lehmann-Nitsche, era necesario contar con estoicismo y calma al momento de proceder a trabajar con las colecciones ya que muchas veces la poca voluntad del director del museo en cuanto al mantenimiento y ordenamiento de las mismas, jugaba en contra de los proyectos presentados por los encargados de sección ${ }^{311}$. El acumulamiento de materiales como resultado de la falta de separación entre los espacios destinados a la exhibición de los materiales al público por un lado y aquel reservado para los profesionales deseosos de estudiarlo será advertido por algunos de los estudiosos alemanes encargados de las colecciones antropológicas en América. Hacia 1905 el banquero y filántropo estadounidense Morris Ketchum Jesup (1830-1908) visitaba el American Museum of Natural History, institución de la cual era presidente. Observando las colecciones etnológicas le señalaba a Franz Boas; el cual había reemplazado como curador al antropólogo estadounidense Frederic Ward Putnam (1839-1915); que el arreglo y el etiquetamiento de las mismas era confuso y caótico. A esto se sumarian las críticas del director del museo, el biólogo estadounidense Hermon Carey Bumpus (1862-1943) para el cual las colecciones debían estar ordenadas de una forma que fuera de fácil entendimiento para el público asistente ${ }^{312}$. Al tratar de explicar su sistema de clasificación y ordenamiento a Jesup, detallaba Boas que el elevado número de materiales depositados en el museo exigía la separación entre las colecciones para ser observadas por el público general y aquellas destinadas al estudio por parte de los

309 Bruckner 1999; Daum 2002; Manner 2001; Penny 2002 a; Reichardt 2008; Schaffer 1988; Zimmerman 2001.

${ }^{310}$ En este sentido Glenn Penny ha observado que "They justified their behavior, supported each other's efforts, and often condemned the actions of nonscientists based on a belief that their own efforts served a higher purpose, and that non scientist's interference might hinder these greater goals. They championed their own collecting as part of a broad intellectual project, which promised to raise general levels of knowledge about the "multiplicity of humanity" and the "history of mankind." Penny 2002 a, p.96

${ }^{311}$ Hermann ten Kate a Robert Lehamnn-Nitsche. Legado Robert Lehmann-Nitsche, 19.11.1897, IAI, Carpeta N-0070 b 684.

${ }^{312}$ Darnell 1998; Hinsley 1976; Hyatt 1979; Liss 1990; Stocking 1974 a. 
estudiosos. Al mismo tiempo señalaba que la forma en la cual los materiales eran exhibidos estaba condicionada también por los recursos económicos disponibles y la predisposición del director del museo ${ }^{313}$.

Volviendo al caso de las colecciones de la Sección de Antropología del Museo de La Plata. Estas estaban montadas con aquellos cráneos y esqueletos que Moreno había reunido durante sus viajes por el interior del país; y estarán caracterizadas desde el principio por su carácter transitorio. Entre 1884 y 1889 la sección recibirá diversos nombres ${ }^{314}$. Al mismo tiempo en el proyecto original se pensaba destinar las mismas a una sala especial, mientras que las colecciones especiales destinadas a los estudiosos debían depositarse en un edificio anexo, junto con la biblioteca y los laboratorios. Finalmente los excesivos montos de este plan terminaron por colocar la sala de antropología en un espacio pensando originalmente como patio interior del edificio ${ }^{315}$. Estos sucesivos proyectos que se van sucediendo uno tras otro contribuirán al estado caótico en el cual las prácticas antropológicas se desarrollaban.

Como ha señalado Máximo Farro los proyectos científicos del Museo de La Plata estarán caracterizados por su falta de continuidad. Este mismo autor ha señalado como en la transición entre el siglo XIX y el siglo XX el museo platense irá incrementando su patrimonio material, con un director ausente y con cada encargado de sección librado a su buena suerte. Los trabajos de esta época estarán supeditados a la disponibilidad de recursos materiales para los estudios, recursos económicos para la adquisición de instrumentos, colecciones o publicaciones y finalmente a la última palabra de Moreno ${ }^{316}$.

Finalmente las colecciones serán colocadas en grandes vitrinas de madera de cedro y vidrio que cumplían la función de exhibición y depósito simultáneamente. El uso de este tipo de vitrinas estaba pensado para obtener el máximo beneficio de la luz solar en espacios cerrados. Los cráneos serán colocados en una serie de vitrinas laterales apoyadas sobre las paredes, mientras que los esqueletos serán depositados en una ringlera central de doble piso compuesta por vitrinas individuales (Fig. 18). A esto se sumaban unos muebles con paneles giratorios similares que contenían fotografías, acuarelas y dibujos de tipos indígenas americanos. Como ha señalado Máximo Farro, este tipo de disposición es muy similar a las que podía encontrarse en los principales museos e instituciones antropológicas de Francia e Inglaterra, lugares que Moreno había visitado entre 1880 y $1881^{317}$.

En los dos períodos en los cuales ten Kate estará al frente de la Sección de Antropología las colecciones incorporarán nuevos elementos, ampliándose notablemente. A pesar de esto ten

\footnotetext{
${ }^{313}$ Ibídem.

314 Será denominada: "antropología osteológica", "antropología zoológica", "anatomía comparada humana" y "antropología anatómica".

${ }^{315}$ Farro 2009, 2011.

${ }^{316}$ Farro 2008, 2009.

${ }^{317}$ Ibídem.
} 
Kate se limitará solamente a proponer algún tipo de ordenamiento y clasificación con aquellos elementos que constituían parte esencial de su investigación. Entre sus principales trabajos destaca el ordenamiento de las colecciones fotográficas de tipos raciales a fin de completar su propia colección de tipos propios de América del Sur. Al mismo tiempo montará un laboratorio fotográfico en la Sección Antropológica, con la asistencia técnica de su ayudante en la sección, Charles de la Hitte ${ }^{318}$.

Los primeros cinco meses de Lehmann-Nitsche estarán dedicados a la limpieza de las instalaciones y el ordenamiento de la gran cantidad de materiales, redactando el primer catalogo sistemático de la sección ${ }^{319}$. En este último daba su parecer con respecto a la disposición de las colecciones: "No me parece inútil dar una breve reseña sobre las vidrieras colocadas en la sala antropológica. Como las demás vidrieras del Museo proceden de los primeros años de la fundación de este (1887) y tienen todos los defectos de tales muebles hechos de madera por carpinteros sin experiencia y cuidado especial y en una época en que la museología no se había desarrollado todavía [...] En las paredes de la sala se hallan vidrieras, construidas como antes se hacía en antiguos museos, sobre el modelo de aparadores de comedor, compuestas de un mueble bajo y ancho, y otro superior, alto y más estrecho. Las vidrieras, todas hechas de cedro macizo o enchapado, presentan afuera el color natural de la madera, mientras que adentro están pintadas de un gris verduzco muy claro, tono que hace resaltar las piezas según los experimentos del señor Bruch y que fue adoptado para las principales secciones del Museo; de este mismo color están pintados los armazones de fierro, los pedestales para cráneos y esqueletos, etc.”320.

Hacia 1900 Lehmann-Nitsche ordenaría las colecciones en base al ordenamiento geográfico sugerido por el suizo Enrique Delachaux (1864-1908) a fin de presentar los restos esqueletarios y los cráneos de procedencia imprecisa. En este sentido aclaraba que "Como de buena parte de las piezas no se conoce su pertenencia a tal o cual tribu y solamente su procedencia territorial, elegí por base de clasificación el principio geográfico. Deseaba encontrar una división del país en regiones que correspondiera tanto a las zonas naturales físicogeográficas como a las divisiones políticas. Sé perfectamente que lo que yo anhelaba, es decir una correlación entre las zonas naturales y las zonas políticas, en realidad no existe de un modo bien marcado y sólo aproximadamente; pero cuando un sistema corresponde sólo aproximadamente a los hechos, es suficiente para una clasificación, la que de todos modos es artificial como indispensable para los fines de un catálogo. Los límites naturales entre dos zonas, nunca están marcados, pero sí los políticos, y como para los fines de una catálogo se necesitan límites fijos, es menester tomar como base de división las provincias o territorios. Prefiero, pues, para un catálogo la división defectuosa del señor Delachaux que deja íntegras las

\footnotetext{
${ }^{318}$ Farro 2011.

${ }^{319}$ Farro 2009, 2011; García S. 2010 a; Lehmann-Nitsche 1910 a; Podgorny 1999, 2004, 2008, 2009.

${ }^{320}$ Lehmann-Nitsche 1910 a, p.16.
} 
provincias políticas (Santa Fe y Santiago del Estero), base de nuestra clasificación de la república Argentina"321.

Dicha tarea le resultará totalmente tediosa y carente de importancia, tal como le confesaba a Rudolf Martin. Este último le recordaba que la única forma de sacar provecho del tiempo de residencia en la Argentina será la precisión en los métodos de observación y registro, ya que esto le permitiría contar con un inestimable material de referencia para posteriores comparaciones y la elaboración de valiosas monografías carentes de especulación. Al mismo tiempo le recordaba que la importancia de la Argentina dentro del contexto internacional de la antropología era la ausencia de personas que investigarán acorde a un plan sistemático que respondiera a los objetivos más amplios de aquellos proyectos elaborados en Europa. En este sentido lo llamaba a introducir todas las reformas que creyera necesarias a fin de adaptar las investigaciones antropológicas desarrolladas en la Argentina a los objetivos de los proyectos desarrollados en el Viejo Continente. A partir de esto Lehmann-Nitsche podía estar seguro de obtener el respeto y el reconocimiento por parte de sus colegas europeos; facilitándole su inserción dentro del medio científico académico alemán ${ }^{322}$.

Las reformas propuestas por Martin incluirán la modificación estructural de los espacios de trabajos y de exhibición de los objetos antropológicos. Como podemos ver la introducción de nuevos lineamientos teóricos al momento de la construcción del objeto de estudio, tendrán su correlato "material". La utilización de nuevas técnicas y/o instrumentos, junto con modificaciones en el modo en el cual los objetos son exhibidos pueden implicar cambios en la forma en la cual estos son observados, descriptos, definidos y clasificados. Al mismo tiempo estos procesos no se limitarán solamente al plano abstracto de la reflexión, dando lugar al surgimiento de innovaciones materiales para la construcción, observación, estudio y exhibición de los objetos antropológicos.

\subsection{Los primeros estudios craneológicos}

A partir de este ordenamiento y por las sugerencias de ten Kate comenzará LehmannNitsche a trabajar con los restos óseos de araucanos y tehuelches. Según el holandés estos eran ideales para elaborar un estudio objetivo y científicamente importante para la antropología de América del Sur, por lo cual le recomendará a Lehmann-Nitsche comenzar a trabajar en forma inmediata con los mismos. Ten Kate le advertía que antes de comenzar los trabajos antropométricos con individuos vivos, sacará provecho de las valiosas colecciones osteológicas depositadas en el Museo de la Plata. De esta forma comenzaba Lehmann-Nitsche a redactar

\footnotetext{
${ }^{321}$ Ibídem p.12; Podgorny 1999.

${ }^{322}$ Rudolf Martin a Robert Lehmann-Nitsche. Legado Robert Lehmann-Nitsche, 03.10.1900, IAI, Carpeta N-0070 b 489.
} 
unos breves trabajos vinculados principalmente a las patologías raciales, craneología y la antropometría ${ }^{323}$.

Lo novedoso de dichos trabajos radicará en la búsqueda de establecer una regularidad de las prácticas y los discursos utilizados para dar cuenta del saber antropológico producido. Al igual que con gran parte de los estudiosos alemanes residentes en la Argentina, tendremos detrás de esto el deseo de poder integrar los resultados de estos trabajos al cuerpo de saberes producido en Europa. Para esto será necesario "regularizar" las prácticas antropológicas, tanto a nivel material como a nivel discursivo. Esa era la forma de poder integrar y comparar observaciones, descripciones, resultados y conclusiones de los trabajos realizados en la Argentina con aquellos realizados en el exterior; principalmente aquellos efectuados por otros estudiosos alemanes.

De esta forma el análisis de cráneos, la medición de individuos y la determinación de enfermedades prehistóricas, pueden ser entendidas como un intento de establecer una forma específica de práctica discursiva al interior de la antropología argentina, entendiendo la misma como un conjunto de reglas anónimas; específicas en tiempo y espacio; que definen las condiciones en las cuales se desenvuelve una disciplina ${ }^{324}$. Esto se evidencia también en las primeras publicaciones efectuadas por Lehmann-Nitsche las cuales se caracterizarán por ser editadas primeramente en diversas revistas especializadas alemanas, para posteriormente ser traducidas y publicadas en medios locales o internacionales en español.

Como hemos señalado anteriormente las publicaciones en alemán tenían por objetivo la acumulación de material publicado que le permitiera obtener una posición rentable en los espacios científicos y académicos alemanes, lo cual no significaba descuidar sus contrapartes en la Argentina. Tal como le recomendaba Rudolf Martin era necesario ocupar estos espacios, controlarlos y capitalizarlos a favor de la antropología alemana ${ }^{325}$. En consecuencia los resultados obtenidos a partir de sus primeros trabajos no solo serán publicados en medios especializados alemanes sino que también serán presentados en reuniones y congresos científicos locales, tales como el Primer Congreso Científico Latinoamericano. Hacia 1897 el ingeniero civil y político argentino Ángel Gallardo (1867-1934) le comunicaba a LehmannNitsche que el Comité de Organización de dicho congreso, en su sesión del 19 de noviembre de ese año, había resuelto designarlo integrante del sub-comité de "Ciencias Antropológicas"”26. Esto junto con su designación como socio activo de la Sociedad Científica Argentina y de la Société d'Anthropologie de Paris eran considerados por Lehmann-Nitsche como los primeros

\footnotetext{
${ }^{323}$ Hermann ten Kate a Robert Lehamnn-Nitsche. Legado Robert Lehmann-Nitsche, 01.02 y 19.11.1897, IAI, Carpeta N-0070 b 684.

${ }^{324}$ Foucault 1994.

${ }^{325}$ Rudolf Martin a Robert Lehmann-Nitsche. Legado Robert Lehmann-Nitsche, 03.10.1900, IAI, Carpeta N-0070 b 489.

${ }^{326}$ Congreso Científico Latino-Americano a Robert Lehmann-Nitsche. Legado Robert Lehmann-Nitsche, 19.11.1897, IAI, Carpeta N-0070 b 867.
} 
pasos para poder adentrarse en el contexto científico local y articular los resultados en los contextos científicos europeos, los cuales consideraba de mayor relevancia para su trabajo ${ }^{327}$.

Dicho congreso se celebraría entre el 10 y el 20 de abril de 1898 en la ciudad de Buenos Aires. En el mismo Lehmann-Nitsche presentaba dos breves comunicaciones. Una de estas; intitulada "Antropología y Craneología"; será resultado de las observaciones realizadas sobre los cráneos "fósiles" de Ensenada, Tres Arroyos y Baradero. En este sentido el 11 de octubre de 1897 ten Kate recibía una tarjeta postal de Lehmann-Nitsche en la cual este le consultaba sobre los tres cráneos mencionados. El estudioso holandés le respondía unos meses más tarde alentándolo al estudio de los mismos, ya que al encontrarse los mismos entre los "tipos" más viejos de América del Sur los resultados que podía obtener serían más que fructíferos ${ }^{328}$.

Este trabajo buscaba establecer un estilo de práctica antropológica entendida como una "doctrina de las razas", en palabras de Rudolf Martin y Emil Schmidt. De esta forma el método comparativo se presentaba como el único capaz de "descubrir" ${ }^{329}$ diferencias y semejanzas para “[...] estudiar, en primer lugar, la posición del hombre con relación al reino animal [...]"330 y luego poder establecer la comparación de los individuos entre si $^{331}$. Al hacer uso del concepto de "raza" Lehmann-Nitsche pretendía introducir las reflexiones del psiquiatra alemán Konrad Rieger (1855-1939), Aurél von Török ${ }^{332}$ y Paul Ehrenreich en torno a la construcción y el uso del concepto de dicho concepto y principalmente sus críticas a las representaciones raciales hechas bajo la doctrina del anatomista suizo Anders Adolf Retzius (1796-1860). Con distintos matices estos estudiosos proponían que la craneología se limitase a la determinación de los factores biológicos y luego a la determinación del tipo de raza ${ }^{333}$.

Limitando el papel de las condiciones ambientales y el factor de "lucha por la existencia" en la evolución orgánica de los individuos, las razas serán grupos de individuos establecidos a partir de una serie de características similares, que al mismo tiempo permitían

327 Sociedad Científica Argentina a Robert Lehmann-Nitsche. Legado Robert Lehmann-Nitsche, 16.09.1897, IAI, Carpeta N-0070 b 1014. Société d'Anthropologie de Paris a Robert Lehmann-Nitsche. Legado Robert Lehmann-Nitsche, 10.07.1897, IAI, Carpeta N-0070 b 1006. Robert Lehmann-Nitsche a Ida Lehmann-Nitsche. Legado Robert Lehmann-Nitsche, 21.06.1903, IAI, Carpeta N-0070 1295.

${ }^{328}$ Herman ten Kate a Robert Lehmann-Nitsche. Legado Robert Lehmann-Nitsche, 15.12.1897, IAI, Carpeta N-0070 b 684.

${ }^{329}$ Lehmann-Nitsche 1899 a, p.124.

${ }^{330}$ Ibídem.

${ }^{331}$ Lehmann-Nitsche 1899 a; Martin 1893; Schmidt 1888, 1897

${ }^{332}$ Von Török le escribía a Lehmann-Nitsche felicitándolo por su puesto en el Museo de la Plata, al mismo tiempo que le recordaba la importante tarea que debía desempeñar como representante de la ciencia alemana. Aurél von Török a Robert Lehmann-Nitsche. Legado Robert Lehmann-Nitsche, 24.10.1897, IAI, Carpeta N-0070 b 696.

333 Según Lehmann-Nitsche estas generaban una representación insuficiente y por otro lado, una confusión al traspasar los indicios biológicos a los caracteres de la "raza" propiamente dicha. Citará como ejemplo las discusiones en torno a lo que él denominaba como frente fuyente, la cual a partir de un error de posicionamiento y de óptica se presentaba como uno de los caracteres primitivos distintivos. LehmannNitsche 1899 a. 
diferenciarlos de otros grupos ${ }^{334}$. En este sentido el conjunto de estos grupos constituía para Lehmann-Nitsche "[...] una especie en el sentido científico"335. En este sentido llamaba la atención sobre la construcción "[...] en el gabinete de estudio de nuevas razas artificiales",336, al comparar medidas y no cráneos ${ }^{337}$. Entre las principales propuestas para superar estas aparentes limitaciones, exhortará por la inclusión de nuevas variables como el sexo, las patologías, características individuales, grupos etarios, la "raza" y finalmente la influencia de la cultura en la definición de tipos craneales ${ }^{338}$. Según el antropólogo alemán Otto Ammon (1842-1916) el estudio detallado de las características individuales de cada cráneo primeramente y luego la interrelación entre las mismas, era la única forma de lograr verdaderos resultados en los estudios craneológicos, por lo cual Lehmann-Nitsche debía sacar provecho de contar con acceso a las colecciones osteológicas del Museo de La Plata, aportando datos que los estudiosos en Alemania pudieran aprovechar para los estudios en la línea de investigación sugerida por Ammon. ${ }^{339}$.

Al igual que Virchow, y principalmente Ranke ${ }^{340}$, atribuirá un valor secundario al cráneo, el cual junto con el estudio de los huesos largos y la dentición se revelaban como esenciales a la hora de poder establecer series comparativas y, principalmente, sintetizar el esquema evolutivo de la humanidad ${ }^{341}$. Al mismo tiempo este trabajo buscaba introducir en el contexto científico local aquellas discusiones en torno al cráneo y su orientación, las cuales; como hemos podido apreciar en el primer capítulo; llevaban varios años en el Viejo Continente ${ }^{342}$. Esta recapitulación, sin embargo, estará exenta de detalles sobre las diversas convenciones y acuerdos craneométricos acontecidos a lo largo de la segunda mitad del siglo XIX en Europa. A pesar de esto la introducción de estas discusiones significará el primer

\footnotetext{
${ }^{334}$ Detallaba Lehmann-Nitsche hacia 1904 que "Lo que es raza se puede definir como un grupo somático, caracterizado por cierto número de rasgos comunes a todos los individuos que lo componen; es, pues, una unidad que puede variar en cierto grado entre sus dos extremos." Lehmann-Nitsche 1904, p.164.

${ }^{335}$ Lehmann-Nitsche 1899 a, p.130. Resaltado en el original.

${ }^{336}$ Ibídem p. 136.

${ }^{337}$ Según Lehmann-Nitsche otro de los errores de Retzius era tratar de cuantificar a partir de su método craneométrico aquellas descripciones craneoscopicas realizadas por Blumenbach. Lehmann-Nitsche 1904.

${ }^{338}$ Lehmann-Nitsche 1904 a, 1906 a.

339 Otto Ammon a Robert Lehmann-Nitsche. Legado Robert Lehmann-Nitsche, 14.10.1898, IAI, Carpeta $\mathrm{N}-0070$ b 9.

${ }^{340}$ En este sentido estos autores retomaban las ideas originales planteadas por el zoólogo y antropólogo alemán Johann Friedrich Blumenbach (1752-1840). Señalaba Lehmann-Nitsche: “[...] Blumenbach buscó por una descripción analítica del aspecto general del cráneo á demostrar, á determinar y fijar los caracteres craneales; y trataba muy naturalmente de preferencia este indicio por é1 introducido, examinándolo monográficamente. Este sistema ofrecía una cierta comodidad, un fácil acceso al material; pero nunca Blumenbach perdió de vista que el cráneo era solamente una de las series características de una raza positiva". Lehmann-Nitsche 1899 a, p.135. Resaltado en el original.

${ }^{341}$ Lehmann-Nitsche 1894, 1895 a, 1899 a, 1904; Martin 1893; Schmidt 1888, 1897.

${ }^{342}$ Lehmann-Nitsche 1899 a.
} 
intento por traspasar los estrechos límites de la reflexión antropológica local en torno a los estudios craneológicos. Estas publicaciones sin embargo solo estarán destinadas a engrosar el número de publicaciones de Lehmann-Nitsche, quien no se preocupara en la redacción de instrucciones o manuales que sirvieran para la instrucción y formación de un grupo de investigación en esta línea de trabajo.

Rudolf Martin y Johannes Ranke, al recibir una copia de dicho trabajo, veían con satisfacción lo que ellos consideraban como el inicio de los estudios craneológicos sistemáticos en la Argentina. Según estos, la falta de un plan a partir del cual diagramar y coordinar los diversos trabajos solo daba lugar a la existencia de metodologías que; procurando simplificar el trabajo; revelaban la falta de compromiso de los antropólogos y atentaba contra el mismo desarrollo y credibilidad de la antropología ${ }^{343}$. La importancia de esta sistematicidad estibaba en que los trabajos eran realizados acorde a las series de instrucciones, indicaciones y pedidos que le realizaban a Lehmann-Nitsche a través de la correspondencia privada. De esta forma Martin y Ranke podían asegurarse de contar con una persona que les proveyeran de datos relevados de una forma científica. Al mismo tiempo Martin le recomendaba la formación e instrucción de un grupo de trabajo que lo asistiera en sus tareas. El objetivo mediato de esto era ampliar el espacio de recolección de objetos, y la efectivización de los tiempos de estudio. A largo plazo esto significaba la continuación de lineamientos y objetivos de los proyectos antropológicos alemanes en la Argentina $^{344}$. A pesar de las reiteradas insistencias de Martin en este punto, Lehmann-Nitsche jamás procurará formar un grupo de trabajo, lo cual le hubiera permitido consolidar y ampliar las formas en las cuales las prácticas antropológicas eran realizadas. En este sentido George Stocking ha señalado que la temprana preocupación de Franz Boas en la formación de estudiantes no solo le permitirá ampliar el rango de sus investigaciones y economizar el tiempo en que estas eran realizadas, sino que a través de los mismos logará capitalizar los espacios académicos y científicos donde estas prácticas eran realizadas; tal como afirma Stocking para 1926 gran parte de los departamento académico de antropología en los Estados Unidos estaba dirigido por uno de los estudiantes de Boas.

Si bien la búsqueda de la excelencia profesional y el reconocimiento por parte de los pares no serán vistos negativamente, Martin planteaba en sus cartas una visión altruista de la práctica antropológica; donde el actor individual deberá poner por delante de los objetivos personales la tarea de promocionar y establecer los métodos, técnicas e instrumentos de la

\footnotetext{
${ }^{343}$ Señalaba Ranke que "Nada mas era necesario que medir el ángulo del perfil y el largo y ancho del cráneo. Cualquiera se creía entonces, aún con los más insuficientes conocimientos anatómicos, con el craneometro en mano, autorizado a cooperar y á discutir [...]", agregando al final que "Tanto más absurda fue la teoría, cuanto más errónea la práctica" ya que esta "Aliviaba incontestablemente el trabajo [...] el ejercicio profesional". Ibídem p. 136-137.

${ }^{344}$ Rudolf Martin a Robert Lehmann-Nitsche. Legado Robert Lehmann-Nitsche, 03.10.1900, IAI, Carpeta N-0070 b 489.
} 
antropología alemana. La publicación y la rápida distribución de estos primeros trabajos craneológicos por parte de Lehmann-Nitsche responderán, en parte, a estos objetivos ${ }^{345}$.

Estudiosos como el lingüista argentino Samuel Alejandro Lafone Quevedo (1835-1920) reconocían el valioso aporte que significaba la introducción de nuevos enfoques teóricos en los estudios craneológicos, exhortando al mismo tiempo a Lehmann-Nitsche a "[...] aplicar sus conocimientos a algo más concreto, es decir a estos estudios con aplicación especial de alguna de nuestras razas [...]" por lo cual lo animaba al estudio de las muestras craneológicos depositadas en las colecciones del Museo de la Plata, y especialmente al trabajo sobre los individuos vivos ${ }^{346}$.

Uno de los más vehementes con respecto a estos trabajos será el botánico argentino Nicolás Rojas Acosta (1873-1946), el cual en una serie de cartas expresaba el entusiasmo de "[...] contar con un compañero que sigue el áspero sendero de la ciencia", agregando que "Hombres de su talla necesita la Republica Argentina para encaminarse a la resolución de problemas científicos de alto interés social!" Esta referencia tan elocuente a Lehmann-Nitsche se inscribía dentro de la admiración y el reconocimiento personal que, tanto Rojas, como otros profesaban por los estudiosos alemanes ${ }^{347}$.

\subsection{Cráneos, Vasijas y la "medicina prehistórica"}

La insistencia en el estudio de las colecciones óseas y arqueológicas, permitirán también introducir los elementos depositados en las colecciones del Museo de la Plata dentro de las discusiones internacionales sobre las técnicas y métodos de la cirugía prehistórica ${ }^{348}$. La premisa que guiará el estudio sobre estos materiales será su capacidad de complementar en forma sustancial el análisis de las fuentes escritas, ofreciendo de esta manera una síntesis más precisa sobre las formas médicas de los "pueblos primitivos y prehistóricos"349. Estos puntos habían sido desarrollados en su segundo trabajo doctoral, los cuales podía continuar gracias al acceso a los materiales depositados en el Museo de La Plata continuar con los mismos.

\footnotetext{
${ }^{345}$ Entre las notas y cartas de agradecimiento por el envío de copias de dicho trabajos figuran: Edouard Piette; Francisco de Veyga; E. Hassler; Juan de Dios Carrasquilla; Convenz; Alfred Nehring; Daniel Brinton; L. Boutherey; y el Smithsonian Institut.

346 Samuel Lafone Quevedo a Robert Lehmann-Nitsche. Legado Robert Lehmann-Nitsche, 12.08.1898, IAI, Carpeta N-0070 b 817.

${ }^{347}$ La llegada de Lehmann-Nitsche a la Argentina significará para Rojas; y para otros; la continuación y la consolidación de la presencia de estudiosos alemanes en el país. Esto se transluce en el final de una de las cartas de Rojas a Lehmann-Nitsche, en la cual el primero escribe "Bienvenido sea Ud. a estas regiones Del Plata, enriquecidas por Grisebach, Lorentz, Hieronymus, Berg i (sic) Burmeister". Nicolás Rojas Acosta Robert Lehmann-Nitsche. Legado Robert Lehmann-Nitsche, 14.11.1898; 18.04.1899, IAI, Carpeta N-0070 b 572.

${ }^{348}$ Lehmann-Nitsche 1899 a, 1902 a, 1902 d, 1903 a, 1903 b, 1905 a, 1905 d.

${ }^{349}$ Lehmann-Nitsche 1902 a, p. 29.
} 
En el mencionado Congreso Científico Latinoamericano; y a partir del estudio de dos cráneos recolectados por Francisco Moreno en una serie de antiguos sepulcros situados sobre la margen septentrional del Río Negro; Lehmann-Nitsche realizaba una escueta presentación sobre la evidencia material del "[...] más antiguo comprobante del arte médica en toda SudAmérica" ${ }^{350}$ (Fig. 19) . La elección de estos cráneos no será arbitraria. Junto con las indicaciones de ten Kate la principal motivación tras esta elección será complementar los datos existentes sobre esta serie en Alemania y Francia y retomar las discusiones allí acontecidas. Estos cráneos no eran totalmente desconocidos en el ambiente académico alemán. Hacia mediados de la segundad mitad del siglo XIX Moreno obsequiará cuatro ejemplares de esta serie a Virchow, presentado posteriormente en París un cráneo de esta serie ${ }^{351}$.

Según Lehmann-Nitsche el raspado presente en la calota más antigua; la cual presentaba ciertas semejanzas con cráneos neandertales y botocudos ${ }^{352}$; evidenciaba un caso de operación auxiliar efectuada en el caso de una enfermedad indeterminada, la cual habría propiciado la muerte del paciente. Para el médico francés Louis-Adolphe Bertillon (1821-1883) y A. Bordier la osteítis presente era el resultado de la presencia de sífilis. Broca llamaba la atención sobre un diagnostico tan prematuro. Sin embargo Bordier le recordaba las lesiones sifilíticas presentes en los cráneos polinesios exhibidos en la Exposición Universal de 1878 y los cráneos de Lozère presentados por el médico francés Pierre Barthélémy Prunières (1828-1893) en 1873, como pruebas categóricas de lo que esta enfermedad podía causar a nivel osteológico. La presentación efectuada por Lehmann-Nitsche también llamará la atención de médicos argentinos, los cuales participarán activamente en las discusiones. Daniel Juan Cranwell (1870-1953) y Pascual Palma (1865-1921); dos reconocidos cirujanos; atribuirían el deceso del paciente a una osteomielitis como producto de una lesión traumática ${ }^{353}$.

A fin de profundizar este tipo de estudios, los cuales Lehmann-Nitsche englobaba dentro de la "antro-patología", se complementará el estudio de los elementos óseos con piezas arqueológicas. A partir de esto se buscaba construir un cuadro comparativo de las patologías humanas, haciendo especial énfasis en aquellas que afectaban a los distintos grupos indígenas sudamericanos ${ }^{354}$. Esto será al mismo tiempo causa y efecto de la instalación, en la sala de antropología, de un "gabinete patológico" haciendo uso de una colección de 300 cráneos y cerca de 2.000 huesos sueltos armada por el preparador Santiago Pozzi como resultado de la exploración del Museo en el valle del río Chubut en Patagonia, en 1893. Su análisis, junto con

\footnotetext{
${ }^{350}$ Lehmann-Nitshce 1898 b, p. 196.

${ }^{351}$ Lehmann-Nitsche 1900 e, 1902 a, 1902 d.

352 Moreno 1880.

${ }^{353}$ Lehmann-Nitsche 1902 a; Moreno 1880.

${ }^{354}$ Farro 2009, 2011; Lehmann-Nitsche 1903 c, 1904 g , 1904 h, 1904 i.
} 
el de las piezas arqueológicas peruanas depositadas en el Museo de la Plata, buscará aportar datos a la discusión internacional sobre la existencia de la lepra en épocas precolombinas ${ }^{355}$.

Dichas discusiones pueden ser rastreadas a 1895, año en el cual el médico estadounidense Albert Sidney Ashmead (1850-1911) discutirá sobre la existencia de la lepra en tiempos precolombinos a partir del análisis de las mutilaciones presentes en antiguas vasijas antropomorfas peruanas (Fig. 20). Estas piezas serán consideradas, en su carácter de testimonios materiales, un registro inmutable de la enfermedad. En una lectura ofrecida en 1903 describiría a los huacos peruanos que representaban personas como un "duplicado" material fiel del individuo en vida. En este sentido recordaba "These clay vessels have human form and give rise to our admiration, just as do the statuettes of the Egyptian tombs or the earthen Cuites (sic) found in those of Tanagras among the Greeks. Historians agree in recognizing in these Egyptian and Grecian images the double or duplicate or soul which survives the departed. Death was definite only if these statuettes disappeared" agregando más adelante que "It would have pleased them beyond measure to picture such deformations on the anthropomorphous image supposed to represent the soul of the individual buried" ${ }^{356}$.

Continuando con el estudio de la lepra Ashmead llegaría a conclusiones parciales, descartando la presencia de dicha enfermedad en tiempos precolombinos ${ }^{357}$. A fin de emitir un juicio sobre esta cuestión se comunicará con Virchow. Este analizará las alfarerías peruanas depositadas en el Königliches Museum für Völkerkunde de Berlin, concluyendo que podría tratarse, en todo caso, de sífilis y/o sarna ${ }^{358}$. Ashmead continuará ocupándose del caso, publicando una serie de artículos en revistas médicas norteamericanas y presentando una síntesis de estos trabajos en la primera conferencia internacional sobre la lepra celebrada en el año 1897 en la ciudad de Berlin $^{359}$. A partir del estudio de tres cráneos y algunas vasijas concluirá que las mutilaciones presentes en la nariz, en el labio superior y en los pies eran producto de personas afectadas por la sífilis ${ }^{360}$. En este caso Virchow, a partir del análisis de nuevas alfarerías, se inclinará a pensar que se trataba de lepra ${ }^{361}$.

El análisis de documentos escritos permitirá a otros estudiosos tomar parte en la discusión. Para los médicos alemanes Helmut Polakowsky (1847-1917) y Ernst W. Middendorf (1830-1908), Adolf Bastian y Juan de Dios Carrasquilla Lema (1833-1908), las lesiones visibles en las alfarerías eran el producto de castigos aplicados a los criminales. Por otro lado Karl von

\footnotetext{
${ }^{355}$ Hasta ese entonces este conjunto había permanecido embalado en los depósitos del subsuelo. Farro 2009, 2011.

${ }^{356}$ Ashmead 1903, p. 378-383. Resaltado en el original.

${ }^{357}$ Ashmead 1895 b; Lehmann-Nitsche 1898 a, 1898 b, 1898 c, 1898 d; 1899 b, 1900 e, 1902 d.

${ }^{358}$ Virchow 1958

${ }^{359}$ Para un análisis del papel de Ashmead en la organización de este encuentro ver: Pandilla 2003.

${ }^{360}$ Ashmead 1895 b, 1895 c, 1896, 1897 a, 1897 b.

${ }^{361}$ Virchow 1897.
} 
den Steinen y el naturalista alemán Moritz Alphons Stübel (1835-1904) sugerían que se trataba de algún tipo de enfermedad no determinada ${ }^{362}$. Finalmente tendremos la postura del zoólogo y escritor español Marcos Jiménez de la Espada (1831-1898) para el cual se estaba ante la presencia de una variedad endémica de la tuberculosis conocida como "llaga"363.

Será Carrasquilla Lema el que sugiera a Lehmann-Nitsche tomar parte de estas discusiones, debido al acceso a las valiosas colecciones arqueológicas del Museo de la Plata. En este sentido lo ponía al tanto del estado de la cuestión, de las discusiones internacionales y le recomendaba bibliografía ${ }^{364}$. El poder contar con el acceso a las colecciones del Museo de La Plata le permitiría a Lehmann-Nitsche no atenerse, en parte, a las reglas del circuito comercial en el cual circulaban las piezas arqueológicas utilizadas en estas discusiones. Hacia 1902 Ashmead publicaba una breve reseña en la cual afirmaba que un cura español residente en Lima y amigo suyo le había informado que el precio de los huacos peruanos " [...] has reached an exorbitant figure, owing to a sudden demand for them in Germany. Quite recently an agent for a Berlin museum scoured the towns of old Peru and purchased all the human figured pottery he could find. Those representing disease, mutilation, were greedily snapped up. He paid for one little pot the equivalent of $\$ 100$ in American gold. All kinds of that pottery are now exceedingly scarce there. Evidently German scientists are preparing not to be caught gapping again, through ignorance of the meaning of the representations of disease on pre-Columbian American pottery"365.

Es preciso aclarar que la denuncia de Ashmead no se inscribia en el plano de la condena moral de las prácticas comerciales asociadas a la compra y venta de piezas arqueológicas, sino a la desventaja que significaba competir ante el poder adquisitivo de cietos individuos o el presupuesto invertido por ciertas instituciones. Un año más tarde Ashmead ampliaría esta denuncia detallando que los huacos peruanos habían sido comprados por agentes del Museum für Völkerkunde de Leipzig, y que ante el precio abonado por ellos no había podido competir, agregando que "There is not a pottery with deformed face now in Peru which can be bought. Leipzig has the market for them cornered. The finest collection of these pots, however, can never be obtained, as it belongs to a woman who will not sell. She has a thousand specimens, of which she has promised me photographs" ${ }^{366}$. Esto nos permite apreciar parte de los caminos y espacios a través de los cuales circulaban los objetos de estudio de la antropología, cuya

\footnotetext{
${ }^{362}$ Lehmann-Nitsche 1898 d, 1898 e; Virchow 1897.

${ }^{363}$ Lehmann-Nitsche 1898 d, 1898 e, 1902 d.

364 Robert Lehmann-Nitsche a Juan de Dios Carrasquilla Lema. Legado Robert Lehmann-Nitsche, 06.10.1898, IAI, Carpeta N-0070 b 776.

365 Ashmead 1902, p. 209.

${ }^{366}$ Ashmead 1903, p. 383.
} 
adquisición por parte de estudiosos u instituciones científicas muchas veces estará sujeta a la suerte de los procesos de negociación establecidos con distintos tipos de comerciantes ${ }^{367}$.

Como podemos ver las piezas peruanas no solo eran de importancia para las discusiones internacionales en torno a la existencia de la lepra en tiempos precolombinos por el valor de objetividad que podían aportar, sino por la dificultad económica de poder acceder a las mismas. En este sentido comenzará Lehmann-Nitsche el análisis de 10 vasijas procedentes de localidades ubicadas en el litoral marítimo peruano ${ }^{368}$. El uso de estos materiales le permitiría superar el excesivo valor dado a las noticias de los antiguos cronistas y superar aquellos "[...] provincialismos de escaso valor que no explican científicamente una enfermedad especial [...]" ${ }^{369}$. Si bien el uso de los documentos escritos en la re-construcción histórica de las enfermedades no será negado, los huesos, y en este caso las vasijas, aportarán datos con un valor distinto de objetividad. Mientras que la palabra escrita se mostraba variable y plausible de modificación, las marcas dejadas por la enfermedad en el hueso o bien las representaciones realizadas por el artista tenían la característica de contener la enfermedad en forma estática a lo largo del tiempo ${ }^{370}$.

Lehmann-Nitsche aventuraba la hipótesis de que las vasijas antropomorfas representaban mendigos afectados por la lepra o algún tipo de enfermedad contraída por las condiciones de miseria ${ }^{371}$ (Fig. 21). Estas propuestas generarán una serie de debates en la presentación del joven antropólogo. Para el médico chileno Alberto Valdés y Morel se trataba de un caso de lupus. Por otro lado el médico argentino Baldomero Sommer (1857-1918) opinaba que era un claro caso de castigo aplicado a un criminal. Este trataría de que primara su opinión, justificándola a partir de su participación en los debates acaecidos en la conferencia internacional de la lepra celebrada en Berlin en 1897. Esto, según el propio Sommer, le confería la suficiente autoridad científica e intelectual para proveer de una respuesta definitiva a este

\footnotetext{
${ }^{367}$ Recordemos la anécdota del ornitólogo italiano Roberto Dabbene (1864-1938), quien en 1902; en calidad de viajero naturalista del Museo Nacional de Buenos Aires en una misión política en los Territorios Nacionales de la Patagonia y de la Tierra del Fuego; hacia un alto en la localidad chilena de Punta Arenas. En esta encontrará un negocio peletero propiedad de un comerciante sueco en cuyo exterior un cartel rezaba "Aquí se vende el Mylodon”. El comerciante le ofrecerá a Dabbene un gran trozo de cuero, vértebras, costillas, uñas y fragmentos de maxilar inferior con sus dientes a un precio de 200 libras esterlinas. El elevado precio demandado por el comerciante limitará a Dabbene a conformarse con la adquisición, al valor de un peso chileno, de una fotografía de los restos. Aclaraba el ornitólogo que tiempo después sabrá de la compra de estos restos y su posterior envío a Alemania

${ }^{368}$ Una de las colecciones fue adquirida en 1885 por Moreno al general chileno Arístides Martínez Cuadros (1847-1908) mientras que la otra formaba parte de aquella depositada en el Museo de La Plata hacia 1894 por el novelista y poeta argentino Martín García Merou (1862-1905). Farro 2009, 2011.

${ }^{369}$ Lehmann-Nitsche 1898 d, p. 22.

${ }^{370} \mathrm{El}$ uso de regionalismos por parte de ciertos autores a fin de determinar el tipo de enfermedad representada en las vasijas generaba cierto rechazo por parte de Lehmann-Nitsche quien; ante la falta de contrastación con otras fuentes; se preguntaba: “¿Quién puede atribuir á esos términos vulgares una significación médica exacta?”. Lehmann-Nitsche 1898 d, p. 22.

${ }^{371}$ Lehmann-Nitsche 1898 b, 1898 c.
} 
debate. A través esta intervención Sommer también pretendía poner un alto a las propuestas de Virchow sobre este tema. Para el médico argentino la influencia del estudioso alemán era el impedimento principal para que los “[...] verdaderos sabios como los del último Congreso de Berlin no se decidieran de una manera categórica como yo lo hago [...]”372.

Esta serie de discusiones permitirán ampliar las fuentes utilizadas, dando como resultado un trabajo que se publicaría en las páginas de la Revista del Museo de la Plata ${ }^{373}$. Si bien no se menciona en esta, gran parte de los resultados serán posibles gracias a la estrecha colaboración con el etnógrafo y folklorista argentino Juan Bautista Ambrosetti (1865-1917) y el folklorista y filólogo alemán Rudolf Lenz Danziger (1863-1938). Gracias al primero podrá discernir en torno a las diversas representaciones de enfermedades sobre soporte cerámico en la Argentina. Los contactos establecidos con el segundo serán tal vez los más fructíferos.

Lenz estaba al tanto de la discusión internacional gracias a las publicaciones de la Verhandlungen der Berliner Anthropologischen Gesellschaft. Su principal aporte será un valioso cuerpo de datos referentes a la gramática indígena chilena. Esto permitirá desentrañar el uso de los regionalismos utilizados para designar la enfermedad de la llaga entre los grupos indígenas chilenos y también el uso de este vocablo por parte de las poblaciones campesinas del país trasandino. Al mismo tiempo proveerá importantes datos referentes al uso del término "lupus” por parte de las poblaciones indígenas y campesinas en el Perú y Bolivia ${ }^{374}$. Gracias a esta serie de colaboraciones concluirá Lehmann-Nitsche que se estaba ante la presencia de algún tipo de enfermedad de naturaleza desconocida, pero que sin lugar a dudas no era lepra.

Es interesante notar el matiz que estas propuestas cobrarán en el espacio privado. Si bien en los trabajos publicados Lehmann-Nitsche hacía expresa su altruista misión de "[...] restaurar a la craneología algo de su prestigio perdido" ${ }^{\text {375 }}$, en la correspondencia sostenida con Rudolf Martin le aseguraba que era consciente de que los planteos y propuestas esgrimidos en el contexto científico argentino carecían de novedad en Europa. Al mismo tiempo se lamentaba de que su propia tarea se viera limitada por la carencia de instrumentos y bibliografía adecuada. Ante este panorama desalentador Rudolf Martin le pedía paciencia y mesura. Lo primordial era poder trabajar en forma directa con el material, la carencia de instrumentos y bibliografía podía ser suplida a partir de la colaboración establecida con otros estudiosos en Europa. Al mismo tiempo Martin le sugería que organizará lo más pronto posible un viaje al Viejo Continente,

\footnotetext{
${ }^{372}$ Lehmann-Nitsche 1898 d, p. 5. Resaltado en el original.

${ }^{373}$ Este será, posteriormente, traducido al alemán y editado en distintas publicaciones de esa lengua Lehmann-Nitsche 1899 b, 1900 e, 1902 d.

374 Rudolf Lenz a Robert Lehmann-Nitsche. Legado Robert Lehmann-Nitsche, 29.08.1898, IAI, Carpeta $\mathrm{N}-0070$ b 420.

${ }^{375}$ Lehmann-Nitsche 1904 a, p. 169.
} 
oportunidad en la cual podía llevar los materiales para ser analizados, al mismo tiempo que podía muñirse con lo último en instrumentos y bibliografía ${ }^{376}$.

\subsection{El viaje de los cráneos a Europa}

El 13 de febrero de 1900 Moreno recibía una carta de Lehmann-Nitsche en la cual le pedía una licencia para realizar un viaje a Europa programado para fines de junio de ese mismo año. El principal argumento utilizado será el beneficio y el reconocimiento que obtendría la sección de antropología a su cargo y por extensión el Museo de la Plata, los cuales se manifestaban por encima de cualquier interés o beneficio personal que Lehmann-Nitsche pudiera obtener. En este sentido le recordaba a Moreno que “ [...] llevaba el honroso cargo de representar al Instituto Geográfico Argentino, además del Museo de la Plata en los siguientes congresos: XII Congrés International d'Anthropologie et d'Archéologie Préhistorique, Congrés International des Sciences Ethnographiques, Congrés International des Americanistes a Paris, LXXII Versammlung Deutscher Naturforscher und Ärzte (reunión de naturalistas y médicos alemanes) en Aachen, y ante el Kongress der Deutsche Gesellschaft für Anthropologie de Halle (congreso de la sociedad antropológica de Halle)",377.

Sin embargo, en los argumentos utilizados para describir y justificar esta altruista misión se dejaban traslucir otras razones. La ausencia de laboratorios especializados, instrumentos precisos, y bibliografía actualizada se revelaban como los verdaderos motivos del viaje. Si bien el contexto del museo platense proveía de importantes objetos materiales para las investigaciones, las herramientas materiales y teóricas que permitían una correcta lectura de la historia inscripta en ellos se encontraban más allá de los bordes del Plata. En este sentido argüía Lehmann-Nitsche que "[...] tendré ocasión de realizar en laboratorios especializados ciertos estudios sobre osteología humana que me son indispensables para terminar el catalogo de mi sección que tengo en preparación; estudios que no me es posible realizar aquí por falta de elementos" ${ }^{378}$. Como podemos ver estos intereses personales se escudaban detrás de los supuestos beneficios que obtendría la institución.

Otro punto importante será la posibilidad; y la necesidad; de establecer lazos de sociabilidad científica como así también fortalecer los pre-existentes. Como recordaba Márquez Miranda "En esta nueva comparecencia en Europa debía de ratificar las viejas amistades y

\footnotetext{
${ }^{376}$ Rudolf Martin a Robert Lehmann-Nitsche. Legado Robert Lehmann-Nitsche, 03.10.1900, IAI, Carpeta N-0070 b 489.

${ }^{377}$ Informe sobre un viaje a Europa efectuado durante el segundo semestre del año 1900, presentado al Señor Director del Museo de La Plata por el Dr. Roberto Lehmann-Nitsche, encargado de la sección antropológica", AHPBA-MOP, Año 1901, Letra "M", N Expediente 49, No Archivo 9755. (De ahora en más citado como Informe, 1900.)

${ }^{378}$ Robert Lehmann-Nitsche a Francisco Moreno. Legado Robert Lehmann-Nitsche, 13.02.1900, IAI, Carpeta N-0070 b 791. El resaltado es de nuestra autoría.
} 


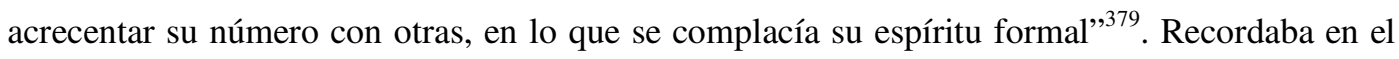
informe presentado las visitas realizadas a: Adolf Bastian, al prehistoriador Albert Franz Ludwig Voß (1837-1906), al médico Karl von den Steinen, Paul Ehrenreich, al lingüista Lucien Adam (1833-1918), Rudolf Virchow, Johannes Ranke, al botánico y lingüista Karl Julius Platzmann (1832-1902), al geógrafo Karl Theodor Sapper (1866-1945) y al geógrafo Friedrich Ratzel (1844-1904)

La visita a distintos museos e institutos científicos permitirán acceder a las importantes colecciones de materiales antropológicos, entre las cuales se encontraban importantes muestras procedentes de Argentina. El estudio sobre estos materiales, su registro escrito y fotográfico, junto con los trabajos desarrollados por los diversos estudiosos que se desempeñaban en estos espacios permitirán concluir y comenzar a desarrollar nuevos trabajos. Muchos de los resultados obtenidos serán resultado del trabajo con los instrumentos adecuados. En este sentido los estudiosos aprovecharán los viajes al extranjero para poder adquirir nuevos instrumentos o bien modificar aquellos pre-existentes para adaptarlos a las condiciones locales en las cuales desempeñaban sus actividades. En este sentido Lehmann-Nitsche daba cuenta de que uno de sus principales objetivos será dedicarse a "[...] la construcción de aparatos antropológicos", ya que en una serie de trabajos antropométricos realizados en la Argentina había notado "[...] la deficiencia de los aparatos empleados.". A fin de poder superar estas limitaciones hará construir un nuevo aparato antropométrico, adquirirá nuevos equipos fotográficos y hará modificar otros. Nuevamente el beneficio colectivo de esta empresa justificaba los gastos acometidos. Una vez vuelto a la Argentina pretendía emplear estos nuevos instrumentos, a la espera de que “...estas nuevas adquisiciones darán los mejores resultados para el conocimiento de nuestras razas

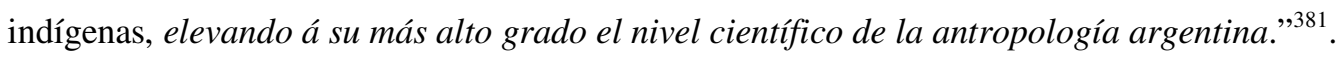

El 25 de junio de 1900 se publicaba en el Registro oficial de la Provincia de Buenos Aires, la decisión del Poder Ejecutivo de la provincia de conceder a Lehmann-Nitsche licencia con goce de sueldo por el tiempo de cuatro meses. En el mismo se declaraba que se había "[...] encontrado conveniente acceder al pedido de licencia que formula dicho empleado [...] por los beneficios que ello puede reportar al Museo de la Provincia [...]"382. Ese mismo día se embarcaba Lehmann-Nitsche a bordo del vapor Aachen, transportando consigo aquellos materiales que le parecían más significativos a fin de poder analizarlos en los espacios

\footnotetext{
${ }^{379}$ Márquez Miranda 1938, p.127. El resaltado es de nuestra autoría.

${ }^{380}$ Informe 1900.

${ }^{381}$ Ibídem. El resaltado es de nuestra autoría.

${ }^{382}$ RO 1900, p. 578. El resaltado es de nuestra autoría.
} 
científicos europeos: cinco cráneos y cuatro mandíbulas inferiores con lesiones artificiales características $^{383}$.

Estos elementos serán exhibidos ante los miembros de la Berliner Gesellschaft für Anthropologie, Ethnologie und Urgeschichte y la Gesellschaft Deutscher Naturforscher und Ärzte (Sociedad de médicos y naturalistas alemanes), siendo las discusiones posteriores sintetizadas en una publicación efectuada en la Versammlung Berliner Gesellschaft für Anthropologie. Ante las explicaciones mágico-religiosas de las lesiones presentes en los cráneos $^{384}$, opondrá y seguirá propuestas como las de Virchow o las del danés Sören Hansen, viendo en la trepanación un "[...] procede rationnel de la chirurgie, en harmonie avec les croyances de se temps" ${ }^{\wedge 85}$. Primeramente sugerirá que se trataba de una trepanación imperfecta practicada en vida, para luego sugerir una operación ejecutada después de la muerte del individuo, aduciendo finalmente que las marcas eran el resultado del proceso de masticación practicado por algún tipo de roedor $^{386}$ (Fig. 22).

Si bien Virchow se veía sorprendido de la calidad de las muestras traídas por LehmannNitsche mostrará cierta reticencia a concluir en forma tan categórica sin haber realizado un mayor número de observaciones sobre otras muestras de esta serie. Lehmann-Nitsche suponía que Virchow veía en él un joven recién graduado y sin experiencia, siendo esto la causa de su desconfianza. La falta de publicaciones que hicieran su nombre conocido en los espacios académicos y eruditos alemanes era una constante preocupación de Lehmann-Nitsche ${ }^{387}$. De esta forma Virchow encomendará al médico alemán Curt Strauch (1868-1931) la comparación de estos ejemplares con los cráneos patagones depositados en la colección de la Berliner Gesellschaft für Anthropologie, Ethnologie und Urgeschichte. Este último sentenciaría que la ablación artificial sugerida por Virchow era la mejor explicación a estas lesiones, agregando que la misma debió ser practicada post-mortem a fin de extraer los ojos y posiblemente el cerebro. Sin embargo, tal como declaraba Strauch, estas conclusiones debían ser consideradas parciales, debido a que solo pudo contar con los cráneos y maxilares " [...] en la breve permanencia de dicho señor (en referencia a Lehmann-Nitsche) entre nosotros (por lo cual) la confrontación no se pudo hacer sino con mucha premura" ${ }^{388}$. Primeramente Strauch descartará la hipótesis de intervención quirúrgica de Moreno y Lehmann-Nitsche. Seguidamente realizará experimentos

\footnotetext{
${ }^{383}$ Dos de estos cráneos habían sido presentados en el congreso científico celebrado en Buenos Aires en 1898.

${ }^{384}$ Referirá especialmente a las propuestas de autores como Broca, el geólogo y prehistoriador francés Gustave Chauvet (1840-1933), Mortillet, el geólogo, antropólogo e inventor estadounidense William John McGee (1853-1912) o las del doctor y antropólogo austriaco Félix Ritter von Luschan (1854-1924).

${ }^{385}$ Lehmann-Nitsche 1902 a, p. 10.

${ }^{386}$ Mientras que von Luschan refutaba esta opinión, Karl von den Steinen no descartaba esta explicación pero llamaba a tener en cuenta la imperfección de los instrumentos utilizados por los indígenas. Lehmann-Nitsche $1900 \mathrm{f}$.

${ }^{387}$ Rudolf Lehmann-Nitsche a Ida Lehmann-Nitsche. Legado Robert Lehmann-Nitsche, 29.01.1901, IAI, Carpeta N-0070 b 1092.

388 Ibídem p. 550.
} 
con roedores vivos, observando que su mordedura dejaba una firma casi semicircular, finiquitando por lo tanto en la inexactitud de la segunda explicación propuesta por LehmannNitsche. Este contestaría estos agravios en 1902, acusando a Strauch de falsear la información y hacer uso de comunicaciones privadas $^{389}$.

Como hemos mencionado anteriormente estos viajes permitirán a los estudiosos ponerse en contacto con viejos y nuevos colegas, acorde a las reglas marcadas por la sociabilidad científica. Aquellos estudiosos residentes en el Nuevo Mundo obtendrán valiosa asistencia y colaboración para finalizar investigaciones inconclusas. Sus contrapartes del Viejo Mundo obtendrán potenciales colaboradores en el "campo", los cuales los proveerán de datos y materiales importantes para los diversos espacios académico-científicos. A partir del contacto establecido con el antropólogo español Gregorio Chil y Naranjo (1831-1901) ${ }^{390}$, LehmannNitsche ampliará sus trabajos en torno a la trepanación craneal y establecerá una serie de paralelos entre las lesiones craneales y los procedimientos quirúrgicos observables en cráneos depositados en colecciones argentinas, españolas y francesas ${ }^{391}$. Profundizando en el establecimiento de analogías planteará la existencia de un proceso operatorio y post-operatorio similar entre las antiguas poblaciones del neolítico europeo y aquellas practicadas por los “pueblos naturales" contemporáneos ${ }^{392}$. De esta forma lesiones, trepanaciones y perforaciones permitirán escrutar en las similitudes de estos y constituir relaciones y paralelismos etnográficos; buscando además inquirir en temas como la tolerancia al dolor y la expresión diferencial de las emociones ${ }^{393}$.

\footnotetext{
${ }^{389}$ Lehmann-Nitsche referirá a la supuesta presentación de los cráneos realizada por Moreno hacia 1880 en el contexto de un congreso antropológico celebrado en París. Por un lado, le recordaba LehmannNitsche a Strauch, que en esa época "[...] ni hubo Congreso antropológico, ni estuve yo entonces en París. Moreno por otro lado, permaneció largo tiempo en Chile para el arreglo de la cuestión de limites [...]". Lehmann-Nitsche 1902 e, p. 2.

${ }^{390}$ Para un análisis del interés de los estudiosos del Museo de La Plata en los cráneos de los grupos guanches ver: Farro 2009, 2011.

391 Resultado de esto serán dos cortos trabajos publicados en Bulletins et Mémoires de la Société d'anthropologie de Paris. En estos establecerá un paralelo entre las lesiones bregmaticas presentes en los cráneos guanches como resultado de procesos trepanatorios terapéuticos y aquella "lesión enigmática" observada por Manouvrier en su cráneo de Menouville. Lehmann-Nitsche 1903 a, 1905 a.

${ }^{392}$ Hacia 1898 señalaba Lehmann-Nitsche que el objetivo de este tipo de estudios era "....] presentar esa rareza de la medicina y de la historia de la cultura [...] pues, tal vez, se encuentran en algún rincón de Sud América tribus indígenas que la ponen (en referencia a las técnicas operatorias) aún en práctica" Lehmann-Nitsche 1898 a, p. 196.

393 Lehmann-Nitsche finalizaba este trabajo aseverando que "II est évident que l'étude directe des matériaux nous reserve encoré bien des surprises. Les peuples primitifs, de méme que les peuples préhistoriques, se caractérisent évidemment par une plus grande résistibilité á rinfection et une sensibilité moins prononcée aux douleurs que les peuples de la civilisation moderne". En un trabajo posterior sobre la artritis deformante observada en los huesos recolectados por el preparador Santiago Pozzi en las exploraciones realizadas en 1893 en el valle del Río Chubut; Lehmann-Nitsche explicaba el origen mecánicos de las lesiones observadas y afirmaba que a partir de estas se podía deducir "[...] una sensibilidad poco desarrollada. Si el indio patagón, enfermo de la arthritis deformans que produce tanto dolor en un europeo, padeciera con la misma intensidad como aquél ¿acaso le sería posible seguir á sus compañeros en las marchas forzadas? [...] Es bien sabido que en las razas primitivas la sensibilidad está
} 
Es preciso señalar que este intercambio de datos y objetos no se limitaba solamente al contexto intercontinental, sino que podremos encontrar una vasta red operando al interior del continente americano. Con respecto a esta es conveniente remarcar que su establecimiento, y la participación en la misma, estará supeditado; en algunos casos; a la nacionalidad de los participantes. De esta forma Hermann von Ihering, escribía a Lehmann-Nitsche para felicitarlo por su serie de trabajos sobre los cráneos patagónicos. En dicha carta indagaba acerca de la cantidad y tipo de cráneos que poseía el Museo de la Plata, adjuntando datos sobre las formas y características craneales de las poblaciones del Brasil. Al mismo tiempo lo consultaba sobre la eventualidad de que el Museo de la Plata tuviera dos o más muestras de cada tipo de cráneo, albergando la posibilidad de que pudiera enviarle aquellos ejemplares que se encontrarán repetidos. Von Ihering deseaba contar con estas muestras a fin de poder comparar el tipo de braquicefalia que estos cráneos presentaban con aquella presente en los grupos Sambaquis y los Tupis, invitando a Lehmann-Nitsche a realizar un trabajo en conjunto ${ }^{394}$.

De esta forma entre São Paulo y La Plata se planteaba la construcción de una cartografía craneológica de los grupos indígenas sudamericanos. El trabajo en conjunto ofrecía ventajas al momento de emprender un proyecto de este tipo. Una de las principales será la ampliación de las redes materiales de aprovisionamiento de datos y objetos. Esto permitirá maximizar y efectivizar el espacio y el tiempo de recolección como así también la cantidad de material obtenido. De esta forma mientras von Ihering podría contar con los valiosos materiales depositados en las colecciones del Museo de la Plata y del Museo Nacional de Buenos Aires, Lehmann-Nitsche se granjeaba importantes contactos en las principales agencias de transporte de Hamburg. Von Ihering le aseguraba que a partir de estas podía contar en forma rápida con los diversos encargos realizados en Europa ${ }^{395}$.

La importancia de estos contactos radicará en particular en los intereses personales de von Ihering para el destino de los estudios craneométricos en Sudamérica. Recordemos que este tendrá a lo largo de la década de 1870 una importante participación en los congresos de la Deutsche Gesellschaft für Anthropologie, Ethnologie und Urgeschichte; siendo sus propuestas el punto de partidas de las principales discusiones destinadas al establecimiento de un sistema craneométrico común para todos los antropólogos alemanes.

Habiendo arribado al Brasil en 1880, sus primeros intereses estarán vinculados a los estudios craneométricos. Una vez designado director del Museu Paulista en 1894 buscará

poco desarrollada: de esto ofrecen una nueva prueba los Patagones” Lehmann-Nitsche 1902 a, p. 29, 1904 g, p. 203.

${ }^{394}$ Hermann von Ihering a Robert Lehmann-Nitsche. Legado Robert Lehmann-Nitsche, 06.09.1903, IAI, Carpeta N-0070 b 345.

${ }^{395}$ Hermann von Ihering a Robert Lehmann-Nitsche. Legado Robert Lehmann-Nitsche, 06.08.1910, IAI, Carpeta N-0070 b 345. 
rápidamente establecer una red de colaboración internacional en base al intercambio de correspondencia y objetos con investigadores en América y Europa. Como correctamente ha señalado Margaret Lopes esto se vinculará al deseo de von Ihering de “[...] construir seu sonho de um Museu Sul-americano, em função de seus próprios trabalhos de dimensões continentais" 396 . Von Ihering pretendía "emancipar" las ciencias geológicas y paleontológicas de la influencia norteamericana, lo cual lo llevará a establecer y fortalecer el trabajo interdisciplinario con estudiosos residentes en Sudamérica ${ }^{397}$.

Como podemos apreciar los contactos con estudiosos residentes en Argentina no se iniciarán con Lehmann-Nitsche. Estos además deben ser entendidos en el deseo de von Ihering por establecer un procedimiento homogéneo en las investigaciones craneológicas sudamericanas. De esta forma confiaba a Lehmann-Nitsche la tarea de revisión de las colecciones de cráneos del Museo de La Plata y el Museo Nacional de Buenos Aires, a fin de que estas se ajustaran a los métodos descriptivos y clasificatorios alemanes, lejos de aquellas posibles interpretaciones hechas bajo la luz de otras convenciones ${ }^{398}$. Como podemos ver la presencia y el papel desempeñado por la ciencia alemana en el desarrollo de los espacios antropológicos argentinos no se circunscribirá al contexto local. Al mismo tiempo el papel de Lehmann-Nitsche en este tipo de colaboraciones, al igual que sucederá con Lenz, se limitará a seguir las instrucciones de otros estudiosos, recopilando y enviando datos e información.

\footnotetext{
${ }^{396}$ Lopes 2003, p.32.

397 El temprano y fluido intercambio epistolar con el zoólogo, geólogo y paleontólogo argentino Florentino Ameghino (1854-1911) ha sido señalado como un punto clave en el desarrollo de las teorías de ambos estudiosos sobre la antigüedad y la disposición geológica de los terrenos de la Patagonia; algo que posteriormente será fundamental en la construcción de la teoría de los puentes continentales de von Ihering. Lopes 1999 a, 2000, 2001, 2003; Podgorny y Lopes 2008.

${ }^{398}$ Hermann von Ihering a Robert Lehmann-Nitsche. Legado Robert Lehmann-Nitsche, 04.11.1911, IAI, Carpeta N-0070 b 345.
} 


\section{La observación sobre individuos vivos: Antropometría y Somatología}

El estudio y el entendimiento del pasado de las poblaciones humanas no se limitarán a las colecciones óseas o a las piezas arqueológicas. Muchas veces este tipo de investigaciones se verán condicionadas a la posibilidad de contar con el material de estudio adecuado. Esto podía resolverse a partir del intercambio de piezas, datos, bibliografía, la visita a diversas instituciones o bien con los viajes de estudio al campo. Sin embargo la ciudad de La Plata; al igual que otras ciudades argentinas de fines del siglo XIX; ofrecerán un espacio alternativo en el cual los estudiosos podían encontrarse con su objeto de estudio al caminar día a día por las pedregosas e inacabadas calles de la joven ciudad. En este sentido los antropólogos realizarán observaciones sobre individuos vivos, en espacios como hospitales psiquiátricos, cárceles, ferias comerciales o simplemente prestando atención al hombre que barría las calles. Estos serán espacios habituales donde los antropólogos realizarán trabajo de campo.

En muchos casos estos estudios no responderán a un plan organizado de investigación, sino que se darán de forma fortuita. Este momento de la práctica antropológica estará configurada y recortada por la necesidad de "poseer" el objeto en sí. La importancia del espacio físico donde la observación era realizada pasará a un segundo plano. Una vez que el antropólogo posaba sus ojos sobre el objeto de estudio este era abstraído de si mismo y de cualquier contexto en el cual se encontrara inserto. La [...] profundización del conocimiento de los indígenas

sudamericanos [...]"399 debía ser realizado, aún en la propia casa del antropólogo.

\subsection{Cárceles, comisarías y los antropólogos como "peritos judiciales"}

El 12 de diciembre de 1897 Lehmann-Nitsche se dirigía a Los Hornos, ciudad aledaña a La Plata, por diligencias privadas. El comisario de la dependencia local le informará sobre el arresto de Amadeo Bezzi, joven que presentaba un raro caso de hendidura media congénita de la parte facial superior. Gracias a las amabilidades del comisario podrá realizar una serie de observaciones preliminares. Luego de esto Bezzi será dejado en libertad, por lo cual LehmannNitsche no podrá continuar con sus investigaciones. Sin embargo en 1899 el joven Bezzi será arrestado nuevamente, acusado de tentativa de violación. Por esto será condenado a 1 año y medio de prisión en la cárcel de La Plata.

El caso de Bezzi no solo será terreno de los estudios antropológicos. Hacia fines del siglo XIX el campo de la criminología se encontraba fuertemente desarrollado en el país. En 1873 se publicaba la Revista Criminal, fundada y dirigida por Pedro Bourel. En la misma se publicaban relatos de "causas célebres" o crónicas criminales contemporáneas, muchas veces

${ }^{399}$ Lehmann-Nitsche 1915 c, p. 385. 
redactados por el propio Bourel. En algunos casos el acento estaba puesto en la descripción del sujeto, en su aspecto y su biografía. En 1887 el escritor costumbrista José Seferino Álvarez (1858-1903) publicaba Galería de ladrones de la Capital. En el mismo se buscaba definir, a partir de la descripción escrita y fotográfica, 200 tipos de criminales con el fin de que pudieran ser fácilmente reconocidos en las calles por los agentes de policía.

En 1898 veía la luz la revista Criminología Moderna, dirigida por el abogado, escritor y anarquista italiano Pietro Gori (1865-1911). En la misma colaborarían prestigiosos intelectuales italianos y argentinos. En sus páginas aparecía una extensa descripción del delito de Bezzi realizada por abogado Ricardo del Campo, por ese entonces vicedirector de la revista, en donde se hará hincapié en la patología del acusado. Las descripciones y conclusiones de Del Campo se basarán exclusivamente en las observaciones de una serie de fotografías de Bezzi, sin realizar jamás un examen del mismo en persona. Esto será un hecho altamente cuestionado por Lehmann-Nitsche, el cual descartaba por completo la importancia de este tipo de enfoques en el estudio de las patologías humanas. Llamativamente en algunos casos, los antropólogos de la época no tendrán un contacto directo con el material, trabajando en base a reproducciones gráficas o información de segunda mano. Ante las diversas dificultades que podían surgir en su transporte a través de las diversas redes materiales, estos objetos serán reducidos a fotografías o simples anotaciones en papel, siendo estas transcripciones el punto de partida para muchos trabajos científicos.

La posibilidad de describir un "raro" caso médico; del cual se registraban pocos en el mundo; llevaba a que Bezzi ocupará las páginas de publicaciones alemanas y argentinas ${ }^{400}$. En este sentido los médicos estadounidenses George Milbre Gould (1848-1922) y Walter Lytle Pyle (1871-1921) publicaban en 1898 Anomalies and Curiosities of Medicine una obra que; como detallaba su amplio subtitulo; pretendía ser "An encyclopedic collection of rare and extraordinary cases, and of the most striking instances of abnormality in all branches of medicine" ${ }^{" 401}$. Ambos galenos aseguraban que a pesar de que la ciencia médica se había vuelta muy estricta con el paso de los años, aquellos casos considerados "curiosos" o "raros" serán destinatarios de amplias crónicas y de un particular interés por parte de diversos estudiosos. Llamaba la atención, según los galenos, que no hubiera publicación médica de la época que no contara entre sus páginas con trabajos dedicados a casos "raros" o "únicos"

La ausencia de una biblioteca médica especializada en el Museo de La Plata, desestimará para Lehmann-Nitsche la posible importancia del caso, al no poder realizar un estudio comparativo de patologías similares. Sin embargo este trabajo permitirá estrechar contactos con otras personas dedicadas a este tipo de estudios. Si esta aislada publicación no

${ }^{400}$ Este será publicado primeramente en Alemania, luego en La Semana Médica y finalmente en la Revista del Museo de La Plata. Lehmann-Nitsche 1901 a.

${ }^{401}$ Gould y Pyle 1898.

${ }^{402}$ Ibídem. 
resultaba significativa para el cuerpo de saberes médicos, si lo era la posibilidad de granjearse importantes vínculos dentro de otros espacios donde cuerpos y datos sobre estos circulaban. Así lo demuestra la ayuda brindada por el criminalista austro-húngaro Iván Vučetić -nacionalizado posteriormente como Juan Vucetich- (1858-1925); jefe de la "Sección Antropométrica" de la Policía de la Provincia de Buenos Aires; gracias al cual Lehmann-Nitsche podrá visitar a Bezzi en la cárcel, complementando y ampliando sus primeras observaciones. Los primeros contactos entre Vucetich y Lehmann-Nitsche datan de diciembre de 1899, oportunidad en la cual el primero enviaba al segundo una obra del criminalista y antropólogo francés Alphonse Bertillon (1853-1914), al mismo tiempo que agradecía el préstamo de un libro del psicólogo y fisiólogo alemán William Lewis Stern (1871-1938) ${ }^{403}$.

El préstamo de bibliografía, el análisis de datos o la posibilidad de contar con instrumentos especializados se contarán entre los beneficios brindados por estas relaciones profesionales, las cuales auxiliaban considerablemente la posibilidad de concluir las investigaciones. De esta forma un caso de braquifalangia observado hacia 1902 en una india Ona residente en la Misión Salesiana de Río Grande en Tierra del Fuego ${ }^{404}$, podía ser resuelto gracias a la consulta de casos similares en la Biblioteca del Circulo Médico Argentino, repositorio bibliográfico que se hacía accesible gracias a la carta de recomendación del médico alemán Otto Wernicke $(1868-1942)^{405}$, y que suplía la carencia de instrumentos adecuados y necesarios para obtener resultados seguros.

Un interesante caso de la conjunción de diversas disciplinas en las prácticas antropológicas de fines del siglo XIX se dará en el caso de Juan B. Passo. El mismo había sido acusado de homicidio. El Juez de Sentencia nombrará perito de parte al médico Samuel de Madrid, al cual se le asignaba la tarea de realizar un informe pericial sobre el estado psíquico y somático del procesado judicial. Para esta tarea De Madrid contará con la asistencia de Lehmann-Nitsche en la parte antropológica y del médico Nicolás Repetto (1871-1965) en el estudio clínico ${ }^{406}$. Llamativamente el abogado defensor de Passo será Pietro Gori, cuyos lineamientos en torno al estudio de la patología humana distaba bastante; como hemos podido ver en el mencionado caso de Bezzi; de aquellos planteados por el antropólogo alemán.

Lejos de ser un estudio con valores netamente científicos, este trabajo contará con una considerable remuneración económica. Sin embargo el accionar de los antropólogos de la época como peritos judiciales no será reconocido por el Estado, por lo cual estos no podían percibir

${ }^{403}$ Juan Vucetich a Robert Lehmann-Nitsche. Legado Robert Lehmann-Nitsche, 22.12.1899, IAI, Carpeta $\mathrm{N}-0070$ b 711.

${ }^{404}$ Lehmann-Nitsche 1903 c, 1904 h, 1904 i.

405 Otto Wernicke a a Robert Lehmann-Nitsche. Legado Robert Lehmann-Nitsche, 09.04.1906, IAI, Carpeta N-0070 b 743.

${ }^{406}$ Lehmann-Nitsche 1900 a; Samuel de Madrid a Lehmann-Nitsche. Legado Robert Lehmann-Nitsche, 15.09.1899, IAI, Carpeta N-0070 b 482. 
dinero al momento de prestar su ayuda en este tipo de casos. De Madrid figurará oficialmente como perito de parte, presentando un valor de 5.000 pesos moneda nacional por sus honorarios. En reconocimiento a la ayuda prestada, Madrid le prometía a Lehmann-Nitsche una remuneración de 2.500 pesos moneda nacional. Sin embargo esto dependía de la regulación que el Estado Provincial realizará sobre sus honorarios y principalmente el momento en que decidieran hacerlo efectivo ${ }^{407}$. Si los antropólogos obtenían un ingreso monetario considerable; que muchas veces superaba holgadamente la remuneración económica que obtenían por unos cuantos meses de investigación y enseñanza; su actuación aportaba a los casos judiciales una opinión calificada y un testimonio basado en la objetividad de los métodos científicos. En este sentido años más tarde el jurista y filósofo Rodolfo Rivarola (1857-1942); futuro presidente de la Universidad Nacional de La Plata; sugería a Lehmann-Nitsche que escribiera al jurista Ernesto Quesada (1858-1934) el cual se encontraba trabajando como fiscal en un juicio. Rivarola; al tanto de la participación de Lehmann-Nitsche en el caso de Juan B. Passo; creía importante que este pusiera a disposición de Quesada el "material de estudio" conseguido en esta experiencia previa, ya que Quesada "querrá estudiar a fondo y muy seriamente la cuestión, aún en el aspecto científico" ${ }^{\text {"408. }}$.

Allí donde "[...] el fraude, la labor de aves negras, etc. dan que hacer a los tribunales [...] ${ }^{, 409}$ la antropología podía aportar sus valiosas técnicas de observación e interpretación de las características anatómicas de los individuos vivos y muertos. La inclusión de estos datos de "valor práctico" 410 sustentaba la base científica de una naciente antropología judicial, interviniendo en casos judiciales, evaluando el estado psíquico y físico de los acusados o bien evaluando casos de filiación natural e hijos "artificiales"411.

El perfeccionamiento de las técnicas de observación, estudio e interpretación de las variedades morfológicas y psicológicas que la Antropología había tenido a lo largo de su historia ofrecerán pruebas calificadas, objetivas y científicas que sustentará los alegatos presentados por el esquema médico-penal y la compleja maquinaria de disciplinas y regulaciones del Buenos Aires finisecular. Esto será posible gracias a una serie de reformas del sistema judicial, a fines del siglo XIX y principios del siglo XX, que organizarán una especie de "poder médico judicial", introduciendo la obligatoriedad de que todo individuo que hace frente a un proceso judicial haya sido analizado por peritos psiquiátricos ${ }^{412}$. Tal como señala Michel Foucault “[...] en el punto, más brevemente, en que se encuentran el tribunal y el sabio, donde se cruzan la institución judicial y el saber médico o científico en general, en ese punto se

${ }^{407}$ Samuel de Madrid a Lehmann-Nitsche. Legado Robert Lehmann-Nitsche, 21.02.1900, IAI, Carpeta N0070 b 482.

${ }^{408}$ Rodolfo Rivarola a Lehmann-Nitsche, 21.01.1918, IAI, Carpeta N-0070 b 570.

${ }^{409}$ Lehmann-Nitsche 1917 e, p.6. Resaltado en el original.

${ }^{410}$ Lehmann-Nitsche 1917 e, p.19.

${ }^{411}$ Lehmann-Nitsche 1900 a, 1904 j, 1904 k, 1904 n, 1904 p, 1905 e, 1917 e, 1919 f.

${ }^{412}$ Foucault 2001. 
formulan enunciados que tienen el status de discursos verdaderos, que poseen efectos judiciales considerables [...]"413, los cuales transforman a los sujetos en individuos "anormales", transformándolos de acusados a condenados. En esta construcción jurídica participarán estudiosos que en muchos casos correlacionaran características físicas particulares de los individuos con determinados comportamientos. Tal como señalaban Gould y Pyle al momento de justificar la publicación de su enciclopedia de curiosidades y anormalidades en medicina "[...] much of the importance of medical jurisprudence lies in a thorough comprehension of the anomalous and rare cases in Medicine. Expert medical testimony has its chief value in showing the possibilities of the occurrence of alleged extreme cases, and extraordinary deviations from the natural. Every expert witness should be able to maintain his argument by a full citation of parallels to any remarkable theory or hypothesis advanced by his clients; and it is only by an exhaustive knowledge of extremes and anomalies that an authority on medical jurisprudence can hope to substantiate his testimony beyond question" ${ }^{, 14}$. Una vez que los sujetos eran condenados y confinados en las cárceles los estudiosos con interés por el estudio de los cuerpos obtendrán un importante espacio donde poder realizar sus observaciones.

\subsection{Ferias y asilos}

Una de las primeras investigaciones realizadas por Lehmann-Nitsche tendrá lugar en $L a$ Exposición Nacional de la Industria de Buenos Aires celebrada en 1898 y que contará con la presencia de dos familias "fueguinas", tal cual se leía en los principales diarios de la época. Las dos familias arribaban a Buenos Aires el 3 de noviembre de 1898, junto con el Teniente Coronel Pedro Godoy (1893-1899) y el comisario de la gobernación Atanasio Navarro ${ }^{415}$. A su llegada serán alojadas provisionalmente en los fondos del teatro de verano mientras se disponían las instalaciones donde se alojarían hasta su regreso. Este teatro se encontraba en los jardines del Pabellón Argentino y era el único de los teatros que se encontraba al aire libre ${ }^{416}$. Finalmente las familias serán expuestas a lo largo de un mes en la Sección Femenina de la exposición, siendo posible observarlos en su vida "cotidiana"417 (Fig.23).

Lehmann-Nitsche no dilapidará la oportunidad de realizar observaciones y estudios sobre uno de los pueblos "naturales" que los estudiosos europeos consideraban, junto a grupos como los Andaman o los Botocudos, como un relicto evolutivo de la humanidad ${ }^{418}$. Los

\footnotetext{
413 Ibídem p. 24-25.

${ }^{414}$ Gould y Pyle 1898 , p. 3.

${ }^{415}$ Las mismas estaban compuestas por dos parejas de individuos jóvenes, teniendo los varones 18 y 22 años y las mujeres 20 y 16. En cuanto a los niños se calculaba que tendrían 8 años uno y 6 meses el otro. ${ }^{416}$ La Prensa 16.10.1898.

${ }^{417}$ Presidida por Teodelina María Florencia Josefa del Carmen Lezica Alvear (1876-1967); la sección femenina se emplazaba en la parte superior del Pabellón Argentino. En la misma se exhibían "objetos de verdadera curiosidad y labores, hechas por damas o señoras de nuestra sociedad." Ibídem p. 5.

${ }^{418}$ Lehmann-Nitsche 1916 g, 1927 g.
} 
instrumentos y métodos utilizados en este estudio no diferirán de aquellos utilizados en sus disertaciones doctorales. Para la determinación de los valores cromáticos de piel, cabello y ojos hará uso de las tablas cromáticas de Broca y del naturalista suizo Paul Benedict Sarasin (18561929). Al momento de realizar las mediciones antropométricas seguirá las indicaciones de Paul Topinard. Tomando en consideración las indicaciones de Martin y Ranke procederá al estudio de las manos y los pies, a fin de poder obtener un cuadro completo sobre la locomoción. Para esto se valdrá del podógrafo de Hans Virchow, gracias al cual obtendrá una idea de la forma general de la mano y del pie para posteriormente estudiar los detalles ${ }^{419}$ (Fig. 24). Complementará el estudio de las falanges de ambas extremidades siguiendo el método propuesto por el alemán Ferdinand Birkner (1868-1944) a fin de poder establecer comparaciones directas con otras mediciones ${ }^{420}$. Este le recomendaría bibliografía que consideraba básica al momento de trabajar con la medición de cuerpos y restos óseos, sugiriéndole la lectura de los trabajos "Untersuchungen an Skeletten" y "Messungen und Beobachtungen an Lebenden" ${ }^{421}$. Para las fotografías se valdrá de las recomendaciones de A. de Mortillet y del fotógrafo Edouard Fourdrignier (1842-1907) ${ }^{422}$; teniendo en cuenta el "método" utilizado por Gustav Fritsch, al momento de ordenar y distribuir las mismas para su publicación $^{423}$.

Un año después de este trabajo otro hecho casual permitirá a Lehmann-Nitsche realizar una serie de estudios antropométricos y fotográficos sobre un grupo de indígenas takshik del grupo Guaicurú. Este grupo conformado por 23 individuos de distinto sexo y edades arribaba a Buenos Aires el 1 de septiembre de 1899 a bordo del vapor "Centauro", luego de una extensa travesía jurídico-legal. El grupo en cuestión había sido "contratado" por el actor y empresario teatral-circense argentino José Podestá (1858-1937) a fin de realizar una gira europea del Martín Fierro y presentarlos en la Exposición Universal de París de $1900^{424}$ (Fig. 25).

La "contratación” del grupo como así también las peripecias del traslado despertará un extenso debate en la prensa escrita. Los principales puntos de discusión serán: la "nacionalidad"

419 El método consistía en cubrir de tinta la superficie de una placa de zinc pulida sobre la cual el individuo coloca su pie de manera perpendicular, levantando el otro pie. Luego colocaba la planta del pie ennegrecida sobre una hoja de papel blanco. Lehmann-Nitsche 1904 o.

${ }^{420}$ En este se medían la longitud externa e interna del tercio basal de las falanges. Lehmann-Nitsche 1904 a.

${ }^{421}$ Ferdinand Birkner a Robert Lehmann-Nitsche. Legado Robert Lehmann-Nitsche, 27.09.1897, IAI, Carpeta N-0070 b 80.

422 El "método de la Escuela de Paris" correspondía a los resultados de los estudios hechos por una comisión encabezada por G. de Mortillet, Léonce Manouvrier y Fourdrignier. Estos recomendaban la fotografía de los indígenas desnudos, de cuerpo entero, perfil y con una relación de 1:12.5. De esta forma se conformaba un verdadero "atlas antropológico" con información científicamente substancial y factible de comparar. Lehmann-Nitsche 1904 o; Podgorny et. al. 2011.

${ }^{423}$ Este consistía sencillamente en disponer una serie de fotografías sobre una cartulina de forma tal que mediante un golpe de vista, pudiera capturarse la esencia común de los retratos y se visualizara el tipo característico del grupo fotografiado. Martínez 2011.

${ }^{424} \mathrm{La}$ propuesta fue una idea esgrimida entre el empresario teatral español Francisco Pastor junto con Eduardo Iribarne. Ballestero, inédito. 
del grupo, la imagen internacional que deseaba proyectar la argentina en la exposición mundial y, principalmente, las denuncias en cuanto al negocio económico vinculado a la "contratación" compulsiva de indígenas para su exhibición en Paris ${ }^{425}$. Esto llevará a la intervención del por entonces Ministro de Justicia Osvaldo Magnasco (1864-1920), el cual ordenará el alojamiento del grupo indígena en el asilo del "Buen Pastor". Enterado de esto, Lehmann-Nitsche se trasladará rápidamente a Buenos Aires a fin de poder realizar sobre el grupo indígena los mismos estudios efectuados un año antes con los onas.

La reticencia del grupo a la hora de verse sometidos a los estudios antropométricos y fotográficos llevará a que Lehmann-Nitsche catalogue su trabajo como "insuficiente en pruebas materiales". Sin embargo justificará su publicación por el hecho de no privar a los centros europeos de contar con datos "[...] sur une tribu des plus intéressantes, même inconnue, de l'intérieur de l'Amérique du Sud" ${ }^{\text {426. }}$. De esta forma la publicación de estos resultados no estaba pensada para contribuir al contexto científico local, sino la posible repercusión de estos trabajos entre los estudiosos europeos.

El estudio efectuado por Lehmann-Nitsche incluirá la descripción antropométrica y somatológica del grupo, el registro del color de la piel, ojos, cabellos y finalmente la reproducción de los tatuajes corporales, haciendo hincapié en aquellos realizados en el rostro. Parte de este interés radicará en complementar aquellos estudios etnográficos iniciados en la década de 1880 entre los grupos indígenas de las zonas oriental y central del Brasil por parte de Karl von den Steinen y principalmente Paul Ehrenreich. Recordemos que este último realizará una exhaustiva investigación somatológica, entre 1887 y 1889, sobre los grupos ipurinas, los yamamadis, y los paumaris ${ }^{427}$. Su principal objetivo no será la redacción de una monografía aislada, sino la elaboración del primero de una serie de trabajos que permitan construir un mapa etnográfico de Sudamérica ${ }^{428}$. Su mirada sobre las poblaciones indígenas americanas tal vez sirva para sintetizar la mirada de los estudiosos europeos, para los cuales parte de la variedad de estadios de evolución cultural observada en las distintas poblaciones indígenas podía vincularse con la pluralidad de contextos ecológicos que caracterizaban América del Sur ${ }^{429}$.

\footnotetext{
${ }^{425}$ En el diario La Prensa se podía leer la llegada de un amplio número de personas "[...] que traen el encargo de procurar familias indígenas de varias tribus, para llevarlas a la próxima exposición de París, y exhibirlas como espectáculo. Se considera seguro que no conseguirán efectuar ese negocio, pues el defensor de menores, bajo cuya tutela están los indígenas, no lo consentirá”. La Prensa, 19.08.1899, p. 5.

${ }^{426}$ Lehmann-Nitsche 1904 o, p. 4.

427 Según Ehrenreich las medidas tomadas sobre 184 individuos, de entre cerca de 17 tribus, despertarán el interés de los científicos europeos. Esto lo complementará con la recolección de cráneos y esqueletos con el propósito de ampliar los conocimientos que se poseían en Europa sobre las relaciones corporales de los indígenas sudamericanos, conocimientos que según el propio estudioso alemán eran escasos. Ehrenreich 1897 a, 1897 c.

${ }^{428}$ Ibídem.

${ }^{429}$ Ibídem.
} 
Finalmente los takshik regresarían al Chaco. Sin embargo gracias a Lehmann-Nitsche el viaje a Paris se concretaría. Las primeras conclusiones del trabajo del antropólogo alemán serían presentadas el 18 de septiembre de 1900 en el XII Congreso Internacional de Americanistas realizado en Paris ${ }^{430}$. Tal como le sugerirían los antropólogos alemanes Jakob Hermann Friedrich Kohlbrugge (1865-1941) $)^{431}$ y especialmente Theodor Koch-Grünberg (1872-1924) ${ }^{432}$, lo ideal sería continuar y ampliar las investigaciones sobre los indígenas del Chaco, pero no en las condiciones en las que realizó su estudio, sino en el mismo Chaco. Según Kohlbrugge y Koch-Grünberg esto significaría un importante avance en el conocimiento de los indígenas de las regiones centrales de América del Sur ${ }^{433}$. Esto lo llevará al estudio de otros grupos aledaños a la zona del Chaco, dando lugar a una serie de trabajos sobre el grupo Guayaki del Paraguay ${ }^{434}$.

\subsection{Instituciones mentales}

Hacia finales del siglo XIX una reseña de los estudios realizados sobre grupos guayakis del Paraguay, afirmaba que el interés en esta "[...] poorly known primitive tribe" ${ }^{435}$ se debía esencialmente a su condición de "[...] living members of the Stone Age [...]"436. La idea del destino de inminente extinción de estos grupos será uno de los principales incentivos para el estudio de los mismos, sacando provecho de cualquier oportunidad que se presentara. Hacia 1899 el francés Charles de La Hitte (1856-1927) afirmaba que "Los Guayaki pertenecen a la misma formación que el Glyptodon, el Mylodón y la Macrauchenia, que fueron contemporáneos al hombre cuaternario. Sus huesos se pueden encontrar en el suelo pampeano, y ahora el abismo entre los guayaquis y el hombre moderno es tan profundo que no puede ser llenado: como un grupo separado dentro de la familia humana su desaparición es fatal" ${ }^{\text {"437 }}$. Similares afirmaciones planteaba en 1895 al momento de publicar en las páginas del diario La Nación un artículo en el cual describía su viaje de ocho meses realizado el año anterior en las selvas orientales de Paraguay ${ }^{438}$. Aquellos hombres que habían caminado juntos a los grandes mamíferos del cuaternario debían ser observados, descriptos y clasificados en forma inminente, ya que, tarde o temprano, seguirían el destino de estos animales.

\footnotetext{
${ }^{430}$ Esto tendría lugar en la sesión acaecida en el Collège de France. Lehmann-Nitsche 1904 o.

431 Jakob Hermann Friedrich Kohlbrugge a Robert Lehmann-Nitsche. Legado Robert Lehmann-Nitsche, 04.01 y 24.02.1905, IAI, Carpeta N-0070 b 373.

432 Theodor Koch-Grünberg a Robert Lehmann-Nitsche. Legado Robert Lehmann-Nitsche, 18.11.1905, IAI, Carpeta N-0070 b 370.

${ }^{433}$ Lehmann-Nitsche 1904 o.

${ }^{434}$ Lehmann-Nitsche 1899 c, 1899 d, 1908 b.

${ }^{435}$ GJ 1899, p. 567.

${ }^{436}$ Ibídem p. 568.

${ }^{437}$ De la Hitte 1899, p. 17.

${ }^{438}$ Martinez 2011.
} 
Las publicaciones de De La Hitte; y posteriormente las que este realizara junto a Ten Kate como resultado del viaje de estudios al Paraguay; tendrán repercusión entre los estudiosos europeos, contribuyendo al interés de estos por los grupos sudamericanos. Hacia febrero de 1895 De La Hitte publicaba un extenso artículo en el diario La Nación donde narraba las circunstancias de su encuentro con un indígena guayakí. La misma ofrecía datos acerca de la naturaleza y cultura de este pueblo poco conocido para los estudiosos de las "razas americanas" y adjuntaba una serie de fotografías ${ }^{439}$. Estos elementos llamarán la atención de los estudiosos en el Viejo Mundo ${ }^{440}$. Contando con el auspicio del Museo de La Plata, Ten Kate y De La Hitte realizarán una estadía de estudio en el Paraguay entre diciembre de 1896 y enero de 1897. Las comunicaciones previas realizadas por Ten Kate y el informe final de dicha investigación incrementarán el interés científico europeo en los guayaquis ${ }^{441}$, algo que llevaba a De La Hitte a afirmar que dicho trabajo era "[...] más conocido en el otro lado del océano que aquí (en referencia a la Argentina) ${ }^{\natural 42}$. Esto nos permite sumar un elemento más al momento de comprender por que los estudiosos residentes en la Argentina priorizaban publicar sus trabajos en medios extranjeros.

Esta última afirmación puede constatarse en la carta que el médico y botánico suizo Emil Hassler (1864-1937) le enviará a Lehmann-Nitsche al momento de enterarse del interés de este último por realizar un estudio sobre los guayakis. Los principales aportes de Hassler se circunscribirán al plano lingüístico, datos obtenidos por este en una serie de expediciones al interior del Paraguay. Al mismo tiempo le deseaba suerte y paciencia al momento de estudiar estos grupos a partir de los lineamientos planteados por la antropología alemana, al tanto de que los estudios craneológicos llevados adelante por ten Kate habían sido hechos siguiendo las convenciones craneométricas establecidas por Broca ${ }^{443}$.

Lehmann-Nitsche reconocía la dificultad al momento de establecer comparaciones en los resultados obtenidos. Esta tarea no será sencilla. Existirán profundas diferencias e incompatibilidades al momento de comparar el índice cefálico o las medidas obtenidas a partir del posicionamiento del cráneo en el plano horizontal según el método planteado por Broca por un lado y aquellas logradas a partir de las recomendaciones de la "Frankfurter Verständigung"

\footnotetext{
${ }^{439}$ La Nación 12.02 y 13.02 de 1895.

${ }^{440}$ En este sentido Karl von den Steinen reseñara este trabajo en el volumen 67 de la revista Globus. Como señalara Lehmann-Nitsche " [...] la publication de M. de La Hitte perd de son mérite; les notices de la presse du Paraguay, dont je veux parler. ne reposent que sur des observations directes de peu d importance et bien que le journal qui les a publiées paraisse en langue allemande, il ne sort pas des limites du continent.”. Lehmann-Nitsche 1899 c, p. 403; Von den Steinen 1895.

${ }^{441}$ Una de las principales referencias a este trabajo será la realizada por Eherenreich en la revista Globus. Ehrenreich 1898.

${ }^{442}$ La Hitte 1899 p. 18.

${ }^{443}$ Emil Hassler a Robert Lehmann-Nitsche. Legado Robert Lehmann-Nitsche, 28.01.1899, IAI, Carpeta N-0070 b 306.
} 
por el otro. La solución parcial a dicho problema será incorporar a los resultados obtenidos por el método francés la altura del rostro y el índice cefálico según el método alemán.

De esta forma se pretendía introducir cierta rigurosidad y complementariedad a los estudios craneométricos, algo que, según los estudiosos alemanes, era casi improbable de conseguir con los métodos de la escuela de Broca ${ }^{444}$. Esto será remarcado y sostenido por varios estudiosos en comunicaciones privadas mantenidas con Lehmann-Nitsche ${ }^{445}$. Entre estos el pintor, fotógrafo y etnólogo italiano Guido Boggiani (1861-1902) señalaba la utilidad de este trabajo en las futuras investigaciones que pretendía realizar sobre de "[...] los territorios habitados por una tribu invisible ${ }^{, 446}$.

El correlato y la complementariedad entre aquellas descripciones y caracterizaciones numéricas realizadas en papel con aquellas efectuadas y materializadas a través de la fotografía, era señalado hacia 1898 por el botánico Rudolf Endlich (?-1915). Luego de un viaje de dos años, entre 1896-1898, a Brasil y Paraguay, decidía hacer un alto en el Museo de la Plata antes de regresar a Alemania. Endlich compartía con Lehmann-Nitsche una serie de observaciones y fotografías realizadas sobre los guayaquis. Las mismas habían tenido lugar en las cercanías de una granja situada entre los distritos de Carayaó y Unión. Un conflicto entre miembros de la granja y los indios guayaquis daba como resultado un infante de 8 años muerto, del cual Endlich adquiriría el cráneo y los restos óseos para ser enviados, junto con otros objetos etnológicos, al Museum für Völkerkunde de Leipzig ${ }^{447}$. El otro infante, una niña de entre cuatro y cinco años, será trasladado a la ciudad de San Bernardino y bautizado con el nombre de "Miguela"448. Nuevamente la red de estudiosos alemanes residentes o de paso por el país se revelaba como una de los recursos más importantes a la hora de estas empresas científicas. No es casual que en la ciudad de San Bernardino estuviera radicado desde 1898 el mencionado Emil Hassler, el cual prometía a Lehmann-Nitsche mantenerlo informado periódicamente sobre todo lo vinculado a "Miguela"449.

Como le recordará Theodor Koch-Grünberg, había que sacar el mayor provecho de poder contar con todo ese valioso material, y más que nada la valiosa red de colaboración entre estudiosos alemanes. Abogar para un mejor funcionamiento y la ampliación de la misma al interior de Sudamérica no solo resultaría beneficiosa para aquellos estudiosos que residían al

\footnotetext{
${ }^{444}$ Lehmann-Nitsche 1899 c.

445 Entre estos podemos mencionar a Karl Brunner; Theodor Koch-Grünberg y Rudolf Schuller (18731923).

446 Guido Boggiani a Robert Lehmann-Nitsche. Legado Robert Lehmnann-Nitsche, IAI, 01.05.1899, Carpeta N-0070 b 1089. Resaltado en el original.

447 Rudolf Endlich a Robert Lehmann-Nitsche. Legado Robert Lehmnann-Nitsche, IAI, 01.11.1898, Carpeta N-0070 b 189.

448 Rudolf Endlich a Robert Lehmann-Nitsche. Legado Robert Lehmann-Nitsche, IAI, 17.01, 06.06 y 14.09 de 1899, Carpeta N-0070 b 189.

${ }^{449}$ Emil Hassler a Robert Lehmann-Nitsche. Legado Robert Lehmann-Nitsche, 28.01.1899, IAI, Carpeta N-0070 b 306.
} 
oeste del Océano Atlántico. La misma se planteaba como una obligación implícita para con aquellos estudiosos residentes en Europa con interés en las investigaciones en Sudamérica, los cuales no siempre podrán realizar viajes de estudio hacia estos parajes. De esta forma el trabajo colectivo garantizaba en cierto modo la consecución de buenos trabajos científicos sobre los grupos indígenas sudamericanos, los cuales, en cierta forma, suplían la necesidad de emprender largos y costosos excursiones al campo ${ }^{450}$.

La rareza de estos casos muchas veces estibaba en la dificultad de poder conseguir fotografías, huesos o muestras de tejido blando. Hacia 1908 se publicaban los resultados del relevamiento antropométrico y fotográfico de una india guayaqui. Estos datos estaban destinados a engrosar el acervo de información que se tenía sobre los caracteres físicos de los indígenas sudamericanos y conformar la "[...] materia prima para futuros estudios comparativos [...]" esperando que estos constituyeran "[...] un ladrillo para una futura obra que, en un porvenir aun lejano, reasuma, nuestros conocimientos sobre las tribus indígenas de la América del Sur." ${ }^{451}$.

Las fotografías y las mediciones realizadas por Lehmann-Nitsche tendrán lugar en la colonia psiquiátrica de Melchor Romero, dirigida por el médico, psiquiatra y filósofo Alejandro Korn (1860-1936), hijo de alemanes y con estrechos vínculos al interior de la colonia de inmigrantes alemanes de la localidad bonaerense de San Vicente ${ }^{452}$. A la mencionada colonia psiquiátrica había sido trasladada la india, bautizada con el nombre de "Damiana", luego de haber desempeñado tareas domésticas en la casa de la familia Korn ${ }^{453}$. El acopio de fotos realizado por Lehmann-Nitsche, al igual que en los trabajos desarrollados anteriormente, se vinculan con el deseo de conformar una colección de fotografías de los grupos indígenas del país, entendidas como un complemento de las observaciones realizadas sobre los individuos vivos. A los dos meses que Lehmann-Nitsche realizará este estudio la niña fallece.

El cráneo junto con el cerebro será remitido a Hans Virchow, el cual presentaría los resultados de su trabajo ante la Berliner Gesellschaft für Anthropologie, Ethnologie und Urgeschichte. Buscando determinar las características raciales de los huesos y las

${ }^{450}$ Theodor Koch-Grünberg a Robert Lehmann-Nitsche. Legado Robert Lehmann-Nitsche, 27.09.1899, IAI, Carpeta N-0070 b 370.

${ }^{451}$ Lehmann-Nitsche, 1908 b, p. 93-98.

${ }^{452}$ Hijo de Carl Adolf Korn (1820/22-1905) un oficial del ejército prusiano que habiendo nacido en Breslau, deberá migrar a Suiza debido a su rechazo a las políticas de Otto von Bismarck (1815-1898) y a su negación a participar en la represión de una huelga de trabajadores textiles en Silesia durante las revoluciones sociales de 1848. En Suiza ejercerá diversas profesiones y se matriculará para estudiar medicina en la Universität Zürich. Luego de 5 semestres abandonará sus estudios y emigrará primeramente a Montevideo y finalmente en 1858 a la ciudad argentina de San Vicente. En esta contraerá matrimonio con la suizo-alemana María Verena Meyer, a la cual había conocido en su tiempo de estudiante de medicina. Tanto Alejando como sus siete hermanos crecerán y serán educados en un contexto dominado plenamente por la presencia de alemanes que habían arribado a San Vicente a partir de 1848.

${ }^{453}$ De la Hitte y ten Kate 1897; Lehmann-Nitsche 1908 b. 
particularidades del cerebro y otros tejidos blandos, subrayaba la importancia de contar con el cráneo y el cerebro de un representante de esta "[...] extraña tribu, cuyos miembros, a pesar de que no se encuentran muy apartados de la vida de los asentamientos, e incluso las ciudades de los blancos, viven en la selva virgen, tímidamente y escondidos, desapareciendo ante cualquier intento de acercamiento, teniendo aun hoy una cultura de la edad de piedra" ${ }^{\text {"45 }}$. En el caso de "Damiana" su especificidad estaba dada por un comportamiento anormal, producto de la libertad y la "espontaneidad instintiva" con la cual se entregaba a satisfacer sus deseos sexuales ${ }^{455}$.

Las ferias de exhibición, asilos de inmigrantes o instituciones psiquiátricas serán aceptados por los antropólogos que se encontraban desarrollando sus trabajos en la Argentina de fines del siglo XIX y principios de siglo XX como lugares legítimos donde realizar sus observaciones. Al mismo tiempo estos espacios resolverán el problema del viaje y de la observación de estos pueblos lejanos en tiempo y espacio. De esta forma Lehmann-Nitsche sabrá hacer uso de estos lugares a fin de poder recolectar datos que pudieran ser de interés para los estudiosos europeos. La posibilidad de un futuro promisorio en Alemania era lo que lo motivaba a hacer frente a las dificultades al momento de realizar estos trabajos, tales como la ausencia de medios técnicos y bibliografía que le permitieran realizar las observaciones del mismo modo que se realizaban en Europa o la falta de interés de las autoridades del museo platense por suplir la carencia de los mismos ${ }^{456}$.

Rudolf Martin, tal vez importunado por las constantes quejas de Lehmann-Nitsche, le recomendaba que no perdiera el tiempo lamentándose por la falta de recursos o los condicionamientos institucionales. Si bien esto podía condicionar los datos obtenidos, era necesario compilar la mayor cantidad posible ya que los grupos indígenas sudamericanos se encontraban en proceso de desaparición. Lehmann-Nitsche debía aprovechar al máximo la posibilidad de poder acceder a los mismos y observarlos, ya que si un viaje al interior de la Argentina para observarlos en el terreno era costoso, más lo era tener que viajar desde Europa para hacerlo, por lo cual encomendaba enfáticamente a Lehmann-Nitsche el envío de datos y fotografías que serian de utilidad para los trabajos realizados en Europa. Si desconfiaba de los resultados obtenidos debía enviar muestras materiales; como huesos o tejido blando; para que fueran analizadas en Europa. La demanda de estos elementos colocaba a los estudiosos en una competencia que tornaba muy difícil el acceso a los mismos. Al momento de dar cuenta de la compra de huacos peruanos en el mercado negro por parte de agentes del Musem für

\footnotetext{
${ }^{454}$ En el original: “[...] merkwürdigen Stamm, dessen Angehörige, obwohl sie nicht weit entfernt von den Ansiedlungen, ja sogar Städten von Weissen im Urwalde leben, doch ein so scheues und verstecktes Dasein führen, dass sie bei jedem Versuche einer Annäherung verschwinden, und welche noch heute eine Steinzeitkultur besitzen". Virchow, H. 1908, p. 117.

${ }^{455}$ Lehmann-Nitsche 1908 b, p.92.

${ }^{456}$ Robert Lehmann-Nitsche a Ida Lehmann-Nitsche. Legado Robert Lehmann-Nitsche, IAI, 22.10.1902, Carpeta N-0070 b 1295.
} 
Völkerkunde de Leipzig, recordaba Albert Ashmead "The Leipzig authorities in collecting specimens even killed a Guayaquis Indian in South America to obtain his skull!’457. En consecuencia Rudolf Martin le aclaraba a Lehmann-Nitsche que el envío de materiales no solo serviría para la obtención de datos seguros para sus trabajos sino que, aseguraba, sería muy valorado por los estudiosos europeos, quienes seguramente los tendrían en cuenta al momento de poder consignar algún futuro puesto de trabajo ${ }^{458}$.

457 Ashmead 1903, p. 383.

458 Rudolf Martin a Robert Lehmann-Nitsche. Legado Robert Lehmann-Nitsche, IAI, 03.10.1900, 18.11.1907, Carpeta N-0070 b 489. 


\section{El estudio de las tradiciones populares}

En 1812 el filologísta alemán Jacob Ludwig Carl Grimm (1785-1863) y su hermano el autor Wilhelm Carl (1786-1859) publicaban Cuentos de la infancia y del hogar, un compendio de 86 cuentos de hadas alemanes ${ }^{459}$. Esta publicación será considerada por muchos autores como uno de las primeras aproximaciones científicas al estudio de la literatura "popular" ${ }^{\text {"460 }}$. Los hermanos Grimm estarán entre los primeros estudiosos en recolectar tradiciones orales sistemáticamente con el objetivo de que estas no se perdieran ${ }^{461}$. Al mismo tiempo será una de las primeras colecciones en la cual sus autores se encarguen de imprimir y publicar las historias.

La recepción de esta publicación no será muy buena, recibiendo críticas de los escritores y poetas del romanticismo alemán, especialmente de Clemens Wenzeslaus Brentano de La Roche (1778-1842) y Carl Joachim Friedrich Ludwig von Arnim (1781-1831) los cuales habían alentado a los hermanos Grimm para la publicación de su trabajo ${ }^{462}$. A pesar de esto colecciones como las realizadas por estos últimos comenzarían a multiplicarse en Europa, en la forma de emprendimientos particulares, publicaciones especializadas o periódicos ${ }^{463}$. Las similitudes que comenzaban a aparecer llamarán la atención de los estudiosos, los cuales comenzarán a indagar en estas buscando una explicación sobre su origen y su significado. De esta forma la generación de estudiosos de los hermanos Grimm comenzará a indagar en cuestiones lingüísticas, culturales y literarias.

A partir de la segunda mitad del siglo XIX el número de publicaciones alemanas dedicadas a la recopilación y análisis de las tradiciones folklóricas se incrementará considerablemente. De esta forma tendremos publicaciones como Germania. Vierteljahrsschrift für deutsche Alterthumskunde editado por el filólogo y germanista suizo Franz Pfeiffer (18151868), la cual sabrá contar entre sus páginas con trabajos sobre lenguaje, literatura, antigüedades y tradiciones sobre viejas costumbres, leyes y leyendas. Mientras que Pfeiffer buscaba

${ }^{459}$ El título original del libro será Kinder-und Hausmärchen.

460 Baumgartner, 1979; David y David 1964; Henig 1946; Kamenetsky 1974; Michaelis-Jena 1971; Mulloy 1955; Robert y Powell 1969

461 Antes de la aparición de Kinder-und Hausmärchen estos habían publicado Über den altdeutschen Meistergesang (1811), Altdänischen Heldenlieder y Balladen und Märchen (1811) y una edición de Hildebrandtslied (1812).

${ }^{462}$ Baumgartner, 1979; Michaelis-Jena 1971.

${ }^{463}$ El periódico semanal irlandés Dublin Penny Journal (1832-1836), sabrá cobijar en sus páginas temas tales como la traducción de caracteres de lengua irlandesa, el origen de la Frenología, excursiones a distintos pueblos de Irlanda, el mejor aprovechamiento del espacio para las vacas y diversas notas sobre antigüedades irlandesas. Otra publicación irlandesa dedicada a la misma temática será la revista semanal The Irish Penny Journal (1840-1841), la cual abarcará temas como anécdotas históricas, cuentos, poemas, fabulas y proverbios. Estos trabajos se sumaban a publicaciones tempranas como Observations on the popular antiquities of Great Britain (1777) editado por el anticuario inglés John Brand (1744-1806), en el cual se describirán costumbres, vestimentas, ceremonias y supersticiones de las poblaciones rurales inglesas. DPJ 1832, vol 1, n 1; TIPJ 1840, vol 1, n 1; OPAGB 1777, vol 1, n 1. 
condensar en su revista la mayor cantidad de elementos y expresiones de la vida alemana; otras como la publicación mensual Am Ur-Quell: Monatschrift für Volkskunde, editada por el folklorista austriaco Friedrich Salomon Krauss (1859-1938), o Alsatia. Jahrbuch für elsässische Geschichte, Sage, Altertumskunde, Sitte und Sprache, editada por el poeta alemán August Daniel Ehrenfried Stöber (1808-1884), buscaban ser un punto de referencia para las investigaciones científicas sobre las tradiciones ${ }^{464}$.

En línea similar se expresaba el filólogo alemán Karl Gotthelf Jakob Weinhold (18231901), fundador de la Berliner Verein für Volkskunde (Sociedad Berlinesa de Folklore) y editor del Zeitschrift fur Volkskunde, el cual será un crítico agudo sobre aquellas publicaciones que solo se limitaban a publicar tradiciones populares y no se enfocaban en el estudio científico de las mismas. Al mismo tiempo, en busca de la profesionalización de la disciplina, diferenciaba entre los estudiosos que trabajan en base a un programa de investigación integral y los "señores folkloristas" ${ }^{465}$ que carecían de la formación teórica y la práctica a partir de la cual obtener verdaderos datos científicos de las tradiciones populares.

Las discusiones en torno a los límites que definían el estudio científico de las tradiciones populares se darán a lo largo de la segunda mitad del siglo XIX, al mismo tiempo que se incrementaban el número de publicaciones y asociaciones especializadas y no especializadas que se abocaban a esta temática. Sin embargo los estudiosos sabrán sacar provecho de ambos emprendimientos. Algunos como el folklorista austriaco Michael Haberlandt (1860-1940) ${ }^{466}$, el historiador del arte austriaco Alois Riegl (1858-1905), el folklorista y germanista suizo Eduard Hoffmann-Krayer (1864-1936) ${ }^{467}$ verán en estas publicaciones una importante colección de información que debía ser pacientemente analizadas a fin de obtener datos científicos ${ }^{468}$. En forma similar se expresaba el oficial de la armada y administrador colonial británico Richard Carnac Temple (1850-1931) quien, hacia 1886, buscando dar una definición científica del folklore, llamaba a la revisión de distintas fuentes de comienzos del siglo XIX en las cuales podían encontrarse valiosos datos sobre las explicaciones "populares" de fenómenos naturales, objetos y hechos históricos, y finalmente una descripción del modo de vida de los individuos que realizaban estas construcciones explicativas ${ }^{469}$.

A lo largo de la década de 1860 el historiador del arte alemán Wilhelm Heinrich Riehl (1823-1897) publicará los volúmenes de su trabajo Historia natural del pueblo alemán, como

\footnotetext{
464 Bringeus et.all. 1988.

${ }^{465}$ Weinhold usará el termino "Herren Volkskundler". Weinhold 1891.

${ }^{466}$ Este será fundador, junto con el orientalista austriaco Wilhelm Hein (1861-1903), del Zeitschrift für Österreichische Volkskunde

${ }^{467}$ Fundador de la Schweizerische Gesellschaft für Volkskunde (1896) y director del Schweizerische Archiv für Volkskunde (1897)

${ }^{468}$ Bausinger 1986.

469 Temple 1886.
} 
base de una política social alemana $a^{470}$ en los cuales haciendo un llamado al establecimiento de un "Folklore como ciencia" ${ }^{471}$ rescataba el trabajo de los hermanos Grimm, el cual a través de la profundidad histórica y geográfica sentaba las premisas para un estudio comparativo de las diversas tradiciones populares ${ }^{472}$. Según el folklorista aficionado ingles George Laurence Gomme (1853-1916), uno de los miembros fundadores de la Folk-Lore Society ${ }^{473}$, la segunda mitad del siglo XIX había sido testigo de la constitución del folklore en una ciencia histórica y no en un mero pasatiempo de recolección fragmentaria de hechos curiosos o rarezas literarias, dando lugar también a la aparición de publicaciones especializadas. En este sentido los estudiosos de distintos campos como la antropología, la mitología comparada, la filología y la historia comenzarán a ver en los estudios folklóricos una fuente a partir de la cual definir ciertos hechos en la historia del hombre.

Aquellas explicaciones observacionales sobre hechos factuales, concebidas por Temple como el objeto de estudio del folklore, serán categorizadas y definidas como creencias arcaicas o conocimientos tradicionales los cuales, sobreviviendo en tiempos modernos, debían ser observadas, recolectadas y clasificadas por los estudiosos ${ }^{474}$. Esto también debe vincularse a un cambio operado a comienzos del siglo XIX en el cual el gran volumen de datos guardados en diversos acervos y su circulación por distintos espacios impondrá nuevas exigencias a la administración del conocimiento. La apropiación y procesamiento de estos datos, como ha señalado Wolfgang Schäffner, descansará sobre una red logística que opera a nivel transnacional. Esta cualidad no referirá únicamente al transporte de los mismos, sino también en lo referido a nuevas formas de transferencia, representación y almacenamiento ${ }^{475}$.

El establecimiento de una distancia temporal con los grupos estudiados será concebido como algo necesario si el folklore pretendía auxiliar en la reconstrucción de la historia del hombre $^{476}$. En trabajos como los del antropólogo ingles Edward Burnett Tylor (1832-1917), el filólogo alemán Friedrich Max Müller (1823-1900), el lingüista ingles Archibald Henry Sayce (1846-1933) o el lingüista y político irlandés William Edward Hearn (1826-1888) puede apreciarse la construcción de un paralelo entre el folklore de los pueblos europeos y aquellas costumbres observadas entre los "salvajes contemporáneos"477. De esta forma el folklore

\footnotetext{
${ }^{470}$ En el original Naturgeschichte des deutschen Volkes als Grundlage einer deutschen Socialpolitik.

${ }^{471}$ En el original "Volkskunde als Wissenschaft".

${ }^{472}$ Riehl 1958.

${ }^{473}$ Fundada en Londres en 1878, será una de las primeras organizaciones establecidas para el estudio del Folklore. Entre sus primeras publicaciones contaremos con The Folk-Lore Record (1878) y The FolkLore Journal (1883). Estas se centrarían primordialmente en el estudio de aspectos vernáculos de las culturas, especializándose en lenguaje, narrativa, música, danzas, medicina, arte, religiosidad y creencias populares. Posteriormente estas publicaciones convergerían en la publicación especializada titulada Folklore (1890). Folklore 1890, vol 1, n 1; Gomme 1885.

${ }^{474}$ Gomme 1885; Powell 1895; Temple 1886.

${ }^{475}$ Schäffner 2008.

${ }^{476}$ Daston y Galison 2010; Fabian 1983; Stocking 1983, 1987.

${ }^{477}$ Hearn 1879; Müller 1872; Sayce 1872; Stocking 1987; Tylor 1889.
} 
europeo nacía viejo. En un tiempo concebido como un registro fragmentario y discontinuo; y al igual que sucediera con los estudios de antropología física; las primeras etapas de la civilización moderna europea serían observadas en los "salvajes contemporáneos"

Aquellos estudiosos de la segunda mitad del siglo XIX interesados en el análisis del folklore serán guiados por la premura de rescatar, coleccionar y catalogar la mayor cantidad de tradiciones folklóricas posibles, las cuales serán concebidas como "vestigios materiales del pasado" que le permitirán determinar en forma precisa el folklore "puro" de cada grupo humano estudiado. De esta forma acercaban su tarea a la de un arqueólogo o un geólogo ${ }^{479}$ que excavando a través de distintas capas de sedimentos va descubriendo los restos materiales producidos por los miembros de una cultura ${ }^{480}$.

Teniendo en cuenta los matices y las variaciones locales podemos observar que aquellos trabajos dedicados al estudio de las tradiciones "populares" llevados adelante en la Argentina a partir de la segunda mitad del siglo XIX seguirán, fundamentalmente, esta directriz de trabajo.

\subsection{Los estudios folklóricos a comienzos del siglo XX}

Como ha señalado Adolfo Prieto a lo largo en las últimas décadas del siglo XIX podemos apreciar un amplio circuito de circulación de la temática criollista, en el cual intervendrán diversos actores e instituciones. Estos participarán para apropiarse de los elementos de esta temática dando lugar a una construcción de múltiples significados. Prieto, enfocándose en el campo de la literatura, ve en el criollismo una de las formas de asimilación de la herencia cultural de los inmigrantes ${ }^{481}$. Entre 1880 y 1890 se ampliarán los espacios a partir de los cuales los elementos criollistas transitaban y se significaban, dando lugar también al

\footnotetext{
${ }^{478}$ Fabian 1983; Stocking 1983, 1987.

${ }^{479}$ En su estudio sobre el hombre temprano en Inglaterra el geólogo y arqueólogo británico William Boyd Dawkins (1837-1929) enfatizaba sobre la importancia y la utilidad de los estudios folklóricos al momento de re-construir la historia del hombre. Dawkins 1880.

${ }^{480}$ Hacia 1885 Edward Clodd (1840-1930) señalaba sobre las publicaciones de The Folk-Lore Society "Can that material be dealt with as the geologist, who, detaching a fragment here and there from various strata, learns the story of their structure and the conditions which placed them in their several layers ? or who, dealing with the rocks en masse, classifies the several formations, determines their order and succession, and their leading characteristics ? I think this twofold method is applicable to the material of folk-lore; it is ample enough for classification upon some broad general principles, whilst its component parts are clear enough in their structure to show what crude philosophy, science, and theology are crystallised or fossilised within them. The rocks, infinitely varied as they are, are compounded of but few elementary substances; the mass of folk-tales is reducible in essential details to a few incidents" Clodd, 1884 p.290.

${ }^{481}$ Prieto afirma que "Para los grupos dirigentes de la población nativa, ese criollismo pudo significar el modo de afirmación de su propia legitimidad y el modo de rechazo de la presencia inquietante del extranjero. Para los sectores populares de esa misma población nativa, desplazados de sus lugares de origen e instalados en las ciudades, ese criollismo pudo ser una expresión de nostalgia o una forma sustitutiva de rebelión contra la extrañeza y las imposiciones del escenario urbano. Y para muchos extranjeros pudo significar la forma inmediata y visible de asimilación, la credencial de ciudadanía de que podían muñirse para integrarse con derechos plenos en el creciente torrente de la vida social". Prieto A. 2006, p. 18.
} 
surgimiento de nuevos formatos y soportes ${ }^{482}$. En este contexto comenzarán a surgir trabajos que buscarán caracterizar y definir los elementos típicos del folklore argentino. Podemos observar trabajos generales que buscarán una descripción densa de los paisajes y las costumbres de los habitantes del interior del país o bien investigaciones centradas en elementos precisos como las diferentes formas y funcionalidades de los tipos de mate ${ }^{483}$.

Juan Bautista Ambrosetti señalaba, como lo hiciera Richard Carnac Temple, que el folklore había "[...] tenido importancia literaria y más bien como pasatiempo agradable de curiosidad; pero actualmente ha perdido ese carácter, para ocupar su puesto entre las ciencias antropológicas" ${ }^{\$ 44}$. Ambrosetti aprovechaba para señalar el desarrollo de este tipo de estudios en Europa (principalmente en Francia, Italia, Inglaterra, Alemania y España) y en los Estados Unidos, las cuales "[...] en casi todas las naciones civilizadas [...] han contribuido al conocimiento, en gran parte, del pasado del Hombre." ${ }^{485}$. A partir de este punto de referencia describía el estado de estas investigaciones en América del Sur como "pobre", a excepción de ciertos trabajos publicados en Brasil ${ }^{486}$.

Al momento en el cual Lehmann-Nitsche arribaba a la Argentina la recolección y estudio de las tradiciones populares se presentaban como esenciales al momento de comprender las "razas primitivas" y los diversos acontecimientos de la historia nacional.

Esta concepción de la tarea folklórica se condecía, principalmente, con los parámetros de investigación esgrimidos en Inglaterra y Estados Unidos. Hacia 1879, el reporte anual de The Folk-Lore Society, detallaba que durante el desarrollo de las sociedades civilizadas, viejas formas, costumbres y ceremonias se volvieron supersticiones y tradiciones de las clases "bajas". En este sentido la recolección, descripción y comparación de este conjunto de tradiciones se convertía en una importante tarea de la antropología en su afán de reconstruir la historia del hombre ${ }^{487}$.

Similares planteos esgrimía el militar y explorador estadounidense John Wesley Powell (1834-1902) en una charla ante la American Folklore Society, quien sintetizaría esta visión de los estudios folklóricos al abreviarlos en lo que él denominaba "Folk-book"

\footnotetext{
482 Bertoni 2001; Blache 2002; Botana 1977; Chiaramonte 1971, 1997; De Diego 2006; Halperín Donghi 1980, 2005; Romero 1978; Prieto A. 2006

${ }^{483}$ Ambrosetti 1893 a, 1893 b; Carranza 1894; Carrizo 1953; Ceppi 1886; Cortazar 1964; Ebelot 1890; Granada 1890,1896; Monner Sans 1895,1896; Soto 1894; Obligado 1955.

${ }^{484}$ Ambrosetti 1893 a, p. 130.

${ }^{485}$ Ibídem.

${ }^{486}$ No dejará, sin embargo, de recordar las notas y anécdotas sobre las costumbres y tradiciones de la provincia de Catamarca, enviadas por Samuel Lafone Quevedo al diario La Nación entre 1883, 1884 y 1885; las cuales serán posteriormente compiladas y publicadas como Londres y Catamarca (1888). Ambrosetti 1893 a; Lafone Quevedo 1888.

${ }^{487}$ Ambrosetti 1917, p. 130; TFR 1879.

${ }^{488}$ Powell 1895, p. 98.
} 
conformaba parte de "the great five books of humanity"489, y que constituían fuentes de información entrelazadas a partir de las cuales era posible estudiar el origen y el desarrollo humano.

Estos trabajos al igual que los de Lehmann-Nitsche, trabajarán sobre el supuesto de la unidad psicológica de la humanidad ${ }^{490}$. Los mismos concebirán la psiquis humana como el rasgo distintivo de la humanidad, siendo el proceso de recapitulación mental plausible de ser rastreado y reconstruido a partir de la comparación ${ }^{491}$. De esta forma Lehmann-Nitsche buscaba insertar sus trabajos dentro de una línea de investigación que otros estudiosos alemanes venían desarrollando en América. En los Estados Unidos Franz Boas proponia una explicación psicológica para el estudio de cómo los distintos grupos culturales adoptaban y modificaban elementos folklóricos. Este componente psicológico, afirmaba Boas, solo era accesible a través de los elementos materiales producidos por estos grupos, los cuales concebía como trazas que reflejaban la historia del pasado ${ }^{492}$. En referencia a los estudios sobre el folklore europeo señalaba "It is quite evident that the modern European fairy-tales do not reflect the conditions of the state of our times, nor the conditions of our daily life, but that they give an imaginative picture of rural life in semifeudal times [... $]^{p 493}$.

En forma similar se expresaba Rudolf Lenz en Chile. Ofreciendo un discurso en la fundación de la Sociedad de Folklore Chileno afirmaba; al retomar los planteos que el historiador alemán Raimund Friedrich Kaindl (1866-1930) hiciera en su trabajo Die Volkskunde, ihre Bedeutung, ihre Ziele und ihre Methode (1903); que el Folklore se ocupaba de la recolección de materiales necesarios para la aplicación del método inductivo y comparativo de la Etnología, la cual se encargaba de investigar “[...] las leyes de la formación de la humanidad con el objeto de presentar un cuadro de su vida síquica" ${ }^{\text {"494. }}$.

Como recordará Tylor en Primitive Culture (1871) el folklore ofrecía una síntesis intelectual que daba unidad y coherencia al estudio del hombre primitivo. El conceptualizar el

\footnotetext{
${ }^{489}$ Estos eran: el "Stone-book", el "Tomb-book", el "Ruin-book" y el "Folk-book". La conjunción de estos tres libros daba como resultado el "Folk-book". Según Powell el cuerpo de tradiciones folklóricas era en sí mismo un "object-lessons" que conformaba un registro material de las explicaciones observacionales sobre hechos factuales construidas por grupos "barbaros". Ibídem, p. 97.

${ }^{490}$ Powell remarcaba que "The grandest fact of all is that the human race is one. We have discovered the intellectual unity of the human race. That which distinguishes man from the lower animals is superior intellect, resulting in superior activities of all the five classes. That superior intellect is every- where constructed upon the same plan. In every land and among every people, two and two make four. In every land and among every people, wherever there are human eyes to se6 it, the moon is round, and then gibbous, and then crescent". Ibídem, p. 99

491 Stocking 1983, 1987.

492 Boas 1891.

493 Boas 1925, p. 496.

${ }^{494}$ Lehmann-Nitsche se haría eco de esta idea en uno de sus manuscritos inéditos: Un capitulo del folklore argentino: El traje popular del hombre. En el mismo afirmaba "Como se ve el "folklore", en sentido científico, no es otra cosa etnología de los pueblos de raza blanca, y todo aquello lo que atañe a esta parte moderna de las investigaciones humanas, también puede decirse es esta la subsección”. Legado Robert Lehmann-Nitsche, IAI, Carpeta N-0070 w 34; Lenz 1909, p. 5.
} 
cuerpo de tradiciones como vestigios materiales del pasado será una forma de convertirlo en datos que fundamenten y sostengan el argumento monogenista evolutivo ${ }^{495}$. El campesino europeo y el gaucho argentino servirán como eslabones entre el hombre civilizado y el salvaje primitivo, la comparación entre estos será posible a través de la naturalización y especialización del tiempo. Haciendo viable la distribución de la humanidad en espacio y tiempo, se hablará de la contemporaneidad de aquellos grupos no-civilizados ${ }^{496}$.

La serie de publicaciones mencionadas anteriormente verán en las tradiciones "populares" vestigios del pasado que se enraizaban y constituían una parte del corpus que sintetizaba y definía el "ser" argentino. El inexorable paso del tiempo y la civilización amenazaba estas "capsulas del tiempo", por lo tanto debían ser recolectadas y archivadas. Esto no dará inicio con Lehmann-Nitsche, como ciertas reconstrucciones biográficas plantean, ni será exclusivo de los círculos legos ${ }^{497}$. Artículos anónimos como el aparecido en 1885 en la revista El Arte; el cual abogaba por la conformación de una base de cantos populares a fin de poder construir una psicología etnográfica a través de la comparación ${ }^{498}$; se condecía con el pedido de rescate de las tradiciones argentinas, a partir de su recolección sistemática, realizado por Paul Groussac (1848-1929) en el World's Folklore-Congress de Chicago en $1893^{499}$.

En 1925 una nutrida concurrencia ocupaba las salas de la legación alemana de Buenos Aires. Luis María Torres, por entonces Director del Museo de La Plata, dedicaba estas palabras en la entrega del título de Doctor Honoris Causa de la Hamburg Universität a Lehmann-Nitsche "[...] desde que llegó a nuestro país, para ser vinculado al departamento de antropología del Museo de La Plata [...] ha desenvuelto una acción múltiple que pudiera condensarse en estos tres capítulos: el estudio, la enseñanza y el trato asiduo y la vinculación amistosa con los hombres de más arraigo en nuestro país; y seguramente, por la combinación de estos tres aspectos de su actividad ha podido encarar sus estudios folklóricos, estudios que han sido el motivo o la razón expresa del reconocimiento de los méritos de la Universidad de Hamburgo

\footnotetext{
495 Tylor 1871.

${ }^{496}$ Fabian 1983; Stocking 1983, 1987.

${ }^{497}$ Entre otros: Bilbao 2004; Cáceres Freyre 1972; Carrizo 1953; Chertudy 1964; Cortazar 1964; García M. 2006; García y Chicote 2008; Guido W. 1975; Marquez Miranda 1938; Teruggi 1997.

${ }^{498}$ El mismo rezaba por qué: "[...] cada artista hiciera un estudio musical de los cantos populares de su región natal, bases que servirán más tarde para un estudio comparativo que no carecería de interés ni de novedad [...] algo así como una psicología etnográfica o una etnografía musical”. Suárez Urtubey 1970, p. 37.

${ }^{499}$ En esta conferencia sobre el gaucho argentino brindada el 14 de julio de 1893, Groussac llamaba a la recopilación inmediata de las tradiciones argentinas antes que la propia evolución de este borrara "[...] nuestras huellas originales [...]" por lo cual era necesario "[...] reunir en colección todos los elementos genuinamente argentinos de la antigua vida campestre, que se tornará muy pronto legendaria". Groussac 1893 , p. 3.
} 
[...]"500. Como veremos más adelante, gran parte de los hombres con "más arraigo" en la Argentina formarán parte de la comunidad alemana, los cuales le proveerán datos y espacio físico donde realizar sus recopilaciones.

En esa misma intervención señalaba Torres que “[...] los estudios del folklore americano eran un campo casi completamente virgen, que solo muy raras veces se había intentado desbrozar [...]". A lo largo de este discurso es posible identificar lo que serán las principales cualidades de los trabajos folklóricos llevados adelante por Lehmann-Nitsche: vinculación a espacios científicos del país y del exterior, el acceso y la implementación de dispositivos tecnológicos "novedosos" para el contexto local, y una actitud casi enfermiza en la recolección de expresiones folklóricas. En la capacidad y posibilidad de aunar estos tres puntos estibará el verdadero merito de los trabajos folklóricos del antropólogo alemán.

$\mathrm{Al}$ momento de recibir su premio expresaba Lehmann-Nitsche su temprano interés en el estudio de las manifestaciones de las "culturas populares" de la Argentina, declarando que al hacerse cargo de la sección antropológica del Museo de La Plata hallo oportunidad para dedicarse "[...] entre otras cosas, inmediatamente al estudio del folklore nacional [...]" Profundizando aún más las características de su trabajo folklórico señalaba "Coleccioné las perfumadas flores de la poesía popular como las hallé y como me fueron obsequiadas; luego trate de arreglarlas, no en el orden alfabético de las soluciones, sino según un sistemas natural; ideal de los botánicos; y ahora que se presentan al paciente lector como entre las hojas de un herbario, espero que no se hayan secado o perdido su aroma campestre" ${ }^{, 502}$.

A lo largo de la segunda mitad del siglo XIX podremos encontrar botánicos como miembros de las sociedades antropológicas europeas, los cuales participaran activamente en las discusiones vinculadas a los mejores métodos de observación de los seres vivos y sus restos óseos. En este sentido es interesante profundizar las discusiones en torno a la incidencia en el campo de la Antropología de aquellos sistemas implementados en la Botánica para la observación, ordenamientos, clasificación y conservación de especímenes. En este sentido el botánico y zoólogo alemán Adolf Ernst (1832-1899) recordaba que su formación botánica lo había provisto de herramientas de observación y recolección al momento de comenzar con la compilación de tradiciones populares en Venezuela ${ }^{503}$.

La cita anterior de Lehmann-Nitsche deja entrever una de las características principales de los trabajos folklóricos de fines del siglo XIX y principios del siglo XX, como tempranamente señalara George Stocking "As a rural world, the "old World", was closely tied to the processes and rhythms of nature. Despite the quickening pace of technological progress,

\footnotetext{
${ }^{500}$ Legado Robert Lehmann-Nitsche, IAI, Carpeta N-0070 126.

${ }^{501}$ Lehmann-Nitsche 1925 f, p. 106.

${ }^{502}$ Legado Robert Lehmann-Nitsche, IAI, Carpeta N-0070 126. El resaltado es de nuestra autoría.

${ }^{503}$ Ernst 1987.
} 
mankind's power over nature was still for the most part manifest directly through the activity of the human hand, wielding tools of a relatively simple character" ${ }^{204}$.

La tarea recopilatoria llevada por Lehmann-Nitsche se ha circunscripto a su compendio de Adivinanzas Rioplatenses (1911), definido como un cuadro representativo de la de la cultura argentina de principios del siglo $\mathrm{XX}^{505}$. Sin embargo antes y después de la edición de esta voluminosa compilación de cuentos, poesías, dichos y versos de la zona del Río de la Plata, existirán trabajos de distinta extensión y comunicaciones con distintos estudiosos que nos servirán para conceptualizar una visión más amplia y precisa de los estudios folklóricos en la Argentina de comienzos del siglo XX. A su vez se ha mencionado escuetamente los distintos mecanismos y las redes de recopilación de datos. Estas se articularán a través de los distintos patrones de sociabilidad establecidos tanto al interior de academia, como de aquellos viabilizados por la comunidad alemana. De esta forma Lehmann-Nitsche podrá recopilar la "materia prima" a partir de la cual definirá el folklore "argentino" como la convergencia de tradiciones y costumbres tanto locales como extranjeras.

\subsection{Librerías, panfletos y la prensa diaria: Las redes de circulación de las tradiciones folklóricas}

Una vez instalado en la ciudad de La Plata, Lehmann-Nitsche la describía en carta a su madre como una ciudad desierta y abandonada, donde las pocas construcciones, mal edificadas, convivían con los animales que pastoreaban y con las sombras de los ignotos habitantes. En palabras un tanto desalentadoras afirmaba "La ciudad está completamente desierta y muerta, sólo en el museo es un hervidero de vida" ${ }^{\text {"506 }}$ (Fig. 26). Sin embargo Lehmann-Nitsche sabrá reconocer la multiplicidad de espacios y soportes en los cuales se manifestaba aquel heterogéneo conjunto de tradiciones "populares" que denominaría como folklore "argentino". La tarea del antropólogo era desechar aquellos elementos superpuestos o mezclados a lo largo del tiempo, a fin revelar la base "[...] genuinamente española, más bien dicho, mediterránea, pero (que) conserva elementos arcaicos, extinguidos en el suelo nativos desde siglos y sobreviviendo en terreno colonial [...]"507.

Si la antropología se ocupaba de las peculiaridades físicas y morales del hombre, era necesario, para "escudriñar la psicología étnica" de un grupo especifico, la recolección de la

\footnotetext{
${ }^{504}$ Stocking 1987, p. 209. El resaltado es de nuestra autoría.

505 Cáceres Freyre 1972; Carrizo 1953; Chertudy 1964; Cortazar 1964; Guido W. 1975; Márquez Miranda 1938; Teruggi 1997.

${ }^{506}$ En el original "Die Stadt ist vollständig ausgestorben und tot, nur im Museum herrscht reges Leben". Robert Lehmann-Nitsche a Ida Lehmann-Nitsche. Legado Robert Lehmann-Nitsche, 13.07.1897, IAI, Carpeta N-0070 b 1295.

${ }^{507}$ Manuscrito "Un capitulo del folklore argentino: el traje popular del hombre", IAI, Carpeta N-0070 w 34.
} 
correspondiente "materia prima"508. En la búsqueda de elementos representativos para la construcción de un cuadro susceptible de compararse con otras recopilaciones folklóricas realizadas comenzará Lehmann-Nitsche a ampliar los espacios de recolección de datos. Bares, fondas, puertos y prostíbulos serán los primeros espacios donde buscará hallar los elementos constitutivos del folklore en su estado más "puro". De esta forma la antropología comenzaba a adentrarse en contextos frecuentados por escritores, periodistas y músicos vinculados en mayor o menor medida a la temática criollista.

Unos de las primeras redes de aprovisionamiento utilizadas por Lehmann-Nitsche será aquella estructurada en torno al existente conjunto de editores, librerías y casas editoras junto con aquellos materiales que podían ser adquiridos en puestos de revistas y estaciones de ferrocarril. El uso de estos últimos espacios permitirá hacer frente a la limitación impuesta por la red de casas editoriales, librerías y editores; las cuales si bien facilitaban y ampliaban la recolección, también la circunscribía a las necesidades e intereses de las mismas, regidas por las pautas de consumo y los vaivenes del mercado literario. Estos espacios aparecen en una pequeña libreta de direcciones la cual; bajo el nombre de "Folkloristische Studien"; compilaba en orden alfabético autores de libros, representaciones teatrales, canciones, y poemas con temática folklórico ${ }^{509}$.

De esta forma en los anaqueles de Lehmann-Nitsche se pueden contabilizar 643 folletos que dan cuenta de las diversas formas en las cuales el folklore "argentino" se presentaba: literatura gauchesca, noticias policiales e históricas, folletos sicalípticos, política nacional e internacional, novelas, piezas teatrales, musicales y manuales de comportamiento social. También es interesante apreciar el lugar de procedencia de estos elementos: Chile (Santiago, Valparaíso, Iquique, Antofagasta, Concepción, Serena y Coquima), Perú (Arequipa, Lima, Tacna y Cuzco), Bolivia (La Paz), España (Madrid, Barcelona, Cremona) e Italia. De esta forma se buscaba constituir una amplia base de datos a partir de la cual establecer explicaciones panamericanas para el folklore ${ }^{510}$. Siguiendo aquellas líneas de investigación fomentadas a lo largo de la segunda mitad del siglo XIX, Lehmann-Nitsche observará en el folklore argentino una expresión local de un fenómeno mucho más amplio que trascendía ampliamente los espacios locales y que tenía su punto de origen en los países ibéricos.

El uso de las redes de editores, librerías y casas editoras; estará posibilitada por los cambios acontecidos hacia fines del siglo XIX. Hacia 1897 el contexto de producción, circulación y consumo de elementos vinculados a la temática folklórica se encontraba fuertemente impulsado desde diversos sectores del espectro social argentino. Los procesos

\footnotetext{
${ }^{508}$ Robert Lehmann-Nitsche a Ida Lehmann-Nitsche. Legado Robert Lehmann-Nitsche, 13.07.1897, IAI, Carpeta N-0070 b 1295.

${ }_{509}^{50}$ Legado Robert Lehmann-Nitsche, IAI, Carpeta N-0070 s 80.

${ }^{510}$ Lissi y Saravia 1986; Prieto A. 2006
} 
inmigratorios darán lugar a la confluencia y mixtura de tradiciones disímiles. Este proceso estará privilegiado por la expansión de las redes de transporte, dando lugar a la ampliación del público lector. Este nuevo grupo tendrá incidencia económica en el acrecentamiento y la profesionalización de los espacios y las redes donde estos elementos eran producidos y circulaban $^{511}$.

Otra de las redes más amplias y fructuosas será la de la prensa diaria o periódica. Pruebas de esto podemos hallarla en una vasta cantidad de recortes fechados hacia 1897 y pacientemente coleccionados por Lehmann-Nitsche. En los mismos podemos hallar avisos publicitarios que cubrirán una amplia gama de aspectos; tales como libros de cuentos para niños, notas explicativas sobre la significancia lúdico-numéricas del juego de la lotería o las distintas formas de diseñar, armar y remontar un barrilete ${ }^{512}$. Dentro de esta red, la prensa publicada en alemán será la que mayor beneficio le brinde. Cierta vez se encontraba asistiendo a un peón de campaña por un caso de cistitis gonorreica, este último asociará el procedimiento operatorio con una cirugía veterinaria practicada asiduamente en el campo ${ }^{513}$.

A fin de proveerse de información y pareciéndole imprescindible la colaboración de "gente de campo", publicará Lehmann-Nitsche un breve artículo en el cual citaba los principales puntos de su investigación y pedía cualquier tipo de comunicación. Los medios gráficos elegidos serán el diario alemán Argentinisches Tageblat ${ }^{514}$; el cual circulaba mucho entre " [...] capataces, mayordomos, chacareros, etc. ${ }^{, 515}$; la revista semanal Das Echo ${ }^{516}$, y los Anales de la Sociedad Rural Argentina ${ }^{517}$. El uso de este recurso por parte de Lehmann-Nitsche cristalizaba en su obra Folklore Argentino II, El caballo retajo, publicado en $1914^{518}$.

El uso de estas publicaciones graficas sustituirá, en parte, la necesidad de transportarse físicamente al terreno para la consecución de datos. De esta forma los antropólogos economizarán tiempo y dinero en la obtención de importantes datos para la realización de su

\footnotetext{
${ }^{511}$ De Diego 2006; Prieto M. 2006.

${ }^{512}$ Legado Robert Lehmann-Nitsche, IAI, Carpeta N-0070 s 13.

${ }^{513}$ Declaraba Lehmann-Nitsche "Al someterlo a un tratamiento sistemático, según el método de Janet, y al hacer la prescripta inyección con una solución de permanganato de potasa, viendo el sujeto la reacción en el campo de operación que el procedimiento indicado trae consigo, exclamó "!Caramba, parece de retajo!". Era la primera vez que oía hablar del "retajo", y pregunté lo que significaba; las explicaciones del campesino despertaron bastante mi curiosidad y desde entonces no perdí de vista tan interesante caso de cirugía veterinaria popular". Lehmann-Nitsche 1914 b, p.151.

514 Fundado por el inmigrante de origen suizo Johann Alemann en 1874, como medio de comunicación para los colonos de la provincia de Santa Fe. Un año después junto a sus hijos Theodor y Ernst se trasladarán a Buenos Aires donde comenzarán a publicarlo en forma esporádica. Con el consabido incremento de la comunidad alemana, la familia Alemann se radicará definitivamente en la ciudad de Buenos Aires, comenzando a partir del año 1889 con la publicación diaria del mismo. Lehmann-Nitsche publicaría su artículo el 15 y el 19 de julio de 1899.

${ }^{515}$ Lehmann-Nitsche 1914 b, p. 151-2.

${ }^{516}$ Das Echo 19.10.1899.

${ }^{517}$ ASRA 20.07.1900.

${ }^{518}$ Lehmann-Nitsche 1914 b.
} 
trabajo. En aquella ciudad de La Plata con sus animales pastoreando entre las construcciones edilicias, con calles mal pavimentadas y completamente "muertas y desiertas", los diarios y revistas circulantes serán una fuente de información primaria en las investigaciones antropológicas.

Si bien Lehmann-Nitsche no dudaba de los resultados positivos de esta forma de recolección de información, si lo hará sobre los magros resultados obtenidos a partir de la publicación echa en un medio especializado como Anales. En este sentido afirmaba "No me equivoqué al recurrir, en busca de colaboradores, al ya citado diario de Buenos Aires y al Echo; gran parte de los resultados de mi encuesta debo a esos periódicos, mientras que, como contestación a un artículo análogo, insertado por mí en los Anales [...], recibí ¡una sola carta!" ${ }^{519}$. Como podemos apreciar los lazos de sociabilidad establecidos entre un investigador y su comunidad de origen serán, en un considerable número de casos, aquellos que permitan la consecución de datos, objetos o instrumentos a fin de completar sus investigaciones.

Los alemanes residentes en el país también proveerán a sus estudiosos coterráneos de espacios físicos donde realizar sus investigaciones. En 1906 Walther Böcking invitaba a Lehmann-Nitsche a realizar una visita a la Estancia La Rhenania, asegurándole la disponibilidad de material para realizar sus investigaciones y las comodidades ofrecidas por las instalaciones del lugar. La mencionada estancia se ubicaba en la localidad santafesina de Rufino, donde Lehmann-Nitsche se trasladaría para realizar trabajos entre el 19 y el 22 de febrero de 1907. Las buenas condiciones climáticas que primarán durante los días que los trabajos eran llevados adelante se condecirán con la posibilidad de compartir las veladas nocturnas con otros alemanes que en ese momento estaban presentes en la estancia, lo cual podía llevar a pensar, como comentaba Böcking, que los trabajos se estaban llevando a cabo no en Rufino sino en la región alemana de Rheinland ${ }^{520}$.

Los resultados de la breve estancia en la Estancia La Rhenania serán una serie de dibujos sobre 29 estribos de suela que posteriormente serán compilados con otros 22 dibujos, realizados en la localidad de Los Toldos en febrero de 1920, en un manuscrito inédito titulado Folklore Argentino X: La edad del cuero crudo ${ }^{521}$.Mientras que los miembros de las comunidades alemanes residentes en el país verán con satisfacción el poder colaborar los trabajos científicos realizados por los estudiosos de su comunidad, estos últimos obtendrán colaboradores que los proporcionarán espacios físicos donde realizar sus trabajos o los proveerán de materiales.

\footnotetext{
519 Ibídem, p. 151-2.

${ }^{520}$ Walther Böcking a Robert Lehmann-Nitsche. Legado Robert Lehmann-Nitsche, IAI, 15.04.1906 y 28.03.1909, Carpeta N-0070 b 43.

${ }^{521}$ Legado Robert Lehmann-Nitsche, Carpeta N-0070 b w 38.
} 


\subsection{Bares, fondas, prostíbulos y puertos: Redes y espacios de la pluralidad del folklore "popular"}

Esta primera etapa de recolección efectuada por Lehmann-Nitsche nos permite comprender el amplio campo de expresión de los fenómenos folklóricos, y los intentos que llevará adelante por tratar de determinar las expresiones locales de un folklore que para él trascendía las fronteras nacionales. Dicha tarea había comenzado mucho antes del inicio de los trabajos folklóricos de Lehmann-Nitsche, el cual rápidamente entablará contacto con personajes de distintos ámbitos del mundo folklórico. De esta forma pretendía abarcar las distintas aristas expresivas de una manifestación cultural que concebía como una sola. Hacia comienzos del siglo XX Lehmann-Nitsche acumulaba; paralelamente a los recortes periodísticos, folletines y panfletos; cerca de 200 páginas de material folklórico, el cual sería la base de futuros trabajos publicados en la serie conocida como Folklore Argentino o bien manuscritos inéditos ${ }^{522}$. De esto darán cuenta una serie de cartas en las cuales se agradecía el envío de trabajos inéditos y/o versiones preliminares de futuras publicaciones ${ }^{523}$.

Mientras que el número de manuscritos inéditos crecía, Lehmann-Nitsche ampliaba sus vínculos en los círculos académicos dedicados al estudio del folklore. Esto le permitirá ampliar el número de informantes como así también acceder a datos y bibliografía de difícil consecución. Paralelamente comenzaba con la traducción al alemán de diversas compilaciones folklóricas, en la cual prestarán especial ayuda diversos miembros de su familia ${ }^{524}$.

A principios de 1900 Rudolf Lenz le escribía desde Chile, incitándolo a la recolección de "Volkspoesie" (poesía popular) le recomendaba una rápida inserción en los ambientes

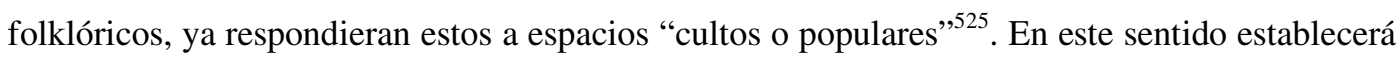
vínculos con personas vinculadas al mundo del espectáculo "popular" y escritores de distintas

${ }^{522}$ Hacia 1910 podemos registrar: Folklore Argentino: cuentos populares (1901); Estudios sobre folklore argentino: versos infantiles (1907); Folklore Argentino X: la edad del Cuero Crudo (1907); Estudios sobre el folklore argentino VI: La fauna en el folklore argentino (1908); Folklore Argentino: Cuentos populares recopilados por Robert Lehmann-Nitsche (1909) y Un capitulo del folklore argentino: el traje popular del hombre (1910). Legado Robert Lehmann-Nitsche, IAI, Carpetas N-0070 w 35, w 38, w 33, w 20 y w 34.

${ }^{523}$ Hacia 1902 Juan Bautista Ambrosetti le recordaba el envío de una serie de dibujos de mates para completar un trabajo. Ese mismo año el Instituto Histórico e Geografico de São Paulo agradecía el envío de Adivinanzas Rioplatenses. Al mismo tiempo Rudolf Lenz acusaba recibo del trabajo sobre el retajo. Juan Bautista Ambrosetti a Robert Lehmann-Nitsche. Legado Robert Lehmann-Nitsche, 27.05.1902, IAI, Carpeta N-0070 b 7. Instituto Histórico e Geografico de São Paulo a Robert Lehmann-Nitsche. Legado Robert Lehmann-Nitsche, 22.07.1902, IAI, Carpeta N-0070 b 1088. Rudolf Lenz a Robert LehmannNitsche. Legado Robert Lehmann-Nitsche, 24.10.1905, IAI, Carpeta N-0070 b 420.

${ }^{524}$ Hacia 1900, en el contexto de su viaje a Europa, aprovechaba la estancia en la finca familiar de Posen para que su hermana Luise tradujera al alemán la obra Los Payadores Gauchos; The Descendants of the Juglares of Old Spain in La Plata. a Contribution to the Folk-Lore and Language of the Argentine Gaucho (1897) del capitán de la armada estadounidense Frederick Mann Page (1852-1900). La misma lo hacia bajo el titulo Los payadores gauchos: die Nachkommen der altspanischen Volkssänger am La Plata; ein Beitrag zur Folklore des argentinischen Gaucho (1900). Legado Robert Lehmann-Nitsche, IAI, Carpeta N-0070 w 47.

${ }^{525}$ Rudolf Lenz a Robert Lehmann-Nitsche. Legado Robert Lehmann-Nitsche, 27.04.1900, IAI, Carpeta $\mathrm{N}-0070$ b 420. 
partes de Latinoamérica y Europa. De esta forma pueden corroborarse un fluido intercambio de correspondencia con personalidades del mundo del entretenimiento como José Podestá; con escritores como el español Daniel Granada (1847-1929), el costarricense Joaquín García Monge (1881-1958) y el argentino Godofredo Daireaux (1849-1916). En este contexto una de las principales figuras que le granjearán importantes contactos será el historiador y diplomático argentino Ernesto Quesada (1858-1934).

Al mismo tiempo comenzaba con la recopilación y transcripción de cuentos que le fueran dictados por habitantes de la urbe platense. A partir de estos buscará definir el espacio, la distribución geográfica y las posibles conexiones regionales establecidas entre los mismos. Parte de aquellos individuos pertenecerán a distintos grupos indígenas desplazados que, insertos en la vida ciudadana, se desempeñaran como servidores policiales o mozos de tareas en diversas reparticiones públicas. Estos se sumaban a aquellos que trabajaban en faenas rurales o establecimientos de campos ${ }^{526}$.

En esta serie de trabajos; al igual que aquellos desarrollados en antropología física; muchas de las recopilaciones no responderán a un plan sistemático de investigación, sino que responderán a sacar provecho de situaciones casuales. En este sentido la presencia de los indígenas araucanos que vivían en el Museo de La Plata le permitirá registrar un importante material narrativo, el cual complementaba aquel obtenido a partir de una serie de encuentros con grupos de araucanos instalados en la localidad bonaerense de Los Toldos. El resultado de esto será un considerable cuerpo de datos con respecto a las supersticiones araucanas sobre a la lutra y el tigre que serán articulados dentro de las discusiones paleoantropológicas establecidas con Ameghino en torno a la supuesta existencia del Grypotherium, la cual, a partir de esta recopilación, Lehmann-Nitsche limitará al terreno de la tradición oral ${ }^{527}$.

A partir de las sugerencias de Rudolf Lenz, Lehmann-Nitsche se adentrará dentro de espacios de investigación concebidos por este último como "vírgenes" 528 . De esta forma comenzará a frecuentar lugares como prostíbulos, fondas, bares y puertos. La recopilación efectuada en estos comenzará muy tempranamente. Hacia 1900, escudándose bajo el

\footnotetext{
${ }^{526}$ Entre las primeras transcripciones de las que queda registro se encuentra el cuento "Upialito" dictado por F. Fernández el 26 de agosto de 1899. Muchas veces recopilará la mayor cantidad posible de cuentos de una misma persona, como en el registro de las versiones santiagueñas de "El avestruz y el sapo", "El avestruz y la garrapata" y "El paisano y el tigre" dictadas por Pedro Blames el 26 de abril de 1901. Legado Robert Lehmann-Nitsche, IAI, Carpeta N-0070 w 20.

${ }^{527}$ Lehmann-Nitsche 1902 b.

${ }^{528}$ En una lectura ofrecida en el Congreso Científico Americano Internacional de Buenos Aires (1910) declaraba que: "La recolección y el estudio de las adivinanzas populares del Plata era campo virgen, trabajo grato para el folklorista y no tarde en empezarlo. Merced al esfuerzo de mis colaboradores, la colección de que dispongo, es bastante completa en lo que se refiere a la República Argentina, y creo que contiene más del noventa por ciento de todas las adivinanzas circulantes, y he ahí mi calculo: en una remesa de cien números, por ejemplo, que recibo, difícilmente hay más que cinco o seis que no estén ya representadas". Lehmann-Nitsche 1911 a, p.23.
} 
pseudónimo de Víctor Borde, afirmaba que el material conseguido en estos espacios podría fácilmente "[...] agotar casi la ciudad de Buenos Aires para el lapso indicado" 529.

Parte de este material, de contenido erótico-escatológico será objeto de cuatro publicaciones. El primero de estos se publicaba hacia 1901 en la colección Kryptádia ${ }^{530}$. El mismo comprendía un pequeño recuento de la utilización de la voz "puta" y de los diversos insultos "populares"; de autor anónimo era sindicado por Víctor Borde como el único "[...] trabajo sobre erótica argentina [...]" anterior a su propia publicación ${ }^{531}$. Unos años más tarde Lehmann-Nitsche publicaba bajo su nombre un trabajo, de temática erótica, en la colección alemana Anthropophyteia ${ }^{532}$. Hacia 1914 en las páginas del Zeitschrift für Sexualwissenschaft ${ }^{53}$ editaría un ensayo sobre los supuestos problemas sexuales vinculados a un impuesto para los solteros en Argentina y Paraguay. Finalmente hacia 1923 publicará, bajo el pseudónimo de Víctor Borde, un compendio titulado Textos eróticos del Río de la Plata.

Esta serie de trabajos nos permite apreciar ciertos aspectos de la práctica antropológica que no han sido debidamente considerados por aquellas reconstrucciones históricas más centradas en la épica personal de los protagonistas. Gran parte del material será recolectado por la red de recopilación que Lehmann-Nitsche articulará a través de sus alumnos de la cátedra de Anatomía Artística (carrera del profesorado de Dibujo). Tanto estos, como el propio LehmannNitsche, frecuentarán bares, tabernas, fondas, puertos y prostíbulos donde se encontraba la "materia prima" para los trabajos.

Estos espacios también nos permiten preguntarnos acerca de la definición identitaria de "argentino" para este heterogéneo conjunto de creencias, tradiciones y costumbres. En estos un

${ }_{529}^{529}$ Borde 1923, p. 4.

${ }^{530}$ Este compendio había sido fundado hacia 1883 por el médico y folklorista ucraniano Isidore Kopernicki (1825-1891) y el etnólogo austriaco-croata Friedrich Salomon Krauss (1859-1938) con el nombre de Kryptádia; Recueil de documents pour servir a l'etude des traditions populaires siendo editado por el filólogo y lingüista francés Bruno Paulin Gaston Paris (1839-1903), el etnólogo francés Eugène Rolland (1846-1909), el filólogo y folklorista francés Élie Henri Anatole Gaidoz (1842-1932), el folklorista francés Émile Henri Carnoy (1861-1930) y el folklorista italiano Giuseppe Pitrè (1841-1916). En el séptimo número de esta recopilación anual de cuentos y música folklórica erótica publicaba Lehmann-Nitsche el trabajo "Chistes y desvergüenzas del Río de la Plata”. Anónimo 1901; Legman 1990. ${ }_{531}$ Borde 1923, p.3.

${ }^{532}$ Este compendio anual de folklore erótico y sexual había sido fundado hacia 1904 por Friedrich Salomon Krauss con el nombre de Antropophyteia: Jahrbucher fur Folkloristische Erhebungen und Forschungen zur Entwicklunggeschichte der geschlechtlichen Moral. En este Lehmann-Nitsche publicaría su trabajo titulado Zu den Anthropophyteia aus Alt Perú. Lehmann-Nitsche 1909 d.

${ }_{533}$ Con el nombre de Zeitschrift für Sexualwissenschaft. Internationales Zentralblatt für die Biologie, Psychologie, Pathologie u. Soziologie des Sexuallebens, comenzaba su publicación en 1908. Sus editores eran el neurólogo y sexólogo alemán Albert Eulenburg (1840-1917) y el dermatólogo y sexólogo alemán Iwan Bloch, (1872-1922). En enero de 1914 Lehmann-Nitsche recibía el pedido de ambos editores a fin de que prestará su colaboración en temas vinculados al folklore sexual argentina. Hacia abril de dicho año una nueva carta de Bloch introducía al neurólogo alemán Bruno Saaler y aprovechaba para consultarle nuevamente sobre la posibilidad de enviar para su publicación algún trabajo sobre el folklore sexual argentino. Finalmente enviará uno intitulado "Angebliche Junggsellensteuer in Argentinien und Paraguay, Sexualprobleme". Lehmann-Nitsche, 1914; Iwan Bloch a Robert Lehmann-Nitsche. Legado Robert Lehmann-Nitsche, 23.04.1914, IAI, Carpeta N-0070 b 8. 
considerable porcentaje de los individuos, que prestaban servicios o bien los consumían, eran extranjeros. En el Censo General de la ciudad de La Plata (1910), se registraban, en el cuatro burdeles, donde había 41 mujeres argentinas y 43 extranjeras, en una población adulta de más de 18.000 mujeres. Esta será una tendencia sostenida en forma casi estable desde la segunda mitad del siglo XIX ${ }^{534}$.

En el primer Censo Nacional (1869) 361 individuos declararán ejercer la prostitución como medio de vida. Menos de la mitad de estos individuos habían nacido o crecido en la Argentina. Los principales países de procedencia serán Austria, Bélgica, Dinamarca, Italia y Rusia. Dicha tendencia se mantendrá en similares proporciones a lo largo de los años ${ }^{535}$. Una serie de iniciativas posteriores como el "Reglamento sobre prostitución" (1875) $)^{536}$ y la ordenanza relativa a la inspección médica de las prostitutas (1888) proveerán de información más precisa sobre la procedencia de las prostitutas. A partir de estos podemos dar cuenta que los lugares donde Lehmann-Nitsche o sus alumnos recogieron parte de sus muestras representativas del folklore "argentino", serán cobijo de apellidos como Diakieviyen, Solthinger, Brantac o Sigitezxenf ${ }^{537}$.

La gran presencia de mujeres extranjeras también puede registrarse en las denuncias de la prensa europea desde mediados de 1860 y en los informes de las asociaciones de vigilancia nacionales. En 1903 el Comité Nacional Alemán para Combatir la Trata de Blancas declaraba que la mayoría de los 35 traficantes de mujeres conocidos en Buenos Aires y La Plata eran “judíos-polacos” y el $65 \%$ de las prostitutas registradas eran polacas, rusas o austro-húngaro ${ }^{538}$. Estos lugares sabrán proveer a Lehmann-Nitsche de un espacio en el cual observar los procesos de confluencia y mixtura de distintas tradiciones folklóricas en ese agregado que conceptualizará como folklore "argentino". Dicha pluralidad también puede observarse en los libros de bajo costo, folletines y panfletos de temática gauchesca que supiera coleccionar ${ }^{539}$.

Sin embargo, tal como advertía Ernesto Quesada, esta multiplicidad no era una característica que sería tan fácilmente aceptada por los sectores más conservadores de la sociedad o de la academia. Al publicar Adivinanzas rioplatenses advertía Lehmann-Nitsche que el grupo XVI (erótico) "[...] no se publica en esta obra, pero por lo menos es menester mencionarlo para completar la estadística de cada sección” ${ }^{\natural 40}$. Seguramente su intención fuera publicar las mismas, sentimiento que no compartirán las autoridades y los editores de la

${ }_{534}^{534}$ CGCLP 1910; Ghisiglieri 2003.

${ }^{535}$ AHM 1890; Carretero 1998; Guy 1994.

${ }^{536}$ Establecido el 5 de enero de 1875, instauraba los "Registros de Prostitutas".

${ }^{537}$ Hacia 1880 un asombrado Adolfo Batiz, subcomisario de Policía, declaraba sobre las prostitutas de alto precio: "Eran conocidísimas en razón de ser extranjeras, polacas, húngaras, austríacas, francesas, tudescas, belgas, turcas, egipcias, suecas, persas, circasianas, inglesas, rusas y otras nacionalidades de la Europa entera". Batiz 1880, p. 80.

${ }^{538}$ AHM 1890; Carretero 1998; CGCLP 1910; Ghisiglieri 2003; Guy 1994.

${ }^{539}$ Ver especialmente Carpeta N-0070 s 80 y N-0070 s 13. Legado Robert Lehmann-Nitsche, IAI.

${ }^{540}$ Lehmann-Nitsche 1911 a, p. 491. 
universidad platense. Este rechazo debe entenderse dentro de un contexto social y político donde desde los espacios de poder se orquestarán y ejecutarán una serie de iniciativas que tendrán por objetivo orientar las lecturas populares y restarle atención a la cada vez más amplia tendencia criollista ${ }^{541}$.

Ante iniciativas como "La Biblioteca de La Nación" 542 del escritor y periodista argentino Roberto Jorge Payró (1867-1928), en la cual se buscaba el enriquecimiento intelectual del sector menos letrado de la población, se antepondrán proyectos como La Cultura Argentina del médico, filósofo y sociólogo italiano Giuseppe Ingegnieri (1877-1925), más conocido como José Ingenieros, y la Biblioteca Argentina del periodista y escritor argentino Ricardo Rojas (1882-1957). Ambas propuestas; escudándose bajo el ideal de subsanar la carencia de emprendimientos editoriales que hicieran accesible al público lector la obra de pensadores, políticos y hombre de letras argentinos; buscaban estructurar, definir e instaurar la identidad y el patrimonio cultural "argentino" ante el cada vez mayor número de inmigrantes ${ }^{543}$.

Ernesto Quesada le confesaba su enojo a Lehmann-Nitsche y se lamentaba que "[...] por escrúpulos poco científicos de la biblioteca universitaria [...] haya usted omitido (de Adivinanzas Rioplatenses) la parte escatológica $[\ldots]^{544}$. A pesar de que el principal objetivo de estos trabajos será evitar que estos retazos del folklore se pierdan en el olvido, la compleja situación institucional y los avatares políticos de un país heterogéneo llevaban a LehmannNitsche a sentenciar sus trabajos a la incomprensión y al olvido ${ }^{545}$. Este se lamentaba de que siendo el campo de los estudios una materia de gran extensión y "[...] poco explorada en la Argentina $[\ldots]^{546}$, se encontrara el mismo atiborrado de la "indiferencia y franca aversión" de aquellas personas que debían velar por el progreso de la ciencia argentina.

De esta forma solamente el compilado Adivinanzas rioplatenses será publicado en órganos de edición vinculados a alguna institución platense. Este ultimo formará parte de la edición denominada Biblioteca Centenaria, la cual será un compendio de obras de carácter

\footnotetext{
${ }^{541}$ Bertoni 2001; Blache 2002; Botana 1985; Chiaramonte 1971, 1997; De Diego 2006; Halperín Donghi 1980, 2005; Romero 1978.

${ }^{542}$ Esta colección; llevada adelante por Payró y José María Teófilo Drago Mitre (1869-1906); sacará, hasta febrero de 1920, 4 títulos mensuales, llegando a sumar un total de 875 números.

${ }^{543}$ Los lineamientos del pensamiento de Rojas ya se delineaban en La Restauración Nacionalista (1909), en donde abogaba por una decisiva reforma de la enseñanza escolar que; destinada a enfatizar los valores de la nacionalidad; "argentinizara" la creciente población inmigratoria. Rojas no planteaba un rechazo abyecto de la misma, sino una asimilación. Ingenieros, por otro lado, no albergaba expectación con respecto a los elementos locales. Para este el pensamiento argentino se encontraba en formación, el cual había que encauzar. Tal como ha señalado Oscar Terán la argumentación científica de Ingenieros trama en sus intersticios más profundos la exclusión de las mayorías, de las cuales la inmigración es un elemento central. Ingenieros 1956; Rojas 1909; Terán 1986.

${ }^{544}$ Ernesto Quesada a Robert Lehmann-Nitsche- Legado Robert Lehmann-Nitsche, 30.04.1917, IAI, Carpeta N-0070 b 551.

${ }^{545}$ El prologo de Adivinanzas rioplatenses rezaba "Tal vez muchos argentinos de hoy no sabrán prestarle mayor atención; dedico, pues, la primera parte de mi folklore argentino al pueblo del 2010". LehmannNitsche 1911 a, p.1.

${ }^{546}$ Legado Robert Lehmann-Nitsche, IAI, Carpeta N-0070 w 34.
} 
histórico, entre las que se incluirían investigaciones arqueológicas y folklóricas, que formaban parte de las publicaciones realizadas como parte de los festejos del centenario de vida independiente de la Nación ${ }^{547}$. Sin embargo esta obra sufrirá demoras impuestas desde la imprenta y las personas encargadas de la publicación ${ }^{548}$. En este sentido Samuel Lafone Quevedo señalaba “[...] aceptaré gustoso un ejemplar cuando llegue a nacer. Las gestiones del cuerpo colegiado que Ud. cita tienen que ser elefantinas, de 11 meses, y la partera necesita otros 11 meses para sacar a luz. N'est ce pas?" ${ }^{549}$.

La indiferencia del público de Buenos Aires y La Plata a las compilaciones folklóricas de Lehmann-Nitsche no se limitaba al ámbito estrictamente académico. Personas por fuera de este ámbito cuestionaran la inversión económica realizadas por las autoridades de la universidad platense en una obra, por demás extensa, que poco aportaba al progreso científico del país ${ }^{550}$. Al mismo tiempo cuestionaban el contexto utilizado para la recolección de los elementos que componían el trabajo. Los espacios donde los estudiosos buscarán observar la cotidianeidad serán vistos por algunas personas ajenas al mundo académico como más propicio a satisfacer necesidades más allá de lo meramente profesional. Este punto se encargaba de señalar una reseña de Adivinanzas Rioplatenses publicada en el diario capitalino Ultima Hora. En la misma se precisaba que dicha obra -cuyo peso los autores estimaban en un kilo y medio- había costado a su autor " [...] una larga y paciente investigación á través de almanaques y tertulias de barrio apartado á base de mate de leche y pan con grasa, con resfríos y toses correspondientes á causa de retirarse á altas horas de la noche de ellas en los crudos inviernos bonaerenses, según reza en el prólogo el autor ${ }^{„ 551}$. El único beneficio posible, agregaban los redactores, se limitaba al uso de las adivinanzas compiladas dentro del circuito comercial de producción de almanaques ${ }^{552}$.

Este contexto tal vez sirva para entender la ausencia del contenido erótico-escatológico en la publicación de 1911. Ernesto Quesada le expresaba hacia 1917, en relación a estos trabajos, "Hago votos por que encuentre usted oportunidad a dar luz esa parte en el "Boletín de la Academia Nacional de Ciencias" que viene dando tanta amplia hospitalidad a sus otros

\footnotetext{
${ }^{547}$ En 1910, la Universidad Nacional de La Plata recibirá un subsidio nacional especial de 50.000 pesos moneda nacional para dichas publicaciones. García S. 2010 a.

${ }^{548}$ Críticas al rechazo de publicación de sus trabajos folklóricos por parte de las instituciones científicas y universitarias platenses pueden encontrarse en distintos trabajos inéditos como Folklore Argentino VIIIVocabulario africano (1911), Folklore Argentino XI-Tejidos criollos y Folklore Argentino XII-El Tango. Legado Robert Lehmann-Nitsche, IAI, Carpetas N-0070 w 34, N-0070 w 35, N-0070 w 40.

${ }^{549}$ Samuel Lafone Quevedo a Robert Lehmann-Nitsche. Legado Robert Lehmann-Nitsche, 17.02.1911, IAI, Carpeta N-0070 b 832.

${ }^{550}$ En una columna aparecida

${ }^{551}$ Diario Última Hora 10.05.1913.

${ }^{552} \mathrm{El} / \mathrm{los}$ redactor/es detallaban irónicamente que solamente habían podido observar en forma soslayada el compilado de Lehmann-Nitsche, ya que el presidente de la Universidad Nacional de La Plata había ordenado no hacer público el contenido del libro antes de su publicación ya que "[...] como dentro de un par de meses comienzan las confecciones de almanaques para 1914, personas poco escrupulosas podrían copiar gran número de adivinanzas y con ello hacer fracasar el éxito de librería y científico que le aguarda á semejante publicación[...]”. Ibídem.
} 
trabajos folklóricos" ${ }^{, 53}$. Quesada se refería al Boletín de la Academia Nacional de las Ciencias en Córdoba, el cual bajo la egida de un comité científico compuesto en su totalidad por científicos alemanes ${ }^{554}$, albergará la serie de monografías II a VI: "El caballo retajo" (1914), "El Chambergo" (1916), "La bota de potro" (1916), "Santos Vega" (1917) y "La Ramada" $(1919)^{555}$.

Este tipo de trabajos se proponían el estudio histórico de los grupos humanos a través de la evidencia aportada por los elementos de la cultura material. Esta metodología ya había sido implementada anteriormente por otros estudiosos alemanes al momento de investigar sobre las manifestaciones folklóricas americanas. En este sentido Boas, en sus trabajos sobre la distribución de los componente folklóricos en la costa noroeste de los Estados Unidos aseveraba que "Comparison of present forms was the only evidence for past history, but this made possible legitimate inferences about how elements had combined"556. En forma similar se expresaba Rudolf Lenz para el cual la importancia de los estudios folklóricos estaba en la comparación de los elementos de la cultura material de las "razas primitivas" americanas, lo cual permitía "[...] comprender la prehistoria desconocida de las naciones de alta cultura" ${ }^{, 557}$. Estos elementos permitirían superar el desconocimiento o la escasa información histórica presente en los documentos escritos.

De esta forma el estudio histórico de objetos "característicos y típicamente genuinos" como la bota de potro o el sombrero chambergo tornaban menester combinar y complementar los datos literarios con aquellas observaciones propias, metodología que destacaban las reseñas aparecidas en revistas y diarios locales. Será a partir de estos elementos que los estudiosos reconstruyan las relaciones y los movimientos de los grupos humanos en tiempo y espacio. Las extensas monografías de Lehmann-Nitsche; redundantes en extensas transcripciones literarias en las cuales se hacían referencia pormenorizada -en muchos casos- sobre el objeto de estudio en cuestión; finalizaban estableciendo un origen europeo para las prendas de vestir gauchescas. Tomado con sorna y burla por algunos, será motivo de orgullo para otros. En este sentido una reseña sobre el trabajo de la bota de potro, aparecida en la revista argentina de humor gráfico $P B T$, señalaba que, acorde a las conclusiones de Lehmann-Nitsche, la misma había sido conocida y utilizada por los griegos, lo cual " [...] era un detalla valioso que no solo pone una aureola de gloria sobre la dulce tierra de Homero, sino que también decora y ennoblece a los

${ }^{553}$ Ernesto Quesada a Robert Lehmann-Nitsche- Legado Robert Lehmann-Nitsche, 30.04.1917, IAI, Carpeta N-0070 b 551.

${ }^{554}$ La presidencia era ejercida por químico y geólogo Adolf Döring, mientras que la dirección del mismo se componía por el botánico Friedrich Kurtz (1854-1921), el físico y matemático August Philipp Oscar Achatz Döring (1844-1917), el geólogo Wilhelm Bodenbender (1857-1941) y el químico Ludwig Harperath (-1931).

${ }^{555}$ Lehmann-Nitsche 1914 b, 1916 d, 1916 e, 1917 a, 1919 a.

${ }^{556}$ Boas 1891, p. 13.

${ }^{557}$ Lenz 1909, p. 5. 
gauchos argentinos, unidos a los ciudadanos de Atenas por el vinculo indestructible del calzado común" 558 .

Mientras que para algunos individuos el contar con trabajos que demostraran la genealogía helénica de los argentinos sería motivo de orgullo, para otros seria invertir dinero en publicaciones que solo contribuían a engrosar los motivos de los almanaques y el acervo de publicaciones de Lehmann-Nitsche, en el cual verían un individuo que sabia aprovecharse de las circunstancias y conveniencias de contar con coterráneos que decidieran editar sus monografías. En este sentido, y con motivo de la publicación de su trabajo sobre Santos Vega, señalaba una nota aparecida en el diario La Idea Nacional "Van ya cinco "estudios" -así llama él [en referencia a Lehmann-Nitsche] al fárrago de incongruencias que reúne sin ton ni son- que la krante (sic) profesor von sifilización (sic) lucubra con el que comentamos hoy, y que llena todo el volumen XXII del Boletín de la Academia Nacional de Ciencias de Córdoba” ${ }^{„ 559}$.

Otro de los espacios donde expondrá resúmenes de estos trabajos o bien parte de los resultados de sus manuscritos inéditos será las reuniones de la Junta de Historia y Numismática Americana. Estas comunicaciones tendrán lugar, especialmente, luego de los sucesos de la Gran Guerra, en un contexto conflictivo para los alemanes residentes en la Argentina. A través de este espacio institucional Lehmann-Nitsche buscará demostrar la antigüedad de los vínculos existentes entre Argentina y Alemania. Como sucediera a lo largo de la década de 1920 muchos estudiosos alemanes residentes en América harán uso político de sus trabajos o de los espacios institucionales en los cuales se desempeñaban. De esta forma el estudio heráldico de un antiguo blasón de armas de los condes de Salm demostraba el origen alemán del gorrete de cuero crudo utilizado por los gauderios y montoneros de la época colonial argentina ${ }^{560}$. En forma similar el estudio lingüístico de la voz suizo-alemana "laube" permitía plantear el origen germánico de la vivienda gauchesca conocida como "ramada" publicaciones científicas argentinas fuera del contexto platense o bien extranjeras ${ }^{562}$, en distintos periódicos y revistas de la egida rioplatense ${ }^{563}$, y finalmente distintos medios gráficos alemanes publicados en Alemania y en la Argentina ${ }^{564}$.

\footnotetext{
${ }^{558}$ Revista $P B T, 30.12 .1916$

${ }_{559}^{5}$ Diario La Idea Nacional, 26.10.1917.

${ }^{560}$ Diario La Nación, 07.09.1917.

${ }^{561}$ Diario La Nación, 12.05.1919; Lehmann-Nitsche 1919 a.

562 Publicaría trabajos en: la Revista de derecho, historia y letras de la Universidad Nacional de Buenos Aires (1908), en los Anales de la Sociedad Científica Argentina (1914); en los Anales de la Facultad de derecho y ciencias sociales de la Universidad Nacional de Buenos Aires (1916); en The Journal of american folk-lore (1918); en la Revista chilena de historia y geografía (1918); en la revista La Quena (1921); en la revista El Hornero (1921) y en la Revista de la Universidad de Buenos Aires (1928). Lehmann-Nitsche 1908 a, 1914 a, 1916 f, 1918 a, 1918 b, 1921 c, 1923 e, 1928 j.

${ }_{563}$ Publicaciones argentinas como el periódico La Prensa y la revista Nativa, junto con la revista uruguaya El Terruño albergarán versiones resumidas de los trabajos sobre Santos Vega, la bota de potro, o las aves sudamericanas. Lehmann-Nitsche 1936 a, 1936 b, 1936 c, 1937 f, 1937 g.

564 Resúmenes de trabajos previos aparecerán en las páginas del Zeitschrift des Deutschen Wissenschaftlichen Vereins zur Kultur-und Landeskunde Argentiniens. Por otro lado temas variados como
} 
Finalmente es preciso mencionar que el difícil contexto social y académico en el cual se desenvolvían las tareas antropológicas vinculadas a la recolección, análisis y publicación del aquellas manifestaciones folklóricas "populares" no será exclusivo de la Argentina. De esto da cuenta la publicación que Lehmann-Nitsche realizará, en 1904, de El cancionero venezolano, Cantos populares de Venezuela recogidos por el Dr. A. Ernst, donde se compilaban los artículos sobre folklore venezolano publicados por Adolf Ernst en la segunda mitad del siglo XIX.

Ernst se ocupara, desde su llegada a Venezuela en 1861, a la recopilación de todas las manifestaciones materiales de la cultura venezolana. De entre sus casi 500 trabajos editados, aquellos realizados entre 1869 y $1893^{565}$ en las publicaciones alemanas Globus y Verhandlugen der Berliner Gesellschaft für Anthropologie y en la venezolana El Cojo Ilustrado, serán referidas por Lehmann-Nitsche como las únicas investigaciones científicas folklóricas realizadas en Latinoamérica. En estos trabajos Ernst advertía que los países latinoamericanos constituían un amplio campo de estudio donde la recolección y conformación de un acervo folklórico, proclives a desaparecer por el avance impetuoso del progreso y del tiempo, no se encontraba entre las principales preocupaciones ${ }^{566}$. En este sentido el publicista alemán Carl Eugen Salzer (1866-1938), exhortaba a la articulación de una red de estudiosos alemanes que se dedicarán a la recopilación sistemática de tradiciones folklóricas en cualquier soporte ${ }^{567}$.

En este particular contexto no solo era necesaria la recolección sistemática de estas tradiciones, sino la utilización de elementos que permitieran efectivizarla y salvar aquellas manifestaciones del paso del tiempo. Hacia 1913 el escritor y antropólogo italiano Giuseppe Pitrè (1841-1916) describía el compendio Adivinanzas Rioplatenses como “[...] uno de los más grandes documentos humanos. Hasta ayer se podía componer la historia de los pueblos sobre documentos de archivo: ahora se puede componerla haciendo hablar a los pueblos mismos" ${ }^{, 58}$. En este sentido uno de las contribuciones de Lehmann-Nitsche al estudio del folklore será la implementación de nuevas tecnologías de recolección, clasificación y distribución de los elementos folklóricos.

la tormenta de Santa Rosa o las embarcaciones marinas serán publicados en el Bundeskalender, una publicación hecha en la Argentina y editado por la Deutscher Volksbund für Argentinien (Confederación alemana para Argentina), órgano de la legación alemana fundada en 1916. En estas últimas publicaciones acentuará sobre la posible influencia o bien el origen ario de las manifestaciones folklóricas americanas. Lehmann-Nitsche 1914 c, 1917 b, 1917 c, 1917 d, 1918 c, 1918 d, 1919 b, 1923 d, 1924 b, 1924 c, 1924 d, $1925 \mathrm{c}$.

${ }^{565}$ En 1869 publicaba "Proben venezuelanischer Volksdichtung", trabajo en el cual señalaba la influencia ibérica en la poesía popular venezolana. Posteriormente publicará en el Verhandlugen der Berliner Gesellschaft für Anthropologie una traducción sobre una serie de historias que una de sus sirvientas contaba a sus niños y más tarde una segunda y una tercera selección de poesía popular venezolana. Ernst 1987.

${ }^{566}$ Hacia 1893 señalaba: "Superfluo nos parece abogar por la conveniencia de una empresa de este género, que en otros países se ha llevado a cabo ya hace mucho tiempo y con singular acierto". Ernst 1987 , p. 14.

567 Bernhard Schädel a Robert Lehmann-Nitsche. Legado Robert Lehmann-Nitsche, 04.11.1915, IAI, Carpeta N-0070 b 1086.

${ }^{568}$ Legado Robert Lehmann-Nitsche, IAI, Carpeta N-0070 1 35. El resaltado es de nuestra autoría. 


\subsection{Tecnologías de recolección}

\subsubsection{El fonógrafo en el trabajo de campo}

Hacia 1874 se publicaba en la primera edición de Notes and queries on anthropology una reflexión sobre los estudios etnográficos musicales "[The researcher] must assume the attitude of a learner, not of a teacher. The music of every people, whether vocal or instrumental, has its own characteristics, and can be estimated rightly only on the evidence supplied by accurate records. General impressions—even those of a trained European musician-are of little value unless the sounds and phrases which they describe can he reproduced. Music may be recorded either in writing, or by means of the phonograph or other recording instrument" ${ }^{\mathrm{N}}$.

La música será concebida como uno más de los elementos que permitían caracterizar el pasado. En este sentido el estudio de música de los grupos indígenas o bien de aquellos grupos desplazados hacia las urbes tendrá por objetivo decodificar el pasado a través de las piezas musicales las cuales, sobreviviendo en el presente, ofrecerán un vasto espacio de alteridad temporal donde el cambio no había sucedido o bien no había incidió en la identidad de la misma $^{570}$. Junto con las estructuras y tecnologías que garantizarán su circulación a través de los distintos puntos del globo, se tornará imperiosa la aplicación de técnicas mediales específicas para su reunión, procesamiento y almacenamiento ${ }^{571}$.

La implementación de dispositivos que permitieran conservar, perdurar y repetir los sonidos en forma indefinida y a voluntad será visualizada por distintos estudiosos como una revolución similar a la causada por la implementación de la fotografía en el trabajo de campo ${ }^{572}$. Como señalaba el francés René Marrage el estudio y el desarrollo de instrumentos capaces de registrar y reproducir las vibraciones de la palabra hablada serán, desde la segunda mitad del siglo XIX, uno de los principales intereses del campo disciplinar de la historia ${ }^{573}$. Si bien existen sustanciales diferencias entre la palabra escrita y la hablada, como modos de comunicación serán capaces de ser reducidas en elementos susceptibles de ser anotados en papela, tornándolas en este sentido susceptible del análisis histórico ${ }^{574}$. A lo largo del siglo XIX nuevas preguntas surgirán al interior de la antropología, las cuales se vinculan, en parte, con los procesos de

\footnotetext{
${ }^{569}$ Frake 1964 [1874], p. 33.

${ }^{570}$ Barz y Cooley 1997; Díaz Viana 1993; Hornbostel 1906; Jackson 2006; Kursell 2008; Merriam 1977; Myers 1992; Nettl 1991; Rice 1987; Siegert 2008; Werkmeister 2010.

${ }^{571}$ Schäffner 2008; Werkmeister 2010.

572 Señalaba Leon Azoulay “Avant l'apparition de la photographie et à son début, nul ne pouvait conjecturer combien il était utile et nécessaire pour le progrès de l'esprit et du bien-être humains, d'avoir une image lumineuse fixée pour un temps indéterminé, susceptible d'être vue à volonté, d'être comparée à d'autres, d'être analysée. Nul non plus ne pouvait concevoir combien le pouvoir visuel de l'homme en serait reculé, combien de régions inconnues seraient ouvertes, combien enfin d'occupations nouvelles viendraient se greffer sur la nouvelle découverte". Azoulay 1900, p. 172.

${ }^{573}$ Marrage 1898.

${ }^{574}$ Harbsmeier 1989.
} 
expansión colonial de las grandes potencias, pero también con el desarrollo e implementación de nuevos instrumentos que modificarán la medialización de los datos recogidos ${ }^{575}$.

Uno de los primeros intentos en la grabación de sonidos podemos encontrarlos en fonoautógrafo del impresor, librero, y escritor francés Édouard-Léon Scott de Martinville (1817-1879). Este formará rápidamente una sociedad con un fabricante de instrumentos musicales para fabricar los fonoautógrafos, logrando vender varios a laboratorios científicos interesados en el estudio de los sonidos vocales ${ }^{576}$. Sin embargo no logrará sacar provecho económico de su invento, principalmente por que el fonoautógrafo será capaz de grabar sonidos, pero no será posible su reproducción ${ }^{577}$ (Fig. 27).

La dominación y conexión de medios técnicos presupone, según Friedrich Kittler, una serie de coincidencias particulares. Junto con la fisiología del ojo, del oído y del cerebro convertida en objeto de estudio podremos presenciar la diferenciación de medios y dispositivos mecánicos ópticos, acústicos y gráficos, la cual se especializará notablemente a partir de la década de $1880^{578}$. En este contexto se enmarcan los trabajos del inventor y empresario estadounidense Thomas Alva Edison (1847-1931). A lo largo de la década de 1870 sus trabajos sobre las capacidades mecánicas de grabación y reproducción de sonidos estarán en relación al desarrollo de un instrumento aplicable a una serie de problemas ${ }^{579}$. Estos confluirán en la demostración pública de su fonógrafo, en 1877. Solo unos meses más tarde, en febrero de 1878, y luego de que le aprobaran la patente del mismo, casi 600 maquinas inundarán el mercado.

En una primera instancia será pensado para los espacios domésticos, por lo cual parte del público lo considerará un mero juguete con poco valor práctico. Sin embargo el gran impulso dado por la prensa y las demostraciones públicas entre 1878 y 1890 facilitará

\footnotetext{
575 En este sentido Werkmeister señala que "Die Frage erscheint berechtigt, verläuft doch gerade die Ausdifferenzierung der Ethnologie als wissenschaftlicher Disziplin der Erforschung von (fremder) Kultur in der zweiten Hälfte des 19. Jahrhunderts historisch nicht nur parallel zur umfassenden Eroberung und Erforschung der Welt durch die europäischen Kolonialmächte, sondern fällt auch in die Epoche der neuen technischen Medien Photoapparat (1839), Phonograph (1877) und Film (1895) und der sich zunehmend technischer Aufzeichnungs- und Darstellungsmedien bedienenden neuen Wissenschaften vom Menschen und dessen Kultur." Werkmeister 2010, p. 32.

${ }^{576}$ Varios estudiosos como el oftalmólogo holandés Franciscus Cornelis Donders (1818-1889), Heinrich Schneebeli y Rene Marage darán cuenta de la utilidad del aparato de Martinville a la hora del estudio de los sonidos. El fonoautógrafo provocará además el desarrollo de otras herramientas para visualizar el sonido como por ejemplo el aparato de flama manométrica del físico alemán Karl Rudolph Koenig (18321901).

${ }^{577}$ Barz y Cooley 1997.

${ }^{578}$ Kittler et al 1987.

${ }^{579}$ Por un lado se encontraba la creación de un parlante para el recientemente patentado teléfono del científico y logopeda británico Alexander Graham Bell (1847-1922). Al mismo tiempo Edison buscaba desarrollar un telégrafo escribiente y una forma de aplicar el teléfono a las necesidades de la empresa Western Union Telegraph Company en la cual se encontraba empleado. Los primeros éxitos de venta motivarán a Edison, él cual buscara ampliar la implementación del fonógrafo en la construcción de juguetes infantiles sonoros, relojes musicales u avisos publicitarios parlantes. Catania 2000, 2003, 2004; Hounshell 1975.
} 
notablemente la inserción del fonógrafo en los espacios científicos (Fig. 28). Como el propio Edison afirmaba la calidad de lo escuchado no era óptimo, algo que no le permitía tomar a la perfección de la voz de la soprano española Adelina Patti (1843-1919), sin embargo, afirmaba, la fortaleza del dispositivo estaba en la capacidad del oyente de discriminar y reconocer los sonidos que del cono emanaban ${ }^{580}$. El fonógrafo no tardará en cruzar el Atlántico para hacerse presente en los espacios científicos europeos.

Los estudios de musicología comparada tendrán un fuerte impulso en Europa, contando entre sus elementos de estudio con muestras musicales sudamericanas. En 1905 el musicólogo austriaco Erich Moritz von Hornbostel (1877-1935) señalaba las descripciones subjetivas efectuadas por músicos que; sin poseer una formación antropológica; se aprestaban a los estudios de musicología comparada.

De esta forma, en los análisis de los materiales recogidos por los viajeros era común encontrar descripciones subjetivas tales como, "música disonante de los nativos", "voz melancólica de una extraña tonada" o bien errores al momento de realizar las transcripciones. Esto era resultado de escuchar los materiales "a la europea" ${ }^{, 51}$. Al mismo tiempo remarcaba Hornbostel que el surgimiento de los estudios científicos de musicología comparada, encontraban su origen en la búsqueda de respuesta a dos interrogantes surgidos a partir de la segunda mitad del siglo XIX: cómo conservar los registros sonoros de la manera más "fiel” y "objetiva" posible por un lado, y la posibilidad de repetición de la experiencia por el otro ${ }^{582}$. Estas serán respondidas, en parte, por el fonógrafo de Edison.

La capacidad de "almacenar" el tiempo ${ }^{583}$, de preservar esas "fugitive sound waves" favorecerá la incorporación del fonógrafo como un dispositivo más en el trabajo de campo. En este los estudiosos verán un dispositivo que permitía la conservación precisa y objetiva de patrones expresivos, tales como lenguaje y música, de los grupos humanos que estudiaban ${ }^{585}$. Al mismo tiempo hará factible la "separación" de los datos de sus "fuentes", es decir los sonidos de los ejecutantes, convirtiendo estos últimos en unidades maleables, transferibles y flexibles, plausibles de ser almacenadas y principalmente ser transportados a cualquier punto del planeta $^{586}$.

\footnotetext{
${ }^{580}$ Thompson 1995.

${ }^{581}$ Hornbostel 1906, p.43.

582 Ibídem.

${ }^{583}$ Brady 1999; Kittler et al 1987.

${ }^{584}$ Edison 1878 , p. 530.

${ }^{585}$ Brady 1999; Kittler et al 1987; Maisonneuve 2006.

${ }^{586}$ Esta preservación "intacta" del pasado serviría no solo para comparar las distintas manifestaciones orales de los diferentes puntos del globo; sino para demostrar científicamente el grado de avance que la cultura europea había alcanzado. Aretz 1991; Brady 1999; Jackson 2008; Kittler et al 1987; Kursell 2008; Maisonneuve 2006; Werkmeister 2010.
} 
Tal como afirma Hans Ulrich Gumbrecht “[...] the gramophone makes present those who are absent or dead" ${ }^{587}$. Siguiendo su análisis podemos señalar que los dispositivos de captura y reproducción de sonido serán asociados, desde los espacios comerciales y eruditos, con la muerte y por ende con la posibilidad de capturar las manifestaciones sonoras en el tiempo para poder traerlas nuevamente al presente. Gumbrecht indica que el gramófono será un elemento indispensable de la vida moderna, pero un emblema de la modernidad estática ${ }^{588}$. Continuando con su análisis lo vinculará con la danza y la expresión de las emociones a través del movimiento del cuerpo, en este punto también podemos vislumbrar una de las características de estos dispositivos y es la separación entre los datos y sus "fuentes", como advierte Gumbrecht "Fascination with rhythm points to a fascination with the separation between the human body, which is capable of incarnating (that is, of becoming and being) a rhythm, and the human mind, which, as source of the dual-level relation between signifiers and signified $[\ldots]^{, 589}$.

\subsubsection{El uso del fonógrafo en los trabajos de campo en América}

En 1908 Benjamin Ives Gilman (1852-1933); por entonces secretario del Boston Museum of Fine Arts; recordaba que el análisis científico de la música se encontraba hacia mediados del siglo XIX en una situación de desventaja con respecto al estudio de otras manifestaciones culturales y artísticas como la pintura y la escultura. La música, como un fenómeno transitorio, no era un objeto con permanencia física en el espacio material, por lo cual se encontraba condenado al terreno del recuerdo y la experiencia única. Precisión y revisión, dos ítems esenciales en la investigación científica, eran posibles en la observación del color y forma, pero no al momento de escuchar los sonidos ${ }^{590}$. En este sentido el fonógrafo como sistema de almacenamiento mecánico que permite grabar y reproducir el flujo temporal de datos acústicos consentirá la autonomía del ojo y el oído. De esta forma los estudiosos caracterizarán estos trabajos, automatizados por la asistencia mecánica, como impersonales y carentes de subjetividad $^{591}$.

Siendo utilizado en campos como la medicina, la psicología y la etología animal ${ }^{592}$, el fonógrafo se incorporará a los estudios antropológicos por su capacidad de grabar el "caos

\footnotetext{
${ }^{587}$ Gumbrecht 1997, p. 108-109.

${ }^{588}$ Ibídem, p. 112.

${ }^{589}$ Ibídem, p. 68-113.

${ }^{590}$ Gilman 1908.

591 Abraham y Hornbostel 1904 a, 1904 b, 1904 c; Azoulay 1900, 1901, 1911; Densmore 1927; Fewkes 1890 a, 1890 b; Gilman 1908; Graf 1974; Grainger 1908; Goddard 1905; Hornbostel 1936; Kittler et al, 1987; Marage 1898; Radick 2005; Rhodes 1952; Science 1890; Werkmeister 2010; Yates 1982.

${ }^{592}$ En 1890 un tal Dr. Blodgett daba cuenta del uso del fonógrafo para la grabación de la historia clínica de sus pacientes. Afirmaba que gracias a este podía obtener de labios de los propios pacientes testimonios durables y dignos de confianza, agregando hacia el final que estos testimonios podían ser utilizados en casos médico-legales, ya que estos podían ser reproducidos en un periodo indefinido de tiempo posterior
} 
sonoro" en tiempo real para luego ser reproducido lentamente ${ }^{593}$. Como señalaban Otto Abraham (1872-1926) y Hornbostel "Luego de que los ritmos son detenidos, es posible una grafía correcta con el alfabeto occidental, incluso la de la notas y medidas individuales" ${ }^{\text {"594 }}$. A comienzos del siglo XX tanto los estudiosos, como los pueblos estudiados por ellos, sentirán una especial fascinación por el fonógrafo, lo cual podemos encontrarlo en un variado número de relatos de viaje de fines del siglo XIX y principios del siglo $\mathrm{XX}^{595}$.

En 1882, el estadounidense Theodore Baker (1851-1934) publicaba su tesis doctoral Über die Musik der nordamerikanischen Wilden, resultado de su trabajo entre los indios Onöndowága de New York. Entre 1874 y 1880 Baker había realizado estudios de musicología en la Universität Leipzig bajo la guía del musicólogo alemán Oscar Paul (1836-1898). Dicho trabajo será visto por algunos musicólogos como el primer trabajo científicamente importante sobre la música "primitiva" americana ${ }^{596}$. La misma caracterizará una forma de construcción del objeto de estudio en el cual las manifestaciones y expresiones sonoras de un determinado grupo cultural, serán conceptualizadas como elementos significativos en la reconstrucción histórica, debido a su notable resistencia al cambio cultural ${ }^{597}$.

Esta será la premisa que guiará las investigaciones de distintos estudiosos que emprenderán una serie de trabajos de campo a fin de poder lograr un registro lo más fiel posible de la música "primitiva" americana. Entre los más significativos podemos mencionar los de la etnógrafa estadounidense Alice Cunningham Fletcher (1838-1923) en 1883, los del filósofo y psicólogo alemán Carl Stumpf (1848-1936) en 1886 y los Franz Boas en 1888. Estos trabajos, sin embargo no podrán fijar en una forma material perdurable la fugacidad del sonido, tal como señalaban Stumpf y Boas ${ }^{598}$.

a la grabación. En la misma época el psicólogo británico Edward Bradford Titchener (1867-1927) declaraba que el fonógrafo era uno de los instrumentos fundamentales en el equipamiento de un laboratorio de psicología. Richard O. Johnson, superintendente del Deaf and Dumb Institute de Indianapolis, proponía su uso en la re-educación de los sordomudos. F. A. Seely, en una reseña sobre el libro Intelligence et Instinct (1892), destacaba la grabación del "lenguaje" de los primates por parte del zoólogo estadounidense Richard Lynch Garner (1848-1920). Esta implementación masiva y veloz del fonógrafo se evidencia en las palabras de Leon Azoulay quien hacia 1900, en un trabajo sobre los museos y los archivos fonográficos, declaraba "Vraiment, il semble inutile de passer en revue toutes les sciences, Tous les arts et toutes les industries susceptibles dès maintenant de tirer profit de la fixation et de la reproduction de la voix, des sons et des bruits par le phonographe". Azoulay 1900, p.74; Science 1890, 1892; Seely 1892; Titchener 1900.

${ }^{593}$ Jackson 2008; Kittler et al 1987; Sieger 2008; Werkmeister 2010.

${ }^{594}$ En el original "Wenn die Rhythmen dann gelähmt und die individuelle Maßnahmen, sogar einzelne Töne erklingen, abendländischen Alphabetismus mit ihren Stäben, kann zu einem gehen exakte Schreibweise". Abraham y Hornbostel 1904, p. 229.

595 Jackson 2008; Sieger 2008; Werkmesiter 2003, 2010.

${ }^{596}$ Baker 1882; Hickerson et.al 1986; Kurkela 1994; Merriam 1977; Stevenson 1973.

${ }^{597}$ Abraham y Hornbostel 1904 a; Baker 1882; Herzog 1936; Kittler et al 1987; Werkmeister 2010.

${ }^{598}$ Fletcher realizará trabajo de campo entre los indios U-Mo'n-Ho'n. Boas y Stumpf lo harán sobre indios en contextos urbanos. Mientras que el primero lo hará sobre los indios Chinook de la costa noreste del 
Esta problemática será resuelta, en parte, por el antropólogo estadounidense Jesse Walter Fewkes (1850-1930), quien en 1889, y ante la renuncia del antropólogo Frank Hamilton Cushing (1857-1900), se ponía al frente de la Hemenway Southwestern Archaeological Expedition $^{599}$. En dicha expedición Fewkes grabará música y dialecto de los indios Peskotomuhkati, significando el primer registro mecánico de dialectos y música indígena con fines científicos ${ }^{600}$. Señalaba Fewkes que la implementación de métodos e instrumentos que permitían registrar y preservar el folklore indígena le daban a los estudios folklóricos un verdadero valor científico, principalmente por el control que permitía ejercer al investigador y sobre todo por la eliminación de la interpretación subjetiva por parte de este último ${ }^{601}$. Las investigaciones de Fewkes darán lugar a una larga serie de trabajos de musicología comparada en la cual el fonógrafo ocupara un lugar central. Como ha señalado Erika Bradi al analizar el uso del fonógrafo por parte de los investigadores del Bureau of American Ethnology, "This return of the recordings is not without irony, since both fieldworkers and often their subjects assumed that by the end of the twentieth century such communities would have long ceased to exist" ${ }^{\prime 602}$.

El número de grabaciones darán lugar al surgimiento de repositorios donde almacenar "[...] la partie vocale, phonique des idiomes et des peuples, ce que sont les bibliothèques et musées pour leurs manifestations écrites ou gravées, ou industrielles, ou artistiques" ${ }^{\text {603 }}$. Esto llevará a Lehmann-Nitsche a efectuar, entre 1905 y 1909, cerca de 250 grabaciones fonográficas las cuales darán como resultado la conformación de cinco colecciones de 125 cilindros de cera en los cuales pueden registrarse diversas expresiones musicales (con o sin acompañamiento) y vocabularios "populares" ${ }^{604}$. Estos buscarán colaborar con el Phonogramm-Archiv des Psycologischen Instituts der Universität Berlin fundado hacia septiembre de 1900 por Carl

pacífico de Estados, el segundo lo hará en ocasión de una exhibición de indios Bella Coola realizada en Alemania en 1885. Boas 1885, 1888; Fletcher 1885, Stumpf 1886.

599 La misma se encontraba bajo el auspicio de la filántropa estadounidense Mary Porter Tileson Hemenway (1820-1894).

${ }^{600}$ Señalaba Fewkes que el principal objetivo en la implementación del fonógrafo era la posibilidad de salvar a las manifestaciones culturales de los Peskotomuhkati de la extinción del tiempo, "The manners and customs of this people are fast dying out. The old pointed caps, ornamented with beads, and the silver disks, which they once wore, are now rarely seen except in collections of curiosities. The old games, dances, and songs are fast becoming extinct, and the Passamaquoddy has lost almost everything which characterized his fathers". Fewkes 1890 b, p. 259.

${ }^{601}$ Detallaba Fewkes que "In observations on the traditions of the Indian tribes, the tendency of the listener to add his own thoughts or interpretations is very great. Moreover, no two Indians tell the same story alike. These are sources of error which cannot be eliminated, but by giving the exact words of the speaker it is possible to do away with the errors of the translator". Ibídem p. 257.

602 Brady 1988, p.35.

${ }^{603}$ Azoulay 1900, p. 175.

${ }^{604}$ Aretz 1991; Bilbao 2004; Caceres Freyre 1972; Carrizo 1953; Chertudy 1964; Cortazar 1964; García M. 2006, García y Chicote 2008; Guido W. 1975. 
Stumpf con la colaboración de, por su entonces estudiante, Erich Moritz von Hornbostel y Otto Abraham $^{605}$.

\subsubsection{Los registros de música "exótica" y "popular"}

Al describir la cultura popular argentina Ángel Rama afirmaba que “[...] nada la expresa mejor que la invención del tango en el Río de la Plata. Junto con la inmigración (interna y externa) el tango fue forjado en burdeles suburbanos, y después de veinte años fue aceptado en los salones de la clase media"606. Entre 1860 y 1930 ciudades como Buenos Aires, Montevideo, Rosario y La Plata serán testigos de la concentración de músicos que, en ambientes como prostíbulos, bares y fondas, ejecutaban piezas de del repertorio "popular", elementos que llamarán la atención de los antropólogos ${ }^{607}$.

El 27 de junio de 1900 un curioso Rudolf Lenz; luego de haber escuchado gran cantidad de música folklórica chilena, le escribía a Lehmann-Nitsche "Ahora he vuelto a la música chilena, especialmente cueca, tonada y su origen, en el cual yo veo un poco de material español. ¿Hay alguien que haya buscado algo de música folklórica argentina para piano o guitarra con letras? Lo que yo he encontrado aquí es generalmente bastante malo. Pero tengo un poco y la historia es muy interesante" ${ }^{, 608}$. Al mismo tiempo le recomendaba que en futuros viajes a Alemania se aprovisionara de bibliografía especializada en el estudio de la música popular americana. Reconociendo el interés por profundizar sus conocimientos teóricos sobre musicología, Lenz cerraba su carta dejando abierta una pregunta que incentivará el inicio de este tipo de estudios por parte de Lehmann-Nitsche: "Conoce usted sobre música popular española"609.

Es muy probable que Lehmann-Nitsche, al momento de recibir la carta de Lenz, tuviera, en el amplio número de materiales recolectados, algunos que se vincularán con la música

\footnotetext{
${ }^{605}$ Hacia 1900 Stumpf y Abraham; los cuales contaban con una ganada reputación en el campo de la acústica y la psicología respectivamente; realizaban, con un fonógrafo Edison, el registro musical de una orquesta teatral tailandés que se presentaba en Berlín, obteniendo 24 fonogramas. El resultado del estudio científico se publicaba bajo el nombre de Tonsystem und Musik der Siamesen (1901). A partir de estas primeras grabaciones realizadas, Stumpf reflexionaba sobre la importancia del Phonogrammarchivs de Viena y la necesidad de que los estudios de musicología comparada en Alemania contarán con un espacio para conservar y estudiar los registros fonográficos. Estas grabaciones constituirán la primera colección del Phonogramm-Archiv en el Psycologischen Instituts de la Universität Berlin. Christensen 2002; Hornbostel 2000 a, 2000 b; Simon 2000; Stumpf 1901, 1908.

${ }^{606}$ Rama 1984, p. 143.

${ }^{607}$ Guy 1994; Rama 1984.

${ }^{608}$ En el original "Ich bin jetzt wieder auf chil. Musik gekommen .bes. Cueca und Tonada und ihre Ursprung, da Ich zufällig einiges spanische Material unter die Finger bekommen habe. Gibt es irgend etwas von argentinischer Volkmusik gesuchtet etwas für Klavier oder Guitarre mit Texten? Was hier gesuchtet is meistens ganz falsch und blech. Aber ich habe doch schon einiges und die Geschichte ist recht interessant". Rudolf Lenz a Robert Lehmann-Nitsche. Legado Robert Lehmann-Nitsche, 27.06.1900, IAI, Carpeta N-0070 b 420.

${ }^{609}$ En el original “Kennen Sie etwas über span. Volkmusik?". Rudolf Lenz a Robert Lehmann-Nitsche. Legado Robert Lehmann-Nitsche, 27.06.1900, IAI, Carpeta N-0070 b 420.
} 
popular. Posiblemente la carta de su colega alemán motivará a Lehmann-Nitsche por emprender un estudio más sistemático de dicho tema. Al igual que en los estudios lingüísticos mapuches, la figura de Lenz será decisiva. Este motivará e incentivará a Lehmann-Nitsche a fin de poder contar con datos e información que fueran funcionales a sus propios objetivos. Hacia 1901 Lenz le pedía que en futuras cartas le remitiera dos o tres ejemplares de distintos autores folklóricos argentinos, especialmente aquellos que tocaban guitarra y fueran "populares", junto con algún ejemplar de los distintos bailes folklóricos. Al mismo tiempo le confesaba cierta preocupación por el atraso en la recepción de la revista alemana Internationale Musikgesellschaft ${ }^{610}$. El no contar con bibliografía actualizada y estar al tanto de los últimos trabajos publicados, era contraproducente a los deseos de Lenz por comenzar un verdadero estudio científico de la música americana. Esto llevaba a sugerirle a Lehmann-Nitsche la realización de algún futuro trabajo en conjunto ${ }^{611}$.

Lenz será también el que estimule a Lehmann-Nitsche por la implementación de nuevas tecnologías para los trabajos de musicología comparada. En 1903 Lenz le confesaba que tenía poca esperanza en el trabajo con los fonógrafos, a los cuales todavía no podía sacarles el mayor provecho, sin embargo, remarcaba, era un instrumento por el cual valía la pena realizar más de un intento ${ }^{612}$. Posiblemente esto incentivará a Lehmann-Nitsche a escribir a la comisión del Phonogrammarchivs der kaiserlichen Akademie der Wissenschaften de Wien ${ }^{613}$. Este había sido fundado el 27 de abril de 1899, siendo el archivo audiovisual de investigación más antiguo del mundo, y al momento en que Lehmann-Nitsche estableciera comunicación sus miembros llevaban varios años en el desarrollo y el mejoramiento de instrumentos y accesorios para la grabación.

Lehmann-Nitsche consultaba a los miembros de dicho archivo en torno a la posibilidad de registrar las lenguas indígenas con el "mejor aparato por entonces disponible" ${ }^{\text {"614 }}$, ya que, al igual que Lenz, consideraba que el método del dictado y la transcripción al papel parecía insuficiente. Exner-Ewarten contestaba dicha petición, recomendándole la utilización del

\footnotetext{
${ }^{610}$ La misma fue fundada en 1888 por el musicólogo alemán Oskar Fleischer (1856-1933).

${ }^{611}$ Rudolf Lenz a Robert Lehmann-Nitsche. Legado Robert Lehmann-Nitsche, 29.03.1901, IAI, Carpeta $\mathrm{N}-0070$ b 420.

${ }^{612}$ Rudolf Lenz a Robert Lehmann-Nitsche. Legado Robert Lehmann-Nitsche, 15.06.1903, IAI, Carpeta $\mathrm{N}-0070$ b 420.

${ }^{613}$ Como declarará el director del mismo; el fisiólogo austriaco Sigmund Exner-Ewarten (1846-1926); la fundación del archivo se relacionaba directamente con el perfeccionamiento de una forma de grabación que permitiera la copia y la reproducción infinita sin perdida de calidad. Este nuevo formato será desarrollado por Fritz Hauser y Ludwig Castagna, los cuales combinarán los procedimientos técnicos implementados por Edison y el alemán Emil Berliner (1851-1929). La grabación seguía las recomendaciones de Edison, es decir en forma perpendicular a la superficie de un disco de cera. A través del proceso de galvanoplastia se obtenía un negativo que servía como matriz metálica para la realización de un número indefinido de copias. Exner 1900, 1902; Hauser 1906.

${ }^{614}$ Lehmann-Nitsche 1908 c, p.1.
} 
fonógrafo promocionado desde el Phonogrammarchivs de Wien ${ }^{615}$. Lehmann-Nitsche descartará el mismo debido a que su excesivo peso dificultaba su traslado al campo, limitando por lo tanto el alcance de las investigaciones que podían realizarse ${ }^{616}$. Sin embargo esto no lo hará apartarse de la idea de llevar a cabo este tipo de estudios. Hacia 1904, estando en viaje de estudios en Europa, sostendrá un encuentro con Félix Ritter von Luschan ${ }^{617}$ el cual le recomendaba el uso del gramófono común. Este era posible de conseguir en cualquier comercio a un precio razonable, y ofrecía resultados óptimos para los fines de las ciencias musicales. Esto lo convertía, según von Luschan, en un instrumento ideal a la hora de poder registrar científicamente, y de forma "cómoda e intachable", la lengua y la música de los grupos indígenas ${ }^{618}$.

\subsubsection{Arcos y guitarras en el Museo de La Plata}

Hacia comienzos de 1905 un grupo Tehuelche; compuesto por 7 individuos y un perro; se detenían en las inmediaciones de la ciudad de La Plata. Dicho grupo volvía de los Estados Unidos, donde había sido expuesto en la Louisiana Purchase Exposition de Sant Louis (1904) por intermedio del señor Vicente Cané ${ }^{619}$ (Fig. 29). Esta oportunidad será aprovechada por Lehmann-Nitsche para realizar en el Museo de La Plata, un conjunto de trabajos que incluirán: retratos, trabajos antropométricos y una serie de registros hablados, cantos y ejecuciones con el

615 Lehmann-Nitsche, 1908 c; Phonogramm-Archivs-Kommission der Akademie der Wissenschaften Wien a Robert Lehmann-Nitsche. Legado Robert Lehmann-Nitsche, IAI, 24.08.1903, Carpeta N-0070 b 888.

${ }^{616}$ Lehmann-Nitsche $1908 \mathrm{c}$.

${ }^{617}$ Von Luschan había grabado los cantos de Abdal Ali durante las excavaciones realizadas hacia 1902 en Sendschirli (Zincirli-Turquía). En Anleitung für ethnographische Beobachtungen und Sammlungen in Afrika und Oceanien (1904) realizará un fuerte llamado a la recolección de grabaciones fonográficas, incluyendo además una serie de recomendaciones sobre el transporte del fonógrafo, la forma de grabar y que preguntar. Esta serie de instrucciones serán repartidas rápidamente a estudiantes, misioneros, viajeros, oficiales y cualquier persona deseosa de prestar sus servicios al Berlin Phonogramm-Archiv. Estas, antes de realizar sus viajes, serán introducidas en los detalles técnicos y metodológicos a través de una serie de pequeñas demostraciones en el propio archivo. Von Luschan 1904 a, 1904 b.

${ }^{618}$ Lehmann-Nitsche $1908 \mathrm{c}$.

${ }^{619}$ El encargado de la sección de antropología de la exposición, el antropólogo y geólogo estadounidense William John McGee (1853-1912), detallaba que "It is the object of the Section of Ethnology at once to gratify instinctive curiosity and to satisfy the more serious impulses of students by bringing together a more complete assemblage of the world's peoples than has hitherto been seen". En este sentido establecerá una importante red de colaboración internacional a fin de contar con grupos indígenas de distintas partes del globo. A través de la colaboración del paleontólogo estadounidense John Bell Hatcher (1861-1904) establecerá contactos con el doctor irlandés Víctor Edward Albert Fenton (1864-1938), el cual desde comienzos de la década de 1890 se desempeñaba como médico del territorio de Santa Cruz en reemplazo de su hermano Arthur Fenton (1861-1942). Los hermanos Fenton organizarían un grupo de 5 hombres adultos, una mujer adulta y una niña de 8 años a cargo de Vicente Cané el cual viajará acompañado del intérprete Juan Wohler. Según la revista Caras y Caretas, Cané había puesto especial cuidado en que los indígenas elegidos sean "los más vigorosos y corpulentos" a fin de que este "grupo que conservará cuanto de primitivo ofrecen sus costumbres y caracteres de vida" supieran cumplir las expectativas de McGee. Caras y Caretas 1904, p. 286; McGee 1904, p. II; Parezo y Fowler 2007. 
arco musical ${ }^{620}$. Tal como declaraba "No había que perder el tiempo para empezar con los registros", reflexionando que "Por primera vez, durante mis ocho años de estada en La Plata, vi coronados mis esfuerzos para encontrarme también con los tehuelches" ${ }^{2621}$. La prisa en el registro de la música y el lenguaje respondía a un eventual viaje de campo a la Patagonia, lo cual se presentaba como una dificultad al momento de transportar los rollos al terreno y exponerlos a las particulares condiciones ambientales de las geografías del extremo sur argentino.

Por ese entonces los sistemas de reproducción y registro de sonido contaban en Buenos Aires con un gran impulso publicitario y una amplia oferta comercial. Desde 1878 podremos encontrar referencias al fonógrafo en las secciones informativas, publicitarias y científicas de distintas publicaciones como los diarios La Prensa, El Nacional, La Unión, El Correo Español, El Comercio del Plata, La República, y La Nación y en las revistas Revista técnica y argentina de los Ferrocarriles, Transporte y Comunicación, y en Caras y Caretas (Fig. 30). El público argentino podrá seguir en forma casi instantánea el desarrollo, la aplicabilidad y el desarrollo de los dispositivos de registro de sonido. En este sentido apenas dos meses después de su patentamiento oficial en los Estados Unidos, el 11 de mayo de 1878, la sección "Científica" del diario La Prensa publicaba una nota referida a la invención del fonógrafo, firmada por el ingeniero y matemático italiano Emilio Rosetti (1839-1908), uno de los miembros fundadores de la Sociedad Científica Argentina.

Los primeros fonógrafos Edison serán importados al país hacia 1899 por parte de Casa Lepage, propiedad del barón belga Henri Lepage (1865-1940), incluyendo entre sus primeras ofertas productos como "Discurso de Bartolomé Mitre", "Un paisano en el Tranway" o "Desafío del gaucho picaflor". Entre fines del siglo XIX y la primera década del siglo XX tendremos otras importantes casas musicales como Casa América de José Lightowler Stahlberg, Casa Gupy y Casa Cassels. A pesar de los precios un tanto elevados de los aparatos, las casas importadoras comenzarán a dar crédito para su adquisición, ingresando, entre 1899 y 1907, 39.256 aparatos, entre fonógrafos y gramófonos ${ }^{622}$. Lehmann-Nitsche optara por un grafófono

\footnotetext{
${ }^{620}$ De esta forma repetía, en parte, aquellos estudios sobre el arco patagónico realizados hacia 1896 por Ten Kate con tehuelches del centro-oeste patagónico en la misma institución. Este describirá el arco y su ejecución por parte de un Tehuelche que, según Ten Kate, tenía "mixed Tehuelche and Araucanian blood". Señalando la analogía estructural y la similitud en la lingüística empleada para denominar el arco musical por parte de Tehuelches, antiguos mayas, indios de Florida y las Islas Salomón, rechazaba las propuestas del etnógrafo estadounidense Otis Tufton Mason (1838-1908) sobre la inexistencia del arco musical en tiempos precolombinos. Ten Kate 1898.

${ }^{621}$ Lehmann-Nitsche 1908 c, p. 916.

${ }^{622}$ ACERA 1908.
} 
Columbia, comercializado en la Argentina por Casa Tagini, propiedad del comerciante industrial italiano José Tagini (1864-?) ${ }^{623}$ (Fig. 31).

Las sesiones de grabación serán efectuadas entre el 19 de enero y el 2 de marzo de 1905. Trabajará con los tres jóvenes del grupo, los cuales eran "[...] muchachos bien despiertos [...]"624, ya que "No se podía hacer gran cosa con el matrimonio mayor". El dominio del español por parte de los tres jóvenes permitirá establecer un rápido acercamiento con LehmannNitsche. De este grupo trabajará con Casimiro y Bonifacio, ya que estos serán los únicos que podían ejecutar el arco musical. La jornada de trabajo abarcará 15 días, estando signada por el extenso calor del verano y los múltiples detalles técnicos a ajustar ${ }^{625}$ (Fig. 32).

$\mathrm{Al}$ momento de registrar el canto y la música interpretada por los indígenas seguirá las indicaciones técnicas y metodológicas de Abraham y von Hornbostel ${ }^{626}$. La tarea se verá en parte facilitada por la familiaridad de los indígenas con el fonógrafo, instrumento que, junto con el gramófono, conocían de su estancia en Sant Louis ${ }^{627}$. Los indígenas, entre el asombro y la tribulación de escuchar sus propias voces reproducidas por un aparato mecánico, cumplieron todos los pedidos de Lehmann-Nitsche, el cual se irá familiarizando lentamente con las sutilezas de la técnica durante el proceso de grabación ${ }^{628}$. Esto nos permite señalar algunos elementos que no han sido debidamente considerados. Esta serie de trabajos musicológicos responderán a las demandas del material musical sudamericano en los espacios científicos alemanes dedicados al estudio comparativo de la música. De esta forma el uso de las indicaciones técnicometodológicas de Abraham y von Hornbostel responde a la necesidad de recolectar los materiales acorde a los parámetros utilizados en el Berliner Phonogramm-Archiv.

\footnotetext{
${ }^{623}$ Este veía la luz en 1887 como resultado del trabajo en conjunto del estadounidense Charles Sumner Tainter (1854-1940), Alexander Graham Bell y su primo el químico irlandés Chichester A. Bell (18481924). El mismo presentaba algunas mejoras importantes respecto del fonógrafo de Edison: los cilindros estaban hechos de cera en lugar de cartón y papel de estaño, lo que permitía grabaciones de mayor duración. Asimismo, la púa flotaba con mayor libertad sobre el cilindro de cera, lo que aseguraba una conversión más clara del sonido. El agregado de un pedal o un motor eléctrico como fuerza motriz solucionaba los problemas de fluctuaciones en la velocidad de giro del modelo de Edison.

${ }^{624}$ Lehmann-Nitsche 1908 c, p. 916.

${ }^{625}$ Ibídem.

${ }^{626}$ Estas indicaciones serán transmitidas a través de comunicaciones personales. Para esa época ambos estudiosos llamaban la atención sobre la gran cantidad de material fonográfico colectado y el creciente número de estudiosos envueltos en su estudio, tornando imperioso la necesidad de establecer una metodología y una serie de instrucciones para el estudio de dicho material. El resultado de esto será Vorschläge für die Transkription exotischer Melodie (1909-1910), trabajo que representará el primer esfuerzo comprensivo para codificar los símbolos empleados en la transcripción de música tradicional y sentará una larga influencia en los estudios de musicología comparada. Abraham y Hornbostel 19091910.

627 Durante la Lousiana Purchase Exposition también se desarrollaron importantes experimentos vinculados a la audición, como el trabajo de por Frank G. Bruner con tehuelches, esquimales, pigmeos africanos, indígenas americanos y filipinos. Coincidiendo con las premisas planteadas por von Hornbostel, resaltaba que a diferencia del registro escrito el fonógrafo permitía la compilación de un material "natural e incorruptible" para el estudio científico de la música. Bruner 1911

${ }^{628}$ Lehmann-Nitsche $1908 \mathrm{c}$.
} 
Al mismo tiempo los trabajos previos permitirán cierta familiaridad de los indígenas para con los instrumentos utilizados para grabarlos, algo que supondrá una ventaja al momento que Lehmann-Nitsche realice sus trabajos. Esto puede evidenciarse al momento de registrar el arco musical. Para esto se utilizarán dos instrumentos que se encontraban entre las colecciones del Museo de La Plata. Lehmann-Nitsche realizará varios intentos fallidos en la búsqueda de un registro de calidad aceptable, algo en lo cual también los indígenas se mostrarán preocupados. Finalmente optará por seguir las recomendaciones de Casimiro y utilizará una guitarra como caja de resonancia. Este colocará el extremo del arco que quedaba libre sobre el dorso del cuerpo de la guitarra, posicionando la boca de esta frente al embudo del gramófono. De esta forma se obtenía un tono mucho más elevado y claro (Fig. 33).

Los registros hablados no satisfarán las pretensiones de Lehmann-Nitsche, para el cual el valor de los mismos radicaba "[...] en el hecho de que la gente puede hablar, decir sus textos ante el embudo tal como se les ocurre, sin tener que demorar o interrumpir el flujo de sus pensamientos y palabras, como pasa con el dictado a pluma." ${ }^{\text {629 }}$. La falta de control ante el proceso de registro junto con el desconocimiento de la lengua indígena serán las principales dificultades que deberá sortear Lehmann-Nitsche.

Ante la naturalidad con la cual los indígenas podían expresarse frente al grafófono se anteponía la necesidad de "[...] conocer exactamente el idioma para poder transportarlo del fonograma al papel", siendo el trabajo de transcripción "penoso y a menudo sin éxito" ya que "Mediante tales dictados pueden estudiarse los fonogramas debiendo decidir los fonéticos su grado de éxito científico" ${ }^{\text {"630 }}$. Como advirtieran los estudiosos abocados a este tipo de estudio, el fonógrafo jamás podía suplantar los registros escritos de la lengua, el canto y la música. La combinación de ambos métodos daba lugar a un registro múltiple del fenómeno, permitiendo un control más riguroso de los resultados. Como señala Kittler el uso de dispositivos de registro mecánico de sonidos permitirá "[...] fix and record the acoustic chaos in real time and reproduce it in slow motion. When the rhythms then become paralyzed and the "individual measures, even individual sounds resound, occidental alphabetism, with its staves, can proceed to an exact notation" ${ }^{631}$. En este sentido los fonogramas registrados por Lehmann-Nitsche serán "[...] incuestionables, y naturales en la medida de lo posible"632.

Al momento de analizar el arco desde su composición estructural y funcional discutirá las explicaciones de apropiación y difusión sostenida, principalmente por investigadores como

\footnotetext{
${ }^{629}$ Lehmann-Nitsche 1908 c, p. 917.

${ }^{630}$ Ibídem p. 928.

${ }^{631}$ Kittler et.all 1987, p. 104.

${ }^{632}$ Lehmann-Nitsche 1908 c, p. 928.
} 
Otis $\operatorname{Mason}^{633}$, y aquellas sobre un origen primitivo, múltiple e independiente sostenida por estudiosos como el arqueólogo estadounidense Marshall H. Saville (1867-1935), el arqueólogo y lingüista estadounidense Daniel Garrison Brinton (1837-1899), el lingüista alemán Karl Theodor Sapper (1866-1945) y Ten Kate ${ }^{634}$. Lehmann-Nitsche optaba por una combinación de ambas propuestas. Llamando al estudio de las tribus vecinas de los Tehuelches, a fin de contar con un contexto geográfico y cultural amplio, aventuraba un origen araucano para el arco musical Tehuelche, proponiendo ver en este una combinación de instrumentos indígenas y europeos, debido principalmente al uso del tendón de caballos europeos como elemento tensante ${ }^{635}$.

Esta propuesta de Lehmann-Nitsche; al igual que otros estudiosos ${ }^{636}$; seguirá, en mayor o menor medida, las directrices planteadas por Adolf Bastian, principalmente a través del concepto de Elementärgedänken (Pensamiento elemental). En este sentido se planteaba un acercamiento histórico a las manifestaciones culturales humanas, rehusando interpretar las similitudes como pruebas de transmisión de costumbres o ideas. De esta forma los instrumentos musicales indígenas serán invenciones independientes limitadas a un contexto geográfico específico que es permeable al contacto y al intercambio cultural, pero el cual debe ser comprobado a partir de evidencias históricas.

Finalmente el 10 de junio Lehmann-Nitsche consignaba en la Compañía Nacional de Transportes Expreso Villalonga las cajas que contenían los 58 tubos fonografofon, los cuales serían enviados, por intermedio de la Elkan \& Cie. Hamburg, a von Luschan ${ }^{637}$. Este acusaba el recibo de lo que consideraba un meritorio aporte al estudio de la musicología comparada. Al mismo tiempo detallaba ciertos pormenores sobre la publicación de los resultados de la investigación sobre las fonograbaciones, consultando además la posibilidad de utilizarlas las

${ }^{633}$ Sus trabajos se basaban en el estudio de la colección musical del United States National Museum, y el cuerpo bibliográfico del Bureau of American Ethnology. Si bien no negaba la posibilidad de invención independiente, la limitaba a objetos simples, de pocas piezas y que desempeñaban solamente una función. Propondrá una introducción temprana del arco por parte de los esclavos africanos traídos a América. En respuesta a las propuestas sostenidas por Ten Kate argumentaba que "It may be laid down as a proposition to which all ethnologists will agree that simple inventions having few parts, functioning in a single action, might arise independently in various parts of the world; but devices consisting of many parts, functioning in unusual ways or having many functions, are less and less likely to have arisen independently" Mason 1898, p. 95.

${ }^{634}$ Brinton 1897; Sapper 1897; Saville1898; Ten Kate 1898.

${ }^{635}$ Lehmann-Nitsche $1908 \mathrm{c}$.

${ }^{636}$ Podemos mencionar los estudios del orientalista y filosofo holandés Jan Pieter Nicolaas Land (18341897) sobre la música javanesa, los de Franz Boas sobre la música chinook, los de Carl Stumpf sobre los bellakula y tailandesa, las de Benjamin Gilman sobre la música china, los de Hornbostel y Abraham sobre la música japonesa y la turca o los de Hornbostel sobre la música tunecina. Abraham y Hornbostel 1903, 1904 a, 1904 b; Boas 1888; Gilman 1892; Hornbostel 1906; Land 1889; Stumpf 1886, 1901.

${ }^{637}$ En carta del 25 de junio Lehmann-Nitsche le detallaba a von Luschan que las cajas contenían las facturas correspondientes como así una muestra de pelo de los Tehuelches que representaban "[...] eine geringe Gegengabe” por la ayuda prestada. Robert Lehmann-Nitsche a Felix von Luschan. Legado Robert Lehmann-Nitsche, 25.07. 1905, IAI, Carpeta N-0070 b 427. 
mismas en el seminario de psicología que se encontraba preparando para dictar en la Universität Berlin $^{638}$.

Las fonograbaciones serán transcriptas y estudiadas por Eric Fisher ${ }^{639}$, interesado principalmente por la permanencia a lo largo del tiempo de la ejecución monosilábica del canto. El trabajo de Fisher se publicará conjuntamente con el de Lehmann-Nitsche en la revista alemana Antrhopos. De esta forma se buscaban registrar, estudiar y aportar elementos para la construcción de una cartografía musical a escala global que se presentará como alternativa a las teorías del "degeneracionismo" que postulaban el pasaje del canto complejo propio de las sociedades civilizadas a formas rudimentarias como el canto indígena ${ }^{640}$.

\subsubsection{Estrategias de recolección}

Los estudiosos implementarán diversas estrategias al momento de poder compilar los materiales necesarios para su investigación. Creemos que este punto no ha sido considerado adecuadamente en trabajos previos sobre las investigaciones folklóricas realizadas por Lehmann-Nitsche. Una anécdota nos permitirá comprender en forma más acabada la dinámica de estas estrategias empleadas por Lehmann-Nitsche al momento de compilar tradiciones folklóricas y "lunfardas", el estado material del espacio en donde dichas actividades eran desempeñadas y finalmente la percepción social sobre las actividades desarrolladas por Lehmann-Nitsche.

En 1905 el poeta y autor teatral argentino José Enéas Riú (1883-1943) se prestaba a realizar una entrevista para el diario platense El Día a fin de poder comprender en forma más precisa las actividades desarrolladas por Lehmann-Nitsche. La curiosidad de Riú, como hemos visto, será una sensación que compartía con el grueso de la población platense hacia el trabajo del antropólogo alemán. Si bien Riú aclaraba que la imaginación pública "festoneaba con fantasmagóricas efectistas alrededor de los actos de Lehmann-Nitsche" a causa de su escasa o nula educación formal, esto se debía, en parte, a los "gustos desusados del sabio" ${ }^{641}$. A pesar del grado de educación necesario para poder comprender en forma precisa las actividades implicadas en el trabajo científico, esto nos indica también la escasa o nula comunicación de los

${ }^{638}$ Robert Lehmann-Nitsche a Felix von Luschan. Legado Robert Lehmann-Nitsche, 13.11.1905, IAI, Carpeta N-0070 b 427.

${ }^{639}$ Fisher se dedicará especialmente al análisis exhaustivo y minucioso de la extensión del sonido, la construcción de la escala musical, del ritmo y el tiempo de los ejecutantes. Eso se veía favorecido por la posibilidad que brindaba el fonógrafo de la repetición a voluntad de cualquier segmento en cualquier punto. Lejos de caer en la simple observación esteticista, la cual llevaba al investigador o al oyente casual a catalogar los cantos indígenas como "primitivos", el estudio científico de estas melodías permitiría establecer, según Fischer, un panorama global de comparación entre las distintas músicas indígenas y determinar patrones de evolución y difusión de las mismas. Fischer 1908.

${ }^{640}$ Lehmann-Nitsche esperaba que estos aportes, los cuales no consideraba muy significativos, justificarán el tiempo perdido en sus intentos por estudiar el arco musical araucano. Robert LehmannNitsche a Felix von Luschan. Legado Robert Lehmann-Nitsche, 05.08.1905, IAI, Carpeta N-0070 b 427.

${ }^{641}$ El Día 23.06.1905, p. 8. 
trabajos desarrollados en el Museo de La Plata por fuera del ámbito académico, algo que se buscará compensar con las charlas o conferencias de popularización científicas ${ }^{642}$.

Al llegar al Museo de La Plata un joven recibía a Riú, acompañándolo hasta el despacho de Lehmann-Nitsche. Dicha persona, de la cual no se aportan otros datos, era uno de los colaboradores del estudioso alemán, el cual contaba con libre entrada a la habitación. Esto sorprenderá a Riú, para el cual este era un joven cualquiera que por el solo hecho de aportar "copiosos datos" gozaba, a su parecer, de una llamativa confianza ilimitada. El estado del despacho de Lehmann-Nitsche era caótico. Con libros que parecían no poder encontrar su lugar, una enorme cantidad de papeles sueltos por toda la habitación, instrumentos antropométricos, material óseo desperdigado, cajas con material apiladas junto a una de las esquinas de la habitación y unos escasos muebles que hacían afirmar al entrevistador que al momento de organizar el despacho seguramente se tuvo en cuenta "[...] la tierra donde fueron recogidas las preciosas y valiosas colecciones antropológicas" ${ }^{" 643}$. Esta precisa descripción de un gabinete antropológico se veía interrumpida por la llegada de Lehmann-Nitsche, el cual confundirá a Riú con uno de los tantos informantes que a diario acudían a su despacho con el objeto de promocionarle "[...] sabroso material para sus amenas correspondencias a Alemania, narrándole ya leyendas indígenas o supercherías gauchescas ó ya versos dictados en argot lunfardo",644.

Aclarada la confusión, Lehmann-Nitsche le mostraba a Riú una enorme carpeta llena de copias de versos gauchescos y lunfardos, material que, en parte, sería sintetizado posteriormente en la serie monográfica "Folklore Argentino". Tal como el propio Lehmann-Nitsche aclaraba el objetivo de esta serie monográfica no se limitaba a la tradición gauchesca, sino al "tipo popular" argentino. En este sentido el "gaucho" y el "compadrito" del mundo suburbano del tango eran expresiones de este, debiendo ser ambas analizadas y comprendidas en conjunto. Estas explicaciones se veían interrumpidas por el ingreso de dos soldados y un "lunfardo" 645 , los cuales ingresaban al despacho del antropólogo con una familiaridad que incomodaba al entrevistador.

Lehmann-Nitsche, lejos de sorprenderse y "obsesionado por la imperiosa pasión de la recolección de datos" ${ }^{646}$, abría su cuaderno de apuntes y le pedía al "lunfardo" una serie de poemas que eran anotados rápidamente en una de las páginas que tenía como epígrafe "Literatura obscena". Esto nos demuestra la temprana recolección que Lehmann-Nitsche hiciera de este material, el cual sería publicado posteriormente bajo el seudónimo de Víctor Borde. Al mismo tiempo, debido a la extensa cantidad del mismo, y cuya inicio ubicaba Riú con gran

\footnotetext{
${ }^{642}$ Sobre este tópico ver especialmente García S. 2010 a.

${ }^{643}$ Ibídem.

${ }^{644}$ Ibídem.

645 Para ese entonces eran denominados como "lunfardos", aquellas personas vinculadas al mundo delictivo.

${ }^{646}$ El Día 23.06.1905, p. 8.
} 
anterioridad a la fecha de la entrevista, refuerzan la hipótesis de que el trabajo anónimo publicado en 1901 es de su autoría. A su vez nos señalaba uno de los tantos espacios que, condenados por el orden social, serán un amplio campo a partir del cual extraer datos científicos: el de la delincuencia y la marginalidad social.

Una vez finalizada la transcripción, era corregida la ortografía y se colocaban notas explicativas de los vocablos desconocidos al margen de la hoja. Los datos suministrados por los informantes no eran gratuitos. Veinte centavos de peso moneda nacional era el valor asignado a los datos suministrados por el peculiar informante. Posterior a la transcripción proseguiría la parte de análisis y adscripción a alguna de las tantas categorías definidas por Lehmann-Nitsche para el estudio científico de las tradiciones populares argentinas ${ }^{647}$.

A partir de los datos suministrados por la entrevista podemos atestiguar la temprana recolección de música "popular". Sabiendo que uno de los soldados podía tocar la guitarra y era conocedor de un repertorio amplio de los ritmos musicales que deseaba registrar, ofrecerá Lehmann-Nitsche uno de los instrumentos musicales que se encontraban en su despacho, registrando una serie de melodías en su fonógrafo. Otro dato interesante es el conocimiento que para esta época tenía Lehmann-Nitsche sobre el repertorio de la música "popular", pidiéndole al soldado que cante y toque determinadas canciones. Tal como presenciaba Riú, la elección de las canciones que posteriormente conformarían su colección de cilindros de cera no será azarosa, sino que responderá a la elección personal de Lehmann-Nitsche sobre lo que él consideraba como elementos representativos de la música "popular". Finalizada esta sesión de grabación se retiraba Riú, agradecido de haber podido presenciar “[...] en los albores del siglo XX á la estupenda representación de un original sainete, interpretado por un antropólogo y tres antropopitecos" ${ }^{\prime 648}$.

\subsubsection{La música "popular” en la casa del alemán}

Luego de unos intensos meses en Europa, retornaba Lehmann-Nitsche a la Argentina los primeros días de enero de 1905. Entre las primeras actividades que insumirán su tiempo se registraba la posible fundación de un centro criollo, el cual bajo el nombre de "La Tradición Nacional" era impulsado por una serie de artistas folklóricos. Designándose como presidente provisorio al señor Juan R. Varela, el proyecto era iniciado con un amplio entusiasmo,

\footnotetext{
${ }^{647}$ A los ojos de Riú el poema lunfardo era simplemente un "pestífero bodrio de poética patria canallesca, acribillado tan bella y reciamente de términos engendrados en el vicio". Pero ante los ojos del científico, tal como le informaba Lehmann-Nitsche, estos eran datos de un valor incalculable, los cuales "[...] magistralmente condimentados con la galanura de un estilo científico [...] será saboreado con suprema delicia en la mesa anatómica del filólogo". Ibídem.

${ }^{648}$ Ibídem.
} 
comprometiéndose Félix Outes y Luis María Torres a colaborar con Lehmann-Nitsche en la redacción de los estatutos del centro criollo ${ }^{649}$.

Entre el 16 de febrero y el 11 de mayo de 1905, Lehmann-Nitsche realizará en su domicilio particular 34 sesiones de grabación donde registrará 36 cantantes. Estas serán complementadas con 6 registros realizados en la lindera ciudad de Ensenada, lugar al cual se trasladará el 12 de abril de 1905. Es interesante resaltar que parte de las personas grabadas vivían en dos habitaciones que Lehmann-Nitsche subarrendaba. En este sentido la disponibilidad de los instrumentos de grabación y de los ejecutantes determinarán los espacios donde las investigaciones se llevaban a cabo. Si bien para la época existían grabaciones de los estilos musicales registrados por Lehmann-Nitsche, la adquisición de los elementos necesarios para construir una muestra representativa era muy elevada, por lo cual, como confesaba en comunicación personal a Hornbostel, la utilización, en este caso, de un fonógrafo Edison le permitirá reducir los $\operatorname{costos}^{650}$. (Fig. 34).

A partir del sobrio montaje material establecido en su domicilio compilará 125 cilindros de cera bajo el rotulo de "Música Criolla"651, la cual será enviada a Berlin junto con dos manuscritos. El primero de estos, compuesto por 232 páginas ${ }^{652}$, contenía una pequeña introducción en alemán y la transcripción de la mayoría de las líricas correspondientes a las piezas musicales grabadas. A su vez se precisaba el género musical, el nombre del autor y el ejecutante, el título de la pieza, la presencia o ausencia de acompañamiento musical, la fecha y la sesión de grabación ${ }^{653}$. El otro manuscrito, de tan solo 18 páginas, consignaba el nombre y la edad del ejecutante ${ }^{654}$.

Lehmann-Nitsche observaba que el corpus sonoro obtenido de estas grabaciones era el resultado del registro del mismo en situaciones artificiales de ejecución. Esta artificialidad será aquella que Hornbostel y Abraham vean como una de las mejores cualidades del fonógrafo, el cual al poder separar la música de los ejecutantes y su contexto, es decir los datos de las fuentes, suprimía las imprudencias en el proceso analítico y permitía analizarlas científicamente en el

\footnotetext{
${ }^{649}$ El Día 21.04.1905.

${ }^{650}$ Robert Lehmann-Nitsche a Erich Moritz von Hornbostel. Legado Robert Lehmann-Nitsche, 22.12.13, IAI, Carpeta N-0070 b 327.

${ }^{651}$ Conforme al ordenamiento y terminología adoptada por Lehmann-Nitsche encontramos: 62 estilos, 29 canciones, 15 milongas, 6 cifras, 4 huellas, 4 tangos, 2 vidalitas, 2 gatos, 2 zambas, 1 aire y 2 expresiones etiquetadas como imitación de música para danza española. Lehmann-Nitsche 1905 a, 1908 c.

${ }^{652}$ El mismo llevaba por título Folklore Argentino. Texte argentinischer Gesänge, phonographiert von Dr. Robert Lehmann-Nitsche.

${ }^{653}$ Aretz 1991; Bilbao 2004; García M. 2006, García y Chicote 2008; Guido W. 1975; Vega 1936.

${ }^{654}$ Este se titulaba Verzeichung der Phonogramme argentinischer Volksmusik. Aufgenommen in La Plata im Jahre 1905. A partir de esto podemos saber que la cantidad de piezas grabadas por cada intérprete es dispar, llegando algunos músicos a grabar solo 1 pieza, mientras que el músico Juan Varela llegará a registrar 14 piezas como solista, 1 dúo y 2 tríos.
} 
gabinete donde la atención del estudioso no se encontraba presa de las distracciones visuales que provocaban la ejecución en vivo ${ }^{655}$.

Los ejecutantes se desempeñaban como empleados en escribanías, despachos oficiales, áreas vinculadas a la construcción y algunos de estos oficiaban como payadores "profesionales" ${ }^{656}$. Casi la totalidad de las grabaciones comenzaban con una voz que detallaba el nombre del ejecutante, el título de la pieza y con información sobre la pieza a ejecutar. En estas sesiones de grabación Lehmann-Nitsche confiará la rotulación de los cilindros a los propios músicos, lo cual ha hecho suponer la ausencia de Lehmann-Nitsche en el momento de efectuar las grabaciones ${ }^{657}$, sin embargo la actuación desempeñada por los payadores "urbanos" debe ser tenida en cuenta.

Estos, al momento que Lehmann-Nitsche realizará las grabaciones, no limitaban su actividad a las zonas rurales, siendo atraídos por la fuerza pujante de las ciudades suburbanas en desarrollo y sus promesas de futuro. Las calles de tierra de La Plata, sabrán acoger a estos payadores para los cuales la música dejará de ser un simple pasatiempo, comenzando a presentarse en almacenes, circos, pequeños teatros suburbanos, cabarets y clubes. Esto nos permite suponer que los mismos serán conscientes de su actuación e importancia en la producción de estos registros sonoros, lo que los llevará a desempeñar un papel más presencial $\mathrm{y}$ activo en lo referido a lo que ellos consideraban como su patrimonio musical. Esta importancia no se limitará al aspecto comercial. En este sentido Lehmann-Nitsche le escribía a Hornbostel a fin de obtener copias galvanoplásticas de las grabaciones del recientemente fallecido Carlos Acevedo ante el pedido reiterado de su familia ${ }^{658}$.

Las extensas jornadas de trabajo como así también las discusiones políticas que empezaban a ocupar la casi totalidad de las mismas serán vistas por ciertos autores como la razón principal que llevará a Lehmann-Nitsche a suspender las sesiones de grabación ${ }^{659}$. Si bien no negamos la incidencia de estos elementos al momento de condicionar las posibilidades y los tiempos de grabación, no creemos que ellos sean la causa directa de la interrupción de las grabaciones. Es preciso señalar que esta "alta politización" no será propia y única de las reuniones celebradas por Lehmann-Nitsche, por lo cual podrían considerarse otros elementos al momento de explicar esta decisión. Por un lado debemos tener en cuenta las condiciones

\footnotetext{
${ }^{655}$ Abraham y Hornbostel 1903.

${ }^{656}$ Este le comentaba a Erich von Hornbostel, en una carta enviada el 22 de diciembre de 1913: "Sänger sind immer bekkante Payadores, welche ihre Kunst gewerbsmässig ausüben, z.B. auch zu politischen Wahlversammlungen engagiert werden, um das Stimmvieh in Stimmung zu brigen [...]". Robert Lehmann-Nitsche a Erich Moritz von Hornbostel. Legado Robert Lehmann-Nitsche, 22.12.1913, IAI, Carpeta N-0070 b 327.

${ }^{657}$ García M. 2006.

658 Robert Lehmann-Nitsche a Erich Moritz von Hornbostel. Legado Robert Lehmann-Nitsche, 13.11.1913, IAI, Carpeta N-0070 b 327.

${ }^{659}$ Bilbao 2004; García M. 2006, García y Chicote 2008.
} 
materiales y técnicas del fonógrafo, que determinarán el tiempo y la cantidad efectiva de grabaciones. Por otro lado el cumplimento de los objetivos impuestos por el propio LehmannNitsche, el cual participará activamente en la selección y la grabación de las piezas.

Finalmente Lehmann-Nitsche enviará sus muestras al Phonogramm-Archiv de Berlin. En comunicación personal a Hornbostel se lamentaba de la pobreza del material. A pesor de esto esperaba obtener datos que le permitieran ampliar y continuar su labor, ya que la dificultad del procesamiento y la evaluación de los mismos le permitían, hasta el momento, delinear conclusiones parciales. El uso del fonógrafo por parte de los antropólogos suplantaba la falta de conocimientos musicales de estos, haciendo posible que llevarán a cabo los registros de diversos datos musicales de interés para que fueran procesados y analizados posteriormente por distintos especialistas. En la misma carta ofrecía Lehmann-Nitsche su punto de vista sobre la música folklórica local, en la cual identificará antiguos elementos arábigos y españoles mezclados, posiblemente, con expresiones indígenas locales.

\subsubsection{Palabras, música y cantos en casa de los hermanos ingleses}

Entre el 01 y el 15 de agosto de 1906 Lehmann-Nitsche; en el marco de su trabajo de campo en el ingenio azucarero La Esperanza (San Pedro de Jujuy, Argentina); registrará cantos y vocabulario de indígenas chiriguanos, chorotes, tobas y wichis que se encontraban trabajando en la zafra. Las grabaciones serán efectuadas con un fonógrafo Columbia en la casa de Walter Leach, uno de los propietarios ingleses del ingenio azucarero ${ }^{660}$.

Las condiciones en las cuales Lehmann-Nitsche registrará los fonogramas no serán, como señalaba, las más óptimas e ideales para un estudio de este tipo. Sin embargo la posibilidad de poder realizar registros sobre uno de los grupos "primitivos" de Sudamérica justifica por si solo el emprendimiento de dicha empresa científica. Si bien el planeamiento y la diagramación de la misma se presentaban muy sencillos en la teoría, la puesta en práctica de la misma se revelará un poco más complicada.

Los indígenas presentarán una marcada resistencia a ser grabados, basándose en la creencia de que el fonógrafo, al registrar y reproducir sus voces, tomaba sus almas. Ante esto Lehmann-Nitsche implementará distintas soluciones. Por un lado; al observar que los indígenas, luego de la extensa jornada laboral, se juntaban en torno a un fogón y comenzaban a cantar, animados, por el alcohol; decidirá proveerles caña de azúcar y otros licores a fin de poder obtener los registros ${ }^{661}$. En otros casos deberá “negociar" en forma abierta ante los portavoces

\footnotetext{
${ }^{660}$ Robert Lehmann-Nitsche a Erich Moritz von Hornbostel. Legado Robert Lehmann-Nitsche, 17.5.1907, IAI, Carpeta N-0070 b 327; Manuscrito Bolivianische Phonogramm, Berlin Phonogramm Archiv, 1906.

${ }^{661}$ Refrendaba este que "Nähe der Fabrikgebäude sich den Alkohol bemerkbar machen, dem bei dieser Gelegenheit auch die holde Weiblichkeit nicht abgeneigt ist; so musste Ich, um die Chatuancadamen zum Singen in den Phonographen zu bringen, einen five o' clock tea geben, wo gewöhnlich Caña, die Stelle
} 
de los grupos indígenas los cuales, conscientes de las necesidades de Lehmann-Nitsche, demostrarán ser grandes negociadores ${ }^{662}$.

Las diversas tácticas de "negociación" implementadas por Lehmann-Nitsche nos permiten apreciar varios puntos del trabajo de campo, alejándolo de la imagen idealizada en la cual el antropólogo llega, realiza su trabajo y vuelve al gabinete científico. El trabajo de campo es atravesado por situaciones imprevistas que escapan del control del antropólogo. Estos deberán implementar una batería de soluciones con los elementos disponibles a fin de poder hacer frente a los imprevistos. Todos los individuos involucrados desempeñan, con mayor o menor injerencia, una tarea activa.

El 15 de julio enviaba por intermedio del ingeniero Wilhelm Hermann, jefe de la expedición alemana al Pilcomayo, los 30 cilindros de cera grabados con un fonógrafo Columbia. El 29 de agosto Hermann le confirmaba a Marius Schneider el envío de los fonogramas en 15 cajas al Museum für Naturkunde ${ }^{663}$. Finalmente el 28 de septiembre Hornbostel le confirmaba a Lehmann-Nitsche que se encontraba en posesión de los 30 cilindros. Si bien no había tenido tiempo de analizarlos con detalle, confesaba que le parecían por demás interesantes ${ }^{664}$.

Parte de los resultados de estos trabajos serian presentados por Lehmann-Nitsche en el XVI Congreso Internacional de Americanistas, celebrado en Wien en 1908. A través de cuadros antropométricos, fotografías y las grabaciones en cilindros de cera ofrecía a los asistentes un cuadro sinóptico de la situación de los grupos indígenas del Chaco ${ }^{665}$. Estas investigaciones serían de especial interés para Paul Eherenreich y para Julius Kollmann, los cuales veían en estas un cuerpo de datos susceptibles de incluir en sus propios trabajos, pudiendo de esta forma ampliar el contexto espacial y temporal estudiado ${ }^{666}$. De esta forma nuevas pruebas reforzaban y avalaban las hipótesis sugeridas en sus trabajos, alentando enfáticamente a Lehmann-Nitsche para que continuara con esta línea de investigaciones ${ }^{667}$.

des bei unsern Damen so beliebten Rosenlikörs vertrat”. Manuscrito Bolivianische Phonogramm, Berlin Phonogramm Archiv 1906, p.2

662 Al momento de realizar los estudios antropométricos y las fonograbaciones con los chorotes, Lehmann-Nitsche se mostrará un tanto frustrado al tener que recurrir a un joven de 15 años que, al conocer parcialmente el español, mediaba entre los deseos de Lehmann-Nitsche y los 100 indios chorotes que trabajan en el ingenio azucarero. Remarcaba Lehmann-Nitsche que este "pilluelo bribón”, como fuera calificado por él, antepondrá ante cualquier pedido que hiciese la pregunta “¿Cuánto paga?” Ibídem p.2.

${ }^{663}$ Hermann a Schneider a Marius Schneider. Berlin Phonogramm Archiv 29.08.1907.

664 Erich Moritz von Hornbostel a Robert Lehmann-Nitsche. Legado Robert Lehmann-Nitsche, 28.09.1907, IAI, Carpeta N-0070 b 327.

${ }^{665}$ La Provincia di Padova 26.09.1908.

${ }^{666}$ Mientras que el primero de estos disertaba sobre el estado actual de los conocimientos etnográficos sobre el sur del Brasil, el segundo lo hacia sobre la supuesta existencia de una raza pigmea en Sudamérica. Ambrosetti 1909; Breton 1911; Boas 1908; Mac Curdy 1908; Markham 1908; Nippen 1908.

${ }^{667}$ La Provincia di Padova 27.09.1908. 


\subsubsection{El envío de las grabaciones al Phonogramm Archiv de Berlin}

El 17 de mayo de 1907 Lehmann-Nitsche le comunicaba a Hornsbostel su deseo de que la totalidad de sus fonograbaciones quedarán depositadas en el Phonogramm Archiv, sabiendo que allí disponían de los medios y especialmente la voluntad de preservarlas, algo que no podía asegurar sucediera en la Argentina. El registro sonoro y escrito de este vasto cuerpo de tradiciones orales, concebido como frágil, debía ser rescatado y preservado para futuros estudios científicos.

Al comunicarle von Luschan lo significativo de sus aportes a las colecciones del Phonogramm Archiv, Lehmann-Nitsche se contentaba con ser una "[...] fértil semilla [...]"668 que había podido fructificar los esfuerzos de las investigaciones llevadas adelante desde Berlin a pesar de las muchas dificultades y hostilidades que el medio local le imponía en este tipo de estudios $^{669}$. Von Luschan lo animaba seguir con paciencia y sosiego este tipo de estudios, ya que desde Berlin se necesitaban personas que, como Lehmann-Nitsche, oficiarán de nexos en la articulación de los espacios de investigación y enseñanza alemanes y argentinos ${ }^{670}$. Como le mencionará Hornbostel era muy valioso para la agenda científica llevada adelante por el Phonogramm Archiv contar con material sudamericano, por lo cual esperaban no solo más envíos por parte de Lehmann-Nitsche, sino también que este supiera "estimular" a otros investigadores en el uso del fonógrafo ${ }^{671}$.

El establecimiento de una infraestructura de recopilación de datos que incluirá medios gráficos especializados y no especializados, alumnos, estudiosos, y la implementación del fonógrafo supondrá un aumento en la eficacia de la recolección de material y datos en el "campo". Focalizando en "[...] el concepto histórico de los países del Plata y no respetando los actuales límites políticos" ${ }^{\text {"72, }}$, buscará identificar y catalogar a partir de la comparación sistemática aquellos elementos psicológicos comunes ${ }^{673}$. Estos serán susceptibles de ser rastreados hasta su umbral, determinando de esta forma el origen y el desplazamiento del hombre a través del espacio y el tiempo. Esta investigación; como señalara hacia 1906 al reflexionar sobre la rápida inserción de los indígenas a la vida cotidiana de la ciudad; debía

\footnotetext{
${ }^{668}$ En el original "Samenkorn auf fruchtbarem". Robert Lehmann-Nitsche a Felix von Luschan. Legado Robert Lehmann-Nitsche, 05.08.1905, IAI, Carpeta N-0070 b 427.

${ }^{669}$ Robert Lehmann-Nitsche a Felix von Luschan. Legado Robert Lehmann-Nitsche, 05.08 y 18.08.1905, IAI, Carpeta N-0070 b 427.

${ }^{670}$ Robert Lehmann-Nitsche a Felix von Luschan. Legado Robert Lehmann-Nitsche, 27.11.1905, IAI, Carpeta N-0070 b 427.

${ }^{671}$ Erich Moritz von Hornbostel a Robert Lehmann-Nitsche. Legado Robert Lehmann-Nitsche, 14.06.07, IAI, Carpeta N-0070 b 327.

${ }^{672}$ Lehmann-Nitsche 1911 a, p.493.

673 Haciendo un análisis comparativo de las obras gráficas de su colección, la cual incluía textos provenientes de los países lindantes a la Argentina, determinaba que "[...] casi todas son de origen europeo y pocas las verdaderamente criollas, y estas últimas descendientes psicológicas de aquellas". Lehmann-Nitsche 1911 a, p.493.
} 
comenzar por la búsqueda del pasado remoto que, superficialmente, se revelaba aun existente en la cotidianeidad de la vida diaria ${ }^{674}$.

Como señalara Friedrich Kittler, al retomar la conceptualización de Heidegger sobre la máquina de escribir, los dispositivos de registro de sonido; oficiando en parte como maquina y en parte como herramienta; permitirán fijar flujos de datos en un soporte material y ser separados de sus fuentes para convertirse en un sistema de almacenamiento, transmisión, transporte y procesamiento. Conformarán un sistema de inscripción ${ }^{675}$ que permitirá que personas que no poseían los instrumentos analíticos necesarios para el estudio del lenguaje y/o la música, recolectaran en forma mecánica datos para ser enviados, en forma estable, a los centros de procesamiento ${ }^{676}$. Tal como afirma Hans Ulrich Gumbrecht "The enthusiasm and the irritation which it generates stem from one and the same cause. Producing human sounds in the absence of human bodies, the gramophone inspires both the fear of ghosts and the hope for eternal life" ${ }^{\circ 77}$. En este sentido los cilindros de cera grabados por Lehmann-Nitsche, actuando como "inmutables móviles", facilitarán la preservación de las palabras y los cantos en el tiempo y proliferarán su conocimiento en distintos espacios del saber.

\footnotetext{
674 "Ellos (los indígenas) se han acostumbrado con inusitada rapidez a su nueva vida. Entretanto, fueron confinados en el ejército, en el cuerpo de bomberos, de organización militar en este país, o bien en el cuerpo policial, donde muestran su valía. Otros trabajan de porteros, sirvientes, etc. El pueblo simple no hace distinción entre la población india y él mismo, a menudo ni siquiera percibe que tiene que ver con aquella. No les va ni mejor ni peor que a otros. El gran público, al cual le gustaría de vez en cuando ir a ver indios, no se da cuenta en absoluto de que el primer policía que pasa por la calle de Buenos Aires es uno de ellos". Lehmann-Nitsche 1906 b, p. 2.

${ }^{675}$ Kittler refiere a estos como Aufschreibesysteme. Kittler 1992.

${ }^{676}$ Kittler 1992, 1997; Tholen 2002.

${ }^{677}$ Gumbrecht 1997, p.113.
} 


\section{La Antropología y las excursiones al campo}

Lehmann-Nitsche, a lo largo de sus 30 años de residencia en la Argentina, emprenderá una serie de excursiones al campo en los que realizara diversos estudios somatométricos y el metódico acopio de vocabulario indígena, fotografías y fonograbaciones. Dichos aspectos han sido puntualizados y descriptos por algunos autores ${ }^{678}$, mencionando en forma soslayada los diversos mecanismos sociales, institucionales e instrumentales articulados por Lehmann-Nitsche a fin establecer y/o insertarse en un conjunto de redes materiales e intelectuales que le permitirán concretar dichos viajes.

Entre fines del siglo XIX y principios del siglo XX el "trabajo en el campo" no implicará necesariamente el desplazamiento geográfico del estudioso a puntos lejanos. Como hemos visto en el capítulo III gran parte de los trabajos de "campo" de Lehmann-Nitsche se desarrollaran en el contexto de comisarías, hospitales psiquiátricos y ferias comerciales. Al mismo tiempo no se ha considerado la cantidad de días de trabajo "en el campo" al momento que los estudiosos se trasladaban al mismo. En el caso de Lehmann-Nitsche hemos podido determinar un estimativo de 74 días de trabajo efectivo en el campo a lo largo de sus 30 años al frente de la Sección de Antropología del Museo de La Plata ${ }^{679}$, muchos de los cuales se daban en el contexto de visitas vacacionales en determinados puntos del país. Es preciso mencionar que la escasa cantidad de días "en el campo" propiamente dicho también responderá a otras cuestiones, tales como el escaso financiamiento institucional o la imposibilidad del estudioso por articular y administrar en forma adecuada las redes de aprovisionamiento de datos y objetos $^{680}$.

Otro punto a señalar es la excesiva atención en las excursiones realizadas por LehmannNitsche a Tierra del Fuego (1902) y al Noroeste argentino (1906). Dichos autores han centrado su atención en la condena moral de las prácticas llevadas adelante por Lehmann-Nitsche, a partir del uso anacrónico de categorías y juicios de valor, restando relevancia o alcance en un análisis histórico ${ }^{681}$. De esta forma han aislando dichas prácticas del contexto global de producción y significación del conocimiento antropológico de la época. Estos viajes; junto aquellos emprendidos a Córdoba (1903), Río Negro (1915-1918), Napalpi (1924) y Curamalal

\footnotetext{
${ }^{678}$ Entre otros: Bilbao 2004; Canio Llanquinao 2011; Dávila da Rosa 2011; Fernández Garay 2009; Malvestitti 2007, 2012.

${ }^{679}$ Ver cuadro 1 en Anexos.

680 Franz Boas, luego de sus excursiones entre 1883 y 1887 a Baffinland y la Costa noroeste estadounidense, sabra gestionar y conducir importantes expediciones científicas; tales como la "Jesup North Pacific Expedition entre (1897-1902) y el East Asiatic Committee (1901-1905); que lo proveerán de importantes elementos para sus investigaciones. Darnell 1998; Hinsley 1976; Hyatt 1979; Jacknis 2002; Liss 1990; Stocking 1974 a.

${ }^{681}$ Entre otros: Arenas 1991; Kriscautzky 2007; Masotta 2000, 2005, 2007; Pepe 2010, 2011; Yujnovsky 2008, 2010.
} 
(1925); estarán determinados, en parte, por la significancia de estos espacios geográficos en distintas agendas científicas europeas.

Las prácticas sobre el terreno deberán hacer frente a fenómenos multivariados, complejos e incontrolables. En este sentido la elección de estos sitios por parte de LehmannNitsche buscará continuar con aquellas empresas previas, a fin de poder construir una imagen completa de aquellas geografías y sus habitantes. Dicha continuidad estará dada, entre otras cosas, en el uso de instrumentos y técnicas similares que buscaban dar estabilidad y credibilidad a la construcción de un objeto de estudio que circulaba entre los distintos nodos de una red de colaboración científica internacional ${ }^{682}$. Como ha señalado Norton Wise el uso de técnicas e instrumentos similares en las prácticas científicas colectivas se vinculará con la demanda de precisión, y en última instancia con la construcción de "unidad" al interior de las distintas disciplinas $^{683}$. La diversidad de miradas; guiadas por un mismo código de observación e interpretación; dará lugar a la construcción de objetos de estudios uniformes, acercando a la antropología al ideal de unidad.

Lorraine Daston y Peter Galison han remarcado que "[...] a single observation could not reveal a truth. Nature was too variable; individual observations were always qualified by particular circumstances. Hence the importance of routinely replicating observations [...] this practice was more often justified as necessary to stabilize the phenomenon and to extract the essential [...]" ${ }^{\prime 684}$. En este sentido otro punto que no ha suscitado la correspondiente atención será el conjunto de individuos de los cuales dependerá el éxito de estos viajes exploratorios. Estos proveerán a Lehmann-Nitsche de la infraestructura logística y material, colaborando activamente en la diagramación y ejecución de los estudios antropológicos. En ciertas ocasiones estos serán los que conciban originalmente la necesidad de realizar dichos viajes de estudio, eligiendo fechas y lugares en los cuales llevarlo a cabo. Junto con esto es necesario considerar también la serie de trabajos y campañas previas realizadas tanto por antropólogos como por otros profesionales. Gran parte de los trabajos llevados adelante por Lehmann-Nitsche buscarán articularse dentro las ideas y conclusiones de estas empresas previas. George Stocking ha notado; en su análisis sobre el surgimiento del concepto antropológico de cultura; "The point is not to deny the role of field experience $[\ldots]$ but simply to suggest some of the complexities envolved" ${ }^{\prime 685}$.

Los antropólogos que se encontraban realizando trabajo de campo hacia fines del siglo XIX y principios del siglo XX, conceptualizarán las excursiones al campo como travesías hacia geografías "lejanas", como una práctica temporalizadora que buscaba la secularización misma del tiempo. Este se presenta discontinuo, especializado y; al igual que aquellas trazas materiales

\footnotetext{
${ }^{682}$ Kuklick y Kohler 1996; Rudwick 1976, 1985.

${ }^{683}$ Wise 1995.

${ }^{684}$ Daston y Galison 2010, p. 234-35.

${ }^{685}$ Stocking 1988, p. 204.
} 
de la geología y la paleontología; conformaba un registro fragmentario que debía ser completado $^{686}$. El reconocimiento de la otredad temporal de los grupos estudiados por parte de los antropólogos de dicha época será una parte esencial del discurso a partir del cual construyan su objeto de estudio. Al mismo tiempo esta sucede en un entramado de personas, instituciones y espacios que condicionan, dan forma y posibilitan la concreción de las excursiones al campo. En este sentido en este capítulo prestaremos especial atención a aquellos viajes realizados a Tierra del Fuego (1902) y el Noroeste argentino (1906), ya que en estos es donde pueden observarse dichos elementos con mayor claridad.

\subsection{La elección de los lugares}

\subsubsection{La construcción del indígena sudamericano: La influencia de los estudios etnográficos alemanes en el Alto Xingú y el Noroeste Argentino}

Como hemos mencionado anteriormente la elección de determinados lugares estará supeditado, en parte, a la continuación y/o ampliación de investigaciones previas. En el caso de Lehmann-Nitsche las mismas estarán condicionadas por aquellos trabajos previos realizados por otros estudiosos, especialmente alemanes. Estos no solo serán punto de partida en lo que respecta a los lineamientos teóricos u los objetivos, sino que brindarán importante información respecto a la infraestructura material y las redes sociales provistas por los distintos grupos locales a ser utilizados para la consecución de los resultados esperados.

Uno de los trabajos que influenciarán en forma tajante las investigaciones de LehmannNitsche serán aquellos desarrollados en el marco de la serie de viajes exploratorios alemanas a la región del Alto Xingú (Brasil Central), los cuales marcarán sin duda un punto de inflexión en la construcción científica de la imagen del indígena sudamericano. Nos centraremos específicamente en las dos primeras expediciones. La primera tendrá lugar en 1884 y participarán el médico psiquiatra Karl von den Steinen; su primo, el pintor y dibujante, Wilhelm von den Steinen y finalmente el geógrafo Otto Claus. La segunda será en 1887, siendo miembros de la misma los primos von den Steinen, el antropólogo Paul Ehrenreich (1855-1914) y el matemático, físico y geólogo Peter Vogel (1856-1915) ${ }^{687}$.

Como han mencionado varios autores esta serie de expediciones estarán integradas y coordinadas a los programas de investigación de los centros de investigación berlineses, principalmente del Ethnologische Museum dirigido por Adolf Bastian. La elección de estos espacios gravitará en torno a los deseos de este último en llevar adelante estudios sistemáticos

\footnotetext{
${ }^{686}$ Fabian 1983.

${ }^{687}$ Dos nuevas expediciones tendrán lugar entre 1896 y 1898, estando estas a cargo del geógrafo y etnógrafo Herrmann Meyer, figurando entre sus compañeros de viaje Theodor Koch-Grünberg y Karl Ranke. Hacia 1901 el territorio sería recorrido por el médico y abogado Max Schmidt (1874-1950), concluyendo esta primera fase pionera de incursiones alemanas a la zona del Alto Xingú. Kraus 2004.
} 
en regiones "desconocidas" para las ciencias del hombre, a fin de incorporar nuevos conocimientos etnográficos y geográficos que profundizarán y vincularan los ya existentes ${ }^{688}$.

Hacia 1904 Ehrenreich explicitaba el objetivo de las empresas bastianas en el Nuevo Mundo, al dar cuenta del significado de los pueblos "naturales" sudamericanos para la antropología europea. En este sentido remarcaba que su estudio permitía establecer una "brecha real" entre los tiempos prehistóricos e históricos. La articulación de estos se daba a partir de una observación arqueológica del proceso evolutivo de la humanidad, en el cual la superposición de distintas capas u estratos evolutivos eran fácilmente identificables. De esta forma los grupos indígenas sudamericanos permitirán observar y entender las raíces históricas de las naciones europeas $^{689}$. Como ha señalado Michael Kraus el mayor o menor existo de estas distintas empresas no se vinculaba a los logros individuales de cada una, sino con su articulación dentro de un plan sistemático el cual consideraba los resultados de estas expediciones un paso más en el objetivo de "[...] cerrar las brechas en las investigaciones etnográficas en el centro de Brasil. En consecuencia los trabajos realizados por Lehmann-Nitsche se insertan dentro de este esquema cooperativo, el cual creía, lo proveería de un futuro en Europa.

Como correctamente señalara Daniel Brinton, las dos primeras expediciones al Alto Xingú caracterizarán una forma de llevar a cabo las investigaciones etnográficas que influirán en los trabajos de otros antropólogos, particularmente alemanes. Si bien los primeros trabajos de cada uno de los miembros estarán influenciados por sus respectivas formaciones académicas ${ }^{690}$, su intensivo trabajo con los objetos de la cultura material en relación a temas vinculados con la religión, la lingüística o el arte, marcará un alejamiento de los estudios americanistas centrados únicamente en la antropología física. Las principales críticas serán esgrimidas por Ehrenreich, el cual abogaba por un enfoque filológico de la evolución y el desarrollo humano ${ }^{691}$.

Los trabajos antropológicos desarrollados por los estudiosos alemanes en el Alto-Xingú; buscando continuar y rectificar las investigaciones del médico y botánico alemán Karl Friedrich Philipp von Martius (1794-1868) ${ }^{692}$; propondrán unas nueva clasificación y división de los

\footnotetext{
${ }^{688}$ Hermannstädter 1996; Kraus 2004; Schaden 1989, 1990; Werkmeister 2010.

689 La cercanía geográfica con África y por lo tanto la proximidad y similitud con otros pueblos "naturales" como los Botocudos, será otro de los elementos por los cuales la etnografía de los grupos indígenas de Sudamérica se manifestaba como un componente básico para el estudio crítico de la evolución cultural. Ehrenreich 1904.

${ }^{690}$ K. Von den Steinen y Ehrenreich, ambos médicos, darán primordial importancia a los estudios somatométricos; Schmidt, de formación abogado, a los estudios etnológicos sobre el derecho; por otro lado Koch-Grünberg se interesará desde un primer momento por los problemas filológicos.

${ }^{691}$ Ehrenreich 1897 a, 1897 b, 1897 c.

${ }^{692}$ Considerado por K. von den Steinen como el fundador de la etnografía brasilera, llegaba a Brasil hacia 1817 como parte de la comitiva de la Gran Duquesa austriaca Caroline Josepha L. F. F. von HabsburgLothringen (1797-1826), la cual viajaba a Brasil para contraer matrimonio con Pedro I (1798-1834). En esa misma excursión viajaba el médico y zoólogo alemán Johann Baptist von Spix (1781-1826). Ambos estudiosos habían recibido el encargo de la Königlich-Bayerischen Akademie der Wissenschaften de estudiar las distintas zonas del Brasil y armar una colección botánica, zoológica y mineralógica. Una vez
} 
grupos indígenas sudamericanos basada en un esquema étnico e interregional ${ }^{693}$. Ehrenreich no descartaba el estudio a nivel antropométrico y somatoscópico, sino que lo limitaba a establecer una primera clasificación etnográfica. Las particularidades geográficas de la parte sur del Continente Americano establecían distintas zonas ecológicas y por lo tanto diferenciaciones importantes al interior de los grupos indígenas. De esta forma Ehrenreich afirmaba que "Una orientación razonablemente satisfactoria, en la confusión ante las numerosas y pequeñas tribus, solo puede realizarse con una segura base lingüística"694.

Los trabajos de Ehrenreich y K. von den Steinen dejarán; como lo recordarán tan enfáticamente unos años después Daniel Brinton y el antropólogo canadiense Alexander Francis Chamberlain (1865-1914); la necesidad de incrementar los estudios lingüísticos en la antropología de América del Sur ${ }^{695}$. Junto con esto también detallarán ciertos recaudos metodológicos y estratégicos a la hora de la recolección del lenguaje que serán tenidos en cuenta por otros estudiosos: igual importancia al análisis de la gramática y la fonética; contar con indígenas bilingües que faciliten el acceso al terreno y colaboren en la recolección y transcripción de datos lingüísticos; utilización de encuestas; especificación del contexto de recolección y duración de las interacciones con los indígenas ${ }^{696}$.

A principios de siglo XX Ehrenreich veía con ojos esperanzados las investigaciones lingüísticas en Sudamérica. Este futuro promisorio se encontraba supeditado a la acción de los estudiosos alemanes. Observando la calidad de los trabajos llevados adelante en lugares como Río de Janeiro, Sao Paulo, Córdoba, La Plata o Georgetown, afirmaba Ehrenreich "Incluso aquí en el extranjero, los investigadores alemanes están en la primera línea, entonces podemos esperar, que Alemania primará por sobre los Estados Unidos en cuanto al papel de liderazgo en

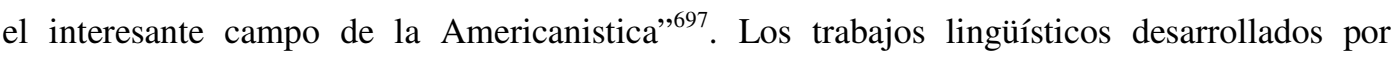
estudiosos alemanes en los Estados Unidos no serán desconocidos por Ehrenreich, quien desde

regresado de este periplo de 10 meses por el interior del Brasil, se encargará von Martius de sistematizar el enorme conjunto de datos lingüístico recolectado. En su trabajo Beiträge zue Etnographie und Sprachenkunde Amerikas zumal Brasiliens (1867), retomaba su idea de la composición étnica del Brasil como un colluvies gentium, es decir de un conjunto de grupos humanos en movimiento fluido constante, y por lo tanto refractarios de cualquier tipo de clasificación que contribuyera a la ciencia etnográfica. Kraus 2004; Schmelz 2000.

${ }^{693}$ Hermannstädter 1996; Kraus 2004; Schaden 1993, 1995.

${ }^{694}$ En el original "Eine einigermassen befriedigende Orientierung in dem Wirrsal der unzähligen kleinen Stämme lässt sich nur auf linguistsicher Basis durchführen”. Ehrenreich 1904, p.42.

${ }^{695}$ El principal trabajo de K. von den Steinen será sobre el grupo lingüístico Bacairi; habiendo indagado también sobre el grupo Aruaque y el Tucano; trabajo en el cual contará con la ayuda de un indígena que, acompañándolo en sus las dos expediciones, le posibilitará reunir un corpus lingüístico cercano a las 400 páginas. Von den Steinen 1887, 1892, 1904, 1942, 1968.

${ }^{696}$ Von den Steinen 1892.

${ }^{697}$ En el original "Auch hier stehen im fremden Dienst deutsche Forscher in erster Reihe, so da $\beta$ wir hoffen dürfen, da $\beta$ Deutschland auch dem amerikanischen Wettbewerb gegenüber noch lange die Führerrolle auf diesem interessanten Gebiete der Amerikanistik sich wahren werde”. Ehrenreich 1904, p. 75. 
1899 venía sosteniendo correspondencia con Franz Boas ${ }^{698}$. Al mismo tiempo este contribuirá a la difusión de la metodología de investigación a la que refería Ehrenreich, ya fuera a través de sus propias publicaciones o en la insistencia que sus alumnos las utilizarán en sus respectivas tesis doctorales ${ }^{699}$. Tal como recordaba Rudolf Martin la formación de estudiantes era una de las estrategias a partir de la cual se podía establecer una forma de práctica científica.

Ehrenreich, sin embargo, llamaba a no ceñirse a estos pequeños avances, ya que Sudamérica seguía siendo, desde el punto de vista lingüístico una "Terra incognita"700. En este sentido llamaba; introduciendo los conceptos antropogeográficos desarrollados por el geógrafo alemán Friedrich Ratzel (1844-1904); de fronteras etnográficas a ampliar los estudios realizados en Sudamérica ${ }^{701}$. A su vez, establecía como principales centros de recolección de datos lingüísticos aquellos espacios que Lehmann-Nitsche sabrá explotar para sus propios trabajos: misiones religiosas, colonias indígenas en las ciudades y espacios donde los indígenas fueran empleados.

Los trabajos llevados adelante por los miembros de las dos primeras expediciones al Alto Xingú tendrán el merito de impulsar en forma significativa la comparación sistemática y metódica de los grupos lingüísticos sudamericanos. A través de esta visión etnolingüística buscarán una comprensión más profunda y objetiva de la historia de estos grupos, promoviendo una forma de investigación que será continuada por otros estudiosos alemanes en Sudamérica, tales como Rudolf Lenz en Chile ${ }^{702}$.

\subsubsection{El enfoque geográfico}

El enfoque geográfico en los estudios etnográficos también tendrá una fuerte influencia en los estudios realizados en el noroeste argentino. En 1904 Lehmann-Nitsche tendrá la oportunidad de encontrarse con el lingüista austriaco Rudolf Riemel Schuller (1873-1932) en el XIV Congreso Internacional de Americanistas celebrado en la ciudad alemana de Stuttgart. En el mismo Schuller le señalaba a Lehmann-Nitsche la pobre calidad de los estudios etnológicos en el Río de la Plata, cuyo estado era "mucho peor que cuando escribían d'Orbigny, y v. Martius" ${ }^{, 703}$. Al mismo tiempo le recomendaba la lectura de Geografía Física y Esférica de las

\footnotetext{
${ }^{698}$ En el cuerpo documental de la American Philosophical Society la primera carta de Ehrenreich dirigida a Boas esta fechada el 18 de febrero de 1899.

${ }^{699}$ Darnell 1998; Hinsley 1976; Hyatt 1979; Jacknis 2002; Liss 1990; Stocking 1974 a.

${ }^{700}$ Ibídem.

${ }^{701}$ Ehrenreich 1897 a, 1897 b, 1897 c, 1904; Von den Steinen 1887, 1892, 1904, 1942, 1968.

${ }^{702}$ Como ha señalado Michael Kraus "Die beiden Reisen Karl von den Steinens zum Alto Xingu bildeten lange Zeit die zentrale Referenz innerhalb der deutschen Amazonienforschung. Sie setzen nicht nur neu Maßstäbe bei der ethnograpischen Erforschung Brasiliens, sondern die von von den Steinen aufgeworfenen Fragen bildeten auch in regionaler Hinsicht noch eine Zeit lang den Bezugs- und Ausgangs-punkt für nachfolgende Expeditionen und führten zu einer regelrechten Systematik bei der Erforschung des östlichen Südamerikas”. Kraus 2004, p. 99.

${ }^{703}$ Schuller 1904 , p. 81.
} 
Provincias del Paraguay, y Misiones Guaraníes (1790) del militar español Félix de Azara (1742-1821), que Schuller re-editara en 1904. Según este la obra de Azara era una de las mas exactas descripciones científicas del siglo XVIII sobre la etnografía de los pueblos del Chaco, los cuales permitían a los estudiosos europeos observar y estudiar; al igual que los diversos grupos indígenas americanos; "[...] la coexistencia de todas las fases de la evolución del homo",704.

En el mencionado congreso Lehmann-Nitsche sostendrá una serie de encuentros personales con Franz Boas, por lo cual es muy posible que este último compartiera con el primero el enfoque metodológico que venía aplicando a sus trabajos. En aquellos publicados entre 1887 y 1904 insistirá que el enfoque geográfico; con sus preguntas acerca de lo universal y lo particular ${ }^{705}$; era el único capaz de dar cuenta de los vínculos entre los elementos materiales, los grupos humanos y el medio ambiente ${ }^{706}$. Posiblemente le insistiera sobre la necesidad de profundizar los estudios lingüísticos en Sudamérica, región que desde ese punto de vista, afirmaba Boas, resultaba desconocida para los estudiosos en Estados Unidos. En 1907 al ser nombrado vicepresidente y encargado de la sección $\mathrm{H}$ de la American Association for the Advancement of Science, constituirá un pequeño grupo de estudiosos que buscará definir aquellas investigaciones que debían ser realizadas para el progreso de la ciencia antropológica, siendo Sudamérica una de las áreas cruciales donde estas debían ser llevadas a cabo ${ }^{707}$.

En el mismo congreso Lehmann-Nitsche tendrá la oportunidad de escuchar los resultados de la Expedición Sueca Chaco-Cordillera (1901-1902) presentados por el conde sueco Carl Gustaf Bloomfield Eric von Rosen (1879-1948); de la cual sabrá obtener importantes y decisivos datos para la concreción de su futuro viaje al noroeste argentino. La tan celebrada expedición, carente del auspicio o aval por parte de instituciones o sociedades científicas suecas, estará impulsada y sustentada, principalmente, por la fortuna personal de von Rosen. Si bien el trabajo en el campo se plantea como una experiencia individual es necesario pensarlo depurado y atravesado institucionalmente, siendo importante la presencia o ausencia del patrocinio institucional. El grupo expedicionario sueco estaba integrado en su mayoría por personas no entrenadas en la observación científica ${ }^{708}$.

\footnotetext{
${ }^{704}$ Ibídem p. 78.

705 Boas 1887 a, 1887 b, 1888 b, 1896 a, 1897, 1904.

${ }^{706}$ La principal influencia de Boas en los estudios geográficos será la del geógrafo alemán Theobald Fischer (1846-1910). Darnell 1998; Hinsley 1976; Hyatt 1979; Jacknis 2002; Liss 1990; Stocking 1974 a. ${ }^{707}$ El grupo incluirá a Frederick Putnam, y a los antropólogos estadounidenses Roland Burrage Dixon (1875-1934), William Henry Holmes (1846-1933) y Alfred Louis Kroeber (1876-1960). Estos representaban respectivamente a: The Archaeological Institute of America, The American Folk-Lore Society, The Anthropological Society of Washington y The American Anthropological Association. Hyatt 1979.

${ }^{708}$ Von Rosen se encargaría de la parte etnográfica y arqueológica, Robert Elias Fries (1876-1966) en botánica; Gustaf Henrik Eberhard von Hofsten (1880-1958) y finalmente Nils E. Nordenskiöld. Nordenskiöld 1999.
} 
Los trabajos de Nordenskiöld y von Rosen estarán orientados desde una perspectiva geográfica. Según los suecos Sudamérica ofrecían la posibilidad de estudiar al hombre en distintas etapas evolutivas, por lo cual la geografía se presentaba como la mejor disciplina al momento de desentrañar las particularidades de un campo de estudio etnológicamente "productivo"709. La importancia de dicha perspectiva sería señalada en oportunidad de observar los restos arquitectónicos incaicos y compararlo con las poblaciones indígenas del Pilcomayo. En este sentido afirmaba Nordenskiöld que las barreras ecológicas, como ríos y bosques, habían aislado a las poblaciones chaquenses unas de otras y del foco civilizatorio incaico condenándolos al primitivismo ${ }^{710}$.

En forma similar se expresaba Ludwig Kersten, para el cual las particularidades geográficas permitían clasificar a las poblaciones indígenas sudamericanas en tres grandes grupos. Destacando la primacía de los estudios lingüísticos en torno al Chaco, se proponía, siguiendo la línea de trabajo planteada por el geógrafo alemán Carl Ritter (1779-1859), realizar una etnografía histórica del Chaco, ya que de esta forma se podía estudiar el curso evolutivo de una población en particular ${ }^{711}$. Kersten planteaba que las diferencias entre las poblaciones indígenas estaban dadas por la introducción de elementos por parte de los españoles y los misioneros; cuya adquisición e incorporación encontraba en los ríos y las frondosas selvas, barreras naturales contra el proceso evolutivo ${ }^{712}$.

Nordenskiöld, una vez regresado a Suecia, mantendrá a lo largo de 1903 una serie de intercambios epistolares con Lehmann-Nitsche. En el mismo agradecía el envío de trabajos, muestras de material etnográfico y confesaba el anhelo de volver a la Argentina y contar con

\footnotetext{
${ }^{709}$ Argumentaba Nordenskiöld que "[...] a peculiar condition found there (en referencia a Sudamérica) is that, close to primitive races, we have had civilized people like the Incas, and this gives us an opportunity to study the important problem of the reasons why certain tribes have developed so much more rapidly tha others. From the Caribbean Sea to Cape Horn we meet with infinitely varied scenery and country, and this makes it possible for us to study how the culture of man has adapted itself to the different natural conditions". Nordenskiöld 1999, p. 2.

${ }^{710}$ Nordenskiöld afirmaba que en Sudamérica solo una combinación de la etnografía y la arqueología permitían esbozar un conocimiento real sobre la historia del desarrollo evolutivo de los pueblos indígenas. Remarcaba que "To what extent the primeval forest prevented the march of the Inca culture eastward, we can see from the fact that close to Cuzco, the capital of the Inca Empire, there where, up to a few years ago, Indians that were still living in the Stone Age. The primeval forest and the unnavigable rivers have been like a wall that prevented the mountain culture from spreading eastward, just as the later stopped the Europeans from penetrating the country to the east [...] If we study the various stage of development reached by the tribes in the rest of South America, leaving out the region of the Andes, we find great contrasts. In many places they seem to have reached a sort of semi-culture, as on the Amazon, on the Couany in Brazilian Guiana, round Lake Valencia in Venezuela, and at Mojos in Bolivia. The Lowest tribes are either border tribes, such as the Yaghan and the Ona in the extreme sout, or the Ge tribes in Brazil, or they are tribes living in the dense forests away from the rivers". Ibídem p. 18-19.

${ }^{711}$ Según el geógrafo y zoólogo alemán Friedrich Ratzel (1844-1904), la ciencia de la geografía hallaba en la figura de Carl Ritter a uno de sus principales impulsores. Los trabajos de este último sobre el problema filosófico de la interacción entre naturaleza y la humanidad, entre lugar/sitio (Schauplatz) e historia, significarán, en palabras de Ratzel, una renovación de la ciencia geográfica. Ratzel 1909.

${ }^{712}$ Kersten 1904.
} 
más tiempo a fin de poder estudiar las colecciones del Museo de La Plata ${ }^{713}$. Es muy posible que a través de esta serie de comunicaciones y los contactos establecidos con von Rosen en Stuttgart contribuyeran a que Lehmann-Nitsche finalmente se decidiera a concretar el mencionado viaje al noroeste argentino, haciendo uso de los mismos espacios que los miembros de la expedición sueca supieran usar para sus estudios ${ }^{714}$.

\subsubsection{Redes de comunicación y transporte}

En la elección de los lugares para la realización de las excursiones al campo operarán dos conceptos importantes: exotismo y aislamiento. A partir de construcciones discursivas operando desde diversos niveles de la sociedad, lugares como Tierra del Fuego o el Chaco eran construidos como "desérticos" y habitados solamente por representantes "primitivos" de la humanidad. Sin embargo, emprendimientos vinculados a la explotación comercial de dicho territorios a lo largo del siglo XIX darán lugar al establecimiento de diversas redes de comunicación y transporte. Si bien el tamaño y la infraestructura de las mismas serán variables, sabrán ser aprovechadas por los estudiosos. De esta forma los estudiosos obtendrán "laboratorios" donde observar y poner a prueba sus teorías sobre la evolución y la existencia anacrónica de formas primitivas de la humanidad en tiempos modernos ${ }^{715}$.

Como ha notado Irina Podgorny, entre otros, la rapidez de las comunicaciones entre determinadas regiones, se relacionaba más con los nudos que articulaban el comercio que con la proximidad geográfica. Esto podemos observarlo en el caso de Tierra del Fuego. A lo largo del siglo XIX una importante infraestructura logística y material para la explotación mercantil de la zona será establecida; principalmente por ingleses y franceses, en mayor medida, junto con alemanes, belgas y norteamericanos ${ }^{716}$; debido a su importancia capital en lo relativo a las rutas comerciales establecidas entre los antiguos territorios españoles y los países ligados al comercio

\footnotetext{
713 Junto con el pedido de trabajos y catálogos sobre las piezas jujeñas depositadas en el Museo de La Plata, Nordenskiöld consultaba sobre la posibilidad de enviar unas "puntas de flecha de madera" a fin de realizar un examen microscópico. Según el estudioso sueco estas serían evidencia de los contactos entre la puna y la zona del Chaco. Haciendo lugar a su solicitud enviaba Lehmann-Nitsche una punta de flecha de Casabindo que sería analizada por Robert Elias Fries. Nils E. Nordenskiöld a Robert LehmannNitsche. Legado Robert Lehmann-Nitsche, 14.01, 21.01 y 28.05 de 1903, IAI, Carpeta N-0070 b 497.

${ }^{714}$ El espacio geográfico jujeño como caso de estudio se encontraba presente en los planes de LehmannNitsche, por lo menos, desde agosto de 1901, tal como le comentaba Ambrosetti en ocasión de remitir el catalogo de piezas jujeñas depositadas en el Museo de La Plata. Juan Bautista Ambrosetti a Robert Lehmann-Nitsche. Legado Robert Lehmann-Nitsche 01.08 y 07.09 de 1901, 20.01.1903, IAI, Carpeta N0070 b 7.

${ }_{716}^{715}$ Podgorny 2001 b, 2002; Podgorny y Lopes 2008.

${ }^{716}$ Comenzando primeramente con balleneros y loberos, se sumarán posteriormente personas vinculadas a la explotación aurífera que establecerán distintos puntos de apoyo para la navegación, puertos de aprovisionamiento y bases de operaciones próximas a las zonas de caza de animales u extracción de materia prima. Paralelamente, y como complemento de las estrategias y actividades comerciales, se desarrollarán importantes estudios geográficos, hidrográficos y etnográficos.
} 
de la lana ${ }^{717}$. Sin embargo; como advertían el gobernador interino de Tierra del Fuego, Teniente Coronel Pedro Godoy, o el empresario e ingeniero rumano Julius Popper (1857-1893) ${ }^{718}$; la falta de estímulo para promover algo que fuera de provecho y de utilidad al país por parte de la dirigencia política argentina, daba como resultado un estado de total abandono e inversión en este territorio.

\subsection{Viaje a Tierra del Fuego (1902)}

En enero de 1902 el diario platense El Día, anunciaba la partida de Lehmann-Nitsche hacia Tierra del Fuego y el sur de Chile, viaje que lo mantendría ausente hasta el abril del mencionado año, con el objetivo de realizar un sistemático estudio de los grupos indígenas del extremo sur de América Meridional ${ }^{719}$. Dicho viaje formará parte de las vacaciones de verano del estudioso alemán, algo que no significaba dejar de aprovechar la oportunidad de poder poder estudiar in-situ aquellos grupos que representaban "[...] por la primitividad de su cultura una reliquia de los grupos étnicos más inferiores" ${ }^{\text {"720 }}$. Al mismo tiempo esperaba poder continuar las investigaciones realizadas sobre indígenas onas en el marco de la Exposición Nacional de la Industria y el Comercio de Buenos Aires (1898), momento en el cual por la deficiencia del instrumental antropológico empleado no había podido cumplimentar sus expectativas.

Aprovechando una "[...] segunda vez (que) difícilmente sería ofrecida!"721, hará uso del instrumental comprado y modificado en el viaje realizado a Europa en 1900, gracias a los cuales esperaba obtener "[...] los mejores resultados para el conocimiento de nuestras razas indígenas, elevando a su más alto grado el nivel científico de la antropología argentina",722. En dicho viaje una de sus tareas y objetivos principales fue la construcción de aparatos antropológicos, los cuales en sus trabajos sobre los onas y los takshik se habían revelado como deficientes. En este sentido hará construir, en una casa especial, un nuevo aparato antropométrico a partir de indicaciones y observaciones propias. Con respecto a la fotografía no solo obtendrá " [...] los

\footnotetext{
${ }^{717}$ Así, la Patagonia podía comunicarse más rápidamente con los puertos ingleses o Nueva York a través de Punta Arenas que a través de la carrera atlántica de los barcos de la marina argentina. En este sentido, Tierra del Fuego hacia la segunda mitad del siglo XIX podía pensarse más lejana de Buenos Aires que de Liverpool. El creciente desarrollo de las tecnologías de comunicación y transporte, favoreció notablemente la circulación de información. Gorla 1983, 1984; Podgorny 2002 a, 2005.

${ }^{718}$ Las soluciones de ambos se centraban primordialmente en la ganadería, la instauración de un puerto libre y la venta de terreno a los pobladores. Estas surgían comparando la situación de Tierra del Fuego con sus vecinos de Punta Arenas (administración chilena) y Malvinas (administración británica). Popper señalaba como una de las principales deficiencias la falta de decisión gubernamental en la venta de terrenos, aun siendo la región fueguina argentina más explotable y habitable que sus vecinos chilenos y británicos. Godoy 1893; Popper 1887.

${ }^{719}$ En la misma nota se afirmaba que "Las excursiones del joven y distinguido sabio, serán de mucha utilidad para nuestro Museo" El Día 03.01.1902.

${ }^{720}$ Lehmann-Nitsche 1916 h, p. 185.

${ }^{721}$ Lehmann-Nitsche 1927 g, p. 61.

${ }^{722}$ Informe 1900.
} 
instrumentos mejor construidos actualmente (en referencia a 1900), sino que modifique también el de Bertillion, simplificándolo para los viajes." 723.

Hacia fines del siglo XIX los servicios navieros a los puertos patagónicos eran atendidos por tres precarios transportes de la Armada Argentina, tristemente celebres por lo errático en sus escalas. Por otro lado la empresa naviera del austrohúngaro Miho Mihanović (1862-1938?) apenas llegaba hasta Carmen de Patagones. En el contexto del conflicto limítrofe con Chile, el por entonces Ministro de Agricultura argentino, Emilio Frers (1854-1923), aseguraba ante el Presidente Julio Argentino Roca la necesidad de afirmar la presencia argentina en la Patagonia con una línea privada de navegación. Como Ministro de Obras Publicas de la provincia de Buenos Aires, Frers había participado en un estudio sobre la creación de puertos provinciales y la instalación de un laboratorio marítimo cerca de Mar del Plata.

Luego de una serie de idas y vueltas Roca se entrevistará personalmente con Antonio María Delfino (1853-1922); un agente marítimo con una larga tradición familiar en el negocio comercial; pidiéndole que interviniera ante alguna de las empresas por él representadas para que se hicieran cargo del tráfico entre Buenos Aires y los puertos patagónicos en las condiciones más económicas que fuera posible ${ }^{724}$. Finalmente Delfino optará por conceder la explotación comercial a la compañía alemana Hamburg Südamerikanische DampfschifffahrtsGesellschaft $^{725}$. Los comienzos de la misma datan de 1869, año en el cual comenzaba a operar la Hamburg-Brasilianische Dampfschiffahrts Gesellschaft, fundada por dos firmas de la localidad inglesa de Tyneside junto con el agente marítimo August Bolten ${ }^{726}$.

En 1872 comenzaban los trayectos que zarpaban desde Hamburg con destino a Río de Janeiro, Santos, Bahía y Buenos Aires, siendo este el primer viaje de la línea al Río de la Plata. Entre 1877 y 1878 comenzará con la navegación directa al Río de la Plata, sin hacer escala en Brasil. En 1882, por primera vez, algunos de los vapores extendieron su viaje a Rosario. Para fines de la década de 1890 la firma contaba, teniendo en cuenta los naufragios y las ventas, con

\footnotetext{
${ }^{723}$ Ibídem.

${ }^{724}$ Roca se entusiasmaba con la idea de Frers, sugiriéndole que hablara sobre el asunto con el Ministro de Marina, el comodoro Martín Rivadavia (1852-1901). Tanto este como Roca conocían a Delfino, gracias al gerenciamiento que este realizará ante la Casa Ansaldo de Genova para la rápida adquisición; en el contexto del conflicto limítrofe con Chile; de los acorazados Garibaldi, San Martin, General Belgrano y Pueyrredón, entre 1895 y 1898. Roca le indicaba a Frers que no llamará a licitación y se comunicará directamente con Delfino. Este le recomendaba al primero que haga el llamado a licitación, algo que ocurrirá a partir de los decretos del 24 de mayo y 27 de julio de 1899. Frers renunciaba a su cargo en septiembre de dicho año, cancelando la licitación y postergando el proyecto. Ante la inexperiencia del nuevo Ministro de Agricultura, Martín García Merou (1862-1905), Roca se entrevistará personalmente con Delfino. Köhler 1907; Seiler 1996.

${ }^{725}$ Ibídem.

${ }^{726}$ Dichas firmas serán el astillero $C$. Mitchell \& Co del escocés Charles Mitchell y la compañía armadora Watts, Milburn \& Co. Finalizada la Hamburg-Brasilianische Dampfschiffahrts Gesellschaft, se establecerá la Hamburg Süd, cuyo registro oficial data del 29 de noviembre de 1871, siendo su primer presidente Heinrich Amsinck (1824-1883).
} 
una flota de 24 vapores. La contratación de Delfino le significará a la naviera alemana un notable impulso de sus actividades en relación al puerto de Buenos Aires, trasuntado en un creciente movimiento de pasajeros y cargas. Gracias al gerenciamiento de Delfino la naviera alemana aceptaba implantar una línea de vapores entre Buenos Aires y los puertos patagónicos. Su única condición era no recibir subsidios ni ayudas de ninguna clase, ni que las recibiera un eventual competidor mientras prestaran el servicio.

El 25 de enero de 1902 Lehmann-Nitsche se embarcaba en el vapor argentino Chubut, el cual formaba parte de la Línea Nacional del Sud. La misma no será una empresa naviera jurídicamente establecida, sino que será el nombre que recibió el servicio implantado entre Buenos Aires y los puertos patagónicos por parte de la Hamburg Südamerikanische Dampfschifffahrts-Gesellschaft. El vapor partiría desde la dársena sur del Puerto de Buenos Aires, con destino a Punta Arenas.

A bordo del vapor llegará a conocer a Eduardo Alejandro Holmberg (h), quien en aquel momento se encontraba al mando de una expedición, comisionada por el Ministerio de Agricultura, encargada de realizar una serie de estudios en la zona interior de Ushuaia ${ }^{727}$. Este tipo de campañas político-científicas promovidas y gestionadas desde el Estado nacional argentino serán características a partir de la segunda mitad del siglo XIX. Las mismas buscarán hacer frente a las problemáticas que significaban la correcta administración y explotación de estos territorios ${ }^{728}$. Recordemos por ejemplo los trabajos del médico y ornitólogo francés Fernando Lahille (1861-1940) en 1896, considerados por Lehmann-Nitsche como el inicio de las investigaciones morfológicas sobre los onas ${ }^{729}$. Los trabajos de Lahille formarán parte de una expedición ${ }^{730}$; gestionada por el Teniente Coronel P. Godoy ante Francisco Moreno y el gobierno central; encargada de "[...] estudiar las producciones naturales del territorio a su cargo",731.

\footnotetext{
${ }^{727}$ La zona asignada se encontraba limitada al Norte por el paralelo $54^{\circ}$, al Oeste por la línea divisoria de Chile y Argentina, al Sur por la costa norte del Lago Fagnano y al Este por el Océano. La comisión exploradora se completaba con el ingeniero agrónomo Cressenso Calcagnini, encargado de las observaciones agrícolas, meteorológicas y la confección del herbario; y el ingeniero Francisco Rossi encargado del relevamiento topográfico de la región. Holmberg 1906.

${ }^{728}$ Podgorny y Lopes 2008.

${ }^{729}$ Mencionaba también los trabajos del naturalista inglés Charles R. Darwin (1809-1882); Francisco P. Moreno; el botánico italiano Carlo Luigi Spegazzini (1858-1926) y Domenico Lovisato (1842-1915); del Teniente de marina chileno Ramón Serrano Montaner (1848-1936); Julius Popper, del cual destaca la falta de preparación y suerte para la observación de los fueguinos; del militar argentino Ramón Lista (1856-1897) y el cirujano de su expedición, Polidoro Segers (1852-1917) y finalmente los del explorador y geógrafo sueco Nils O. G. Nordenskjöld (1869-1928). Lehmann-Nitsche $1927 \mathrm{~g}$.

${ }_{730}$ Designado Lahille como encargado de las observaciones geológicas y zoológicas, partía, el 16 de enero de 1896, junto con el botánico ruso Nikolai Michailovich Albov (1866-1897), y los asistentes Emilio Beaufils y Charles de Lahitte.

${ }^{731}$ Lahille 1897, p. 3.
} 
Con el objetivo claro de la mensuración del territorio en cuanto a sus riquezas naturales propensas a la explotación comercial, la misión de Holmberg viabilizará la consecución de valiosos datos en el estudio de las poblaciones indígenas argentinas. Holmberg se entregaba a la exploración de los confines del Estado nacional argentino, convencido, al igual que LehmannNitsche, que la exploración y el conocimiento de estos parajes asignados al terreno de la fantasía eran una ventana para la comprensión precisa del pasado histórico. En este sentido se permitía hacer un llamado de atención a "[...] los que á estudios americanos se dedican, sobre la urgente necesidad de estudiar estos indios (en referencia a los onas) lo más pronto que sea posible, pues sólo quedan de ellos tres o cuatro, que, dada la prontitud con la que desaparecen, dentro de muy poco tiempo, con toda seguridad, se llevarán a la tumba el secreto impenetrable de su religión, sus costumbres y su lengua" ${ }^{\text {"732 }}$.

Lehmann-Nitsche sacará provecho de las redes establecidas por Holmberg para la realización de su trabajo. Estas le proveerán al primero de lugares donde realizar sus trabajos, aprovisionarse y descansar. Es muy posible que si Lehmann-Nitsche hubiera decidido realizar este trabajo por fuera del marco institucional y los recursos de los cuales disponía Holmberg, el tan mentado viaje de excursión a Tierra del Fuego finalizará en la dársena sur del puerto de Buenos Aires. Como podemos apreciar la elección de los lugares donde realizar las excursiones al campo, como así también la naturaleza y la extensión de las observaciones no dependerán en forma exclusiva de la voluntad del estudioso. Una situación similar sucederá al instante de trabajar con los datos y los objetos recolectados en el campo. En este caso los tiempos planteados por el estudioso para la obtención de resultados podía no coincidir con la demanda de resultado por parte de las instituciones o bien de los mecenas que financiaban las expediciones $^{733}$.

\subsection{El Noroeste Argentino (1906)}

El caso del noroeste argentino será muy similar al de Tierra del Fuego. Este se presentaba como un espacio con recursos que, explotado adecuadamente por la administración nacional, prometía rivalizar con el tabaco y el azúcar de Paraguay y la Habana, el café de Brasil,

\footnotetext{
${ }^{732}$ Holmberg 1906, p. 52.

${ }^{733}$ Dando cuenta de los trabajos de Boas al momento de procesar la información contenida en sus diarios de campaña señala Hinsley "In working up field data, financial considerations played a determinative role. Boas' own method proceeded by stages. After returning from the field, he first copied his notebooks, handing over the originals to the Bureau as its property. He then hired stenographers or students to copy the transcribed texts, word for word, onto cards for the dictionary, advancing his own money. These cards he sold to the Bureau. When the work was too large to be completed at one time, he sent half the dictionary, the Bureau paid him for it, and he reimbursed himself; then he continued with the other half, advancing money to his assistants, getting reimbursed by the government. When the dictionary was on cards, Boas recalled the cards from Washington and condensed them, combining all references on a single card for each word". Hinsley 1976, p. 314.
} 
el algodón de Louisiana o con el arroz y el añil de la India ${ }^{734}$. Esto era advertido por ingeniero y topógrafo alemán Arthur Eduard von Seelstrang (1838-1896), el cual recorrerá el territorio a cargo de la Comisión Exploradora del Chaco (1875). Este último también daba cuenta de las nulas iniciativas por parte de la dirigencia política. Al igual que lo hicieran Godoy o Popper, Seelstrang pondrá el acento en el deber patriótico que significaba la administración de los recursos descubiertos por la ciencia. Sin embargo la falta de interés e inversión por parte del Estado nacional, llevará a que los estudiosos hagan uso de aquellas redes de transporte y comunicación vinculadas a emprendimientos comerciales privados, especialmente aquellos gerenciados por extranjeros.

En consonancia con el punto anterior es preciso destacar, en el caso del noroeste argentino, el papel desempañado por los comerciantes y empresarios ingleses Walter (18581944) y William Edmund Leach (1851-1932) dueños del ingenio azucarero La Esperanza ${ }^{735}$. Como veremos su intervención será crucial en la serie de expediciones antropológicas al Gran Chaco emprendidas entre fines del siglo XIX y principios del siglo XX. Los estudiosos sabrán sacar provecho de las vías de comunicación y transporte que los Leach desarrollarán a fin de expandir sus horizontes comerciales. Al mismo tiempo será de gran utilidad el conocimiento etnográfico que estos comerciantes ingleses tenían sobre los indígenas de la zona.

Hacia 1899; en la búsqueda de una ruta más rápida y económica para el transporte de sus productos; descenderán por el río Bermejo, atravesando el Chaco, y llegando al Paraguay ${ }^{736}$. En dicha expedición participará el Capitán Zorrilla; prefecto del Puerto Resistencia; encomendado por el gobierno nacional, sin embargo el encargado de la navegación será Capitán Henry Bolland de la marina mercantil británica, descripto por Arthur Austin Greaves Dobson; editor del diario de viaje de dicha expedición; como un "[...] well-know pilot of the Parana [...]"737. Dicha expedición también sabrá emplear a los ingenieros "Kage and Elstrang" (sic), los cuales, indica Dobson, se encontraban vinculados a emprendimientos ferroviarios de la zona. Si bien desconocemos datos sobre el tal "Kage", es muy posible que "Elstrang" sea Arthur Eduard von Seelstrang, que como hemos mencionado contaba con vasta experiencia en la región del Gran Chaco. Los emprendimientos ferroviarios a los cuales refiere Dobson deben ser aquellos vinculados con la Compañía Forestal del Chaco, una compañía de capitales franco-alemanes ${ }^{738}$.

\footnotetext{
${ }^{734}$ Seelstrang 1976.

${ }^{735}$ Para los detalles de la formación del Ingenio azucarero La Esperanza ver especialmente Campi 1999; Cutolo 1968; Sierra e Iglesias 1997.

${ }^{736}$ Para una lista de los integrantes de la expedición ver Dobson 1900.

${ }^{737}$ Bolland participaría posteriormente de una comisión exploradora del gobierno boliviano destinada a la exploración del Río Paraguay. Ibídem p. 14.

${ }^{738}$ La misma se establece en 1902 a partir de la unión de la compañía francesa Portalis Frères y Cía de los hermanos Carlos y Federico Portalis y las alemanas Harteneck y Cía, de los hermanos alemanes Karl y Albert Harteneck por un lado y Gerb und Farbstoffwerk H. Renner \& Co Actiengesellschaft de Hermann Renner. Los hermanos Portalis se encontraban vinculados a La Compagnie Francaise des Chemins de Fer de la Province de Santa Fe, de la cual habían obtenido su concesión en 1887; a través de
} 
En la mencionada expedición al Bermejo, Dobson y Walter Leach realizarán una serie de observaciones antropológicas sobre un grupo de indios que Dobson identificará como matacos. Esto será posible gracias a que uno de los indígenas del grupo había trabajado unos años antes en el ingenio azucarero, lo cual facilitará el acercamiento del grupo expedicionario. Dicha oportunidad será aprovechas por Leach y Dobson para dar cuenta de las principales características somatométricas del grupo como una descripción de la vestimenta, sus hábitos alimenticios y sus viviendas. Dobson estimaba una población aproximada de 50.000 indígenas habitando el Chaco, afirmando que estos grupos ofrecían la posibilidad de observar en forma directa las primeras etapas evolutivas de la humanidad ${ }^{739}$.

Finalmente es preciso mencionar la actuación de los hermanos Leach en el financiamiento y el control de ramales ferroviarios. El 22 de noviembre de 1890 el Ferrocarril Central Norte Argentino llegaba a la localidad jujeña de Pampa Blanca, estación por la cual los hermanos enviaban sus productos a los mercados del sur. Sin embargo la distancia que debían recorrer hasta ese punto era de 40 kilómetros, por lo cual el tendido de la línea ferroviaria interesará rápidamente a los hermanos Leach. Estos financiarán parte de la empresa, cediendo forma gratuita al gobierno nacional el terreno que utilizó el trazado de esa línea a cuenta de futuros fletes sin costo. Dicho terreno consistía en una franja de 30 metros de ancho desde la finca La Urbana, por el Sur, hasta el Río Negro por el Norte, y los terrenos que ocuparon las estaciones ferroviarias de San Pedro y El Quemado. Finalmente el ramal ferroviario Perico-San Pedro era inaugurado el 13 de febrero de 1904. Más tarde se construiría un desvío ferroviario de San Pedro al Ingenio La Esperanza Los contactos obtenidos por los Leach en esta empresa proveerán a los investigadores formas rápidas y económicas de desplazarse sobre el terreno.

\subsection{Espacios de observación}

Como han señalado varios autores el "laboratorio" no es un espacio físicamente definido que ocupa un lugar determinado y específico, sino que se constituye a través de un

la firma Portalis Carbonnier Fils et Compagnie, quien a su vez al año siguiente lo entregaría a la compañía francesa Fives Lille. A principios de siglo XX contaban con dos importantes emprendimientos: uno en las cercanías de Reconquista, el cual había comenzado como exportador de quebracho a las fábricas de tanino en los Estados Unidos, y una segunda fábrica de tanino en el pueblo de Five Lilles (actualmente Vera y Pintado) al norte de Santa Fe. Los Harteneck comenzaban sus inversiones en la zona a través de la explotación de bosques de quebracho en el norte santafesino para su importación a Alemania. Posteriormente se asociarán con el empresario y banquero español Carlos Casado del Alisal (1833-1899), el cual tenía la concesión del Ferrocarril Oeste Santafesino. La adquisición de maquinaria en la ciudad belga de Amberes les permitirá instalar una nueva fábrica en la localidad santafesina de Calchaquí. Finalmente es preciso mencionar que existirán otros emprendimientos extranjeros en la zona como la primera fábrica de tanino en la localidad correntina de Peguahó, propiedad de la firma alemana Erwig \& Schmidt, instalada en 1899. Hicks 1956; Lütgens 1911; Niklison 1916; Peyret 1889; Poussou 2000; Regalsky 1999; Riet 1912; Romero 1977; Scalabrini Ortiz 1983.

${ }^{739}$ Señalaba Dobson que "In the Indian Chaco, more so even than in the Australian "aborigene", we see an ungarnished representative of the 1st Stone age, a representative of a human race that has maintained itself for perhaps 100,000 years without intellectual improvement”. Dobson 1900, p. 53. 
complejo entramado de prácticas específicas, junto con las tecnologías materiales y discursivas asociadas a las mismas ${ }^{740}$. Tal como sugiere Lorraine Daston los procesos observacionales en ciencia no dependerán exclusivamente de un espacio concreto al cual podemos denominar "laboratorio", sino que estos son una forma de experiencia que requiere del entrenamiento de la mente y el cuerpo, utilidades materiales, técnicas de descripción y visualización, canons de evidencia, formas especializadas de razonamiento y redes de comunicación y transporte ${ }^{741}$. En este sentido las observaciones antropológicas en las excursiones al campo serán efectuadas en espacios como misiones religiosas, comisarías, ingenios azucareros o reducciones indígenas; ya que las mismas al formar parte de una serie de prácticas específicas no dependerán del espacio físico concreto para dale validez científica. Como hemos señalado anteriormente en esta serie de observaciones serán importantes aquellos trabajos realizados previamente por otros estudiosos, con los cuales Lehmann-Nitsche entablará contacto. De esta forma podrá insertarse en las redes de colaboradores y los espacios de observación previamente establecidas por estos, a fin de ser utilizadas para los objetivos de sus propias investigaciones.

\subsubsection{Edificios de madera y zinc: observaciones antropológicas en las comisarías fueguinas}

Los destacamentos policiales del territorio fueguino serán uno de los espacios más utilizados por los estudiosos a fin de poder realizar observaciones sobre los indígenas que habitaban dicho territorio. Principalmente el uso de las mismas se vinculará a la dificultad de contar con los medios adecuados para el desplazamiento sobre el terreno. Lehmann-Nitsche hará uso de la Comisaría de Río Grande como así también de la red de destacamentos policiales dispersos por el territorio fueguino (Fig. 35). No solo los antecedentes de los trabajos de Lahille serán importantes en esta caso, sino también las recomendaciones realizadas por Eduardo Holmberg hijo durante el viaje hacia Tierra del Fuego, tal como precisaba Lehmann-Nitsche en el primero de sus dos diarios de campaña ${ }^{742}$. Estos también detallarán los métodos e instrumentos empleados, como así también de los pormenores del viaje. De esta manera dichos diarios completan los resultados publicados a través de sencillos trabajos aparecidos de forma irregular, entre 1905 y 1927 en las páginas de la Revista del Museo de La Plata, y que serán publicados en alemán en las páginas del Deutsche Medizinische Wochenschrift.

\footnotetext{
${ }^{740}$ Latour y Woolgar 1986; Lynch 1991; Shapin 1988.

${ }^{741}$ Daston y Lunbeck 2011, p.3.

${ }^{742}$ El primero de los diarios estaba compuesto por 229 páginas. El mismo incluirá también una fotografía del vapor Chubut y dos recortes periodísticos que daban cuenta de los pasajeros que se embarcaban. El segundo diario, de tan solo 41 páginas, contendrá algunas notas antropológicas, una fotografía y un artículo de periódico. Legado Robert Lehmann-Nitsche, IAI, Carpetas N-0070 11 y N-0070 13.
} 
Lehmann-Nitsche relataba en correspondencia a su madre, como las primeras observaciones realizadas distarán de ser las esperadas por él, alejándose de aquella aventura idealizada más propicia para el terreno de la literatura fantástica que para un trabajo de campo en el extremo sur de América Meridional a principios de siglo $\mathrm{XX}^{743}$. Dichas observaciones serán realizadas en los márgenes del paraje denominado Puerto Hope, momento en el cual un "[...] toldo europeo y dos chozas indígenas [...]"744 llamarán la atención de los pasajeros del pequeño vapor Elena. Inmediatamente Lehmann-Nitsche consultará con el capitán del vapor la posibilidad de detenerse momentáneamente en la orilla para poder observar más de cerca las construcciones.

$\mathrm{Al}$ aproximarse a la orilla un español saldrá a recibirlos y le presentará a las dos indias con las que vivía. Lehmann-Nitsche realizará una serie de fotografías y, a partir del relevo lingüístico, determinará a las mismas como alacaluf. El mismo estará guiado por las instrucciones del Handbuch zur Aufnahme fremder Sprachen de Hans Georg Conon von der Gabelent $^{745}$. Este aseguraba que el registro lingüístico sistemático facilitaba notablemente la recolección de datos útiles para la ciencia. Al mismo tiempo aseveraba que el uso de una guía o manual, aseguraba por un lado la claridad y uniformidad de los datos, por el otro la posibilidad de contar con elementos de control y contraste para los datos somáticos o fotográficos ${ }^{746}$. De esta forma el registro de los vocablos; como las mediciones antropométricas o las fotos; se presentaba como una forma de inscribir elementos tipológicos que permitían registrar, almacenar y codificar la otredad temporal del grupo indígena, y no, como han visto ciertos autores, su negación ${ }^{747}$.

En la mañana del 2 de marzo el vapor Elena bordeaba los márgenes de la localidad de Río Grande. Cerca de las 10.30 el capitán Juan Leoni fondeaba frente a la Prefectura del puerto. Gracias a un pequeño bote y la colaboración de los pasajeros desembarcaban todo el equipaje. Una vez en tierra se presentaba ante el grupo de estudiosos Ernesto de Rosis, comisario de la localidad y encargado de proveer al grupo los recursos materiales y humanos necesarios para el viaje que se aprestaban a realizar. De esta forma con la asistencia de gendarmes y cargueros el equipo se aprovisionaba con caballos para el transporte y el traslado, municiones y armas ${ }^{748}$. Al

\footnotetext{
${ }^{743}$ Robert Lehmann-Nitsche a Ida Lehmann-Nitsche. Legado Robert Lehmann-Nitsche, 06.03.1902, IAI, Carpeta N-0070 b 1295.

${ }^{744}$ Lehmann-Nitsche 1916 i, p. 188.

${ }^{745}$ Lehmann-Nitsche había utilizado el mismo en su trabajo sobre los onas de 1898. Volverá a utilizarlo en 1903 para el registro del Ahúnikdnki patagónico y en 1915-16 para el Gününa Künü puelche. Legado Robert Lehmann-Nitsche, IAI, Carpetas N-0070 16 y N-0070 17.

${ }^{746}$ Gabelentz 1892.

747 Yujnovsky 2008.

${ }^{748}$ Principalmente gendarmes, cargueros, caballos para el transporte y el traslado, municiones y armas. Holmberg 1906; Legado Robert Lehmann-Nitsche, IAI, Carpetas N-0070 11 y N-0070 13.
} 
mismo tiempo de Rosis les facilitaba un pequeño local anexo a la comisaría a fin de dejar el equipaje y los instrumentos.

Si bien las inclemencias del clima no ofrecían unas condiciones óptimas de trabajo, el espacio físico de la comisaría suplía la totalidad de las necesidades. La misma, según Holmberg, era " [...] un solo cuerpo de edificio de madera y zinc [...] A los fondos, una pequeña huerta en la que vi algunas legumbres destinadas al consumo, y una línea de carpas y pequeñas habitaciones en que viven algunas indias, mujeres de los gendarmes."749. Esta situación será similar a la de las dependencias policiales, en las cuales los gendarmes apostados habían tomado mujeres indígenas como "esposas", situación de la cual Lehmann-Nitsche sacará provecho.

El trabajo en este tipo de espacios no será novedoso. En su expedición de 1896, Fernando Lahille realizará en la Comisaría de Río Grande una serie de fotografías, medidas antropométricas y la recolección de costumbre y lenguaje de 81 indios onas, entre hombres, mujeres y niños ${ }^{750}$. Estos habían sido trasladados desde las cercanías de la Misión de Río Grande, en San Sebastián, acusados de asesinar a Eduardo Williamson y Emilio Traslaviña, dos empleados de la Sociedad Explotadora de Tierra del Fuego ${ }^{751}$. Lahille hará uso de una pequeña casa anexa a la comisaría a fin de que pudiera usarla de "laboratorio" ${ }^{\text {, }}$. La misma era facilitada por el jefe de Policía, el cual lo auxiliará en la toma de notas para los estudios lingüísticos y las mediciones antropométricas ${ }^{753}$. Como complemento y evidencia visual de estas afirmaciones publicará una serie de planchas fotográficas que representan "tipos" indígenas de todas las edades; siendo parte de las mismas realizadas por el Teniente Coronel Pedro Godoy en Bahía Sloggett, en la costa norte del Canal Beagle ${ }^{754}$. La colaboración de individuos con escasa o nula formación en la observación antropológica y de los mismos indígenas, ponen de manifiesto la necesidad de contar con el auxilio de personas locales en una tarea que, lejos de la sociabilidad compartida por los estudiosos en el espacio cerrado del laboratorio o la academia, se realiza en contextos que no son del dominio exclusivo de la ciencia ${ }^{755}$.

\footnotetext{
${ }^{749}$ Holmberg 1906, p. 68.

${ }^{750}$ El jefe de Policía, Ramón L. Cortés detallaba la reducción de 17 varones adultos; 28 mujeres adultas; 10 menores de 10 a 15 años; 13 menores de 5 a 10 años y 13 menores de 2 a 5 años. AGN. MI, 1899, Exp.175.

${ }^{751}$ Sobre la historia de la misma ver Couyoumdjian 2000.

${ }^{752}$ Lahille 1926, p.340.

753 Realizará 34 medidas somatométricas sobre 8 hombres y 7 mujeres elegidos como representantes “típicos” de la raza ona. Según Lahille "La valeur des mesures anthropométriques est, d'aprés l'opinion générale, roportionelle au nombre des sujets examinés et au degré de pureté (!) de la varietés qu'on étudie" Haciendo uso del lenguaje cuvieriano, agregaba que cualquier naturalista, habituado a la observación minuciosa y a la subordinación de caracteres, que se le diera un grupo del mismo origen para su estudio “[...] ils choisissent les sujets qu'ils considèrent comme étant les plus typiques et s'ils les mesurent avec tout le soin nécessaire [...]”. Ibídem p.352.

${ }^{754}$ Lahille 1897, 1926.

${ }^{755}$ Kuklick y Kohler 1996.
} 
Volviendo a Lehmann-Nitsche. El 6 de marzo de 1902, a las 11 de la mañana, el grupo expedicionario de Holmberg partía de la comisaría de Río Grande (Fig. 36). Luego de una cabalgata de casi 45 kilómetros arribaban al destacamento policial del paraje denominado "Río del Fuego". Inmediatamente se pondrán en contacto con el encargado del mismo, el sargento correntino Fermín Quinto. Detallaba Holmberg que este correntino rígido y disciplinado era capaz de mantener orden dentro de un cuerpo de oficiales compuesto por "[...] aquellos vencidos que la vida arrojó a tan apartado lugar, bebedores y jugadores que ya nadie soportaba y que encuentran en Río del Fuego, económico sanatorio." ${ }^{\text {756 }}$. A su vez constataba que de los 9 individuos allí apostados, 4 tenían un "matrimonio a la fueguina", es decir con mujeres indígenas y sin partida en el Registro Civil.

La lejanía de los núcleos semi-urbanos, detentores de ciertas características de civilización, determinaban la primitividad del emplazamiento policial como así también la de sus habitantes. De esta forma las "[...] dos, tres chozas hechas de los troncos del fago; una carpa, caballos, perro y algunas mujeres [...]”, serán los resultados del “[...] alejamiento completo de un centro de civilización [...]"757. Sin embargo esto le permitirá a LehmannNitsche, a lo largo de dos días, realizar una serie de observaciones sobre 4 indias onas y una yagan, distinción étnica a la cual llegaba luego de un breve examen lingüístico ${ }^{758}$.

\subsubsection{La South American Missionary Society}

Las actividades desarrolladas por los misioneros salesianos como así también por los anglicanos de la South American Missionary Society contribuirán notablemente a acrecentar el conocimiento y la "visibilidad" de los grupos indígenas del extremo sur de América Meridional, en los principales centros de estudio europeos. Hacia fines de la década de 1880 establecían la primera misión en el Chaco paraguayo, expandiéndose posteriormente ${ }^{759}$. La precisa documentación sobre sus actividades incluirá la compilación de datos antropométricos y lingüísticos ${ }^{760}$, el envío de partes óseas -principalmente cráneos-, y la participación activa de los misioneros en los espacios comerciales y científicos de exhibición de indígenas en Europa.

\footnotetext{
${ }^{756}$ Holmberg 1906, p. 70.

${ }_{757}^{75}$ Lehmann-Nitsche 1916 h, p. 185.

${ }^{758}$ En un escueto trabajo aparecido en 1916 presentará Lehmann-Nitsche sus observaciones sobre una indígena yagan de 15 a 16 años, de nombre Anolsh y cuyo sobrenombre era Carmen. Sabiendo el escaso valor e importancia científica que podía llegar a tener la publicación de un relevamiento antropológico de un solo individuo; especialmente si se tenía en cuenta el extenso y detallado trabajo descriptivo sobre los Yagan hecho por el francés Paul Hyades, como parte de la Mission Scientifique du Cap Horn (182-1883), no podía dejar pasar la oportunidad de dar cuenta de las características de un individuo que representaba “[...] por la primitividad de su cultura, una reliquia de los grupos étnicos más inferiores". LehmannNitsche, 1916 h, p.185. Con respecto a los trabajos antropológicos de la Mission Scientifique du Cap Horn ver especialmente el tomo 7.

${ }^{759}$ Martinez 2010.

${ }^{760}$ Muchos de estos serán editados en publicaciones propias de las misiones, como por ejemplo el South American Missionary Magazine.
} 
Hacia 1886 el médico y antropólogo inglés John George Garson (ca.1861-1932) afirmaba que; desde la publicación del recuento etnológico realizado por el marino y astrónomo británico Robert Fitzroy (1805-1865); las contribuciones realizadas por miembros de la South American Missionary Society, especialmente aquellas realizadas por el misionero anglicano ingles Thomas Bridges (1842-1898), serán las de mayor relevancia antropológica “[...] not only for much valuable information regarding the people, but also for most of the description of the skeletons and skulls" ${ }^{, 61}$. En su recuento sobre las principales características anatómicas de los indígenas fueguinos Garson se lamentaba de lo escaso y limitado del material osteológico presente en el Museum of the Royal College of Surgeons de Inglaterra, el cual poseía 4 o 5 esqueletos incompletos y 11 cráneos, siendo 7 de estos últimos enviados por Bridges ${ }^{762}$.

Los salesianos no solo enviarán muestras óseas a Europa. En este sentido otra de las acciones desempeñadas en la visibilización de los grupos indígenas será su exhibición en distintos escenarios europeos, actividad en la cual podemos observar una postura contradictoria. En 1899, el salesiano Giuseppe María Beauvoir (1850-1930) podrá observar la exhibición de 9 indios onas transportados a París por el ballenero y empresario belga Maurice Maître a fin de ser exhibidos L'Exposition universelle. Inmediatamente se pondrá en contacto con el diplomático chileno Gonzalo Bulnes Pinto (1851-1936), quejándose de las condiciones en los cuales los indígenas eran exhibidos (casi desnudos y alimentados con carne cruda). Luego de la intervención del cónsul chileno Carlos Antúnez González (1847-1898), Maître y los 7 indígenas restantes serán embarcados el 18 de febrero de 1890 en el vapor Orotaba con destino a Punta Arenas $^{763}$.

Sin embargo hacia 1892 Beauvoir participará; en el marco de la Exposición ItaloAmericana; de la denominada Mostra delle missioni cattoliche americane, celebrada en Génova con motivo del "descubrimiento" de América ${ }^{764}$. En la misma trasladará 5 indígenas alacaluf, 1 ona y diversos objetos de "la Patagonia y Tierra del Fuego" "765 que serán exhibidos el 21 de agosto, demostrando, en palabras de Mario Bottaro, autor de la memoria del certamen, “[...] lo

${ }^{761}$ El por entonces secretario de la sociedad, el reverendo R. J. Simpson, aseveraba que "[...] the contributions made by the Rev. Thom Bridges, the chief of their Mission in Tierra del Fuego, to the cause of science had been so much valued and so handsomely acknowledged". Garson 1886, p. 142-157.

${ }^{762}$ Más adelante afirmaba Garson que "The series of adult skulls in the College of Surgeons' Museum is composed of seven males and two females. Six of the former and both of the latter belong to the Yahgan tribe, having been obtained directly or indirectly through the South American Missionary Society". Ibídem p. 148.

${ }_{763}$ Baez y Mason 2006; Ballestero 2011; Beauvoir 1915; Borgatello 1924; De Agostini 1925.

${ }^{764}$ Junto con la exposición celebrada en 1898 en la ciudad italiana de Turín será la única en la cual, dentro un contexto católico, se exhiban nativos transportados para dicho fin. Las cordiales relaciones entre las autoridades de la ciudad y la cúpula jerárquica católica posibilitarán la existencia de una sección ministerial autónoma.

765 En la edición del Boletín Salesiano se anunciaba "Exposición Italo-Americana de Génova, Inauguración del Departamento de las Misiones Católicas el 21/08/1892. R.P.José Beauvoir, presenta objetos y a los indígenas traídos de la Patagonia y Tierra del Fuego". Esto también era afirmado por otro de los asistentes a dicha exposición, el antropólogo alemán Eduard Georg Seler (1849-1922), en su informe publicado en el Internationales Archiv für Ethnographie. BS 1892; Seler 1893. 
stato morale e materiale delle popolazioni selvagge e idolatre dell'America all'epoca della scoperta, l'antico statu delle regioni ora civili e l'efficacia delle missioni" ${ }^{766}$. El periodo de exhibición será aprovechado por estudiosos como el italiano Raffaello Zampa y el francés Jules T. E. Hamy para realizar importantes estudios ${ }^{767}$.

Aquellos individuos deseosos de llevar adelante trabajos antropológicos en aquellos parajes recónditos de la geografía del sur de América, encontrarán en las misiones salesianas hospitalidad y buena predisposición por parte de sus miembros. Los contactos establecidos con los salesianos simplificarán también el acceso a material bibliográfico producido tanto por estos como por otros estudiosos italianos. Al mismo tiempo estos cumplirán, en parte, la demanda de los estudiosos por contar con elementos óseos e indígenas vivos sobre los cuales realizar sus observaciones $^{768}$.

\subsubsection{Somatometria indígena en las misiones salesianas}

Habiendo finalizado los trabajos en la comisara de Río Grande, los miembros de la expedición de Holmberg se trasladarán hacia la Misión Salesiana de la Candelaria $^{769}$, por ese entonces dirigida, en lo que respectaba al oficio religioso, por el salesiano Giovanni Zenone (1872-1941) y por el hermano Juan Ferrando en lo que respectaba a la parte administrativa ${ }^{770}$ (Fig. 37). Según los valores de los censos poblaciones efectuados por los salesianos, la población indígena de la misión era de 80 individuos $^{771}$. Según Holmberg la labor de los salesianos; la cual equiparaba a la labor mítica realizada por Manco Capac y Mama Oello entre los incas; imprimía una nueva vida en los indígenas, en la cual “[...] sin quebrar los moldes

\footnotetext{
${ }^{766}$ Bottaro 1892, p. 45-46.

${ }^{767}$ Zampa se centrará en la medición y descripción de 4 indígenas, presentando sus resultados como una muestra científica y objetiva de la primitividad de los indígenas del sur chileno-argentino. El carácter dúctil y la curiosidad de los indígenas al ser observados y medidos por los dispositivos antropométricos, le recordará el desarrollo mental de cualquier infante europeo, hecho que colocaba a los indígenas en los albores de la evolución humana. Hamy por otro lado, realizará una extensa descripción de los elementos materiales traídos con los indígenas, mencionando solamente las diferencias craneales entre los alacaluf y los onas, pudiendo de esta forma dividir al grupo en dos "razas". Ballestero 2011; Hamy 1895; Zampa 1892.

${ }^{768}$ Ver por ejemplos las recomendaciones bibliográficas efectuadas por Beauvoir a Lehmann-Nitsche. Giuseppe María Beauvoir a Robert Lehmann-Nitsche. Legado Robert Lehmann-Nitsche, 08.07.1916, IAI, Carpeta N-0070 b 71.

${ }^{769}$ Para detalles de la fundación y el establecimiento definitivo de los salesianos en Tierra del Fuego ver Bruno 1981 y Bascope Julio 2010.

${ }^{770}$ Zenone había llegado para la fundación de la Candelaria y pasará más de 30 años en Tierra del Fuego. Para principios de siglo XX junto con otros hermanos de la congregación salesiana comenzarán a realizar un importante trabajo de predica nómada. Ferrando oficiaría como mayordomo, maestro catequista e instruiría a los indígenas en lo referido a las tareas de trabajo en el campo. Bascope Julio 2010; Holmberg 1906; Legado Robert Lehmann-Nitsche, IAI, Carpetas N-0070 11 y N-0070 13.

771 Hacia 1898 la misma era de 250 individuos. El aumento en la mortandad será producto de una conjunción de elementos como el hacinamiento y la propagación de enfermedades epidémicas. Bruno 1981; Dabbenne 1904; BS 1889-1902; Casali et.al 2006; Martinic 1973, 2003.
} 
antiguos, despiertan su razón y su moral" ${ }^{, 772}$. La palabra de las escrituras cristianas, junto con la enseñanza de tareas vinculadas a la labranza de la tierra y el trabajo manual señalaban, según Holmberg, el camino a través del cual el indígena ingresaba a la vida civilizada.

El grupo de Holmberg partirá, sin embargo Lehmann-Nitsche se hospedará en la Misión Salesiana entre el 2 y el 5 de marzo. La concentración de indígenas en un solo lugar era una oportunidad que Lehmann-Nitsche no deseaba perder. Al mismo tiempo la colaboración de los salesianos, principalmente de Juan Ferrando, será indispensable para la consumación de los estudios antropológicos. Entre las principales ayudas brindadas destacaba la disposición y preparación de un cuarto para realizar los trabajos antropométricos, la transcripción de los resultados de las mediciones efectuadas por Lehmann-Nitsche y la preparación de los indígenas para las fotografías. Esta asistencia será la que permita "[...] estudiar y medir un gran número, tanto de hombre como de mujeres [...]"773, afirmando que si el trabajo final constaba de importancia era solo por " [...] la abnegada ayuda de esos misioneros que se interesaron en sumo grado por mis investigaciones"774. (Fig. 38)

El informe final del trabajo daba cuenta de los detalles y características somatométricas de 17 hombres y 23 mujeres. La elección de los instrumentos utilizados estará determinada por su capacidad de transporte al terreno, por sus condiciones de uso bajo ciertas condiciones climáticas, y por su capacidad al momento de captar y codificar de la manera científicamente más precisa y real las partes corporales observadas. A partir del instrumental de Martin; junto con sus recomendaciones teóricas; calculaba la talla y los índices del cuerpo, la cabeza y las extremidades ${ }^{775}$.

Lehmann-Nitsche también relevará el color de piel, ojos y cabellos. Las particularidades cromáticas de las poblaciones humanas se presentarán como datos con condiciones cualitativas y cuantitativas equilibradas. A esto se vincula la capacidad de los instrumentos cromáticos al momento de representar con la mayor realidad posible el color "natural" de la piel, el cabello o

\footnotetext{
${ }^{772}$ Holmberg 1906, p. 65.

${ }^{773}$ Lehmann-Nitsche 1927 g, p. 64.

${ }^{774}$ Ibídem.

${ }^{775}$ Para el cálculo de la talla corporal seguirá las disposiciones establecidas por Martin, colocando al individuo de pie contra una tabla de madera donde primeramente se calculaban los valores relativos a la cabeza. Luego de esto sentaba al individuo para, y acorde a las recomendaciones de von Luschan, calcular la altura del vértice. Esto permitía un grado de control sobre los resultados, ya que la diferencia entre la talla total y la altura recién determinada debían corresponderse con el largo de la extremidad inferior. A la hora del cálculo de los valores medios absolutos tomará como guía los trabajos del médico alemán Wilhelm Pfitzner (1853-1903), los cuales, según Lehmann-Nitsche, no gozaban del merecido reconocimiento. Pfitzner, a partir de sus trabajos sobre proporciones corporales y esqueletares en adultos, proponía la talla, por sobre el largo del tronco, como medida de referencia, dando como resultado proporciones corporales más uniformes. Al momento de calcular el largo de la membrana natatoria de las manos hará uso del método desarrollado por el antropólogo alemán Ferdinand Birkner (1868-1944). El mismo consistía en que el individuo extendiera completamente sus dedos para posteriormente doblarlos en un ángulo de $90^{\circ}$, midiendo, con el compás normal, el largo externo del dedo medio (mano derecha) desde el punto más alto del capítulo hasta la punta del dedo. Birkner 1895; Lehmann-Nitsche 1927 g; Martin 1914; Pfitzner 1902.
} 
los ojos. Al igual que con los datos cuantitativos, la fabricación de instrumentos para el relevo de datos cualitativos estará vinculada a la búsqueda de exactitud, precisión y cuantificación de las observaciones realizadas, las cuales deben ser entendidas en relación al deseo de establecer un consenso dentro de un conjunto de estudiosos determinado ${ }^{776}$. Las tablas cromáticas operarán como un traductor de las palabras del lenguaje de uso diario, usado para describir los colores observados en la realidad, a un lenguaje numérico que se ajustará al criterio de precisión científica de la observación antropológica ${ }^{777}$.

En este sentido tendremos un importante número de emprendimientos en torno al desarrollo del mejor dispositivo práctico y metodológico que guiará y determinará la "lectura" de los colores. De esta forma mientras que hacia 1874 la tabla cromática de Broca ${ }^{778}$ (Fig.39) era reproducida en el primer número de Notes and Queries in Anthropology, la Internationalen Farbenskala de Otto Radde ${ }^{779}$, aparecida tres años más tarde, llamaba la atención de los estudiosos alemanes e ingleses (Fig. 40). Uno de los primeros intentos por estandarizar una escala cromática aplicable a los grupos indígenas sudamericanos podemos encontrarlo en las pesquisas antropológicas realizadas, entre 1896 y 1897, por el médico alemán Karl Ernst Ranke (1870-1926), hijo del antropólogo Johannes Ranke, como miembro de la expedición alemana al Río Xingú. Este publicaba en 1898 un trabajo sobre el color de la piel de los indígenas sudamericanos en el cual se incluía una tabla con un total de 13 tonos de piel $^{780}$ (Fig. 41).

Finalmente Lehmann-Nitsche optará por una combinación de instrumentos. Para la caracterización del cutis utilizará la escala promovida por Broca, descartando aquella diseñada y

\footnotetext{
${ }^{776}$ Daston y Lunbeck 2011; Daston y Galison 2010; Dias 2004; Podgorny 2006, 2008, 2009; Wise 1995. ${ }^{777}$ Fischer 1907; Fischer y Saller 1928; Hintze 1927; Martin 1914; Meiners 1792; Von Luschan 1916.

${ }^{778}$ Broca había comenzado sus trabajos hacia 1863, con un grupo de expertos que incluirá a Félix-Paul Simonot, el anatomista Louis Pierre Gratiolet (1815-1865) y el químico francés Michel Eugène Chevreul (1786-1889). La tabla se componía de 54 tipos de colores. Los primeros 20 números representaban los ojos, correspondiendo los restantes a la piel y al sistema piloso. Las principales referencias al momento de su elaboración serán los bustos depositados en el museo de la Société d'anthropologie de Paris, cartas cromáticas representadas en obras generales y álbumes particulares. Una vez seleccionado el color este se pintaba en base de acuarela, a partir de lo cual se garantizaba una reproducción exacta y uniforme del color. Finalmente se realizaba una impresión cromolitográfica, la cual ofreciendo los mismos resultados que el cromograbado, resultaba más económica en dinero y tiempo. Los resultados eran presentados un año después, sin embargo el mismo será muy criticado, especialmente al interior de la propia academia francesa, especialmente por Topinard. Broca 1863; Topinard 1886 b, 1886 c; Pouchet 1863.

${ }^{779}$ Esta se basaba en los trabajos de Chevreul. La escala se componía de 14 paneles o cartones numerados y con nombre, los cuales oficiaban como color cardinal o básico para las variantes de tono. Un artículo anónimo señalaba que el trabajo de Radde proporcionaba al arte, la industria y la ciencia un sistema uniforme libre de las arbitrariedades del ojo que observaba un color o las incertidumbres del lenguaje que lo describían. Al mismo tiempo que el proceso de estenocromía utilizado por Radde permitía una impresión clara, suave y constante de color, dando como resultado una reproducción "natural" del color resistente a la luz, el aire o la humedad. Junto con esto se abarataban los tiempos y los costos de impresión, dándole a la tabla cromática una mayor accesibilidad. Según los estudiosos, lo voluminoso de la misma limitaba su uso en los viajes de exploración, circunscribiéndose en un principio al ámbito de la industria y el comercio. La demanda por una versión más pequeña dará lugar a la edición, un año después, del Taschenausgabe von Radde's internationaler Farbenscale, la cual con sus $120 \mathrm{~cm}$ de ancho, $24 \mathrm{~cm}$ de ancho y un precio de 6 marcos podía ser fácilmente transportada en un estuche o en un bolsillo. Anónimo 1877, 1878; Radde 1877.

${ }^{780}$ Ranke (h) 1898.
} 
promovida por von Luschan, ya que el material cerámico con el cual estaban hechos los discos cromáticos dificultaban su uso bajo la luz solar, limitando el trabajo y dificultando la comparación cromática con la parte cutánea ${ }^{781}$ (Fig. 42). Al momento del estudio del iris se valdrá de la caja cromática de Rudolf Martin ya que esta contenía colores "más naturales",782, asegurando la cientificidad y seguridad de los resultados obtenidos ${ }^{783}$. Esta contaba además con ciertas ventajas a la hora de ser transportada al terreno. Las lengüetas de metal que sujetaban la placa de aluminio eran fácilmente maniobrables, lo que permitía desmontar la tabla cromática con relativa facilidad (Fig. 43). Como podemos observar la elección de los instrumentos no solo estará condicionada por la efectividad de los mismos al momento de obtener datos útiles para las investigaciones, sino también por la capacidad de transporte de los mismos al terreno.

Los datos cuantitativos y cualitativos serán volcados en distintos cuadros descriptivonuméricos de múltiples entrada. Esto facilitaba la comparación entre tablas referidas a distintos grupos indígenas, pudiendo establecer similitudes, diferencias, proximidades y lejanías "evolutivas" "784. La abstracción de objetos de estudio a números a ser inscriptos gráficamente permitirá la uniformidad del lenguaje, trascendiendo los límites del los lenguajes locales. Al mismo tiempo los objetos convertidos en números podían ser almacenados y transportados de una forma más eficaz y económica. Con esto no solo se buscaba un estudio metódicamente preparado que respondiera a un plan sistemático de investigación, sino también, la reproducción de las condiciones de control del gabinete, transformando el "campo", a través de los instrumentos, en un laboratorio que se articulaba con otros espacios de la práctica científica ${ }^{785}$. De esta forma el lenguaje numérico en el cual la información cuantitativa y cualitativa era traducida, será capaz de viajar a través de las distintas redes de información, dándole cierta independencia del lugar donde se recolectaron la información o la persona encargada de hacerlo.

781 Esta abarcaba 36 placas de vidrio opaco dispuestas en dos filas numeradas sucesivamente. Los números 1 a 6 correspondían a los colores más comunes entre las poblaciones europeas, siendo los números 7 a 36 una escala tonal decreciente desde las variables más claras a las más oscuras. Martin 1914; Von Luschan 1916.

${ }^{782}$ Martin 1914, p. 192.

${ }^{783}$ El dispositivo promovido por Martin se componía de 16 modelos oculares de vidrio de tamaño natural "[...] mit wissenschaftlicher Genauigkeit hergestellten [...]". La sucesión tonal era: marrón oscuro, marrón, marrón claro, verdoso, gris oscuro, gris claro, azul oscuro, azul, azul claro y albino. Los ojos de vidrio eran construidos por la firma F. Müller Söhne. Estos eran recibidos en Zürich, donde P. Hermann se encargaba de terminar la tabla cromática. Estos; cubiertos en su base por un algodón que los protegía de posibles daños; eran colocados en una base de madera enmarcada en aluminio, cuyo color era neutral. Los parpados y la forma de los tejidos blandos circundantes al ojo daban una sensación de relieve. El investigador también contaba un espacio en el cual podía ir agregando la variabilidad tonal del iris, la cual, según los desarrolladores del dispositivo, era extraordinaria. Este modelo podía ser adquirido por 65 marcos o 80 francos. Ibídem p. 192.

${ }^{784}$ Buscando la posterior comparación entre los resultados obtenidos en este viaje de campaña y el que realizara hacia 1906 al Ingenio azucarero de Ledesma, afirmaba que los "[...] estudios sistemáticamente preparados de antemano y realizados después en el propio terreno y en las mismas condiciones de comodidad cual si fuese en un gabinete, siendo muy contados los que se ajustan a estas exigencias." Lehmann-Nitsche 1906 d, p.53.

${ }^{785}$ Podgorny 2006, 2008, 2009. 
Lehmann-Nitsche sabrá mantener y sacar provecho de la red articulada alrededor de los misioneros salesianos a lo largo del tiempo. En este sentido mantendrá una serie de intercambios epistolares, entre 1926 y 1928, con Antonio Tonelli. En la primera de estas comunicaciones le hacía llegar a Lehmann-Nitsche, por intermedio del Padre Macchi, los dos primeros números de la revista Contributi scientifici delle missioni Salesiane del Venerabile Don Bosco en donde podría encontrar los trabajos lingüísticos de los misioneros Antonio Colbacchini (1881-1960) y Alfredo Trombetti (1866-1929) sobre los bororos de Brasil.

En la misma carta prometía Tonelli un próximo envío con el trabajo del padre Giovanni Zenone el cual comprendía una gramática y un glosario Selknam. Al mismo tiempo Tonelli le pedía a Lehmann-Nitsche la remisión de su trabajo sobre el grupo lingüístico Tshon, ya que Zenone se encontraba completando un glosario sobre el grupo lingüístico Aus, y consideraba dicho trabajo de suma importancia, siendo imposible de encontrar en el acervo bibliográfico de Torino. Tonelli le aseguraba que dicho gesto sería muy agradecido por el propio Zenone y la dirección del Museo etnologico e delle Missioni salesiane ${ }^{786}$. Los contactos establecidos con Tonelli no solo proveerán a Lehmann-Nitsche de datos limitados solamente a Tierra del Fuego, sino que le permitirán acceder a los trabajos editados e inéditos de miembros salesianos cuyas misiones estaban asentadas en otras regiones, como por ejemplo los trabajos lingüísticos del padre Justo Bottignoli sobre el grupo Guarani ${ }^{787}$.

\subsection{Ingenios azucareros}

Sin lugar a dudas el principal promotor, y posiblemente ideólogo del viaje hacia el Ingenio azucarero La Esperanza, será el fotógrafo de dicha expedición, el alemán Frank Karl Bruch (1869-1943) ${ }^{788}$. Este le escribía a Lehmann-Nitsche hacia septiembre de 1903 desde la localidad jujeña de San Pedro. Por ese entonces Bruch formaba parte de una expedición, junto a Francisco Moreno y una comitiva de geólogos alemanes, destinada a la búsqueda de yacimientos de hidrocarburos. Dicha ciudad había sido elegida como lugar de descanso, luego de que los exploradores pasarán tres días en la selva rodeados de garrapatas y otros insectos que les había hecho imposible conciliar el sueño.

\footnotetext{
786 Antonio Tonelli a Robert Lehmann-Nitsche. Legado Robert Lehmann-Nitsche, 28.06.1926, IAI, Carpeta N-0070 b 688.

${ }^{787}$ En esta misma carta consultaba Tonelli sobre los casos de esteatopigia en los Bosquimanos y sus vínculos con los casos americanos. Antonio Tonelli a Robert Lehmann-Nitsche. Legado Robert Lehmann-Nitsche, 04.08 y 12.10.1928, IAI, Carpeta N-0070 b 688.

${ }^{788}$ Nacido en una familia de libreros e imprenteros en Münich; llegará al país en 1887 para trabajar junto a su padre en la imprenta Compañía Sudamericana de Billetes de Banco de Buenos Aires. Un año más tarde ingresaba al Museo de La Plata, junto con su padre, para trabajar como fotógrafo en los talleres de la imprenta. Desempeñándose como fotógrafo e ilustrador participará de diversas exploraciones a lo largo del país, siendo nombrado hacia 1901 encargado de la sección de zoología. Para un análisis de las tareas desempeñadas por los Bruch en el Museo de La Plata ver especialmente Martínez 2010.
} 
En la mencionada ciudad Bruch tendrá la oportunidad de visitar el ingenio azucarero $L a$ Esperanza, ya que estaba al tanto de que muchos indios acudían a trabajar allí durante la época de la cosecha de la caña de azúcar. Confesando el asombro que le provocaba poder observar de forma tan simple y sencilla tipos "prácticos de chorotos (sic), chiriguanos y matacos", se lamentaba de no poder contar con una cámara adecuada para poder retratarlos. En este sentido le proponía a Lehmann-Nitsche la realización conjunta de un viaje de campaña a los ingenios azucareros de La Esperanza y Ledesma seguro de que esto resultaría en un trabajo "monumental" 789 .

Si bien no tenemos datos del número exacto de indígenas presentes en el ingenio azucarero al momento en el que Lehmann-Nitsche y Bruch realizarán sus estudios, es posible suponer un estimativo del mismo a través del informe del inspector Miguel Vidal, del Departamento Nacional del Trabajo, hacia 1914. En dicho año se entrevistaría con 16 caciques a fin de conocer las condiciones en las cuales eran contratados para trabajar en los ingenios azucareros Esperanza y Ledesma. Los indígenas le comentaban a Vidal que; a pesar de la deficiente alimentación y vestimenta provistas; en épocas de trabajo se desplazaban cerca de 2800 individuos, siendo en años anteriores un número promedio de 4000. Entre los meses de diciembre y marzo los capataces y peones comenzaban con la "contratación” y el traslado de los indígenas, en un número que promediaba los 400 individuos $^{790}$.

\subsubsection{Los trabajos en el Ingenio azucarero Esperanza}

Otro de las personas que tendrán un importante papel será el por entonces director del Museo de La Plata, Samuel Lafone Quevedo. Las redes de sociabilidad al interior de la comunidad inglesa en las cuales este último participaba garantizarán la posibilidad de utilizar el ingenio como espacio de observación. En este sentido Lehmann-Nitsche sostenía que Lafone Quevedo "[...] valiéndose, pues de las relaciones que mantiene con la colonia inglesa del país y especialmente con los industriales azucareros del norte, pudo proporcionarse en la región del noroeste de la república, oportunidad favorable de llevar a cabo con éxito una investigación antropológica." ${ }^{791}$.

Lafone Quevedo se comunicaba hacia junio de 1906 con Walter Leach consultándolo acerca de la posibilidad de que Lehmann-Nitsche y Bruch se trasladasen hasta allí para realizar un estudio antropológico sobre los indígenas chaqueños que se hallaban trabajando en la zafra. Leach le respondía inmediatamente "We shall be very pleased to see Dr. Robert Lehmann-

\footnotetext{
${ }^{789}$ Escribía Bruch que "Sollten Sie also nächstes Jahr Lust haben, daß wir zusammen diese Tour nach Esperanza u. Ledesma unternehmen, so kann Ich Ihnen für ein Monumental-Werk garantieren". Frank Karl Bruch a Robert Lehmann-Nitsche. Legado Robert Lehmann-Nitsche, 22.09.1903, IAI, Carpeta N0070 b 60 .

${ }^{790}$ Unsain 1914.

${ }^{791}$ Lehmann-Nitsche 1906 d, p. 53.
} 
Nitsche y Mr. Charles Bruch any time that they may care to come up" ${ }^{\text {"792 }}$. Con estos elementos a favor partirán Bruch y Lehmann-Nitsche hacia San Pedro de Jujuy, instalándose en forma inmediata en casa de los hermanos Leach. Tal como lo informaban medios gráficos como $\mathrm{La}$ Prensa o el Deutsche La Plata Zeitung los estudiosos planeaban una estadía de un mes a fin de poder llevar adelante sus estudios ${ }^{793}$. Una vez llegados se pondrán en contacto con Lafone Quevedo, poniéndolo al tanto sobre las buenas condiciones laborales que ofrecían el trabajo en el ingenio y la hospitalidad de los hermanos Leach $^{794}$.

Los trabajos de Bruch y Lehmann-Nitsche tendrán lugar entre el 1 y el 15 de agosto. Los hermanos Leach tendrán una activa participación en los mismos, tal como se dejaba en claro al momento de publicar los resultados de dicha campaña "Don Walter nos hospedó en su casa particular y puso á nuestra disposición un lugar adecuado para nuestros estudios, y al frente mismo de nuestra pieza, interesándose vivamente en nuestros trabajos, al conocer su índole; no se cansaba de mandarnos gente día a día y cada mañana, llevándonosla hasta personalmente, para ser examinada"795. Esto también lo afirmaba una publicación en el diario La Nación la cual relataba "Los Sres. Leach prestan todo su concurso e influyen para que los indios no pongan resistencia a los estudios a que se les somete y puedan los señores de la comisión llenar cumplidamente su cometido" ${ }^{\text {,796. }}$.

De esta forma los hermanos Leach transformaban las habitaciones de su casa en espacios propicios para la observación antropológica. En este sentido una de las crónicas de dicho viaje publicadas en las páginas del diario La Prensa relataba "Don Gualterio Lea (sic), copropietario del ingenio "La Esperanza", hospedó a los viajeros en su casa, poniendo a su disposición un lugar independiente y apropiado para fotografiar y medir á los ejemplares elegidos con toda la comodidad de un gabinete. Fue allí, en aquel improvisado laboratorio antropológico, donde fueron detenidamente estudiados 160 individuos de distintas razas y mestizages (sic), número extraordinario si lo comparamos con las modestas cifras obtenidas por misiones científicas expresamente enviadas desde Europa" ${ }^{\text {,797 }}$. Si bien el redactor de la nota no mencionaba dichas expediciones, veremos más adelante que en año subsecuente la casa de los hermanos Leach se transformará en un punto casi "obligado" al momento realizar trabajos científicos en la zona del norte argentino. De esta forma las redes de colaboración articuladas

\footnotetext{
${ }^{792}$ Walter Leach a Samuel Lafone Quevedo, 21.06.1906, AHMLP.

${ }^{793}$ La Prensa 29.07.1906; Deutsche La Plata Zeitung 20.07.1906.

794 A los pocos días Lafone Quevedo respondía dicha comunicación y le agradecía por el envío de materiales lingüísticos y arqueológicos. Samuel Lafone Quevedo a Robert Lehmann-Nitsche. Legado Robert Lehmann-Nitsche, 07.08.1906, IAI, Carpeta N-0070 b 817.

${ }^{795}$ Lehmann-Nitsche1906 d

${ }^{796}$ La Nación 13.08.1906.

${ }^{797}$ La Prensa 12.10.1906. El resaltado es de nuestra autoría.
} 
alrededor de empresarios y comerciantes extranjeros residentes en la Argentina parecieran desempeñar un papel más importante que el financiamiento institucional.

Los trabajos llevados a cabo por Bruch y Lehmann-Nitsche incluirán una serie de estudios somatométricos, fonograbaciones y 157 fotografías de frente y perfil en un grupo compuesto por 50 chiriguanos, 30 chorotes, 50 matacos y 30 tobas $^{798}$. Los estudios somatométricos serán realizados acorde a los métodos y técnicas empleados en el estudio de los onas (1898 y 1902) y los "takshik" del grupo Guaicurú (1899). Esta continuidad responde al objetivo de Ehrenreich por construir un cuadro comparativo que resumiera y caracterizará las principales características físicas de los grupos indígenas sudamericanos.

En lo concerniente a la fotografía es preciso destacar la inclusión de una serie de modificaciones introducidas por Lehmann-Nitsche y por Bruch a fin de obtener en una sola placa fotográfica la foto frontal y de perfil de un mismo individuo. Esto suponía dejar de utilizar la silla de Bertillion, la cual permitía a los individuos a ser retratados permanecer erguidos durante el tiempo que duraba la exposición pero no se presentaba apta para su transporte al terreno $^{799}$. Esto permitirá también realizar, como complemento a las fotos frontales y de perfil, una serie de retratos "artísticos" tomados en tres cuarto de perfil ${ }^{800}$. Al igual que sucediera con las fotos realizadas en el viaje a Tierra del Fuego, estas fotografías, junto con otras, formarán parte del catalogo de postales impresas por la casa editora Rosauer.

Una vez vueltos a la ciudad de La Plata, diversas publicaciones en los medios gráficos de la época se encargaban de dar cuenta de los "interesantes resultados" obtenidos por la comisión exploradora del Museo de La Plata. De esta forma tendremos resúmenes publicados en La Nación, en el Deutsche La Plata Zeitung y en la revista Caras y Caretas $^{801}$. En todas estas

${ }^{798}$ El Deutsche La Plata Zeitung auguraba promisorios resultados sobre estas investigaciones. Deutsche La Plata Zeitung 12.08.1906.

799 Según Lehmann-Nitsche "El aparato fotográfico empleado por el señor Bruch, tiene la cámara de 18 por 24 centímetros, y un aplanático de Suter adaptado justamente para estos retratos; se evita con él la desfiguración de la fisonomía como también la dureza que se observa en muchas fotografías. Por medio de una hojalata pintada de negro mate que se coloca alternativamente delante de cada mitad del vidrio opaco, se logra exponer cada mitad de una placa fotográfica separadamente, obteniendo así relevamientos de frente y de costado, del mismo individuo, en una sola placa, con lo que se evita equivocaciones. En todas nuestras operaciones fotográficas, la maquina y el indígena se colocaban en el mismo lugar, y los retratos resultaron así de la misma reducción. Con mover la máquina un poco hacia delante al tomar la fotografía de costado, obteníamos fácilmente y si mecanismo especial la reducción igual de la vista de frente sin necesidad de la silla de Bertillon, que no es apta para llevarla en viajes". Lehmann-Nitsche 1906 d, p. 55-6.

${ }^{800}$ Este interés por la dimensión "estética" de la fotografía puede vincularse, como ha señalado Máximo Farro, con la publicación, en 1904, del atlas antropológico Die Sammlung Boggiani von Indianertypen aus dem centralen Südamerika, un compilado fotográfico realizado por el pintor, dibujante, fotógrafo y etnólogo italiano Guido Boggiani (1861-1902). Farro 2009, 2011; Martínez 2010.

${ }^{801}$ En la publicación de La Nación se detallaba la realización de 200 retratos indígenas de frente y de perfil, la medición de 60 chorotis (sic), la compilación de su vocabulario "hasta la fecha desconocido", y finalmente los "interesantes cantos de tobas y chiriguanos, fijados en fonógrafos". Similares resultados 
publicaciones, las cuales eran acompañadas por reproducciones de las fotos realizadas por Bruch, se acentuaba la realización de las placas fotográficas y las grabaciones fonográficas, positivos resultados que se supeditaban en forma exclusiva a la ayuda prestada por los hermanos Leach (Fig. 43).

Lehmann-Nitsche, por su parte, expondrá los resultados en una conferencia titulada "Eine anthropologische Studienreise nach Jujuy". La misma tendría una amplia promoción a lo largo de 4 días en los principales diarios alemanes que circulaban en Buenos Aires y La Plata. En estos se destacaba principalmente la proyección de imágenes luminosas realizadas a partir de fotografías originales de dicho viaje ${ }^{802}$. La charla se efectuaría el día 11 de octubre a las 20.30 hs en el salón de actos públicos del diario La Prensa, y estaría organizada por el Deutsche Wissenschaftlichen Verein (Sociedad Científica Alemana).

El día posterior a la conferencia el diario La Prensa se hacía eco de dicho evento ${ }^{803}$. En un sucinto resumen remarcaba el matutino que dicha exposición constituía la primera de una serie de conferencias "sobre asuntos científicos" organizadas por el Deutsche Wissenschaftlichen Verein $^{804}$. Los asistentes a dicha gala, en su mayoría miembros de la comunidad alemana, escucharán los pormenores previos del viaje, una sinopsis comparativa de las “costumbres nacionales” entre las poblaciones norteñas y del litoral. La introducción a los resultados del viaje se encargaba de resaltar la invalorable ayuda prestada por los Leach. Seguidamente los asistentes se veían maravillados por las proyecciones luminosas y principalmente por las grabaciones fonográficas de voces y cantos indígenas que les harían escuchar.

Por último es interesante mencionar que a partir de estas publicaciones, junto con las recomendaciones personales realizadas entre estudiosos la casa de los hermanos Leach se convertía en un punto de visita obligado al momento de llevar adelante un viaje exploratorio al norte argentino. En este sentido hacia octubre de 1911 el sociólogo, etnólogo e historiador de las religiones Sigfrid Rafael Karsten (1879-1956) agradecía a Lehmann-Nitsche las cartas de

eran publicados, un día antes, en el Deutsche La Plata Zeitung. Por su parte en Caras y Caretas daba cuenta de los estudios antropométricos y las observaciones descriptivas realizadas, las cuales, según la revista, fueron realizadas "según los sistemas adoptados por la antropometría moderna". Dicha publicación incluirá una serie de fotografías entre las cuales podemos encontrar un grupo de chiriguanos, tobas y chorotes, tres retratos de mujeres y finalmente una foto de medio cuerpo en la cual se retrata un "tipo característico de mataco". Caras y Caretas 22.09.1906, p. 25; Deutsche La Plata Zeitung 19.08.1906; La Nación 20.08.1906.

${ }^{802}$ Ver ediciones del 6, 7, 10 y 11 de octubre del Deutsche La Plata Zeitung y 9 y 10 del mismo mes en el Argentinisches Tageblatt.

${ }^{803}$ La nota incluía la foto de un indio chiriguano, uno mataco y finalmente la del cacique chorote Chapá.

${ }^{804}$ Ya hacia 1908 los miembros del comité de publicaciones sugerían a los miembros de dicha sociedad la publicación y difusión periódica de los resultados de sus investigaciones. Deutschen Wissenschaftlichen Verein a Robert Lehmann-Nitsche. Legado Robert Lehmann-Nitsche, 09.07.1908, IAI, Carpeta N-0070 b 925. 
presentación y recomendación que le facilitaban la estancia en el ingenio La Esperanza, lugar en el cual realizará una serie de observaciones lingüísticas sobre los grupos indígenas chorote ${ }^{805}$.

Lehmann-Nitsche volverá a hacer uso del espacio de los ingenios azucareros para sus trabajos de campo. A lo largo de la década de 1920 realizará diversos estudios en los ingenios azucarero Ledesma y El Tabacal ${ }^{806}$. El uso de estos espacios, como así también los recursos metodológicos implementados provendrán de trabajos previos de otros individuos. En el caso de El Tabacal ${ }^{807}$, será de importancia un breve trabajo de A. de Llamas sobre la lenguas indígenas. Según este último su trabajo ofrecía un elemento preciso a aquel estudioso que deseara "[...] ejercitar (sus) dotes etnográfico-perceptivas y desentrañar del lenguaje lo que tienen en común con otros dialectos é idiomas Sud-Americanos" ${ }^{\prime 808}$.

Al igual que lo hiciera Lehmann-Nitsche 15 años más tarde, Llamas sugería que la reconstrucción histórica de los pueblos indígenas era posiblemente solamente a través del estudio sistemático de los componentes materiales y abstractos que habían caracterizado su cultura, de esta forma eran necesario el estudio en conjunto de "[...] los elementos complejos que nos legaron, en sus monumentos (si los hubiesen tenido), en sus industrias, en sus artes, en sus armas y en sus idiomas alma mater que con las luces de la etimología guía al filósofo y al historiados por camino seguro al través obscuro de los tiempos y las edades antropológicas" ${ }^{\text {"809 }}$. Como podemos apreciar la utilidad de los estudios lingüísticos al momento de estudiar la historia de los grupos humanos será advertida también por individuos por fuera del ámbito académico.

\subsubsection{Los trabajos en el Ingenio azucarero Ledesma}

El caso del ingenio Ledesma será muy similar al de La Esperanza. Lehmann-Nitsche estaba al tanto de las investigaciones previas que habían tenido lugar allí. Hacia la segunda mitad del siglo XX señalaba la ausencia de datos "científicos" con respecto a las investigaciones de tipo lingüístico en el noroeste del país. Las únicas excepciones serán los trabajos de Eric von

\footnotetext{
${ }^{805}$ Luego de esta carta Karsten emprenderá un viaje a través del Chaco. El 2 de junio de 1912 le escribía nuevamente a Lehmann-Nitsche desde casa de los hermanos Leach agradeciéndole el envío del vocabulario chorote, el cual le permitiría finalizar con el trabajo lingüístico. Karsten confesaba que nuevas aristas habían emergido en el proceso de investigación, lamentándose por el escaso tiempo del que disponía para continuar las investigaciones. Otro de los puntos por los cuales expresaba inconformidad era el no haber podido llevar hasta el Chaco el fonógrafo que había adquirido en Buenos Aires. En este sentido esperaba recibir un fonógrafo que había adquirido en Salta, a fin de poder grabar el canto de los chorotes y los tobas. Sigfrid Rafael Karsten a Robert Lehmann-Nitsche. Legado Robert LehmannNitsche, 27.10.1911 y 02.06.1912, IAI, Carpeta N-0070 b 358.

${ }^{806}$ Lehmann-Nitsche 1924 h, 1924 i, 1925 k, 1927 h.

${ }^{807}$ Fundado en 1918 en el departamento de Orán, provincia de Salta, por el político y empresario argentino Robustiano Patrón Costas (1878-1965).

${ }^{808}$ Llamas 1909, p. 3.

${ }^{809}$ Ibídem. Resaltado en el original.
} 
Rosen y el vocabulario relevado en 1909 por Salvador Santiago Lorenzo Debenedetti (18841930). Los relevos etnográficos de este último tendrán lugar en el ingenio azucarero Ledesma, propiedad de David Ovejero González (1859-1931) y Ángel Zerda (1837-1931) ${ }^{810}$. Estos serán descriptos por Debenedetti como "[...] personas altamente calificadas y atentas $[\ldots]^{811}$, siempre dispuestas a colaborar en los más mínimos detalles del trabajo antropológico. Estos también le facilitarán el acceso al soporte material y logístico provisto por la población local y el personal militar destinado a la defensa de estos puntos ignotos del país. En este sentido Debenedetti contará con la ayuda de un Teniente apellidado Quintana quien le facilitará el acceso a los emplazamientos indígenas y colaborará asiduamente al momento de entablar "entrevistas con (los) caciques" ${ }^{\prime 12}$. Los emprendimientos privados y los actores involucrados en los mismos se revelan como primordiales al momento de obtener objetos e información, economizando tiempo y muchas veces reduciendo significativamente los costos de la campaña en si. Estos elementos evidencian como la práctica de la antropología es una empresa colectiva que depende de la actuación de múltiples actores.

Como hemos señalado anteriormente la importancia de las redes de informantes y aprovisionamiento por otros estudiosos será aprovechada extensamente por Lehmann-Nitsche, un elemento poco mencionado por él o sus reconstrucciones biográficas. De esta forma; y valiéndose de los datos del trabajo de Debenedetti; realizará Lehmann-Nitsche dos excursiones de campo al mencionado ingenio en 1921 y 1924. En la primera ocasión lo hará como encargado de una misión científica del Museo de la Plata. Durante su estadía en el establecimiento azucarero realizará recopilaciones de grupos lingüísticos que calificará como escasamente conocidos. El mismo estibaba no en la falta de compilaciones lingüísticas; ya que podemos encontrar vocabularios registrados por militares, miembros de expediciones exploratorias y misioneros; sino en la supuesta falta de autenticidad de estos datos, producto del relevo simultaneo de un gran número de informantes ${ }^{813}$.

Según Lehmann-Nitsche al no limitarse a trabajar exclusivamente con un indígena, se omitía la importancia de las diferencias dialectales entre los distintos informantes consultados. En este sentido el trabajo centrado en un solo informante era la única manera de establecer bases

\footnotetext{
${ }^{810}$ Para ese entonces el clan compuesto por las familias Ovejero y Zerda constituía uno de los polos político-económico del norte argentino. Hacia 1900 el ingenio producía, aun con una significativa merma en sus ingresos, 315.000 pesos moneda nacional, siendo esto el equivalente al $82,87 \%$ del presupuesto de la provincia de Jujuy (380.109,38 pesos moneda nacional), y un 59.65\% del de la provincia de Salta (528.005,04 pesos moneda nacional). El poder político será también un espacio donde este poderoso clan azucarero extenderá una fastuosa red de control. En este sentido se registrará una sucesión familiarempresarial en las sucesivas gobernaciones de Ángel Zerda (1901-04 y 1906-07) David Ovejero (190406), Luis Linares Usandivaras (1907-10) y finalmente Avelino Figueroa (1910-1913). Cutolo 1968.

${ }^{811}$ Salvador Santiago Lorenzo Debenedetti a Juan Bautista Ambrosetti, 12.07.1909, Museo Etnográfico Juan B. Ambrosetti, Legajo 19.

${ }^{812}$ Ibídem.

${ }^{813}$ Las principales excepciones serán los trabajos de Samuel Lafone Quevedo (1888), Lucien Adam (1899) y Theodor Koch-Grünberg (1903). Lehmann-Nitsche 1926 d, 1926 e.
} 
sólidas e indiscutibles para el establecimiento de una lingüística comparativa interamericana ${ }^{814}$. Para esto trabajará con dos indígenas que se encontraban en el ingenio Ledesma para trabajar en la zafra de la caña de azúcar.

De uno de estos; descripto como "[...] un hombre joven, francachón y accesible [... $]^{1815}$; apuntará 301 vocablos que estarán categorizados siguiendo el ordenamiento propuesto por la Tabelle zur Aufnahme südamerikanischer Sprachen, editada por el Königliche Museum für Völkerkunde de Berlin, la cual era caracterizada por Lehmann-Nitsche como un "[...] cuaderno muy práctico que contiene las palabras más necesarias, en alemán, español y portugués, y además hay espacio en blanco para los vocablos americanos" ${ }^{\wedge 16}$. Dicha tabla se organizaba en una libreta/libro fácilmente transportable en cuya primera parte constaba de un espacio a completar con el nombre del idioma y una llamada a pie de página que rezaba "Sírvase remitir el manuscrito al Museo Real Etnográfico" ${ }^{817}$. El cuerpo de esta libreta/libro de apuntes contaba con 66 páginas en las cuales se detallaban el nombre de la tribu, las categorías lingüísticas en las cuales se debían agrupar las palabras relevadas, aclaraciones, y finalmente espacio en blanco para que el estudiosos pudiese agregar más palabras que no estuvieran en las categorías previamente definidas ${ }^{818}$. El uso de dicha tabla le permitirá comparar fácilmente sus listas con los trabajos de Lucien Adam y Koch-Grünberg, estableciendo analogías y diferencias ${ }^{819}$.

Con respecto al segundo de sus informantes precisaba Lehmann-Nitsche que este era “[...] capitanejo y generalísimo de todos los Tobas del Chaco argentino" ${ }^{\text {"20 }}$, el cual se había desplazado hacía el ingenio para que su gente trabajara en la cosecha, lugar donde será visitado repetidas veces por el antropólogo alemán. La recopilación, la cual auguraba muy buenos resultados, quedará trunca debido a la intervención de un lenguaraz de la misma tribu que Guachurí de nombre José, el cual, motivado supuestamente por los celos, convencerá al primero para que cese con la colaboración. De esta forma la lista solo contendrá 135 vocablos. Los

\footnotetext{
${ }^{814}$ Lehmann-Nitsche $1926 \mathrm{~d}$.

${ }^{815}$ Ibídem p. 187.

${ }^{816}$ Lehmann-Nitsche 1910 d, p. 114.

${ }^{817}$ Tabelle zur Aufnahme südamerikanischer Sprachen 1902, p. 1.

${ }^{818}$ Legado Robert Lehmann-Nitsche, IAI, Carpetas N-0070 16 y N-0070 17.

${ }^{819}$ El primero de estos publicaba hacia 1899 su gramática comparada de los dialectos de la familia, considerada por el propio Adam como el primer libro científico de esta temática publicado en Europa ${ }^{819}$. El segundo de estos había realizado un importante trabajo de campo entre 1903 y 1905 en el noroeste de la amazonia, específicamente en la zona limítrofe entre Brasil y Colombia. El resultado de los trabajos de Koch-Grünberg se traducirá en una lista de más de 1.300 objetos etnográficos, 1.000 fotografías, así como nueve grandes vocabularios con textos en diferentes idiomas y anotaciones gramaticales. Al mismo tiempo realizaba varias listas de vocabularios sobre una muestra de 31 comunidades, algo que según Koch-Grünberg permitiría el estudio y la clasificación de sus idiomas. Las categorías usadas por Lehmann-Nitsche a fin de poder establecer las comparaciones con los trabajos de Adam y KochGrünberg serán: partes del cuerpo; elementos y naturaleza; casa, utensilios y armas; vestidos; familia; animales; plantas, números; adjetivos; tiempo; lugar y verbos. Adam 1899; Koch-Grünberg 1995; Lehmann-Nitsche $1926 \mathrm{~d}$.

${ }^{820}$ Ibídem p. 193.
} 
resultados de estos trabajos serían articulados con los trabajos realizados en $1906^{821}$, procurando establecer una sólida cartografía lingüística de la zona Chaqueña.

Al momento de su segunda visita al ingenio Lesdesma, la recolección de datos astronómicos y cuentos del folklore norteño ocuparán la mayor parte del tiempo. A partir de estos últimos datos comenzará a elaborar un manuscrito inédito intitulado Folklore Argentino: cuentos populares $^{822}$. Guía fundamental en este estudio serán aquella información provista por periódicos y revistas. En este sentido podemos mencionar especialmente los recortes periodísticos; intercalados entre las transcripciones realizadas en el ingenio Ledesma; sobre los trabajos compilatorios de distintas leyendas y tradiciones del norte argentino, realizados por el escritor argentino Juan Carlos Dávalos (1887-1959) ${ }^{823}$. Este último tendrá a comienzos de la década de 1920 una ganada reputación en el campo folklorista. Hacia 1924 comenzaba a sintetizar el que sería uno de sus más mas reconocidos trabajos Los casos del zorro. Fabulas campesinas de Salta $(1925)^{824}$.

Una copia de dicho libro, publicado en Buenos Aires y Córdoba por la Librería Científica y Literaria El Ateneo del español Pedro García, podremos encontrarla en la "Biblioteca Criolla" de Lehmann-Nitsche. El trabajo de Davalos le consentirá a LehmannNitsche contar con un conjunto de datos que le permitirá sistematizar, organizar y contrastar con las fabulas y relatos del zorro recopilados entre sus informantes y colaboradores indígenas de la región norpatagónica argentina, buscando de esta manera la posibilidad de fijar las áreas geográficas de las mismas a través de los elementos propios de cada una ${ }^{825}$.

\footnotetext{
${ }^{821}$ Recordemos el vocabulario mataco, compuesto por 111 vocablos, relevado por Lehmann-Nitsche en su estadía en el ingenio azucarero La Esperanza.

${ }^{822}$ La recolección sería efectuada entre el 19 y el 24 de julio, siendo dos los interlocutores principales, ambos procedentes de la provincia de Jujuy: Manuel Martínez, del departamento de Humahuaca, y Fraac Cabezas, de la ciudad de Abra Pampa. Gracias a estos podrá acopiar los siguientes cuentos: "El súri y el sapo"; "El zorro y el cuervo"; "El zorro y la chuña"; "El zorro y la perdiz"; "El zorro y el perro" y finalmente "El zorro y el quirquincho".

${ }^{823}$ También estarán presente los trabajos "Vivar del Cid" de Mario Falco y "Con el filo, con el filo 1" Hacha" de Rafael Cano, ambos publicados en La Prensa. Legado Lehmann-Nitsche, IAI, Carpeta N-0070 w 20.

${ }^{824}$ Este compilaba una serie de fabulas y cuentos que Davalos había oído contar en su niñez “[...] a los muchachos del campo y a las criadas indígenas de mi casa". Ya siendo mayor, y en una de sus continuas incursiones al interior de Salta, había podido escucharlas nuevamente en los fogones compartidos con los gauchos. Estos cuentos serán para Davalos "[...] viejos como la civilización [...]", conservado sin alterar sus elementos esenciales, los cuales podían ser rastreables hasta la India. Fabulas, leyendas o cuentos eran para el escritor salteño "[...] manifestaciones del alma nativa [...]", radicando su importancia en el estudio del hombre en el hecho de que estas "[...] reflejan singulares aspectos de la naturaleza y el espíritu americano". En este sentido la tarea del folklorista estivaba en poder desentrañar estos elementos primarios en las fábulas una vez que estas se habían integrado al colectivo folklórico oral y literario. Davalos 1925, p. 7-8.

${ }^{825}$ Tal como explicitaba una reseña periodística anónima adosada a la última página del ejemplar del libro de Davalos presente en la "Biblioteca Criolla" de Lehmann-Nitsche, las fabulas del zorro recolectadas por el escritor argentino; el cual aclaraba el autor eran propias de las poblaciones campesinas de la provincia de Salta; sin embargo muchas de las mismas eran "universalmente conocidas" pero las mismas estaban
} 


\subsubsection{Reservas indígenas}

Una serie de importantes relevos de datos astronómicos, lingüísticos y fotográficos por parte de Lehmann-Nitsche será efectuada en la reserva indígena de Napalpí en 1924. En un discurso leído en el Congreso científico internacional americano, celebrado en la ciudad de Buenos Aires en 1910, Lehmann-Nitsche se mostraba partidario de la existencia de las mismas ${ }^{826}$. Comparando la situación argentina con los Estados Unidos de América, proponía la creación de reservas, dado que en el país del norte estas habían propiciado a ciertas tribus indígenas "[...] un alto grado de civilización y un bienestar considerable" ${ }^{827}$. Según LehmannNitsche en la Argentina de principios del siglo XX la "extirpación” del indígena regía las políticas que determinaban el doblamiento y la correcta administración del territorio nacional.

La importancia económica de los pueblos indígenas argentinos era construida también a partir de similares empresas acometidas en Alemania, y de las cuales Lehmann-Nitsche estaba al tanto. El principal ejemplo será Hamburgische Kolonialinstitut, fundado en 1908. Este se encargaba de diagramar y planificar las políticas más adecuadas para las colonias alemanas en África, Asía y Oceanía. Tiempo después de su fundación el comerciante naviero Eduard Woermann (1863-1920); miembro de una familia de Hamburg con larga tradición en el comercio marino y con diversos intereses económicos en las colonias del sudoeste de África; ofrecía un cuantioso premio al trabajo que propusiera las medidas prácticas más eficientes para elevar la tasa de nacimiento y reducir la mortandad infantil indígena en las colonias alemanas ${ }^{828}$.

Los estudiosos alemanes participarán y promocionaran activamente este tipo de proyectos, los cuales, en su función de salvaguardar la vida de los indígenas, ofrecían a los antropólogos la oportunidad de contar con un espacio para la observación de los mismos. En 1903 Franz Boas señalaba que "[...] carried on whit the greatest energy, because all the Indian tribes, their languajes and customs, are disappearing with incredible rapidity” ${ }^{\sharp 29}$. Estimando la desaparición de gran parte de la información en 5 años, sugerirá consecuentemente la creación de reservas antropológicas en un trabajo en conjunto entre el gobierno de los Estados Unidos y el Bureau of American Ethnology.

Boas estimaba que en el plazo de 5 años la inversión seria cercana a los 237.000 dólares, pero los beneficios posteriores para el gobierno serían mayores ya que los estudiosos

"[...] adaptadas al medio en que se han conservado, tomando así los caracteres de las que pueden ser realmente autóctonas". El resaltado es de nuestra autoría.

${ }^{826}$ Hacia 1906 remarcaba que el indígena era "[...] un elemento irremplazable que debió ser destinado á hacer posible la explotación general de las regiones tropicales y subtropicales”. Entre los miembros en el mencionado congreso, habrá quienes adhieran a la propuesta de Lehmann-Nitsche por razones humanitarias, tal como Ameghino, y otros, como Ambrosetti, para los cuales el propio avance del progreso a las regiones indígenas; traducido como introducción de enfermedades, el alcohol y la presencia de los "blancos", los condenaba a la desaparición. Lehmann-Nitsche 1906 d, p.54, 1915 c.

${ }^{827}$ Lehmann-Nitsche 1915 c, p. 4.

${ }^{828}$ Becker 2005.

${ }^{829}$ Boas 1903, p. 265. 
tendrían un espacio ideal para solucionar temas como la adaptación de la raza negra o los problemas de la migración ${ }^{830}$. Finalmente el Bureau of American Ethnology no aceptará la propuesta de Boas, como así tampoco The Carnegie Institution for Science que también había sido contactada por este último ${ }^{831}$. Un caso interesante, como veremos más adelante, será el del etnógrafo alemán Friedrich Christian Mayntzhusen (1873-1949), quien llegando a Paraguay en 1900 terminará comprando 120.000 hectáreas en la zona del Alto Paraná, estableciendo una importante reserva indígena que proveerá de datos, objetos e indígenas a diversos estudiosos alemanes dispuestos al estudio de los grupos Aché-Guayakí.

En el caso específico del norte argentino Lehmann-Nitsche se encargaba de remarcar que el indígena chaqueño era un valioso elemento en el progreso de la zona "Una cosa es mandar á la gente desde una cómoda oficina y otra trabajar uno mismo en las horas caniculares. El indio es, pues, un valioso elemento para el progreso industrial de todo el Norte de la Republica y debe ser amparado por el Gobierno" ${ }^{\text {832 }}$. En forma afín se expresaría el por entonces presidente argentino Roque Sáenz Peña (1851-1914) para el cual; en el contexto de la campaña militar al Chaco de 1912 al mando del Coronel Enrique Rostagno (1868-¿?); el indígena era un factor económico importante indispensable de conservar.

Similar postura será la de José Elías Niklison (1875-1920). Enviado en calidad de inspector del Departamento Nacional del Trabajo al ingenio azucarero Las Palmas; propiedad de los hermanos irlandeses Richard (1844-1891) y Charles Hardy (1859-1913); podrá estar en contacto con un importante grupo de matacos, a los cuales definiría como "[...] un obrero fuerte, laborioso e irremplazable en el ambiente y en la especialidad de ciertas labores propias de la región" ${ }^{833}$. En este sentido el inspector Vidal se preguntaba ¿Pueden los ingenios de Jujuy prescindir en absoluto del elemento indígena? Dicha interpelación era contestada de forma negativa debido a tres elementos primordiales para la prosperidad económica de la zona: la enorme cantidad de individuos disponibles, la posibilidad de omitir las mismas condiciones laborales exigidas por obreros no-indígenas y finalmente el económico pago dispensado a los indígenas ${ }^{834}$.

Al momento de concretar la campaña a la reserva indígena de Napalpí, será de vital importancia la estrecha colaboración prestada por el ornitólogo y entomólogo argentino Enrique Lynch Arribálzaga (1856-1935) y Eufemio Galván Bruque. El primero de estos creaba en 1907, en la ciudad de Resistencia (Chaco-Argentina), la Sociedad Protectora de Indios. La misma será

\footnotetext{
${ }^{830}$ Ibidem.

${ }^{831}$ Hyatt 1979.

${ }^{832}$ La Prensa 12.10.1906.

${ }^{833}$ Niklison 1915, p.54.

${ }^{834}$ En su informe describiría Vidal los fallidos ensayos llevados adelantes con obreros andaluces, rusos, japoneses, hindúes y finalmente criollos. Unsain 1914, p.13.
} 
de corta existencia, sin embargo sentará las bases para la fundación de la reducción laica para indígenas de Napalpí, en 1911, de la cual Lynch Arribálzaga será responsable entre 1913 y 1916.

La misma consistía en un territorio de 20.000 hectáreas, ubicado a 120 kilómetros de Resistencia, sobre la traza del ferrocarril Barranqueras al Oeste ${ }^{835}$. Esta será para Lynch Arribálzaga la mejor solución en torno al problema de la integración del indígena en la sociedad argentina de principios de siglo XX. Llegaba a dicha solución luego de haber estudiado extensamente distintos tipos de emprendimientos en la zona como las misiones jesuíticas y franciscanas junto con el análisis exhaustivo de casos internacionales como los desarrollados en Brasil y especialmente Estados Unidos. Llamativamente este último caso, detallado por Lynch en su informe presentado ante la Dirección General de Territorios Nacionales, será el que retome un año después Lehmann-Nitsche en su disertación de 1915 sobre la necesidad de destinar territorios reservados a los indígenas de Patagonia, Tierra del Fuego y $\mathrm{Chaco}^{836}$.

El objetivo principal de la reducción indígenas de Napalpí, será “[...] atraer, amparar y civilizar a los indígenas de la Republica Argentina que se hallen aún en estado salvaje o de tribu" a fin de convertir a las nuevas generaciones en "[...] gente laboriosas, medianamente instruidas, aptas para diversos oficios y de costumbres morales, sin pretender levantarlas bruscamente hasta niveles sociales superiores, antiéticos con el medio del que salen y del cual no será posible apartarlas por completo [...]" ${ }^{, 837}$. A pesar de que la evolución cognitiva de los indígenas; la cual según Lynch Arribálzaga era un estadio intermedio entre el niño y el adulto; no les permitiría destacar en las sutilezas de las artes refinadas como la pintura o la música, era lo suficiente para aprender los rudimentos de tareas agrícolas y ganaderas en regiones que solo sus cuerpos, criados y fortalecidos por la pertenencia a la naturaleza indómita y salvaje de aquellas geografías, podían soportar ${ }^{838}$. De esta manera se buscaba que los indígenas se incorporarán, a través del trabajo y la educación, a la “[...] masa civilizada del país [...]”839.

Ciertos elementos del plan implementado por Lynch Arribálzaga en la reducción serán de suma importancia al momento en que Lehmann-Nitsche efectuara su trabajo. Uno de esto será la designación de Galván Bruque como primer administrador de la reducción. Como señalara Lynch Arribálzaga la persona que desempeñara dicho puesto debía poseer " [...] un carácter y experiencia tales que pueda ganarse pronto la voluntad y la confianza de los

\footnotetext{
${ }^{835}$ La misma se inspiraba principalmente en los trabajos llevados adelante por el coronel Cândido Mariano da Silva Rondon (1865-1958) en Brasil y aquellos realizados por el publicista norteamericano Francis Ellington Leupp (1849-1918) en Estados Unidos. Lynch Arribálzaga 1914.

${ }^{836}$ Recordemos también que un esbozo de estas ideas serán presentadas por Lynch Arribálzaga en el Congreso Internacional de Americanista celebrado en 1910 en la ciudad de Buenos Aires. LehmannNitsche 1915 a; Lynch Arribálzaga 1914.

${ }^{837}$ Lynch Arribálzaga 1914, p. 39-96.

${ }^{838}$ Ibídem.

${ }^{839}$ Ibídem p. 39.
} 
indígenas" ${ }^{840}$. En este sentido Bruqe podía hablar fluidamente toba, por lo cual se encargará de oficiar como mediador en las investigaciones de Lehmann-Nitsche. Una vez vuelto a La Plata este continuará consultando a Galván Bruque sobre las traducciones efectuadas, enviándole resultados para su corrección ${ }^{841}$.

Por otro lado tendremos el plan de educación básica para los indígenas asentados en Napalpi. Este estará basado en aquellos implementados por los Estados Unidos y Canadá en sus propia reducciones, los cuales establecían entre otros puntos ligeras nociones de astronomía, cosmografía y rudimentos de dibujo lineal. Estos elementos facilitarán la recopilación de datos astronómicos realizada por Lehmann-Nitsche. Este realizará los trabajos casi siempre de noche y con cielo despejado, ya que de esta forma los indígenas podían identificar los elementos astronómicos fácilmente, siendo estos trasladados a una carta sideral por Lehmann-Nitsche, la cual después sería reproducida gráficamente en un formato reducido y acentuando solamente los elementos sobre los cuales se quería puntualizar. Para los distintos grupos indígenas asentados en la reducción de Napalpi dicha carta sideral no será un elemento ajeno, ya que similares objetos serán utilizados para su educación dentro de la reducción ${ }^{842}$.

Lynch Arribálzaga también le recomendaba a Lehmann-Nitsche la visita a otra serie de establecimientos en los cuales los indígenas se encontraban asentados, especialmente la misión de San Francisco de Asís de Laishí en Formosa, establecida el 25 de marzo de 1901. Al mismo tiempo le sugería ponerse inmediatamente en contacto con el prefecto de dicha misión, el sacerdote franciscano Fray Pedro Iturralde, a fin de conseguir una carta de recomendación que le permitiera insertarse con facilidad en los diversos espacios científicos y canónigos en donde los indígenas y los productos de su cultura material circulaban, ya que dicha recomendación era la única manera de que sus trabajos en Formosa rindieran una "buena cosecha científica"

La recomendación de Lynch Arribálzaga no era desacertada. Iturralde colabora asiduamente con aquellos estudiosos dedicados al estudio de los grupos indígenas. Recordemos el folleto Soñando con los niños del Chaco editado en 1918 por Estanislao Zeballos; por ese entonces decano interventor de la Facultad de Derecho de la Universidad de Buenos Aires; en el cual se incluían medio centenar de fotografías cedidas por Iturralde. A su vez es preciso mencionar que la estrecha colaboración de este último con el mundo docto estará supeditada a una cuestión central: justificar las propuestas de expansión de su obra pastoral en el Chaco Central ante la autoridad política de turno ${ }^{844}$. Al momento de informar al Ministerio del Interior sobre los resultados de las tareas llevadas adelante en la misión, aclaraba que el mismo no

\footnotetext{
${ }^{840}$ Ibídem p. 42.

${ }^{841}$ Lehmann-Nitsche 19251.

${ }^{842}$ Lehmann-Nitsche 1923 b, 1923 c, 1924 h, 1924 i, 1925 1, 1927 h; Lynch Arribálzaga 1914.

${ }^{843}$ Lynch Arribálzaga a Lehmann-Nitsche, 21.05.1924, IAI, Carpeta N-0070 b 424.

${ }^{844}$ Iturralde 1909; Zeballos 1918.
} 
obedecía al "[...] purito de una vana ostentación, sino al deseo de ilustrar la opinión pública [...]" y a riesgo de que su exposición "[...] pudiera pecar de apasionada [...]" adjuntaba el informe oficial del Inspector Santiago Bello presentado ante la Dirección de Tierras y Colonias $^{845}$.

Juntos con las recomendaciones epistolares por parte de Lynch Arribálzaga, obtendrá Lehmann-Nitsche ideas claves para la elaboración de sus trabajos. En la misma carta en la cual le recomendaba establecer contacto con Iturralde, le prometía el pronto envío de un trabajo suyo sobre el mito toba del avestruz de la Vía Láctea, el cual consideraba un interesante estudio sobre la astronomía indígena por las conexiones y similitudes que podía establecer con las versiones de dicho mito por parte de otros grupos indígenas ${ }^{846}$. Meses más tarde remitía Lehmann-Nitsche sus trabajos sobre la astronomía de los grupos chaqueños, retomando de esta forma la comunicación estrictamente científica con Lynch Arribálzaga, el cual en comunicaciones anteriores le expresaba sus preocupaciones por la masacre de Napalpi.

\subsection{La masacre de Napalpi}

Es preciso hacer una mención aparte sobre el movimiento indígena de Napalpi y la posterior masacre. Dicho movimiento se caracterizó por su carácter complejo y multidimensional. Los principales trabajos se han centrado en la caracterización mesiánica o milenarista de dicho movimiento mientras que otros han focalizado su análisis en la condición de "explotado" del indígena y su inserción dentro del sistema productivo económico capitalista $^{847}$. No queriendo adentrarnos en discusiones que distan de los objetivos de este trabajo, pretendemos puntualizar la interacción entre la antropología y los factores políticos involucrados.

El comienzo del movimiento indígena puede ubicarse en las acciones llevadas adelante por el entonces gobernador del Territorio Nacional del Chaco y Formosa, Fernando Centeno, destinadas principalmente a favorecer a los productores algodoneros de la zona en desmedro de los grupos indígenas acrecentarán el clima de descontento ${ }^{848}$. Los enfrentamientos entre los grupos indígenas y los colonos irán escalando en su violencia, llegando los indígenas a tomar la vida de un colono francés en respuesta a la muerte de un chamán por parte de la policía local en un confuso episodio. El comienzo de la huelga; en la cual concluirán representantes de los

\footnotetext{
${ }^{845}$ Dicho informe constaba de una detallada descripción de la ubicación y características de los edificios de la misión como así también un minucioso censo sobre la población indígena asentada en dicho establecimiento. Iturralde 1909, p. 7.

${ }_{846}$ Lynch Arribálzaga a Lehmann-Nitsche, 21.05.1924, IAI, Carpeta N-0070 b 424.

${ }^{847}$ Ver especialmente: Cordeu y Siffredi 1971; Díaz y García 2005; Iñigo Carrera 1997; Gordillo 2006; Miller 1999; Trinchero 2000, 2005; Wright 2003.

${ }^{848}$ Entre las principales medidas adoptadas se reglamentaba la prohibición de salir a los integrantes de la reserva del ámbito del territorio nacional junto con la decisión de que los grupos indígenas entregarán el $15 \%$ de su producción de algodón.
} 
grupos toba y mocoví junto con campesinos originarios de la provincia de Corrientes que se habían refugiado en el monte como respuesta a la tensa situación social que acarreaba la explotación de los hacendados; comenzará a afectar la producción de la propia reducción como así también la de los campos lindantes. De esta forma el 18 de julio de 1924 el gobernador Centeno dará la orden de proceder con rigor para con los sublevados. A la mañana siguiente más de 130 policías, junto con civiles y con la ayuda de un avión biplano pusieron punto final al movimiento indígena.

Con un saldo de cerca de 500 indígenas muertos, Lynch Arribálzaga renunciaba a la dirección de la reducción. A través de una carta leída en el Congreso Nacional, Lynch Arribálzaga denunciaba no solo la matanza cometida en Napalpi sino también el proceder de la policía local a fin de evitar cualquier tipo de investigación. Hacia septiembre de ese mismo año le escribía a Lehmann-Nitsche señalando "[...] la forma franca y sensacional como ha sido revelado al congreso los sucesos de Napalpi de que fue Ud. testigo" ${ }^{\text {"849 }}$. Lynch Arribálzaga se refería a la exposición realizada por el socialista Francisco Pérez Leirós (1895-1971), el cual a lo largo de 6 horas presentó pruebas ostensibles de la responsabilidad del gobernador Centeno ante la masacre, pidiendo su inmediata destitución y reclamando una comisión investigadora parlamentaria de siete miembros para determinar la cantidad de indígenas muertos ${ }^{850}$.

Lynch Arribálzaga señalaba que las afirmaciones de Pérez Leirós; el cual lo mencionaba; le valdrá una citación policial a pedido del diputado Saccone a fin de que clarifique su postura ante la masacre de Napalpi. Visiblemente preocupado por dicha situación le confesaba a Lehmann-Nitsche que se veía forzado "[...] a decir la verdad sobre el origen de la versión [...]”. Condicionado por la violenta persecución policial hacia aquellas personas que pudieran aportar datos concretos sobre los sucesos del 19 de julio ${ }^{851}$, le pedía a LehmannNitsche si podía declarar ante la comisión investigadora ya que a diferencia de él este se encontraba "[...] fuera del alcance del machete policial chaqueño [...]", siendo el estudioso alemán un testigo preferencial de las "[...] atrocidades cometidas contra los indios". Lynch Arribálzaga, preocupado por el destino de aquellos que se atrevían a ofrecer testimonio sobre los hechos ocurridos en Napalpi, le recomendaba a Lehmann-Nitsche ser lo más "parco" (sic) posible en su testimonio, evitando "dar el nombre de cualquier residente en el territorio que

\footnotetext{
${ }^{849}$ Lynch Arribálzaga a Lehmann-Nitsche, 18.08.1924, IAI, Carpeta N-0070 b 424.

${ }^{850}$ En uno de los pasajes más celebres de la intervención de Pérez Leiros este advertía que "El país reclama justicia. Debemos aparecer ante el mundo como nación civilizada que castiga a los bárbaros; el Gobierno debe demostrar que no quiere manchar sus prestigios por la acción de hombres que por encontrarse a mil kilómetros de Buenos Aires creen que pueden proceder como se procedía en un feudo hace 500 años"

${ }^{851}$ En uno de los párrafos de su carta leída en el Congreso Nacional señalaba: "La matanza de indígenas por la policía del Chaco continúa en Napalpí y sus alrededores; parece que los criminales se hubieran propuesto eliminar a todos los que se hallaron presentes en la carnicería del 19 de julio, para que no puedan servir de testigos si viene la Comisión Investigadora de la Cámara de Diputados"
} 
haya colaborado con la pesquisa, para no exponerlo a persecuciones", ya que como le recordaba Lynch Arribálzaga, el se encontraba lejos de esas amenazas ${ }^{852}$.

La carta de Lynch Arribálzaga no deja dudas sobre la observación directa de los sucesos de Napalpi por parte de Lehmann-Nitsche. Su silencio ante los sucesos acaecidos la mañana del 19 de julio ha sido objeto de la más fuerte condena moral por parte de una serie de trabajos ${ }^{853}$. Sin centrarnos en un juicio moral ante la postura adoptada por Lehmann-Nitsche, es preciso tener en cuenta el expreso pedido de cautela por parte de Lynch Arribálzaga. En carta a este último, fechada el 28 de septiembre de 1924, confesaba Lehmann-Nitsche haber sido interrogado sobre los sucesos de Napalpi y ser requerido de aportar "[...] datos o pruebas que revelen excesos cometidos por la policía en la persona de los indígenas". Tranquilizando a un temeroso Lynch Arribálzaga afirmaba Lehmann-Nitsche haber hecho caso de las recomendaciones de este último, declarando que "no había presenciado esos hechos" y asegurándole que no había "[...] suministrado datos o pruebas que sobre ellos se relacionen" Estos elementos deberían ser considerados al momento de realizar una condena moral e históricamente anacrónica sobre las dinámicas de interacción entre la política y las prácticas antropológicas de principios de siglo XX.

\footnotetext{
${ }^{852}$ Lynch Arribálzaga a Lehmann-Nitsche, 18.08.1924, IAI, Carpeta N-0070 b 424.

${ }^{853}$ Ver entre otros Echarri 2001; Gordillo 2004, 2006; Solans 2008.

${ }^{854}$ Lehmann-Nitsche a Lynch Arribálzaga 28.09.1924, IAI, Carpeta N-0070 b 424.
} 


\section{Redes de cooperación}

A lo largo de sus 30 años de residencia en la Argentina Lehmann-Nitsche supo canalizar a su favor recursos y dádivas a través de las redes sociales y científicas en las que estaba inserto. A lo largo de sus excursiones al campo aprovechará para establecer redes locales entre los pobladores para utilizarlos posteriormente en la recolección de objetos y datos. Esta estrategia utilizada por los estudiosos sabrá aprovechar y sacar ventaja de las posibilidades que presentaba la ampliación de las redes de transporte y comunicación; principalmente las líneas telegráficas y los ferrocarriles; las cuales a lo largo del siglo XIX permitirán la movilización de recursos, personal, colecciones de objetos y datos entre las instituciones científicas y las regiones a explorar $^{855}$.

Este recurso metodológico e instrumental le permitirá a Lehmann-Nitsche sortear las dificultades y carencias económicas y materiales al momento de emprender dispendiosas campañas al interior del país, las cuales muchas veces dependerán de los vaivenes económicos e institucionales del Museo de La Plata. La utilización de estas redes economizará tiempo y, principalmente, dinero. Al mismo tiempo le permitirá construir y extender una red de informantes, recolectores y traductores que le darán a estas investigaciones un carácter continuo y permanente, pudiendo recolectar entre 1899 y 1926 un portentoso cuerpo documental que contendrá canciones, mitos y dialectos de los grupos indígenas del norte, centro y sur de la Argentina.

Al mismo tiempo se sacaba provecho del conocimiento que estas personas tenían de los lugares y sus pobladores, ya sea por relaciones laborales, sociales o comerciales. A pesar de que en estas redes los actores principales serán personas que no cuenten con inserción y/o instrucción formal dentro de los espacios científicos institucionalizados, pudiendo llegar a considerar su conocimiento ambiguo e indeterminado, en el centro científico se convertiría en un conocimiento fundado y preciso ${ }^{856}$.

Al mismo tiempo Lehmann-Nitsche se insertará dentro de la red de estudiosos alemanes que se encontraban realizando investigaciones en América. De esta forma podrá formar parte de diversas empresas cooperativas a larga escala, promovidas desde los espacios científicos alemanes. En forma similar al caso de los trabajos de Franz Boas en los Estados Unidos analizados por George Stocking, podemos decir que Lehmann-Nitsche no fue un "pensador teórico sistemático" ${ }^{\prime 857}$. Por un lado sus trabajos estarán basados en la articulación de elementos de investigaciones editadas previamente o de los resultados inéditos que otros estudiosos compartían a través de la correspondencia privada. Por otro lado re-estructurará, añadirá o

\footnotetext{
${ }^{855}$ Podgorny y Schäffner 2000; Podgorny 2002 a; Schäffner 2008.

${ }^{856}$ Latour 1987, 1992.

${ }^{857}$ Stocking 1982, p. 196.
} 
suprimirá elementos acorde a los reducidos objetivos de sus investigaciones, los cuales, en muchos de los casos, se articulaban dentro de proyectos más amplios.

Entre los principales proyectos cooperativos a larga escala en los cuales LehmannNitsche participará, destacan aquellos concernientes a la recolección de material lingüístico, mitológico y astronómico de los grupos indígenas americanos. En los mismos interactuarán diversos estudiosos alemanes. Estos, a pesar de sus singularidades, buscarán el establecimiento de un programa empírico que tendrá por objetivo la construcción de una cartografía etnográfica del Continente Americano. En menor medida mencionaremos también los trabajos realizados sobre la Formación Pampeana en la primera década del siglo XX, lo cual evidenciará como el uso de los vínculos académicos y sociales le permitirá a los estudiosos granjearse el acceso a recursos teóricos y materiales que pudiera aportar evidencia a sus trabajos por un lado y suplir la falta de conocimiento específicos sobre determinados temas por el otro. La colaboración establecida entre estos estudiosos se presentaba como un garante de la objetividad del conocimiento generado. Tal como han señalado Lorraine Daston y Peter Galison " [...] shared procederes, shared rules, shared constructions - the essence of communicable thought, all to be refomulated in terms of structure. Here lay objectivity" ${ }^{\prime 858}$.

\subsection{La red de colonos ingleses}

Una de las redes de aprovisionamiento de datos sobre el sur argentino será aquella articulada alrededor de la comunidad de colonos, misioneros y estancieros ingleses. Entre estos destacan sobre todo los integrantes de la familia Bridges. Lehmann-Nitsche estará al tanto, desde muy temprano, sobre las investigaciones llevadas adelante por miembros de esta familia. Hacia 1898, al recibir carta del reverendo anglicano Thomas Bridges (1842-1898), anotaba Lehmann-Nitsche en el margen de la misma "El autor del diccionario Yahgan"

Bridges había aprendido ciertos rudimentos del idioma yagan en la isla Keppel, donde un grupo de indígenas habían sido trasladados por la South American Mission Society. Posteriormente recolectara, entre 1864 y 1879 , cerca de 30.000 voces yagan, a partir del cual confeccionará su Yamana-English: a dictionary of the speech of Tierra del Fuego ${ }^{860}$. Ulteriormente traduciría al yagan versiones de los Evangelios de San Lucas y San Juan (1881 y 1886) y de los Hechos de los Apóstoles (1883). La colaboración con estudiosos vinculados a la órbita del Museo de La Plata llevará a la publicación de un trabajo intitulado "Datos sobre

\footnotetext{
${ }^{858}$ Daston y Galison 2010, p. 293.

${ }^{859}$ En el original "Der Verf. Des Yahgan Wörterbuch". Thomas Bridges a Robert Lehmann-Nitsche. Legado Robert Lehmann-Nitsche, 1898, IAI, Carpeta N-0070 b 57.

${ }^{860}$ El mismo será publicado en 1933 y 1987 por sus descendientes.
} 
Tierra del Fuego comunicados por el Rev. Thomas Bridges" (1892), aparecido en el tercer tomo de la Revista del Museo de La Plata.

Eduardo Holmberg (h), sin ser un especialista en las ciencias del hombre, dejaba en claro el valor que las investigaciones de Bridges tenían para Lehmann-Nitsche "Cuando el misionero Bridges llegó a Tierra del Fuego, fue a indios de este grupo a los que primero conoció (en referencia a los onas). De ellos aprendió algunas palabras, dándose cuenta de que no hablaban la lengua general, pues los demás onas no lo entendían. Estos indios no se relacionan con los del interior de la isla, y según el Sr. Bridges, deben ser los últimos representante de una invasión á Tierra del Fuego anterior á la llevada á cabo por los onas que hoy la recorren” ${ }^{\Perp 861}$.

De los miembros de la familia Bridges el de mayor relevancia dentro de la red de colaboradores de Lehmann-Nitsche será el hijo de Thomas, Stephen Lucas Bridges (18741949). Trabajos como los de Carlos R. Gallardo o los del explorador estadounidense Charles Wellington Furlong (1874-1967) sabrán valerse de valiosos datos etnográficos aportados por Stephen Bridges. Tanto Lehmann-Nitsche como Holmberg dejarán asentado, el primero en su diario de viaje y el segundo en su informe oficial, la autoridad de Stephen Bridges en cuanto al estudio científico de los grupos indígenas de Tierra del Fuego.

Para Lehmann-Nitsche el trabajo de Stephen Bridges, a pesar de no contar con las herramientas metodológicas para el procesamiento de la información obtenida, era de un valor preeminente, ya que el mismo era el resultado de un trabajo de campo prolongado y en constante contacto con los indígenas ${ }^{862}$; algo que como hemos visto no será característico de sus propios trabajos. La estancia que Lehmann-Nitsche efectuará en la Misión de la Candelaria responderá en parte a la posibilidad de insertarse y articular este entramado eclesiástico de recolección de datos a sus necesidades ${ }^{863}$. Esta breve estadía en la misión salesiana será la que le granjeará la posibilidad de establecer un breve contacto con Stephen Bridges. Este último le comunicaba brevemente sus conjeturas, a partir de datos lingüísticos, de la división de los Selknam en dos grupos: Shilk’nam y Mánekenku. Dicha información le será de utilidad a Lehmann-Nitsche para conformar un cuerpo de datos que contrastará y corroborara posteriormente, con apuntes tomados del indígena Casimiro en paso por el Museo de La Plata hacia 1905. A partir de esta síntesis de datos Lehmann-Nitsche extractará aquellas palabras que no se correspondían con los grupos lingüísticos indígenas reconocidos para la parte septentrional de Sudamérica. Las diferencias y similitudes al interior de estos lo llevarán a plantear la existencia de un solo grupo lingüístico denominado Tshon.

\footnotetext{
${ }^{861}$ Holmberg 1906, p. 51.

${ }^{862}$ Legado Robert Lehmann-Nitsche, IAI, Carpeta N-0070 11 y 12.

863 No solo contará con la ayuda de los salesianos al momento de realizar los diversos estudios somatométricos, sino que podrá acceder a un preciso informe censual sobre la demografía de la población, sus movimientos migratorios y también obtendrá valiosos datos de las recopilaciones lingüísticas efectuadas por Giovanni Zenone sobre los Selknam, entre 1894 y 1897.
} 
Buscando dar forma a esta idea confeccionará Lehmann-Nitsche un vocabulario en el cual integrará una serie de datos procedentes de diversas fuentes: los que el mismo recolectara, aquellos provenientes de un glosario lingüístico de lenguas patagónicas y onas que Sthepen Bridges le obsequiará a Lafone Quevedo y principalmente a un conjunto de 209 palabras del dialecto Tä'uüsn (sic) apuntadas por Carlos Ameghino ${ }^{864}$. Todo este conjunto de datos sería ordenado siguiendo las indicaciones de la Tabelle zur Aufnahme südamerikanischer Sprachen. En la edición utilizada por Lehmann-Nitsche pueden contabilizarse 702 vocablos anotados por él mismo ${ }^{865}$.

Una vez regresado a La Plata, y con necesidad de más datos que sustentarán sus trabajos sobre los grupos fueguinos, establecerá Lehmann-Nitsche una fluida correspondencia con Stephen Bridges. Hacia septiembre de 1902 este se encontraba de paso por la ciudad de Buenos Aires. Respondiendo una invitación de Lehmann-Nitsche, visitará el Museo de La Plata, oportunidad en la cual intercambiarán ciertas anotaciones y bibliografía. Con la finalidad de que Lehmann-Nitsche pudiera ampliar su base de datos etnográficos y lingüísticos sobre los fueguinos organizarán un nuevo encuentro, al cual Bridges, debido a una serie de visitas personales y de negocios deberá suspender imprevisiblemente.

Disculpándose por dicho imprevisto, le recomendaba Bridges la lectura del libro $L a$ Australia Argentina (1898) de Roberto Jorge Payró. Al mismo tiempo le recordaba que se aprestará a finalizar con un libro sobre gramática ona escrito por salesianos, el cual Bridges le había prestado al momento de conocerse y que quería llevarse en su viaje de regreso a Tierra del Fuego $^{866}$. La importancia de los trabajos de la red de misioneros salesianos al momento de la construcción de la cartografía lingüística del extremo sur de América Meridional, se reflejaba en las palabras de Stephen Bridges, el cual tranquilizaba a Lehmann-Nitsche y le aseveraba "No me olvidaré de sus encargos de frases y leyendas Onas" ${ }^{\circledR 67}$.

Hacia 1904 Lehmann-Nitsche, ante la evaluación poco favorable a sus intereses académicos, retomaría la comunicación con Stephen Bridges. Tal como le confesaba a su madre la posibilidad de conseguir una posición científico-académico en Alemania comenzaba a tornarse lejana. El único modo de evitar esto era la publicación de una mayor cantidad de

${ }^{864}$ Dicha compilación data de 1900 y lleva por nombre "Vocabulario Tehuelche, Tehues, Pampa, Araucano". Lehmann-Nitsche 1913, 1923 g.

${ }^{865}$ Legado Robert Lehmann-Nitsche, IAI, Carpetas N-0070 16 y N-0070 17.

${ }^{866}$ Stephen Lucas Bridges a Robert Lehmann-Nitsche. Legado Robert Lehmann-Nitsche, 16.09.1902, IAI, Carpeta N-0070 b 56.

${ }^{867}$ Stephen Lucas Bridges a Robert Lehmann-Nitsche. Legado Robert Lehmann-Nitsche, 21.09.1902, IAI, Carpeta N-0070 b 56. 
trabajos o bien colaborar asiduamente con el envío de datos a los estudiosos en Alemania ${ }^{868}$. En consecuencia Lehmann-Nitsche indagaba en sucesivas cartas a Stephen Bridges sobre la existencia de nuevos datos concernientes a los onas. Bridges se excusaba explicándole que desde el último encuentro que ambos habían sostenido, diversas ocupaciones vinculadas a la Estancia Harberton habían ocupado su tiempo y que además no había podido aprender “[...] a great deal fresh about the Indians" ${ }^{\$ 669}$. En la misma carta le comentaba sobre un posible viaje a Buenos Aires en mayo de ese mismo año, oportunidad en la cual podría, si Lehmann-Nitsche así lo deseaba, llevar consigo un joven indio mestizo que podía hablar fluidamente Shilk'nam y Mánekenku.

Esto nos permite entrever ciertos matices del trabajo de campo que no han merecido la correspondiente atención por parte de otras reconstrucciones bio-bibliográficas. Bridges aclaraba en dicha carta que el destino final de su viaje no era Buenos Aires, sino Paraguay. Esto implicaba que dejaría al indígena al cuidado de Lehmann-Nitsche, volviendo por él en su viaje de regreso. Esta carta da cuenta, en parte, la forma en la cual los estudiosos solucionaban la imposibilidad o la dificultad de desplazarse al campo. Si el presupuesto destinado por el Museo de La Plata a las misiones científicas no podía solventar un nuevo viaje a Tierra del Fuego, Lehmann-Nitsche podía disminuir los costos a través de la red de misioneros y residentes en la zona que podían proveerlos del material de estudio sin necesidad de trasladarse al terreno propiamente dicho. En este sentido Bridges cerraba su carta remarcándole a Lehmann-Nitsche "Please let me now if it would suit you to pay his expenses there and back"

Con respecto a este último punto es preciso mencionar la invitación realizada por el itinerante viajero naturalista italiano Clemente Onelli (1864-1924), el cual en una pequeña misiva le comunicaba a Lehmann-Nitsche la llegada de dos indígenas patagónicos a Buenos Aires a los cuales Onelli asesoraría para debatir el destino de sus tierras con el por entonces Ministro de Agricultura, Honorio Pueyrredón ${ }^{871}$. En este sentido Onelli consultaba a LehmannNitsche sobre su interés en dichos indígenas, ofreciéndose Onelli a organizar un encuentro en su domicilio particular.

\footnotetext{
${ }^{868}$ Robert Lehmann-Nitsche a Ida Lehmann-Nitsche. Legado Robert Lehmann-Nitsche, 21.06.1903, IAI, Carpeta N-0070 b 1295.

869 Stephen Lucas Bridges a Robert Lehmann-Nitsche. Legado Robert Lehmann-Nitsche, 16.02.1904, IAI, Carpeta N-0070 b 56.

${ }^{870}$ Stephen Lucas Bridges a Robert Lehmann-Nitsche. Legado Robert Lehmann-Nitsche, 16.02.1904, IAI, Carpeta N-0070 b 56.

${ }^{871}$ Dichos indígenas serán Miguel Ñancuche Nahuelquir, jefe de una comunidad de 300 miembros asentados en la colonia Cushamen del Alto Chubut, y su capitanejo Napal. Esta no será la primera mediación de Onelli en beneficio de este grupo indígena. Recordemos que hacia 1899 había oficiado de lenguaraz en el encuentro sostenido por el grupo indígena comandado por Nahuelquir y el por entonces presidente Roca con el objeto de la creación de la colonia Cushamen. Caras y Caretas, 24.06.1899
} 
A la red articulada alrededor de la familia Bridges, debemos sumar el conjunto de colonos y estancieros ingleses establecidos en la zona chilena y argentina de Tierra del Fuego. Estos posibilitarán a los estudiosos el acceso a distintos espacios donde poder observar, recolectar, analizar y codificar su objeto de estudio en un amplio espectro ${ }^{872}$. Gracias a esta heterogénea y amplia red, Lehmann-Nitsche podrá realizar diversos estudios somatométricos, fotografías y la recolección de canciones, vocabularios, cuentos, relatos y demás expresiones linguíísticas ${ }^{873}$.

Las facilidades y comodidades provistas por los extranjeros afincados en estos paramos alejados de las buenas costumbres de la civilización sabrán suplir las inclemencias experimentadas. Este marcado contraste queda reflejado en el informe presentado por el ingeniero Pastor Tapia ante la Oficina Nacional de Tierras y Colonias. Habiendo sido designado responsable de la mensura y el amojonamiento de tierras vendidas el 16 de noviembre de de 1897, afirmaba "La habitación de las estancias de los caballeros ingleses en la Tierra del Fuego, con ricas alfombras, tapices y demás accesorios, reúne todo el confort deseable a las inclemencias de la atmosfera en la estación de los fríos" ${ }^{\circledR 74}$. Entre estos caballeros ingleses podemos mencionar al neozelandés Alexander Allan Cameron (1868-1950), primer administrador de la Sociedad Explotadora de Tierra del Fuego. El 21 de junio de 1902 Lehmann-Nitsche recibía de este una carta junto con 10 fotos de indígenas onas y la promesa del envío de cualquier tipo de material que pudieran recolectar y fuera de interés para el estudioso alemán ${ }^{875}$.

\subsection{La red de informantes indígenas}

La red de informantes y colaboradores indígenas será sobre la que descansen los objetivos y los resultados de las excursiones al campo emprendidos por Lehmann-Nitsche a la zona de la Patagonia septentrional en 1915 y 1925. Estos lo proveerán de datos, a la vez que le posibilitarán el acceso a diversos círculos familiares indígenas de la zona, los cuales lo proveerán de espacios utilizados como centros estratégicos de descanso, aprovisionamiento de alimento y procesamiento de datos. En este sentido es interesante profundizar en el intercambio epistolar sostenido entre Lehmann-Nitsche y alguno de sus informantes indígenas a fin de comprender la forma en la cual este último debió implementar y articular sus estrategias.

\footnotetext{
${ }^{872}$ Hacia 1895 se registraban un total de 26 familias inglesas en la zona de Tierra del Fuego, ocupando las zonas de Isla de los Estados, Lapataia, Bahía Thetis, San Sebastian, Harberton y Ushuaia. Parte de la recopilación efectuada por Lehmann-Nitsche será en Bahía Inútil. Hospedándose momentáneamente en una estancia, propiedad de unos ingleses de apellido Clark, apuntará una serie de palabra de un indígena Selk' nam que se desempeñaba en la misma como peón.

${ }^{873}$ Legado Robert Lehmann-Nitsche, IAI, Carpeta N-0070 11 y 12.

${ }_{875}^{874}$ Pastor Tapia 1898.

${ }^{875}$ Alexander A. Cameron a Robert Lehmann-Nitsche. Legado Robert Lehmann-Nitsche, 21.06.1902, IAI, Carpeta N-0070 b 103.
} 
La articulación de esta red comenzará en la ciudad de La Plata hacia agosto de 1899, oportunidad en la cual entrará en contacto con un joven mapuche, de nombre Lemudeu, que se desempeñaba como bombero y le proveerá de dos relatos en lengua mapuche ${ }^{876}$. Este primer contacto le valdrá la oportunidad de conocer a otros representantes indígenas que se desempeñaban en diversas tareas en la mencionada ciudad. El grupo de indígenas residentes en contextos urbanos facilitarán notablemente el trabajo de los antropólogos, los cuales podrán realizar en forma frecuente diversos encuentros con sus interlocutores.

Hacia 1901 entrará en contacto con Juan Castro, cuyo nombre en mapudungun era Katrülaf, el cual se desempeñaba como vigilante. Este vínculo temprano con Castro le facilitará la inserción dentro de la comunidad mapuche residente en La Plata, ampliando notablemente la red de colaboradores e informantes indígenas ${ }^{877}$. Entre los principales interlocutores de este grupo debemos mencionar a Nahuelpi, conocido con el nombre castellano de Antonio González, con el cual trabajará entre abril y diciembre de 1901 y de enero a mayo de 1902.

En la correspondencia con Nahuelpi se aprecia la activa participación de los informantes indígenas. Lehmann-Nitsche enviaba conclusiones parciales de sus análisis para que estos corrigieran cualquier posible error en las transcripciones realizadas por él. Al mismo tiempo enviaba trabajos terminados para que los indígenas pudieran ver el resultado de su colaboración. En muchos casos, contar con una separata que analizaba en forma científica su lenguaje no será suficiente. Las exigencias de la vida en la ciudad los llevaban a exigir una remuneración económica que realmente compensará las horas de trabajo ${ }^{878}$. En la ciudad de La Plata, a principios de siglo $\mathrm{XX}$, los indígenas no serán los únicos individuos creyentes en que el análisis comparativo de los grupos lingüísticos de la Patagonia pudiera pagar un alquiler.

Los indígenas encontraban en su actividad de informantes una invalorable contribución al trabajo del estudioso alemán. En este sentido Nahuelpi; el cual había regresado al sur instalándose en la localidad de Mencué (Río Negro, Argentina); describiéndose a si mismo como "el amigo de los cuentos" de Lehmann-Nitsche, le escribía a este último asegurándole de que no encontraría "[...] otro indio como yo, de un corazón noble, altivo [...]". Mostrando interés en la tarea lingüística llevada adelante por Lehmann-Nitsche, le remarcaba que no

\footnotetext{
${ }^{876}$ Malvestitti 2012.

${ }^{877}$ En la carta que Castro le escribiera a Lehmann-Nitsche hacia fines de mayo de 1908 le pedía a este que por favor le presentará sus saludos a Juan Salva, en referencia a Juan Salva Marinau, otro de los principales colaboradores e informantes de Lehmann-Nitsche en las recopilaciones lingüísticas mapuches. Juan Castro a Robert Lehmann-Nitsche. Legado Robert Lehmann-Nitsche, 25.05.1908, IAI, Carpeta N0070 b 1292.

${ }^{878}$ Nahuelpi a Robert Lehmann-Nitsche. Legado Robert Lehmann-Nitsche, 21.05.1902, IAI, Carpeta N0070 b 1292.
} 
dudará en escribirle si deseaba saber "[...] alguna cosa ignorada todavía [...]”879. Los indígenas sabrán obtener beneficios de la posición social de Lehmann-Nitsche, usándola para favorecer e intermediar en su inserción dentro de los distintos contextos de la sociedad argentina de comienzos del siglo XX. En este sentido una vez que Nahuelpi decidiera trasladarse con su familia a la provincia de Neuquén, Lehmann-Nitsche intercederá para que este pudiera reintegrarse al batallón del ejército del cual formaba parte ${ }^{880}$. Una situación similar acontecerá con Juan Castro. En los últimos días de mayo de 1908 le escribía a Lehmann-Nitsche desde la cárcel pública de la localidad bonaerense de Mercedes. Se adjuntaba a la carta un rebenque de regalo y un pedido expreso por parte de Castro: el envío de 10 a 12 pesos. Tal como declaraba este último la proximidad de la libertad lo encontraba sin un centavo y nadie que le prestará algún tipo de ayuda ${ }^{881}$.

Este pedido de ayuda nos abre varias perspectivas en el análisis de las estrategias implementadas por los antropólogos al momento de granjearse la colaboración de sus informantes y el papel de estos últimos en este particular vínculo. El aporte de dinero será una de las tantas estrategias implementadas por Lehmann-Nitsche a fin de asegurarse la colaboración de sus informantes. Tanto su condición de indígenas como el valor del dinero no serán elementos desconocidos para estos. En este sentido no es ilógico suponer que siendo conscientes de su condición de indigenidad y de las necesidades de los antropólogos, sacaran partido de esto.

De esto daba cuenta Juan Bautista Ambrosetti, al referirse a sus trabajos de campaña entre los indígenas del noroeste argentino. Señalaba este último como los indígenas sabrán “[...] explotar la credulidad del bajo pueblo de la ciudad y cual nuevos Zíngaros adivinan el porvenir y venden remedios y talismanes, principalmente para el amor, y éntrelos que descuella, en primera línea, la pluma del Caburei" ${ }^{\circledR 82}$. Destacaba lo normal que era ver a la mayoría de los indígenas haciendo uso de trajes de elaboración europea, y lo difícil que era adquirir objetos de su industria primitiva. Estos elementos nos permiten discutir aquellos trabajos que condenan, a partir de una moralidad anacrónica, los esquemas explicativos de fines del siglo XIX, posicionando a los indígenas en un papel pasivo de resistencia y no como actores activos dentro del complejo entramado de la construcción de conocimiento.

Gracias a Nahuelpi, la red de informantes y colaboradores indígenas de LehmannNitsche se ampliaba considerablemente. En este sentido podrá entrar en contacto con Antonio

\footnotetext{
${ }^{879}$ Nahuelpi a Robert Lehmann-Nitsche. Legado Robert Lehmann-Nitsche, 29.12.1902, IAI, Carpeta N0070 b 1292.

${ }^{880}$ Nahuelpi a Robert Lehmann-Nitsche. Legado Robert Lehmann-Nitsche, s/f, IAI, Carpeta N-0070 b 1292.

${ }^{881}$ Juan Castro a Robert Lehmann-Nitsche. Legado Robert Lehmann-Nitsche, 25.05.1908, IAI, Carpeta N-0070 b 1292.

${ }^{882}$ Ambrosetti 1894, p. 391.
} 
Coron, Kolüngür y Juan Salva Marinau ${ }^{883}$. Posteriormente Lehmann-Nitsche se trasladará a los Toldos, ciudad de la cual era oriundo Coron, para llevar adelante trabajos en abril de 1911 y febrero de 1920, llegando a recolectar en estos dos encuentros 7 relatos. Sin embargo los puntos más sobresalientes de estos encuentros será la posibilidad de entrar en contacto, gracias a Juan Salva Marianu, con Namuncura, el cual era tío de Antonio Coron ${ }^{884}$.

Los datos suministrados por Coron se articularían posteriormente con aquellos suministrados por Ramón Lienan, el cual en una epístola mecanografiada desde el Hotel América de Buenos Aires se refería a si mismo como estudiante indígena ${ }^{885}$. Esto permitirá publicar dos cortos trabajos que buscarán complementar el trabajo sobre el grupo lingüístico $\mathrm{Het}^{886}$. Posteriormente estos trabajos serían ampliados gracias a los datos suministrados por monseñor cordobés Pablo Cabrera (1857-1936) ${ }^{887}$, al cual conocía por ser ambos miembros la Academia Nacional de Ciencias y de la Junta de Historia y Numismática Americana.

Los contactos establecidos y los trabajos previos realizados con los indígenas residentes en La Plata serán también de gran utilidad al momento de realizar una serie de excursiones a la zona de Río Negro hacia 1915. Gracias a sus informantes indígenas, tal como dan cuenta comunicaciones personales con Lafone Quevedo, podrá organizar cuidadosamente este viaje de campaña. Esta serie de viajes se encontraban en la agenda de Lehmann-Nitsche desde mediados

\footnotetext{
${ }^{883}$ Con Kolüngür trabajará entre mayo y julio de 1901 llegando a compilar 9 fabulas, 4 relatos y 5 cantos mapuches. Los trabajos con Juan Salva Marianu tendrán lugar los meses de febrero, mayo y junio de 1906 y posteriormente julio y diciembre de 1907. Los resultados de estos trabajos serán 4 fabulas, 5 relatos y 5 cantos. Los trabajos llevados adelante con Antonio Coron comenzarán en diciembre de 1907, y serán realizados entre la Plata y Buenos Aires.

${ }^{884}$ Este le escribiría posteriormente a Lehmann-Nitsche, descripto por el propio Coron como un "inolvidable señor y amigo", para confirmarle que había vuelto con toda seguridad a su lugar de residencia en Los Toldos. Antonio Coron a Robert Lehmann-Nitsche. Legado Robert Lehmann-Nitsche, 16.04.1911, IAI, Carpeta N-0070 b 1292.

${ }^{885}$ En dicha carta expresaba sus disculpas por no haber estado presente cuando Lehmann-Nitsche fue a buscarlo en el edificio de la calle Lima. Por las anotaciones hechas al margen de mencionada carta por parte Lehmann-Nitsche se puede saber que Lienan era chileno y que el objetivo del estudioso alemán era recolectar textos araucanos. Ante este fallido encuentro Lienan le confirmaba una inmediata visita al Museo de La Plata a fin de brindar los datos que Lehmann-Nitsche necesitaba y concretar de esta manera su propio deseo de visitar las instalaciones de la mencionada institución. Ramon Lienan a Robert Lehmann-Nitsche. Legado Robert Lehmann-Nitsche, 16.04.1919, IAI, Carpeta N-0070 b 1292.

${ }^{886}$ Una primera versión será presentada en 1924, en el contexto del XXI Congreso de Americanistas de Göteborg bajo el nombre "Das Chechehet, eine isollerte und augestorbene, fisher unbekannte Sprache der argentinischen Pampa". Esta será traducida al español, hacia 1930, y publicada en las páginas de la RMLP con el nombre "El Idioma Chechehet". Lehmann-Nitsche 1925 m, 1930 h.

${ }^{887}$ Por ese entonces Cabrera era director del Museo Histórico Provincial, el cual contaba con un importante acervo documental del periodo colonial e histórico gracias a la estrecha relación y vinculación de Cabrera con antiguas familias de Córdoba. Para ese entonces Cabrera contaba una importante colección privada diversos elementos de valor artístico e histórico del período colonial, los cuales había comenzado a coleccionar hacia fines del siglo XIX. Ganando notoriedad entre historiadores, etnólogos, arqueólogos y lingüistas, se hará cargo de la cátedra de etnografía indígena argentina de la Universidad Nacional de Córdoba, recibiendo el título de Doctor Honoris Causa de dicha casa de estudios en 1928. Será miembro de la Academia Nacional de Ciencias, del Instituto Geográfico Argentino y presidente de la filial cordobesa de la Junta de Historia y Numismática Americana.
} 
de 1912. En septiembre de dicho año el por entonces director interino del Museo de La Plata, el químico Enrique Herrero Ducloux (1877-1962), lo consultaba sobre sus ideas respecto al programa de expediciones científicas proyectado para los inicios del siguiente año ${ }^{888}$. LehmannNitsche le contestaba haciendo saber sus planes para comenzar una serie de trabajos sobre los indios concentrados en Bragado y los Toldos, especialmente los araucanos ${ }^{889}$, trabajo que el Consejo Académico del Museo de La Plata evaluaría positivamente. Sin embargo, una "serie de delicados asuntos familiares"; tal como Lehmann-Nitsche le comunicaba a Lafone Quevedo; lo obligarán a viajar a Europa hacia fines de 1912. Dicha estadía se extendería debido a su casamiento con Juliane Dillenius (1884-1949), retornando a la Argentina el 27 de marzo de $1913^{890}$.

Finalmente en marzo de 1915 Lehmann-Nitsche emprendía su postergado viaje a la zona de la Patagonia septentrional, a fin de poder estudiar a los "últimos representantes de los Puelches" ${ }^{\$ 91}$. Un año más tarde realizará otra excursión entre Carmen de Patagones y Colonia Frías, donde además de continuar su trabajo con los Puelches realizará relevos sobre representantes Araucanos. Desde Valcheta (Río Negro-Argentina) se comunicaba con Lafone Quevedo, detallándole el penoso e incomodo recorrido a lomo de caballo le informaba sobre su encuentro con Isidora, una mestiza puelche trilingüe.

Gracias a su "maestra" podrá apuntar un completo vocabulario que posteriormente utilizará para el análisis de los componentes lingüísticos de los mitos. Isidora lo ponía en conocimiento de que su hermana, residente en la estación de Corral Chico, la cual "sabia sobre textos y mitos". Atraído por la posibilidad de compilar estos datos se trasladará LehmannNitsche a dicho paraje, vislumbrando también la posibilidad de dirigirse a Pringles a fin de poder trabajar con un anciano puelche ${ }^{892}$. Este informante en cuestión será Juan Millan. Este anciano indígena; el cual se definía a si mismos como mitad araucano y mitad puelche; proveerá a Lehmann-Nitsche de una "verdadera cosecha" en referencia a la lista de palabras ${ }^{893}$. Estos

\footnotetext{
${ }^{888}$ Herrero Ducloux a Lehmann-Nitsche, 04.09.1912, AHMLP, Carpeta CN 14 (1912-1916).

${ }^{889}$ Lehmann-Nitsche a Herrero Ducloux, 08.10.1912, AHMLP, Carpeta CN 14 (1912-1916).

${ }^{890}$ A principios de diciembre de 1912 Samuel Lafone Quevedo, ya oficiando como director del museo platense, recibía un pedido de licencia por parte de Lehmann-Nitsche entre el 15 de diciembre de dicho año y el 28 de febrero de 1913, debido a una situación familiar que requería su presencia en Alemania. Ante la ausencia de respuesta por parte de Lafone Quevedo, el cual se encontraba en Córdoba, el pedido era reiterado unos días después por Lehmann-Nitsche, embarcándose finalmente a Europa el 12 de diciembre de 1912. Una vez arribado al Viejo Mundo podrá resolver la liquidación de una serie de bienes que eran administrados por su madre. Lehmann-Nitsche a Lafone Quevedo, 07.12 y 11.12 de 1912, AHMLP, Carpeta CN 11 (1912-1917).

${ }^{891}$ Lehmann-Nitsche 1918 e, p.12.

${ }^{892}$ Lehmann-Nitsche a Lafone Quevedo, 01.01.1915, AHMLP, Carpeta CN 14 (1912-1916), LehmannNitsche, 1919 d.

${ }^{893}$ Robert Lehmann-Nitsche a Samuel Lafone Quevedo. Legado Robert Lehmann-Nitsche, 07.02.1916, IAI, Carpeta N-0070 b 817.
} 
aportes llevarán a Lehmann-Nitsche a advertir que "[...] los Puelche de Falkner representan un conjunto geográfico y no lingüístico como hemos creído hasta la fecha" ${ }^{\natural 94}$.

La determinación geo-etnica hecha por Falkner, y seguida luego por otros autores, será vista como la causante de las dificultades al momento de clasificar los grupos étnicos de la parte austral de Sudamérica ${ }^{895}$. Esta afirmación se condecía con aquellas conclusiones esbozadas en los trabajos lingüísticos llevados adelante por los miembros de la primera y la segunda expedición alemana al Río Xingú. Estos se encargarán de señalar que la prevalencia del punto de vista geográfico en la clasificación etnográfica de los grupos no había producido resultados significativos, consagrando el punto de vista lingüístico por su eficacia al momento de clasificar la heterogeneidad étnica de sudamericana.

Un año más tarde emprenderá un nuevo viaje hacia el sur argentino. En comunicaciones personales sostenidas con Lafone Quevedo puede entreverse que muchos de los trabajos realizados serán determinados por la casualidad o bien por la imposibilidad de cumplir los objetivos originales. Recorriendo las localidades de Viedma, donde ante la ausencia de indios puelches se dedicará a fotografiar "[...] gran cantidad de hachas conservadas en colecciones particulares (ya que) los coleccionistas son tan evitados de sus tesoros que por nada quieren separarse de ellos" ${ }^{\$ 96}$. Posteriormente se trasladará a Viedma y seguidamente a la Isla de Sauce Blanco, en el departamento de Adolfo Alsina. En esta última localidad conocerá a Pablo Awe, propietario de un establecimiento rural, el cual le introducirá al indio Millaluan; de madre puelche y padre araucano; el cual había adoptado el nombre de Bartolo Alfaro y residía en Primera Angostura. Lehmann-Nitsche trabajará los días finales de febrero con dicho indígena logrando valiosos datos en cuanto a leyendas y creencias que darán cuenta de la cosmogonía de los pueblos puelches ${ }^{897}$.

Una vez vuelto de su viaje a la Patagonia septentrional se encontraba Lehmann-Nitsche con una serie de cartas de Rudolf Lenz. Este le comentaba acerca de sus próximas publicaciones, ciertos asuntos de la vida académica en Chile y pormenores de la vida familiar.

\footnotetext{
${ }^{894}$ Robert Lehmann-Nitsche a Samuel Lafone Quevedo. Legado Robert Lehmann-Nitsche, 07.02.1916, IAI, Carpeta N-0070 b 817. Resaltado en el original.

${ }^{895}$ Lehmann-Nitsche propondrá una clasificación gloso-etnica. A partir de esta la categoría geo-etnica "Puelche" de Falkner será dividido en 4 grupos lingüísticos designados según el vocablo utilizado para la palabra "hombre" en: 1) la lengua Che, 2) la lengua Künnü, 3) la lengua Kün’k y 4) la lengua Het, separada de la lengua Künnü y que representaba la lengua autóctona del sur y sudoeste de Buenos Aires extinguida hacia fines del siglo XVIII. Dentro de estas divisiones incluía los siguientes grupos: 1) Lengua Che: Moluche y Puelche de Falkner y actuales araucanos, 2) Lengua Künnü: Tehuelkünnü (Falkner), Tuelche (Rama sur de Hervás) y Puelche (D'orbigny), 3) Lengua Kün'k: Patagones (Pigafetta y D'orbigny), Tehuelche (D'orbigny) y Yacana-künnü (Falkner), y finalmente 4) Lengua Het: Chechehet y una fracción de los Divihet (Falkner), Tuelche (Rama norte de Hervás) y Patagones (Dobrizhoffer). Lehmann-Nitsche 1918 e.

${ }^{896}$ Robert Lehmann-Nitsche a Samuel Lafone Quevedo. Legado Robert Lehmann-Nitsche, 07.02.1916, IAI, Carpeta N-0070 b 817.

${ }^{897}$ Ibídem.
} 
Al mismo tiempo le recordaba cierto grupo de historias recolectadas de los indios Mapuches y que compilara en su extenso trabajo Estudios Araucanos ${ }^{898}$. La necesidad de poder ampliar los datos recogidos por Lenz y la imposibilidad de emprender un nuevo viaje de campaña serán solucionadas gracias a la ayuda de Juan José Catriel, un viejo barrendero de la ciudad de la Plata. A sus 70 años el hijo del famoso cacique Cipriano Catriel; el cual en vez "[...] del cetro soberano que le esperaba tuvo que conformarse ;con la humilde escoba de barrendero! [...]"ק99; le relataba en castellano el cuento del viejo Tatrapi que tanto interesaba a Lehmann-Nitsche.

Estos datos complementaban aquellos relevados por Lehmann-Nitsche entre 1915-1916 y le permitían comenzar a esquematizar los límites geográficos y las zonas de contacto entre el oeste de la Argentina y Chile. Al momento de cotejar la fidelidad y exactitud de estos datos será de invalorable ayuda, tal como lo atestigua la asidua colaboración de Nahuelpi. Esto le permitirá determinar, al igual que lo hiciera con sus trabajos sobre tradiciones folklóricas, una matriz americana inserta y amalgamada dentro del conjunto de tradiciones cristianas adoptadas, en mayor o en menor medida, por los grupos indígenas sudamericanos.

La colaboración con indígenas no se limitará al estudio de los mitos y la astronomía de la Patagonia septentrional. En este sentido se relacionará en la ciudad de Buenos Aires con el indígena toba Martín Tomás, el cual se desempeñaba como aprendiz mecánico del Arsenal de Guerra. Hacia junio de 1922 el padre de este, el cacique Juan Tomás, se trasladaba a la Capital Federal a fin de gestionar la concesión de tierras fiscales. Dicho momento será aprovechado por Lehmann-Nitsche para corroborar los datos recolectados en Orán y Ledesma por un lado y recopilar nueva información por el otro ${ }^{900}$. Esta serie de encuentros le permitirá ir dando forma final a sus síntesis sobre mitología y astronomía indígena. Como veremos en el próximo apartado estos trabajos serán pensados, gestionados y articulados a partir de la red de estudiosos alemanes residentes en Sudamérica. Esta red será la de mayor importancia en la carrera profesional de Lehmann-Nitsche, quien dependerá de la misma para gran parte de su producción científica.

\subsection{La red de estudiosos alemanes}

La colaboración entre los diversos estudiosos alemanes que se encontraban realizando trabajos en distintos partes del Continente Americano, especialmente en Sudamérica, solventará las carencias metodológicas, materiales y económicas de los contextos en los cuales estos desarrollaban sus tareas. En la cuantiosa correspondencia personal de Lehmann-Nitsche, depositada en el Ibero-Amerikanisches Institut de Berlin, es posible observar el entramado de

${ }^{898}$ Rudolf Lenz a Robert Lehmann-Nitsche. Legado Robert Lehmann-Nitsche, 23.09.1917, IAI, Carpeta $\mathrm{N}-0070$ b 440.

${ }^{899}$ Lehmann-Nitsche 1930 i, p. 52.

${ }^{900}$ Lehmann-Nitsche 1923 h, 1923 i, 1924 h, 1924 i, 1925 k, 1927 h. 
esta red de colaboración con otros estudiosos. En la misma podemos encontrar consultas y pedidos sobre bibliografía y objetos, recomendaciones personales para presentar a diversos institutos o personas, análisis sobre la situación social y política del país donde estos realizaban sus tareas, críticas hacia las falencias de las instituciones locales y finalmente un llamado a la necesidad de aunar el colectivo de estudiosos alemanes residentes en Sudamérica, o que desarrollarán tareas allí. En este sentido es interesante analizar las diversas formas de interacción y las prácticas al interior de este grupo de estudiosos que darán lugar a la construcción de un objeto de estudio. Este será heterogéneo, contando sus participantes con intereses, objetivos y anhelos personales, sin embargo serán llamados a actuar como un solo individuo.

Como hemos mencionado anteriormente los principales proyectos en los cuales Lehmann-Nitsche se verá involucrado será aquellos concernientes a la construcción de una cartografía etnográfica de los indígenas sudamericanos, un proyecto que, como veremos, otros estudiosos alemanes venían realizando hace años en la parte norte del Continente Americano. En esta serie de trabajos podremos ver una serie de estrategias adoptadas por Lehmann-Nitsche que serán las que caractericen su participación en otro tipo de proyectos colectivos: 1) su participación estará vinculada a la importancia atribuida a estos temas por otros estudiosos y 2) el uso los vínculos sociales y académicos que facilitan: a) el acceso a las pruebas materiales; b) el uso de nuevos instrumentos y técnicas para la interpretación de los mismos, y c) suplen la falta de conocimientos de Lehmann-Nitsche en los temas sobre los cuales quería participar.

\subsubsection{Las nuevas investigaciones sobre la Formación Pampeana}

En 1899 Lehmann-Nitsche descubría en forma casual el atlas humano de Monte Hermoso, el cual Ameghino había exhumado en $1887^{901}$. La impericia del antropólogo en cuestiones geológicas y paleontológicas lo llevará a pedir la colaboración de otros dos estudiosos extranjeros que se desempeñaban en el Museo de La Plata: el paleontólogo suizo Santiago Roth -nacido como Kaspar Jacob- (1850-1924) y el geólogo alemán Rudolph Hauthal $(1854-1928)^{902}$. De esta forma el compartir una lengua en común o los lazos de sociabilidad a partir de la comunidad de origen se tornan importantes al momento de comenzar una empresa colectiva.

\footnotetext{
${ }^{901}$ Para trabajos que analicen las discusiones paleontológicas, geológicas y arqueológicas en la Argentina de fines del siglo XIX y principios del siglo XX ver especialmente Podgorny 2001 b, 2005, 2009, 2011 b; Podgorny y Politis 2000; Zarate y Podgorny 2011.

902 Lehmann-Nitsche justificaba esto argumentando que solo trabajo en conjunto entre geología, paleontología y antropología era el camino a seguir si se quería comprender "[...] las manifestaciones extinguidas de la raza humana [...]". Recordemos que Lehmann-Nitsche también había colaborado con Roth y Hauthal en la revisión sobre los últimos hallazgos de la caverna de Ultima Esperanza (Chile). Lehmann-Nitsche 1906 e, p.224.
} 
En este caso particular es preciso señalar que a hacia 1900 desde diversos espacios institucionales y reuniones científicas internacionales se abogaba por la colaboración entre antropología, geología y paleontología al momento del estudio de la antigüedad del hombre, tal como el pedido del "Consejo permanente" $" 903$ de estudiosos del XII Congrès international d'anthropologie et d'archéologie préhistoriques, celebrado en Paris en $1900^{904}$, en el cual Lehmann-Nitsche presentará dos comunicaciones preliminares sobre los hallazgos de "tierras cocidas" extraídas de la formación pampeana, las cuales consideraba como restos de fogón y por ende evidencia de actividad humana ${ }^{905}$.

Como hemos mencionado anteriormente los lazos sociales establecidos a partir de compartir una lengua o un mismo lugar de origen serán de gran importancia al momento de poder acceder a los recursos instrumentales y financieros que garantizaban el éxito de un determinado trabajo. Un claro ejemplo de esto será la obra de Lehmann-Nitsche Nouvelles recherches sur la formation pampéenne et l'homme fossile de la République Argentine publicada en 1907. Las dos secciones que componen este trabajo; Geología y Paleoantropología; serán resultado de una red de estudiosos alemanes — principalmente-, suizos y belgas ${ }^{906}$. Varios puntos merecen ser mencionados a fin de poder entender la dinámica de las prácticas antropológicas desarrolladas en la Argentina entre fines del siglo XIX y principios del siglo XX por un lado y encuadrar el papel de Lehmann-Nitsche dentro de los proyectos colectivos en los que participaba por el otro.

\footnotetext{
${ }^{903}$ El mismo estaba formado por el arqueólogo francés Alexandre Louis Joseph Bertrand (1820-1902); el geólogo y paleontólogo italiano Giovanni Capellini (1833-1922); el ingeniero e historiador francés Paul Cazalis de Founduce (1838-1931); el arqueólogo francés Ernest Chantre (1843-1924); el geólogo belga Edouard Dupont (1841-1911); el prehistoriador, geólogo y numismático inglés John Evans (1823-1908); el príncipe ruso Boris Borisovich Galitzine (1862-1916); el antropólogo inglés John Lubbock (18341913); y finalmente Rudolf Virchow.

${ }^{904}$ Estos llamaban a la aplicación de la anatomía comparada a la cuestión del origen del hombre, los caracteres anatómicos del hombre primitivo y de las razas humanas prehistóricas y el estudio de los restos etnográficos que permitieran "iluminar" sobre el estado social de las poblaciones prehistóricas. Dichas propuestas se condecían con algunos de los principales puntos discutidos en el XII Congreso Internacional de Americanistas celebrado al mismo tiempo. Un considerable número de trabajos presentados responderán a estos puntos propuestos. Tendremos aquellos que abordaban hallazgos de restos humanos o arqueológicos específicos hasta los que versaban sobre cuestiones más generales, como la reconstrucción plástica del Phitecanthropus presentado por Leonce Manouvrier. CIAAP 1902.

904 . Dichas propuestas se condecían con algunos de los principales puntos discutidos en el XII Congreso Internacional de Americanistas celebrado al mismo tiempo ${ }^{904}$.

${ }_{905}$ Estas tendrán lugar en la duodécima edición del Congrés International d'Anthropologie et Archéologie Préhistoriques, celebrado en la ciudad de París y en el trigésimo primer congreso anual de la Deutschen Anthropologische Gesellschaft realizado en Halle. Lehmann-Nitsche 1900 c, 1901 d.

${ }^{906}$ En la sección geológica del trabajo colaborarán: Carl Burckhardt, Santiago Roth, Hermann von Ihering, el geógrafo y meteorólogo suizo Johann Jakob Früh (1852-1938) y el geólogo alemán Johann Heinrich C. G. G. Steinmann (1856-1929). En la sección antropológica del trabajo confluían los estudios y aportes del geólogo alemán Ferdinand Zirkel (1838-1912), del médico y anatomista belga Hector Louis François Leboucq (1848-1934), Rudolf Martin, del paleontólogo de vertebrados estadounidense William Berryman Scott (1858-1947), del anatomista alemán Heinrich Wilhelm Gottfried Waldeyer (1836-1921) y del médico alemán Paul Rudolf August Bartels (1874-1914).
} 
Participar dentro de proyectos que implicaban la participación de distintos especialistas suplía la falta de conocimientos en determinadas áreas. Estos colaborarían ya fuera a partir de la redacción de trabajos especiales o bien intercediendo a fin de que otros estudiosos realizarán análisis. En este sentido será decisiva la participación de Carl Burckhard en el trabajo sobre la Formación Pampeana. No solo será el encargado de redactar la sección geológica del mismo, sino que coordinará la colaboración de distintos geólogos y paleontólogos alemanes; tanto residentes en América como en Europa; a fin de obtener acceso a los recursos instrumentales y bibliográficos que permitieran el análisis de los sedimentos de la Formación Pampeana ${ }^{907}$. Al mismo tiempo, al momento de viajar a Europa, redactara precisas instrucciones sobre los criterios que debían utilizar para seleccionar y empacar muestras de ostras para su envío al Viejo Mundo ${ }^{908}$.

En la sección paleoantropológica del trabajo podemos identificar otro importante elemento a la hora de acceder a los individuos y/o las instituciones que proveían a los estudiosos de los recursos técnicos: la posibilidad de viajar a Europa. En 1900 y 1904 Lehmann-Nitsche viajará a Europa. En el primero de estos viajes llevará restos de "tierras cocidas", ostras y cráneos a fin de que fueran analizados por distintos estudiosos europeos. Muchas veces la presentación de estos elementos en distintas veladas sociales también podía devenir en el establecimiento de alianzas cooperativas. En el mencionado viaje a Europa en 1900 LehmannNitsche será invitado a la "soirée" ofrecida por el príncipe Roland-Napoleón Bonaparte. En la misma llegará a conocer a Ferdinand Zirkel. Este invitará a Lehmann-Nitsche a la ciudad alemana de Leipzig, en la cual se desempeñaba como profesor de mineralogía y geología de la universidad local. Ante el pedido de Lehmann-Nitsche decidirá auxiliarlo a través del análisis microscópico de arcilla quemada ${ }^{909}$.

En este mismo viaje visitará Zürich donde podrá acceder al estudio directo sobre los restos fósiles de Baradero y a la colección de mamíferos pampeanos recolectados por Santiago

\footnotetext{
${ }^{907}$ Burckhard gestionará y coordinara la participación de Hermann von Ihering para un análisis sobre la Ostrea arbórea proveniente de la zona del Tala. A fin de contar con un estudio comparativo de ostras con las de Entre Ríos de la colección Bravard, exhortaba a Lehmann-Nitsche a remitir los resultados de los trabajos de von Ihering y una serie de ostras a Johann Heinrich Steinmann; por ese entonces director del Geologische Institut de la Albert-Ludwigs-Universität de Freiburg. Es muy probable que en 1901 Burckhard, de visita en Basel, pidiera a Johann Jakob Früh el examen macro y microscópico de la caliza de la Formación Pampeana. Finalmente desde Europa le recomendaba enfáticamente a Lehmann-Nitsche; ante lo que consideraba la ausencia de colaboración por parte de Roth y Hauthal; que consultara cualquier tipo de dudas geológicas y paleontológicas con el químico, geólogo y zoólogo alemán Adolf Döring (1848-1925). Adolf Döring a Robert Lehmann-Nitsche. Legado Robert Lehmann-Nitsche, 29.08.1906, 29.01.1907 IAI, Carpeta N-0070 b 158. Carl Burckhardt a Robert Lehmann-Nitsche. Legado Robert Lehmann-Nitsche, 11.07.1900, 14.10.1900, 27.03.1901, 09.04.1901, 20.05.1901, 15.12.01901, IAI, Carpeta N-0070 b 64. Hermann von Ihering a Robert Lehmann-Nitsche. Legado Robert LehmannNitsche, 06.09.1903, IAI, Carpeta N-0070 b

908 Carl Burckhardt a Robert Lehmann-Nitsche. Legado Robert Lehmann-Nitsche, 08.02.1901, IAI, Carpeta N-0070 b 64.

909 Ferdinand Zirkel a Robert Lehmann-Nitsche. Legado Robert Lehmann-Nitsche, 26.11.1900, IAI, Carpeta N-0070 b 769; Informe 1900.
} 
Roth depositados en el museo paleontológico de la Eidgenössische Technische Hochschulek ${ }^{910}$. Al mismo tiempo en este viaje se reunirá con Rudolf Martin quien prometía un trabajo sobre los restos fósiles de Baradero. Este último aseguraba la participación de geólogo suizo Karl David Wilhelm Mayer-Eymar (1826-1907) ${ }^{911}$ en el análisis de las ostras estudiadas por von Ihering, ya que desconfiaba de los resultados obtenidos con los recursos instrumentales disponibles en Sudamérica ${ }^{912}$.

En el segundo viaje a Europa, en 1904, Lehmann-Nitsche obtendrá la colaboración de Hector Leboucq, Paul Bartels y Heinrich Wilhelm Waldeyer. Estos analizarán las falanges y la vértebra cervical de los restos fósiles humanos del arroyo Frías (Buenos Aires, Argentina) ${ }^{913}$ en el Anatomische Institut de Berlin. Dos años más tarde Bartels enviaba los resultados. Según este la demora se debía a la calidad del papel en el cual deseaban enviar las reproducciones de los objetos analizados, la cual no garantizaba la resistencia de las mismas durante el envío a Argentina. Como podemos ver la calidad de las reproducciones no solo se limitará a la

${ }^{910}$ En septiembre 1901 Martin enviaba la versión final de su trabajo a la Argentina, el mismo incluía 5 fotografías sobre el cráneo. De estas solamente una se ajustaba a los estándares que Martin exigía para una publicación internacional. La dificultad de producir imágenes de calidad se vinculaba, en este caso, con el mal estado del material. Esto a su vez podía dar la impresión de que se estaba ante los restos de uno de los especímenes más antiguos de la Argentina, sin embargo el examen minucioso de los mismos evidenciaba características que podían encontrarse en el hombre contemporáneo de América del Sur. De esta forma, para Martin, los restos de Baradero no representarán una forma humana específica distinta a la del hombre actual, articulándose por lo tanto con las conclusiones de von Ihering y Steinmann sobre la antigüedad de los estratos que contenían dichos restos. Burckhardt 1907; Informe 1900; Lehmann-Nitsche 1907 b.

${ }^{911}$ Para ese entonces se desempeñaba como profesor de estratigrafía y paleontología en la Universität Zürich.

912 Ante la envergadura de este proyecto colectivo Martin manifestaba satisfacción y al mismo tiempo llamaba a la paciente revisión de cada uno de los elementos utilizados como evidencia. En este sentido le recordaba a Lehmann-Nitsche que sacará provecho de su estadía en Europa para establecer contactos con paleontólogos y geólogos del Viejo Mundo, ya que esta era la única forma de obtener resultados científicos para este trabajo. Martin no deseaba formar parte de una publicación prematura la cual sin duda afectaría en forma negativa su carrera académico-científica. Tal como se encargaba de remarcar "Yo no soy un adicto a la publicación, prefiero esperar años antes de dar una visión inadecuada". Similar actitud mostrará ante la insistencia de Lehmann-Nitsche por presentar los resultados parciales de la investigación en los congresos y reuniones científicas que tendrían lugar en Francia y Alemania. Finalmente enviaría los resultados de sus trabajos en septiembre de 1901, descartando que los restos de Baradero representarán una forma humana específica distinta a la del hombre actual. Burckhardt 1907; Informe 1900; Lehmann-Nitsche 1907 b. Rudolf Martin a Robert Lehmann-Nitsche. Legado Robert Lehmann-Nitsche, 27.04.1900 y 04.05.1900, 10.10.1900, IAI, Carpeta N-0070 b 489.

${ }^{913}$ Dichos restos habían sido encontrados por Ameghino en 1870 e incluirán: un esqueleto casi completo compuesto por omoplatos, huesos largos y falanges de las extremidades superiores e inferiores, y columna vertebral. Este conjunto será vendido al coleccionista y preparador italiano Antonio Pozzi, el cual un año más tarde los revenderá al Musée civique de Milán. Tres años más tarde Ameghino retomará las excavaciones en el mismo sitio, obteniendo el hueso iliaco izquierdo incompleto, varias falanges y un diente. Años más tarde Ameghino consultaba a Pozzi; el cual hacia hacía 1886 había ingresado en calidad de preparador al Museo de La Plata; sobre el destino de los restos. Este le afirmaba que los mismos no formaban parte de la colección vendida en 1871. Santiago Roth, de visita al museo milanés en 1890 , tampoco podrá obtener información sobre el destino de los restos. Ameghino 1915 a; Lehmann-Nitsche 1907 b. 
"fidelidad" al momento de transmitir la imagen del objeto, sino también a poder garantizar la duración de la misma durante su circulación a través de las distintas redes de colaboradores ${ }^{914}$.

Esta nueva estadía en Europa también permitirá acceder a los restos de Fontezuelas (erróneamente denominado Pontimelo) ${ }^{915}$, depositados el Musée zoologique de l'université de Copenhague. En el mencionado instituto contará con la colaboración de los zoólogos daneses Hector Frederik Estrup Jungersen (1854-1917); director del instituto; Adolf Herluf Winge (1857-1923) y Sören Hansen ${ }^{916}$. Una vez vuelto a la Argentina Lehmann-Nitsche se aprestará a estudiar los cráneos de Arrecifes y Chocorí; las osamentas de La Tigra; y finalmente el atlas de Monte Hermoso ${ }^{917}$, siendo esta las únicas piezas sobre las que trabaje en forma directa.

Como podemos ver los viajes a Europa junto con el uso de los lazos sociales y académicos garantizarán el acceso a materiales y recursos técnicos necesarios para su interpretación. En muchos casos la participación de Lehmann-Nitsche en estos proyectos colectivos estará determinada por la demanda de otros estudiosos sobre objetos o datos antropológicos sudamericanos necesarios para sus investigaciones. En este sentido Franz Boas lo invitaba a contribuir con algún trabajo sobre la evidencia de la antigüedad del hombre en Sudamérica al futuro XV Congreso Internacional de Americanistas, el cual tendría lugar en la ciudad canadiense de Quebec, entre el 10 y 15 de septiembre de $1906^{918}$. Al mismo tiempo Aleš Hrdlička felicitaba a Lehmann-Nitsche por su "[...] valuable contribution to the study of the fossil man of South America" yse confesaba "[...] anxious to obtain some skeletal material

\footnotetext{
${ }^{914}$ Estos contratiempos podían ser solventados, en parte, por una detallada y minuciosa descripción del material, del proceso de estudio del mismo, y de los instrumentos utilizados para dicho fin; tal como hacía Bartels en su carta. Paul Bartels a Robert Lehmann-Nitsche. Legado Robert Lehmann-Nitsche, 21.03.1906, IAI, Carpeta N-0070 b 94.

${ }^{915}$ Roth había comunicado por primera vez este descubrimiento, a través del naturalista alemán August Christoph Carl Vogt (1817-1895), a la Société d'Anthropologie de Paris. Ameghino suponía que Roth pudo haberse equivocado y escrito "Fontizelos" por Fontezuelas o bien Vogt haber leído "Pontimelo". Roth rectificará esto a través de una publicación realizada en 1889. Ameghino 1915 a, 1915 b; Roth 1889.

${ }^{916}$ Hansen había estudiado los restos en 1881, concluyendo en que la contemporaneidad del hombre fósil con la megafuana no era algo absolutamente probado. Similar conclusión esgrimirá en 1888 al momento de publicar una importante monografía sobre los hallazgos de fósiles humanos realizados por el paleontólogo y zoólogo danés Peter Wilhelm Lund (1801-1880) en Lagoa Santa. Posteriormente tendrá una activa participación en la discusión internacional sobre la antigüedad del hombre americano. Hansen 1888; Roth 1889.

${ }^{917}$ El cráneo de Arrecifes había sido descubierto hacia 1888 por José Monguillot en los bordes del arroyo Merlo. Este será depositado en el Museo Etnográfico de Buenos Aires, donde su director, Juan Bautista Ambrosetti confiara su descripción a Lehmann-Nitsche. El cráneo de Chocorí era descubierto el mismo año por Francisco Larrumbe, empleado del Museo de La Plata, en las proximidades de Mar del Sud, entre el arroyo Chocorí y el arroyo Seco. Las osamentas de La Tigra eran descubiertas también hacia 1888 por André Canesa en las proximidades del Mar del Sud, entre el arroyo La Tigra y el arroyo Seco. El atlas de Monte Hermoso era hallado por Carlos y Florentino Ameghino en la homónima ciudad. LehmannNitsche 1907 b.

${ }^{918}$ En el mismo se presentarían diversos trabajos que buscaban dilucidar la antigüedad y la evolución del hombre en América. Podemos mencionar: los trabajos lingüísticos del entomólogo y antropólogo norteamericano Cyrus Thomas (1825-1910); los estudios arqueológicos sobre analogías arquitectónicas de Alphonse Gagnon y el trabajo de Aleš Hrdlička sobre la exhumación de unos restos humanos que servirían para dar cuenta de la existencia temprana del hombre en América. CIA 1906.
} 
from S.A [Sudamérica]”, por lo cual consultaba a su par alemán por la posibilidad del envío de algunas piezas $^{919}$.

Los estudiosos se mostrarían un tanto escépticos a las conclusiones de LehmannNitsche sobre los estudios de la Formación Pampeana. El merito de los mismos radicaba en los nuevos materiales que se aportaban a las discusiones internacionales y en el carácter colectivo de la obra. En este sentido Joseph Deniker al momento de otórgale el segundo puesto en el Prix Broca $^{920}$, destacaba de la misma su redacción efectuada en francés y puntualizaba que el mismo era "[...] le premier essai de coordonner tout ce que l'on savait jusqu'en 1907 sur l'homme préhistorique en Argentine",921.

Como sucediera con otros trabajos suyos, Lehmann-Nitsche no continuaría las investigaciones sobre la Formación Pampeana. Para comienzos de la segunda década del siglo XX comenzara a publicar otra serie de trabajos que pretendían colaborar con la construcción de una cartografía etnográfica de los grupos indígenas sudamericanos. La continuidad que puede notarse en la publicación de trabajos sobre esta temática responderá en parte a su inserción dentro de proyectos cooperativos a larga escala emprendidos por otros estudiosos alemanes. En este sentido analizaremos las dinámicas de esta red de colaboración, en la cual LehmannNitsche se integrará muy tempranamente.

\subsubsection{La construcción de una cartografía etnográfica: Los trabajos lingüísticos}

Uno de los primeros contactos establecidos por Lehmann-Nitsche al momento de llegar a la Argentina será con Rudolf Lenz. Como hemos visto con anterioridad este será una figura central en las investigaciones lingüísticas y folklóricas de Lehmann-Nitsche, las cuales coordinará y sistematizará. Hacia 1889 era contratado por Lenz había sido por el recientemente fundado Instituto Pedagógico de Santiago de Chile para enseñar lenguas modernas, actividad que venía desempeñando en los establecimientos secundarios de las ciudades alemanas de Wolfenbüttel y Köln ${ }^{922}$.

\footnotetext{
${ }^{919}$ Aleš Hrdlička a Robert Lehmann-Nitsche. Legado Robert Lehmann-Nitsche, 23.03.1908, IAI, Carpeta $\mathrm{N}-0070$ b 330.

${ }^{920}$ Dicho galardón era un reconocimiento anual, instaurado hacia 1881 por la Société d'Anthropologie de Paris, destinado a "[...] récompenser le meilleur mémoire sur une question d'anatomie humaine, d'anatomie comparée ou de physiologie se rattachant à l'anthropologie". En el mismo año que LehmannNitsche competirian los médicos franceses Aimé-François Legendre (1867-1951), Charles Perrier (18621938), los italianos Giocchino Leone Sera y Sergio Sergi, y finalmente el antropólogo ucraniano Kazimierz Stołyhwo. Legendre se adjudicará el primer lugar, con un premio de 1000 francos. LehmannNitsche obtendrá el segundo lugar con una remuneración de 300 francos, mientras que Sera se adjudicaba el último puesto y 200 francos. Société d'Anthropologie de Paris a Robert Lehmann-Nitsche. Legado Robert Lehmann-Nitsche, 06.02.1911, IAI, Carpeta N-0070 b 1006.

${ }^{921}$ BSAP 1881.

${ }^{922}$ El decreto de fundación del instituto data del 29 de abril de 1889. Lenz formaba parte de un grupo de profesores alemanes que constituirán el primer cuerpo académico del mismo. Estos eran: Jürgen Heinrich Schneider (1892 -1902) para pedagogía y filosofía; Frederic Emil Hans Steffen Hoffman (1865-1936) para geografía e historia; Friedrich Ludwig Christian Hanssen (1857-1919) para filología, gramática
} 
Las diferencias fonéticas que percibía entre el español que podía escuchar en las calles del Santiago de fines del siglo XIX y aquel que había aprendido en su tiempo universitario lo motivarán a emprender un estudio lingüístico sistemático y profundo, comenzando con la lengua mapuche. Esto se vinculaba con la suposición de Lenz de que la ausencia de instrucción educativa formal era directamente proporcional a la "pureza" del lenguaje. En este sentido las lenguas indígenas, consideradas como las muestras más primitivas del lenguaje, constituirán los materiales más interesantes para la comprensión de la evolución del lenguaje humano ${ }^{923}$. Al igual que sucediera con Lehmann-Nitsche, el interés de Lenz por aquellos elementos "vulgares" de la cultura diaria, mal visto por los círculos sociales y académicos más tradicionales, lo llevarán a publicar sus primeras reflexiones en medios alemanes ${ }^{924}$.

Los contactos de Lehmann-Nitsche con Lenz comenzarán con un breve intercambio de publicaciones en 1897. Un año más tarde ambos estudiosos se conocerían personalmente, en ocasión de un viaje de Lenz a la Argentina. A pesar del tiempo vacacional que Lenz había planeado con su familia en Buenos Aires, los intereses científicos no estarán ausentes. Junto con el obsequio de 20 valiosos ejemplares sobre gramática indígena por parte de Bartolomé Mitre, Lenz atenderá diversas consultas efectuadas por Lehmann-Nitsche, principalmente aquellas vinculadas con recomendaciones bibliográficas sobre lingüística ${ }^{925}$.

En sucesivas cartas reconocerá el sustancial cuerpo de datos lingüísticos recolectados por Lehmann-Nitsche, recomendándole diversas lecturas para su sistematización y ordenamiento, como así también la importancia de la recolección de datos en el propio terreno, por lo cual sugería la realización de un viaje de campaña al interior del sur argentino-chileno. A fin de facilitar dicho viaje adjuntaba Lenz precisas instrucciones sobre como viajar en el interior de Chile, junto con el detalle de los sitios donde conocidos miembros de la comunidad alemana local podían alojarlo en su travesía por el país trasandino.

A partir de esto Lenz esperaba ampliar el espacio de recolección de textos araucanos y poder contrastar aquellos elementos descriptos por la literatura de viaje, producto de individuos que no contaban con la correcta formación científica ${ }^{926}$. En este sentido al momento de que

general y latín; para ciencias naturales Friedrich Richard Adelbart Johow Biehler (1859-1933) y Friedrich Albert Taupp (1867-1928); Rainald von Lilienthal para matemáticas, el cual será reemplazado hacia 1907 por August Tafelmacher (1860- ¿?) y finalmente Alfred Beutell en química y mineralogía. Alonso 1937; Gutiérrez 1920, 1938; Mellafe Rojas 1988; Vicuña 1937-38.

${ }^{923}$ Lenz 1897, 1912, 1933, 1924, 1977.

${ }^{924}$ Ver por ejemplo Chilenische Studien (1891-1892) publicados en la revista Phonetische Studien de Marburg dirigida por el filólogo y lingüista alemán Wilhelm Viëtor (1850-1918).

${ }^{925}$ Meses más tarde Lenz le escribiría agradeciéndole las deferencias tenidas para con su persona durante su estadía en Buenos Aires y pidiéndole a Lehmann-Nitsche que presentará su "Estudios Araucanos" en el futuro congreso científico de 1898 en Buenos Aires. Rudolf Lenz a Robert Lehmann-Nitsche. Legado Robert Lehmann-Nitsche, 05.02 y 04.04 de 1898, IAI, Carpeta N-0070 b 420.

${ }^{926}$ El principal trabajo recomendado por Lenz será A Description of Patagonia and the adjoining parts of South America, with a grammar and a short vocabulary, and some particulars relating to Falkland's Islands (1774) de Thomas Falkner. Al mismo tiempo, ante el envío de un conjunto de poesías populares argentinas por parte Lehmann-Nitsche, Lenz le enviaba su trabajo Über die gedruckte Volkspoesie von 
Lehmann-Nitsche realizará su viaje a Tierra del Fuego, elaborará Lenz una minuciosa guía elaborada en la cual este detallaba la forma de traducir los textos araucanos al español, como así también la función y participación de los informantes indígenas. Una vez llegado a La Plata, recibía Lehmann-Nitsche una carta de felicitación y aliento por parte de Lenz, como así también la consulta ansiosa por los resultados de su viaje a Tierra del Fuego ${ }^{927}$.

Al mismo tiempo Lenz lo mantendrá al tanto de las actividades de otros estudiosos alemanes en Sudamérica, introduciendo a Lehmann-Nitsche con algunos de estos. Este será el caso del etnólogo y lingüista Rudolph Riemel Schuller (1873-1923). Comenzando un breve intercambio en $1903^{928}$, al año siguiente ambos estudiosos intercambiarán una serie de cartas en las cuales Schuller le recomendaba diversos trabajos sobre los indios del Gran Chaco y lo ponía al tanto sobre las "negociaciones" ante el redactor de la revista de poesía gauchesca y nativista uruguaya El fogón, a fin de que pudiera brindarle una suscripción más económica a LehmannNitsche ${ }^{929}$.

Schuller agradecía el envío de trabajos por parte de Lehmann-Nitsche, asegurándole que los distribuiría entre sus conocidos. A la vez lo ponía al tanto de una serie de trabajos linguísticos aparecidos en las páginas de diversas publicaciones de Uruguay, España y Bolivia, favor que Schuller le pedía congratulará con el envío de una serie de publicaciones de la Revista del Museo de la Plata ${ }^{930}$. Dentro de esta serie de envíos se incluirán una importante cantidad de datos y apuntes bibliográficos sobre el grupo lingüístico quechua, los cuales Schuller usaría para contrastar con datos que se encontraba recolectando sobre los Tupi-Guarani, sacando provecho de contar con importantes recursos bibliográficos en la biblioteca del Museo Emilio Goeldi (Brasil), lugar donde había sido contratado hacia $1909^{931}$.

El intercambio de bibliografía se encontrará entre los principales favores entre estudiosos, de esta forma harán frente a la carencia de material, ya fuera por la dificultad de acceso o la falta de interés institucional en la adquisición del mismo. Hacia 1922 Schuller se encontraba en México, vinculado al Departamento de enseñanza industrial y comercial. En una

Santiago de Chile: ein beitrag zur chilenischen volkskunde. Rudolf Lenz a Robert Lehmann-Nitsche. Legado Robert Lehmann-Nitsche, 27.04 y 27.06 de 1900; 12.12.1901; 28.08.1902, IAI, Carpeta N-0070 b 420.

${ }^{927}$ Rudolf Lenz a Robert Lehmann-Nitsche. Legado Robert Lehmann-Nitsche, 28.08.1902, IAI, Carpeta $\mathrm{N}-0070$ b 420.

${ }^{928}$ En esta Schuller lo consultaba sobre la vida y las actividades de Eric Boman. Schuller a Robert Lehmann-Nitsche. Legado Robert Lehmann-Nitsche, 26.11.1903, IAI, Carpeta N-0070 b 653.

${ }^{929}$ Con respecto a los trabajos sobre los indígenas del Gran Chaco le recomendaba la lectura de los trabajos de Ehrenreich sobre los guayakis, como así también una serie de trabajos suyos sobre los charruas uruguayos. Posteriormente Schuller invitaría a Lehmann-Nitsche a una conferencia suya en la cual expondría su hipótesis sobre el origen chaqueño de los indios charruas uruguayos. Schuller a Robert Lehmann-Nitsche. Legado Robert Lehmann-Nitsche, IAI, 19.03.1904, 08.04.1904, 11.05.1904 y 21.05.1904, IAI, Carpeta N-0070 b 653.

${ }^{930}$ Schuller a Robert Lehmann-Nitsche. Legado Robert Lehmann-Nitsche, 17.12.1907, IAI, Carpeta N0070 b 653 .

${ }^{931}$ Schuller a Robert Lehmann-Nitsche. Legado Robert Lehmann-Nitsche, 23.02.1911, 29.05.1911 y 16.07.1911, IAI, Carpeta N-0070 b 653. 
carta consultaba a su par argentino sobre la vida y actividad de distintos personajes de los círculos científicos argentinos, como Torres, Zeballos, Outes y Lafone Quevedo, mientras que lo ponía al tanto de los estudiosos alemanes residentes en México ${ }^{932}$. Meses más tarde le comentaba del pésimo estado de las bibliotecas mexicanas, las cuales se caracterizaban por la ausencia de material bibliográfico ${ }^{933}$.

Al mismo tiempo, y por recomendaciones de Lenz, comenzara Lehmann-Nitsche a establecer una base de datos lingüísticos para el norte argentino. Los primeros pasos en la construcción de la mismas datan de 1903, oportunidad en la cual se comunicaba con José Cuellar Fernández, director de la revista Recuerdos de la Patria, a fin de solicitarle los números de dicha publicación con notas referidas la gramática y el vocabulario Quechua, los cuales serán remitidos ${ }^{934}$. Ignorando la metodología de recolección de datos y las fuentes utilizadas por este último, procederá Lehmann-Nitsche a ordenarlos y catalogarlos según las instrucciones provistas por la Tabelle zur Aufnahme südamerikanischer Sprachen. Desconocer el contexto o la forma en la cual los datos eran recolectados no era un problema para los estudiosos. A partir del uso de los mismos instrumentos de ordenamiento, procesamiento y catalogación de los datos obtendrán resultados homogéneos, plausibles de ser comparados.

Dentro de las redes de recolección de datos sobre la zona del norte, y especialmente del Gran Chaco, será de importancia el vínculo establecido con Friedrich Christian Mayntzhusen. La particularidad de sus estudios sobre grupos indígenas del Paraguay, principalmente los AchéGuayakí, iniciados hacia 1904, serán que estos tendrán lugar a lo largo de más de 40 años de residencia en la propia colonia que esta fundará y en la cual se asentarán un importante número de indígenas de este último grupo étnico ${ }^{935}$.

Habiendo llegado a Paraguay en 1900, se asentará temporalmente en la colonia de Hohenau fundada por Carlos Reverchón, Wilhelm Closs y los hermanos Ambrosio y Esteban Scholler ${ }^{936}$. Seguramente en la elección de este lugar tuviera influencia la tarea etnográfica desarrollada por Reverchón. Tal como lo dejará sentado Juan Bautista Ambrosetti en sus

${ }^{932}$ Schuller a Robert Lehmann-Nitsche. Legado Robert Lehmann-Nitsche, 21.03.1922, IAI, Carpeta N0070 b 653 .

${ }^{933}$ Schuller a Robert Lehmann-Nitsche. Legado Robert Lehmann-Nitsche, 20.07.1922, IAI, Carpeta N0070 b 653 .

${ }_{934}$ Cuellar detallaba que los números comprendían gramática y el vocabulario, como así también el valor de cada cuadernillo. Lehmann-Nitsche seguirá comunicándose con Cuellar Fernández a fin de recomendar autores y obras que tenían por objetivo el estudio de la lengua Quechua a la espera de que este le remitiera en forma casi exclusiva cualquier tipo de recopilación que pudiera efectuar al respecto. José Cuellar Fernández a Robert Lehmann-Nitsche. Legado Robert Lehmann-Nitsche, 28.06 y 16.07 de 1903, IAI, Carpeta N-0070 b 137.

935 Entre los estudios previos utilizados por Mayntzhusen podemos mencionar los de: el misionero austriaco Martin Dobritzhoffer (1717- 1718), del jesuita polaco Florián Paucke (1719-1780), del médico suizo Johann Rudolf Rengger (1795-1832), del botánico suizo Emil Hassler (1864-1937), Paul Ehrenreich, Karl von den Steinen, Theodor Koch Grünberg, Ludwig Kersten y el padre Friedrich Vogt entre otros.

${ }_{936}$ Con un flujo inicial de descendientes de alemanes asentados en Brasil, la colonia incorporará rápidamente familias alemanas, suizas y austriacas provenientes de Europa. 
trabajos exploratorios en Misiones, Reverchón era conocido en la zona litoraleña por las importantes colecciones etnográficas depositadas en las instalaciones de su Ingenio Azucarero cercano a Villa Encarnación (Misiones, Argentina) ${ }^{937}$. En 1904 Mayntzhusen recibirá una importante herencia familiar la cual invertirá en la compra de 120.000 hectáreas en la zona del Alto Paraná con la intención de dedicarse al obraje y a la colonización. Finalmente en 1907 quedaba establecida la "Colonia Mayntzhusen", la cual se sumaba a otros asentamientos alemanes en el Paraguay ${ }^{938}$.

Las primeras acciones de Mayntzhusen estarán destinadas a la colonización y explotación de la tierra ${ }^{939}$. Al mismo tiempo comenzarán sus trabajos sobre los Aché-Guayakí, cuyos resultados serán presentados en el decimosexto Congreso de Americanistas celebrado en la ciudad de Buenos Aires en 1910940. Al mismo tiempo conocerá personalmente a LehmannNitsche, oportunidad en la cual intercambiarán distintas opiniones en cuanto a la situación de los guayakis y los estudios más propicios de realizar. Una vez vuelto a su colonia recomendaba a Lehmann-Nitsche una serie de trabajos sobre lingüística guaraní, pidiéndole además le recuerde a Bruch el envío de una serie de fotografías que este último le había prometido ${ }^{941}$.

Ocupaciones vinculadas a los negocios de la colonia y el destino de los guayakis comenzaban a ocupar la mayor parte del tiempo de Mayntzhusen. Con respecto a este último tema aventuraba una re-localización de los mismos en una de las misiones jesuitas de La Compañía de Jesús. Junto con la salvaguarda de los indígenas esto le proveería, como le comunicaba a Lehmann-Nitsche, un espacio ideal en donde profundizar sus observaciones, principalmente aquellas vinculadas a la deformación craneal, el nacimiento de los indígenas, el

\footnotetext{
937 Ambrosetti 2008.

${ }^{938}$ Los primeros alemanes llegaban al distrito de los Altos entre 1879 y 1880, seguido de la fundación de San Bernardino en 1881. Posteriormente tendremos el arribo de migrantes alemanes, polacos y ucranianos a Encarnación en 1884, mismo año en el cual un nutrido grupo de alemanes se asentarán en Villarica. En 1887 el escritor alemán Bernhard Förster (1843-1889) fundaba la colonia Nueva Germania. Un año más tarde colonos alemanes y suizos arribaban a la Colonia Fulgencio Yegros. A fines del siglo XIX tendremos asentamientos de alemanes en la colonia Villa Elisa.

939 En 1908 hacia imprimir en Hamburg una cartilla de presentación. Esta contaba en sus primeras páginas con una descripción de las características naturales y productivas de la colonia. A continuación se detallaba la reglamentación del proceso de colonización, la ley paraguaya de inmigración y finalmente se anexaba un plano con los lotes de la urbanización planificada. Mayntzhusen 1908.

940 Presentaria dos trabajos. El primero de estos, "Über vorkolumbianische Siedelungen und Urnenfriedhöfe der Guaraní am Alto Paraná”, será presentado en la sección de arqueología y etnología de Bolivia y el Alto Paraná. En el mismo detallaba que a partir de los sitios por el excavados podía pensarse un sustrato cultural en común para la familia Guaraní, a la cual se la pensaba compuesta por distintos grupos. Al mismo tiempo planteaba ciertas afinidades estilísticas y decorativas con los grupos centrales de Brasil estudiados por el antropólogo alemán Max Schmidt (1874-1950). El segundo trabajo consistía en los resultados preliminares sobre los primeros estudios antropométricos que había realizado sobre los guayakís, a partir de los cuales pretendería determinar su dispersión geográfica. Mayntzhusen 1912.

${ }_{941}$ Estos trabajos eran Historia de la provincia del Paraguay de la Compañía de Jesús (1673) del padre jesuita Nicolás del Techo (1611-1680) y el Tesoro de la lengua guaraní (1639) del también padre jesuita Antonio Ruiz de Montoya (1585-1652). Mayntzhusen a Robert Lehmann-Nitsche. Legado Robert Lehmann-Nitsche, 18.01.1911, IAI, Carpeta N-0070 b 446.
} 
cuidado parental, ritos de pubertad, mitología y antropografía. Estos elementos le habían sido señalados por Karsten como relevantes para la comprensión de este grupo indígena ${ }^{942}$.

Para esto solicitaba a Lehmann-Nitsche el envío de material bibliográfico e instrumentos, ya que la lejanía de la colonia dificultaba la adquisición de dichos elementos. Mayntzhusen, a cambio, se comprometía al envío de un flujo continuo de datos sobre los Guayakis $^{943}$. En sentido se lamentaba de no contar con el tiempo necesario para que prosperara la idea de una colonia de indígenas chaqueños en Misiones, por lo cual le recomendaba a Lehmann-Nitsche que continuará con dicha idea ya que este contaba con el tiempo, los recursos y principalmente los debidos contactos ${ }^{944}$. Por último es preciso mencionar que; al igual que sucediera con el caso de Stephan Bridges, Mayntzhusen también "proveerá" de indígenas a Lehmann-Nitsche. En este sentido este último le comunicaba a Lehmann-Nitsche sobre una breve visita en a Buenos Aires, oportunidad en la cual se hospedaría en la localidad de Santos Lugares junto con un indígena guayaki, invitando al estudioso del Museo de La Plata a realizar los estudios que deseara ${ }^{945}$.

Como hemos visto en el caso de Mayntzhusen los favores prestados serán en pos de obtener algún tipo de retribución a cambio. En 1911 el historiador de las religiones finlandés Sigfrid Rafael Karsten (1879-1956) emprendía su viaje a través de Sudamérica, focalizando especialmente en el norte argentino y en Bolivia. Este le pedirá a Lehmann-Nitsche una carta de recomendación para ser presentada a los hermanos Leach, del ingenio azucarero La Esperanza. Gracias a dicha recomendación, y luego de haber estado unos meses en el Gran Chaco, Karsten comenzaba a sistematizar sus notas de campo en la tranquilidad del predio azucarero. De esta forma el colega en el campo se transformaba en un informante clave y en una oportunidad de ampliar y completar nuevas investigaciones o bien de comenzar nuevas.

Una de las formas de asegurarse de la fiabilidad de los datos recolectados para con las propias investigaciones, será recomendar y proveer de instrucciones de recolección o bien trabajos propios que sirvieran como referencia metodológica. En este sentido Karsten le confirmaba a Lehmann-Nitsche la recepción de su vocabulario choroti, agradeciéndole la oportunidad de poder contar con un "importante material" que el gustosamente ampliaría. De esta forma Lehmann-Nitsche se aseguraba de ampliar aquellos datos recolectados por el mismo

\footnotetext{
${ }^{942}$ Mayntzhusen a Robert Lehmann-Nitsche. Legado Robert Lehmann-Nitsche, 25.10.1911, IAI, Carpeta $\mathrm{N}-0070$ b 446.

${ }^{943}$ Las investigaciones de Mayntzhusen; como mucho de los trabajos antropológicos de la época, se encontraban supeditadas al precepto de la inminente desaparición de los pueblos que estudiaban, por lo cual el relevo compulsivo de datos se tornaba una necesidad. En una de sus cartas Mayntzhusen confesaba a Lehmann-Nitsche la triste muerte de 21 indígenas de su reducción como causa de distintas enfermedades, reduciendo considerablemente el número total de la misma, algo que junto con la tristeza que le provocaba, imprimía la necesidad de incrementar el ritmo de sus investigaciones. Mayntzhusen a Robert Lehmann-Nitsche. Legado Robert Lehmann-Nitsche, 20.03.1912, IAI, Carpeta N-0070 b 446. ${ }^{944}$ Ibídem.

${ }^{945}$ Mayntzhusen a Robert Lehmann-Nitsche. Legado Robert Lehmann-Nitsche, 27.08.1920, IAI, Carpeta N-0070 b 446.
} 
hacia 1906, datos que consideraba insuficientes para poder constituir una muestra significativa que le permitiera establecer comparaciones en la zona del gran Chaco ${ }^{946}$. El arribo de un nutrido contingente de indios tobas y chorotis al ingenio de los hermanos Leach permitirá a Karsten ampliar la base de datos lingüísticos tomando el trabajo de Lehmann-Nitsche como guía. Al mismo tiempo le confirmaba que haría uso del mismo en próximos trabajos en el Ingenio Ledesma y Cochabamba (Bolivia) ${ }^{947}$.

Los participantes en esta red de colaboración esperaban que la reciprocidad funcionara en ambos sentidos. Una vez regresado a Europa, Karsten le encomendaba a Lehmann-Nitsche mantenerlo al corriente sobre la presencia de los indios choroti a algunos de los ingenios azucareros en la época de zafra. Esto le permitiría diagramar un trabajo de campo en dichos lugares, invitando a Lehmann-Nitsche a participar del mismo ${ }^{948}$.

\subsubsection{La construcción de una cartografía etnográfica: Los trabajos mitológicos}

Esta serie de trabajos lingüísticos se vincularán estrechamente con aquellos sobre mitología y astronomía de los pueblos indígenas. Según Lehmann-Nitsche solo a través de la articulación de estos datos en un solo modelo explicativo era posible construir una cartografía etnográfica de Sudamérica en la cual se precisaran las áreas geográficas y las zonas de interacción ${ }^{949}$. Como podremos ver esta propuesta no será novedosa sino que responderá a la lectura de una serie de trabajos recomendados por Schuller en los cuales destaca Mythen und Legenden der südamerikanischen Urvölker und ihre Beziehungen zu denen Nordamerikas und der alten Welt (1905) de Eherenreich ${ }^{950}$. En dicho trabajo se planteaba un modelo explicativo bicausal para la similitud temática de los mitos americanos: Primeramente debía considerarse la existencia de una antigua "capa" de mitos y cuentos diseminada por todo el Nuevo Mundo. Posteriormente se registraba una "infiltración y difusión" de elementos aislados o bien la combinación de estos, difundiéndose de norte a sur.

Llamando la atención sobre la ausencia de este tipo de investigaciones en Sudamérica, se planteaba el trabajo en conjunto con la lingüística, a fin de poder tener un control sobre la veracidad de los datos mitológicos y astronómicos relevados. La correspondencia entre zonas

\footnotetext{
${ }^{946} \mathrm{Si}$ bien ambos estudiosos reconocían como única labor científica previa aquellos trabajos realizados por Nordenskiöld y von Rosen, cuestionaban la calidad y cantidad de los datos recolectados. En este sentido afirmaba Karsten que "Über diese Indianer hat wohl Nordenskiöld etwas geschrichen, aber ich habe dennoch unter ihnen einige neue interessante Entdeckungen gemacht". Karsten a Robert LehmannNitsche. Legado Robert Lehmann-Nitsche, 02.06.1912, IAI, Carpeta N-0070 b 358

${ }_{947}$ Ibídem.

${ }^{948}$ Karsten a Robert Lehmann-Nitsche. Legado Robert Lehmann-Nitsche, 08.06.1928, IAI, Carpeta N0070 b 358.

${ }^{949}$ Lehmann-Nitsche 1928 1, 1930 i, 1936 e, 1936 h, 1937 h.

${ }^{950}$ Al momento de comentarle la próxima aparición de su trabajo "Religion und Mythologie", Schuller le seguirá sugiriendo los trabajos de Ehrenreich como el mejor modelo al momento de estudiar la mitología de los grupos sudamericanos. Schuller a Robert Lehmann-Nitsche. Legado Robert Lehmann-Nitsche, 20.07.1922, IAI, Carpeta N-0070 b 653.
} 
"mitológicas" y "lingüísticas" será una de las principales herramientas metodológicas empleadas por Lehmann-Nitsche. Estas a su vez mostraban la ausencia de aislamiento entre las distintas zonas estipuladas para el continente americano, pudiendo observar superficies de contacto y de divergencia ${ }^{951}$. Al mismo tiempo configuraba un requisito analítico: tomar los mitos y creencias astronómicas de una región lingüística y someterlos a un examen comparativo. Tal como aseguraba Ehrenreich este tipo de metodología podía ser desconocido en Sudamérica, pero no así en la región norte del Continente Americano ${ }^{952}$. Esta referencia podría especificarse a los trabajos llevados adelante en los Estados Unidos por Franz Boas.

Este último planteaba hacia 1896 que el estudio de los elementos lingüísticos, mitológicos, astronómicos y raciales debían ser estudiados acordes a su propio método, pero que sin embargo estos debían confluir en la reconstrucción histórica de la historia de la humanidad, a fin de poder determinar las interacciones entre los grupos humanos y su desplazamiento en el espacio $^{953}$. Al igual que sucediera con los estudios lingüísticos la extensa red de estudiantes de Boas le permitirá cubrir un amplia área geográfica. En 1905 articulará y coordinara las investigaciones de sus estudiantes a fin de poder construir un mapa que mostrará la interacción entre los diversos círculos mitológicos. De esta forma pretendía establecer un correlato entre psicológico de los fenómenos geográficos, siguiendo aquellas ideas planteadas por Friedrich Ratzel, Adolf Bastian y Theobald Fischer ${ }^{954}$. Como veremos más adelante la red de alumnos articulada por Boas alrededor de sus alumnos será una de las principales estrategias implementadas para la consecución de este y otros proyectos.

Lehmann-Nitsche, a diferencia de Boas, deberá articular su red de recolección en base a la ayuda prestada por otros estudiosos. Gracias a Lenz podrá ponerse en contacto con el folklorista y etnólogo inglés Richard Eduard Latcham (1869-1943) ${ }^{955}$. Este era consultado por Lehmann-Nitsche sobre relatos mitológicos y datos astronómicos de los grupos indígenas chilenos, principalmente los mapuches. Uno de los interés principales será el motivo del sol y la luna entre el mencionado grupo indígena. Unos meses pasarían antes de que Latcham contestara la carta de su colega residente en Argentina, ya que su trabajo como ingeniero de minas lo mantenía mucho tiempo fuera de Santiago de Chile.

\footnotetext{
${ }^{951}$ Lehmann-Nitsche 1930 h.

952 Ehrenreich 1905.

953 Boas 1896 b.

${ }^{954}$ Estos trabajos no iniciarán formalmente con Boas, sino que este retomará un proyecto iniciado en 1890 por John Wesley Powell y el folklorista y traductor estadounidense Jeremiah Curtin (1835-1906). Darnell 1998; Hinsley 1976; Stocking 1974 a.

955 Nacido en Bristol (Inglaterra) cursará sus estudios secundarios en dicha ciudad, ingresando posteriormente al Polytechnic Institute de Londres, donde se graduará como Ingeniero civil en 1888. Rápidamente aceptará un puesto en el Departamento de Colonización chileno. Sus principales trabajos estarán enfocados en la construcción de caminos, algo que lo llevará a entrar en contacto con los grupos indígenas chilenos. Lothrop 1945.
} 
Latcham lo proveerá de los datos recogidos durante la permanencia de tres años, entre 1888 y 1891, entre los grupos mapuches del sur de Chile. Al mismo tiempo le recomendaba, ante la posible dificultad de acceder a bibliografía especializada, la lectura de las obras del chileno Tomas Guevara (1865-1935), el cual, según Latcham, había hecho uso de muchas de sus apuntes personales para la redacción de sus trabajos ${ }^{956}$. Lehmann-Nitsche ya contaba con dichos trabajos, los cuales habían sido suministrados por el propio Guevara ${ }^{957}$. A partir de este cuerpo de datos Lehmann-Nitsche buscaba establecer en forma adecuada una serie de analogías en la repetición de los elementos del diluvio por un lado y los motivos del sol y la luna por el otro. Esto le permitía establecer una serie de vínculos entre Argentina, Chile, Brasil, Paraguay, Perú y Bolivia ${ }^{958}$. La importancia de estos trabajos radicará en la síntesis comparativa establecida por Lehmann-Nitsche, el cual resumirá y abreviará en estos un considerable número de datos procedentes del relevo directo con los grupos indígenas por un lado y gran parte de los compendios bibliográficos de relatos de misioneros y viajeros ${ }^{959}$.

\subsubsection{La clasificación e interpretación de la cartografía etnográfica}

La clasificación y la interpretación de este amplio cuerpo de datos, como veremos más adelante, será también resultado de una serie de sugerencias metodológicas de Rudolf Lenz. Hacia la primera década del siglo XX este insistiría en una serie de cartas sobre la necesidad de que Lehmann-Nitsche realizará un viaje a Chile, oportunidad en la cual podían avanzar más rápida y profundamente en el proyecto de generar una cartografía lingüística de Sudamérica. Dicho viaje se concretaría el 21 de enero de 1912, fecha en la cual Lehmann-Nitsche partía de "viaje de placer", tal cual titulaba el diario chileno El Mercurio, junto con los estudiantes de la Facultad de Física de la Universidad Nacional de Buenos Aires José B. Collo (1887-1968) y Teófilo Isnardi (1890-1966), quienes viajaban como delegados estudiantiles a fin de procurar el

\footnotetext{
956 Ricardo Latcham a Robert Lehmann-Nitsche. Legado Robert Lehmann-Nitsche, 20-12-1916, IAI, Carpeta N-0070 b 411.

957 Dichos trabajos serán Historia de la civilización de Araucanía (1898) y Costumbres judiciales $i$ enseñanza de los araucanos (1904), los cuales Guevara le había obsequiado en 1905, con el objetivo de que Lehmann-Nitsche le brindará su "lisonjero concepto" sobre estas. Guevara, a fin de retribuir las deferencias del estudioso alemán, comenzará a cotejar y relevar información entre sus informantes araucanos. Tomas Guevara a Robert Lehmann-Nitsche. Legado Robert Lehmann-Nitsche, 22.07.1905 y 11.09. 1905, IAI, Carpeta N-0070 b 269.

${ }^{958}$ Lehmann-Nitsche 1919 b, 1919 d, 1930 g, 1930 i, 1937 h.

959 El propio Latcham confesaba años más tarde la importancia de los trabajos de astronomía de Lehmann-Nitsche a la hora de realizar un trabajo sobre las ideas religiosas de los antiguos peruanos en el cual había tenido que "[...] pasar en revista todas las creencias cósmicas de los indios sudamericanos, para determinar las corrientes que pueden haber influenciado los conceptos de los diferentes pueblos del antiguo imperio incaico" Ricardo Latcham a Robert Lehmann-Nitsche. Legado Robert Lehmann-Nitsche, 06.03.1927, IAI, Carpeta N-0070 b 411.
} 
acercamiento con sus pares chilenos ${ }^{960}$. Como podemos este tipo de viajes servirá para gestionar en forma más rápida, precisa y elaborada los objetivos de los trabajos en conjunto. Esta larga travesía le permitirá a Lehmann-Nitsche contar con varios días a partir de los cuales comenzaba a integrar, por sugerencia de Lenz, los datos linguísticos del sur de la Argentina con aquellos recolectados en los ingenios azucareros del noreste del país. Siguiendo las indicaciones de su par chileno también buscaría extender esta articulación con datos de la zona del Gran Chaco en general.

En dicha zona y en el Noroeste argentino recopilará datos astronómicos en 1924, en oportunidad de su viaje a la reserva indígena de Napalpi. Uno de los elementos fundamentales que garantizará en ese momento la consecución de buenos resultados será el plan de educación básica para los indígenas asentados en la mencionada colonia indígena. Este estará basado en aquellos implementados por los Estados Unidos y Canadá en sus propias reducciones, los cuales establecían entre otros puntos ligeras nociones de astronomía, cosmografía y rudimentos de dibujo lineal, elementos que facilitarán la recopilación de datos astronómicos realizada por Lehmann-Nitsche.

Estos trabajos serán realizados casi siempre de noche y con cielo despejado, ya que de esta forma los indígenas podían identificar los elementos astronómicos fácilmente, siendo estos trasladados a una carta sideral por Lehmann-Nitsche, la cual después sería reproducida gráficamente en un formato reducido y acentuando solamente los elementos sobre los cuales se quería puntualizar. Para los distintos grupos indígenas asentados en la reducción de Napalpi dicha carta sideral no será un elemento ajeno, ya que similares objetos serán utilizados para su educación dentro de la reducción ${ }^{961}$. Prueba de esto sería un trabajo de Lynch Arribálzaga sobre el mito toba del avestruz de la Vía Láctea que enviaba a Lehmann-Nitsche, por considerarlo un interesante estudio sobre la astronomía indígena por las conexiones y similitudes que podía establecer con las versiones de dicho mito por parte de otros grupos indígenas ${ }^{962}$.

La compilación de las concepciones astronómicas de los grupos indígenas no implicaría, como hemos vistos, un desplazamiento del antropólogo fuera del gabinete de investigación. En este sentido en 1921 Clemente Onelli extendía una invitación a Lehmann-Nitsche a fin de que asistiera al Jardín Zoológico de Buenos Aires a observar a un grupo de indios susques que había traído desde Jujuy ${ }^{963}$. Finalmente Onelli relevaría a pedido de Lehmann-Nitsche una serie de

\footnotetext{
${ }^{960}$ Para detalles de la visita de estos dos estudiantes ver los siguientes diarios chilenos: La Mañana 02, 10, 11 y 12 de febrero de 1912; El Sur 03.02.1912, La Aurora 06.02.1912. Sobre los diarios argentinos ver especialmente: La Prensa 21.01.1912, 03.02.1912 y Deutsche La Plata Zeitung 21.01.1912. ${ }^{961}$ Lehmann-Nitsche 1923 b, 1923 c, 1924 h, 1924 i, 1925 1, 1927 h; Lynch Arribálzaga 1914.

962 Al recibir este trabajo Lehmann-Nitsche remitiría sus trabajos sobre la astronomía de los grupos chaqueños a fin de poder establecer comparaciones. Lynch Arribálzaga a Lehmann-Nitsche, 21.05.1924, IAI, Carpeta N-0070 b 424.

${ }^{663}$ Onelli había hecho publicar una foto de dos de los indios en el diario La Razón, agregando "Publiquen esta fotografía; tengo mis razones, que son las siguientes: los antropólogos y los etnólogos del mundo se develan para estudiar y tener datos de la agrupación indígena que vive aislada en la Puna de Atacama en
} 
datos que incluirán: apellido, la composición familiar y principalmente las palabras quechuas usadas para denominar elementos astronómicos como la Cruz del Sur y las Tres Marías ${ }^{964}$.

La matriz analítica a partir de la cual Lehmann-Nitsche analizará este cuerpo de datos será también resultado de las recomendaciones de otros estudiosos. En 1917 Rudolf Lenz le recomendaba los trabajos del psicólogo, filósofo y fisiólogo alemán Wilhelm Maximilian Wundt (1832-1920) ${ }^{965}$. Entre los principales trabajos de este último, le remarcaba Lenz a Lehmann-Nitsche, era de vital importancia la lectura de Grundzüge der physiologischen Psychologie (1874) y la comprensión exacta del concepto de "Völkerpsychologie"966. A partir del mismo Wundt sugería analizar los fenómenos psicológicos con las herramientas analíticas y metodológicas de las ciencias naturales, ya que esta era la única manera de poder obtener un conocimiento material y objetivo de los mismos ${ }^{967}$.

La aplicación de esta metodología de análisis llevará a Lehmann-Nitsche a intentar transcribir aquellos conceptos abstractos y subjetivos de la experiencia inmediata; en palabras de Wundt; a distintos soportes materiales. Por consiguiente utilizará reproducciones fotográficas de las figuras que los indígenas del norte argentino formaban en un juego en el cual trenzaban cordeles de hilo entre sus dedos creando distintas figuras, las cuales eran vistas por LehmannNitsche una especie de cartografía celestial "primitiva".

A medida que los trabajos iban siendo editados los distribuirá entre diversos institutos y personas, momento en el cual también solicitara su colaboración a través del envío de datos astronómicos y/o bibliográficos ${ }^{968}$. La necesidad de contar con un la mayor cantidad posible de

un punto llamado Susques [...] Los estudios antropométricos y etnológicos son muy escasos hasta ahora. Bien pues, le proporciono ahora a estos señores sabios la ocasión única de poder estudiar, puede decirse a domicilio, sin los sinsabores desagradables de un viaje largo [...] sin necesidad de gastos mayores y comisiones científicas con arrieros, con peones, con recuas de mulas y forraje para el viaje; y ningún sabio viene a verlos en estos días que pasan en Buenos Aires, en el Jardín Zoológico”. La Razón 07.07.1921

${ }^{964}$ Onelli a Robert Lehmann-Nitsche. Legado Robert Lehmann-Nitsche, 14.10.1921, IAI, Carpeta N-0070 b 508 .

965 Rudolf Lenz a Robert Lehmann-Nitsche. Legado Robert Lehmann-Nitsche, 23.09.1917, IAI, Carpeta N-0070 b 440.

966 De esta manera se proveía a las "Geisteswissenschaften" (historia, políticas, arte y religión) con una base empírica proveniente de las ciencias naturales. En consecuencia la "Völkerpsychologie" se transformaba en una ciencia entre bordes, o como Wund precisaba una historia natural de la mente humana. Como refiriera James Sully al momento de realizar una reseña sobre la obra de Wundt "In order to transform it [the concept of mental faculty] into a scientific conception, it would have been necessary to regard mental phenomena as the obverse of material processes". Sully 1876, p. 22; Wundt 1874, 1913, 1920.

${ }^{967}$ Wundt 1896.

968 Entre las instituciones que acusarán recibo de sus publicaciones podemos mencionar: La Biblioteca Nacional de Chile; la Biblioteca Amador Baquerizo de Ecuador; la Sociedad Anónima Espasa-Calpe y la Sociedad Cultura Guaraní de Argentina; la Sociedad Chilena de Historia Natural; la biblioteca de la Facultad de Filosofía y Letras de Buenos Aires; la Sociedad de Geografía e Historia de Guatemala; Akademie der Wissenschaften de Heildelberg; la Anthropologischen Gesellschaft de Viena; la Berliner Gesellschaft für Anthropologie, Ethnologie und Urgeschichte y el Kaiser-Friedrich Museum de Berlin, y la Società Italiana d'Antropologia. Entre los diversos estudiosos podemos mencionar: el coleccionista de arte, historiador y arqueólogo ecuatoriano Jacinto Jijón y Caamaño (1890-1950); el arqueólogo alemán 
datos sobre las diversas regiones americanas, se inscribía en la intención de Lehmann-Nitsche de poder determinar "ciclos mitológicos". A partir de estos buscará aislar detalles característicos a fin de poder establecer similitudes y diferencias, zonas de convergencia, aislamiento y dispersión geográficos, y finalmente puntos de "intercambio" ${ }^{969}$. Esta idea no será novedosa en contexto antropológico. Hacia fines del siglo XIX y principios del siglo XX, podemos mencionar los trabajos del geógrafo y etnógrafo alemán Richard Andree (1835-1912) y el etnógrafo austriaco Moriz Winternitz (1863-1937). Ambos buscarán aislar los componentes esenciales de los mitos universales a fin de poder construir una matriz explicativa común ${ }^{970}$.

En el ámbito sudamericano esta idea podemos encontrarla en el trabajo "Kulturkreise und Kulturschichten in Südamerika" (1913) del sacerdote alemán Wilhelm Schmidt (1868$1954)^{971}$. En este trabajo se planteaba el análisis relacional de la historia cultural de los grupos humanos sudamericanos a partir de la conjunción de: el concepto de "Elementalgedanke" de Adolf Bastian, los estudios del geógrafo alemán Oskar Ferdinand Peschel (1826-1875), las teorías de migración cultural de Friedrich Ratzel, y finalmente la sinopsis que realizará sobre este último punto el etnólogo alemán Leo Frobenius (1873-1938) a través de su concepto de “círculos culturales". Finalmente Schmidt establecía tres círculos culturales para Sudamérica ${ }^{972}$. Haciendo un llamado por profundizar este tipo de análisis ya que, a pesar de contar el extremo sur del Continente Americano con una riquezas de materiales mitológicos no había investigaciones; a excepción de los trabajos de Ehrenreich; que sacaran provecho de los $\operatorname{mismos}^{973}$.

Friedrich Max Uhle; los historiadores brasileños Basílio de Magalhães (1874-1957) y João Batista Ribeiro de Andrade Fernandes (1860-1934); el botánico chileno Gualterio Looser Schallemberg (18981982); el estadounidense Stansbury Hagar (1869-1945?); el médico chileno Aureliano Oyarzún Navarro (1858-1947) y los alemanes Theodor Koch-Grünberg, Walter Lehmann, Alfred Maßß y Carl Bezold (1859-1922). Legador Robert Lehmann-Nitsche, IAI.

${ }_{969} \mathrm{La}$ ampliación del contexto geográfico de los datos llevará a los estudiosos a la realización de comprobaciones exactas y detalladas grupo por grupo, efectuando posteriormente el establecimiento de paralelos exhaustivos de gran alcance. En este sentido en el contexto de una charla sobre astronomía popular gallega en el patronato Pascual Vega, Lehmann-Nitsche afirmaba "[...] no dejaré de entrelazar, cuando sea menester, en las ideas astronómicas de Galicia, las que se han formado en otros pueblos del orbe, ubicándolas por vía comparativa en el sitio que ocupan dentro del mundo de los conceptos primitivos"Lehmann-Nitsche 1924 e, p. 371.

${ }_{970}$ Andree 1891; Winternitz 1901.

${ }^{971}$ Este trabajo sintetizará una línea de pensamiento desarrollada a lo largo de una serie de de 12 volúmenes titulada Der Ursprung der Gottesidee, cuyo primer número aparecía en 1912. En esta obra planteaba un modelo explicativo de migraciones y zonas de interacción como explicación de la evolución del monoteísmo al politeísmo.

${ }^{972}$ Estos eran: circulo de los pueblos recolectores-cazadores nómadas, circulo de los pueblos sedentarios y finalmente los pueblos de alta cultura. Schmidt 1913.

973 En este sentido Ehrenreich remarcaba "Weit mehr noch als Objekte und Produkte der materiellen Kultur sind solche der Ideenwelt, vor allem Mythen und mystiche Motive von Volk zu Volk gewandert". Años más tarde Lehmann-Nitsche se sumaba a esta reflexión afirmando que "Varios son los caminos que pueden llevarnos a descubrir o restablecer aquellas antiquísimas corrientes étnicas entre ambos mundos. Mientras las sendas existentes en el campo antropológico propiamente dicho, es decir, aquellas que se refieren a los caracteres físicos tanto del hombre americano como del asiático, nos han conducido a terrenos desiertos donde no brota el árbol del conocimiento y del saber que tan asiduamente se busca, 
La lectura de estos trabajos seria sugerida por el etnólogo alemán Konrad Theodor Preuss (1869-1938), ante el envío que Lehmann-Nitsche realizará sobre sus trabajos de mitología indígena ${ }^{974}$. Al mismo tiempo que le sugería la traducción al alemán de ciertos trabajos que serían de interés para aquellos estudiosos dedicados a este tipo de trabajos, ya que como le recordaba Preuss no todos entendían español ${ }^{975}$. Finalmente le recomendaba que consultara con astrónomos datos históricos con respecto a la posición de las constelaciones en determinadas épocas del año. En este sentido la cercanía entre el Museo de La Plata y el Observatorio Astronómico, ambos situados en los terrenos del bosque platense, facilitará la consulta de datos ${ }^{976}$.

Entre los primeros miembros de esta institución que atenderán las consultas de Lehmann-Nitsche figura el ingeniero y astrónomo argentino Félix Aguilar (1884-1943). Consultado este sobre la "configuración del cielo de Cuzco", remitía inmediatamente una detallada planilla con los ortos y ocasos de $\alpha$ Lyr (estrella de Vega) en el cielo cuzqueño hacia el año 1600. Al mismo tiempo adjuntaba una serie de instrucciones con las cuales LehmannNitsche podía aprender a calcular el valor aproximado de ortos y ocasos para una estrella o constelación en una fecha dada. Gracias a la gentil colaboración de Aguilar no solo obtenía Lehmann-Nitsche la información requerida, sino que lograra recibir las herramientas metodológicas y la instrucción formal necesaria para el cálculo, procesamiento y entendimiento de futuros datos ${ }^{977}$. Al mismo tiempo; ante la falta de recursos bibliográficos en las instituciones científicas del bosque; consultaba al astrónomo estadounidense Charles Dillon Perrine (1867-

parece que las huellas que cruzan por el terreno psíquico prometen mejor resultado". Ehrenreich 1905, p. 100; Lehmann-Nitsche 1922, p. 22. Los resaltados son de nuestra autoría.

${ }^{974}$ Una de las principales sugerencias serán los trabajos de Koch-Grünberg. A su vez, ante los deseos de Lehmann-Nitsche de adentrarse dentro del mundo de los mitos centroamericanos y especialmente aquellos relacionados con el dios Tezcatlipoca, exhortaba Preuss a la paciente revisión del Códice Borgia, a fin de que pudiera ilustrarse con una de las más fieles representaciones gráficas de la mencionada deidad. Konrad Theodor Preuss a Robert Lehmann-Nitsche. Legado Robert Lehmann-Nitsche, 15.07.1921, IAI, Carpeta N-0070 b 534.

${ }^{975}$ Se refería especialmente al Archiv für religionswissenschaft, publicado en Leipzig, y del cual Preuss era una de los redactores. Konrad Theodor Preuss a Lehmann-Nitsche, 02.04.1928, IAI, Carpeta N-0070 b 534 .

${ }^{976}$ Esta última institución inauguraba su edificio en 1885. Sus orígenes, como ha señalado Marina Rieznik, deben vincularse con las misiones internacionales que, en 1882, tenían por objetivo observar el pasaje de Venus por delante del Sol. En dicho año Dardo Rocha, gobernador de la provincia de Buenos Aires, dictaba un decreto provincial que destinaba la financiación de la misión del Bureau des Longitudes de Francia en la provincia a su cargo, alegando que los instrumentos utilizados serian utilizados, posteriormente, para la fundación de otro observatorio en la ciudad de La Plata. A partir de este antecedente el Poder Ejecutivo destinaría 200.000 pesos moneda nacional a la edificación del nuevo observatorio astronómico, nombrando como director a Francis Beuf (1834-1899), un ex oficial de la marina francesa y amplio promotor de los trabajos del Bureau des Longitudes en la observación de Venus. Rieznik 2010 a y 2010 b

${ }^{977}$ Félix Aguilar a Robert Lehmann-Nitsche. Legado Robert Lehmann-Nitsche, 06.09.1918 y 02.08.1919, IAI, Carpeta N-0070 b 19. 
1951), por entonces director del Observatorio Astronómico de Córdoba, sobre una serie de antiguas obras referidas al estudio de las estrellas y las constelaciones ${ }^{978}$.

Por último es preciso mencionar que los astrónomos también sabrán sacar provecho de los contactos de Lehmann-Nitsche al interior del mundo científico y universitario platense. Estos serán de utilidad para otros científicos alemanes con intenciones de estudiar o ejercer la docencia en la ciudad. En este sentido en 1911 el astrónomo alemán Friedrich Wilhelm Ristenpart, por ese entonces director del Observatorio Astronómico Nacional de Chile, le pedía a Lehmann-Nitsche que intercediera ante las autoridades necesarias a fin de que contrataran al astrónomo alemán Johannes Franz Hartmann (1865-1936) como Director del Observatorio Astronómico de la Plata, tras la renuncia del astrónomo italiano Francisco Porro Di Somenzi (1861-1937) ${ }^{979}$. Según Ristenpart el desarrollo de las ciencias astrofísicas en Sudamérica solo sería posible a través de científicos alemanes ${ }^{980}$.

De esta forma hacia junio de 1911 Lehmann-Nitsche recibía a través del Kaiserlich Deutsche Gesandtschaft copia de una carta del por entonces Ministro del Interior argentino, Indalecio Gómez (1850-1920), al Ministro de Alemania, el barón Hilmar Freiherr von dem Bussche-Haddenhausen (1867-1939). En dicha misiva se comprometía a encomendar al Senador González ${ }^{981}$ para que consultara con Lehmann-Nitsche la conveniencia o no de contratar a Hartmann para el puesto dejado vacante por Di Somenzi ${ }^{982}$. Inmediatamente Lehmann-Nitsche se pondrá en contacto con Hartmann, el cual por entonces se desempeñaba como profesor de la Georg-August-Universität y director del Universitätssternwarte de la ciudad alemana de Göttingen. Hartmann le hacia saber que ya había enviado una carta en la cual detallaba las condiciones bajo las cuales podría considerar aceptar el puesto. La falta de respuesta por parte de las autoridades correspondiente lo llevaba a declinar la propuesta ${ }^{983}$.

\footnotetext{
978 Insistirá particularmente con el libro Coelum Astrónomico-Poeticum (1662) del poeta y escritor protestante alemán Philipp von Zesen (1619-1689). Esta obra será una de las principales referencias históricas al momento de emprender un estudio histórico y cultural de la astronomía. Sin embargo la misma no se encontraba entre la amplia y valiosa colección bibliográfica del Observatorio Astronómico de Córdoba. Charles Dillon Perrine a Robert Lehmann-Nitsche. Legado Robert Lehmann-Nitsche, 27.07.1920, IAI, Carpeta N-0070 b 987. Para una historia del Observatorio Astronómico de Córdoba ver especialmente Rieznik 2010 a y 2010 b.

${ }^{979}$ Este se había desempeñado como director interino ante la renuncia de Di Somenzi.

${ }^{980}$ Recordemos que Ristenpart, una vez en su puesto, logrará intermediar a través de la legación alemana en Chile y el apoyo del astrónomo ruso Karl Hermann Struve (1854-1920), la inmediata contratación de los astrónomos alemanes Walter Zurhellen (1880-1916), como jefe de la sección de astrofotografía, y Richard Prager (1883-1945) a cargo de la sección de cálculos. Friedrich Wilhelm Ristenpart a Robert Lehmann-Nitsche. Legado Robert Lehmann-Nitsche, 11.06.1911, IAI, Carpeta N-0070 b 591. González Polanco, 2002.

${ }^{981}$ Si bien Gómez no detallaba el nombre del senador, para la fecha de la carta el único senador en su cargo con dicho nombre será Joaquín Víctor González (1863-1923), el cual será senador por la Rioja entre 1907 y 1916 . BDHHSNA.

${ }^{982}$ Kaiserlich Deutsche Gesandtschaft a Robert Lehmann-Nitsche. Legado Robert Lehmann-Nitsche, 03.06.1911, IAI, Carpeta N-0070 b 303.

983 Johannes Franz Hartmann a Robert Lehmann-Nitsche. Legado Robert Lehmann-Nitsche, 14.12.1911, IAI, Carpeta N-0070 b 303.
} 
Finalmente el puesto de director del Observatorio Astronómico de la Plata recaería en la figura del argentino Nicolás Bessio Moreno (1879-1916), el cual lo ocuparía hasta 1916. Dicho puesto sería ocupado por Hartmann en 1922, luego de un periodo de prueba de un año. Posteriormente este le detallaba a Lehmann-Nitsche los problemas presupuestarios para la compra de materiales adecuados para las investigaciones en el laboratorio y en el campo, contrariedades sobre las cuales, a pesar de explicarlas claramente ante el Consejo Superior de la universidad platense, no había tenido respuesta adecuada ${ }^{984}$. Lehmann-Nitsche, lo tranquilizaba al comentarle que similares percances le sucedían en el Museo de la Plata.

Hacia la segunda mitad del siglo XX las investigaciones estructuralistas en el campo de las ciencias sociales harían uso de las cartografías etnográficas a fin de reflexionar sobre la definición temporal de los mitos y las concepciones astronómicas.

En este sentido el antropólogo belga Claude Lévi-Strauss (1908-2009) afirmaba que "[...] la función significativa de la lengua no está ligada directamente a los sonidos mismos, sino a la manera en que los sonidos se encuentran combinados entre sî". Por lo tanto el objetivo del estudio estructuralista de los mitos suponía "[...] definir cada mito por el conjunto de todas sus versiones" $"$. Mitos y concepciones astronómicas indígenas serán visualizados como un medio formal de narrativa, dándole existencia material a elementos abstractos y subyacentes, propio del terreno de la mente. Este será el camino a partir del cual se buscará la "lectura" de estos registros materiales del pensamiento. En este sentido el antropólogo y filósofo francés Lucien Lévy-Bruhl (1857-1939), afirmaba que el llamado pensamiento "primitivo" se encontraba determinado por representaciones emocionales que durante mucho tiempo habían permanecido insondables para la antropología, algo que con el estudio relacional de la lengua, los mitos y la astronomía, emprendidos intensivamente a comienzos del siglo XX, se hacía visible ${ }^{986}$. En estas investigaciones los trabajos de Lehmann-Nitsche aportaran el considerable cuerpo de datos que había sabido recolectar. Sus reflexiones, sin embargo, pasarán prácticamente inadvertidos.

\footnotetext{
984 Ante los ojos de las personas de las personas encargadas de la administración del presupuesto universitario podía parecer excesivo un gasto de 4.000 a 5.000 pesos moneda nacional en un equipo de observación especial para viajes, instrumentos astrofísicos de la firma Carl Bamberg y un instrumento fotométrico Zeiss. Sin embargo Hartmann no concebía otra forma posible de fotografiar en forma completa los cielos del sur. Johannes Franz Hartmann a Robert Lehmann-Nitsche. Legado Robert Lehmann-Nitsche, 15.05.1922, IAI, Carpeta N-0070 b 303.

985 Lévi-Strauss 2009, p. 231-239.

${ }^{986}$ Lévy-Bruhl 1947, 1963.
} 


\section{La enseñanza de la Antropología}

\subsection{La enseñanza de la Antropología en la Universidad de Buenos Aires}

El 09 de agosto de 1821 era fundada la Universidad de Buenos Aires. El 18 de enero de 1881; en el contexto de un proceso de nacionalización de diversas instituciones como la Biblioteca Pública de la Provincia de Buenos Aires o el Archivo Provincial; pasara a la órbita del gobierno nacional. El 13 de febrero de 1896 se firmaba el decreto por el cual se establecía la Facultad de Filosofía y Letras $^{987}$. Como ha señalado Pablo Buchbinder la fundación de la misma se vinculará estrechamente a tres cuestiones: 1) la necesidad de contar con un espacio institucional a partir del cual conformar un ámbito público para la práctica y ejercicio de las humanidades, 2) la transformación del sistema educativo y su rol central en los procesos de formación de la nacionalidad y 3) las críticas hacia la falta de profesionalismo en los trabajos histórico-filosóficos ${ }^{988}$.

En marzo de 1896 se sancionaba el primer plan de estudios. El mismo abarcaba cuatro años. Los tres primeros correspondían a la licenciatura. Una vez obtenido este título podía accederse a cursar el último año que correspondía al doctorado ${ }^{989}$. Este primer plan sería modificado en 1899. Junto con nuevos requisitos para el ingreso los cursos se dividían en generales o especiales. A los del primer grupo se le agregaba un curso de lenguas clásicas y uno arqueología, mientras que los del segundo grupo podían optar por un grupo de asignaturas de Historia, Filosofía Literatura y un curso de Ciencias de la Educación. Una vez finalizados los cursos el grupo de los alumnos generales obtenían el título de Doctor en Filosofía y Letras. Aquellos que habían preferido los cursos especiales conseguían el título de Profesor en el área elegida.

Como sucediera años más tardes en los primeros cursos de antropología dictados por Lehmann-Nitsche, el interés por los estudios humanísticos será escaso. Las perspectivas de una rápida inserción laboral se reflejaban en el escaso número de inscriptos. Mientras que en 1898 facultades como Derecho y Medicina superaban holgadamente los 200 inscriptos, solo 13 lo hacían en Filosofía y Letras. Esta tendencia se mantendrá a lo largo de los años, y si bien podremos apreciar hacia comienzos del siglo XX un leve crecimiento del número de inscriptos en Filosofía, será igualado o superado por aquellos que lo hacían en el Profesorado. El ideal

\footnotetext{
${ }^{987}$ La misma había sido creada en 1882 . Con una existencia solo nominal sería eliminada en 1883 cuando la ley de presupuesto universitario prescindió de las partidas vinculadas a la misma. Buchbinder 1997, 2005; Halperin Donghi 1962.

988 Para profundizar las discusiones sobre estos puntos ver especialmente: Buchbinder 1997, 2005; Halperin Donghi 1962.

${ }^{989}$ Para detalles del plan de estudios ver AUBA 1896.
} 
romanticista del cultivo del saber y la práctica de la ciencia era dejado de lado por el pragmatismo de insertarse rápidamente en el mercado o bien mejorar la situación laboral.

En estos primeros años, y a pesar de las modificaciones introducidas, el carácter general del plan de estudios será enciclopedista, con una enseñanza intensiva y monográfica. Cada profesor delimitaba un tema concreto y lo desarrollaba a lo largo del curso. Muchas veces, como en el caso de Lehmann-Nitsche, los programas se repetían cada año con escasas o nulas modificaciones. El escaso número de asistentes justificaba la escasa innovación de los profesores. Esto será remarcado por Ernesto Quesada al momento de hacerse cargo del curso de Sociología en 1904; en reemplazo del abogado Antonio Dellepiane (1864-1939); al mismo tiempo que subrayaba la necesidad de darle una impronta y una orientación científica al estudio de las humanidades ${ }^{990}$. El ciclo de conferencias iniciado por Lehmann-Nitsche el año anterior pretendería cubrir esa insuficiencia.

El 15 de septiembre de 1902 la sección "Noticias Universitarias" del diario La Nación, daba cuenta de un pedido de Lehmann-Nitsche en el cual solicitaba a las autoridades de la Facultad de Filosofía y Letras de Buenos Aires dictar un curso de "antropología somática americana" dos veces por semana ${ }^{991}$. El redactor de la nota rememoraba los primeros trabajos de Lehmann-Nitsche, promoviendo el interés de los centros científicos europeos por las "razas prehistóricas de la América del Sur". El entusiasmo que buscaba transmitir la misma se debiera, posiblemente, a que el autor de la misma no fuera otro que el propio antropólogo alemán, buscando promocionar sus cursos ${ }^{992}$.

Días más tardes se anunciaba en las páginas de La Nación, La Prensa, y el Deutsche La Plata Zeitung la inauguración del curso libre de antropología, fijado para el día 25 de septiembre de dicho año ${ }^{993}$. La falta de quórum en las sesiones del Consejo Académico de la Facultad de Filosofía y Letras, sumado a una serie de problemas internos y la necesidad de asegurar "la mayor asistencia", postergaban el curso de Lehmann-Nitsche, en forma tentativa, para marzo de $1903^{994}$.

\footnotetext{
990 Buchbinder 1997.

${ }^{991}$ Hacia finales de 1902 adjuntaba Lehmann-Nitsche los programas de los cursos libres de "Antropología General" y "Etnología Argentina". Llamativamente este curso no será dictado. Robert Lehmann-Nitsche a Rodolfo Rivarola. Legado Robert Lehmann-Nitsche, 07.11.1902, IAI, Carpeta N N-0070 b 1033.

992 Dicha noticias también se encargaba de resaltar el papel de Lafone Quevedo y Ambrosetti; en las ramas de la lingüística y el folklore respectivamente; al momento de la difusión del conocimiento antropológico sobre la Argentina. La Nación 15. 09.1903, p. 4.

${ }^{993}$ La Nación 17.09.1903; La Prensa 17.09 y 23.09 de 1903; Deutsche La Plata Zeitung 22.09.1903.

994 Rodolfo Rivarola a Robert Lehmann-Nitsche. Legado Robert Lehmann-Nitsche, 29.10.1902, IAI, Carpeta N-0070 b 1033.
} 


\subsection{Las conferencias antropológicas de Robert Lehmann-Nitsche}

Finalmente en septiembre de 1903 comenzarían el dictado de esta serie de conferencias por parte de Lehmann-Nitsche (Fig. 44). El semanario argentino Argentinisches Tageblatt se encargaba, algunos días antes, de destacar ciertos elementos: la posibilidad de que las damas asistieran a dicho curso y el uso de proyecciones luminosas que facilitarían el entendimiento de los contenidos de la disertación ${ }^{995}$. El uso pedagógico de dicho aparato también llamará la atención de un columnista del matutino El Diario, destacando que el mismo era "ofrecido galantemente" por el médico Horacio G. Piñero (1869-1918), encargado del curso de Psicología en la Facultad de Filosofía y Letras $^{996}$. Este último y Lehmann-Nitsche sabrán intercambiar datos vinculados a los trabajos sobre el método experimental promovido por Wundt, el cual Piñero buscaba introducir en la Argentina ${ }^{997}$.

La conferencia de Lehmann-Nitsche será de entrada libre y gratuita, contando con un considerable número de asistentes. La misma comenzaba con un intento de definir en forma clara la antropología, las distintas especializaciones, el campo de trabajo y finalmente su significado específico como ciencia ${ }^{998}$. Posteriormente se pasaría al tema central de la misma: la pigmentación en las distintas razas. A fin de ilustrar adecuadamente sus ideas centrales se valdrá de fotografías, proyecciones luminosas y tablas cromáticas de su laboratorio. De esta forma podrá ilustrar la histología del iris y del cutis, la distribución pigmentaría en las diferentes partes del cuerpo y en las distintas razas ${ }^{999}$.

La prensa local estaba segura que la serie de conferencias brindada por LehmannNitsche sería “[...] utilísima para la alta cultura intelectual y científica del país"1000. Esto llevaba a que ciertas editoriales le hicieran notar al por entonces Ministro de Educación argentino Juan

995 Argentinisches Tageblatt 24.09.1903. Sobre la asistencia de las mujeres y los cursos libres ver Buchbinder 1997. Con respecto al uso de las proyecciones luminosas en la enseñanza universitaria ver especialmente García S. 2010 a.

996 El Diario, 23.09.1903.

997 En este sentido llevará adelante una serie de experimentos psicofisiológicos, estudios de fisiología general -trabajos que desarrollaba ya en el Laboratorio de Fisiología de la Facultad de Ciencias Médicas de Buenos Aires- y experimentos "psicométricos", destinados a medir la duración de los actos psíquicos a través del estudio de los tiempos de reacción. Hay que agregar también la existencia de un específico instrumental para estudios antropométricos, que apuntaban a determinar la "fórmula física del sujeto" a través de la medición de aspectos físicos en grandes cantidades de sujetos. Arnaiz et.al 1997; Navarro 1911; Piñero 1901.

998 Afirmaba Lehmann-Nitsche que "La antropología era la ciencia del hombre, como la zoología es la ciencia del reino animal y la fitología del reino vegetal”. A partir de esto proponía un encadenamiento evolutivo de las ciencias y la posición privilegiada que la antropología debía detentar, ya que si “[...] las investigaciones comienzan con la fitología que comprende el estudio de las plantas como los seres organizados más inferiores y sigue con la zoología que abarca el reino animal, ó seres orgánicos más desarrollados, para terminar con la ciencia antropológica que estudia al hombre como el más completo de todos los seres de la escala zoológica, la especie superior". Buenos Aires 28.09.1903, p. 7; La Prensa 25.09.1903, p. 5; Buenos Aires 28.09.1903, p. 7.

999 Caras y Caretas 03.10.1903; Deutsche La Plata Zeitung 25.09 y 27.09 de 1903; La Nación 27.09.1903; La Prensa 26.09.1903.

${ }^{1000}$ La Nación 27.09.1903, p. 6. 
Ramón Fernández (1857-1911) la anomalía que suponía que ante el gran numero de interesados y el prodigioso material existente no existiera una cátedra de antropología en ninguna universidad argentina ${ }^{1001}$. Este último punto era detallado por uno de los tantos periodistas que presenciarán la primera conferencia de Lehmann-Nitsche "Este país, se presta para estudios de esta naturaleza, pues hay aquí diferentes razas que ofrecen posibilidades, lo cual no pasa en los países europeos, donde por lo general, hay mucha homogeneidad como raza entre los habitantes de una nación"1002.

El papel de la prensa en este primer ciclo de conferencias brindado por LehmannNitsche será fundamental no solo al promocionar las mismas, sino al brindar precisos resúmenes sobre los principales puntos desarrollados por él. De esta forma la enseñanza de la antropología se continuaba a través de las columnas periodísticas. La prensa destacaba estas conferencias como parte esencial de investigaciones realizadas por otros estudiosos. Al momento de exponer sobre la variedad de cabello en las distintas razas humanas, las columnas periodísticas presentaban la charla de Lehmann-Nitsche como una "continuación lógica" de aquellos trabajos realizados en África por el fisiólogo y antropólogo alemán Gustav Theodor Fritsch (1838-1927), junto con aquellas desarrolladas por el lingüista austriaco Friedrich Müller (1834-1898) ${ }^{1003}$. El énfasis de las notas en mostrar la importancia de las investigaciones de Lehmann-Nitsche en el conjunto de saberes antropológicos, nos permite suponer a este último como autor de las mismas.

La importancia de la promoción ejercida por la prensa puede constatarse en la tercera de las conferencias. Esta trataría sobre fisonomía y el cráneo en las distintas razas, y serie ampliamente publicitada ${ }^{1004}$. La presencia de un público mayor, en comparación a las otras conferencias se vincularía a la posibilidad de observar y manipular una serie de cráneos, moldes y fotografías ${ }^{1005}$ que Lehmann-Nitsche había llevado a fin de ilustrar su lectura sobre los debates antropológicos acaecidos desde la segunda mitad del siglo XIX en torno a los acuerdos craneométricos. A partir del uso de estos elementos se acentuaba ante los asistentes la importancia de los estudios craneológicos al momento de estudiar y clasificar las razas humanas. Si bien era posible una aproximación al momento de observar las características externas, estas solo eran evidencia suficiente, según Lehmann-Nitsche, para aquellas personas que carecían de una formación profesional en antropología. Finalmente se aclaraba ante los

\footnotetext{
1001 Deutsche La Plata Zeitung 27.09.1903.

1002 Buenos Aires 28.09.1903, p. 7.

1003 Deutsche La Plata Zeitung 02.10.1903; La Prensa 02.10.1903.

1004 Buenos Aires 05.10.1903; Deutsche La Plata Zeitung 04.10.1903; La Nación 03.10.1903; La Prensa 03.10 .1903

1005 Estas últimas correspondían a las empleadas por el criminalista francés Alphonse Bertillon en sus trabajos Ethnographie moderne: les races sauvages (1883) y La Photographie judiciaire, avec un appendice sur la classification et l'identification anthropométriques (1890).
} 
asistentes que aquellos cráneos con rasgos primitivos depositados sobre la mesa, podían ser observados, si uno prestaba atención, en individuos que poblaban actualmente las ciudades ${ }^{1006}$.

Similar sorpresa recibirían tiempo después los asistentes al momento de poder comparar un cráneo europeo y otro patagón, en el contexto de una conferencia sobre la clasificación de las razas humanas. Mientras que el primero "presenta a simple vista y observación algo casi artístico, el cráneo del indígena por su forma grosera y de líneas gruesas dice a la distancia que

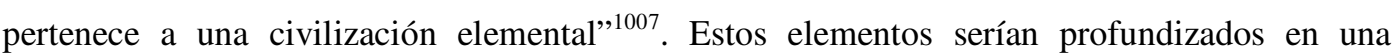
conferencia que Lehmann-Nitsche brindará en el Centro Archipiélago Canario, oportunidad en la cual disertara sobre el origen y desarrollo de las poblaciones canarias durante la época de la conquista española ${ }^{1008}$.

La posibilidad de que los asistentes pudieran manipular instrumentos antropométricos será otro de los elementos que jugarán a favor de la alta concurrencia de los asistentes. En una conferencia sobre los diferentes tipos de ojos, boca y nariz que podían observase en las razas humanas, los asistentes serán invitados a observar la colección de láminas cromolitográficas, utilizándolas a su vez para realizar una clasificación cromática entre ellos mismos. Luego de este acercamiento a la práctica antropológica Lehmann-Nitsche obsequiará a cada uno con las tarjetas postales realizadas a partir de las fotografías de indígenas de Tierra del Fuego que el mismo efectuara en su viaje de $1902^{1009}$. Dicha fotografía correspondía específicamente a uno de los indígenas que, oficiando como ayudante en la Comisaría de Río Grande, había colaborado con Lehmann-Nitsche durante su trabajo en el campo, haciendo de traductor y mediador con otros indígenas. La postal presentaba al individuo como un "Indio Ona" y agregaba "caso típico de ojo mongólico". La misma presentaba la siguiente leyenda en la parte inferior "Recuerdo del Curso libre de Antropología dado en los meses de Setiembre, Octubre, y Noviembre de 1903 en la Facultad de Filosofía y Letras de Buenos Aires por el Dr. R. Lehmann-Nitsche"1010 (Fig. 45).

Otro de los elementos que suscitará la concurrencia masiva y el asombro de los asistentes será la presencia de individuos vivos sobre los cuales realizar estudios antropológicos. Al momento de ofrecer su conferencia sobre antropometría, uno de los principales puntos de su programa científico, las teorías y las demostraciones prácticas serán ilustradas a través de la presencia del individuo más alto y al más pequeño de la Capital Federal, algo que despertaba el entusiasmo de los periódicos que cubrían las conferencias de Lehmann-Nitsche. Por un lado se

${ }^{1006}$ Deutsche La Plata Zeitung 10.10.1903; La Prensa 17.10.1903.

1007 Buenos Aires 26.10.1903; Deutsche La Plata Zeitung 23.10.1903; La Nación 24.10.1903, p. 6; La Prensa 23.10.1903.

${ }^{1008}$ Buenos Aires 26.10.1903; Deutsche La Plata Zeitung 24.10.1903; El Día 15.10.1903; Memorándum del Centro Archipiélago Canario de La Plata 1903.

1009 Deutsche La Plata Zeitung 18.10.1903; La Prensa 17.10.1903.

${ }^{1010}$ Legado Robert Lehmann-Nitsche, IAI, Carpeta N-0070 s 31. 
presentaba al señor Karl Grebe, un ciudadano alemán de 1.98 metros de altura. El contraejemplo recaía en la persona de Manuel Jesús Alarcón, ciudadano chileno con solo 1.16 metros de altura $^{1011}$ (Fig. 46).

El exotismo despertado por la variabilidad humana en el público en general será uno de los elementos que dará un fuerte impulso a los cursos libres de Lehmann-Nitsche, el cual conferencia tras conferencia buscaba que los ejemplos que ilustraban sus presentaciones no solo fueran explicativos y convincentes, sino principalmente que propiciaran un efecto de curiosidad y gusto por lo exótico entre los asistentes. Gracias a la difusión hecha por esto, junto con la extensa propaganda dada por la prensa escrita, los cursos crecían en número de concurrentes, tal vez no maravillados por las lecturas ofrecidas por Lehmann-Nitsche, sino expectantes de ver que nuevos "fenómenos" ofrecería el conferenciante.

La repercusión de dicha demostración pública llevará a la elaboración de una nota especial publicada en el segmento ilustrado del diario La Nación. En la nota titulada "Enanos y gigantes", se daba cuenta del acertado "espectáculo" montado por Lehmann-Nitsche a fin de causar la mayor impresión entre los asistentes. Primeramente presentará a Alarcón, y a medida que disertaba sobre los diversos factores que influyen y determinan el tamaño corporal, hará ingresar a Grebe. De esta forma la escasa talla de Alarcón "se hacía más notable", dando lugar que entre el público las personas comentarán como este parecía aún más pequeño ${ }^{1012}$. Una vez finalizada la conferencia, los periodistas de La Nación se proponían el objetivo de encontrar una persona más pequeña que Alarcón.

Gracias a su "olfato reportivo (sic)" los periodistas conocerán al chileno Juan de Díaz Pacheco que "[...] en cuanto a la edad lo deja tamañito a Alarcón, y no digamos nada respecto a la altura" ${ }^{\prime 1013}$. Pacheco tenía 58 años de edad y según los periodistas medía solamente 78 centímetros, algo que le había hecho ganar el apodo de "general liliputiense". Profundizando la investigación se revelaba un detalle no aclarado por Lehmann-Nitsche y que pone en evidencia el fuerte vínculo entre la antropología y los empresarios vinculados a las empresas de entretenimiento con base en la exhibición de lo exótico. Tanto Pacheco como Alarcón trabajaban juntos en un teatro de marionetas propiedad del ecuatoriano Nicanor Checa. Habiendo brindado espectáculos en Ecuador, Perú, Bolivia y Chile, la compañía de Checa llegaba a la Argentina a fin de que Alarcón y Pacheco, las dos estrellas centrales de su espectáculo, fueran exhibidos en distintas partes del país. Como cualquier empresario deseoso de generar buenas ganancias para su negocio, la primera parada de la gira había sido Buenos Aires (Fig. 47).

${ }^{1011}$ La Nación 30 y 31 de octubre 1903; Deutsche La Plata Zeitung 31.10.1903; La Prensa 30 y 31 de octubre de 1903.

${ }^{1012}$ La Nación 05.11.1903.

${ }^{1013}$ Ibídem p. 11. 
Por un lado Checa obtendrá una promoción gratuita a través del curso de LehmannNitsche y la repercusión generada en la prensa. Por otro lado el estudioso alemán contaba con muestras representativas para ilustrar sus clases, satisfaciendo el gusto por la observación de lo exótico y lo desconocido por parte del público de las ciudades. Los periodistas que habían desentramado esta vinculación entre antropología y entretenimiento se encargaran de remarcar que Alarcón y Pachecho "[...] nada tienen de personajes sobrenaturales, por más que, de acuerdo con la tradición, se quisiese dotarlos de algún poder o habilidad extrahumanos"1014.

En esta serie de conferencias también participarán especialistas de diversas áreas. Por un lado servía para cubrir las deficiencias de Lehmann-Nitsche en diversos temas, ilustrando de forma más detallada diversos puntos de su programa. Por otro lado ampliaba el número de personas que acudían a las mismas, motivados por ver las demostraciones de los colaboradores. Este será el caso del escultor alemán Richard Aigner (1867-1925), el cual asistirá a LehmannNitsche al momento de demostrar las distintas formas de calcular las proporciones del cuerpo humano, en el contexto de su conferencia sobre la evolución histórica de los distintos métodos $\operatorname{antropométricos}^{1015}$. Aigner contaba para la fecha con un considerable reconocimiento del medio local por haber sido el realizador de la escultura art déco de la tumba de Rufina Cambaceres Bacichi (1883-1902) ${ }^{1016}$. La asistencia de Aigner se justificaba también en la concepción de la antropometría que Lehmann-Nistche buscaba transmitir al público. El estudio histórico de la misma revelaba sus orígenes lejos "[...] de los gabinetes de hombres de ciencia", ya que la misma nacía "[...] en el taller del artista" ${ }^{1017}$, la cual luego se alejará de la búsqueda del ideal de belleza armónica, ingresando al campo de la ciencia antropológica para ser desarrollada "[...] con criterio de naturalista" $" 1018$.

El avance de la antropología no puede separarse de la evolución de campos artísticos como la escultura, la pintura o el grabado, donde el perfeccionamiento y la mejora de técnicas de reproducción y representación del cuerpo humano borra los supuestos límites entre ambos espacios. De esta forma aquellos artistas con notables capacidades escultóricas y/o pictóricas tendrán un vínculo estrecho con algunos estudiosos de la época, oficiando en algunos casos como nexos entre estos.

\footnotetext{
1014 Ibídem.

1015 Deutsche La Plata Zeitung 06.11.1903; La Prensa 07.11.1903.

${ }^{1016}$ Hija del escritor y político argentino Eugenio Modesto de las Mercedes Cambaceres Alais (18431888) y la bailarina italiana Aloysia Stéphana Bacichi (1855-1924). Fallecida la noche de su decimonoveno cumpleaños será enterrada el día siguiente en el cementerio de la Recoleta. Un tiempo después uno de los cuidadores notificaba que encontró el ataúd de Rufina abierto y con la tapa rota. Esto dará lugar a muchas especulaciones e historias. La versión oficial declara que fue un robo, ya que la difunta fue sepultada con sus mejores joyas. Otras versiones sugieren que Rufina había sufrido catalepsia y por lo tanto habría sido sepultada viva, siendo las marcas en el ataúd resultado de sus esfuerzos por salir del mismo.

${ }^{1017}$ Buenos Aires 09.11.1913, p. 9.

1018 Ibídem.
} 
Los trabajos de Aigner lo llevarán a pasar una temporada en München. En esta se ponía en contacto con el médico Johannes Rückert (1854-1923), el cual se desempeñaba como profesor de anatomía descriptiva y topográfica de la Ludwig-Maximilians-Universität de München y era conservador de la Neue anatomische Anstalt. Ante el encargo de Rückert de una serie de moldes y reproducciones de tipos anatómicos sudamericanos, Aigner lo pondrá en contacto con Lehmann-Nitsche. Al mismo tiempo Aigner le comunicaba a este último sobre una nueva serie de técnicas escultóricas galvanoplásticas, las cuales permitían detallar de forma más realista las características anatómicas humanas, algo que Aigner consideraba de gran importancia tanto para el arte escultórico como para la antropología ${ }^{1019}$. El registro de la correspondencia entre Aigner y Lehmann-Nitsche datas hasta 1928. El tema de las mismas será, principalmente, nuevas técnicas de reproducción y grabado que Aigner iba aprendiendo en sus viajes a Europa y que rápidamente comunicaba a Lehmann-Nitsche, el cual costeará, en algunas oportunidades, parte de los costos de viaje $\mathrm{e}^{1020}$.

El primer ciclo de conferencias era cerrado con una visita al Museo de La Plata. Parte de esta elección estará supeditada al tema elegido por Lehmann-Nitsche: el indígena fósil argentino y el actual. El material necesario para ilustrar dicha exposición se tornaba imposible de transportar hasta la Facultad de Filosofía y Letras de Buenos Aires. No bastaba para esta clausura la simple exhibición de unos cuantos cráneos, moldes o fotografías. La necesidad de exponer largas series de cráneos, esqueletos, y elementos materiales construidos por los indígenas justificaba el cambio de lugar. Conjuntamente con este motivo se revelaba otro en los anuncios de la prensa: la concurrencia de "los hombres de ciencia de la metrópoli".

En su primera incursión en el mundo de la enseñanza Lehmann-Nitsche buscaba dejar una buena impresión ante sus colegas, haciendo gala de las vastas colecciones antropológicas depositadas en Museo de la Plata y del potencial de dicha institución en el desarrollo científico argentino. Sin embargo estos deseos no se consumarán en forma total ${ }^{1021}$. A pesar de que todos los medios aclaraban que la entrada al museo era gratuita y que a la conferencia podían asistir todas aquellas personas que lo desearan, uno de los diarios de la época se encargaba de señalar la asistencia "[...] un público selecto, si bien poco numeroso" ${ }^{1022}$, compuesto principalmente por hombres de ciencia y un reducido grupo de estudiantes ${ }^{1023}$. Como podemos ver, aquellas notas que destacaban la amplia concurrencia de personas a las conferencias y el entusiasmo de las mismas parecían no coincidir con las verdaderas repercusiones que estaban logrando.

1019 Richard Aigner a Robert Lehmann-Nitsche. Legado Robert Lehmann-Nitsche, 02.06.1905, IAI, Carpeta N-0070 b 3.

${ }^{1020}$ Richard Aigner a Robert Lehmann-Nitsche. Legado Robert Lehmann-Nitsche,16.03.1925, IAI, Carpeta N-0070 b 3.

${ }^{1021}$ El Día 15.11.1903; El Mercurio 15.11.1903; La Prensa 15.11.1903

${ }^{1022}$ El Día 16.11.1903, p. 5.

${ }^{1023}$ Buenos Aires 16.11.1903; El Gladiador 20.11.1903. 
A pesar de esto las autoridades de la Facultad de Filosofía y Letras de Buenos Aires estarán muy complacidas con los resultados de este primer ciclo de conferencias, los cuales habían sobrepasado sus expectativas. A fin de poder colaborar en forma más activa con estos solicitaban a Lehmann-Nitsche que les remitiera una lista de las obras que considerará fundamentales para su curso, "[...] en el deseo de hacer de la biblioteca de esta facultad un instrumento de trabajo a la altura de las necesidades actuales de la enseñanza superior [...]"1024. Como podemos apreciar en este pedido de Miguel Cané, el estado de las bibliotecas universitarias con respecto al material antropológico distaba de ser el ideal, y particularmente con la ausencia de obras en alemán, consideradas por Lehmann-Nitsche las más optimas al momento de la enseñanza. La demora en los procesos de traducción perjudicaba mantenerse actualizados con respecto a las últimas novedades. Sin embargo Cané le pedirá que “[...] en lo que respecta á las obras no escritas en idiomas latinos, agradecería me indicara las traducciones que de ellas existen en francés, italiano ó español"1025. Los estudiantes, años más tarde, solicitarían a las autoridades universitarias la posibilidad de contar con cursos complementarios de alemán, a fin de no verse demorados por las reglas del mercado editorial ${ }^{1026}$.

La supuesta buena repercusión de la primera serie de conferencias llevará a LehmannNitsche a repetir dicha experiencia al año siguiente. Estas formarán parte de un ciclo de lecturas anunciadas por la prensa local como "cursos especiales de historia natural". A diferencia del año anterior, las autoridades de la Facultad de Filosofía y Letras de Buenos Aires, decidían asignarle a Lehmann-Nitsche la cantidad de 50 pesos moneda nacional por cada conferencia dictada, aclarando que las mismas debían dictarse a lo largo de dos meses, a razón de una conferencia semanal ${ }^{1027}$.

La prensa local tendría nuevamente una significativa participación en la difusión de las clases, contribuyendo considerablemente al incremento del número de asistentes. En este sentido el diario La Prensa divulgaba bajo el nombre de "cursos especiales de ciencias naturales" el programa temático de las conferencias, a fin de proporcionarles a los interesados una “[...] guía segura para su asistencia a los cursos"1028. En la misma puede observarse el tema

\footnotetext{
${ }^{1024}$ Miguel Cané a Robert Lehmann-Nitsche. Legado Robert Lehmann-Nitsche, 28.11.1903, IAI, Carpeta N-0070 b 1033.

1025 Ibídem.

${ }^{1026}$ García S. 2010 a.

1027 Horacio G. Piñero a Robert Lehmann-Nitsche. Legado Robert Lehmann-Nitsche, 07.05.1904, IAI, Carpeta N-0070 b 1033.

${ }^{1028}$ Los conferenciantes serían: Samuel de Madrid el cual daría nociones generales de los sistemas óseo y muscular en los humanos. Juan Bautista Ambrosetti trataría sobre arqueología general y argentina. Fernando Lahille disertaría sobre zoología general, complementadas con las del entomólogo francés Jean Brèthes (1871-1928) y las de Eduardo Ladislao Holmberg (1852-1937). El botánico italiano Carlo Luigi Spegazzini (1858-1926) brindaría una introducción general a la Botánica. El ingeniero argentino Eduardo Aguirre (1857-1923) expondría sobre mineralogía y geología. Florentino Ameghino ofrecería dos conferencias paleontológicas. La Prensa 23.01.1904, p. 8.
} 
central que guiará las conferencias de Lehmann-Nitsche: el hombre prehistórico y su antigüedad en la Argentina.

El objetivo principal del programa ofrecido por la Facultad de Filosofía y Letras de Buenos Aires era ofrecer un panorama general a aquellas personas ajenas al mundo de las "ciencias naturales" deseosas de introducirse en su estudio pero indecisas al momento de decidirse sobre emprender o no una carrera dentro esta. La formación y capacitación de personas interesadas en la antropología era una idea que entusiasmaba a Lehmann-Nitsche, tal como se lo comentaba a su madre. Por un lado podría dar forma a un grupo de alumnos que lo auxiliarán y continuarán con su plan de trabajo. Al mismo tiempo aquellos individuos que solo desearán dedicarse en forma amateur obtenían una serie de herramientas que los guiaban a la hora de recolectar valiosos datos para las investigaciones de Lehmann-Nitsche. Tal como se lo transmitiera a su madre su idea era reducir, en cierta manera, la pérdida de valiosa información por causa de personas con buenas intensiones y deseos de colaborar, pero sin la mínima instrucción básica ${ }^{1029}$. Como veremos más adelante este proyecto jamás se concretará.

El 23 de abril de 1904 en el discurso de asunción de las nuevas autoridades de la Facultad de Filosofía y Letras de Buenos Aires, el escritor y político argentino Miguel Cané (1851-1905) se congratulaba que bajo su gestión las aulas de la universidad haya iniciado “[...] el estudio de las razas humanas a la luz de los últimos resultados obtenidos por la investigación científica" ${ }^{1030}$. También señalaba la "coincidencia realmente feliz" de que al mismo tiempo que Lehmann-Nitsche daba inicio a los estudios filológicos y antropológicos, Samuel Lafone Quevedo abriera su primer curso de arqueología americana, a la cual Cané describía como una "poderosísima ciencia auxiliar","031.

Al mismo tiempo observaba que las lecturas de Lafone Quevedo y Lehmann-Nitsche constituían las bases para el estudio científico del pasado en América, y principalmente para su enseñanza, teniendo la institución de la calle Viamonte 430 el privilegio de ser la primera en el continente que ofrecía un espacio formal para su enseñanza, por lo cual, señalaba Cané "[...] debemos hacer todo lo que este en nuestro poder por radicar estos estudios en esta Facultad, incorporándolos definitivamente a nuestro plan"1032. En este sentido en su sesión del 4 de mayo de 1904, el Consejo Académico de la Facultad de Filosofía y Letras de Buenos Aires aprobaba el programa del curso que Lehmann-Nitsche dictaría ese mismo año. El mismo se basaba por completo en la serie de charlas paleoantropológicas brindadas en el contexto de los "cursos especiales de historia natural" organizados anteriormente por la mencionada casa de estudios.

${ }^{1029}$ Robert Lehmann-Nitsche a Ida Lehmann-Nitsche. Legado Robert Lehmann-Nitsche, 24.03.1904 y 18.04.1904, IAI, Carpeta N-0070 b 1295.

${ }^{1030}$ RUBA 1904, p. 6.

1031 Ibídem.

1032 Ibídem. 
Dicho curso sería de entrada libre tanto para los alumnos de la facultad como para aquellos interesados particulares ${ }^{1033}$.

El papel de la prensa, en este segundo ciclo de conferencias, será más preponderante. Las páginas de los diarios serán el espacio preferido al momento de discutir el controversial tema elegido por Lehmann-Nitsche. Entre las primeras polémicas podemos mencionar aquella acontecida entre el Deutsche La Plata Zeitung y el Argentinisches Tageblatt. El primer diario afirmaba lo novedoso de la enseñanza de la paleoantropología en las aulas universitarias sudamericanas como así también en el uso de dicha denominación para el estudio paleontológico de los seres humanos ${ }^{1034}$. Si bien estaban en lo cierto con respecto al primer punto, no lo era así con el último. Esto será remarcado por el Argentinisches Tageblatt, el cual en una corta columna señalaba que esta "nueva" palabra aparecía en la cuarta edición del Meyers Konversations-Lexikon ${ }^{1035}$. También señalaban como dato anecdótico una conferencia paleoantropológica ofrecida en 1870 por el médico y pedagogo alemán Otto Dreßler y los cursos de paleoantropología dictados por el anatomista polaco Bernhard Rawitz (1857-1932) en la Universität zu Berlin unos años después ${ }^{1036}$.

El Deutsche La Plata Zeitung se encargaba de remarcar que aquellas rectificaciones aparecidas en las páginas del Argentinisches Tageblatt podían deberse a una posible confusión de sus redactores con el concepto de prehistoria o el de "Vorgeschichte" usado por los franceses, haciendo referencia a las discusiones llevadas adelante en 1867 por parte de los miembros de la Société d'anthropologie de Paris. En dicha columna periodística se hacia notar además que la combinación de vocablos utilizadas por los estudiosos al momento de definir un área de la ciencia en cursos para principiantes no merecían una discusión tan profunda. Al mismo tiempo remarcaban que acorde a los vocablos utilizados por otras disciplinas de las ciencias naturales, Lehmann-Nitsche hacía uso del adjetivo "palaios" para referirse en la actualidad a las formas fósiles de la especie humana, tal como la palabra paleoetnología de la tradición francesa e italiana refería a la etnología de las razas humanas extintas, observando de esta forma la separación entre el estudio físico y psíquico del hombre en tiempos geológicos antiguos. Según el redactor de esta nota, afirmar que el concepto de paleoantropología y el uso que se hiciera de este hacia 1870 en las aulas de la Universität zu Berlin era el mismo que se

${ }^{1033}$ La Prensa 09.05.1904; La Nación 09 y 12 de mayo de 1904.

1034 En original "Ebenso wie dieses Wort ganz neu, ist es auch das erste Mal, daß eine derartige Vorlesung an irgendeiner Hochschule der Welt gehalten wird". Deutsche La Plata Zeitung 10.05.1904, p. 6.

${ }^{1035}$ Enciclopedia iniciada por el editor e industrial alemán Carl Joseph Meyer (1796-1856).

${ }^{1036}$ Cerraban esta nota rectificatoria aclarando que en estas ocasiones las lecturas habían estado pensadas y orientadas especialmente para las damas, explicando que "[...] die Herren Studenten und Wissenschaftler, die diesen Vortrag angeret, scheinen mehr faible für die Damen zu haben, als für den angeregten Vortrag"Argentinisches Tageblatt 11.05.1904, p. 7. Resaltado en el original. 
discutía en las clases de Lehmann-Nitsche, era negar el avance y el desarrollo del conocimiento científico $^{1037}$.

La respuesta del Argentinisches Tageblatt no se haría esperar. El redactor de la nota, ateniéndose al significado gramatical de cada lexema usado en la construcción de la palabra "paleoantropología" tal como sugería el Deutsche La Plata Zeitung, hacía notar en forma muy irónica que tanto "palaios" como "anthropologie" provenían del antiguo griego, por lo cual su uso por parte de Lehmann-Nitsche para describir el estudio de las formas fósiles de la especie humana, no suponía novedad alguna, como así tampoco remarcar que este era histórico, somático y físico, ya que todos los conceptos generales dentro de la historia natural revertían dicha cualidad. El redactor de la nota citaba diversos autores que habían escrito sobre la prehistoria y la paleoantropología desde la primera mitad del siglo XIX, como Nicolás Joly (1812-1885), para remarcar que Lehmann-Nitsche no podía hablar sobre la introducción de un nuevo concepto al campo de las ciencias, sino este debía limitarse a una "contribución", una "corrección" o una "contemplación" sobre las tesis principales de una vieja disciplina como la paleoantropología ${ }^{1038}$.

La discusión lejos de terminar recrudecía con la respuesta publicada en el Argentinisches Tageblatt. En un artículo se admitía el uso de la palabra "paleoantropología" en 1870. Sin embargo se aclaraba que para esta época se desconocía la $4 / 5$ partes del conocimiento que revestía dicha disciplina en la actualidad. En forma sarcástica la redactora de la nota, bajo el seudónimo de "Flora", hacia notar a los redactores que esto era igual a afirmar que 1/5 de la misma ya había sido "fundada" (gegründet), aceptando por lo tanto la antigüedad del concepto que ellos querían presentar como novedoso ${ }^{1039}$.

Mientras estas fervorosas discusiones tenían lugar la discusión sobre el proceso evolutivo del hombre despertaría nuevas controversias, principalmente luego de la presentación de unos calcos de los cráneos y restos fósiles europeos, junto con una serie de proyecciones luminosas y material paleontológico y geológico de las colecciones del Museo de la Plata, cedido por Moreno ${ }^{1040}$. A partir del uso de estos materiales se aseveraba que no existían motivos para separar al hombre del conjunto de los demás mamíferos, siendo su estudio zoológico, anatómico y fisiológico totalmente plausible ya que este, al igual que los demás organismos bióticos del mundo, obedecía la misma "ley irrefutable de evolución" 1041.

${ }^{1037}$ Deutsche La Plata Zeitung 15.05.1904

${ }^{1038}$ Argentinisches Tageblatt 16.05.1904.

1039 Argentinisches Tageblatt 18.05.1904.

${ }^{1040}$ Estos correspondían a los hallazgos de Eguisheim y de la cueva de Cro-Magnon en Francia, el cráneo y los restos óseos de Galley Hill y Brunn en Inglaterra, los restos óseos de Grimaldi en Francia y finalmente los restos de industria lítica de Boehmia en la República Checa. La Nación 24.05 y 07.06 de 1904; La Prensa 24.05, 04.06, 14.07.1904, 21.07.1904, 26.07.1904, 27.07 de 1904.

${ }^{1041}$ La Prensa 05.06.1904, p. 8. 
Esto dará lugar a la aparición de notas y suplementos especiales en la prensa local, la cual contribuía a la difusión y a la instalación del "eternamente curioso tema del mono-hombre o hombre-mono"1042. En una nota especial del diario La Nación en la cual se ofrecía una "reconstrucción extraordinaria" de los restos hallados en Java por Dubois, pudiéndose apreciar dos ejemplares de los supuestos "ancestros" del hombre en una escena familiar ${ }^{1043}$. Esto tendrá por resultado un folleto especial del pastor bautista suizo Pablo Besson (1848-1932), el cual no compartía las explicaciones científicas sobre el origen y la evolución del hombre ${ }^{1044}$. Citando las explicaciones de Burmeister en torno al principio de la invariabilidad de las especies y la ley de inmutabilidad, remarcaba que ambos se encontraban establecidos con anterioridad en los capítulos del Génesis de la Biblia. Según Besson "Exagerando las semejanzas, las analogías y acortando las distancias, las diferencias entre los animales y los hombres, el doctor LehmannNitsche busco a nuestro padre-mono"1045. A fin de demostrar su punto, Besson hará uso de todos los argumentos esgrimidos por Lehmann-Nitsche, adaptándolos a su marco explicativo religioso. De esta forma no negará la recapitulación ontogenética de la filogenia, pero aclaraba que "[...] el hombre debe comenzar por el estado más inferior, y recorrer las fases del fetus como el pez, el cerdo o el gibon; pero a proporción que va desarrollándose se distingue más y más del simiesco el fetus humano; repasa toda la escala de la naturaleza organizada y si no para en la estación del mono y le sobresale, es que no fue engendrado a la semejanza del mono, sino conforme a la imagen del primer hombre" ${ }^{, 1046}$.

El folleto seguía desplegando esta idea de Besson, el cual explicaría las diferencias y semejanzas evolutivas entre el hombre y los monos antropomorfos a partir de elementos como la dentición, el volumen cerebral, la posición de los ojos o la posición erecta. Valiéndose de las críticas de Burmeister en torno a la teoría darwiniana de la evolución, Besson negaba rotundamente la transformación de las especies. A las explicaciones materialistas del zoólogo y filosofo alemán Ernst Heinrich Philipp August Haeckel (1834-1919) o del anatomista y zoólogo ruso Ilja Iljitsch Metschnikow (1845-1916) en cuanto al papel desempeñado por la genética y el azar en la aparición del hombre anatómicamente moderno, anteponía Besson la voluntad divina, la cual explicaba la aparición del hombre "con alma viviente", verdadero elemento que lo

\footnotetext{
${ }^{1042}$ La Nación 30.06.1904.

1043 Ibídem.

1044 Nacido cerca de Neuchatel (Suiza) hijo de un predicador y una practicante protestante. Estudiará teología en la Université de Neuchâtel bajo la guía del teólogo suizo Frédéric Louis Godet (1812-1900). Trasladándose a Alemania estudiará con el teólogo y filósofo Lobegott Friedrich Constantin von Tischendorf (1815-1874) y el teólogo luterano Christoph Ernst Luthardt (1823-1902). Separándose de la Iglesia protestante, viajará a Francia como evangelista entrando en contacto con una pequeña congregación bautista. En 1881 un grupo de creyentes bautistas suizo-franceses, miembros de una pequeña colonia agrícola en Santa Fe (Argentina), solicitaban su ayuda para instaurar la obra bautista en el país, arribando Besson al país ese mismo año. A finales de 1882 se trasladó a Buenos Aires, donde se destacó por su lucha a favor de la libertad religiosa y de cultos.

1045 Besson 1904, p. 1.

1046 Ibídem p. 2.
} 
distinguía de los demás seres vivos y no las particularidades anatómicas ${ }^{1047}$. El alma, como soplo divino que conectaba a los seres humanos con el Creador, se tornaba un elemento imposible de estudiar, ya que su comprensión se encontraba por fuera de las capacidades del hombre, algo que, ante los ojos de Besson, Lehmann-Nitsche se empeñaba en no reconocer.

Las observaciones de Besson no se enmarcaban dentro de una crítica específica en torno a los conceptos científicos de origen y evolución del hombre. Su apertura a la libertad religiosa y de cultos, junto con su formación teológica-filosófica, lo llevarán a tratar de mediar y consensuar entre las explicaciones científicas y eclesiásticas, participando en forma activa en ambos contextos. Esta publicación de Besson debe entenderse dentro de su postura crítica en torno a los postulados transformistas y especialmente a la falta de educación profesional al momento de investigar y emitir juicios de opinión sobre cuestiones del mundo científico.

Para detallar este último punto Besson citaba una conferencia del escritor Julio Navarro Monzó (1882-1943) en la cual este último manifestaba su postura favorable en torno a las teorías transformistas que explicaban el origen y la evolución de la especie humana. Según Besson esto solo servía para agregar más confusión al tema. Por otro lado no encontraba veracidad científica en atribuir, tal cual como hacía Monzó, una antigüedad de 250.000 años a los cráneos fósiles hallados en Heidelberg y Neanderthal, y menos aún a la hipótesis de ausencia de lenguaje en esos tiempos. Según Besson esto se debía a que "[...] el conferenciante no tiene ninguna autoridad de naturalista [...]", por lo cual escribía a Lehmann-Nitsche a fin de que se expidiera en cuanto a las afirmaciones de Mozó. De esta forma Besso haría uso de explicaciones científicas contrapuestas a fin de afirmar las explicaciones sostenidas desde la Iglesia protestante en cuanto al origen y evolución del hombre y, al mismo tiempo, criticar aquellas elucidaciones científicas que le parecían incorrectas ${ }^{1048}$.

El 16 de agosto de 1905 el consejo académico de la Facultad de Filosofía y Letras de Buenos Aires ${ }^{1049}$ se reunía a fin de tratar diversas cuestiones administrativas ${ }^{1050}$. Uno de los temas será determinar la lista de candidatos para profesores de las distintas cátedras a fin de someterlas a la decisión del consejo superior de dicha casa de estudios. En una primera terna

1047 Ibídem p. 3.

1048 Pablo Besson a Robert Lehmann-Nitsche. Legado Robert Lehmann-Nitsche, junio de 1913, IAI, Carpeta N-0070 b 69.

${ }^{1049}$ El mismo estaba compuesto por Horacio G. Piñero, el médico y político José María Ramos Mejía (1849- 1914), Rodolfo Rivarola, Estanislao Severo Zeballos, el abogado José Nicolás Matienzo (18601936), el historiador, sociólogo, y pedagogo Juan Agustín García (1862-1923), Samuel Lafone Quevedo, el abogado Ernesto Weigel Muñoz y el escritor y poeta Rafael Obligado (1851-1920). La Nación 17.08.1905; La Prensa 17.08.1905.

${ }^{1050}$ Entre otros temas se discutía la designación de Carlos M. Aguilar como suplente de la cátedra de Historia Universal. Rafael Obligado destinaba varias ediciones del diccionario de la Real Academia Española a la biblioteca de la FFyL. Al mismo tiempo Indalecio Gómez era postulado como académico honorario. Miguel Cané era designado como delegado titular al consejo superior de la UBA. Finalmente se sancionaba el proyecto de Rodolfo Rivarola sobre las clasificaciones de los exámenes, estableciendo las designaciones de suficiente e insuficiente. La Nación 17.08.1905. 
será elegido Florentino Ameghino, el cual declinará la oferta. Ante esto se armará una segunda en la cual participarían Lehmann-Nitsche, Francisco Moreno y Félix Outes ${ }^{1051}$. Finalmente el 10 de septiembre de 1905 Lehmann-Nitsche era nombrado, por decreto del gobierno central, profesor de antropología de la Facultad de Filosofía y Letras de Buenos Aires, anunciándose la inauguración de su curso para el martes 26 de dicho año ${ }^{1052}$. Esta noticia tendría amplia repercusión en los periódicos alemanes internacionales, destacando que era la primera cátedra de antropología en Sudamérica ${ }^{1053}$. Es interesante mencionar en este punto la importancia que tendrá el dictado de los cursos libres como un mecanismo que posibilitara la posterior creación de cátedras universitarias ${ }^{1054}$. Por otro lado, como veremos sucintamente con el caso de Franz Boas, la formación de alumnos también será pensada como un medio para la profesionalización y la institucionalización de la práctica antropológica.

\subsection{La enseñanza de la Antropología en la Universidad Nacional de la Plata}

Como ha sido señalado hacia fines del siglo XIX la Universidad Nacional de Buenos Aires atravesaba por una serie de críticas que apuntaban al "profesionalismo" de sus carreras, alejándose del ideal de cultivo del saber que profesaban ciertos docentes de esta alta casa de estudios. Al mismo tiempo ciertos sectores sociales comenzarán a ver con cierto temor la "masificación" y la perdida de valores culturales ante el ascenso de nuevos sectores sociales ${ }^{1055}$. Susana García ha señalado que las discusiones en torno a la "cuestión universitaria" entre fines del siglo XIX y principios del siglo XX orbitarán alrededor del tipo de gobierno universitario, las formas de financiamiento y la preocupación por el tipo de formación. Estos elementos serán centrales para comprender el contexto en el cual se gesta y se implementa el proyecto universitario platense.

La tercera universidad nacional nacía de un proyecto planificado y sistematizado, contando con la figura central de Joaquín Víctor González (1863-1923). Buscando la formación de un nuevo intelectual que se adaptará a las necesidades sociales locales y se abocará a las tareas de la investigación científica y la enseñanza, se nutrirá de varios elementos para la elaboración de su proyecto: 1) las críticas vertidas hacia el modelo universitario de Buenos Aires, 2) los conflictos acaecidos en 1903 y 1904, 3) sus propias experiencias sobre el estudio de los modelos educativos de Europa y Estados Unidos ${ }^{1056}$. De esta forma González; inspirado

\footnotetext{
1051 García S. 2010 a.

1052 Buenos Aires 14.09.1905; La Nación 11.09.1905; La Prensa 12.09.1905.

1053 Allgemenine Zeitung 09.01.1906; Nordeutsche Allgemenine Zeitung 23.01.1906; Tägliche Rundschau 05.01.1906; Saale Zeitung 06.01.1906.

${ }^{1054}$ García S. 2010 a.

1055 García S. 2010 a; Romero 1978.

1056 A fines de 1903, una huelga estudiantil por unas fechas de exámenes en la Facultad de Derecho inició un conflicto que derivará en la reforma de los estatutos y del sistema de gobierno de la Universidad porteña. En 1904 los debates se centrarán en torno a la necesidad de una nueva ley universitaria.
} 
fuertemente por el modelo universitario inglés de Oxford; buscaba convertir a La Plata en una verdadera ciudad universitaria, diferenciándose de las universidades de Buenos Aires y de Córdoba ${ }^{1057}$.

La ciudad de La Plata contaba con un centro superior de estudios desde el 18 de abril de 1897, cuando en el antiguo edificio del Banco Hipotecario se dictaba la primer clase de "Historia del Derecho" a cargo de Jacob Larrain. De esta forma se concretaban los planes iniciados en 1889 por los senadores provinciales Rafael Hernández (1840-1903), Emilio J. Carranza (1828-¿?), Marcelino Aravena (1831-1903) y Valentín Fernández Blanco (18501928). Estos habían presentado el 12 de junio del mencionado año un proyecto de ley para la creación de una Universidad provincial en la recientemente fundada ciudad de las diagonales ${ }^{1058}$. La ley será sancionada por la Cámara de Diputados de la Legislatura provincial el 27 de diciembre de 1889 y promulgada el 02 de enero de 1890, sin embargo habrá que esperar casi una década para que el nuevo centro superior de estudios comience a funcionar como tal.

El 08 de febrero de 1897 se sancionaba el "Decreto Reglamentario" redactado por Juan José Dardo Rocha (1838-1921). Seis días más tarde se reúne la primera Asamblea Universitaria cuyos miembros habían sido designados por el Poder Ejecutivo, eligiendo a Rocha como el primer rector de la Universidad Provincial de La Plata, nombre que mantendría hasta su nacionalización en 1905. Esta misma asamblea establecería una serie de medidas para el funcionamiento de las cátedras, dejando que cada unidad académica estableciera las condiciones de admisibilidad, el nombramiento de personal y la adaptación de planes y programas de estudio a partir de los que estaban vigentes en las universidades nacionales. Finalmente se establecían cuatro Facultades: Derecho y Ciencias Sociales, Ciencias Físico-Matemáticas, Química y Farmacia y Ciencias Médicas ${ }^{1059}$.

Entre 1897 y 1905 el número de alumnos será muy bajo, lo cual se sumaba al escaso presupuesto destinado al funcionamiento de la universidad provincial, y la falta de reconocimiento a nivel nacional de los títulos expedidos. Estos elementos se irán conjugando, dando forma al contexto en el cual desde diversos espacios se comenzará a reclamar por el establecimiento de un centro universitario de excelencia. Utilizando las instituciones científicas

\footnotetext{
${ }^{1057}$ Buchbinder 2005; García S. 2010 a.

1058 El nuevo centro de estudios superiores se justificaba como una reparación histórica por la nacionalización de la Universidad de Buenos Aires y como un elemento que permitiría arraigar y acrecentar la población de La Plata, evitando que tanto los residentes locales debieran desplazarse a la Capital Federal para continuar sus estudios universitarios y al mismo tiempo atrayendo nuevos estudiantes. Esta propuesta tendrá una amplia repercusión en la ciudad de La Plata, con una especial recepción por parte de los jóvenes. El 13 de junio de 1897 cerca de 150 jóvenes provenientes del Colegio Nacional, del Instituto Argentino y de la Sociedad Literaria se movilizarán al domicilio particular de de Rafael Hernández a fin de manifestarle su apoyo. García S. 2010 a; Romero 1978.

1059 Buchbinder 2005; García S. 2010 a.
} 
y educativas ya existentes en la ciudad de La Plata ${ }^{1060}$, se planificaba el establecimiento de una universidad "científica" y "moderna" que pudiera hacer frente a las múltiples necesidades de la República Argentina, primando la comprensión y el estudio científico de la realidad social y política de los tiempos que corrían ${ }^{1061}$.

El 12 de febrero de 1905 Marcelino Ugarte (1855-1929), por ese entonces gobernador de la provincia de Buenos Aires, recibía la amplia memoria en la cual González detallaba su proyecto. En el mismo se detallaba la transferencia de diversas instituciones científicas y educativas provinciales ya existentes a la Nación, las cuales incluirían: la Facultad de Agronomía y Veterinaria, el Observatorio Astronómico, la Escuela Práctica de Santa Catalina, el Museo y la Biblioteca pública de la provincia, el Instituto de Artes y Oficios, el terreno donde luego fue edificado el Colegio Nacional, la Escuela Normal, el edificio del Banco Hipotecario, un lote de terreno sobre la actual Plaza Rocha y una serie de quintas y chacras ${ }^{1062}$. Entre agosto y septiembre de 1905 se debatirá y aprobará en ambas cámaras legislativas el proyecto de Ley de creación de la universidad nacional en La Plata. Finalmente el 17 de marzo de 1906 Joaquín V. González asumía como primer Presidente de la Universidad Nacional de La Plata.

En este contexto, el 7 de febrero de 1906 Lehmann-Nitsche era designado, por decreto del Poder Ejecutivo de la Nación, profesor de antropología en el Instituto del Museo de La Plata $^{1063}$. Mientras que el diario La Prensa hacia referencia al curso a realizarse en Buenos Aires, el Kujawischer Bote de su Posen natal, comentaba con jactancia el inicio de las clases de antropología en el Museo de La Plata, y de cómo aquel hijo del terrateniente Eduard Adolph Robert Lehmann, unía la enseñanza y la práctica de la antropología en un mismo instituto científico $^{1064}$.

Llamativamente el mismo decreto que designaba a Lehmann-Nitsche como profesor de antropología en el Instituto del Museo de La Plata, asignaba al pedagogo Rodolfo Senet (18721938) los cargos de profesor de antropología y jefe del laboratorio de Psicología de la Sección Pedagógica de la Facultad de Ciencias Jurídicas y Sociales de la Plata. Senet, al igual que

${ }^{1060}$ Estas serán: el Museo de la Plata, el Observatorio Astronómico y la Facultad de Agronomía y Veterinaria.

${ }^{1061}$ De esta forma se buscaba un programa integral que: 1) formara dirigentes políticos y docentes para los diversos niveles de enseñanza, 2) hiciera lugar a las preocupaciones por el mantenimiento del orden social y la unidad nacional y 3) respondiera a las demandas de los científicos que buscaban un espacio a partir del cual legitimar sus prácticas y saberes. Las innovaciones del proyecto de González se proyectarán a través de la búsqueda de un régimen de gobierno interno y la autonomía económica, la inclusión de nuevas disciplinas y/o la re-valorización de aquellas ya existentes, la importancia de la práctica científica teórica y experimental, la unidad de los distintos niveles de enseñanza y la difusión social de los conocimientos generados. Buchbinder 2005; García S. 2010 a.

1062 Barba 2005; Buchbinder 2005; García S. 2010.

1063 Enterado de dicha designación felicitaba Rudolf Martin a Lehmann-Nitsche. Comentándole los pormenores de la enseñanza universitaria de la antropología, deseaba que prontamente pudiera LehmannNitsche contar con un grupo estable de alumnos. Lehmann-Nitsche, 1921 a; Rudolf Martin a Robert Lehmann-Nitsche. Legado Robert Lehmann-Nitsche, 01.01.1906; IAI, Carpeta N-0070 b 489.

${ }^{1064}$ Kujawischer Bote 20.04.1907; La Prensa 15.03.1907. 
Lehmann-Nitsche, combinaría las funciones de enseñanza e investigación ${ }^{1065}$. El curso de Senet será de carácter teórico-demostrativo, complementado con investigaciones en las escuelas de La Plata $^{1066}$. Junto con Lehmann-Nitsche se designaba a Desiderio Aguiar como profesor suplente de antropología en Instituto del Museo de La Plata, dictando la parte de antropología psíquica hasta 1908, año en el cual pediría licencia ${ }^{1067}$.

Entre las primeras discusiones al momento de comenzar el dictado de los cursos en el Instituto del Museo de La Plata se encontrará la organización del plan de estudios. LehmannNitsche, junto con los geólogos Santiago Roth y Walter Schiller, proponía dividir el año en semestres, tal como se practicaba en las universidades alemanas ${ }^{1068}$. Esta propuesta sería impresa en un folleto, en el cual se argumentaban las principales razones que aconsejaban esta división. Los principales puntos era: la división del año en dos semestres, el primero desde el 15 de marzo al 9 de julio, comprendiendo el segundo desde el 1 de agosto al 30 de noviembre. Esto permitía abarcar la enseñanza de una materia específica o bien una parte de la misma susceptible de individualizarse. Al mismo tiempo se establecía un periodo de receso invernal desde el 9 al 31 de julio ${ }^{1069}$.

El escaso interés por el avance de este tipo de carreras se condecía con el bajo número de alumnos en los cursos antropológicos. Como señala Susana García solo 6 alumnos comenzarán en 1906 los cursos de ciencias naturales, pero esto no amedrentaba a LehmannNitsche, para el cual el bajo número de alumnos permitía una atención particular de las necesidades de cada uno. Agregaba además que, a diferencia de los asistentes a los cursos dictados en la Facultad de Filosofía y Letras de Buenos Aires, los alumnos de La Plata se encontraban "[...] preparados en mejor grado para las ciencias naturales, y más aptos, por consiguiente, a seguir un curso de antropología dictado bajo el punto de vista del naturalista"1070. Recordemos que la formación propuesta comprendía distintos cursos de botánica, paleontología, zoología, geología, petrografía, mineralogía, etnología, antropología y un complemento de lingüística ${ }^{1071}$.

1065 Comenzando sus cursos en 1907, realizaba una investigación antropométrica en 1200 sujetos concurrentes al Colegio Nacional y a la Escuela Normal, cuyos resultados fueron publicados en Archivos de Pedagogía y Ciencias Afines. Según el pedagogo Víctor Mercante (170-1934), organizador de la sección pedagógica, la enseñanza de la antropología en la formación de profesores estaba destinada, junto con el estudio de la anatomía y fisiología del sistema nervioso y la psicología, a conocer las diversas aptitudes del alumno. En este sentido el estudio del sistema nervioso quedaba a cargo de Manuel Beatti, mientras que el curso de psicología era dictado por Carlos Francisco Melo (1873-1931). Mercante 1909

1066 Luego de su jubilación en 1921, los alumnos de Senet, pasarían cursar con Lehmann-Nitsche. Anónimo 1906, 1907; García S. 2010 a; Podgorny 2006

1067 García S. 2010 a.

1068 García S. 2010 a, 2010 b.

${ }^{1069}$ García S. 2010; Lehmann-Nitsche 1906; La Nación 02.11.1906.

${ }^{1070}$ Lehmann-Nitsche 1921 a, p.14.

1071 García S. 2010 a. 
El programa que dictara Lehmman-Nitsche será el mismo para los cursos de Buenos Aires y de La Plata ${ }^{1072}$. En ambos casos los centros de estudiantes publicaban una serie de apuntes a fin de completar el aprendizaje. En el caso del Museo de la Plata se hacía en las páginas de El Museo, Revista del Centro de Estudiantes ${ }^{1073}$. En el curso capitalino corría a cargo del Boletín del centro de estudiantes de Filosofía y Letras. Esto también formaba parte de una decisión de las autoridades de la Facultad de Filosofía y Letras. Al mismo tiempo se les exigía a los profesores que se encontraban de viaje en el extranjero la remisión de obras a fin de engrosar el acervo bibliográfico ${ }^{1074}$. Del mismo modo cuando estos viajaban al exterior se les encargaba; o ellos mismos procuraban; adquirir colecciones de enseñanza ${ }^{1075}$.

Las publicaciones de la revista de la Facultad de Filosofía y Letras eran editadas por el centro de estudiantes de dicha facultad. Las mismas se basaban en los apuntes trasncriptos por la entonces estudiante Juliane Dillenius. El contar con estas lecciones era indispensable a fin de seguir el desarrollo de los cursos y la preparación de los respectivos exámenes. En estas lecciones el conferenciante sintetizaba resultados de sus propias investigaciones e introducían apreciaciones personales sobre los temas vistos. Como ha señalado Susana García, para el caso de la enseñanza de las ciencias naturales en el Museo de La Plata, la introducción de cursos de taquigrafía y de alemán ofrecía una serie de herramientas para que los estudiantes obtuvieran el mayor provecho de estas clases ${ }^{1076}$.

Los temas vistos a lo largo de las primeras clases en el Instituto del Museo de La Plata serán los mismos que brindará en su primera serie de conferencias en Buenos Aires: una introducción histórica de la antropología, la clasificación y subdivisión de la antropología, el estudio en conjunto de las variaciones pigmentarias de la piel, el pelo, los ojos y la fisonomía de las distintas partes corporales y el cráneo. De esta forma, y discutiendo las clasificaciones y divisiones propuestas por Daniel Brinton, Emil Schmidt, y el antropólogo español Luis Hoyo Sainz (1868-1951) ${ }^{1077}$, Lehmann-Nitsche se acercaba a la división propuesta por Schmidt,

1072 La Facultad de Filosofía y Letras de Buenos Aires publicaba un índice temático editado por la Imprenta Mena.

${ }^{1073}$ Esta será la revista estudiantil más antigua que se reconoce en La Plata. Siendo editada entre 1906 y 1908 por el Centro de Estudiantes del Museo, será sucedida por la Revista del Centro de Estudiantes de Química y Farmacia. Comenzando con un formato bimestral, no tardará en convertirse en una edición mensual. En sus páginas no solo hallaremos información científica, sino también biografías, homenajes, crónicas de viajes, fiestas, servicios, análisis políticos, y debates sobre el estado nacional e internacional de la ciencia. García S. 2010 a.

${ }^{1074}$ Horacio G. Piñero a Robert Lehmann-Nitsche. Legado Robert Lehmann-Nitsche, 19.07.1904, IAI, Carpeta N-0070 b 1033.

1075 García S. 2010 a.

1076 García S. 2010 a.

${ }^{1077}$ Las divisiones propuestas por estos estudiosos no se alejaban demasiado de la utilizada por LehmannNitsche. Brinton proponía en 1892 una división en cuatro especialidades: Somatología, Etnología, Etnografía y Arqueología. Por otro lado Schmidt presentaba dos grandes grupos: Antropología naturalista por un lado y Antropología Histórica o Prehistórica por el otro. Finalmente tendremos el esquema sugerido por Hoyo Sainz el cual constaba de tres partes: Antropología General, Antropología Descriptiva y Antropología Filosófica. Lehmann-Nitsche 1907 e. 
considerando al hombre como género y no como individuo. Definiendo a la antropología como "el estudio físico y psíquico del género humano bajo el punto de vista comparativo"1078, la dividía en antropología en física y psíquica, proponía cuatro combinaciones: 1.a) Antropología zoofísica; 2.a) Antropología filofísica; 3.b) Antropología zoopsíquica y 4.b) Antropología filopsiquica.

Es interesante mencionar que el curso finalizaba discutiendo la "unidad" y la "pluralidad" del género humano, punto para el cual se tornaba de "importancia esencial" el estudio de los caracteres psíquicos, ya que estos reflejaban la importancia de los caracteres físicos ${ }^{1079}$. Siguiendo las líneas de estudio desarrolladas en Alemania, y especialmente los consejos brindados por Rudolf Martin, advertía Lehmann-Nitsche que en el estudio histórico del hombre era necesario "[...] recurrir a los más antiguos documentos, a las representaciones icnográficas [...]" ${ }^{\prime 1080}$. En este sentido el 16 de junio de 1907, dentro del marco del ciclo de extensión universitaria, se brindaba una conferencia en torno a los "dibujos primitivos", la cual contará con una amplia promoción en la prensa local ${ }^{1081}$. Para ilustrar el tema en forma adecuada Lehmann-Nitsche hará uso de una serie de dibujos indígenas, relevados en 1898 en el contexto de Exposición Nacional de la Industria celebrada en la ciudad de Buenos Aires, y un conjunto de dibujos realizados por niños de la ciudad de La Plata de 3 a 6 años de edad. El conjunto de dibujos se exhibía en 8 grandes planchas que permitían una reproducción a mayor escala de los mismos ${ }^{1082}$ (Fig. 48).

El uso de este tipo de reproducciones proporcionaba por un lado una sensación de mayor cercanía con los objetos y fenómenos a estudiar, y por otro una evidencia visual que sustentaba las explicaciones propuestas por el conferenciante. Como destacaba la prensa local, presente en el momento de la conferencia, el uso de este tipo de elementos hacía "[...] más

\footnotetext{
${ }^{1078}$ Lehmann-Nitsche 1908 d, p.15.

1079 Lehmann-Nitsche 1907 e, p. 8.Resaltado en el original.

${ }^{1080}$ Lehmann-Nitsche 1908 d, p. 1. Resaltado en el original.

${ }^{1081}$ El Día 13, 15 y 17 de junio 1907; La Nación 16 y 17 de junio de 1907; La Prensa 13 y 16 de junio de 1907.

${ }^{1082}$ La conferencia tendrá lugar en el salón de la biblioteca. Este tipo de conferencias. La misma seria publicada posteriormente en la revista El Museo. Este tipo de trabajos se insertaba dentro de una serie de estudios previos surgidos a lo largo del siglo XIX y principios del siglo XX como búsqueda de elementos materiales o expresiones culturales que permitieran matizar la supuesta "homogeneidad" biológica de las "razas" gracias al carácter material y simbólico de los dibujos. Las principales referencias utilizadas por Lehmann-Nitsche serán los trabajos del pedagogo alemán Siegfried Levinstein y del filósofo francés Georges-Henri Luquet (1876-1965), autores formados en los trabajos del psicólogo ingles James Sully (1842-1923) y del maestro de arte inglés Ebenezer Cooke (1853-1911). Al igual que estos, LehmannNitsche sostendrá que; tal como la ontogenia recapitula la filogenia; lo mismo sucede a nivel espiritual, por lo cual tomará a los dibujos como un medio de expresión donde la representación gráfica no es más que el lenguaje de su pensamiento. Por lo tanto, la expresión gráfica es un claro indicio del estado evolutivo de la mente del autor del dibujo. Esta idea podemos hallarla en trabajos previos realizados principalmente en el Amazonas por el médico militar francés Jules Nicolás Crevaux (1847-1882), Richard Andrée, Karl von den Steinen, Theodor Koch-Grünberg y los del médico y antropólogo francés Ernest Théodore Hamy (1842-1908). Ballestero 2011.
} 
comprensivas sus deducciones para la numerosa concurrencia $[\ldots]^{1083}$, agregando que de esta forma la demostración de las analogía era extremadamente sencillo.

La colaboración de la prensa en este tipo de conferencias, al igual que en el dictado de las clases y cursos de antropología, continuaba una vez finalizada la disertación del conferenciante $^{1084}$. Tal como se anunciaba en las páginas de El Día, uno de los diarios de mayor circulación en la ciudad platense, las futuras ediciones comenzarían a publicar extractos de la conferencia, añadiendo que se intercalarían reproducciones de los principales dibujos exhibidos por Lehmann-Nitsche ${ }^{1085}$. Similar publicación harían los editores de la revista Caras y Caretas, los cuales se lamentaban de que los indígenas fueguinos no realizaran una representación de los “principales hombres públicos" de la época ${ }^{1086}$. Este tipo de conferencias no serán exclusivas de los miembros del mundo académico platense o capitalino. En este sentido dicha conferencia sería brindada nuevamente el 14 de julio y el 16 de octubre de ese mismo año en el local del Club Austro-Húngaro de Buenos Aires, dentro del marco de presentaciones de la Deutschen Wissenschaftlicher Verein, bajo el título de "Indianische Bleistifzeichungen"1087.

En 1906 se organizaba un curso especial de anatomía artística. El Consejo Académico; del que Lehmann-Nitsche formaba parte; designaba a este último como responsable de su dictado. Al igual que otros profesores, este deseaba acumular cátedras. El mencionado curso de anatomía artística abarcaba en dos semestres los temas de osteología y miología del cuerpo humano, respectivamente ${ }^{1088}$. En el primer semestre serán invitados los alumnos del curso de antropología, asistiendo solamente un reducido número ya que el horario del curso se superponía con otros del Instituto del Museo de La Plata. El número total de alumnos será de 28, algo que para Lehmann-Nitsche mostraba el éxito del curso. Para futuros cursos se planteaba la posibilidad de circunscribir la parte de osteología a los alumnos del segundo año solamente, lo cual permitiría ampliar considerablemente su contenido, enseñando micología y proporciones corporales a partir del tercer año ${ }^{1089}$.

Los resultados de estos cursos serán satisfactorios, a pesar del poco conocimiento preparatorio que acusaban los alumnos con respecto al cuerpo humano, situación que llevará a la propuesta de un liceo de medicina al año siguiente, ante el Honorable Consejo Superior de la Universidad Nacional de La Plata, el cual resolvía pasar el proyecto a la comisión didáctica y de disciplina. La propuesta del liceo de medicina se venía discutiendo en La Plata, desde la

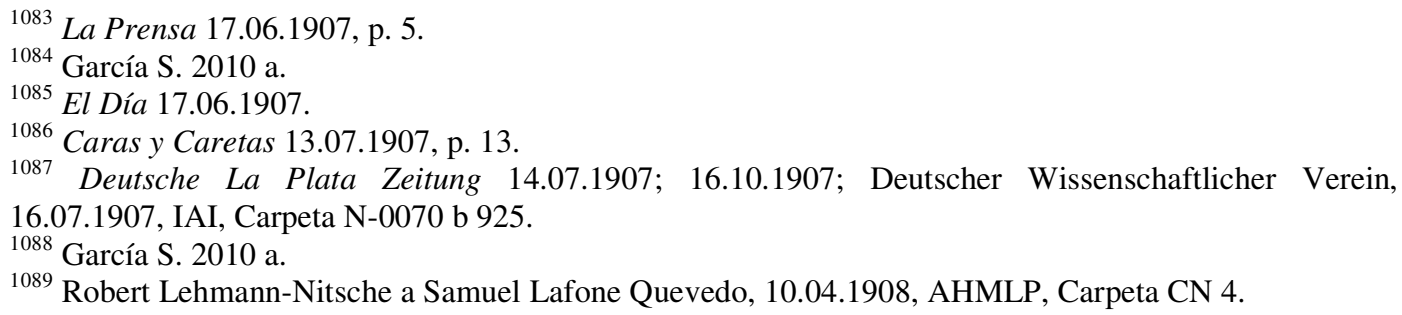


creación de la universidad provincial. La enseñanza de la medicina no había podido organizarse más allá la escuela de parteras, en parte por la falta de cuerpos para las clases demostrativas y prácticas ${ }^{1090}$. Lehmann-Nitsche justificaba este nuevo pedido argumentando que aquellos jóvenes interesados en proseguir una carrera en el mundo de las ciencias naturales, podían contar con una importante formación práctico-teórica sobre una de las principales ciencias que formaban parte del desarrollo histórico de la antropología ${ }^{1091}$.

Dicha idea, reconocía Lehmann-Nitsche, no era novedosa en el contexto académico platense, pero la ausencia de resultados concretos y el éxito de propuestas académicas anteriores lo animaban a presentar este nuevo proyecto, inspirado en las escuelas preparatorias de farmacia y medicina francesas de Besançon, Clermont y Poitiers. Elementos como el progreso científico de la investigación y la enseñanza se entremezclaban con la gloria académica que le revestiría a la Universidad Nacional de La Plata en caso de aprobar el proyecto.

La falta de recursos y de personal calificado parecía hacer fracasar el proyecto antes de iniciar, sumado a la existencia de la Facultad de Medicina de la Universidad Nacional de Buenos Aires, cuya existencia formal databa de 1822. Sin embargo este último punto, visto como un obstáculo, se transformaba en otro de los motivos que justificaban el proyecto sugerido por Lehmann-Nitsche: la existencia de una sola Facultad de medicina en la provincia de Buenos Aires implicaba una sobrepoblación estudiantil, perjudicando la instrucción de los alumnos. En este sentido la creación de una "[...] facultad incompleta [...]"1092 platense se presentaba como la mejor solución para la aglomeración estudiantil en Buenos Aires.

De esta forma los cursos de medicina ofrecidos en La Plata podían brindar dos años de instrucción preparatoria para que luego el estudiante pueda optar por ingresar a la Facultad de Medicina de la Universidad Nacional de Buenos Aires o su homóloga en Córdoba. Al mismo tiempo servía para aquellos alumnos que cursaban la carrera de ciencias naturales, complementando la carencia de conocimientos en torno al cuerpo humano. El cuerpo de docentes de la Universidad Nacional de La Plata contaba con calificados docentes que podían impartir las clases de este liceo de medicina, sin necesidad de que los profesores de la capital se trasladasen a La Plata. La única función de los mismos sería el control de los contenidos y la metodología de enseñanza ${ }^{1093}$. El problema del espacio se resolvería fácilmente haciendo uso de alguno de los edificios ocupado por la Facultad de Agronomía platense. El tema volvería a tratarse en 1918. El Consejo Superior de la Universidad Nacional de La Plata sancionaba la creación de una "Escuela preparatoria de ciencias médicas", la cual se instalaría por unos meses en los sótanos del Museo de La Plata ${ }^{1094}$.

${ }^{1090}$ García S. 2010 a.

1091 Deutsche La Plata Zeitung 22.02.1908.

${ }^{1092}$ Lehmann-Nitsche 1915 d, p. 199. El resaltado es de nuestra autoría.

1093 Ibídem.

${ }^{1094}$ Diario El Día, 15.04.1918; García S. 2010 a. 
Hacia finales de enero de 1909 regresaba Lehmann-Nitsche a la Argentina a bordo del vapor alemán Cap Arcona, perteneciente a la Hamburg Südamerikanische DampfschifffahrtsGesellschaft ${ }^{1095}$. A su regreso surgirán una serie de situaciones en torno a la enseñanza de las ciencias naturales y a la situación política particular de la ciudad de La Plata. Por un lado, como ha examinado Susana García, tendremos la revisión del plan de estudios de Ciencias Naturales a causa de la escasa presencia de alumnos, lo cual se sumaba a la falta de ingreso de nuevos estudiantes. El Consejo Académico determinaba que la causa de estos problemas eran las deficiencias del plan de estudio, para lo cual nombraba una comisión revisora formada por Herrero Ducloux, Santiago Roth, y el zoólogo Miguel Fernández (1882-1950). Finalmente se aprobaba en octubre de 1909 una ordenanza sobre la organización de las escuelas del Museo y los estudios de ciencias naturales ${ }^{1096}$. Mientras estas discusiones tenían lugar, Lehmann-Nitsche participaba en las demostraciones públicas por el cumplimiento del artículo 48 de la Constitución Nacional, el cual determinaba las condiciones para ejercer como funcionario público $^{1097}$.

Luego de las discusiones surgidas al interior del propio Museo de La Plata en torno a la modificación del plan de estudios, hacia octubre de 1909 se aprobaba una ordenanza en torno a la organización de las escuelas de dicho museo y los estudios de ciencias naturales. De esta forma se reconocían cuatro escuelas: 1) Ciencias geológicas, 2) Botánica, 3) Zoología y 4) Ciencias Antropológicas. Como ha señalado Susana García esto no introducirá cambios sustanciales en torno al contenido de los planes de estudio, relacionándose esta división con la administración de la enseñanza, algo que se plasmaría con la nueva organización de los estudios de ciencias naturales que entraría en vigencia al año siguiente ${ }^{1098}$.

Situación similar se podía apreciar en la Facultad de Filosofía y Letras de Buenos Aires, donde el plan de estudios no sufrirá cambios sustanciales entre 1909 y 1912, primando

\footnotetext{
1095 Deutsche La Plata Zeitung 27.01.1909; El Día 28.01.1909

1096 García S. 2010 a.

1097 Dicho artículo determinaba que para ejercer cargo de funcionario público se requería tener mínimamente 25 años, cuatro años de ciudadanía en ejercicio, ser natural de la provincia que lo elija o bien dos años de residencia inmediata en ella. Los residentes platenses consideraban que este artículo llevaba más de 20 años siendo quebrantado, ya que la mayoría de los funcionarios públicos no residían en la ciudad de La Plata. Esto dará lugar a una serie de reuniones que comenzarán el 14 de julio en las instalaciones de la Liga de Fomento de la ciudad platense de los Hornos. Ante la renuncia del médico Ángel Alsina, del maestro de esgrima uruguayo Pedro Mendy (1872- ¿?), Orestes Manuel Olazábal Pueyrredón (1891-1925) y Carlo Luigi Spegazzini, asumían la función de intermediarios el ingeniero Rufino Arroyo, Daniel C. de la Canal y Lehmann-Nitsche. Estos junto a otro importante número de personas serían nombrados "comisarios" encargados de organizando a los vecinos de la zona que le había sido asignada. Luego de una manifestación por la ciudad se dirigirán a la casa de gobierno, donde se le entregaba al gobernador un petitorio firmado por más de 7.000 vecinos en el cual se reclamaba el cumplimiento del artículo 48 de la Constitución Nacional, la formación del padrón electoral de La Plata y la sanción de la ley que convertía a esta ciudad en sección electoral. El Día 15.07 y 10.08 de 1909; Caras y Caretas 14.08.1909.

1098 García S. 2010 a.
} 
sobre todo el estudio del hombre desde el punto de vista de la antropología física, algo que favorecía a los estudiantes del doctorado de ciencias naturales de la Facultad de Ciencias Exactas, Físicas y Naturales de la Universidad Nacional de Buenos Aires ${ }^{1099}$. Como dato es preciso mencionar la participación más activa de los estudiantes, los cuales se encargaban de realizar presentaciones especiales sobre determinados temas. Esto podemos apreciarlo en pequeñas notas al margen que Lehmann-Nitsche realizará en su copia del plan de clases, donde el nombre de un alumno era anotado al lado del tema sobre el cual exponía ${ }^{1100}$. También debemos agregar la presencia del programa de un curso especial de antropología a cargo de Félix Outes, intercalado en el programa de plan de clases para 1911 de Lehmann-Nitsche. Outes presentaba un plan de 12 temas dividido en dos partes. Mientras que la primera parte discutía sobre el problema arqueológico del hombre terciario en Europa y posteriormente su vida durante el pleistoceno europeo; la segunda parte trataba los mismos temas pero enfocados en las regiones argentinas de la Pampa, Córdoba y la Patagonia ${ }^{1101}$.

El interés del establecimiento de un plan de estudios acorde a los estamentos de las universidades alemanas no se limitará al contexto local. Una vez consolidada la experiencia de las cátedras de antropología en Argentina, se buscará extender la misma a otros países. Tal como expresaba Rudolf Martin desde Zürich, el deber de los estudiosos en otros países era extender el sistema internacional de la enseñanza antropológica enfatizando en los conceptos y prioridades de la antropología alemana ${ }^{1102}$. De esta forma al estar de visita en Chile, LehmannNitsche será entrevistado por la prensa chilena en el hotel Oddó. En dicha nota confesaba que a pesar de ser este un viaje de estricto placer esto no le impedía aprovechar su tiempo para “[...] hacer propaganda útil en pro de la difusión de la enseñanza de la antropología á la cual no se le presta en este país (en referencia a Chile) la atención que merece, según noticias que tengo". En clara referencia a los trabajos llevados adelante por Lenz, abogaba por la apertura de cátedras especiales de "antropología general, etnología general, arqueología y etnología chilena, como igualmente favorecer estudios especiales de araucanismo". Aquellas comunicaciones sostenidas con Lenz a lo largo del primer decenio del siglo XX le permitían a Lehmann-Nitsche esgrimir críticas contra el escaso interés gubernamental por el progreso de estas disciplinas. Al respecto agregaba que "Es necesario organizar en Chile estas ciencias universitariamente, que es lo único que falta; pues hombres preparados para enseñarlas los hay muy distinguidos en este país" ${ }^{\text {"103 }}$.

\footnotetext{
1099 Ibídem.

${ }^{1100}$ De esta forma en1909 Sofía Suárez exponía sobre la talla del cuerpo humano. María Cambiggi sobre las proporciones del mismo. María Laura Gassi en torno a la craneoscopía y craneometría. Adela Nuñez presentaba un trabajo sobre los huesos largos de los esqueletos de la tribu calchaquí. Finalmente Luisa Ferreira disertaba los tipos de orejas y uso en la clasificación tipológica humana. Lehmann-Nitsche 1909 f.

${ }^{1101}$ Curso Especial de Antropología, 1911.

1102 Rudolf Martin a Robert Lehmann-Nitsche. Legado Robert Lehmann-Nitsche, IAI, 18.11.1907, Carpeta N- 0070 b 489.

${ }^{1103}$ El Mercurio 28.01.1912.
} 
En visita al Museo Nacional de Historia Natural de Santiago no se ahorrara las diatribas e invectivas en cuanto a las instalaciones y a la disposición de las colecciones del establecimiento dirigido por el Dr. Eduardo Moore (1910-1929). Esgrimía Lehmann-Nitsche que el Museo reunía "[...] todas las condiciones de un gran museo, faltándole solo modernizarlo, es decir, dotarlo de nuevas instalaciones de que carece desgraciadamente por falta de fondos". Dichos fondos debían ser expedidos por el Gobierno chileno, a fin de que el Museo ocupara su lugar "[...] como uno de los más completos de Sudamérica"1104.

En cuanto a la distribución de las diversas secciones recomendaba colocar en el primer patio una fuente o algún elemento de grandes proporciones que maravillarán a los visitantes y sacar de allí los talleres que "afean considerablemente el establecimiento". Al mismo tiempo proponía la creación de un museo al "aire libre", algo que no faltaba en ningún museo de "primer orden". El mismo, instalado en los jardines de los patios interiores, debía consistir en una vivienda típica de araucanos que diera a conocer las costumbres de dicho grupo. Maravillado por los ejemplares de la Biblioteca, argumentaba la falta de una adecuada sección de antropología, ya que la existente no guardaba relación con el desarrollo de las demás ${ }^{1105}$.

Similares discusiones tendrán lugar en la ciudad de La Plata, cuando Lehmann-Nitsche insista sobre lo provechoso de montar un "jardín paleontológico". Los supuestos beneficios de la instalación del mismo parecen que estibarán más en la posibilidad de que el costoso proyecto quedara en manos del artista plástico alemán Josef Pallenberg (1882-1946) que en el valor pedagógico y educativo del mismo. Este último se encontraba en la Argentina como integrante de la "Exposición Hagenbeck", la cual tenía lugar en el barrio de Palermo ${ }^{1106}$. Lehmann-Nitsche visitará la exposición, oportunidad en la cual sostendrá un encuentro con Hagenbeck. Este le haría saber sobre sus deseos de agregar una sección sobre "la pampa argentina" en su famoso Tierpark Hagenbeck de la ciudad alemana de Stellingen, proponiéndole a Lehmann-Nitsche la realización del redituable negocio.

Este último intercedería ante el comisionado del Poder Ejecutivo Comunal, Luis María Doyhenard Chilavert (1857-1916), a fin de que se aprobara y subvencionara desde el gobierno local la instalación del jardín paleontológico. Este se mostraba entusiasmado con la idea, considerando posible que para fines de 1911 se pudieran ver las primeras reproducciones en el bosque platense ${ }^{1107}$. Luego de una estadía en el Museo de La Plata, Pallenberg volvería a Hamburg. La cantidad de reproducciones y el costo de los mismos serían discutidos por

\footnotetext{
${ }^{1104}$ Las ultimas noticias 30.01 .1912

${ }^{1105}$ Ibídem.

${ }^{1106}$ Esta misma exposición era visitada marino y periodista francés Carlos Lemeé (1828-1914), el cual también propondría la creación de un jardín paleontológico en la Argentina. Diario El Día 25.09.1910, 10.01.1911; Diario La Prensa 05.01.1911; Diario La Reforma 25.09.1910; García S. 2010 a.

${ }^{1107}$ Diario El Día 25.09.1910, 10.01.1911; Diario La Ciudad 03.02.1911; Diario La Prensa 05.01.1911.
} 
Lehmann-Nitsche, quien quería obtener la mayor cantidad de piezas al precio más barato ${ }^{1108}$. Finalmente el proyecto, al igual que muchos otros, quedaría en la nada. El tiempo invertido por Lehmann-Nitsche en la realización de negocios que pudieran ser beneficiosos para él o un determinado grupo de individuos cercanos, será tiempo perdido en la instrucción y formación de alumnos que permitieran profesionalizar e institucionalizar los espacios de la antropología.

\subsection{La formación de alumnos}

Al momento que los estudiosos alemanes llegaban a América, ya fuera contratados o buscando algún puesto en los institutos y/o universidades locales deberán hacer frente a la carencia y/o ausencia de recursos y personas que le permitieran llevar adelante sus proyectos. Como hemos visto en los capítulos V y VI diversas estrategias serán implementadas para solventar la adquisición de los objetos y los medios técnicos para su estudio. Tal como señalaba Rudolf Martin en 1901 en su conferencia inaugural del semestre de verano en la Universität Zürich estos no serán los problemas más graves. La ausencia de profesionales formados; tal como le recordaría a Lehmann-Nitsche en sucesivas cartas; era una de las principales fuentes del caos en el cual se encontraba la Antropología a comienzos del siglo $\mathrm{XX}^{1109}$.

Una evaluación similar realizaba Franz Boas en los Estados Unidos. Luego de implementar una serie de proyectos tales como nuevos sistemas de ordenamiento de las colecciones o la restricción de ingreso a los amateurs a las sociedades científicas, se concentrará a lo largo de las dos primeras décadas del siglo XX en la expansión del departamento de antropología de la Columbia University de New York y en la formación de estudiantes. Esto le permitirá la constitución de un grupo de trabajo que por un lado lo asistirá en sus investigaciones, y por el otro le permitirá ocupar lugares claves en los principales institutos y universidades estadounidenses en los cuales estos eran designados ${ }^{1110}$. Como podemos ver, tanto para Martin como para Boas la profesionalización de la disciplina y la definición de sus espacios pasará por la formación de estudiantes.

\footnotetext{
${ }^{1108}$ El 17 de junio de 1911 Pallenberg enviaba desde Hamburg el precio final de las 10 reproducciones encargadas por Lehmann-Nitsche, el cual ascendía a 35.000 pesos moneda nacional. El detalle de los precios era el siguiente: Megatherium 6.000 pesos; Mylodon 3.000 pesos; Mastodon 7.000 pesos; Glyptodon 3.000 pesos; Panochtus 3.000 pesos; Doedicurus 3.500 pesos; Hoploporus (sic) 1.000; Macrauchenia 3.500 pesos; Smilodon 1.000 pesos y Toxodon 4.000 pesos. Unos meses más tarde y ante la inclusión de nuevas reproducciones el precio aumentaba a 47.500 pesos moneda nacional. Los precios que se modificaban eran: Smilodon 2.000 pesos; Glyptodon 2.500 pesos; Macrauchenia 4.000 pesos; Mastodon 8.000 pesos. Se agregaban las siguientes reproducciones: Hippidion 3.500 pesos; Scelidotherium 2.000 pesos; y Lestodon 5.000 pesos. Josef Pallenberg a Robert Lehmann-Nitsche. Legado Robert Lehmann-Nitsche, IAI, 17.07.1911, Carpeta N-0070 b 516.

${ }^{1109}$ Martin 1901.

${ }^{1110}$ Darnell 1998; Hinsley 1976; Stocking 1974 a.
} 
El 12 de junio de 1891 el canadiense Alexander Francis Chamberlain obtenía su grado de "Doctor of Philosophy in Antropology" en la Clark University de Massachusetts"1111. Su trabajo había sido supervisado por Franz Boas, quien enseñara antropología en dicha casa de estudios entre 1888 y 1892. Luego de su paso por Chicago; donde trabajará como asistente de Frederic Putnam en la Columbian Exposition de 1893; llegará a New York, donde en 1896 será designado como profesor de antropología en la Columbia University y curador de la sección antropológica del American Museum of Natural History ${ }^{112}$. Como ha señalado algunos autores a excepción de los vínculos con Putnam, Boas estará prácticamente excluido de las redes personales e institucionales que determinaban la dinámica de las prácticas antropológicas en los Estados Unidos de fines del siglo XIX ${ }^{1113}$.

Esto contribuirá a que renuncie primeramente a su puesto de curador, y finalmente al American Museum of Natural History en 1906, concentrándose exclusivamente a las actividades del Department of Anthropology de la Columbia University, del cual era responsable. Ese mismo año propondría su expansión a través de la creación de un fondo económico especial que les permitiera a los estudiantes y a los graduados vinculados al mismo realizar investigaciones en varias partes del mundo. Un año más tarde estudiantes que luego ocuparían cargos en diversas universidades e institutos comenzaban su entrenamiento en Columbia bajo la supervisión de Boas: Edward Sapir (1884-1939), Frank Gouldsmith Speck (1881-1950), Robert Harry Lowie (1883-1957) y Alexander Aleksandrovich Goldenweiser (1880-1940) ${ }^{1114}$.

La formación de un grupo de trabajo era vista también como una estrategia al momento de asegurar el éxito de los proyectos a gran escala. Los estudiantes no solo asistirían sus tutores a través de la recolección de objetos en viajes al campo o el ordenamiento y el análisis de los mismos en el laboratorio; sino que el estudioso vera en estos un medio a partir del cual instalar una metodología que diera unidad y continuidad a los proyectos. Un ejemplo de esto será el proyecto del Handbook of American Indian Languages, proyecto sobre el cual Boas seleccionará personalmente las personas involucradas. Con su primer volumen publicado en 1911, los siguientes tres contaran con distintas contribuciones de estudiantes formados por Boas. En este sentido George Stocking ha señalado que estos 4 volúmenes dan cuenta del crecimiento de la influencia de Boas y su excesivo control sobre la forma en la cual los trabajos debían ser realizados ${ }^{1115}$.

\footnotetext{
${ }^{1111}$ El trabajo se publicaria en 1892 bajo el nombre The Language of the Mississaga Indians of Skugog. A Contribution to the Linguistic of the Algonkian Tribes of Canada. Chamberlain 1892.

${ }^{1112}$ Darnell 1998; Hinsley 1976; Hyatt 1979; Jacknis 2002; Liss 1990; Stocking 1974 a.

${ }^{1113}$ Hinsley 1976; Stocking 1974 a.

${ }^{1114}$ Hyatt 1979; Liss 1990.

1115 No todos sus discípulos estarán de acuerdo con esta forma de trabajo. En este sentido Alfred Kroeber caracterizaba a Boas como "[...] as a powerful father figure, cherishing and supporting those with whom he identified in the degree that he felt they genuinely were identifying with him, but, as regards others, aloof and probably fundamentally indifferent, coldly hostile if the occasion demanded. A true patriarch in short, with patriarchal strength and outlook". Kroeber 1956, p. 156; Stocking 1974 b.
} 


\subsubsection{Las tesis doctorales dirigidas por Lehmann-Nitsche}

El caso de Lehmann-Nitsche para la Argentina diferirá completamente del descripto anteriormente para Boas. Es cierto que las condiciones de los contextos sociales e institucionales donde ambos se desempeñaran difieren y es necesario considerar estas particularidades al momento de establecer una comparación. Sin embargo, como han señalado varios autores, el interés puesto por Boas en el entrenamiento de estudiantes y en la formación de un grupo de investigación será justamente en pos de poder superar las limitaciones y las carencias impuestas por el contexto local al momento de poder definir la dinámica de las prácticas antropológicas ${ }^{1116}$. Por lo tanto es posible reconocer cierta apatía por parte de Lehmann-Nitsche al momento de promocionar la formación de estudiantes y el establecimiento de un grupo de investigación. Varios elementos deben ser tenidos en cuenta al momento de identificar las causas de esto. Por un lado tendremos el bajo número de alumnos que seguían los cursos con regularidad y los problemas de financiamiento para la adquisición de materiales destinados a la enseñanza ${ }^{1117}$. Por otro lado hemos podido ver, en forma llamativa, como en el caso del jardín paleontológico, que Lehmann-Nitsche sabrá mostrarse enfático al momento de poder conseguir financiamiento para actividades que no se relacionaban con la enseñanza.

En la primera década del siglo XX el énfasis estará en la publicación de la mayor cantidad de trabajos posibles, con el objetivo de poder hacerse conocer en el mundo antropológico, y eventualmente conseguir un puesto en el Viejo Mundo. Sin embargo, tal como le recordaba Martin, esto no debía ir en desmedro de la enseñanza de la Antropología. Mientras que el estudioso suizo le comentaba sobre 108 nuevos estudiantes en sus cursos, los cuales se sumaban a los practicantes y candidatos doctorales, enfatizaba que, a pesar de que esto le quitará tiempo de sus investigaciones personales, la formación de estudiantes era una de las obligaciones de los antropólogos, y al mismo tiempo el único camino para generar un poco de orden al interior de la disciplina ${ }^{1118}$.

Al enterarse de la designación de Lehmann-Nitsche como profesor universitario de antropología, Rudolf Martin no ahorraba en palabras de felicitaciones para lo que consideraba como un importante paso para su carrera profesional y una significativa oportunidad para la difusión de la antropología alemana en Sudamérica. Con este último punto se vinculaba la necesidad de poder interceder por los alumnos a fin de garantizarles puestos en diversos espacios institucionales y académicos. En este sentido hacia 1907 Martin le comentaba el poco tiempo que encontraba para sus investigaciones, ya que no solo debía supervisar los trabajos de sus 9 candidatos doctorales y sus 24 practicantes, sino también pensar los posibles destinos

\footnotetext{
${ }^{1116}$ Darnell 1998; Hinsley 1976; Hyatt 1979; Jacknis 2002; Liss 1990; Stocking 1974 a.

1117 García S. 2010 a.

1118 Rudolf Martin a Robert Lehmann-Nitsche. Legado Robert Lehmann-Nitsche, 12.02.1906, IAI, Carpeta N-0070 b 489.
} 
laborales de los mismos una vez que finalizaran su formación profesional. Comentando a Lehmann-Nitsche la inscripción de 240 estudiantes en sus clases de antropología y 86 en las de anatomía, Martin reflexionaba en un tono cómico que sus propias investigaciones tal debían esperar hasta el año $1909^{1119}$.

Mientras tanto, en la ciudad de La Plata, Lehmann-Nitsche comenzaba a trabajar junto a Juliane Dillenius en Craneometria Comparativa de los antiguos habitantes de la Isla y del Pukara de Tilkara. Este trabajo presentado en agosto de 1911 será la primera tesis doctoral dirigida por Lehmann-Nitsche. A partir del análisis de los caracteres somáticos del material craneológico recolectado por una excursión de la Facultad de Filosofía y Letras de la Universidad Nacional de Buenos Aires a la zona de la Quebrada de Humahuaca, pretendía Dillenius contribuir a la historia de la mencionada región y de la Diaguito-Calchaqui ${ }^{1120}$.

A partir del trabajo sobre la muestra de 70 cráneos que componían el trabajo, pretendía Dillenius introducir ciertos lineamientos en lo referente a su estudio y su clasificación. Según la joven investigadora el carácter provisorio del catalogo del Museo Etnográfico de Buenos Aires daba lugar a la acumulación del más variado material sin consideración de índole, limitándose a indicar la procedencia de los mismos. De esta forma llamaba a seguir el ejemplo del Catálogo de la sección antropológica del Museo de La Plata editado por Lehmann-Nitsche en 1911.

Con respecto al estudio de los materiales, estos se harán acorde a las nuevas convenciones craneométricas establecidas en el XIII Congrès International d'Anthropologie et d'Archéologie Préhhistorique de la ciudad de Mónaco, celebrado en $1906^{1121}$. Recordemos que Lehmann-Nitsche buscaba promocionar las mismas desde 1907, con el estudio de los cráneos de Arrecifes y Chocorí, las osamentas de La Tigra, y el atlas de Monte Hermoso para su trabajo sobre la Formación Pampeana ${ }^{1122}$. Tanto en este trabajo, como en el de Dillenius, se buscaría también promocionar el uso del instrumental antropométrico de Rudolf Martin en el contexto local. A pesar de que los mismos eran recomendados desde el espacio del congreso monegasco, muchas veces los estudiosos se inclinarán por el uso de aquellos instrumentos que ellos

1119 Rudolf Martin a Robert Lehmann-Nitsche. Legado Robert Lehmann-Nitsche, 18.11.1907, IAI, Carpeta N-0070 b 489.

${ }^{1120}$ Dillenius 1913 a. Para un análisis de la expedición como así también de las discusiones en torno al problema de la "cultura calchaquí" ver Pegoraro 2009.

${ }^{1121}$ Para este momento gran parte de los antropólogos alemanes habían dejado de lado los lineamientos planteados por la "Frankfurter Verständigung", mientras que los franceses mantenían la ilusión, según George Papillault, de contar con una técnica uniforme. En el mencionado congreso de Mónaco se definirá 24 mediciones craneométricas para el cráneo, 8 para la mandíbula inferior, 19 mediciones cefalométricas y los tres principales instrumentos a ser utilizados: el compás de corredera, el compás de espesor y la cinta métrica. La comisión encargada de esto estaba formada por: Hamy, Georges Papillault, el antropólogo francés René Verneau (1852-1938); el médico y cirujano italiano Vincenzo Giuffrida Ruggeri (1872-1921); Georges Hervé; Von Luschan; el médico alemán Abraham Lissauer (1832-1908); el antropólogo genovés Eugène Pittard (1867-1962); el cirujano y ginecólogo francés Samuel-Jean Pozzi (1846-1918); el antropólogo italiano Giuseppe Sergi; y el patólogo alemán Heinrich Wilhelm Gottfried Waldeyer (1836-1921). Hrdlička 1919; MacCurdy 1908; Papillault 1906; Tildesley 1928; von Luschan 1906.

${ }^{1122}$ Dillenius 1913 a; Lehmann-Nitsche 1907. 
evaluaban como más prácticos al momento de dar cuenta de tal o cual caracreteristica. En este sentido Dillenius remarcaba que "[...] en la práctica el uso adecuado llega á imponerse por sí mismo. El calibrador, compás de espesor y cinta métrica de que nos hemos servido, son los instrumentos construidos en Zürich según indicaciones especiales del profesor doctor R. Martin, que mucho preferirnos á otros por ser livianos, muy manuables y muy exactos" ${ }^{\text {"1123 }}$.

A partir de la determinación de pequeñas diferencias craneológicas y somáticas, Dillenius planteaba la existencia de una divergencia entre los antiguos habitantes de La Isla y los del Pukará de Tilcara. Finalmente el 11 de septiembre de 1911 el trabajo era aprobado y se le confería el grado de Doctora en Filosofía y Letras. Dos años más tarde, en 1913, aparecía el que sería el último trabajo editado de Dillenius, el cual comprendía un análisis craneométrico sobre una colección de calotas medievales encontradas en las refacciones de la Anthropologisch-Prähistorisches Sammlung de la ciudad alemana de Münich ${ }^{1124}$. Ese mismo año Dillenius contraía matrimonio con Lehmann-Nitsche, naciendo al año siguiente su primera hija $^{1125}$. Si bien esto ha sido visto como la causa principal del fin de la carrera profesional de Dillenius $^{1126}$, es preciso mencionar que la ausencia de publicaciones por parte de esta última no significara el cese en sus actividades científicas, colaborando en forma constante en los trabajos de Lehmann-Nitsche.

Un año después del trabajo de Dillenius, el 27 de junio de 1912 para ser más exactos, Teodoro de Urquiza presentaba Paleo-Antropología Argentina. Nuevas investigaciones sobre el atlas de Monte Hermoso, trabajo presentado para obtener el grado de Doctor en Ciencias Naturales en la Universidad Nacional de La Plata y que también será dirigido por LehmannNitsche ${ }^{1127}$. En dicho trabajo se retomaba el problema del hombre fósil a partir del análisis del atlas de Monte Hermoso, enfocándose en los parámetros utilizados para distinguir entre el género humano y sus predecesores fósiles ${ }^{1128}$. Luego de pasar revista sobre los trabajos geológicos y paleoantropológicos previos realizados sobre la Formación Pampeana; a partir de un sucinto resumen del compendio Nouvelles recherches sur la formation pampéenne et l'homme fossile de la République Argentine publicado por Lehmann-Nitsche en 1907; Urquiza se aprestaba a analizar las principales características métricas del atlas de Monte Hermoso y las de 60 esqueletos depositados en Museo de La Plata a fin de poder contar con la

\footnotetext{
${ }^{1123}$ Dillenius 1913 a, p. 24.

${ }^{1124}$ Dillenius 1913 b.

${ }^{1125}$ Los hijos del matrimonio Lehmann-Nitsche/Dillenius y sus respectivas fechas de nacimiento son: Hiltrud en 1914; Goetz en 1915; Gudrun en 1917; Helga en 1923 y Gisela en 1925.

${ }^{1126}$ Arenas 1991; Carreras 2008.

${ }^{1127}$ Este había colaborado previamente con Carlos Marelli, quien le solicitará la consulta de material para la redacción de su trabajo doctoral La complicación y sinostosis de las suturas del cráneo cerebral de los primitivos habitantes de la República Argentina, presentado para obtener el grado de doctor en ciencias naturales en la Universidad Nacional de Buenos Aires en 1909 y dirigida por Félix Outes. Carlos Marelli a Robert Lehmann-Nitsche. Legado Robert Lehmann-Nitsche, 04.06.1910, IAI, Carpeta N-0070 b 485; García S. 2010 a.

${ }^{1128}$ Podgorny 2001 b.
} 
cantidad suficiente de datos osteométricos que le permitieran "ubicar zoológicamente" el atlas encontrado por Ameghino ${ }^{1129}$.

Las medidas y las correlaciones realizadas por Urquiza lo llevaban a concluir que la vértebra pertenecía a un individuo del género Homo aunque no sapiens, opinión divergente a la de Ameghino para el cual el atlas pertenecía a un precursor del hombre, distinto al género Homo $^{1130}$. Finalmente una comisión examinadora compuesta por Lehmann-Nitsche, Luis María Torres, Santiago Roth, Salvador Debenedetti y el zoólogo argentino -nacido en AlemaniaMiguel Fernández (1883-1950); otorgaban a De Urquiza el grado de "Doctor en Ciencias Naturales". Es posible que las pocas perspectivas de una rápida inserción dentro del mundo científico y/o académico llevaran a que De Urquiza no continuará con su carrera, sin embargo, como hemos visto en el caso de Boas, muchas veces esto dependerá de la buena voluntad y de la intervención de sus tutores.

Rudolf Martin, quien constantemente alentará a Lehmann-Nitsche por el establecimiento de un grupo de investigación estable, le comentaba a este último que las obligaciones académicas e institucionales condicionaban el tiempo que podía dedicarle a sus investigaciones y al entrenamiento de los estudiantes. Al respecto, tal como le explicaba en 1906, la solución estibaba en la redacción de un manual que sintetizará los objetivos, los métodos y las técnicas antropológicas. En consecuencia le comentaba que a partir del mes de abril tendría finalmente tiempo libre para poder concluir su propio manual antropológico, al cual consideraba necesario para darle continuidad al entrenamiento de sus estudiantes ${ }^{1131}$. En este sentido se ha señalado que la preeminencia de los enfoques metodológicos implementados por Boas a lo largo de la segunda década del siglo XX se deberá a una combinación de elementos: por un lado la ausencia de manuales que sintetizarán los métodos y técnicas de investigación, y por el otro la insistencia de Boas en que sus estudiantes tomaran sus trabajos como modelo de investigación ${ }^{1132}$. Sobre este punto señalaba Margaret Mead (1901-1978), una de sus estudiantes, "Boas disliked textbooks and seldom sent us to his own written work. He gave us the gist in his lectures and assumed we would resort to it only when we needed the actual material" $" 1133$.

Hacia 1911 Lehmann-Nitsche enviaba al diario chileno El Ferrocarril una lista de sus últimas publicaciones. El autor de la nota, posiblemente por sugerencia del antropólogo alemán, refería a su trabajo "Forschungenmethode einer wissenschaftlichen Ethnologie" como un escrito

\footnotetext{
${ }^{1129}$ Urquiza 1912, p. 66.

${ }^{1130}$ Podgorny 2001 b; Urquiza 1912.

1131 Señalaba Martin "In April werde ich von dieser 2 Jahre bestehenden Last befreit und dann will ich mein Lehrbuch beendigen, das immer notwendiger wird, da die Zuhörer und Studenten im Quelle hier immer beständig zunehmen.”. Rudolf Martin a Robert Lehmann-Nitsche. Legado Robert LehmannNitsche, 01.01.1906, IAI, Carpeta N-0070 b 485.

1132 Darnell 1998; Hinsley 1976; Stocking 1974 a.

${ }^{1133}$ Mead 1959, p. 31.
} 
en el cual "[...] desarrolla el autor un nuevo método de investigación de una Etnolojía (sic) científica, ideado por él"1134. La obra a la cual se hacia referencia en el artículo periodístico había sido presentada por Lehmann-Nitsche en el Congrès international d'expansion économique mondiale, celebrado en la ciudad de Bruselas entre el 24 y el 28 de septiembre de 1905.

Este "nuevo método de investigación" era propuesto como respuesta a una de las principales preguntas planteadas por los organizadores del congreso "Quels sont, dans les pays neufs, les meilleurs modes de faire des observations ethnographiques et sociologiques en vue d'arriver à une connaissance scientifique de l'état social, des mœurs et des coutumes des indigènes et de les élever à une civilisation supérieure?"1135. A diferencia de Rudolf Martin que demorará varios años en abreviar los métodos y técnicas antropológicas en las 1181 páginas de su Lehrbuch der Anthropologie (1914); el supuesto método de Lehmann-Nitsche se sintetizaba tan solo en 4.

Sin siquiera ser un breve esquema de un modelo de investigación, el trabajo se limitará a cuestionar la falta de financiamiento institucional para expediciones etnográficas sistemáticas, mencionando a continuación la ausencia de apoyo oficial e institucional por parte de los gobiernos nacionales y universitarios en el establecimiento de cursos especializados de etnografía en las universidades y los museos. Lehmann-Nitsche planteaba como primer paso necesario la resolución de estos puntos antes de elaborar un método de investigación antropológico. Si bien este último punto es cierto, no hemos podido dar cuenta de que Lehmann-Nitsche continuara con la redacción de este "nuevo método de investigación" o que intercediera de alguna forma para lograr mejoras en las condiciones de enseñanza y formación de estudiantes.

Hacia mediados de la segunda década del siglo XX se publicaba una nueva edición ampliada del Lehrbuch der Anthropologie de Rudolf Martin en 3 amplios tomos. Al mismo tiempo en los Estados Unidos la capacidad administrativa de Boas había logrado concentrar alrededor del Department of Anthropology de la Columbia University los procesos de institucionalización y profesionalización de la antropología estadounidense. Lejos de ser el "padre" de la misma, esto será posible gracias a la extensa red de discípulos que ocuparán puestos en diversos institutos y universidades ${ }^{1136}$. Para esa misma época en la Argentina,

\footnotetext{
${ }^{1134}$ Diario El Ferrocarril, 09.04.1911.

${ }^{1135}$ Lehmann-Nitsche 1905 h, p. 1.

1136 Entre otros podemos mencionar: Melville Jean Herskovits (1895-1963) como profesor en la Northwestern University en 1927 y director del departamento de antropología en 1928; Alfred Louis Kroeber como profesor en la University of California en 1901, director del Lowie Museum of Anthropology en 1909 y secretario de la American Anthropological Association en 1903; Edward Sapir como director de la división antropológica del Geological Survey of Canada en 1920, profesor en Yale University en 1931 y posteriormente director del departamento de antropología; Frank Gouldsmith Speck como profesor y director del departamento de antropología de la University of Pennsylvania en 1925; Robert Harry Lowie como curador asistente del American Museum of Natural History en 1909 y profesor
} 
Lehmann-Nitsche comenzaba a ver más cercano su futuro y tan ansiado retorno a Alemania, pero no como resultado de su actividad académica, sino como consecuencia del cese de la misma. Al retirarse, no dejará un grupo de discípulos que continuarán con su obra. De esta forma el temprano anhelo de Rudolf Martin por difundir y establecer una forma de práctica antropológica acorde a los parámetros establecidos en Alemania, jamás se vería cumplido.

en la University of California desde 1917; Alexander Aleksandrovich Goldenweiser quien entre 1910 y 1939 desempeñara diversos cargos académicos en la Columbia University, la New School for Social Researchor, y la University of Washington entre otras. 


\section{Congresos y sociedades científicas}

\subsection{Congresos}

En el ámbito local la asistencia a los congresos serviría para instalar nuevos temas o bien re-interpretar los estudios locales a partir de la introducción de metodologías o instrumentos novedosos en el ámbito local. Al mismo tiempo servirá para insertarse dentro de los espacios científicos locales. Como hemos visto en los puntos 3.1 y 3.2 del Capítulo III, el acceso a las colecciones craneológicas del Museo de La Plata le permitirá a Lehmann-Nitsche la presentación de dos trabajos en el contexto del Primer Congreso Científico Latinoamericano, celebrado en la ciudad de Buenos Aires entre el 10 y el 20 de abril de 1898.

En el primero de estos, intitulado "Antropología y Craneología" buscaba sintetizar aquellas discusiones que habían acontecido a lo largo de la segunda mitad del siglo XIX en Europa en torno al cráneo y su orientación, haciendo especial énfasis en aquellas recomendaciones de Rudolf Martin, Emil Schmidt y Rudolph Virchow. El segundo de los trabajos, una escueta presentación sobre la evidencia material del “[...] más antiguo comprobante del arte médica en toda Sud-América" ${ }^{, 137}$, pretendía continuar con las discusiones que ejemplares de la serie de cráneos patagónicos sobre los cuales se trabajaba, habían suscitado en los espacios científicos franceses.

El punto más importante, tal como le comunicaba a su madre, era la designación como integrante del sub-comité de "Ciencias Antropológicas"1138. Esto junto con su nombramiento como socio activo de la Sociedad Científica Argentina y de la Société d'Anthropologie de Paris eran considerados como los primeros pasos para poder adentrarse en el contexto científico local y articular los resultados en los contextos científicos europeos, los cuales consideraba de mayor relevancia para su trabajo ${ }^{1139}$.

Como hemos visto en el Capítulo II las muestras de cráneos que permitieron a Lehmann-Nitsche elaborar estos trabajos serán llevadas en su viaje a Europa, realizado en 1900. Los mismos serían presentados en diversas reuniones científicas y veladas privadas. La asistencia a congresos, especialmente en el ámbito internacional, se presentaba como una posibilidad de actualizar los conocimientos, estrechar lazos con antiguos colegas, establecer nuevos vínculos profesionales y la posibilidad de adquirir nuevos materiales científicos, tales

\footnotetext{
${ }^{1137}$ Lehmann-Nitsche 1898 a, p. 196.

1138 Congreso Científico Latino-Americano a Robert Lehmann-Nitsche. Legado Robert Lehmann-Nitsche, 19.11.1897, IAI, Carpeta N-0070 b 867.

1139 Sociedad Científica Argentina a Robert Lehmann-Nitsche. Legado Robert Lehmann-Nitsche, 16.09.1897, IAI, Carpeta N-0070 b 1014. Société d'Anthropologie de Paris a Robert Lehmann-Nitsche. Legado Robert Lehmann-Nitsche, 10.07.1897, IAI, Carpeta N-0070 b 1006. Robert Lehmann-Nitsche a Ida Lehmann-Nitsche. Legado Robert Lehmann-Nitsche, 21.06.1903, IAI, Carpeta N-0070 1295.
} 
como instrumentos o bibliografía. Junto con la posibilidad de visitar y acceder a colecciones depositadas en los principales centros de estudios, tendremos el diálogo con los círculos científicos más allá de las fronteras, los cuales serán fundamentales en el establecimiento de los temas a ampliar en el ámbito local.

Lo largo y costosos de estos viajes condicionaba muchas veces la cantidad de actividades desarrolladas por los estudiosos, los cuales buscaban la realizar la mayor cantidad de estas en el menor tiempo posible. En algunos casos las licencias con goce de sueldo permitían hace frente a parte de los gastos. Tal es el caso del viaje emprendido en 1900 en el cual, el Poder Ejecutivo de la provincia, concedía a Lehmann-Nitsche licencia con goce de sueldo por el tiempo de 4 meses $^{1140}$. En otros casos las asignaciones oficiales por parte de las universidades a las cuales los estudiosos se encontraban vinculados servían para cubrir los costos. Al momento de participar en el XIV Congreso Internacional de Americanistas, celebrado en la ciudad alemana de Sttutgart entre el 18 y el 24 de agosto de 1904, Lehmann-Nitsche será designado como delegado de la Facultad de Filosofía y Letras de Buenos Aires, elegido para dicho cargo por Horacio G. Piñero. Junto con la designación se le asignaban 1.000 francos en concepto de gastos de viaje, más una serie de giros que Lehmann-Nitsche ira solicitando una vez en Europa $^{1141}$.

Lehmann-Nitsche se embarcaba el 15 de julio a bordo del vapor "Duca di Galliera", de la compañía italiana La Veloce Linea di navigazione italiana a vapore societa anonima, con una licencia de 4 meses acordada con el gobierno de la provincia. Esto le permitirá realizar una primera parada en la ciudad alemana de Greifswald, para asistir a la trigésimo quinta reunión general de la Deutschen Anthropologischen Gesellschaft (Sociedad Antropológica Alemana), celebrada el día 4 de agosto. En dicha oportunidad presentaba una versión preliminar de sus investigaciones sobre el hombre fósil de la Formación Pampeana. Luego de dicha presentación visitará unos museos en Escandinavia, para finalmente dirigirse a Sttutgart, una ciudad en la cual los estudiosos ahí reunidos se proponían ilustrar sus avances con respecto al estudio las tribus indígenas de América, a través de trabajos que indagaban en su origen, su distribución geográfica, su historia, su naturaleza corporal, sus lenguas, su cultura, su mitología, los ritos, las costumbres, y sus prácticas. Al mismo tiempo se proponían dilucidad la historia del "descubrimiento" del continente americano y su colonización ${ }^{1142}$. En este sentido la presentación del trabajo "Europäische Märchen unter den argentinischen Araukaner" por parte de Lehmann-Nitsche se enmarcaba dentro del llamado a aumentar el número de estudios filológicos en Sudamérica ${ }^{1143}$.

${ }^{1140}$ RO 1900, p. 578.

${ }^{1141}$ Horacio G. Piñero a Robert Lehmann-Nitsche. Legado Robert Lehmann-Nitsche, 08 y 19 de julio, 05.11 de 1904, IAI, Carpeta N-0070 b 1033.

1142 IAK 1904.

${ }^{1143}$ Berliner Böser-Courier 25.08.1904; Berliner Tageblatt 25.08.1904; Tagliche Rundshau 24,08.1904. 
Los congresos internacionales también servían para adentrarse en nuevas investigaciones. Las presentaciones realizadas por otros estudiosos o bien las sugerencias hechas en encuentros personales presentaban nuevas aristas que explotar en el amplio campo de estudio sudamericano. Podemos citar la presentación de Ehrenreich en el congreso de Sttutgart. Este versaba sobre la proliferación y migración de los mitos de los grupos indígena sudamericanos, llamando la atención sobre la necesidad de recolectar materiales en la región austral de Sudamérica a fin de obtener un mapa completo de las distintas "provincias etnográficas" ${ }^{1144}$. Los esfuerzos coordinados de distintos estudiosos se presentaba necesario si se quería revelar una zona geográfica tan amplia como Sudamérica. En este sentido los trabajos de Lenz y Lehmann-Nitsche, señalaba Ehrenreich, eran un augurioso comienzo, incitando a ambos estudiosos a profundizar los mismos ${ }^{1145}$.

Este tipo de eventos también servían para evaluar el estado de la práctica científica en los diversos países. Como señalaban las publicaciones periódicas de la época, las exposiciones de los estudiosos ofrecían al mismo tiempo un panorama prometedor y desolador con respecto al estado de la ciencia en Sudamérica. Por un lado daban cuenta de una región con importantes y valiosos materiales a la espera de ser relevados, recolectados y estudiados. Por otro lado este último punto también señalaba la poca importancia dada a esta tarea con anterioridad a la llegada de los estudiosos europeos. Estos eran transformados en las páginas de la prensa local, asignándoseles un papel que rozaba la descripción heroica. Lejos de su hogar estos hombres se adentraban en un terreno que ofrecía una multiplicidad de oportunidades para el estudio del hombre, pero que, al mismo tiempo carecía de la infraestructura, el presupuesto y principalmente la intención de explotarlas en la forma adecuada ${ }^{1146}$.

Esta situación sería advertida posteriormente por la prensa argentina. En 1908 se celebraba en la ciudad de Wien el XVI Congreso Internacional de Americanistas. LehmannNitsche participaría en el mismo en calidad de delegado de la Universidad Nacional de La Plata $^{1147}$. Un día más tarde, a bordo del vapor "Savoia" de la compañía italiana La Veloce Navigazione Italiana a Vapore, partiría también Juan Bautista Ambrosetti, en calidad de

\footnotetext{
${ }^{1144}$ El Congreso de Americanistas de Sttutgart será un espacio de presentación y promoción de estos estudios que buscaban determinar la migración y la integración de prácticas culturales como una manera de entender el movimiento de los hombres en el tiempo y el espacio. En este sentido podemos citar la amplia concurrencia a las presentaciones de los trabajos de Jonkheer L. C. van Panhuys sobre el análisis de la costumbre de "Halloween" en Chicago, la de Stansbury Hagar sobre el asterismo peruano y las relaciones con otros rituales sudamericanos, y la de Raoul de la Grasserie sobre la lengua tehuelche. Grasserie 1904; Hagar 1904; Van Panhuys 1904.

${ }^{1145}$ Eherenreich 1904.

1146 Allgemeine Zeitung 23.08.1904; Hamburgische Correspondent 25.08.1904; Kölnische Zeitung 20, 24 y 25 de agosto de 1904; Neues Tageblatt 24 y 25 de agosto de 1904; Vorsichte Zeitung 20, 21 y 25 de agosto de 1904.

${ }_{1147}$ Cartas Presidencia 1906-1910, AHMLP, Capeta CN 1; Deutsche La Plata Zeitung 04 y 05 de agosto de 1908; La Nación 04.08.1908; La Prensa 04.08.1908.
} 
representante de la Universidad Nacional de Buenos Aires ${ }^{1148}$. No dejaba de asombrar a la prensa local que las investigaciones científicas sobre América despertarán tanto interés en los contextos científicos europeos, pasando prácticamente desapercibidas en el contexto local. La respuesta de Ambrosetti marcaba con claridad el interés personal y colectivo que estos temas suscitaban en Europa, observando que "En los museos de Berlin pueda usted encontrar las piezas más importantes y fundamentales de la arqueología de América, exactamente como en el British Museum de Londres se halla todo lo que se refiere al arte y a la historia de la Grecia Antigua" ${ }^{, 149}$.

Esto no hacía más que plantear severas dudas al periodista que realizará la entrevista donde Ambrosetti reflejará de forma tan clara y precisa el estado de la ciencia antropológica en la Argentina de comienzos del siglo XX, donde en los espacios de investigación se contaban solamente con moldes, reproducciones o representaciones de aquellos objetos que se deseaban estudiar y que se encontraban depositados en los principales centros de estudios europeos. Dicho periodista, al igual que lo plantearan gran cantidad de estudiosos de la época, se retiraba pensando sobre " $[\ldots]$ lo desapercibido que pasan en América las cuestiones de la misma, que

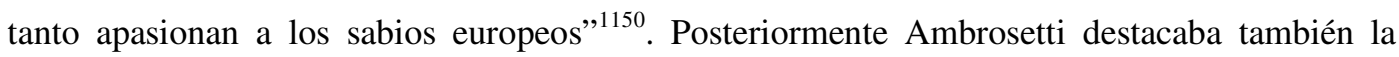
participación de distintos estudiosos que podían ser considerados como miembros de la comitiva argentina por su calidad de "conocedores de la República Argentina". En este sentido destacaba la presencia de Karl von den Steinen, de Rudolph Hauthal; por entonces director del Roemer- und Pelizaeus-Museum de la ciudad alemana de Hildesheim; el General alemán Alfred Arent; ex director y fundador de la Escuela Superior de Guerra; y finalmente el antropólogo y botánico checo Alberto Vojtěch Frič (1882-1944).

La prensa europea también sabría colaborar en mantener al tanto de las últimas investigaciones ocurridas en América, como así también los principales temas discutidos en los congresos internacionales. En el caso del congreso de Sttutgart, luego de los periódicos locales los principales medios presentes serán los de Berlin, Hamburg y Münich, todos estos importantes centros de antropología. De esta forma aquellos estudiosos que no habían podido asistir, y aquellas personas ávidas del consumo de noticias del mundo de la ciencia, podían contar con resúmenes precisos de la casi totalidad de las ponencias científicas, junto con una serie de apreciaciones personales de los periodistas que acentuaban los principales puntos expuestos por los estudiosos.

${ }^{1148}$ En dicha reunión científica la Argentina contará con tres delegados. A la actuación de LehmannNitsche y Ambrosetti debemos sumarle la del cónsul general en Viena, Germán Burmeister, en calidad de delegado del Gobierno Nacional. A petición de los organizadores del congreso, se conformarán comisiones de adherentes domiciliados en Viena a fin de que pudieran acompañar y atender las necesidades de los delegados extranjeros. La comitiva argentina será acompañada por el geólogo austriaco Emil Ernst August Tietze (1845-1931) y el pintor, también austriaco, Karl Wenzel Zajicek (1860-1923). Ambrosetti 1909; Breton 1911; Boas 1908; Mac Curdy 1908; Markham 1908; Nippen 1908. ${ }_{1149}$ La Argentina 04.08.1908.

${ }^{1150}$ La Argentina 04.08.1908, p. 5. 
Como hemos señalado estos viajes le permitían a los estudiosos profundizar contactos previos con otros colegas, o bien entablar nuevos vínculos. Muchas de estas veces esto no responderá a intereses puramente personales, sino que también responderán a las necesidades de las instituciones que representaban, las cuales como hemos vistos, llegaban a solventar parte de los gastos que implicaba el traslado al Viejo Mundo. En ambos casos ambas partes involucradas conseguían beneficios: El investigador que volvía a América obtenía importantes conexiones en Europa, las cuales les proveían de bibliografía, instrumentos, y vínculos a importantes centros de estudio u otros estudiosos. Por otro lado aquel que se quedaba en Europa ganaba un agente en el extranjero, el cual tenía el acceso a importantes colecciones o bien podía llevar adelante trabajos sobre el terreno. De esta forma en el congreso de Sttutgart el empresario alemán Theodor Wanner (1875-1955), de activa participación en la fundación de diversas asociaciones vinculadas a la promoción y el estudio del arte y la ciencia ${ }^{1151}$, a responsable de las funciones administrativas de la Württembergischen Verein für Handelsgeographie ${ }^{1152}$, se acercaba a Lehmann-Nitsche a fin de que este pudiera facilitar el acercamiento a instituciones de Buenos Aires que tuvieran en sus colecciones piezas "raras"1153. Como hemos visto en el capítulo VII, pareciese que el interés de Lehmann-Nitsche se enfocará más en la posibilidad de mediar en negocios privados antes que en la profesionalización e institucionalización de la práctica antropológica.

Tal como ha sido advertido por diversos autores, los congresos científicos son una expresión de la profesionalización e internacionalización de la ciencia. En este sentido María Margaret Lopes ha señalado que "Os congressos constituem 'loci' especiais para se compreender e acompanhar a circulação de pessoas, idéias e práticas científicas e tecnológicas,

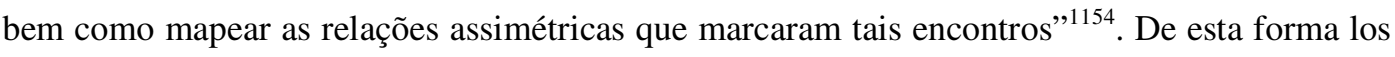
congresos científicos internacionales, que recibirán un notable impulso gracias al avance de los medios de transporte y comunicación, serán espacios donde se buscará regularizar, estandarizar y homogeneizar la práctica y el lenguaje científico ${ }^{1155}$.

Al mismo tiempo estos viajes significaban la posibilidad de volver a sus tierras natales y visitar a sus familiares, sin que esto signifique la interrupción de sus actividades científicas.

${ }^{1151}$ Por ejemplo la Vereins zur Förderung der Naturaliensammlung y la Vereins zur Förderung der Wissenschaft en Stuttgart.

${ }^{1152}$ La misma nacía como una iniciativa privada del conde Karl von Linden (1838-1910). En 1902 Wanner ingresaba como tesorero. Después de la muerte del conde von Linden, el por entonces duque Wilhelm von Urach (1864-1928) se convertía en el nuevo presidente de la asociación, dedicándose exclusivamente a tareas ceremoniales y designado a Wagner encargado del funcionamiento administrativo.

1153 Theodor Wanner a Robert Lehmann-Nitsche. Legado Robert Lehmann-Nitsche, 11.08.1904, IAI, Carpeta N-0070 b 761.

${ }_{1154}$ Lopes 2012, p. 1.

1155 Lopes 2012; Rassmussen 1996 
Estos momentos eran aprovechados para la realización de pequeñas conferencias y charlas en círculos científicos locales o entidades amateurs. De esta forma la población podía ser partícipe de los frutos laborales cosechados en el extranjero por los estudiosos, los cuales obtenían un prestigio dentro de la comunidad local. En algunos casos estas charlas se vinculaban a otro tipo de actividades, como la beneficencia. De esta forma el periódico alemán Kujawischer Bote ofrecía a sus lectores un "Ferienreise nach Süd-Chile und Feuerland" por tan solo 50 rublos rusos. Aquellos deseosos de transportarse a tan paradisíacas y exóticas geografías solo debían asistir al restauran del Mäusertum de Kruszwica, en la cual Lehmann-Nitsche ofrecería una síntesis de sus viajes al sur del continente americano ${ }^{1156}$. Las ganancias obtenidas por el cobro de la entrada sería destinado en su totalidad a los fondos del Deutscher Frauenverein zur Pflege und Hilfe für Verwundete im Kriege (Asociación de mujeres alemanas para el cuidado y la asistencia a los heridos en la guerra $)^{1157}$. Similar objetivo tendrá la organización de una velada científica, organizada por la Sociedad Geográfica de La Paz, en el marco del XVI Congreso Internacional de Americanistas. En dicha velada se ofrecerán 7 conferencias, a las cuales el público solo podrá acceder con unas tarjetas especiales. El dinero recaudado por las mismas sería donado a orfanatos infantiles de la zona ${ }^{1158}$.

La participación en eventos benéficos, junto con el aumento del prestigio social, también ofrecía tiempo para la preparación de conferencias destinadas a un público más especializado, oportunidad en la cual Lehmann-Nitsche ofrecía en el auditorio de la Gesellschaft für pommersche Geschichte, Altertumskunde und Kunst una lectura sobre la vida espiritual de los indios fueguinos, organizada por el médico y etnógrafo alemán Georg Hermann Theodor Buschan (1863-1942) ${ }^{1159}$. Este último estaba muy al tanto de los trabajos de Lehmann-Nitsche, con el cual mantenía una correspondencia fluida desde 1896. Cuando este último realizara su primer viaje a Europa en 1900, Buschan le lo consultaba sobre la posibilidad de presentar algún trabajo en las sesiones de la Berliner Gesellschaft für Anthropologie, Ethnologie und Urgeschichte, remarcando que el tema elegido fuera "lo más exótico posible", debiendo

\footnotetext{
${ }^{1156}$ Kujawischer Bote 04 y 10 de octubre de 1904.

1157 Dicha asociación había sido creada en 1866 por la entonces reina de Prusia Augusta Marie Luise Katharina von Sachsen-Weimar-Eisenach (1811-1890), para el tratamiento de los soldados afectados por la guerra. Dicha entidad será un importante antecedente para otro tipo de asociaciones de "mujeres patrióticas". Al momento en que Lehmann-Nitsche ofrecía su charla la entidad estaba presidida por la condesa Charlotte Clementine Editha von Itzenplitz (1835-1921). Misch 1917; von Itzenplitz 1917.

${ }^{1158}$ Las conferencias serían: 1) "La Facultad de Filosofía y Letras de la Universidad Nacional de Buenos Aires y sus exploraciones arqueológicas en la República Argentina" por Salvador Debenedetti; 2) "El hombre fósil pampeano" por Lehmann-Nitsche; 3) "Escritura jeroglífica de México y Centro América" por Eduard Seler; 4) "Cabezas indígenas, artefactos de piedra, su clasificación y lugar de hallazgos en el Brasil" por Carlos Simoene da Silva; 5) "La posición histórica de los aymaraes en el antiguo Perú" por Maz Uhle y 6) "Tiahunacu a través de las edades" por Belisario Díaz Romero. El Diario 18.06.1910; El Comercio 18.06.1910; El Tiempo 18.06.1910; La Época 18.06.1910; La Tarde 18.06.1910

${ }^{1159}$ General-Anzeiger fur Stettin und die Provinz Pommern 20.10.1904.
} 
considerar presentar una ampliación de su primer trabajo sobre los fueguinos ${ }^{1160}$. Como en otras oportunidades la prensa local no solo haría una amplia promoción del evento, sino que ofrecería una completa síntesis de la presentación, resaltando el papel de los científicos alemanes en el desarrollo de la ciencia en América, cuyo estado, en muchos casos, era igualado al de sus primitivos habitantes ${ }^{1161}$.

Los congresos también serán vistos como elementos que revestían de prestigio a los países organizadores. En 1910 la Argentina compartiría con México la sede del XVII Congreso Internacional de Americanistas. Como se remarcaba en diversas publicaciones, dicho congresos se insertaba en los festejos independentistas de ambos países ${ }^{1162}$. Ambrosetti señalaba que las valiosas ruinas mexicanas, elementos primordiales en el estudio de la arqueología americana, eran motivo suficiente para honrar a México como futura sede; al mismo tiempo recordaba el valor único de los objetos paleontológicos, arqueológicos y principalmente la existencia de grupos indígenas primitivos como causas suficientes para que la ciudad de Buenos Aires sea agraciada con la misma distinción ${ }^{1163}$. Tal como declaraba Eduard Seler, este será el principal motivo por el cual en 1908 se aprobará la moción de designar a la Argentina como una de las sedes del congreso de americanistas, ya que esta era un país “[...] importante para todas las cuestiones que se relacionan con la historia de las tribus primitivas y con las primeras formaciones sociológicas e industriales de naciones aspirantes de la civilización, y-last not least - de ver y estudiar las ricas colecciones de los museos de las dos capitales, de la nación $y$ de su provincia principal, ${ }^{1164}$.

Según el presidente argentino José Figueroa Alcorta (1860-1931) la Argentina celebraba su centenario independentista " [...] ofreciendo al mundo el espectáculo de un pueblo que absorto en la faena de su prosperidad y engrandecimiento, se yergue, no obstante, [...] ante la evocación de sus orígenes históricos"1165. Este congreso se inscribirá dentro de las celebraciones oficiales argentinas, adoptando el espíritu de celebración del pasado por un lado y el posicionamiento de la Argentina como un presente, y un futuro, altamente promisorio en el plano social, político y científico por el otro. El Gobierno Nacional designaba a Lehmann-Nitsche, Juan Bautista Ambrosetti y Francisco Pascasio Moreno encargados de la organización del mismo.

\footnotetext{
${ }^{1160}$ Georg Hermann Theodor Buschan a Robert Lehmann-Nitsche. Legado Robert Lehmann-Nitsche, 12.09.1900, IAI, Carpeta N-0070 b 65.

1161 General-Anzeiger fur Stettin und die Provinz Pommern 24.10.1904.

1162 Caras y Caretas 24.07.1909; Deutsche La Plata Zeitung 01.05.1910; Deutsche Tagezeitung 10.01.1910; Geographischer Anzeiger 01.02.1910; Geographischer Monatsbericht 01.02.1910; José Nicolás Mattienzo a Robert Lehmann-Nitsche. Legado Robert Lehmann-Nitsche, 13.05.1910, IAI, Carpeta N-0070 b 1033; Lehmann-Nitsche 1912 ¿; Morning Advertiser 12.11.1909; Morning Post 13.11.1909; Rivet,1910; The Times 16.11.1909.

${ }^{1163}$ La Provincia di Padova 29.09.1908.

${ }^{1164}$ Lehmann-Nitsche, 1912 p. 76 . El resaltado es de nuestra autoría.

1165 RHDL 1910, p. 65.
} 
En el contexto celebratorio el Consejo Superior de la Universidad Nacional de La Plata, invocando la disposición del artículo 9 de la ley número $6286^{1166}$, se dirigía a la "Comisión del Centenario" "1167 solicitando 53.000 pesos moneda nacional para la impresión y difusión de obras de carácter histórico y científico. Para el presidente Figueroa Alcorta el centenario de la revolución de mayo de 1810 significaba un festejo de la "libertad y civilización continental" 1168 , por lo cual la inversión de 53.000 pesos moneda nacional se consideraba "[...] un verdadero servicio á las letras y á la cultura patria [...]"1169. La conmemoración de la independencia de la corona española era también una celebración del progreso provisto por la ciencia. El estado "primitivo" y "embrionario" de las investigaciones y de la enseñanza de la ciencia era el mismo que caracterizaba aquellos invaluables materiales que era objeto de su investigación. Como recordaba Victorino de la Plaza, ministro de relaciones exteriores y protector del congreso, el material de estudio depositado en suelo americano, especialmente el de la región sur del continente, ofrecía una evidencia científica única para la resolución de los principales interrogantes de la ciencia, sin embargo los programas de investigación en torno a los mismos “[...] se desenvuelven en forma relativamente incipiente, como es, por otra parte, natural, tratándose de un pueblo en vías de formación" ${ }^{\text {1170. }}$.

En el pedido del Consejo Superior de la Universidad Nacional de La Plata se destacaba que miembros de docentes de dicha casa de estudios habían elaborado una serie de importantes trabajos de revisión histórica a base de “[...] prolijos trabajos de investigación, libros y manuscritos de gran importancia histórica, relacionados unos con la etnografía y la geografía del país [...]" "1171. Al mismo tiempo, con el objeto de lograr una mayor representatividad de los institutos que componían la universidad y estimular a los "jóvenes estudiosos consagrados a la

${ }^{1166}$ Dicha ley era sancionada el 13 de febrero de 1908. El artículo en cuestión señalaba que "El Poder Ejecutivo ayudará con los recursos necesarios a las universidades, para la impresión y difusión de obras científicas, históricas y literarias, con que se resuelva contribuir a la conmemoración de la independencia y para la adjudicación de premios con tal objeto". MCC 1910.

${ }^{1167}$ Ésta sería presidida por Marco Aurelio Avellaneda (1835-1911). Lo vocales serán: el intendente municipal Manuel José Güiraldes Guerricó (1857-1941), el periodista y abogado Norberto Camilo Quirno Costa (1844-1915), el General José Ignacio Garmendia (1841-1925), el historiador y político Juan Benjamín Terán (1880-1938), el agropecuario industrial Vicente Lorenzo del Rosario Casares (18441910), el abogado Leonardo Pereyra Iraola (1867-1943), Carlos Enrique José Pellegrini Bevans (18461906), Luis Ortiz Basualdo Dorrego (1849-1920), Carlos Estrada, José Guerrico, José de Apellaniz y por último a Arturo Z. Paz.

${ }^{1168}$ Discurso pronunciado por el presidente Figueroa Alcorta 1910.

${ }^{1169}$ La Nación 25.02.1910.

${ }^{1170}$ A fin de no menospreciar la tarea desempeñada por los estudiosos residentes en el país, agregaba De la Plaza "[...] no habéis de asombraros, lo espero, si no encontráis en el concurso de nuestros colaboradores en este país una grande acumulación de obras analíticas o sintéticas sobre los puntos culminantes de nuestro programa, aun cuando es satisfactorio decir que no os encontraréis tampoco en medio de un vacío de ideas y desenvolvimiento científico [...] vuestros colaboradores argentinos [...] dedican con amor su tiempo y cultivan con asiduidad los problemas que, vinculados por vuestro especial genero de materias, encuentran para ello elementos de practica importancia en la vasta extensión de la republica donde pueden arrancarse del misterio restos y reliquias de generaciones que en otros tiempos cruzaron como errantes sobre valles y llanos solitarios". Lehmann-Nitsche, 1912 p. 69.

${ }^{1171}$ La Nación 25.02.1910. 
labor científica e histórica"1172, se creía convenientemente agregar obras "[...] escritas y preparadas, después de exploraciones y trabajos de laboratorios y gabinete por distinguidos del

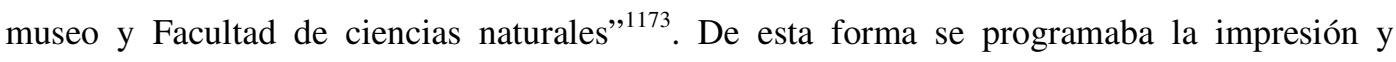
difusión de 12 volúmenes que conmemoraran la epopeya del pasado histórico, el cual era constituido como a base a partir de la cual se celebraba la épica del promisorio futuro intelectual y científico del país ${ }^{1174}$. La publicación de los trabajos científicos de los estudiosos del Museo de la Plata era un reconocimiento a "[...] la grande y gloriosa falange de los conquistadores y descifradores de las civilizaciones pasadas"1175.

Los festejos patrios se imbricaban de la retórica progresista, la cual se hacía presente en las palabras de Alejandro Rosa (1854-1914), director del Museo Mitre, para el cual las investigaciones llevadas adelante por estos estudiosos serían "[...] luz blanca que disipara con su esplendor y brillo las tinieblas de la America precolombina" ${ }^{" 176}$. Según Rosa, la celebración de un congreso con tal importancia en Argentina será un reconocimiento a aquellos estudiosos residentes en el país, los cuales, al igual que otros a lo largo de América del Sur, debían hacer frente a las difíciles condiciones de investigación del medio local. Al mismo tiempo hará un llamado de atención a aquellas personas encargadas de decidir sobre la inversión económica en ciencia $^{1177}$. Estas condiciones poco idílicas de investigación eran las que llevaban al rector de la Facultad de Filosofía y Letras de Buenos Aires, José Nicolás Matienzo, a dar cuenta de la abnegación de “[...] los placeres y comodidades de la civilización contemporánea, los sacrificios de tiempo y de salud que exige el culto de la verdad"1178 para aquellos que lo profesaban en América del Sur.

\footnotetext{
1172 Ibídem.

1173 Ibídem.

${ }^{1174}$ Los tomos I y II comprendían la obra de El Paraguay Católico del naturalista y filólogo español José Sánchez Labrador (1717-1798). El tomo III correspondía a la obra A Description of Patagonia and the adjoining parts of South America de Thomas Falkner. El tomo IV era una antigua obra de Ludovico Josepho Chorrorain intitulada Instituciones philosophicae, ad usum studiosis Juventus. De naturaleza similar será el V tomo, una obra inédita del Fray Elias del Carmen Phisica generalis-nostri philosophici cursus generalis. El tomo VI, de autor anónimo, Apuntes de filosofía moral. Los tomos VII y VIII comprenderían la primera versión castellana de la obra Rudimenta juris naturae et Pentium. Los siguientes tomos correspondían a trabajos científicos originales de profesores de la UNLP. De esta forma el tomo IX de la colección era Investigaciones arqueológicas en las provincias de Catamarca y Tucumán en 1907 y 1908 de Luis María Torres y Carlos Bruch. El tomo X correspondía a Los primitivos habitantes del delta del Paraná de Luis María Torres. El tomo XI era asignado a la obra de Lehmann-Nitsche Estudio sobre folklore argentina: adivinanzas rioplatenses. Cerraba la colección el tomo XII con la obra del abogado español Enrique del Valle Iberlucea (1877-1921). A estas obras se adjuntaba el Diccionario de Argentinismos del jurisconsulto y lingüista Lisandro Segovia.

1175 La Nación 03.05.1912, p.6.

${ }^{1176}$ Lehmann-Nitsche 1912, p. 60.

${ }^{1177}$ Destacaba Rosa que "Por eso es que han seducido a los pensadores de todos los países, y si aun los de la America del Sur no ocupan en ellos el prominente lugar que les corresponde, atribuidlo más bien a la falta de medios de investigación y no de poca simpatía de sus hombres por esos proficuos estudios". Ibídem

${ }^{1178}$ Ibídem p. 65.
} 
En línea con esta idea se expresara el presidente de la Universidad Nacional de La Plata, Joaquín Víctor González. Este declaraba que el interés de los estudiosos por América del Sur era fácilmente comprensible desde el punto de vista político, social y científico, ya que en esta región, a diferencia del norte, “[...] la obra de la cultura [...] fue detenida y puesta en peligro de zozobrar durante medio siglo" y en consecuencia "El pasado obró con más fuerza en esta" ${ }^{1179}$. La presencia contemporánea del pasado; encarnada en aquellos "primitivos" grupos humanos que habitaban al interior del país, presente en las tradiciones campesinas del interior o en los suburbios de la metrópolis; se tornaba problema y objeto de estudio al mismo tiempo. Los primeros contactos con los Estados Unidos, justificados por la búsqueda del "[...] reinado del orden y de la paz institucional [...]” daban ahora lugar a "[...] buscar el más próximo calor de la vida científica y social de la sabia Europa"1180.

Si bien las condiciones edilicias y la posibilidad de contar con material de trabajo actualizado influían en el avance de una investigación, esta estaba destinada al fracaso seguro si no se cumplían las condiciones básicas y elementales para dar cuenta de un conocimiento objetivo, la presencia del estudioso en el campo no podía estar sujeta a deliberaciones ${ }^{1181}$. Para Quesada era necesario "tocar para creer", por lo cual Europa podía vanagloriarse; con acertada razón; de sus archivos, museos y bibliotecas; todos estos importantes repositorios de valiosos materiales americanos, pero "[...] por mas tesoros y tesoros que encierren, nada reemplaza la impresión del ambiente, de los factores físicos de clima y lugar, en que se ha desenvuelto una sociabilidad dada"1182.

A pesar de contar con la riqueza de material de estudio señalada por Quesada, la falta de inversión por parte de las autoridades argentina en temas vinculados al trabajo científico será un constante presente en los congresos locales e internacionales, siendo esto últimos donde se acentúe mucho más fuerte la crítica. Como ejemplo podemos citar el Congrès international d'expansion économique mondiale, celebrado en la ciudad de Bruselas entre el 24 y el 28 de septiembre de 1905. Este tendrá por objetivo principal analizar las causas y consecuencias del proceso económico que se vivía a principios del siglo XX. El progreso industrial, el establecimiento de nuevas vías de comunicación, y la apertura de nuevos territorios para las

\footnotetext{
${ }^{1179}$ Lehmann-Nitsche 1912, p. 93.

${ }^{1180}$ Esto se evidenciaba en los trabajos de Berg y Burmeister en el Museo Nacional, los cuales habían otorgado "ciudadanía científica" a la Argentina, o bien en los sabios alemanes que desde hacía más de 30 años llevaban adelante su tarea en la "silenciosa y olvidada" academia de ciencias cordobesas. Ibídem p. 93.

1181 Puntualizaba Quesada que "Nada más prudente ni acertado: estoy convencido que los estudios americanistas, si han de ser realmente fecundos para la historia de la civilización, exigen que los sabios que a ellos se dedican, si son europeos, vengan a America, vean con sus propios ojos, palpen la realidad de las cosas y no se contenten con el pálido reflejo que se obtiene por la lectura de las obras de misioneros y cronistas, ó de viajeros más ó menos deficientes en sus observaciones. Es menester investigar en la propia tierra americana [...]”. Ibídem p. 81-82. El resaltado es de nuestra autoría.

1182 Ibídem p. 83-86.
} 
principales potencias europeas eran los principales temas que serían tratados en esta reunión ${ }^{1183}$. Lehmann-Nitsche participaría en la sección de "Expansión civilizatoria a los nuevos países"1184. El principal objetivo de la misma será la organización de las ciencias sociales en torno a los intereses político-económicos de las potencias europeas. Los organizadores del congreso buscaban agentes coloniales para la organización de instituciones como así también exposiciones o cualquier tipo de evento científico que mostrará al mundo el estado político, económico, social y científico del país en cuestión y que serian los encargados de organizar estas instituciones como así también exposiciones o cualquier tipo de evento científico que mostrará al mundo el estado político, económico, social y científico del país en cuestión ${ }^{1185}$.

Al momento de su exposición Lehmann-Nitsche focalizaba en la falta de dinero para expediciones etnográficas sistemáticas ${ }^{1186}$. Al mismo tiempo daba cuenta de la falta de apoyo oficial e institucional de los gobiernos nacionales y universitarios para el establecimiento de cursos especializados de etnografía en las universidades y los museos. Como señalaba los periódicos alemanes que cubrían este evento la preocupación por la enseñanza de la antropología no era una cuestión propia del contexto nacional argentino, sino que se enmarcaba dentro de una inquietud más amplia, que involucraba su inserción dentro de las estrategias político-económicas de las principales potencias europeas ${ }^{1187}$.

Los congresos no estarán exentos de las situaciones políticas que acontencían en los países anfitriones. En este sentido estos espacios científicos podían ser utilizados como vías diplomáticas a través de las cuales facilitar un acercamiento en aquellos conflictos iniciados en

${ }^{1183}$ Cyrille Justin Médard Van Overbergh a Robert Lehmann-Nitsche. Legado Robert Lehmann-Nitsche, 15.05 y 30.09 de 1905 , IAI, Carpeta N-0070 b 864.

${ }^{1184}$ Las otras secciones eran "Educación”, "Estadística internacional”, "Política económica aduanera", Marina, y finalmente "Medios y agentes de expansión”. Congrès international d'expansion économique mondiale 1905.

${ }^{1185}$ En esta sección expondrán el Padre Franciscus de Cleyn (1860-1951) de la Compañía de Jesús, sobre las mejores estrategias para la colonización y administración de los "nuevos" territorios. El folklorista y anticuario ingles Edward William Brabrook (1839-1930) sobre la importancia de los estudios etnográficos en los procesos de expansión Jean Luc de Ceuster discutía sobre la formación de escuelas coloniales destinadas a brindar una instrucción básica a las personas para la correcta explotación del territorio. El barón Alphonse de Haulleville (1861-1938) ofrecía un ambicioso plan para la formación de personas destinadas a "carreras de ultramar". Alexandre de Hemptinne hacia un llamado al perfeccionamiento en la instrucción de aquellas personas destinadas a enseñar en condiciones poco favorables, privadas de las comodidades europeas y forzadas a modificar sus hábitos. Edouard de Jonghe (1878-1950) abogaba por la implementación de cursos de etnografía en las universidades belgas. Brabrook 1905; Ceuster 1905; Cleyn 1905 ; Congrès international d'expansion économique mondialeDocuments préliminaires 1905; Congrès international d'expansion économique mondiale-Rapports section V 1905; De Jonghe 1905; Haulleville 1905 ; Hemptinne 1905.

1186 Tal como señalaba la crítica recogida por periódicos como el Deutsche Tageszeitung y el Hannoversches Tageblatt, "Jede andere Wissenschaft würde sich sträuben, mit dem Material zu arbeiten, das ihr gelegentlich von anderer Seite zugeworfen wird; die Ethnologie soll sich aber kümmerlich von den Brosamen nähren, die ihr Zoologen, Botaniker, Mineralogen, Geologen, Polarfahren, Tiefseeforscher (!) zuwerfen. Für derartige Studien ist immer Geld und Interesse vorhanden gewesen, für Volkerkünde in kaum nennenswertem Grade".

${ }^{1187}$ Deutsche Tageszeitung 13.05.1906, p.6. 
el terreno político. En el caso del XVII Congreso Internacional de Americanistas de 1910, los periódicos locales destacaban la presentación del austriaco Arthur Posnansky (1873-1946), no tanto por la calidad de su trabajo sobre las "razas" y monumentos prehistóricos del altiplano andino, sino por la peculiar situación política existente entre la Argentina y Bolivia, desde el fallo del presidente Figueroa Alcorta con respecto a los conflictos limítrofes entre Bolivia y Perú. Como era de esperarse Bolivia rehusará el envío de delegados oficiales, sin embargo la intervención de Lehmann-Nitsche y de Manuel Vicente Ballivián (1848-1921), presidente de la Sociedad Geográfica de la Paz, posibilitaban la presencia de Posnansky en el certamen científico.

La faceta política de las prácticas científicas cobraba, en este caso, una utilidad práctica que excedía el campo de la propia disciplina, siendo funcional a intereses ajenos. La prensa valoraba este hecho como "[...] un factor eficiente en el acercamiento de los hombres de ambos países que estarán llamados á allanar en principio y salvar las asperezas creadas por la ruptura de las relaciones diplomáticas"1188. Este camino diplomático se materializaba en la resolución del gobierno boliviano, el cual designaba una comisión de ciudadanos que, bajo la guía de Ballivián, debían recibir a los delegados del congreso de americanistas, los cuales, antes de arribar a México para la clausura de dicho evento científico, realizarían un viaje de estudio a través de Bolivia y Perú ${ }^{1189}$.

Una parte importante de los congresos científicos será la realización de salidas "al campo", momento en el cual los espacios exteriores se convertirán en verdaderos laboratorios en los cuales los científicos debatirán sobre uso de instrumentos, técnicas y procedimiento al momento de la construcción de su objeto de estudio. Estos sitios serán espacios construidos y negociados para la producción de conocimiento científico ${ }^{1190}$. Recordemos por ejemplo las excursiones organizadas por el Congrés International des Sciences Ethnographique de 1900 a los dólmenes de Boury y de Trie-Château. De igual modo los asistentes a la primera sesión del XVII Congreso Internacional de Americanistas se trasladaban desde Buenos Aires hacía México, sede de la segunda sesión, realizando una pequeña estadía en Bolivia, donde visitarán diversos emplazamientos históricos y arqueológicos, algo que la prensa local llamaba "excursión científica". De esta forma el grupo de estudiosos visitará las ruinas de Tiahuanaco y las islas del Lago Titicaca ${ }^{1191}$. La posibilidad de visitar sitios de importancia para las investigaciones en boga será uno de los elementos con los cuales los organizadores de los congresos promocionarán y validarán la elección de sus ciudades como posibles sedes de estos

\footnotetext{
${ }^{1188}$ La Nación 03.05.1910, p 6.

${ }^{1189}$ La Nación 03.05.1910; La Prensa 20.05.1910.

${ }^{1190}$ Kuklick y Kohler 1996; Rudwick 1976, 1985; Schumaker 2001.

${ }^{1191}$ El Comercio 16.06.1910; El Tiempo 16.06.1910; La Época 10, 12, y 14 de junio de 1910
} 
eventos científicos. De esta forma los "fenómenos" científicos podían ser observados y estudiados in-situ ${ }^{192}$.

La visita a estos sitios arqueológicos también revestirá interés fuera del mundo científico-académico, ya que las mismas tenían una importancia política y económica para el país anfitrión. La presencia de los estudiosos en el país era un elemento de importancia al momento de atraer inversores y capital extranjero. Tal como rezaban las columnas sociales de la prensa local "El estudio que van a verificar de nuestro país los americanistas ha de ser muy útil porque lo que más necesitamos es que se haga propaganda de las considerables riquezas que tiene nuestro suelo [...] no exploradas por falta de capitales" ${ }^{" 193}$. En este sentido también se hacia participe de estos eventos a miembros de la sociedad con alto poder adquisitivo. En el caso de la visita a las ruinas de Tiahuanaco, Manuel Vicente Ballivián y el General José Manuel Inocencio Pando Solares harían circular invitaciones en los principales puntos de encuentro para los miembros de las acaudaladas familias residentes en $\mathrm{La} \mathrm{Paz}^{1194}$.

La asistencia a los distintos congresos, especialmente aquellos de carácter internacional, permitirá a los estudiosos la compra y venta de piezas, catálogos y colecciones. Recordemos que los estudiosos residentes en América aprovecharán la oportunidad de trasladarse a Europa para asistir a la mayor cantidad de reuniones y congresos científicos. En este sentido la circulación de los estudiosos ampliaba notablemente la de los objetos antropológicos dentro del mercado comercial. Uno de los puntos más importantes del viaje de Lehmann-Nitsche a Europa en 1904 será la presentación del trabajo compilatorio Die Sammlung Boggiani von Indianertypen aus dem centralen Südamerika, editado por la prestigiosa casa Roberto Rosauer, la primera casa editora de tarjetas postales en la Argentina (Fig. 49). Dicha colección formaba parte de un proyectado Atlas antropológico compuesto por la colección de fotografías montada por Guido Boggiani $^{1195}$.

\footnotetext{
${ }^{1192}$ Lopes 2012.

${ }^{1193}$ El Diario 17.06.1910, p. 6. El resaltado es de nuestra autoría.

${ }^{1194}$ La misma rezaba: "José Manuel Pando y Manuel V. Ballivián, comisionados para la recepción de los distinguidos huéspedes del XVII Congreso Internacional de Americanista, tienen el honor de invitar a Ud. al paseo arqueológico que se verificará el día de mañana 21 del que rige, a los monumentos prehistóricos de Tiahuanacu". La Tarde 20.06.1910.

${ }^{1195}$ En 1887 realiza su primer viaje con destino a Buenos Aires, y en 1888 llega hasta Asunción del Paraguay. A lo largo de su estadía se insertará rápidamente en los círculos intelectuales y científicos locales. Luego de haber recorrido varias veces la región chaqueña vuelve a Italia hacia 1893. Resultado de esas exploraciones serán una serie de importantes anotaciones e ilustraciones publicadas en una obra titulada I Caduvei [Mbya o Guaicuru]. Viaggio d'un artista nell'America Meridionale (1895). Al mismo tiempo diversas sociedades científicas, como la Societá Geográfica Italiana y La Societá Romana d'Antropología y la Reale Academia dei Licei de Roma comienzan a publicar sus trabajos. Hacia 1896 regresa al Paraguay comenzando con un amplio registro fotográfico, realizando más de 400 fotografías en placas de vidrio con retratos de indígenas angaites, lenguas, sanapanás, caduveos, tobas, payaguás, bororo y chamacoco, que conforman el primer registro fotográfico de esos grupos. Al mismo tiempo comienza a publicar una importante serie de trabajos sobre lingüística, etnografía, geografía e historia del lugar, en
} 
La presentación de esta llamativa colección será anunciada con entusiasmo por la prensa local, la cual comentando el trágico final de Boggiani y su peón Félix Gavilán, se alegraba de que tan valiosos material no se hubiera perdido y que, gracias al desinteresado trabajo de Lehmann-Nitsche, fuera accesible al público ${ }^{1196}$. Entre uno de los mayores interesados podemos mencionar al fotógrafo de la corte real Alphons Adolph (1853-1934), el cual le solicitaba intermediara con la casa Rosauer a fin de conseguir 101 tarjetas postales de la colección Boggiani, extendiendo después su pedido a otras postales exóticas que la casa editora vendiera $^{1197}$.

En el mismo viaje Lehmann-Nitsche adquiría una serie de 24 reproducciones cromolitográficas representando a los distintos tipos raciales. Las mismas eran editadas en suiza bajo el auspicio de Rudolf Martin, el cual subvencionaba la misma a partir de un aporte superior a los 40.000 francos suizos. América era representada por 4 imágenes: un esquimal, un sioux, un caraiba y finalmente un ona ${ }^{1198}$. Esta última foto correspondía a uno de los integrantes del grupo exhibido en 1898 en Buenos Aires y fotografiado por Lehmann-Nitsche, el cual enviaba una copia a Rudolf Martin hacia fines de $1902^{1199}$.

Al mismo tiempo iniciará una serie de tratativas con el Königliche Museum für Völkerkunde de Berlin a fin de adquirir 100 reproducciones en yeso de diferentes obras escultóricas y arquitectónicas de culturas mesoamericanas y andinas. Las mismas habían sido seleccionadas por Lehmann-Nitsche del catalogo de moldes del mencionado museo ${ }^{1200}$. Esta compra se enmarcaba dentro de una estrategia educativa y científica promovida por el Museo de la Plata. Como señalaban los diarios de la época la calidad y detalle de estas reproducciones los convertían en un instrumento decisivo tanto a la hora de la enseñanza como de las investigaciones más minuciosas. La colección comprendía reproducciones de piezas procedentes del valle alto de México, Puebla, Cholula, Tula, Yucatán, Chiapas, Guatemala, Honduras y algunas piezas peruanas, entre las que destacaban La Puerta del Sol de Tiahuanaco, una placa grabada de Chavín y dos estatuas de Huaraz. A diferencia de las piezas originales, las

importantes medios como la Revista del Instituto Paraguayo, en el Boletín del Instituto Geográfico Argentino y en la Sociedad Geográfica Italiana. Martinez 2010; Giordano 2002.

${ }_{1196}$ Berliner Neueste Nachrichten 20.12.1904; Deutsche Reichanzeiger 20.12.1904; Nordeutsche Allgemeine Zeitung 22.12.1904; Vorsischte Zeitung 20.12.1904.

1197 Alphons Adolph a Robert Lehmann-Nitsche. Legado Robert Lehmann-Nitsche, IAI, 18.08, 02.09, 14.09, 27.10 de 1904.

${ }^{1198}$ El Día 10.014.1904.

1199 Agradeciéndole el envío de la copia, le confiaba Rudolf Martin que hacia principios de febrero de 1903 el trabajo sería enviado a imprimir. Rudolf Martin a Robert Lehmann-Nitsche. Legado Robert Lehmann-Nitsche, 02.12.1902, IAI, Carpeta N-0070 b 489.

${ }_{1200}$ Dicho catalogo se organizaba de la siguiente manera. Primero se dividían geográficamente las distintas regiones del mundo, de esta forma el continente americano quedaba conformado por dos regiones: Sudamérica y Norteamérica. Estas regiones geográficas eran a la vez sub-divididas en una serie de cuadrantes alfa-numéricos que asociaban a cada grupo etnográfico una letra y un número. De esta forma el comprador podía identificar rápidamente en el mapa la procedencia geográfica y étnica de las piezas que deseaba adquirir. Ethnographische Sammlung Karte 1887. 
cuales se encontraban depositadas en México y Berlin, las reproducciones contaban con la ventaja de estar completas y sin imperfecciones, dos características primordiales para su estudio y la enseñanza ${ }^{1201}$ (Fig. 50).

En la compra de dichos objetos pueden observarse las distintas estrategias empleadas para obtener un mejor precio en la adquisición de piezas arqueológicas o bien sus reproducciones. Como en toda tratativa comercial las ofertas y contraofertas buscaban obtener los mejores productos a los precios más bajos, actividad que como hemos visto anteriormente, será desempeñada tenazmente por Lehmann-Nitsche. En ese sentido Karl von den Steinen le comunicaba que el precio de las reproducciones de yeso, las cuales eran realizadas en los talleres de modelado del Königliche Museum für Völkerkunde, ascendían a 391.90 marcos alemanes. Sin embargo, aclaraba von den Steinen, podían realizar una rebaja a dicho precio a partir del valor de las piezas procedentes de Tierra del Fuego que Lehmann-Nitsche había ofrecido al museo berlinés en un total de 120 marcos. Dicho precio, remarcaba von de Steinen, había sido aceptado por la comisión de expertos de dicha institución, pero no podía elevarse ni un centavo más. Si este trato le parecía justo el valor total por las reproducciones se reducía a 271.90 marcos alemanes.

Meses más tarde von den Steinen le comunicaba a Lehmann-Nitsche que el precio por las reproducciones ascendía a 533 marcos, el cual con el descuento prometido se reducía a 413 marcos con los gastos de envío incluidos, precio en el cual cerraría la compra de las reproducciones. De esta forma la elección de Lehmann-Nitsche al frente de la selección de las piezas estará por su habilidad para negociar los mejores precios ante un contexto social y científico que le era más familiar. Las piezas arribaban al país en 1905. Años más tarde, al momento de adquirir calcos relacionados al hombre prehistórico europeo, la dirección del Museo de la Plata le reiteraba que estaba autorizado a adquirir más colecciones vinculadas a dicho tema "[...] siempre que sus precios le parezca conveniente" ${ }^{\text {"202 }}$. Como sucediese con el malogrado proyecto del jardín paleontológico, las habilidades comerciales de Lehmann-Nitsche parecían estar en más estima que sus capacidades en la enseñanza y la investigación.

\subsection{Sociedades Científicas}

A lo largo de su carrera Lehmann-Nitsche buscará formar parte de diversas sociedades científicas locales e internacionales, ya fuera en calidad de miembro o corresponsal. Dichas instituciones serán uno de los actores principales dentro del entramado de la construcción del conocimiento científico. Estos serán espacios donde circularán información, objetos y

\footnotetext{
${ }^{1201}$ El Diario 19.08.1905.

${ }^{1202}$ Karl von den Steinen a Robert Lehmann-Nitsche. Legado Robert Lehmann-Nitsche, 26.01 y 14.06 de 1905, IAI, Carpeta N-0070 b 964; Museo de la Plata a Robert Lehmann-Nitsche. Legado Robert Lehmann-Nitsche, 21.11.1922, IAI, Carpeta N-0070 b 963.
} 
producciones científicas, de esta forma los estudiosos residentes en Sudamérica obtendrán cierta "visibilidad" ante los espacios académicos y científicos europeos. Como ha señalado Irina Podgorny la pertenencia a estos espacios eruditos será uno de los pasos a la adquisición de credibilidad científica, espacios para la promoción de la discusión académica, la comunicación personal y el establecimiento de relaciones de colaboración científica ${ }^{1203}$.

Como ha sido señalado por diversos autores, la tradición europea de estos espacios será la estimulación de la investigación y la difusión a través de sus publicaciones. A partir de tempranos ejemplos en Londres, con la fundación de la Royal

Society en 1662, y París, con la Académie des Sciences fundada en 1666, multiplicidad de sociedades y academias científicas que se establecerán en las grandes capitales europeas. A lo largo del siglo XIX las primeras sociedades dedicadas al estímulo de amplios espacios del saber darán lugar a espacios más especializados e institucionalizados ${ }^{1204}$. Al mismo tiempo comenzarán a surgir las asociaciones para el avance de la ciencia, encontrando en el modelo alemán un punto de referencia ${ }^{1205}$. De esta forma Lehmann-Nitsche se vinculará desde muy temprano a estos espacios eruditos.

\subsubsection{Beneficios y obligaciones}

Los primeros vínculos de Lehmann-Nitsche con este tipo de espacios serán en función de sus tesis doctorales. De esta forma entre 1893 y 1896 se relacionará con la Berliner Gesellschaft für Anthropologie, Ethnologie und Urgeschichte (1893), la Historische Gesellschaft de Posen (1893), la Deutsche Anthropologischen Gesellschaft (1894), la Historische Gesellschaft de Bromberg (1895), la Pracownia Antropologiczna de Posen (1895), la Anthropologischen Gesellschaft Wien (1896) y el Museum schlesischer Altertümer de Breslau $(1896)^{1206}$. En algunos de los casos, será Rudolf Martin el que le sugiera asociarse a algunas de

\footnotetext{
1203 Podgorny 2009.

${ }^{1204}$ En Alemania podemos mencionar: la Königliche Societät der Wissenschaften Göttingen (1751), la Naturhistorische Gesellschaft Hannover (1797) y la Deutsche für Naturkunde Württemberg (1814), Deutsche Botanische Gessellschaft (1882) En Bélgica: la Société Royal des Sciences de Liège (1835) y la Société Scientifique de Bruxelles (1875). En España: la Real Academia de Ciencias Exactas y Naturales (1847) y la Real Sociedad Española de Historia Natural (1871). En Estados Unidos: la Academy of Natural Sciences of Philadelphia (1812), la New York Academy of Sciences (1817), la California Academy of Sciences (1853) y la Chicago Academy of Sciences (1857). En Gran Bretaña: la Geological Society (1807), la Royal Astronomical Society (1841) y la Chemical Society (1841). En Francia: la Société Botanique (1854) y la Société Zoologique (1876). Pyenson y Sheets-Pyenson 1999

${ }^{1205}$ Inspirados la Gesellschaft Deutscher Naturforscher und Aertze (1822), tendremos: la British Association for the Advancement of Science (1831), la American Association for the Advancement of Science (1848) y la Association Française pour l'Avancement des Sciences (1870). Pyenson y SheetsPyenson 1999

${ }^{1206}$ Legado Robert Lehmann-Nitsche, IAI, Carpeta N-0070 b 895, N-0070 b 938, N-0070 b 805, N-0070 b 1174, N-0070 b 988, N-0070 b 960, N-0070 1039.
} 
estas sociedades, como en el caso de la Berliner Gesellschaft für Anthropologie, Ethnologie und Urgeschichte $^{1207}$.

En las revistas de dichas sociedades publicará pequeños trabajos que correspondían a avances parciales de sus dos trabajos doctorales ${ }^{1208}$, obteniendo posteriormente acceso a importantes recursos instrumentales y bibliográficos para completar la redacción de los mismos. También enviará borradores de dichos trabajos doctorales y consultas a diversos especialistas vinculados a estos espacios eruditos. Estos le enviarían sugerencias, correcciones y diversos esquemas gráficos que ilustraban las dudas del joven Lehmann-Nitsche ${ }^{1209}$. Una vez finalizado sus dos tesis doctorales remitirá copias de los mismos a estos espacios, los cuales, en mayor o menor medida, los harán circular entre sus diversos socios ${ }^{1210}$. Al mismo tiempo los resumes sobre reuniones científicas aparecidos en la prensa de la época le permitía seguir de cerca las actividades de otras sociedades de las cuales no formaba parte.

Una vez en Argentina, Lehmann-Nitsche, tal como le decía en carta a su madre y a Rudolf Martin, buscara vincularse rápidamente a las sociedades científicas locales, al mismo tiempo que lo hacia con las internacionales. De esta forma en 1897 era nombrado miembro correspondiente de la Société d'Anthropologie de Paris y socio activo de la Sociedad Científica Argentina $^{1211}$. Al mismo tiempo se relacionará con el antecesor de la Deutschen Wissenschaftlicher Verein, la Deutsche Akademische Vereinigung (Asociación Académica Alemana). A través de la misma comenzará a obtener visibilidad social y científica al interior de los grupos académicos locales y de la sociedad civil, gracias a una serie de charlas de divulgación popular. Generalmente las mismas consistirán en resúmenes de obras de otros autores, relatos de viajes y expediciones, o bien sobre los últimos descubrimientos científicos. En este sentido la primera charla ofrecida será sobre el "Pithecanthropus erectus", descubierto por el anatomista holandés Marie Eugène François Thomas Dubois (1858-1940) en 1891, siendo ampliamente promocionada en la prensa alemana que circulaba en la Argentina ${ }^{1212}$.

Estas lecturas serán presentadas nuevamente, o bien resúmenes de las mismas, en diversos espacios e instituciones vinculadas a la comunidad alemana residente en la Argentina. Mientras que los miembros de dicha comunidad podrán disfrutar de charlas sobre la medicina prehistórica en el hall principal del "Deutscher Turnverein" de Buenos Aires" (Gimnasio

\footnotetext{
${ }^{1207}$ E. Schmidt a Robert Lehmann-Nitsche. Legado Robert Lehmann-Nitsche, IAI, 13.11.1896, Carpeta $\mathrm{N}-0070$ b 638.

1208 Historischen Gesellschaft für die Provinz Posen a Robert Lehmann-Nitsche. Legado Robert Lehmann-Nitsche, IAI, 29.07.1895, 19.10.1897, Carpeta N-0070 b 938.

${ }^{1209}$ E. Schmidt a Robert Lehmann-Nitsche. Legado Robert Lehmann-Nitsche, IAI, 21.03.1896, Carpeta $\mathrm{N}-0070$ b 638.

${ }^{1210}$ Legado Robert Lehmann-Nitsche, IAI, Carpeta N-0070 b 895, N-0070 b 938, N-0070 b 1174, N-0070 b 988, N-0070 b 960, N-0070 1039.

${ }^{1211}$ Legado Robert Lehmann-Nitsche, IAI, Carpeta N-0070 1006, N-0070 1014.

${ }^{1212}$ Argentinisches Tageblatt 08.10 y 11.10.1897; Deutsche La Plata Zeitung 10.10.1897.
} 
Alemán) ${ }^{1213}$, los estudiosos podían estrechar lazos con la comunidad alemana local, cuyos miembros demostrarán en futuras investigaciones ser los principales proveedores de apoyo logístico, monetario, datos y objetos. A charlas dirigidas a un público general, como la ofrecida en el "Deutscher Turnverein", se le sumaban algunas para grupos más reducidos, como la brindada dentro del programa de conferencias científicas del "Deutscher Frauen-Verein" (Club de mujeres alemanas). Las mujeres asistentes a esta charla no salían de su asombro ante las palabras de Lehmann-Nitsche, en las cuales se revelaba que el ordenanza de la policía y el del cuartel de bomberos eran indios araucanos ${ }^{1214}$.

En algunos casos serán estos individuos, los cuales asistían con periodicidad a las galas científicas organizadas por la Akademische Vereinigung, los que le sugieran a Lehmann-Nitsche la repetición y ampliación de ciertos temas. Tal será el caso de la mencionada charla sobre medicina prehistórica, la cual será oficiada nuevamente en 1899. A diferencia de aquella que brindara en el "Deutscher Turnverein" de Buenos Aires en 1898, esta contará con muestras de preparados, tal como anunciaba la invitación oficial y repetían los diarios alemanes que para ese entonces circulaban en Buenos Aires y La Plata ${ }^{1215}$.

En la serie de conferencias organizadas por la Deutsche Akademische Vereinigung jugaran un papel fundamental dos diarios alemanes de amplia circulación en la Argentina: el Argentinisches Tageblatt, y el Deutsche La Plata Zeitung. Estos anunciaban las conferencias con tres o cuatros días de anticipación, ofreciendo una sinopsis del tema que se ofrecería y del conferenciante. Posteriormente publicaban precisos resúmenes de los mismos. De esta forma la comunidad alemana residente en la Argentina tendría una activa participación en la vida científica del país.

Mientras tanto Lehmann-Nitsche se iba adentrando en la sociedad civil platense de la época; participando de agasajos en la casa de diplomáticos, cenas para "despedir la soltería" y fiestas ofrecidas por comerciantes de la ciudad; sin descuidar los vínculos con la comunidad alemana. Esto implicaba ciertas responsabilidades y obligaciones al interior de la sociedad civil y científica alemana residente en el país. De esta forma Lehmann-Nitsche junto con Santiago Roth y Rudolph Hauthal, serán los principales responsables de una excursión programada por la Deutsche Akademische Vereinigung a la ciudad de La Plata. El programa comenzaba con el recibimiento del contingente de 40 personas, entre hombres y mujeres, en la estación central de ferrocarriles. Posteriormente se realizaba un almuerzo en el Restaurant Germania y finalmente la visita al Museo de la Plata, en la cual los asistentes contarán con la guía de LehmannNitsche, Roth y Hauthal; los cuales además realizarán presentaciones de sus trabajos y objetos de las colecciones a su cargo. Los diarios alemanes destacaban la suerte de los socios de la

1213 Argentinisches Tageblatt 10.09.1898; Deutsche La Plata Zeitung 10.09.1898.

1214 Argentinisches Tageblatt 01.07.1901; Deutsche La Plata Zeitung 05.07.1901.

1215 Deutsche La Plata Zeitung 07.07 y 09.07.1899. 
Deutsche Akademische Vereinigung, los cuales podían contar con anfitriones que desempeñaban un papel tan importante en el desarrollo de la ciencia local, y que al mismo tiempo tenían una participación activa en los principales espacios y eventos científicos de Europa ${ }^{1216}$.

Esto no significaba descuidar las responsabilidades y obligaciones al interior del colectivo de estudiosos argentinos. En muchas de las visitas de diplomáticos, funcionarios, y científicos alemanes a la Argentina, serán los estudiosos alemanes residentes en el país los que oficien de nexo entre ambas partes y en muchos casos deberán hacer frente a situaciones fortuitas. Tal es el caso de la visita del geógrafo alemán Albrecht Friedrich Karl Penck (18581945) a la Argentina en 1907. En dicho año Elina González Acha de Correa Morales (18611942); futura primera presidenta de la Sociedad Argentina de Estudios Geográficos; se comunicaba con Lehmann-Nitsche a fin de resolver una serie de inconvenientes acontecidos ante la llegada de Penck.

El primero de estos era la supuesta promesa de Luis María Torres de ofrecer alojamiento al geógrafo alemán en el Museo de la Plata y un pasaje general para que este pudiera viajar a gusto entre La Plata y Buenos Aires. No solo esto se encaminaba a no cumplirse, sino que no habían dispuesto a una persona que supiera español y alemán, y pudiera oficiar de guía a Peck. Ante esto Correa Morales le pedía a Lehmann-Nitsche que intercediera ante Torres para la adquisición de los pasajes gratuitos y lo consultaba sobre la posibilidad de oficiar como guía y traductor; y sobre la posibilidad de que la Deutsche Wissenschaftlicher Verein asumiera los gastos de alojamiento y transporte. Ante esta situación Correa Morales deseaba saber la opinión de Lehmann-Nitsche sobre proponerle a Penck que desista de su viaje a la Argentina, tal como le había sido sugerido por el geólogo alemán Anselmo Windhausen (1882-1932), y esperará a que el próximo año la Universidad Nacional de Buenos Aires cursará una invitación oficial y se responsabilizará de los gastos ${ }^{1217}$.

La participación en las sociedades científicas locales e internacionales garantizaba, entre otras cosas, la circulación y promoción de los trabajos redactados por los estudiosos. En muchos casos las propias sociedades de las cuales los estudiosos formaban parte serán las que les soliciten algún tipo de trabajo para la publicación en revistas especializadas, revistas de divulgación o presentaciones en diversos tipos de acontecimientos científicos y sociales. De esta forma Lehmann-Nitsche redactaba trabajos e informes sobre la tradición de caza indígena para la Sociedad Argentina de Estudios Geográficos, elaboraba un resumen sobre la madera del cardón y la aplicación a la ebanistería nacional para la Sociedad Argentina de Ciencias Naturales, remitía fotos e informes del XVII Congreso Internacional de Americanistas a la Sociedad Jurídico-Literario de Ecuador, o presentaba extensos y descriptivos resúmenes de las

\footnotetext{
${ }^{1216}$ Argentinisches Tageblatt 20.07 y 26.07.1903; Deutsche La Plata Zeitung 23.07 y 26.07. 1903. 1217 Elina González Acha de Correa Morales a Robert Lehmann-Nitsche. Legado Robert LehmannNitsche, IAI, 21.09.1907, Carpeta N-0070 b 1022.
} 
excursiones a Tierra del Fuego (1902) y el Noroeste Argentina para las veladas científicas de la Deutsche Wissenschaftlicher Verein ${ }^{1218}$. Tal como esta última se encargaba de señalar con respecto a la difusión de los trabajos científicos de los estudiosos alemanes residentes en Argentina "La empresa planeada solo puede llegar a una conclusión satisfactoria a través de la cooperación de la mayoría de los socios de la asociación" ${ }^{" 1219}$. Este tipo de cooperación operaba en varios niveles. Por un lado los estudiosos obtendrán un espacio que les proveía de un modo económico y eficaz para que sus obras comiencen a circular dentro del círculo de estudiosos de distintos países. Tal como hemos visto en los demás capítulos la circulación se posibilitaba a través de las redes de intercambio institucional, y al mismo tiempo a partir de recomendaciones personales de otros estudiosos. De esta forma podemos constatar la recepción simultánea de los trabajos de Lehmann-Nitsche en diversos repositorios nacionales e internacionales.

Uno de los principales espacios a partir de los cuales Lehmann-Nitsche buscará posicionarse en el ámbito científico local será sin dudas La Junta de Historia y Numismática Americana. Sus actividades habían comenzado hacia 1892, con una serie de tertulias organizadas en la casa del coleccionista y numismático Enrique Peña (1848-1924) y Alejandro Rosa. Entre los asistentes a estas veladas se encontraban el general Bartolomé Mitre (18211906), el médico y abogado Ángel Justiniano Carranza (1834- 1899), el filatelista José Marcó del Pont (1851-1917), el legislador y coleccionista Alfredo Meabe (1849-1916), el escritor uruguayo Clemente L. Fregeiro (1853-1923) y Ernesto Quesada en calidad de "oyente". Hacia 1893, Bartolomé Mitre estimaba necesario "[...] era necesario que la Junta diera señales de vida, haciendo algo práctico y de utilidad, y no limitarse a acuñar medallas" ${ }^{1220}$. Llamativamente el 04 de junio de 1893, la acuñación de la primera medalla daba inicio formal a la Junta de Numismática Americana. En 1895 se ampliaría el número de miembros y se cambiaría la denominación a Junta de Numismática e Historia Americana, con el objetivo de admitir a otros estudiosos $^{1221}$.

El 11 de septiembre de 1906 José Marcó del Pont le remitía a Lehmann-Nitsche el diploma que lo certificaba como miembro activo de la Junta de Numismática e Historia Americana $^{1222}$. Este último agradecía a Enrique Peña; por entonces presidente de la misma; por dejarlo estar en el "[...] seno de la más alta inteligencia argentina [...]"1223. El Deutsche La

${ }^{1218}$ Legado Robert Lehmann-Nitsche, IAI, Carpetas N-0070 b 1022, N-0070 b 866, N-0070 b 1009.

1219 En el original alemán "Da sich das geplante Unternehmen nur durch das Zusammenarbeiten der Mehrzahl der Vereinsmitglieder zu einem befriedigenden Abschluss bringen lässt". Deutsche Wissenschaftlicher Verein a Robert Lehmann-Nitsche, IAI, 09.07.1908, Carpeta N-0070 b 925

${ }^{1220}$ Boletín de Junta de Historia y Numismática 1926, p. 229.

${ }^{1221}$ Pegoraro 2009; Ravina 1996; Romero 1989

1222 José Marcó del Pont a Robert Lehmann-Nitsche. Legado Robert Lehmann-Nitsche, 11.11.1906, IAI, Carpeta N-0070 b 957.

${ }^{1223}$ Robert Lehmann-Nitsche a Enrique Peña. Legado Robert Lehmann-Nitsche, 15.11.1906, IAI, Carpeta N-0070 b 957. 
Plata Zeitung mencionaba en una escueta nota de 5 párrafos que el antropólogo alemán era el primer miembro activo no-argentino, desconociendo que Fregeiro, nacido en Uruguay, era parte de la misma ${ }^{1224}$.

En la redacción sobre las disposiciones para el funcionamiento y las formalidades para la designación de nuevos socios, Ernesto Quesada tendrá un importante papel. A partir de una propuesta suya se estipulaba que la presentación de las nuevas candidaturas debía ser hecha por tres miembros activos de la junta, los cuales debían dar cuenta de la trayectoria de los postulantes a partir de sus obras publicadas. En este sentido es posible suponer que Quesada, debido al vínculo amistoso entre ambos, impulsara la candidatura de Lehmann-Nitsche.

Los estatutos de la Junta de Numismática e Historia Americana estipulaban que una vez designado los nuevos socios activos, estos debían leer un trabajo sobre algún tema de su elección en el acto de su incorporación. En el caso de Lehmann-Nitsche la preparación de la misma se dará al mismo tiempo que gestionaba la adquisición de otras de las insignias que acreditaban la condición de miembro de la junta: una medalla conmemorativa de plata ${ }^{1225}$. Finalmente el 16 de junio de 1907, Lehmann-Nitsche presentaba dos lecturas como parte de su conferencia: "El origen de la bota de potro" y "El juego de la taba", los cuales presentaba como parte de una supuesta obra en preparación intitulada Origen de algunas costumbres populares del Río de La Plata.

A principios de siglo XX las sesiones de la Junta de Numismática e Historia Americana serán el espacio de reunión y discusión de gran parte de los estudiosos vinculados al estudio del hombre. En este sentido Lehmann-Nitsche buscará promocionar a través de las mismas sus trabajos folklóricos e históricos. Muchas de estas presentaciones corresponderán a avances parciales de sus investigaciones -que en algunos casos no se completarían- o bien resúmenes de obras publicadas ${ }^{1226}$. La difusión de su obra también se verá favorecida por ciertas decisiones institucionales de la Junta de Numismática e Historia Americana, tales como la conformación de una biblioteca formada por todas las obras escritas de sus socios ${ }^{1227}$.

${ }^{1224}$ Rezaba dicha nota "Prof. Dr. R. Lehmann-Nitsche wurde als erster nichtargentiner zum aktiven Mitgliede der Junta de Historia y Numismatica Americana zu Buenos Aires ernannt”. Diario Deutsche La Plata Zeitung, 16.11.1911.

${ }^{1225}$ La compra de la misma era opcional. Estas eran realizadas en la Fábrica Nacional de Medallas, propiedad de José Bellagamba y Constante Rossi. El costo de la misma era de 10 pesos moneda nacional. En el caso de Lehmann-Nitsche se agregarían 3 pesos más debido a la insistencia de este en grabar su nombre. Junta de Historia y Numismática Americana a Robert Lehmann-Nitsche. Legado Robert Lehmann-Nitsche, 24.01.1907, IAI, Carpeta N-0070 b 957.

${ }^{1226}$ Luego de su lectura inaugural, podemos constatar 35 presentaciones realizadas por Lehmann-Nitsche. Las mismas abarcarán temas como: "El primer poeta criollo del Río de La Plata", "La casa natal de San Martín en Yapeyu", "La boleadora indígena en nuestras guerras" o "Causas criminales sobre intentada independencia en los años 1908 y 1809".

1227 Junta de Historia y Numismatica Americana a Robert Lehmann-Nitsche. Legado Robert LehmannNitsche, 24.07.1927, IAI, Carpeta N-0070 b 957. 
Al mismo tiempo que se obtendrán beneficios de la participación en las sociedades científicas, tendremos diversas obligaciones al interior de las mismas. Estas podían ser desde la distribución de los trabajos de otros miembros, la redacción de trabajos especiales, la participación en charlas y eventos especiales o bien cuestiones vinculadas a la organización y funcionamiento de dichas sociedades. Un ejemplo de esto es el proyecto de la Sociedad Científica Argentina por instruir una "Organización didáctica" en Buenos Aires, cuyos objetivos eran "[...] la cultura pública y auxiliar al estado en su obra en este orden fundamental de actividades y difundir sus beneficios a todo aquel que desea aprender, tendiendo si es posible a crear un ambiente propicio al estudio".

Con esto en mente se comunicaban con Lehmann-Nitsche a fin de que formara parte activa de la misma, "[...] en la seguridad de que el señor profesor no querrá negarnos su auxilio [...]”. Meses más tarde Lehmann-Nitsche se sumaba a dicha organización, significando "[...] la gratitud de la Institución por el patriotismo y el amor a la cultura pública con que usted ha querido responder a su llamado."1228. Como miembro titular de dicha organización deberá organizar cursos y conferencias en los cuales repitiera los contenidos de los programas oficiales de las instituciones a las cuales se encontraba vinculado ${ }^{1229}$. Este tipo de discursos, en los cuales se mezcla el patriotismo, la entrega desinteresada por los beneficios del país y el amor por la ciencia, será una de las características en común de las sociedades científicas sudamericanas ${ }^{1230}$.

Otro ejemplo de esto podemos encontrarlo en la correspondencia sostenida con la Sociedad Argentina de Estudios Geográficos. En 1921 Elina González Acha de Correa Morales le escribía a Lehmann-Nitsche a fin de saber sobre su participación en un encuentro de la Sociedad Geográfica de Buenos Aires en la cual se definirían autoridades y el programa de la misma. Según Correa Morales dicha sociedad surgía a partir de la iniciativa de un grupo de jóvenes que contaban con "[...] los mejores deseos de formar un centro serio de estudios geográficos, (pero) estuvieron al principio algo desorientados”. Correa Morales; al mismo tiempo que confirmaba la colaboración del geólogo alemán Hans Keidel (1877-1954), del botánico argentino Cristóbal María Hicken (1875-1933) y del paleontólogo argentino Juan José Nágera Ezcurra (1887-1966); le escribía a Lehmann-Nitsche y le pedía a este, y a Juliane Dillenius, su colaboración o "[...] por lo menos asistir a las primeras asambleas para dejar

1228 Sociedad Científica Argentina a Robert Lehmann-Nitsche. Legado Robert Lehmann-Nitsche, IAI, 01.05 y 21.08.1916, Carpeta N-0070 1014. El resaltado es de nuestra autoría.

${ }^{1229}$ Aclaraba la Sociedad Científica Argentina que "Los propósitos de la "Organización" (en referencia a la Organización didáctica) eran la repetición de los cursos o de algunas de las conferencias que los profesores dan en los institutos oficiales correspondientes, siendo la entrada a ellos del todo libre". Para esto se les pedía indicar a los miembros activos: 1) Tema del curso o de la o las conferencias que se propone dar; 2) Horas, días y local en que se desea hacerlo pudiendo contar desde luego con el de esta Sociedad y el de los institutos de enseñanza que se solicitarán al efecto; 3) Aparatos, instrumentos o elementos que puedan serle necesarios para sus fines. Sociedad Científica Argentina a Robert LehmannNitsche. Legado Robert Lehmann-Nitsche, IAI, 01.01.1917, Carpeta N-0070 1014.

${ }^{1230}$ Lopes, 1999 b. 
encaminado un centro de estudios geográficos serios que tanta falta hace entre nosotros", en la seguridad de que "[...] Ud. que tanto ha hecho por la cultura de esta mi tierra, lleve ahora sus luces a la obra de la juventud" ${ }^{1231}$. Finalmente tanto Lehmann-Nitsche, como Juliane Dillenius y los demás estudiosos mencionados por Correa Morales, formarían parte de la Junta Directiva de dicha sociedad, la cual quedaba constituida como la Gaea Sociedad de Estudios Geográficos ${ }^{1232}$. Al crearse posteriormente la "División de Etnografía" de dicha sociedad Lehmann-Nitsche sería nombrado presidente, participando también en la elaboración de dos bocetos para el escudo de la misma ${ }^{1233}$.

\subsubsection{La Gran Guerra}

La Gran Guerra de 1914 producirá cambios y tensiones sociales, que en el caso de la Argentina se traducirá de diversas maneras: problemas locales de inflación, desocupación, descenso en el número de inmigrantes, periodos de interrupción en las comunicaciones, modificaciones en los diversos niveles de enseñanza en los cuales se comenzarán a acentuar la historia y la lengua nacional, etc. ${ }^{1234}$. Estos elementos incidirán en el grupo de estudiosos locales. Al mismo tiempo aquellos miembros de origen alemán se verán inmersos en una serie de agudos conflictos al interior de la sociedad civil y académica platense. Estos pueden ser rastreados a través de las publicaciones de la prensa local y en la correspondencia privada de Lehmann-Nitsche, la cual al mismo tiempo da cuenta de los diversos emprendimientos y debates que se suscitaron en el conjunto de estudiosos, a nivel internacional, a favor y en contra de los estudiosos de origen alemán.

Hacia comienzos de 1914 los vínculos entre Alemania y Argentina se encontraban en un punto álgido. En materia de importación y exportación entre ambos países, la Argentina era el principal socio alemán en Latinoamérica, superado solamente por los Estados Unidos. En forma similar los capitales y las inversiones alemanas en el país se ubicaban en segundo lugar, detrás

1231 Elina González Acha de Correa Morales a Robert Lehmann-Nitsche. Legado Robert LehmannNitsche, IAI, 24.03.1921, Carpeta N-0070 b 1022

${ }^{1232}$ La Junta Directiva quedaba conformada de la siguiente manera: 1) Presidente: Elina González Acha de Correa Morales; 2) Vice-presidente $1^{\circ}$ : Cristóbal María Hicken; 3) Vice-presidente $2^{\circ}$ : Hans Keidel; 4) Secretario de actas: Osvaldo Bugallo; 5) Secretario de correspondencia: Elisa S. Bachofen; 6) Tesorera: Esther S. Bachofen; 7) Vocales: Carlos Ameghino, Francisco de Aparicio, Simón Chavance, Carlos Correa Luna, Lucio Correa Morales, Roberto Dabbene, Arturo V. Frugone, Carlos Gallardo, Roberto Gomez, Roberto Gomez Adams, Federico Graef, Pascual Guaglianone, Agnes Lanfredi Costa, Juliane Dillenius de Lehmann-Nitsche, Robert Lehmann-Nitsche, Juan José Nájera, Raul Pietranera, Federico Reichert, Walter Schiller, Guillermo Schulz, Pedro Serié y Berta Wernicke. Osvaldo Bugallo a Robert Lehmann-Nitsche. Legado Robert Lehmann-Nitsche, IAI, 14.07.1922, Carpeta N-0070 b 1022

${ }^{1233}$ Elina González Acha de Correa Morales a Robert Lehmann-Nitsche. Legado Robert LehmannNitsche, IAI, 10.11.1927, Carpeta N-0070 b 1022.

1234 Agulla 2001; Buch 2001; Cattaruzza 2001; Fernández López 2001; Fernández Stacco 2002; Klappenbach 2002; Ranea 2002; Romero 2001. 
de Gran Bretaña ${ }^{1235}$. En el caso particular de los estudiosos de origen alemán, hasta el inicio de la Gran Guerra podemos notar una rápida aceptación por parte de las comunidades locales argentinas, principalmente por el vacío académico y científico que estos vinieron a ocupar ${ }^{1236}$. Sin embargo a partir de 1914 el prestigio y la prosperidad que habían logrado acumular se verán cuestionados duramente.

A partir de agosto de 1914 diarios como La Prensa y La Nación comenzaban a capitalizar los sentimientos nacionalistas de la sociedad porteña, declarando la entrega total de esta última a la causa de los aliados. Al mismo tiempo los periódicos alemanes que circulaban en el país comenzaban a reafirmar las causas nacionales de Alemania, incentivando la solidaridad entre los miembros de la comunidad alemana argentina ${ }^{1237}$. Será en las páginas de los periódicos donde comiencen a verse las primeras consecuencias de la guerra en la comunidad local. Un caso particular será el que involucré a Lehmann-Nitsche y el senador argentino -nacido en España- Enrique del Valle Iberlucea (1877-1921).

A principios de 1914 la administración del Museo de La Plata había resuelto establecer en los días que el museo se abría al público una guardia compuesta de un vigilante, 3 cadetes de policía, los porteros de servicio del personal del museo y un "jefe superior de guardia". Dicha función le tocaría oficiar a Lehmann-Nitsche el domingo 15 de noviembre del mencionado año. Ese día Enrique del Valle Iberlucea, junto con una comitiva de 60 personas del Ateneo Popular $^{1238}$, había decidió realizar una excursión a la ciudad de La Plata que incluiría: El Bosque, La Escuela Superior de Física, el Internado del Colegio Nacional de la Universidad y el Museo de La Plata $^{1239}$. Al arribar a este el portero se acercará a pedirle su bastón, obteniendo una brusca negativa por parte de Del Valle Iberlucea, el cual alegaba que era profesor de la Universidad Nacional de La Plata y Senador Nacional. Los miembros de la comitiva adoptarán una postura similar, negándose a entregar los bastones. Ante un nuevo intento y un nuevo desmán, será Lehmann-Nitsche el que intente interceder.

Según la denuncia efectuada por este último antes de que pudiera mediar algún tipo de palabra Del Valle Iberlucea le grito en voz alta: “¿Qué quiere usted de mi? ¿Usted quiere mi bastón?, no se lo voy a entregar insolente". Continuando con su relato, Lehmann-Nitsche aclara que trato de explicar que él estaba oficiando como funcionario inspector del Museo de La Plata

1235 Entre alguno de los principales emprendimientos podemos mencionar: 1) el Banco Alemán Transatlántico, que financiará la deuda de la provincia de Buenos Aires e invertirá en la construcción del Puerto de Santa Fe; 2) el capital puesto en la explotación del tanino en el Noroeste y el petróleo en el Sur; 3) la Compañía Alemana Transatlántica de Electricidad, que monopolizará el mercado de la electricidad y el Tramway.

${ }^{1236}$ Podgorny y García S. 2000.

${ }^{1237}$ Bryce 2008; Friedrich 2008; Newton 1977; Sauveur-Henn 1995, 2010.

${ }^{1238}$ Esta asociación ligada al Partido Socialista había sido fundada por del Valle Iberlucea. La visita al Museo de La Plata se enmarcaba dentro del programa de visitas anuales a instituciones científicas de La Plata. Podgorny y García S. 2000.

1239 Ibídem. 
y que por lo tanto debía hacer cumplir el reglamento, siendo interrumpido por Del Valle Iberlucea el cual lo interpelará "Usted no tiene derecho alguno de estar aquí, insolente, aquí no estamos entre sus prusianos, estamos en una Republica. Usted no es argentino, usted es súbdito del Kaiser, es un alemán, mejor dicho animal. Yo soy senador nacional”1240.

En forma inmediata Lehmann-Nitsche se dirigirá, junto con un vecino de la ciudad y a los tres empleados que habían compartido con él la guardia en el Museo de La Plata, a radicar la denuncia a la Comisaría $3 a$ de La Plata ${ }^{1241}$. El día después Lehmann-Nitsche les escribía al geólogo alemán Lutz Witte (1885-1963) y a A. Kuss a fin de que fueran sus padrinos dándoles pleno poder " $[\ldots]$ para proceder del modo que juzguen conveniente y considerando la gravedad de los insultos inferidos" ${ }^{1242}$. Estos se comunicaban con Del Valle Iberlucea, el cual les aclaraba que no estaba acostumbrado a resolver sus problemas a través de terceros y mucho menos padrinos. Agregaba además que no veía en un "duelo de honor" la manera de solucionar los problemas personales, alegando que Lehmann-Nitsche veía en esto un pretexto para encauzar la declarada hostilidad de los profesores alemanes a su persona. Esto último, según Del Valle Iberlucea, se debía a una serie de charlas brindadas por él en la Facultad de Filosofía y Letras de Buenos Aires en las cuales trataba conceptos del imperialismo germánico. Finalmente Del Valle Iberlucea recomendaba a los padrinos de Lehmann-Nitsche que dejarán el asunto en manos de las autoridades de la universidad platense, publicando la carta de respuesta en el periódico socialista La Vanguardia, algo que Witte y Kuss le informaban a LehmannNitsche ${ }^{1243}$.

Este periódico titulaba en una columna "Ehrenerklärung!!...desahogo imperialista de un profesor alemán". En la misma se referían a Lehmann-Nitsche como "un profesor alemán de la universidad de La Plata" que, molesto por las apreciaciones de Del Valle Iberlucea sobre el imperialismo germánico, había utilizado la excusa del reglamento del Museo de La Plata para “[...] el desahogo patriotero [...] y pretendió, como se estila entre "caballeros", lavar con sangre la afrenta". Cerrando la nota con la carta del "compañero" Del Valle Iberlucea, el redactor de la nota aclaraba que "En las universidades alemanas, los estudiantes se emborrachan con cerveza y

${ }^{1240}$ Bahía Blanca 27.11.1914; La Gazeta 21.11.1914; La Tarde 21.11.1914; La Unión 23.11.1914.

${ }^{1241}$ La misma decía: "Hallándome de servicio como jefe superior de la guardia, fui advertido por los ordenanzas que el señor Enrique del Valle Iberlucea se había negado en forma brusca a entregar su bastón al portero, como más adelante a los ordenanzas que se le acercaron con el mismo pedido. Al ejemplo dado por el citado señor, seguían los socios del Ateneo Popular de Buenos Aires a quienes no se pedía la entrega de los respectivos bastones, habiéndose negado el señor Del Valle, presidente de aquel Instituto. Pedí yo entonces a un ordenanza la chapa numerada. Viéndome a mí el señor Del Valle, a una distancia de cuatro a cinco metros aproximadamente, se me acercó, y sin que yo hubiera pronunciado palabra alguna, empezó a insultarme con términos ofensivos. Le expliqué tranquilamente que estaba de servicio y plenamente autorizado para hacer respetar el Reglamento. La contestación del citado señor era repetición y aumento de aquel vocabulario, interrumpido a cada rato por la alusión a la senaduría nacional y el profesorado universitario. Dado el carácter ofensivo y personal del lenguaje adoptado por el señor Del Valle Iberlucea, me abstuve de contestarle y me retiré". García y Podgorny 2000, p. 24.

${ }^{1242}$ La Gazeta 25.11.1914; La Unión 30.11.1914.

1243 Ibídem. 
acostumbran luego ensayar duelos de honor, dándose tajos en el rostro con espadines especiales. Posiblemente, esta costumbre habrá impulsado al profesor alemán a enviar sus padrinos al doctor del Valle Iberlucea",1244.

El diario La Gazeta repetiría el contenido de esta nota, detallando que las lecciones de Del Valle Iberlucea habían "sacado de quicio" a Lehmann-Nitsche, el cual era conocido por ser un caballero "sumamente patriota". Al mismo tiempo brindaba otra versión del asunto, aclarando que al momento de llegar al Museo de La Plata, Lehmann-Nitsche se encontraba en la escalinata del mismo y fue en ese momento que le exigió al senador nacional su bastón, el cual al negarse hizo "rebosar la ira al sabio alemán". Junto con la reproducción de la carta de Del Valle Iberlucea, la nota cerraba aclarando que "[...] sin género de dudas (Lehmann-Nitsche) debe haber hecho proezas como gran espadachín allá en sus mocedades"1245.

Ese mismo día el Argentinisches Tageblatt refutaba la nota publicada en La Vanguardia. En una columna titulada "Los dirigentes de los socialistas locales" 1246 daban cuenta de las malintencionadas conferencias de Del Valle Iberlucea, al cual describían como una persona "con muy poco entendimiento de la naturaleza alemana"1247. Al mismo tiempo se asombraban de que un senador socialista y profesor universitario buscará en un terreno neutral como una universidad nacional, incentivar los sentimientos antialemanes de los estudiantes. El mismo diario comentaba con asombro e ironía que esto sucedía en las clases "Historia mundial" de la Facultad de Filosofía y Letras de Buenos Aires donde Del Valle Iberlucea era profesor suplente $^{1248}$. Su actitud, junto con las publicaciones de La Vanguardia, era vista por los redactores del Argentinisches Tageblatt como otra de las formas de ataque a las cuales debía hacer frente la comunidad alemana ${ }^{1249}$.

El 20 de noviembre el diario La Unión notificaba que según el sumario policial los conflictos se habían iniciados por Del Valle Iberlucea ${ }^{1250}$. Por otra parte publicaciones como La Sociedad, órgano del Centro Regional La Plata de la Liga Social Argentina, se avergonzaban y mofaban de la postura asumida por el senador nacional, haciéndole saber que era de público conocimiento para los asistentes al Museo de La Plata que se estaba en la Argentina, un país de

\footnotetext{
1244 La Vanguardia 19.11.1914.

1245 La Gazeta 19.11.1914.

${ }^{1246}$ En el original alemán "Die führenden Kreise der hiesigen Sozialisten”. 19.11.1914.

1247 En el original alemán "Der Senator Dr. Del Valle Iberlucea, der blutwenig von deutschem Wesen verstehen wird". Argentinisches Tageblatt 19.11.1914.

${ }^{1248}$ Argentinisches Tageblatt 21.11.1914

1249 Aclaraba el redactor de la nota "Man sieht aber, wenn es gegen die verhassten Deutschen geht, sind die Sozialisten alle auf dem Plan, und ihr Parteiblatt marschiert Arm in Arm mit Blättern, zu denen sie sonst im schärfsten Gegensatz steht. Von dem Blatte sollte man doch etwas mehr Sachlichkeit erwarten dürfen”. Argentinisches Tageblatt 19.11.1914.

${ }^{1250}$ La Unión 20.11.1914.
} 
libertad tal que permitía a los representantes del pueblo argentino servirse "[...] de las inmunidades del cargo y pronuncié irónicamente las frases de Argentina para sus caprichos"1251.

Finalmente el 28 de noviembre de 1914, los empleados del Museo de La Plata serían citados a declarar. El portero, Pascual Luque, el jefe de preparadores, Juan Durione, y el ayudante preparador, Octavio B. Fernández, ratificarían y ampliarían su denuncia ante el Consejo Académico del Instituto del Museo. Ambos coincidían en que Del Valle Iberlucea había acusado a Lehmann-Nitsche llamándole "prusiano", invitándolo a "defender su patria", e incitando al público a "¡a acabar con este kaiserismo!" 1252 . Finalmente el asunto quedaría archivado, sin embargo da cuenta del ambiente de tensión en el cual los estudiosos y la comunidad alemana vivían en la época de la Primera Guerra Mundial.

Los diarios también tendrán un interesante papel al momento de publicar análisis críticos a los trabajos científicos desarrollados por los estudiosos alemanes en el país, especialmente si estos se dedicaban a cuestiones vinculadas a las tradiciones "argentinas". El sentimiento nacionalista cobraría especial fuerza en contra de las investigaciones folklóricas de Lehmann-Nitsche. Hacia 1915 un editorial del diario Crónica de Buenos Aires daba cuenta de los trabajos del "paleontólogo Leman Nietzche" (sic). Preguntándose acerca de los motivos que habían impulsado a Lehmann-Nitsche a venir a la Argentina, la nota ofrecía rápidamente a sus lectores la respuesta a este interrogante: el dinero. Dando cuenta del "[...] hermoso estipendio" que cobraba Lehmann-Nitsche por "[...] descubrir fósiles a pedido del gobierno nacional [...]”; motivo por el cual se había domiciliado en La Plata; ya que "[...] estos alemanes, por más sabios que sean, o quizá por eso mismo, románticos y todo, no se descuidan"1253.

La riqueza fosilífera argentina, tal como aclaraba la nota, no necesitaba descubrirse ya que algunos de estos elementos "[...] se muestran solos [...] y algunos se muestran por allí, vivitos y coleando". Este último párrafo iba dedicado a aquellos representantes del gobierno acusados de simpatías germanófilas, que eran aquellos que garantizaban, según la nota, la presencia de Lehmann-Nitsche en el país, al cual acusaban de ponerse al servicio del Kaiser y ser "[...] a-leman-ische-zeitung". Claramente esto apuntaba también contra la postura adoptada por Theodor Alemann durante la guerra, el cual manifestaba implícitamente en su diario, la superioridad cultural alemana. Seguidamente la nota sentenciaba que los estudios sobre folklore argentino realizados por un alemán "[...] resulta tan desopilante como un puchero con "chucrute" [...]", pero no se podía esperar otra cosa, agregaba, del "pródigo gobierno "alemanoide" argentino ${ }^{1254}$. A este último lo acusaban de regalarle 50.000 pesos moneda nacional a Lehmann-Nitsche por esta obra, en referencia al subsidio otorgado a la Universidad Nacional de La Plata.

${ }^{1251}$ La Sociedad 29.11.1914.

1252 García y Podgorny 2000.

1253 Crónica 15.01.1915

1254 Ibidem. 
Un tono similar tendrá la noticia de la publicación del trabajo de Lehmann-Nitsche sobre Santos Vega, aparecida en La Pelea Nacional de Buenos Aires. Con el título de "La Ciencia en Solfa. La Kaucho von Sandos Fega ¡Makana!”, la nota afirmaba que la publicación efectuada por Lehmann-Nitsche se inscribía como punto culmine de la sistemática destrucción de "[...] las tradiciones más netamente criollas [...]", con el pretexto de servir al país. Dando cuenta de las anteriores publicaciones referida a la temática folklórica; a las que describían como un "[...] fárrago de incongruencias que reúne sin ton ni son [...]"; aclaraba que la presente monografía; a la cual haciendo un juego literal la calificaba de "escrito simiesco"; era un intento de "bavarismo" por destruir las tradiciones más propias de la Argentina. Abundando en improperios para con la metodología de recolección sistemática y comparación promovida por la ciencia alemana, el autor de la nota cerraba la misma burlándose de la traducción al alemán que Lehmann-Nitsche realizará con parte de Santos Vega, afirmando la tristeza que daba ver convertido en un alemán al personaje de la poesía de Rafael Obligado ${ }^{1255}$.

Al mismo tiempo que en la prensa local argentina realizaba estas valoraciones de los trabajos folklóricos de Lehmann-Nitsche o bien reproducían detalles del incidente de este con Del Valle Iberlucea, se reunía en Francia la Société préhistorique de dicho país. Emil Taté, presidente de la mencionada sociedad, inauguraba el encuentro con un discurso patriótico y emotivo en el cual llamaba a recordar aquellos miembros que combatían en la armada. Entristecido por la muerte de Joseph Déchelett, un socio de Roanne, llamaba a la expulsión de la Société préhistorique de todos los miembros de nacionalidad alemana y astro-húngara, moción aprobada por unanimidad ${ }^{1256}$. Unos meses más tarde Lehmann-Nitsche se enteraba de esta decisión, situación ante la cual expresaba su mayor rechazo, tal como le comunicaba a los miembros de la Berliner Gesellschaft für Anthropologie, Ethnologie und Urgeschichte ${ }^{1257}$.

La situación era similar en otros países donde los estudiosos de origen alemán desempeñaban sus tareas. Rudolf Lenz escribía desde Chile describiendo una situación en la cual los tiempos de alegría y paz habían quedados sepultados en el pasado desde el inicio de la guerra. A pesar del capital alemán invertido en Chile, a pesar de las contribuciones de persones de origen alemán en amplios sectores de la sociedad chilena, “[...] el estado de ánimo, como en casi todas partes, en general no es favorable para nosotros [...]". Las esperanzas de Lenz para la reversión de esta situación se basaban, tristemente, en las desgracias sufridas por otros compatriotas, tal como le aclaraba a Lehmann-Nitsche a pesar de todo "[...] la situación no es tan mala como la suya $[\ldots]^{p 1258}$.

\footnotetext{
${ }^{1255}$ La Pelea Nacional 27.10.1917.

1256 BSPF 1914.

1257 Robert Lehmann-Nitsche a Berliner Gesellschaft für Anthropologie, Ethnologie und Urgeschichte. Legado Robert Lehmann-Nitsche, IAI, 10.04.1915, Carpeta N-0070 b 895.

${ }^{1258}$ En el original alemán "Da Ich habe aufgeschrieben was jeder bekommen hat. Seit Ausbruch des Krieges hat man zu nicht mehr Lust und Ruhe. Für unsern Heldelnkampf selbst haben wir ja die besten
} 
Lenz no estaba tan errado, si bien su carta estaba fechada en febrero de 1915, la misma se había adelantado considerablemente a una serie de eventos del conjunto de estudiosos argentinos. Hacia agosto de 1916 las páginas de La Nación, La Prensa y La Razón daban cuenta de un acto de apoyo a los aliados por parte de un grupo de médicos argentinos. Bajo titulares como "Homenaje de simpatía a los aliados" y "Manifestación de simpatía a los aliados", se daba cuenta de una reunión de médicos argentinos celebrada en la casa del médico argentino Carlos Madariaga (1870-1935) con el objeto de "tributar un homenaje de simpatía los aliados" como indicaba La Nación o "exteriorizar su simpatía por la causa de los aliados" como lo hacia La Prensa.

El homenaje en cuestión consistía en dos álbumes que serían enviados a la Facultad de Medicina Paris y a la Biblioteca central de la Universidad Católica de Lovaina en Bélgica. Los mismos estaban ilustrados por el artista argentino Cesáreo Bernaldo de Quirós (1879-1969), dentro de los cuales se encontraba una extensa dedicatoria redactada por el médico Francisco Anselmo Sicardi (1856-1927). La misma sería publicada en las páginas de La Nación, La Prensa y La Razón, dando cuenta de la firma de los 58 concurrentes, 31 adherentes, e invitando a aquellos que quisieran sumar su apoyo a pasar por la casa del médico Carlos Madariaga a firmar los álbumes ${ }^{1259}$. Posteriormente se publicaba en las páginas de La Nación una carta de agradecimiento que el presidente francés le hacía llegar a Madariaga, en la cual el primero se declaraba "[...] muy conmovido por el elocuente homenaje tributado por un grupo de intelectuales argentinos [...]", ordenando que el manifiesto redactado por estos sea llevado a conocimiento del ejercito $^{1260}$.

Días más tarde el Deutsche La Plata Zeitung daba cuenta de la reunión celebrada en la casa de Madariaga, haciendo votos por que cualquier causa pudiera reunir un conjunto tan numerosos de individuos, entre los cuales se contaban diputados, senadores, abogados. Si alguno se encontraba deseoso de conocer detalladamente los asistentes se invitaba a leer las publicaciones de La Nación, La Prensa y La Razón, los cuales habían publicado los nombres de todos los asistentes y de los adherentes. Esta irónica invitación recordaba que "aquí la cantidad era mayor que la calidad". Dando cuenta del manifiesto redactado por Sicardi aclaraba el redactor de la columna que no podía cuestionar la expresión de una simpatía o sentimiento, aún si las mismas provenían de la altanería de una persona como Sicardi, el cual demostraba su

Hoffnungen, aber wie lange wird es noch dauern bis alle, auch England am Boden liegen! Hier ist die Stimmung, wie fast überall, im Allgemeinem uns ungünstig, aber es ist doch lange nicht so schlimm, wie bei Ihnen und gar in den Vereinigten Staaten, die hoffentlich auch bald der Teufel holt". Rudolf Lenz a Robert Lehmann-Nitsche. Legado Robert Lehmann-Nitsche, IAI, 23.02.1915, Carpeta N-0070 b 420.

${ }^{1259}$ La Nación 10.08.1916; La Prensa 10.08.1916; La Razón 10.08.1916.

${ }^{1260}$ La Nación 12.08.1916 
completa ignorancia del desarrollo histórico de las relaciones entre Alemania y los demás países involucrados en la guerra ${ }^{1261}$.

Los miembros de la Deutsche Wissenschaftlichen Verein se mostrarían ampliamente indignados por lo que consideraban una injustificada expresión de odio hacia los miembros de la comunidad alemana local. De esta forma llamaban a una reunión de emergencia, que se realizaría el 19 de agosto ${ }^{1262}$. En esta se diagramaban una serie de respuestas a la "hostil y odiosa" manifestación por parte de los intelectuales argentinos. La primera de estas era la redacción de un manifiesto que se publicaría en los órganos de todos los espacios académicos alemanes y diarios argentinos ${ }^{1263}$. La segunda resolución señalaba que los representantes del gobierno alemán y austriaco debían enviar hacer llegar, a través de embajadas y legaciones diplomáticas, copias del manifiesto a las universidades de sus respectivos países. La última resolución aclaraba que la Deutsche Wissenschaftichen Verein sería la que lleve adelante las gestiones de los dos primeros puntos, enviando una copia del manifiesto a sus miembros, los cuales, si estuvieran de acuerdo, debían firmar el manifiesto y dar autorización a la publicación de sus nombres ${ }^{1264}$. Un día antes el físico alemán Richard Martin Gans (1880-1954) le enviaba una copia del manifiesto a Lehmann-Nitsche, a fin de que lo evaluara ${ }^{1265}$. Este efectuará un borrador en el cual traducía el manifiesto que sería posteriormente publicado en alemán y español.

En el manifiesto se destacaba el tono malicioso y odioso con de la manifestación de simpatía por los aliados por parte de los intelectuales argentinos reunidos en la casa de Carlos Madariaga, destacando que estos solo buscan "[...] rebajar al pueblo y la ciencia alemana, con afirmaciones infundadas e irrazonables y falsean hechos históricos". Los altos cargos universitarios y políticos desempeñados por los intelectuales argentinos era lo que; según la proclama de los estudiosos alemanes; colocaba una opinión particular en el terreno masivo de lo público.

Los estudiosos alemanes residentes en Buenos Aires, Córdoba y La Plata planteaban el manifiesto público como una declaración de mera defensa, en la cual se busco la participación de personas por fuera de la comunidad alemana ${ }^{1266}$. De esta forma se enfatizaba sobre la adhesión de individuos que no tenían vínculos sanguíneos con Alemania o Austria, pero que estaban vinculados a través de diversos lazos de sociabilidad tales como: haber estudiado en

\footnotetext{
${ }^{1261}$ Deutsche La Plata Zeitung 12.08.1916.

1262 Deutschen Wissenschaftlichen Verein a Robert Lehmann-Nitsche. Legado Robert Lehmann-Nitsche, IAI, 15.08.1916, Carpeta N-0070 b 925.

${ }^{1263}$ Deutschen Wissenschaftlichen Verein a Robert Lehmann-Nitsche. Legado Robert Lehmann-Nitsche, IAI, 21.08.1916, Carpeta N-0070 b 925.

${ }^{1264}$ Ibídem.

1265 Richard Martin Gans a a Robert Lehmann-Nitsche. Legado Robert Lehmann-Nitsche, IAI, 20.08.1916, Carpeta N-0070 b 925.

${ }^{1266}$ Deutschen Wissenschaftlichen Verein a Robert Lehmann-Nitsche. Legado Robert Lehmann-Nitsche, IAI, 05.09.1916, Carpeta N-0070 b 925.
} 
Alemania o alguna institución vinculada a la misma; llevar adelante negocios con empresas o personas alemanas; y finalmente aquellos que simplemente manifestaban algún tipo de simpatía. Según los estudiosos esta era la forma de mostrar al mismo tiempo la cohesión al interior de la comunidad alemana argentina, su pertenencia a la Argentina y el rechazo al conflicto bélico que acontecía en Europa.

A medida que la guerra llegaba a su fin los efectos de la misma seguían repercutiendo al interior de la comunidad alemana residente en la Argentina. Hacia mediados de diciembre de 1917 la Convención Patriótica del Comité Nacional de la Juventud volvía a retomar aquellas ideas redactadas por la pluma de Francisco Anselmo Sicardi y llamaba a la ruptura de las relaciones con Alemania. En pequeños volantes repartidos al público llamaban a asistir a una manifestación en la Plaza del Congreso, remarcando que la asistencia era deber de todo ciudadano.

Posteriormente se celebraría una reunión en el Teatro Nuevo donde se designaría una comisión compuesta por el ensayista Leopoldo Lugones (1874-1938) y los abogados Osvaldo Magnasco, Felipe Yofre (1848-1939), Joaquín Víctor González (1863-1923) y Alfredo Lorenzo Palacios (1880-1965). Dicha comisión llamaba a suspender las relaciones diplomáticas con Alemania, afirmando que esto era la canalización de la voluntad popular. La comisión sabrá capitalizar dos acontecimientos a fin de argumentar que sus propuestas eran un bien a los intereses del pueblo y gobierno argentinos y a la solidaridad para con las otras naciones civilizadas del mundo. Por una lado el hundimiento del velero argentino Monte Protegido y el vapor argentino Toro; acontecidos en abril y junio de 1917 respectivamente. Por otro lado el escándalo generado por los telegramas del embajador alemán Karl von Luxburg (1872-1956), en los cuales aconsejaba que los barcos argentinos fueran "hundidos sin dejar rastros". Como consecuencia del escándalo generado por estas revelaciones, los días del 12 al 14 de septiembre se repitieron ataques contra las instituciones alemanas en Buenos Aires.

Usando estos elementos la comisión de intelectuales realizará una reconstrucción histórica del pasado alemán, mostrando que el hundimiento de las naves argentinas o la aversión de las palabras del embajador von Luxburg solo eran la expresión de una tradición imperialista cuya única ambición era la expansión y destrucción de la civilización. Llamando a la acción inmediata la comisión de intelectuales advertía que el espíritu de esta política se encontraba presente en el día a día, en "[...] los sucesivos desplantes de sus agentes oficiales, de sus escritores, de sus súbditos y de sus propagandistas, sinceros o mercenarios, del interior y del exterior" ${ }^{267}$. El nivel de fantasía de los integrantes de esta comisión era tal que veían el creciente número de colectividades alemanas en América como un plan orquestado para la

${ }^{1267}$ Lugones et.all. 1984, p 11. 
ocupación de la misma ${ }^{1268}$. Al mismo tiempo que estos panfletos conspirativos circulaban, otros llamaban a firmar listas de protesta contra las "Las inhumanas condiciones de paz" impuestas a Alemania, aclarando que en esta "[...] mueren millares de seres a consecuencia del brutal bloqueo" 1269 .

Las sociedades científicas alemanas en la Argentina no solo colaborarían con la distribución de este tipo de panfletos entre sus socios, sino que llevarían adelante diversos actos de beneficencia con el objetivo de recaudar fondos destinados a paliar las consecuencias devastadoras de la guerra, las cuales se sumaban a las condiciones de rendición y paz. En el caso de la Deutschen Wissenschaftlichen Verein estos esfuerzos serían canalizados a través de las acciones de Wilhelm Keiper (1872- $i$ ?). Al comienzo de la guerra este buscará entablar relaciones con prominentes intelectuales y políticos argentinos que se manifestarán a favor de Alemania, como el militar José Félix Uriburu (1868-1932) o Ernesto Quesada. Este último, junto con otros intelectuales, publicará trabajos y libros pro-alemanes, facilitados por la Empresa Editorial Germana establecida por Keiper.

Al mismo tiempo Keiper sería editor del órgano oficial de la Unión Alemana para la Argentina $^{1270}$. Según Claus Friedrich esta nace de una iniciativa de la sección regional de Hamburg de la Asociación para los alemanes en el extranjero ${ }^{1271}$, principalmente por los intereses comerciales en Sudamérica ${ }^{1272}$. Los objetivos principales de la Unión Germánica para Argentina, al igual que otras instauradas en distintos países de Sudamérica, serán la reanudación y la ampliación de las relaciones comerciales alemanas después de la guerra, a través de las acciones de los ciudadanos alemanes residentes en el extranjero. El papel de estos será fuertemente impulsado por Theodor Alemann, miembro de la asociación y dueño del Argentinisches Tageblatt. Mientras tanto Keiper impulsaría la apertura de nuevos grupos locales en toda la Argentina. Para 1917 se publicaban en las páginas del "Der Bund", órgano oficial de la Unión Germánica para Argentina, un total de 3.027 miembros distribuidos entre Buenos Aires, Bahía Blanca, Córdoba, Rosario y Mendoza. A partir de estos centros se impulsaría la recaudación de fondos de beneficencia para ser enviados a Alemania y la participación activa en las diversas asociaciones de asistencia social alemanas en la Argentina ${ }^{1273}$.

\footnotetext{
1268 Se leía en uno de los pasajes "Si se examinara ahora el incremento tan a designio promovido y oficialmente facilitado, y la específica situación de las colectividades alemanas y su descendencia, actuantes en el vasto escenario de nuestro continente, desde el Canadá al Cabo de Hornos, no sería difícil percibir la gravedad del problema que se venía incubando para América, y especialmente para alguna de sus más confiadas nacionalidades, bajo las sugestiones de una fuerza brutal de conjunto, la más formidable que los siglos hayan visto premeditar y organizar". Ibídem.

${ }^{1269}$ Legado Robert Lehmann-Nitsche, IAI, Carpeta N-0070 139.

${ }^{1270}$ En alemán Deutscher Volksbund für Argetinien. La traducción oficial será Unión Germánica en la Argentina.

${ }^{1271}$ En alemán Verein für das Deutschtum im Ausland.

${ }^{1272}$ Friedrich 2008.

${ }^{1273}$ Bryce 2008; Friedrich 2008; Newton 1977; Sauveur-Henn 1995, 2010.
} 
Mientras estas acciones tenían lugar, parte de los estudiosos franceses llamaban a tomar un curso de acción contra la gran crisis que atravesaba la humanidad. En este sentido la École d'Anthropologie de Paris convocaban a los antropólogos de todas las naciones a la defensa de la civilización y a la renovación de las ciencias antropológicas. Planteando estos objetivos como elementos indivisibles y concatenados, buscaban devolver a la Antropología "[...] le goût de recherches desintereses, l'indépendence de pensée, la valeur intellectuelle et morale qu'elles auraient perdues sous l'influence néfaste de l'Allemagne"1274.

La École d'Anthropologie de Paris se presentaba a si mismo como uno de los espacios a partir de los cuales revertir la profunda crisis en la cual estaba subsumida la humanidad. Evocando las causas históricas de su fundación y el espíritu de Paul Broca como garantes de su autonomía y libertad, el político y economista francés Yves Guyot (1843-1928); en ese momento director de la École; convocaba a la fundación del Institut International d' Anthropologie, el cual sería de carácter permanente y estaría conformado por todos los antropólogos de las naciones aliadas. El objetivo era la centralización de colecciones, publicaciones, recursos instrumentales y bibliográficos. Esto, según Yves Guyot, era para cubrir las carencias de dichos elementos como otra de las tantas consecuencias de la guerra. Este altruista objetivo buscaba disimular en realidad otro de los puntos de la propuesta que será la reorientación de los estudios antropológicos a fin de proscribir los discursos generados desde las ciencias sociales alemanas. Tal como aclaraban en la convocatoria, la experiencia de la guerra había desenmascarado la "[...] domesticité de la science allemande, sa fause érudition, son mercantilisme henote, son habilité à déformer les théories, et même les observations anthropologiques, pour appuyer les visées de l' impérialisme allemand"1275.

Esta situación provocará la renuncia de muchos estudiosos alemanes a la École d'Anthropologie de Paris, entre ellos Lehmann-Nitsche, el cual les recordaba que era miembro titular desde $1897^{1276}$. Al mismo tiempo participaba este último de eventos de la comunidad alemana local que buscaban revertir la imagen de Alemania en el plano social y científico. Mientras aumentaba su participación en el grupo local de platense de la Unión Germánica para Argentina $^{1277}$, asistía a las reuniones de la Deutschen Wissenschaftlichen Verein donde se delineaban las últimas correcciones al trabajo "Lo que hizo Alemania durante la guerra"1278. Esta última llamaba también a combatir la ausencia de bibliografía, colecciones e instrumentos que estaban sufriendo los principales institutos y universidades europeas. Sin hacer énfasis en

${ }^{1274}$ Circular École d'Anthropologie 1918, p.27.

1275 Ibídem, p. 27.

${ }^{1276}$ Robert Lehmann-Nitsche a la Société d'Anthropologie de Paris. Legado Robert Lehmann-Nitsche, IAI, 23.08.1919, Carpeta N-0070 b 1006.

${ }^{1277}$ El grupo local había sido iniciado el 19 de marzo de 1917. La comisión inicial estaba compuesta por: 1) Presidente: Santiago Pereira; 2) Vocales: Robert Lehmann-Nitsche y H. Hoffman; 3) Secretarios: Vicente Anzoátegui y A. Zingoni.

1278 Deutschen Wissenschaftlichen Verein a Robert Lehmann-Nitsche. Legado Robert Lehmann-Nitsche, IAI, 18.08.1920, Carpeta N-0070 b 925. 
ningún país en particular los miembros de las comunidades científicas alemanas en Sudamérica debían, a pesar del propio aislamiento y sorna que sufrían en el contexto local, dar el ejemplo del carácter colectivo y cooperativo que implicaba el trabajo científico, tal como rezaba la circular de la Deutschen Wissenschaftlichen Verein ${ }^{1279}$.

En forma simultánea, en los Estados Unidos, Franz Boas llevaba adelante una empresa similar. Estando al tanto de las pésimas condiciones edilicias y materiales con las cuales los estudiosos debían llevar adelante sus trabajos, iniciará una serie de comités de ayuda destinados a la recolección de bibliografía y otros elementos que pudieran paliar en forma parcial dicha carencia. Enterado de la situación particular de Berlin, en la cual se constataba una carencia de literatura sudamericana, escribía Boas a Lehmann-Nitsche a fin de que organizara con "[...] some of your South American friends [...]" una comisión que destinada a la compra de libros sudamericanos para ser enviados a las librerías de los países que más lo necesitaran ${ }^{1280}$.

Boas será en América uno de los principales impulsores de los comités de ayuda para los centros científicos en Alemania y en Austria. A pesar de las desavenencias económicas por las cuales atravesaba la sección antropológica de Columbia University de New York, materializadas en la escasez de bibliografía e instrumentos adecuados para el trabajo, Boas había ampliado los trabajos de la comisión de ayuda dándole la forma de una sociedad, la Emergency Society for German and Austrian Science and Art, en la cual contaría con la ayuda del historiador de la literatura alemán Frederick Heuser (1878-1961). Al mismo tiempo que le enviaba los planes de la misma a Lehmann-Nitsche y le relataba los esfuerzos de la Sociedad Alemana local, le reiteraba el pedido de ayuda a este último, instándolo a formar una empresa similar en la Argentina ${ }^{1281}$.

Durante el transcurso de la Gran Guerra las sociedades científicas alemanas con sede en Argentina, funcionaran como espacios de contención y protección para los estudiosos que desempeñaban sus profesiones en el país. La vinculación de la Deutschen Wissenschaftlichen Verein con iniciativas como la Unión Germánica para Argentina, dan cuenta de los intentos por integrar aquellos espacios en los cuales los ciudadanos de origen alemán se definían y se veían representados. Al mismo tiempo serán espacios donde se capitalizaran los esfuerzos y la solidaridad no solo de los ciudadanos de origen alemán, sino de aquellas personas que profesaban su simpatía hacia a ellos o bien el rechazo a las manifestaciones que llamaban a un total rechazo y expulsión de los alemanes. Funcionando como espacios donde se buscaba un refuerzo de la identidad y de los lazos de pertenencia, las sociedades científicas alemanas en la

${ }^{1279}$ Deutschen Wissenschaftlichen Verein a Robert Lehmann-Nitsche. Legado Robert Lehmann-Nitsche, IAI, 01.04.1920, Carpeta N-0070 b 925.

${ }^{1280}$ Franz Boas a Robert Lehmann-Nitsche. Legado Robert Lehmann-Nitsche, IAI, 28.01.1920, Carpeta N-0070 b 84.

${ }^{1281}$ Franz Boas a Robert Lehmann-Nitsche. Legado Robert Lehmann-Nitsche, IAI, 05.11.1920, Carpeta N-0070 b 84. 
Argentina buscaron oficiar como espacios de cohesión y protección frente a la fragmentación política, económica y social de la sociedad alemana residente en la Argentina como consecuencia de Gran Guerra.

El impacto y las consecuencias de la guerra europea seguirán repercutiendo una vez finalizado el conflicto armado. En el caso particular de Lehmann-Nitsche podemos constatar su participación en diversos grupos alemanes antirrepublicanos residentes en la Argentina que apoyaban al Kaiser. Al mismo tiempo es cuando gran parte de sus publicaciones se centren exclusivamente en documentar la temprana presencia de los alemanes en el Río de la Plata y su papel fundamental en la historia de la región.

El 27 de enero de 1917, en el predio de la Sociedad Rural Argentina, Lehmann-Nitsche será uno de los oradores principales en los festejos por el natalicio del Emperador alemán Guillermo II (1859-1941). Su discurso, el cual un periodista del diario La Unión describía como amplio y con una fina diplomacia para salvar posibles desavenencias, trataba sobre la actualidad de la situación alemana. El periodista remarcaba que no podía reproducir la totalidad del discurso, debido a su extensión, pero que el mismo se encuadraba dentro de la tónica de las lecturas ofrecidas ese día, en las cuales se resaltaba la figura del emperador Guillermo II y se denunciaba la información tendenciosa y las imputaciones malevolentes a la imagen de Alemania en el mundo ${ }^{1282}$.

Unos meses más tarde en el Hotel Argentino de la Plata una nutrida concurrencia asistía a la constitución de un "centro germanófilo", tal como se leía en las páginas del diario platense El Día. La propuesta era impulsada por Santiago Pereira, el cual sería designado presidente del mismo. El resto de la comisión directiva estaba compuesta por Lehmann-Nitsche y un tal señor Hoffman que oficiaban como vocales, y los secretarios Vicente Anzóategui (1866-1935) y el señor Zingoni ${ }^{1283}$. El vínculo de Lehmann-Nitsche con este tipo de espacios era advertido por Wilhelm Keiper, el cual como editor del órgano oficial de la Unión Alemana para la Argentina, el cual lo invitaba a oficiar una serie de charlas en las reuniones de la mencionada asociación $^{1284}$.

Solo tres meses después de esta comunicación con Keiper, ofrecía Lehmann-Nitsche, en una de las reuniones del grupo local platense ${ }^{1285}$ de la Unión Alemana para la Argentina, una lectura sobre las características raciales de los alemanes ${ }^{1286}$, repasando indicadores como el color de la piel, cabellos, ojos y tamaño corporal. Esta presentación debe enmarcarse dentro de

\footnotetext{
1282 Diario La Unión, 29.01.1917.

${ }^{1283}$ Diario El Día, 20.03.1917.

1284 Wilhelm Keiper a Robert Lehmann-Nitsche. Legado Robert Lehmann-Nitsche, IAI, 28.04.1917, Carpeta N-0070 b 360.

1285 Estos grupos eran denominados en alemán como "Ortsgruppe".

${ }^{1286}$ El título de la lectura era "Über die Rassenmerkmale der Deutschen”.
} 
las discusiones al interior de la Unión Alemana para la Argentina. Recordemos que el objetivo de su establecimiento, promovido desde espacios como el Deutsche La Plata Zeitung y el Argentinisches Tageblatt, era la cohesión de los inmigrantes de habla alemana. De esta forma confluirán en su interior personas provenientes de provenientes del Imperio Alemán, del Imperio Austro-Húngaro, de Suiza, del Volga y de otras partes de los Balcanes. Uno de los primeros problemas será la denominación del grupo. Para Theodor Alemann el mismo debía denominarse como "Unión Germánica", haciendo hincapié en elementos como la lengua y la cultura a la hora de definir la partencia al grupo. Por otro lado Keiper argumentaba que la Unión debía tener una vinculación con el Imperio Alemán, por lo cual era partidario de la denominación "Unión Alemana". En este sentido Lehmann-Nitsche destacaba en su presentación la importancia del lenguaje a la hora de definir, caracterizar y clasificar a una raza.

De esta forma desde la Antropología se aportaban elementos científicos para la determinación de la raza alemana y la definición exacta de sus fronteras geográficas ${ }^{1287}$. Dos años más tarde, en un discurso ofrecido en el Deutsche Klub, resaltaba enfáticamente la importancia del espíritu alemán en la definición identitaria. Frente a las consecuencias del final de la Gran Guerra y ante el creciente antialemanismo presente en la sociedad argentina, Lehmann-Nitsche llamaba a los ciudadanos alemanes en el extranjero a "ser y continuar siendo alemanes" ${ }^{1288}$. Exhortaba además a los padres de familias alemanas en el extranjero a transmitir a sus hijos el espíritu, la voluntad, los sentimientos, y el carácter nacional; siendo estos los elementos que definían a un alemán en extranjero ${ }^{1289}$. El concepto de "Deutsch sind und bleiben", sería reproducido por el Deutsche La Plata Zeitung, el cual lo usaría para pedir colaboración en la construcción de escuelas alemanas en la zona de Dock Sud. Si LehmannNitsche llamaba a no dejarse consumir el corazón y la boca ante los agravios inferidos contra los alemanes residentes en Argentina ${ }^{1290}$, desde el Deutsche La Plata Zeitung se llamaba a hacer uso del corazón y las manos para ayudar a los constructores de las escuelas y posibilitar que los niños obtener y conservar la "alemanidad"1291.

\footnotetext{
${ }^{1287}$ Diario Deutsche La Plata Zeitung, 22.08.1917.

${ }^{1288}$ En el discurso original: Deutsch sind und bleiben!. Diario Argentinisches Tageblatt, 20.03.1919

${ }^{1289}$ En el discurso original: "Was können wir aber Tatsächliches tun, wir hier, fern von den Bühnen des Weltgeschehens? Deutsch sind und bleiben! Weihen wir uns und unsere Kinder unserem eigenem Geiste, unserem eigenen Willen und Fühlen, unserer völkischen Eigenart, lassen wir doch das uns Wesensfremde, die fremde Sprache, fremdes undeutsches Gebahren, den anderen. Haben sie vielleicht irgend etwas nur versucht, sich ihrerseits uns innerlich zu nähern?". Diario Argentinisches Tageblatt, 20.03.1919

${ }^{1290}$ Alegaba Lehmann-Nitsche en el original alemán "Einfach, schlicht, ohne besonders Vorbereitungen vereinen sich heute, in innerlich würdiger Fassung, deutsche Männer und deutsche Frauen, aber die gemeinsame Empörung gegen zugemutet unerhörte Schmach darf nicht in unserer gesamtes Denken und Fühlen verzehren; auf die Herzen, auf die Mund!” Diario Argentinisches Tageblatt, 20.03.1919.

${ }^{1291}$ El concepto original alemán es Deutschtum. Se leia en las páginas del diario "Deutsch wollen wir sein, und unsere Kinder sollen deutsch bleiben. Auf das Herz und auf die Hand!. Helft uns unser Schulbaus bauen und unsere Kinder dem Deutschtum erhalten". Diario Deutsche La Plata Zeitung, 20.05.1919. El resaltado es de nuestra autoría.
} 
Esta locución pública se condecía con la participación de Lehmann-Nitsche en diversas asociaciones porteñas partidarias del Kaiser y del Imperio Alemán ${ }^{1292}$. Una de estas asociaciones será la "Schwarz-Weiss-Rot"1293. A comienzos de 1922 Alfred Pass, miembro de la mencionada asociación, le escribía a Lehmann-Nitsche para avisarle de una futura reunión en la cual le gustaría discutir la posibilidad de un ciclo de conferencias nocturnas. Aprovechando la oportunidad lo invitaba también a una reunión donde debían discutirse importantes temas vinculados a las actividades futuras de la Junta Ejecutiva y el Comité ${ }^{1294}$. La reunión tendría lugar el 11 de septiembre del mencionado año, siendo el tema oficial por el cual se la convocaba los incidentes en torno a la inauguración de un monumento recordatorio a la guerra ${ }^{1295}$.

Al mismo tiempo que "Schwarz-Weiss-Rot" discutía temas como la fundación de una asociación que nucleara a los clubes alemanes de Buenos Aires y alrededores ${ }^{1296}$, enviaba una nota a sus socios en las cuales los invitaba a participar de la próxima reunión donde LehmannNitsche y Alfred Pass se encargarían de presentar el estatuto de la asociación. Cerrando la invitación con "un saludo alemán" adelantaba la carta que uno de los requisitos que se le exigiría a los nuevos postulantes seria contar con la "garantía moral" de alguno de los viejos $\operatorname{socios}^{1297}$. Lehmann-Nitsche recibía dicha carta y al mismo tiempo una de Alfred Pass en la cual este le proponía anular el artículo 1 en el cual se establecía que sus miembros podían incluir a las asociaciones de habla alemana. A cambio proponía que los representantes de dichas asociaciones fueran alemanes o descendientes de alemanes, entendiendo por alemán: aquellos perteneciente al Imperio Alemán, naturalizados, y los austríaco alemanes "arrebatados" por el tratado de Versalles. Entre los excluidos figuraban: holandeses germano parlantes, suizos y escandinavos. Finalmente Pass pretendía modificar el artículo 10 declarando que se rechazaba vigorosamente la participación de los representantes del Argentinisches Tageblatt, el cual debía ser considerado un diario suizo-argentino y no alemán ${ }^{1298}$. Este rechazo se enmarca dentro de la

\footnotetext{
1292 Podgorny 2002 b.

1293 Su nombre "Negro, Blanco, Rojo" hacia referencia a los colores de la bandera imperial. En oposición a la coalición formada por Socialdemócratas, Católicos de Centro y por el Partido Democrático; promoverán una confederación de asociaciones alemanas con un acceso muy restringido. Ibídem.

1294 Verein "Schwarz-Weiß-Rot" a Robert Lehmann-Nitsche. Legado Robert Lehmann-Nitsche, IAI, 11.08.1922, Carpeta N-0070 b 1075.

1295 Verein "Schwarz-Weiß-Rot" a Robert Lehmann-Nitsche. Legado Robert Lehmann-Nitsche, IAI, 08.09.1922, Carpeta N-0070 b 1075.

1296 El proyecto tenía por nombre "Verband Deutscher Vereine für Buenos Aires und Umgebung". Legado Robert Lehmann-Nitsche, IAI, Carpeta N-0070 b 1075.

1297 Todas las cartas del periodo de 1923 cerraran con la formula "Mit deutschem Gruss". Verein "Schwarz-Weiß-Rot" a Robert Lehmann-Nitsche. Legado Robert Lehmann-Nitsche, IAI, 08.08.1923, Carpeta N-0070 b 1075.

1298 En la carta original de Pass "Unter Deutschen verstehen wir: Reichsdeutsche, naturalisierte, Deutschösterreicher ebenso Bewhoner früherer deutscher Gebiete, die dur das Diktat von Versailles uns entrissen wurden". Alfred Pass a Robert Lehmann-Nitsche. Legado Robert Lehmann-Nitsche, IAI, 08.08.1923, Carpeta N-0070 b 1075.
} 
postura crítica e imparcial que este último diario ira adquiriendo a lo largo del desarrollo de la Gran Guerra ${ }^{1299}$.

Otro de los modos de participación y colaboración con este tipo de asociaciones será la donación de dinero. Tal como argumentaba una carta de la Asociación Nacional de Oficiales Alemanes $^{1300}$, los requisitos para poder ser miembro no se limitaban a ser oficial del ejército o soldado, sino que podían participar de la misma cualquier "alemán leal""1301 y cada hombre que pensará en su pueblo. Apelando a estos sentimientos hacían un llamado a los alemanes residentes en el extranjero para que enviarán donaciones monetarias a Alemania. La suma de estos esfuerzos individuales, aclaraba la carta, podía ser capaz de presentar lucha a la esclavitud ejercida por las altas finanzas judías ${ }^{1302}$. Unos meses más tarde Lehmann-Nitsche recibía una carta agradeciendo las donaciones efectuadas ${ }^{1303}$. Otro de los grupos en los cuales participará efectuando y articulando donativos será el grupo local del Partido Nacional-Popular Alemán ${ }^{1304}$, los cuales en 1923 le escribían pidiéndole autorización para usar su casa como lugar donde aceptar las donaciones ${ }^{1305}$. Al mismo tiempo demostraba interés por colaborar económicamente con otros emprendimientos y actividades de este tipo en el extranjero, tal como da cuenta su preocupación por auxiliar al desarrollo de la fiesta del partido popular de la gran Alemania a desarrollarse en la zona alpina del Tirol" ${ }^{1306 .}$

A lo largo de la década de 1920 Lehmann-Nitsche participará activamente en la organización de visitas de diversos estudiosos alemanes a Buenos Aires. Estas visitas, lejos de limitarse a cuestiones meramente académicas estarán atravesadas por un componente político. Uno de los primeros interesados será geógrafo alemán Karl Theodor Sapper (1866-1945). En un intercambio de cartas entre 1920 y 1924 le expresaba a Lehmann-Nitsche su deseo de visitar Argentina, consultándolo sobre la posibilidad de que financiaran su viaje, ya que era muy difícil conseguir apoyo estatal o privado para dicha empresa. Lehmann-Nitsche le respondía que existía la posibilidad de que la Institución Cultural Argentino-Germana se hiciera cargo de los gastos, sin embargo la visita del prehistoriador alemán Hugo Obermaier (1877-1946) se encontraba primera en la agenda, haciendo imposible costear dos viajes. Finalmente le

${ }^{1299}$ Bryce 2008; Lütge 1981; Newton 1977; Saint Sauveur-Henn 1995

${ }^{1300}$ El nombre original en alemán es Nationalverband Deutscher Offiziere.

${ }^{1301}$ El término utilizado será "treudeutsche".

1302 En la carta podía leerse "Durch den Valutastand wir jede noch so kleine, im Auslande gestiftete Geldsumme in Deutschland zum Vermögen. Ein solches ist aber im Kampf gegen die Versklavung dur die jüdische Grossfinanz notwenig". Nationalverband Deutscher Offiziere a Robert Lehmann-Nitsche. Legado Robert Lehmann-Nitsche, IAI, 19.04.1922, Carpeta N-0070 b 1073.

${ }^{1303}$ Nationalverband Deutscher Offiziere a Robert Lehmann-Nitsche. Legado Robert Lehmann-Nitsche, IAI, 27.07.1922, Carpeta N-0070 b 1073.

${ }^{1304}$ En alemán Deutschnationale Volkspartei.

1305 Ortsgruppe Buenos Aires der Deutschnationalen Volkspartei a Robert Lehmann-Nitsche. Legado Robert Lehmann-Nitsche, IAI, 03.07.1923, Carpeta N-0070 b 1077.

${ }^{1306}$ En alemán Großdeutschen Volkspartei für Tirol. Großdeutschen Volkspartei für Tirol a Robert Lehmann-Nitsche. Legado Robert Lehmann-Nitsche, IAI, 13.02.1922, Carpeta N-0070 b 1076. 
recomendaba que se encuentre con Oscar Rodríguez Saráchaga; representante de la Institución Cultural Argentino-Germana; que se encontraba próximo a visitar Berlin y Hamburg ${ }^{1307}$. El encuentro tendría lugar a fines de noviembre de 1925. En este se programa un futuro viaje para el año 1927. Sapper le comentaba a Lehmann-Nitsche que esto le permitía contar con más tiempo para la preparación de las conferencias y las presentaciones. De esta forma podría transmitir al público argentino la verdadera imagen del investigador alemán, algo que si se hubiera dejado llevar por su apremio en viajar de forma inmediata a Argentina hubiera sido un fracaso $^{1308}$.

En enero de 1926 Obermaier le comunicaba a Lehmann-Nitsche de su futuro viaje a la Argentina ${ }^{1309}$. Su visita será organizada por la Institución Cultural Argentino-Alemana, la cual designaba a Lehmann-Nitsche como miembro de la comisión de recepción ${ }^{1310}$. Con el auspicio de la mencionada institución y la Facultad de Filosofía y Letras de la Universidad Nacional de Buenos Aires, ofrecerá Obermaier, entre julio y agosto, un total de 8 conferencias ${ }^{1311}$. Entre estas conferencias habrá también diversas galas en honor al prehistoriador alemán, como así también veladas científicas en institutos alemanes, españoles y encuentros en el domicilio particular de Lehmann-Nitsche.

Antes de la partida de Obermaier se ofrecerá una cena en su honor. Juliane Dillenius será la encargada del discurso de despedida, donde remarcaba el gran acierto de los miembros de la Institución Cultural Argentino-Alemana al traer al país a un estudioso como Obermaier. Luego de repasar el ciclo de conferencias que este último ofreciera, destacaba la importancia de sus trabajos, principalmente aquellos realizados durante el periodo de guerra, los cuales lejos de las hipótesis y las especulaciones brindaban una comprensión científica sobre la prehistoria española ${ }^{1312}$. Recordemos que al momento de estallar la Gran Guerra se le prohibirá a Obermaier continuar los trabajos que venía efectuando en el Institut de Paléontologie Humaine

\footnotetext{
${ }^{1307}$ Robert Lehmann-Nitsche a Karl Theodor Sapper. Legado Robert Lehmann-Nitsche, IAI, 29.10.1925, Carpeta N-0070 b 803.

${ }^{1308}$ Karl Theodor Sapper a Robert Lehmann-Nitsche. Legado Robert Lehmann-Nitsche, IAI, 30.11.1925, Carpeta N-0070 b 608.

${ }^{1309}$ Las primeras cartas entre Obermaier y Lehmann-Nitsche datan de 1906. Hasta su visita el tema principal de las mismas será el hombre fósil, tópico central de los trabajos de Obermaier.

${ }^{1310}$ Los otros miembros eran: el paleontólogo argentino Martin Doello Jurado (1884-1948); Salvador Debenedetti; Elina Correa Morales y Leonidas Silva. Institución Cultural Argentino-Alemana a Robert Lehmann-Nitsche. Legado Robert Lehmann-Nitsche, IAI, 08.07.1926, Carpeta N-0070 b 503.

${ }^{1311}$ Estas serán: 1) Sábado 17 de julio "La era glaciar y su fauna gigantesca"; 2) Miércoles 21 de julio "La primera aparición del hombre"; 3) Sábado 24 de julio "La vida de nuestros antepasados cuaternarios y su arte mobiliario"; 4) Miércoles 28 de julio "Los más antiguos artistas: las cuevas pintadas del sur de Francia y norte de España"; 5) Sábado 31 de julio "El arte expresionista del Levante de España"; 6) Miércoles 4 de agosto "El arte primitivo africano"; 7) Sábado 7 de agosto "El hombre primitivo a principios de la actualidad geológica (10.000-5.000 a. J. C); y 8) Miércoles 11 de agosto "Los primeros pastores, agricultores y arquitectos (5.000-2.500 a. J.C). Legado Robert Lehmann-Nitsche, IAI. Carpeta $\mathrm{N}-0070$ b 503.

${ }^{1312}$ Legado Robert Lehmann-Nitsche, IAI. Carpeta N-0070 b 503.
} 
de Paris, supuestamente por pedido de su director el paleontólogo francés Pierre Marcellin Boule (1861-1942).

Según Dillenius los verdaderos trabajos científicos eran aquellos que no respondían a ambiciones de ninguna especie, y que lejos de la arrogancia buscaban contribuir al progreso de la ciencia. Como recordaba a continuación Lehmann-Nitsche, las particulares condiciones que habían condicionado la permanencia de Obermaier en España habían permitido al público ibérico el acceso a las obras del "sabio alemán". Al momento de especificar aquellas particulares condiciones se limitaba a aclarar que el comienzo de la Gran Guerra había "retenido" a Obermaier en la península Ibérica. Sin embargo más adelante, en un pasaje con un tono político más elevado, Lehmann-Nitsche definía a Obermaier como el "prototipo del legendario erudito alemán”. El uso de esta figura será para hacer una defensa de los estudiosos alemanes en el extranjero, los cuales no solo poseían una preparación científica sistemática, sino que además ostentaban un "carácter sincero y noble", y principalmente un desinterés personal al momento de realizar las investigaciones.

Mientras que la visita de Obermaier tenía lugar, Sapper se comunicaba con LehmannNitsche. Luego de contarle de la fundación del Instituto Americanista le mencionaba el poco interés del estado por financiar la compra de publicaciones en español o destinar fondos para la compra de inmuebles o la contratación de empleados. Esto era resultado de un contexto general en el cual, según Sapper, era posible aunar un objetivo común entre la población alemana, especialmente aquellos grupos residiendo en el extranjero. En consecuencia Lehmann-Nitsche le proponía centralizar institucionalmente aquellas voluntades disueltas, algo que para Sapper se encontraba muy lejos de poder realizarse. Para ejemplificar su punto enumeraba una serie de institutos como el Institut fur Grenz- und Auslandsdeutschtum de Marburg, fundado en 1919, y el Auslandsinstitut de Stuttgart fundado en 1917. Estos institutos tenían por propósito brindar una formación científica en el estudio de temas como la "nacionalidad" y la "psicología de los pueblos" $" 1313$ a través de conferencias y grupos de trabajo destinados a los estudiantes de cualquier carrera, en los cuales debían participar profesores de las distintas facultades ${ }^{1314}$. Sapper se mostraba partidario de estas iniciativas, sin embargo, agregaba, las diferencias de objetivos y metodologías hacían imposible pensar en un trabajo en conjunto de estos institutos $^{1315}$.

Según Sapper la mejor forma de contribuir desde los espacios científicos con la promoción del "deutschtum" era el trabajo en conjunto de los estudiosos alemanes residentes en Alemania con aquellos que se encontraban viviendo en el extranjero. Estas pequeñas acciones individuales eran mucho más sencillas de coordinar y llevar a cabo, siendo el primer paso antes

\footnotetext{
${ }^{1313}$ Los términos utilizados serán respectivamente: Volkstum y Völkerpsychologie.

${ }^{1314}$ Fittbogen 1929.

1315 Karl Theodor Sapper a Robert Lehmann-Nitsche. Legado Robert Lehmann-Nitsche, IAI, 14.02.26, Carpeta N-0070 b 608 .
} 
de encauzar las mismas institucionalmente. Sapper deseaba continuar el camino iniciado por Obermaier y contribuir a fortalecer la imagen alemana en el extranjero. Al mismo tiempo esto le permitiría acceder a importantes materiales bibliográficos que eran de suma importancia para el funcionamiento de su instituto. Tal como le recordaba en varias cartas era muy difícil el intercambio de materiales con Latinoamérica. Mencionando ciertas leyes sancionadas por el Imperio Alemán en 1897 -llamativamente el mismo año que Lehmann-Nitsche llega a la Argentina- en las cuales se imponían serias trabas a la adquisición de material literario procedente de Latinoamérica, aludía soslayadamente a las actitudes un tanto mezquinas de ciertos coleccionistas compulsivos, en referencia a los trabajos del geógrafo alemán Otto Quelle (1879-1959), el cual se encontraba al frente del Instituto de Investigación Iberoamericano ${ }^{1316}$ de la Rheinische Friedrich-Wilhelms-Universität de Bonn. Sapper destacaba la habilidad de Quelle para procurarse rápidamente cualquier material procedente de Latinoamérica y la escasa iniciativa al momento de compartir el mismo ${ }^{1317}$.

En 1927 Sapper llegaba a la Argentina. Lehmann-Nitsche será el encargado de presentarlo en la Facultad de Humanidades de la Universidad Nacional de La Plata. Al igual que sucediera con Obermaier, su figura será utilizada para destacar las virtudes de la ciencia alemana, uniendo su progreso y sus logros al del pueblo alemán. En este sentido el discurso de bienvenida ofrecido Lehmann-Nitsche estará articulado por la historia de la ciudad de Würzburg, en la cual Sapper había fundado el Instituto Americanista del cual era director.

Würzburg era presentada como cuna de "glorias de la ciencia germánica". El punto de inicio de su prestigiosa historia intelectual se ubicaba en la fundación de la Julius-MaximiliansUniversität en el año 1402. Los primeros profesores dejaban su estela en una "galería de perfiles espirituales", siendo continuada por Rudolf Virchow el cual diera un rumbo nuevo al estudio de los problemas "más sublimes de la vida". Seguidamente se encadenaba la figura del físico alemán Wilhelm Conrad Röntgen (1845-1923), el cual; en palabras de Lehmann-Nitsche; desde su modesto gabinete de física había enriquecido a la humanidad entera, con sus trabajos sobre la radiación electromagnética que darían lugar al descubrimiento de los rayos X.

Según Lehmann-Nitsche todos estos personajes compartían una serie de características, las cuales pretendía hacer extensible a todos los estudiosos alemanes: Por un lado el afán del estudio por el progreso científico, el cual era equiparado con el progreso del espíritu; y por otro el desinterés en esta empresa. En este punto, tal como sucediera con Obermaier, se deja entrever una crítica contra las expulsiones de estudiosos alemanes residentes en el extranjero durante el transcurso de la Gran Guerra. En consecuencia Lehmann-Nitsche remarcaba que los estudiosos alemanes no limitaban su tarea a las fronteras geográficas o a la nacionalidad. El progreso

\footnotetext{
${ }^{1316}$ El nombre original es Ibero-Amerikanische Forschungsinstitut.

${ }^{1317}$ Karl Theodor Sapper a Robert Lehmann-Nitsche. Legado Robert Lehmann-Nitsche, IAI, 14.02.26, Carpeta N-0070 b 608 .
} 
científico era planteado casi como una misión pastoral, en la cual el estudioso alemán "Arrastrado por el impulso soberano de la curiosidad más noble por el afán de gozar el saber del saber sale "campo afuera", pasando los límites de la patria, los contornos del continente, y lanzándose a la conquista espiritual del mundo, del universo"1318.

Esta misión podía leerse en los panfletos del Instituto para la investigación del Nuevo Mundo $^{1319}$ que Saller repartiera entre los asistentes a sus conferencias. Su segundo apartado ponía como uno de los objetivos del instituto "[...] anudar y reanudar las relaciones entre los sabios de americanos y alemanos (sic) ${ }^{\$ 1320}$. En consecuencia Lehmann-Nitsche y la Institución Cultural Argentino-Germana serán unos asiduos promotores de la visita de estudiosos alemanes al país, principalmente aquellos cuyos trabajos daban cuenta de la identidad cultural del mundo ibero-americano y especialmente su unidad histórica, cultural y lingüística. En este contexto se enmarca la visita del americanista alemán Walter Lehmann (1878-1939) en 1929, el cual entre el 02 de agosto y el 07 de septiembre ofreció un programa de 12 conferencias sobre "Las antiguas culturas de Méjico y Central-América"1321.

Mientras que las conferencias de los estudiosos se encargaban de remarcar la unidad y la continuidad histórica de los pueblos latinoamericanos, ofreciendo herramientas científicas para la comprensión de este fenómeno, Lehmann-Nitsche se encargaba de resaltar las cualidades de los oradores extranjeros. Esto se enmarcaba dentro de la inquietud existente al interior de los grupos políticos antirrepublicanos en los cuales Lehmann-Nitsche participaba, donde la definición de lo alemán era la principal preocupación. Mientras que desde estos espacios políticos se exaltaban las cualidades de los guerreros y el patriotismo del pueblo alemán ${ }^{1322}$, la presencia de los estudiosos alemanes en el país permitía a Lehmann-Nitsche dar cuenta de cualidades como el sacrificio, la voluntad inquebrantable, el rechazo de la búsqueda de la gloria personal, el amor por el cultivo del saber y principalmente la solidaridad desinteresada. Estos elementos, extensibles a todos los alemanes, constituían parte esencial del "Deutschtum". En este sentido estas conferencias serán plataformas a partir de las cuales describir y promocionar los elementos que componían el "Deutschtum" o "ser alemán".

\footnotetext{
1318 Legado Robert Lehmann-Nitsche, IAI, Carpeta N-0070 b 803.

${ }^{1319}$ El nombre original será Institut für Amerikaforschung.

${ }^{1320}$ Legado Robert Lehmann-Nitsche, IAI, Carpeta N-0070 b 608.

${ }^{1321}$ Podgorny 2002 b.

1322 Ibídem.
} 


\section{Consideraciones Finales}

Mientras el siglo XX nacía, Rudolf Martin concluía en que solo una palabra podía definir el estado internacional de la práctica antropológica: Caos. Según este último, esto era resultado de la falta de consenso en la metodología de investigación, siendo consecuencia de la ausencia de un sistema y un método estandarizado de enseñanza. Martin encontraba la evidencia para estas afirmaciones al observar la multiplicidad de manuales y guías de observación, los intentos de acuerdos y convenciones craneométricas, la amplia diversidad de instrumentos, y la acumulación de materiales en museos y laboratorios. El tan ansiado orden solo era posible, según Martin, a través de la profesionalización e institucionalización, dos características que solo podían conseguirse a partir de la instrucción y la educación formal. La necesidad de una metodología homogénea y unificada se vincula, como ha señalado Irina Podgorny, con uno de los principales problemas de los estudiosos: la autenticidad para definir y construir su objeto de estudio $^{1323}$.

A fin de poder comprender las condiciones de posibilidad para las prácticas y el trabajo antropológico en la Argentina de fines del siglo XIX y principios del siglo XX que darán lugar al surgimiento y la constitución del "objeto antropológico", se tomo como caso de estudio la producción literaria de Robert Lehmann-Nitsche. Su llegada al Museo de La Plata en 1897 será vista por Martin como un importante paso al momento de sistematizar y promover una forma de práctica acorde a los parámetros de la antropología alemana. La práctica y la enseñanza de la antropología deben ser entendidas a través de su relación con la cultura material, las redes de circulación de información, los espacios de encuentro así como las prácticas de observación y registro que mediaron/intervinieron entre los objetos y los actores. Al mismo tiempo, en el caso de la Argentina, ambas deberán articularse en un contexto caracterizado por la carencia de recursos y las dificultades para la consecución de apoyo institucional ${ }^{1324}$.

En el capítulo I; tomando como punto de partida las afirmaciones de Rudolf Martin sobre el estado "caótico" de la práctica antropológica; se busco dar cuenta de los espacios y las prácticas antropológicas en Europa a partir de la segunda mitad del siglo XIX. Focalizando en los debates craneométricos acontecidos en Alemania y Francia, principalmente, se pudo constatar la falta de consenso a nivel internacional. Esto se materializaba en la existencia simultánea de manuales y guías de observación, instrucciones e instrumentos destinados a la observación y la clasificación de los objetos de interés para el estudioso, en nuestro caso el cráneo. Para tratar de explicar este fenómeno se preciso la confluencia de factores como: a)

\footnotetext{
1323 Podgorny 2004, p. 151.

${ }^{1324}$ Farro 2010; García S. 2010 a; Podgorny 1999, 2001 b, 2002 b, 2004.
} 
intereses personales e institucionales de los actores/instituciones involucrados y b) la disponibilidad de recursos estructurales y financieros.

En el capítulo II se constató la incidencia de estos elementos al momento de la llegada de Robert Lehmann-Nitsche al museo platense. Repasando en forma sintética las tareas llevadas adelante por el antropólogo holandés Herman Frederik Carel ten Kate Jr. pudo verse que las mismas estaban supeditas en forma exclusiva a sus objetivos personales y no a la implementación de un plan sistemático de investigación. Seguidamente se confirmo que la contratación de Lehmann-Nitsche estará vinculada a los intereses particulares de Martin en contar por un lado con una persona que le garantizara el acceso a las colecciones depositadas en el Museo de La Plata, y por el otro en la posibilidad de promover e instalar una antropología "alemana" a través de un profesional formado.

El capítulo III analiza los primeros estudios llevados adelante por Lehmann-Nitsche en sus primeros años en el Museo de La Plata. Las temáticas elegidas responderán a la posibilidad de insertar los datos generados a partir de las colecciones depositadas en el museo platense en las discusiones internacionales. A partir de las comunicaciones personales de Lehmann-Nitsche con su madre y especialmente con Rudolf Martin, se puso comprobar que el primero nunca tendrá como objetivo inicial una carrera permanente en la Argentina. Pensando su estadía en el país como algo transitorio, Lehmann-Nitsche buscará hacer, en el menor tiempo posible, el mayor uso de las colecciones del museo platense. Esto nos permitió tener otra perspectiva sobre la amplitud de cuestiones abarcadas, como así también el rápido cambio entre estas. Como vimos en los demás capítulos esta será la característica que atraviese todos sus trabajos.

En el capítulo IV se describió y analizó las observaciones antropométricas y somatológicas sobre individuos vivos realizadas en la Argentina entre fines del siglo XIX y las primeras décadas del siglo XX. La realización de estos trabajos en espacios tales como hospitales psiquiátricos, cárceles, ferias comerciales, misiones religiosas, comisarías o ingenios azucareros; nos permitió describir y analizar la naturaleza de aquellos denominado "trabajo de campo". En el periodo de tiempo analizado la práctica antropológica estará configurada y recortada por la necesidad de "poseer" el objeto en sí. De esta forma la elección de estos por parte de los antropólogos como lugares donde llevar adelante sus observaciones resolverá la viabilidad de los objetos y el problema del viaje, los cuales estarán condicionados por la disponibilidad de recursos económicos, tiempo y no siempre estarán recompensados por el éxito $^{1325}$.

${ }^{1325}$ Ballestero 2011; Farro 2010; Podgorny 1999, 2001 b, 2002 b, 2004. 
Al mismo tiempo se remarco la importancia de individuos e instituciones ajenos al mundo de la Antropología que proveerán a los estudiosos de: a) espacios donde realizar sus trabajos; b) acceso a redes de transporte y comunicación; c) alimentos, datos, objetos e indígenas. Se prestó especial atención a la red de colaboración establecida a partir de la comunidad alemana residente en el país. Estos elementos nos permitieron dar cuenta del carácter colectivo en la construcción del conocimiento por un lado, y la importancia de las redes establecidas a partir de los lazos de sociabilidad determinados por la pertenencia a una comunidad de procedencia.

En el capítulo V se presentaron los trabajos de colección de materiales criollistas llevados adelante desde la Antropología, en la Argentina de comienzo del siglo XX. Se destacaron ciertos elementos que no habían sido considerados adecuadamente hasta el momento: a) la economización de tiempo y dinero en el acopio de material gráfico a partir de la articulación de una red que incluirá: el circuito existente de editores, librerías y casas editoras, puestos de revistas, estaciones de ferrocarril y los medios gráficos alemanes que circulaban en la época, siendo estos últimos los mas fructuosos; b) la importancia de la figura de Rudolf Lenz. Este será el que le recomiende el uso de espacios no "habituales" en la recolección de datos, tales como bares, fondas, prostíbulos y puertos. Al mismo tiempo será el que le recomiende la incorporación de nuevas tecnologías en los procesos de recolección de datos; c) en consecuencia con el último párrafo se dio cuenta de la incorporación del fonógrafo y su importancia como dispositivo que efectiviza la recolección, conservación y transporte de datos; y d) la inserción de los trabajos de grabación de indígenas y músicos "populares" en los proyectos de cartografía musical llevados adelante por el Phonogramm-Archiv de Berlin.

En el capítulo VI se trabajo sobre las características de las prácticas antropológicas en el contexto de las excursiones al campo. En el caso concreto de la Argentina se señalaron dos elementos que condicionarán, en parte, la elección de los lugares: a) la significancia que determinados espacios geográficos tenían en las distintas agendas científicas europeas y b) la continuidad de empresas previas, evidenciada en el uso de instrumentos y técnicas similares. Seguidamente se puntualizó sobre las estrategias implementadas y articuladas por los antropólogos a fin de poder concretar dichos viajes. Tal como ha señalado Irina Podgorny las mismas se insertan en un contexto donde instituciones y particulares se están disputando los recursos económicos del Estado y los mecenazgos privados ${ }^{1326}$. Para esto se consideraron los viajes realizados por Lehmann-Nitsche a Tierra del Fuego en 1902 y al Noroeste argentino en 1906. Dentro de las principales estrategias implementadas se destacaron: a) el uso de redes de

\footnotetext{
${ }^{1326}$ Podgorny 2004, p. 154.
} 
comunicación y transportes establecidas por empresas y comerciantes extranjeros tales como la compañía alemana Hamburg Südamerikanische Dampfschifffahrts-Gesellschaft en el caso de Tierra del Fuego; y los comerciantes y empresarios ingleses Walter y William Edmund Leach en el Noroeste argentino; b) la realización de las observaciones en espacios que aseguraban la concentración de un número de indígenas, tales como comisarías, misiones religiosas, ingenios azucareros y reservas indígenas. De esta forma planteamos que los espacios observacionales no referirán a un espacio físicamente definido, sino a un complejo entramado de prácticas concretas asociadas a un conjunto de tecnologías materiales y discursivas.

El capítulo VII describió y analizó las redes de cooperación a partir de las cuales Lehmann-Nitsche se proveerá de datos y objetos para sus investigaciones. Se prestó especial atención a las redes organizadas alrededor de los colonos ingleses, los misioneros salesianos, los informantes indígenas que vivían en la ciudad de La Plata y especialmente los estudiosos alemanes. A fin de dar cuenta sobre las estrategias implementadas en la construcción/establecimiento/inserción de estas redes y sus dinámicas, se tomo como principal punto de referencia los proyectos impulsados por los estudiosos alemanes destinados a la construcción de una cartografía etnográfica para los indígenas sudamericanos, basada, principalmente, en la compilación de datos lingüísticos, mitológicos y astronómicos. En este sentido las redes de colaboración serán un recurso metodológico e instrumental que le permitirá a los estudiosos: a) sortear las dificultades económicas y las carencias materiales al momento de emprender dispendiosas campañas al interior del país, las cuales muchas veces dependerán de los vaivenes económicos e institucionales de sus respectivos lugares de trabajo; b) economizar tiempo y, principalmente, dinero en la obtención de objetos materiales y datos; y c) acceder a recursos y medios técnicos para el estudio de los materiales recolectados

El capítulo VIII se centro en los ciclos de conferencias/cursos libres y finalmente las cátedras de Antropología en las universidades nacionales de Buenos Aires y La Plata. Se analizo la importancia de los mismos como: a) espacios a partir de los cuales institucionalizar y profesionalizar la práctica de la antropología por un lado; y b) estrategias que permitieran superar las limitaciones y las carencias impuestas por el contexto local al momento de poder definir la dinámica de estas prácticas. Tomando como punto de comparación la tarea educativa desarrollada por Franz Boas en los Estados Unidos, se pudo constatar para el caso de la Argentina, entre 1903 y 1930, la ausencia de un proyecto de formación profesional a largo que plazo que colaborara en la sistematización del trabajo en el campo y en el gabinete. A pesar de las notas celebratorias escritas en la prensa sobre los cursos antropológicos de LehmannNitsche; cuya autoría podía ser de este último; estos no tendrán el objetivo de construir y definir los espacios de la práctica profesional de la antropología. Estas conclusiones surgen a partir de 
constatar la ausencia de: a) discípulos/graduados que continuarán la obra de Lehmann-Nitsche más allá de este; b) discípulos/graduados de Lehmann-Nitsche en los principales espacios científicos/académicos Argentinos: c) un manual/guía/libro que sintetizará los objetivos, los métodos y las técnicas del modelo de práctica antropológica que pretendía construirse.

Finalmente en el capítulo IX se analizo el papel de los congresos y las sociedades científicas, tanto en el plano local como en el internacional. En el caso de los congreso se pudo determinar que: a) en el plano local serán espacios a partir de los cuales instalar nuevos temas o bien re-interpretar los trabajos previos a la luz de nuevas metodologías y/o instrumentos. Al mismo permitirán a los antropólogos adentrarse e insertarse dentro del conjunto de estudiosos locales; b) en el plano internacional serán espacios a partir de los cuales reafirmar y establecer alianzas/lazos sociales y académicos. También permitirán la circulación de los objetos/ideas sudamericanas junto con la compra/adquisición recursos técnicos y bibliográficos.

En el apartado sobre las sociedades científicas se analizó su papel en la circulación de información, objetos y producciones científicas. Se destacó su importancia como espacio a partir del cual adquirir credibilidad científica, promocionar la discusión académica y establecer de relaciones de colaboración científica. En este punto se pudo comprobar la importancia de las sociedades científicas alemanas en la circulación, difusión y promoción de los trabajos de Lehmann-Nitsche. Junto con esta serie de beneficios también se detallaron diversos tipos de obligaciones que implicaban la pertenencia a este tipo de espacios, tales como: a) la distribución de los trabajos de otros miembros; b) la redacción de trabajos especiales; c) la participación en charlas y eventos especiales; y d) cuestiones vinculadas a la organización y funcionamiento de dichas sociedades.

Finalmente se dedico un punto especial al desempeño de las sociedades científicas locales e internacionales en el contexto de la Gran Guerra de 1914. En el caso argentino se pudo dar cuenta de dos tendencias marcadas: Por un lado el rechazo de a los estudiosos alemanes, y por el otro la serie de iniciativas destinadas a la recaudación de fondos destinados a paliar las consecuencias devastadoras de la guerra, tanto para la sociedad civil como científica. En el caso concreto de las sociedades científicas alemanas residentes en Argentina se pudo constatar su funcionamiento como: a) espacios de protección para los estudiosos alemanes residentes en el país; b) espacios desde los que se plantea la reconquista científica y cultural de la Argentina. En este sentido se destaco la serie de iniciativas organizadas por Lehmann-Nitsche y la Institución Cultural Argentino-Germana en la promoción y organización de visitas de estudiosos alemanes al país, principalmente aquellos cuyos trabajos daban cuenta de la identidad cultural del mundo ibero-americano y los vínculos/similitudes históricas entre Alemania y Argentina. En este sentido estos espacios serán plataformas a partir de las cuales describir y promocionar los elementos que componían el "Deutschtum” o "ser alemán". 
El 01 de abril de 1930; luego de un trámite de dos años; Lehmann-Nitsche presentaba su renuncia oficial al puesto de Jefe del Departamento de Antropología del Museo de La Plata ${ }^{1327}$. Sus 30 años de residencia en la Argentina dan cuenta de una sucesión de proyectos inacabados que jamás lograrán concretarse. Esta falta de sistematicidad y continuidad darán como resultado un estado caótico de la práctica antropológica en la argentina igual o mayor al que podía apreciarse en 1897. Al momento de comprender las causas de esto es necesario considerar las limitaciones estructurales/económicas/institucionales del contexto local. Ciertos elementos surgidos al momento de analizar la correspondencia privada, aportan nuevos datos que pueden ser contrastados al momento de analizar la confusa sucesión de temas presentes a lo largo de la obra de Lehmann-Nitsche. Su principal objetivo al momento de arribar al Museo de La Plata será realizar la mayor cantidad de publicaciones con los materiales a los cuales tenía acceso, seguro de que una breve estadía le permitirá acumular prestigio académico suficiente para conseguir un lugar en los espacios científicos y académicos de Alemania.

El carácter transitorio que este pensaba para su estadía en La Plata, será el que pueda apreciarse en sus trabajos, los cuales se suceden uno tras otro sin responder a un plan sistemático de investigación -y posteriormente de enseñanza- que contribuyera a la profesionalización de las prácticas antropológicas y la institucionalización/definición de sus espacios. Es factible pensar que una vez que la posibilidad de un retorno y un promisorio futuro en Alemania desaparecían en los planes de Lehmann-Nitsche, este se limitará a cumplir con las actividades que le garantizaban una permanencia y una posición estable en la Argentina.

Sin menospreciar los condicionamientos del contexto local, podemos ofrecer un contraejemplo. Al mismo tiempo que Lehmann-Nitsche se acogía a los beneficios de la jubilación, Franz Boas en los Estados Unidos controlaba en forma directa/indirecta los principales espacios de investigación y enseñanza de la Antropología. A lo largo de más de tres décadas había logrado construir y definir claramente los espacios de la práctica antropológica. La base central de esto será por un lado la construcción y la articulación de una red de alianzas institucionales y por el otro el entrenamiento de estudiantes que lo asistieran y continuaran su obra. Haciendo un análisis de los trabajos de Boas por profesionalizar la práctica antropológica, Arnold Krupat ha señalado que la clara definición de los objetivos y métodos de la Antropología por parte del estudioso alemán, convirtieron al antropólogo en "[...] a kind of "connoisseur of chaos" $^{1328}$.

${ }^{1327}$ Los trámites habían sido iniciados hacia 1928. Un año más tarde el Gobierno Nacional informaba a la Universidad Nacional de La Plata sobre la concesión del beneficio de la jubilación a Lehmann-Nitsche. Ministro de Hacienda de la Nación a Robert Lehmann-Nitsche. Legado Robert Lehmann-Nitsche, IAI, 27.12.1928, Carpeta N-0070 1 19. Ramón Loyarte a Robert Lehmann-Nitsche, AHMLP, 09.11.1929, Carpeta P 229. Robert Lehmann-Nitsche a Luis María Torres, AHMLP, 01.04.1930, Carpeta L 32.

${ }^{1328}$ Krupat 1988, p. 108. 
El ejemplo de Boas no pretende asignarle al individuo un papel central y fundamental en la historia de una determinada práctica científica, a las cuales no pueden asignársele actos fundadores o "padres". Sin embargo los individuos formarán parte del complejo entramado de relaciones en las cuales se vincularán los distintos espacios a partir de los cuales se construirá y se institucionalizará el "objeto antropológico". Haciéndonos eco de las palabras de Foucault, nos alejamos de la noción y la función fundadora asignada a los sujetos. En este sentido es necesario acentuar la capacidad productiva del conocimiento como práctica colectiva y de reubicar los individuos y sus conocimientos en el desarrollo del saber. 